\title{
Waste Isolation Pilot Plant Annual Site Environmental Report for 2008
}

\author{
U.S. Department of Energy
}

September 2009

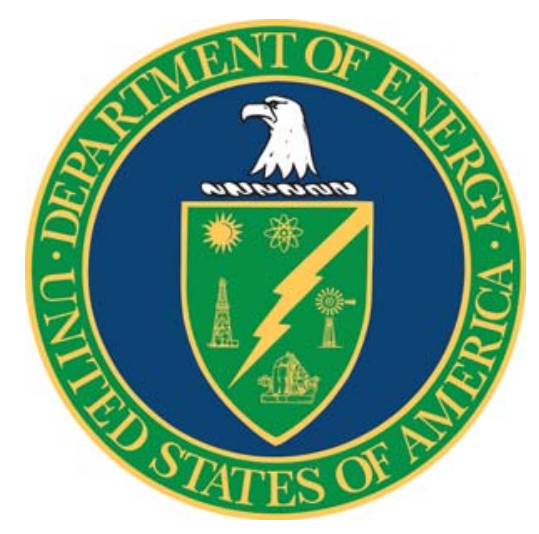



This document has been submitted as required to:

Office of Scientific and Technical Information

P.O. Box 62

Oak Ridge, TN 37831

Prices available from (865) 576-8401

Additional information about this document may be obtained by calling (800) 336-9477. Copies may be obtained by contacting the National Technical Information Service, U.S. Department of Commerce, 5285 Port Royal Road, Springfield, VA 22161

Processing and final preparation of this report was performed by the Waste Isolation Pilot Plant Management and Operating Contractor for the U.S. Department of Energy under Contract No. DE-AC29-01AL66444. 
Waste Isolation Pilot Plant Annual Site Environmental Report for 2008

DOE/WIPP-09-2225

This page intentionally left blank 


\section{TABLE OF CONTENTS}

ACRONYMS, ABBREVIATIONS, AND UNITS OF MEASURE $\ldots \ldots \ldots \ldots \ldots \ldots$ xii

EXECUTIVE SUMMARY $\ldots \ldots \ldots \ldots \ldots \ldots \ldots \ldots \ldots \ldots \ldots \ldots \ldots \ldots$

CHAPTER 1 - INTRODUCTION . . . . . . . . . . . . . . . . . . . . 1-1

$1.1 \quad$ WIPP Mission . . . . . . . . . . . . . . . . . . . . 1-1

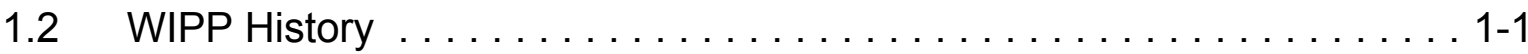

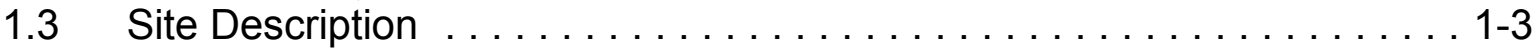

1.3.1 WIPP Property Areas . . . . . . . . . . . . . . . . . 1-4

1.3 .2 Population . . . . . . . . . . . . . . . . . . . . . 1-6

1.4 WIPP Environmental Stewardship . . . . . . . . . . . . . . . 1-6

1.4.1 Environmental Monitoring Plan . . . . . . . . . . . . 1-6

1.4.2 WIPP Facility Environmental Monitoring Program and

Surveillance Activities . . . . . . . . . . . . . . . . . . 1-8

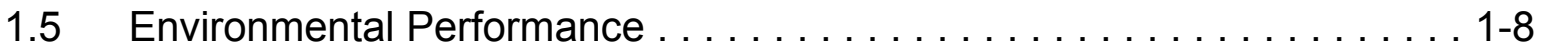

1.6 Organization of this Annual Site Environmental Report . . . . . . . . . . 1-9

CHAPTER 2 - COMPLIANCE SUMMARY . . . . . . . . . . . .

2.1 Comprehensive Environmental Response, Compensation, and

Liability Act . . . . . . . . . . . . . . . . . . . . . . . . . . . . 2-1

2.2 Resource Conservation and Recovery Act . . . . . . . . . . . . . . 2-2

2.3 National Environmental Policy Act . . . . . . . . . . . . . . . . . . . 2-6

2.4 Clean Air Act . . . . . . . . . . . . . . . . . . . . . . . 2-7

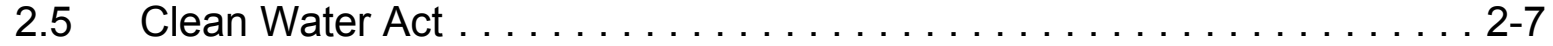

2.6 New Mexico Water Quality Act . . . . . . . . . . . . . . . . . . . . . 2-8

2.7 Safe Drinking Water Act . . . . . . . . . . . . . . . . . . . . 2-9

2.8 National Historic Preservation Act . . . . . . . . . . . . . . . . . . 2-10

2.9 Toxic Substances Control Act . . . . . . . . . . . . . . . . . . . . 2-10

2.10 Federal Insecticide, Fungicide, and Rodenticide Act . . . . . . . . . 2-10

2.11 Endangered Species Act . . . . . . . . . . . . . . . . . . . 2-11

2.12 Migratory Bird Treaty Act . . . . . . . . . . . . . . . . . 2-11

2.13 Federal Land Policy and Management Act $\ldots \ldots \ldots \ldots \ldots \ldots$. . . . . . . . . . . . . . . . . . . .

2.14 Atomic Energy Act . . . . . . . . . . . . . . . . . . . . . . . . . . . . 2-12

2.15 DOE Orders . . . . . . . . . . . . . . . . . . . . . . 2-13

2.15.1 DOE Order 151.1C, Comprehensive Emergency

Management System . . . . . . . . . . . . . . . . . 2-14

2.15.2 DOE Order 231.1A, Chg. 1, Environment, Safety and

Health Reporting . . . . . . . . . . . . . . . . . . . . . . . . . 2-14

2.15.3 DOE Order 414.1C, Quality Assurance . . . . . . . . . . . . . . . . 2-14

2.15.4 DOE Order 435.1, Radioactive Waste Management . . . . . . . . 2-14

2.15.5 DOE Order 450.1A , Environmental Protection Program . . . . . . 2-14

2.15.6 DOE Order 451.1B, Chg. 1, National Environmental Policy

Act Compliance Program . . . . . . . . . . . . . . . . . . . . 2-15

2.15.7 DOE Order 5400.5, Chg 2, Radiation Protection of the

Public and the Environment . . . . . . . . . . . . . . 2-15 
2.16 Executive Orders . . . . . . . . . . . . . . . . . . . 2-15

2.16.1 Executive Order 13423, Strengthening Federal

Environmental, Energy, and Transportation Management . . . . 2-16

CHAPTER 3 - ENVIRONMENTAL MANAGEMENT SYSTEM $\ldots \ldots \ldots \ldots \ldots \ldots$ 3-1

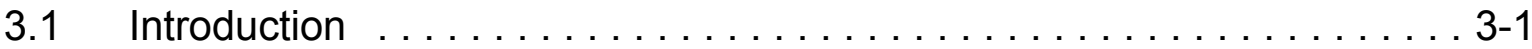

3.2 WIPP EMS Continuous Improvement Cycle $\ldots \ldots \ldots \ldots \ldots \ldots \ldots . . .1$

3.2.1 Environmental Policy . . . . . . . . . . . . . . . . . .

3.2.2 Environmental Aspects . . . . . . . . . . . . . . . . 3-2

3.2.3 Legal and Other Requirements $\ldots \ldots \ldots \ldots \ldots \ldots \ldots \ldots \ldots .3 .3$

3.2.4 Objectives, Targets, and Programs . . . . . . . . . . . 3-3

3.2.5 Resources, Roles, Responsibility, and Authority . . . . . . . . . 3-4

3.2.6 Competence, Training, and Awareness . . . . . . . . . . . . . 3-4

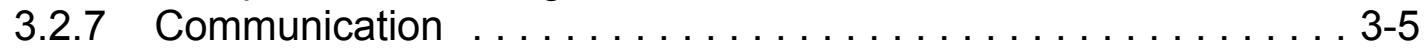

3.2.8 EMS Documentation . . . . . . . . . . . . . . . 3-5

3.2.9 Control of Documents and Control of Records . . . . . . . 3-6

3.2.10 Operating Control ......................... 3-6

3.2.11 Emergency Preparedness and Response . . . . . . . . . . 3-6

3.2.12 Measuring and Monitoring Environmental Performance . . . . . 3-6

3.2.13 Evaluation of Compliance . . . . . . . . . . . . . . 3-12

3.2.14 Nonconformity, Corrective and Preventive Action . . . . . . . . 3-12

3.2.15 EMS Internal Audit .......................... 3-13

3.2.16 Management Review ....................... 3-13

3.2.17 Status of EMS Implementation $\ldots \ldots \ldots \ldots \ldots \ldots \ldots \ldots \ldots \ldots$

CHAPTER 4 - ENVIRONMENTAL RADIOLOGICAL PROGRAM INFORMATION . 4-1

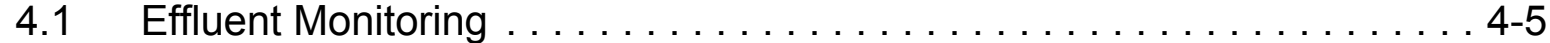

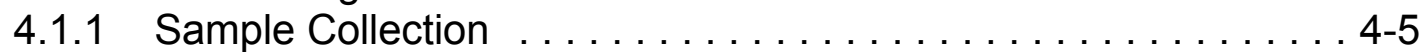

4.1 .2 Sample Preparation . . . . . . . . . . . . . . . .

4.1.3 Determination of Individual Radionuclides . . . . . . . . . . 4-6

4.1.4 Results and Discussion . . . . . . . . . . . . . . . 4-6

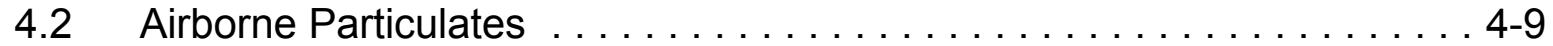

4.2.1 Sample Collection . . . . . . . . . . . . . . . . . 4-9

4.2.2 Sample Preparation . . . . . . . . . . . . . . . . 4-9

4.2.3 Determination of Individual Radionuclides . . . . . . . . . . 4-10

4.2.4 Results and Discussion . . . . . . . . . . . . . . . . 4-10

4.3 Groundwater . . . . . . . . . . . . . . . . . . . . 42

4.3.1 Sample Collection $\ldots \ldots \ldots \ldots \ldots \ldots \ldots \ldots \ldots \ldots \ldots .4 .12$

4.3.2 Sample Preparation . . . . . . . . . . . . . . . . 4-12

4.3.3 Determination of Individual Radionuclides . . . . . . . . . . 4-12

4.3.4 Results and Discussion ... . . . . . . . . . . . . . . . 4-13

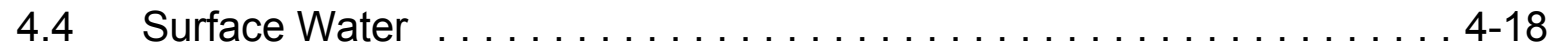

4.4.1 Sample Collection . . . . . . . . . . . . . . . 4-18

4.4.2 Sample Preparation ..................... 4-19

4.4.3 Determination of Individual Radionuclides . . . . . . . . . . 4-19

4.4.4 Results and Discussion ................... 4-20 
4.5 Sediments $\ldots \ldots \ldots \ldots \ldots \ldots \ldots \ldots \ldots \ldots \ldots \ldots \ldots \ldots \ldots \ldots .4 .24$

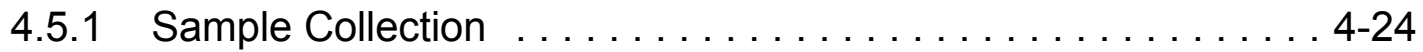

4.5.2 Sample Preparation ...................... . 4-24

4.5.3 Determination of Individual Radionuclides . . . . . . . . . 4-25

4.5.4 Results and Discussion . . . . . . . . . . . . . 4-26

4.6 Soil Samples . . . . . . . . . . . . . . . . . . . . 4-31

4.6.1 Sample Collection $\ldots \ldots \ldots \ldots \ldots \ldots \ldots \ldots \ldots \ldots \ldots .4 .31$

4.6.2 Sample Preparation ...................... 4-31

4.6.3 Determination of Individual Radionuclides . . . . . . . . . . 4-32

4.6.4 Results and Discussion . . . . . . . . . . . . . . . . . 4-32

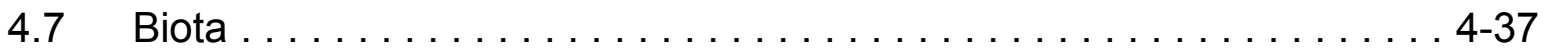

4.7.1 Sample Collection . . . . . . . . . . . . . . . . . . . 4-37

4.7 .2 Sample Preparation . . . . . . . . . . . . . . . . . . 4-37

4.7.4 Results and Discussion ................... . 4-38

4.8 Potential Dose from WIPP Operations $\ldots \ldots \ldots \ldots \ldots \ldots \ldots \ldots \ldots 4-41$

4.8.1 Dose Limits . . . . . . . . . . . . . . . . . . . 4-41

4.8.2 Background Radiation . . . . . . . . . . . . . . . 4-41

4.8.3 Dose from Air Emissions . . . . . . . . . . . . . . . . . . 4-42

4.8.4 Total Potential Dose from WIPP Operations . . . . . . . . 4-43

4.8.5 Dose to Nonhuman Biota . . . . . . . . . . . . . . . . . . . . . 4-46

4.8.6 Release of Property Containing Residual Radioactive

Material . . . . . . . . . . . . . . . . . . . . 4 4-48

4.9 Radiological Program Conclusions $\ldots \ldots \ldots \ldots \ldots \ldots \ldots \ldots \ldots 4-48$

CHAPTER 5 - ENVIRONMENTAL NONRADIOLOGICAL PROGRAM

INFORMATION ........................ 5-1

5.1 Principal Functions of Nonradiological Sampling . . . . . . . . . . 5-1

5.2 Land Management Programs . . . . . . . . . . . . . . . . . . 5-1

5.2 .1 Land Use Requests . . . . . . . . . . . . . . . . . 5-2

5.2 .2 Wildlife Population Monitoring . . . . . . . . . . . . . 5-2

5.2 .3 Reclamation of Disturbed Lands . . . . . . . . . . . . 5-2

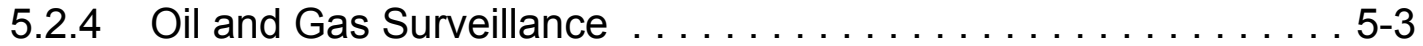

$5.3 \quad$ Meteorological Monitoring $\ldots \ldots \ldots \ldots \ldots \ldots \ldots \ldots \ldots \ldots \ldots$ 5-3

5.3 .1 Climatic Data . . . . . . . . . . . . . . . . . . 5-4

5.3.2 Wind Direction and Wind Speed $\ldots \ldots \ldots \ldots \ldots \ldots \ldots \ldots$

$5.4 \quad$ Volatile Organic Compound Monitoring . . . . . . . . . . . . . . . 5-8

$5.5 \quad$ Hydrogen and Methane Monitoring $\ldots \ldots \ldots \ldots \ldots \ldots \ldots \ldots \ldots . . \ldots \ldots \ldots$

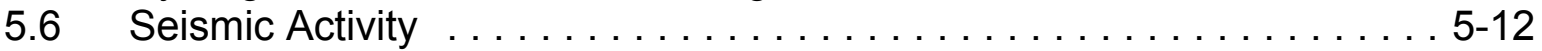

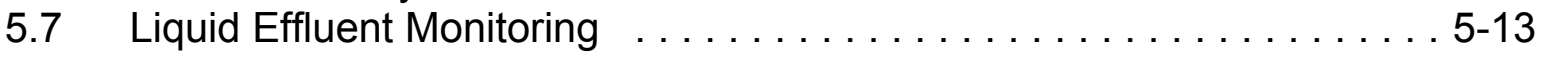

CHAPTER 6 - SITE HYDROLOGY, GROUNDWATER MONITORING, AND PUBLIC DRINKING WATER PROTECTION . . . . . . . . . 6-1

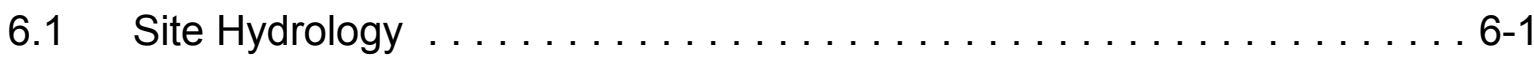

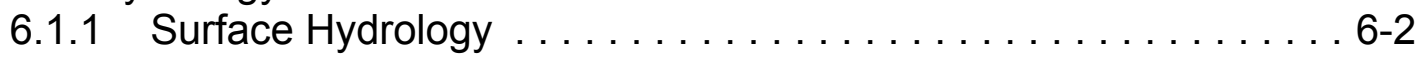

6.1 .2 Subsurface Hydrology $\ldots \ldots \ldots \ldots \ldots \ldots \ldots \ldots \ldots .6 \ldots \ldots \ldots$ 
6.2 Groundwater Monitoring $\ldots \ldots \ldots \ldots \ldots \ldots \ldots \ldots \ldots 6.5$

6.2.1 Program Objectives .................... . 6-5

6.2 .2 Summary of 2008 Activities . . . . . . . . . . . . . . 6-5

6.2 .3 Groundwater Quality Sampling $\ldots \ldots \ldots \ldots \ldots \ldots \ldots \ldots 6.7$

6.2.4 Evaluation of Groundwater Quality $\ldots \ldots \ldots \ldots \ldots \ldots \ldots 6$. 6.10

6.2.5 Groundwater Level Surveillance . . . . . . . . . . . . 6-10

6.2.6 Pressure Density Surveys $\ldots \ldots \ldots \ldots \ldots \ldots \ldots \ldots \ldots \ldots .6 .6 \ldots \ldots \ldots$

6.3 Drilling Activities . . . . . . . . . . . . . . . . . . . . . 6-26

6.4 Hydraulic Testing and Other Water Quality Sampling . . . . . . . . 6-26

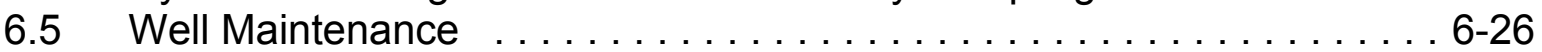

6.6 Shallow Subsurface Water Monitoring Program . . . . . . . . . . 6-27

6.6.1 Shallow Subsurface Water Quality Sampling . . . . . . . . . . . 6-30

6.6.2 Shallow Subsurface Water Level Surveillance . . . . . . . . . . 6-30

6.7 Public Drinking Water Protection . . . . . . . . . . . . . . . 6

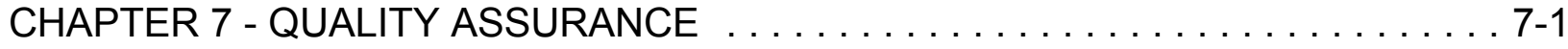

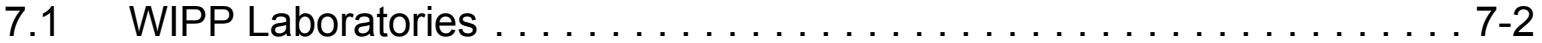

7.1 .1 Completeness . . . . . . . . . . . . . . . . . . . .

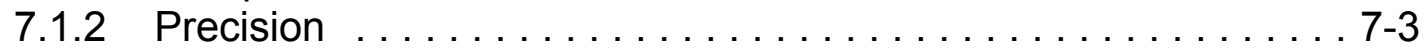

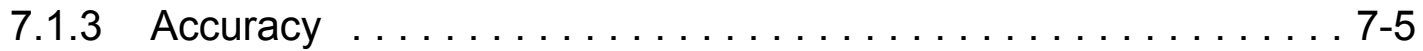

7.1 .4 Comparability . . . . . . . . . . . . . . .

7.1.5 Representativeness . . . . . . . . . . . . . . . . 7-7

$7.2 \quad$ CEMRC . . . . . . . . . . . . . . . . . . . . . . . . . .

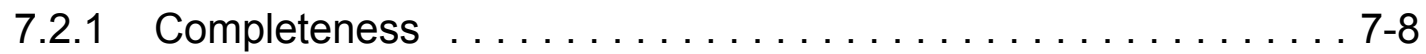

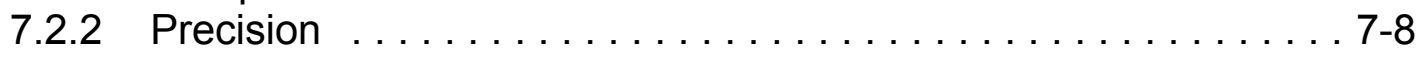

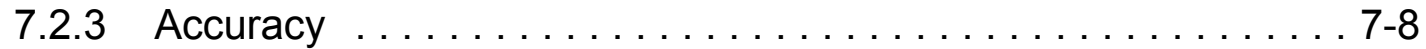

7.2 .4 Comparability . . . . . . . . . . . . . . . . . . . 7-10

7.2.5 Representativeness . . . . . . . . . . . . . . . . . 7-10

7.3 TraceAnalysis, Inc. . . . . . . . . . . . . . . . . . . . . . .

7.3.1 Completeness . . . . . . . . . . . . . . . . . . .

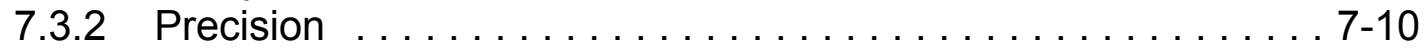

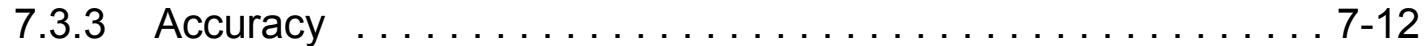

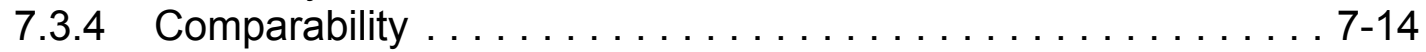

7.3.5 Representativeness . . . . . . . . . . . . . . . . . . 7-14

7.4 Hall Environmental Analysis Laboratory $\ldots \ldots \ldots \ldots \ldots \ldots \ldots \ldots .7-15$

7.4.1 Completeness ......................... 7-15

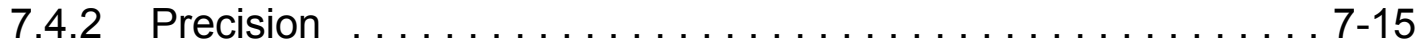

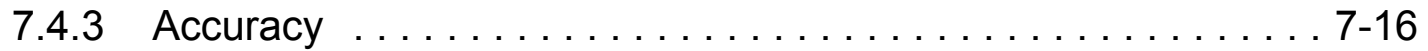

7.4 .4 Comparability .................

7.4.5 Representativeness . . . . . . . . . . . . . . . 7-18

Appendix A - References $\ldots \ldots \ldots \ldots \ldots \ldots \ldots \ldots \ldots \ldots \ldots \ldots$ A-1

Appendix B - Active Environmental Permits $\ldots \ldots \ldots \ldots \ldots \ldots \ldots$ B-1

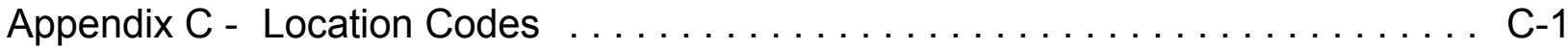


Appendix D - Radiochemical Equations . . . . . . . . . . . . . .

Appendix E - Time Trend Plots for Detectable Constituents in Groundwater . . . . E E-1

Appendix F - Groundwater Data Tables $\ldots \ldots \ldots \ldots \ldots \ldots \ldots \ldots \ldots$ F-1

Appendix G - Air Sampling Data: Concentrations of Radionuclides in Air Filter Composites .........................

Appendix $\mathrm{H}$ - Comparison of Detected Radionuclides to the Radiological Baseline .......................... 
Waste Isolation Pilot Plant Annual Site Environmental Report for 2008

DOE/WIPP-09-2225

This page intentionally left blank 


\section{LIST OF TABLES}

Table 1.1 - Environmental Monitoring Sampling $\ldots \ldots \ldots \ldots \ldots \ldots \ldots \ldots \ldots$ 1-7

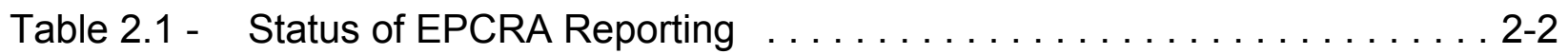

Table 2.2 - Permit Modification Notifications and Requests Submitted in 2008 . . . 2-4

Table 3.1 - Site Environmental P2 Goals Scorecard - FY $2008 \ldots \ldots . \ldots \ldots \ldots$. . . . . .

Table 3.2 - EMS Effectiveness Indicators Environmental Stewardship, Compliance, Continual Improvement ................ 3-10

Table 4.1 - Radioactive Nuclides Monitored at the WIPP Site . . . . . . . . . . . . . . 4-3

Table 4.2 - Activity (Bq) of Quarterly Composite Air Samples from the WIPP Effluent Monitoring Stations A, B, and C for $2008 \ldots \ldots \ldots \ldots \ldots$. 4-7

Table 4.3 - Average, Minimum, and Maximum Radionuclide Concentrations $\left(\mathrm{Bq} / \mathrm{m}^{3}\right)$ in Air Filter Composite Samples from Stations on or Near the WIPP Site $\ldots \ldots \ldots \ldots \ldots \ldots \ldots \ldots \ldots \ldots \ldots \ldots \ldots \ldots \ldots \ldots \ldots .11$

Table 4.5 - Results of Duplicate Groundwater Sample Analyses for Sampling Round 26. Units are in $\mathrm{Bq} / \mathrm{L} \ldots \ldots \ldots \ldots \ldots \ldots \ldots \ldots \ldots \ldots .4 .16$

Table 4.6 - Results of Duplicate Groundwater Sample Analyses for Sampling Round 27. . . . . . . . . . . . . . . . . . . . . . . . 4-17

Table 4.7 - Uranium Concentrations $(\mathrm{Bq} / \mathrm{L})$ in Surface Water Taken Near the WIPP Site

Table 4.8 - Americium and Plutonium Concentrations in Surface Water Taken Near the WIPP Site . . . . . . . . . . . . . . . 4 4-22

Table 4.9 - Selected Radionuclide Concentrations (Bq/L) in Surface Water Near the WIPP Site

Table 4.10 - Results of Duplicate Surface Water Sample Analyses Taken in 2008

Table 4.11 - Uranium Concentrations (Bq/g) in Sediment Samples Taken Near the WIPP Site. See Appendix C for Sampling Location Codes . . . . 4-26

Table 4.12 - Americium and Plutonium Concentrations (Bq/g) in Sediment Samples Taken Near the WIPP Site 
Table 4.13 - Gamma Radionuclides and ${ }^{90} \mathrm{Sr}$ Concentrations (Bq/g) in Sediment Samples Taken Near the WIPP Site

Table 4.15 - Uranium Concentrations (Bq/g) in Soil Samples Taken Near the WIPP Site

Table 4.16 - Americium and Plutonium Concentrations (Bq/g) in Soil Samples Taken Near the WIPP Site

Table 4.17 - Selected Radionuclide Concentrations (Bq/g) in Soil Samples

Taken Near the WIPP Site

Table 4.18 - Results of 2008 Duplicate Soil Sampling and Analysis

Table 4.19 - Radionuclide Concentrations (Bq/g Wet Mass) in Vegetation Samples Taken Near the WIPP Site

Table 4.20 - Results of Duplicate Vegetation Sample Analysis . . . . . . . . . . . . 4-39

Table 4.21 - Radionuclide Concentrations (Bq/g Wet Mass) in Quail, Fish, Rabbit, Javelina, and Deer Samples Taken Near the WIPP Site $4-40$

Table 4.22 - Annual Estimated Average Radiation Dose Received by a Member of the Population of the United States from Naturally Occurring Radiation Sources

Table 4.23 - WIPP Radiological Dose and Release Summary 4-45

Table 4.24 - General Screening Results for Potential Radiation Dose to Nonhuman Biota from Radionuclide Concentrations in Surface Water $(\mathrm{Bq} / \mathrm{L})$, Sediment $(\mathrm{Bq} / \mathrm{g})$, and Soil $(\mathrm{Bq} / \mathrm{g})$ Near the WIPP Site in 2008

Table 4.25 - Comparison of Dose to the Whole Body to EPA Limit of $25 \mathrm{mrem} /$ Year per 40 CFR §191.03(b)

Table 4.26 - Comparison of Dose to the Critical Organ to EPA Limit of $75 \mathrm{mrem} /$ Year per 40 CFR §191.03(b)

Table 4.27 - Comparison of EDEs to EPA Limit of $10 \mathrm{mrem} /$ Year per 40 CFR $\S 61.92$

Table 5.1 - Concentrations of Concern for Volatile Organic Compounds, from Module IV of the Permit . . . . . . . . . . . . . . . . . .

Table 5.2 - Repository Air VOC MRLs $\ldots \ldots \ldots \ldots \ldots \ldots \ldots \ldots \ldots \ldots .5 .10$ 
Table 5.3 - Disposal Room VOC MRLs . . . . . . . . . . . . . . . 5-11

Table 5.4 - Hydrogen and Methane MRLs Action Levels and MCDs . . . . . . 5-12

Table 5.5 - Sewage Lagoon and H-19 Analytical Results for January

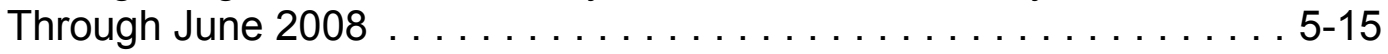

Table 5.6 - Sewage Lagoon, H-19, and Infiltration Control Pond Analytical Results for July Through December $2008 \ldots \ldots \ldots \ldots \ldots \ldots$. . . . . . . . .

Table 6.1 - Summary of 2008 DOE WIPP Region Groundwater Monitoring Program .................... 6

Table 6.2 - Analytical Parameters for Which Groundwater Was Analyzed . . . . . 6-9

Table 6.3 - Water Level Elevations for the September 2008 Potentiometric Surface Calibration, Culebra Hydraulic Unit . . . . . . . . . . . 6-16

Table 6.4 - Pressure Density Survey for $2008 \ldots \ldots \ldots \ldots \ldots \ldots \ldots \ldots .6 .6 \ldots \ldots .6 .24$

Table 6.5 - 2008 SNL Well and Water Quality Sampling Testing Activities . . . . 6-26

Table 6.6 - 2008 Survey Data . . . . . . . . . . . . . . . . . . . . 6-27

Table 6.7 - 2008 Shallow Subsurface Water Quality Sampling Results . . . . . 6 6-30

Table 7.1 - Mixed Analyte Performance Evaluation Program Review for WIPP Laboratories, 2008 . . . . . . . . . . . . . . . . . 7-6 
Waste Isolation Pilot Plant Annual Site Environmental Report for 2008

DOE/WIPP-09-2225

This page intentionally left blank 


\section{LIST OF FIGURES}

Figure $1.1-\quad$ WIPP Location $\ldots \ldots \ldots \ldots \ldots \ldots \ldots \ldots \ldots \ldots \ldots \ldots \ldots \ldots \ldots \ldots \ldots .1-3$

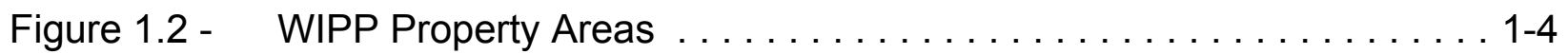

Figure 3.1 - WIPP EMS Continuous Improvement Cycle . . . . . . . . . . 3-1

Figure 3.2 - WIPP BTUs/Building Square Footage $\ldots \ldots \ldots \ldots \ldots \ldots$ 3-8

Figure 3.3 - FY 2008 WIPP Disposed Versus Recycled Materials . . . . . . . . . . 3-9

Figure 3-4 $-\quad$ Yearly Water Usage at WIPP $\ldots \ldots \ldots \ldots \ldots \ldots \ldots \ldots \ldots \ldots$

Figure 4.1 - Air Sampling Locations on and Near the WIPP Site . . . . . . . . 4-9

Figure 4.2 - Routine Surface Water Sampling Locations . . . . . . . . . . . . 4-19

Figure 4.3 - Sediment Sampling Sites $\ldots \ldots \ldots \ldots \ldots \ldots \ldots \ldots \ldots \ldots .4 .25$

Figure 4.4 - $\quad$ Routine Soil and Vegetation Sampling Areas . . . . . . . . . . 4-31

Figure 4.5 - Dose to the Whole Body for the Hypothetical Maximally Exposed Individual at the WIPP Fence Line . . . . . . . . . . 4-49

Figure 4.6 - Dose to the Critical Organ for Hypothetical Maximally Exposed individual at the WIPP Fence Line . . . . . . . . . . . . . . . 4-50

Figure $4.7-\quad$ WIPP EDE to the Off-Site MEI $\ldots \ldots \ldots \ldots \ldots \ldots \ldots \ldots \ldots .51$

Figure $5.1-\quad$ WIPP Precipitation Report for $2008 \ldots \ldots \ldots \ldots \ldots \ldots \ldots$. . . . . . . .

Figure 5.2 - WIPP High Temperatures for $2008 \ldots \ldots \ldots \ldots \ldots \ldots \ldots \ldots .4$

Figure 5.3 - WIPP Average Temperatures for $2008 \ldots \ldots \ldots \ldots \ldots \ldots \ldots$ 5-5

Figure 5.4 - WIPP Average Low Temperatures for $2008 \ldots \ldots \ldots \ldots$. . . . . . . 6

Figure 5.5 - Wind Speed Report for $2008 \ldots \ldots \ldots \ldots \ldots \ldots \ldots \ldots \ldots$ 5-7

Figure 5.6 - Typical Disposal Room VOC Sampling Locations . . . . . . . . . . 5-8

Figure 5.7 - Seismograph Station Locations $\ldots \ldots \ldots \ldots \ldots \ldots \ldots \ldots .5 .12$

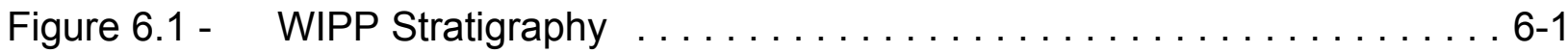

Figure 6.2 - Groundwater Level Surveillance Wells . . . . . . . . . . . . 6-7 
Figure 6.3 - Water Quality Sampling Program Wells $\ldots \ldots \ldots \ldots \ldots \ldots$ 6-7

Figure $6.4-\quad$ Hydrograph of WQSP-1 $\ldots \ldots \ldots \ldots \ldots \ldots \ldots \ldots \ldots \ldots$ 6-12

Figure $6.5-\quad$ Hydrograph of WQSP-2 $\ldots \ldots \ldots \ldots \ldots \ldots \ldots \ldots \ldots \ldots 6.13$

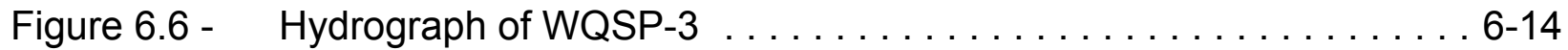

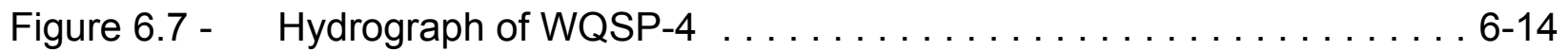

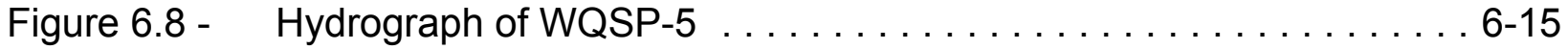

Figure $6.9-\quad$ Hydrograph of WQSP-6 $\ldots \ldots \ldots \ldots \ldots \ldots \ldots \ldots \ldots \ldots 6.15$

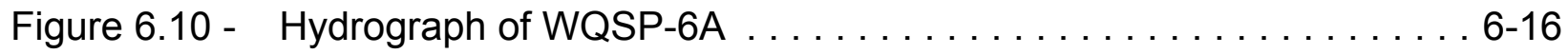

Figure 6.11 - Model-Generated September 2008 Freshwater Head Contours in the Model Domain . . . . . . . . . . . . . . . . . . . . . . . . 6-20

Figure 6.12 - Model-Generated September 2008 Freshwater Head Contours (5-Foot Contour Interval) in the WIPP Vicinity with Blue Water Particle Track From Waste Handling Shaft to WIPP LWB ... . . . 6-21

Figure 6.13 - Measured Versus Modeled Scatter Plot for PEST-Calibrated MODFLOW-2000 Generated Heads and September 2008 Observed Freshwater Heads

Figure 6.14 - Frequency of Modeled Freshwater Head Residuals . . . . . . . . . . 6-23

Figure 6.15 - Modeled Residual Freshwater Head at Each Well . . . . . . . . 6-23

Figure 6.16 - Location of SSW Wells (Piezometers PZ-01 through 15, C-2811, C-2505, C-2506, C-2507) . . . . . . . . . . . . . . 6-29

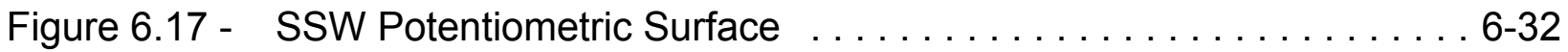




\section{ACRONYMS, ABBREVIATIONS, AND UNITS OF MEASURE}

$\begin{array}{ll}\text { ALARA } & \text { as low as reasonably achievable } \\ \text { Am } & \text { americium } \\ \text { ANOVA } & \text { analysis of variance } \\ \text { ANSI } & \text { American National Standards Institute } \\ \text { AOC } & \text { Area of Concern } \\ \text { ASER } & \text { annual site environmental report } \\ \text { ASME } & \text { American Society of Mechanical Engineers } \\ \text { BCG } & \text { biota concentration guide } \\ \text { BLM } & \text { U.S. Department of the Interior, Bureau of Land Management } \\ \text { Bq } & \text { becquerel/becquerels } \\ \text { Bq/L } & \text { becquerels per liter } \\ \text { Bq/m } & \text { becquerels per cubic meter } \\ & \\ \text { CAO } & \text { Carlsbad Area Office (now Carlsbad Field Office) } \\ \text { CAP88 } & \text { computer code for calculating both dose and risk from radionuclide } \\ \text { CBFO } & \text { emissions } \\ \text { CERCLA } & \text { Carlsbad Field Office } \\ \text { Comprehensive Environmental Response, Compensation, and Liability } \\ \text { CEMRC } & \text { Act } \\ \text { CFR } & \text { Carlsbad Environmental Monitoring and Research Center } \\ \text { CH } & \text { Code of Federal Regulations } \\ \text { Ci } & \text { contact-handled } \\ \text { cm } & \text { curie } \\ \text { Co } & \text { centimeter } \\ \text { Cs } & \text { cobalt } \\ \text { CY } & \text { cesium } \\ \text { d } & \text { calendar year } \\ \text { DMP } & \text { day } \\ \text { DOE } & \text { detection monitoring program } \\ \text { DOELAP } & \text { D.S. Department of Energy } \\ \text { DP } & \text { discharge permit } \\ \text { E } & \text { East } \\ \text { EDE } & \text { effective dose equivalent } \\ \text { EH } & \text { DOE Environment, Safety, and Health } \\ \text { EIS } & \text { Environmental Impact Statement } \\ \text { EMS } & \text { Environmental Management System } \\ \text { EO } & \text { Executive Order } \\ \text { EPA } & \text { U.S. Environmental Protection Agency } \\ \text { EPCRA } & \text { Emergency Planning and Community Right-to-Know Act } \\ \text { ESPC } & \text { Energy Savings Performance Contract } \\ & \\ & \end{array}$




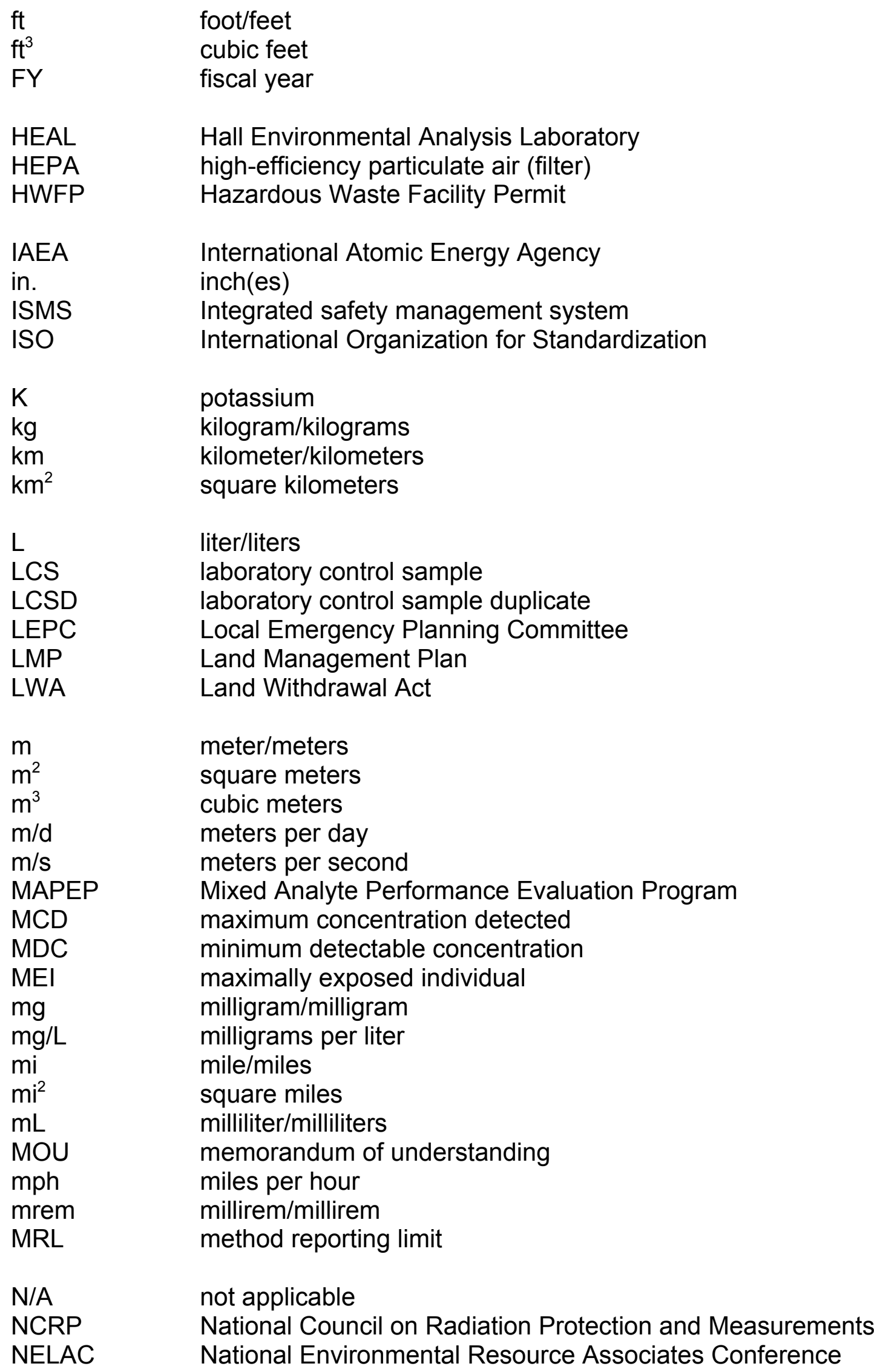




$\begin{array}{ll}\text { NEPA } & \text { National Environmental Policy Act } \\ \text { NESHAP } & \text { National Emission Standards for Hazardous Air Pollutants } \\ \text { NIST } & \text { National Institute of Standards and Technology } \\ \text { NMAC } & \text { New Mexico Administrative Code } \\ \text { NMED } & \text { New Mexico Environment Department } \\ \text { NMIMT } & \text { New Mexico Institute of Mining and Technology } \\ \text { NMSA } & \text { New Mexico Statutes Annotated } \\ \text { NOV } & \text { Notice of Violation } \\ \text { NPDES } & \text { National Pollutant Discharge Elimination System } \\ \text { NQA } & \text { Nuclear Quality Assurance } \\ \text { NRC } & \text { U.S. Nuclear Regulatory Commission } \\ \text { NRIP } & \text { National Institute of Standards and Technology Radiochemistry } \\ & \text { Intercomparison Program } \\ \text { Oz } & \text { ounce/ounces } \\ \text { P2 } & \text { pollution prevention } \\ \text { PABC } & \text { Performance Assessment Baseline Calculation } \\ \text { PCB } & \text { polychlorinated biphenyl } \\ \text { pCi } & \text { picoCuries } \\ \text { pH } & \text { measure of the acidity or basicity of a solution } \\ \text { PIP } & \text { production-injection packer } \\ \text { ppmv } & \text { parts per million by volume } \\ \text { ppbv } & \text { parts per billion by volume } \\ \text { Pu } & \text { plutonium } \\ \text { Pub. L. } & \text { Public Law } \\ \text { QA } & \\ \text { QC } & \text { quality assurance } \\ \text { rad } & \text { quality control } \\ \text { RBL } & \text { radiation absorbed dose } \\ \text { RCRA } & \text { room based limits } \\ \text { rem } & \text { Resource Conservation and Recovery Act } \\ \text { RER } & \text { Roentgen equivalent man } \\ \text { RH } & \text { relative error ratio } \\ \text { RPD } & \text { remote-handled } \\ \text { SD } & \text { relative percent difference } \\ \text { SEIS-II } & \text { standard deviation (also, soil deep) } \\ \text { SERC } & \text { Second Supplemental Environmental Impact Statement } \\ \text { SI } & \text { State Emergency Response Commission } \\ \text { SNL } & \text { soil intermediate } \\ \text { SOP } & \text { Sandia National Laboratories } \\ \text { SOW } & \text { standard operating procedure } \\ \text { SPDV } & \text { statement of work } \\ \text { Sr } & \text { site and preliminary design validation } \\ & \text { strontium } \\ & \end{array}$




$\begin{array}{ll}\text { SR/DL } & \text { Santa Rosa/Dewey Lake } \\ \text { SS } & \text { surface soil } \\ \text { SSW } & \text { shallow subsurface water } \\ \text { SU } & \text { standard unit } \\ \text { SWMU } & \begin{array}{l}\text { solid waste management unit } \\ \text { semivolatile organic compound }\end{array} \\ \text { SVOC } & \text { total dissolved solids } \\ \text { TDS } & \text { total organic carbon } \\ \text { TOC } & \text { total organic halogen } \\ \text { TOX } & \text { total propagated uncertainty } \\ \text { TPU } & \text { TraceAnalysis, Inc. } \\ \text { Trace } & \text { transuranic (waste) } \\ \text { TRU } & \text { Toxic Substances Control Act } \\ \text { TSCA } & \text { treatment, storage, and disposal facility } \\ \text { TSDF } & \text { total suspended solids } \\ \text { TSS } & \\ & \text { uranium } \\ \text { U } & \text { United States } \\ \text { U.S. } & \text { United States Code } \\ \text { U.S.C. } & \text { U.S. Fish and Wildlife Service } \\ \text { USFWS } & \text { underground storage tank } \\ \text { UST } & \text { Upper Tolerance Limit Value } \\ \text { UTLV } & \text { Volatile Organic Compound } \\ \text { VOC } & \text { West } \\ \text { W } & \text { Waste Isolation Pilot Plant } \\ \text { WIPP } & \text { WIPP Groundwater Quality Sampling Program } \\ \text { WQSP } & \text { Washington TRU Solutions LLC } \\ \text { WTS } & \end{array}$

Symbols

degrees Celsius

degrees Fahrenheit

less than

less than or equal to

microCurie

microgram

micromhos

percent

plus or minus

radionuclide concentration

sigma 


\section{EXECUTIVE SUMMARY}

\section{Purpose}

The purpose of the Waste Isolation Pilot Plant Annual Site Environmental Report for 2008 (ASER) is to provide information required by U.S. Department of Energy (DOE) Order 231.1A, Environment, Safety, and Health Reporting. Specifically, the ASER presents summary environmental data to:

- $\quad$ Characterize site environmental management performance.

- $\quad$ Summarize environmental occurrences and responses reported during the calendar year.

- $\quad$ Confirm compliance with environmental standards and requirements.

- $\quad$ Highlight significant facility programs and efforts.

- $\quad$ Describe how compliance and environmental improvement is accomplished through the WIPP Environmental Management System (EMS).

The DOE Carlsbad Field Office (CBFO) and the management and operating contractor (MOC), Washington TRU Solutions LLC (WTS), maintain and preserve the environmental resources at the Waste Isolation Pilot Plant (WIPP). DOE Order 231.1A; DOE Order 450.1A, Environmental Protection Program; and DOE Order 5400.5, Radiation Protection of the Public and the Environment, require that the affected environment at and near DOE facilities be monitored to ensure the safety and health of the public and workers, and preservation of the environment.

This report was prepared in accordance with DOE Order 231.1A, which requires that DOE facilities submit an ASER to the DOE Headquarters Chief Health, Safety, and Security Officer. The WIPP Hazardous Waste Facility Permit (HWFP) Number NM4890139088-TSDF (treatment, storage, and disposal facility) further requires that the ASER be provided to the New Mexico Environment Department (NMED).

\section{Major Site Programs}

\section{Mission}

The WIPP mission is to safely dispose of transuranic (TRU) radioactive waste generated by the production of nuclear weapons and other activities related to the national defense of the United States. In 2008, 5,265 cubic meters $\left(\mathrm{m}^{3}\right)$ of TRU waste were disposed of at the WIPP facility, including $5,216 \mathrm{~m}^{3}$ of contact-handled $(\mathrm{CH}) \mathrm{TRU}$ waste and $49 \mathrm{~m}^{3}$ of remote-handled $(\mathrm{RH})$ TRU waste. From the first receipt of waste in March 1999 through the end of $2008,57,873 \mathrm{~m}^{3}$ of TRU waste had been disposed of at the WIPP facility. 
Monitoring and Surveillance

It is the policy of the DOE to conduct its operations at the WIPP facility in compliance with applicable environmental laws and regulations; to protect human health and the environment; and to implement sustainable practices for enhancing environmental, energy, and transportation management. This is accomplished through a rigorous EMS. A key element of the EMS is measuring and monitoring environmental performance. At the WIPP facility, this consists of radiological and nonradiological environmental monitoring and surveillance and assessment of compliance with applicable environmental regulations. As part of this EMS, the DOE collects data needed to detect and quantify potential impacts that WIPP facility operations may have on the surrounding environment. The Waste Isolation Pilot Plant Environmental Monitoring Plan (DOE/WIPP-99-2194) (WIPP Environmental Monitoring Plan) outlines major environmental monitoring and surveillance activities at the WIPP facility and the WIPP facility quality assurance/quality control (QA/QC) program as it relates to environmental monitoring.

WIPP facility employees conduct both effluent monitoring (i.e., point source monitoring at release points such as the exhaust shaft) to detect radionuclides and quantify dose rates, and traditional pathway and receptor monitoring in the broader environment. The WIPP facility environmental monitoring program is designed to monitor pathways that radionuclides and other contaminants could take to reach the environment surrounding the WIPP facility. Pathways monitored include air, groundwater, surface water, soils, sediments, vegetation, and game animals. The goal of this monitoring is to determine if the local ecosystem has been, or is being, adversely impacted by WIPP facility operations and, if so, to evaluate the geographic extent and the effects on the environment.

The Waste Isolation Pilot Plant Land Management Plan (DOE/WIPP-93-004) (LMP) was created in compliance with the WIPP Land Withdrawal Act of 1992 (LWA) (Public Law [Pub. L.] 102-579, as amended by Pub. L. 104-201, National Defense Authorization Act for Fiscal Year 1997). This plan identifies resource values, promotes multiple-use management, and identifies long-term goals for the management of WIPP project lands. The LMP includes a land reclamation program that addresses both the short-term and long-term effects of WIPP facility operations. WIPP personnel also conduct surveillance in the region surrounding the site to protect the WIPP facility from trespass.

In this report, the WIPP facility environmental monitoring and surveillance programs are grouped as follows:

Environmental Radiological Programs

- $\quad$ Airborne particulates

- Biota

- Effluent

- Groundwater

- Sediments 
- $\quad$ Soil

- $\quad$ Surface water

Environmental Nonradiological Programs

- $\quad$ Hydrogen and methane monitoring

- $\quad$ Land management

- $\quad$ Liquid effluent

- Meteorology

- Seismic activity

- Volatile organic compounds

Groundwater Protection Programs

- Groundwater levels

- Groundwater quality

- $\quad$ Pressure density surveys

- $\quad$ Shallow subsurface water levels

- Shallow subsurface water quality

Sustainable Practices

- $\quad$ Energy use

- Use of environmentally preferred products

- Water use

- Waste generation/recycling

In 2008, the results of each of these monitoring and surveillance programs, observations, and analytical data, demonstrated that (1) compliance with applicable environmental requirements was achieved; (2) the operations at the WIPP facility have not had a negative impact on human health or the environment; and (3) sustainable practices are being implemented.

\section{Environmental Compliance}

The WIPP facility is required to comply with applicable federal and state laws and DOE orders. In order to accomplish and document compliance with certain requirements, the following submittals, which are required on a routine basis, were among those prepared in 2008:

New Mexico Submittals

A. Hazardous Waste Facility Permit

- $\quad 2007$ Annual Site Environmental Report 
- $\quad$ Semiannual Volatile Organic Compound (VOC), Hydrogen, and Methane Data Summary Report

- $\quad$ Mine Ventilation Rate Monitoring Report

- $\quad$ Quarterly Solid Waste Management Unit (SWMU) Activities Progress Reports

- Waste Minimization Statement

- WIPP Groundwater Detection Monitoring Semiannual Groundwater Monitoring Reports

- Geotechnical Data Report

- $\quad$ Monthly Water Level Reports

B. Discharge Permit (DP-831)

- Semiannual Discharge Monitoring Reports

C. Superfund Amendments and Reauthorization Act of 1986

- $\quad$ Emergency and Hazardous Chemical Inventory Report

- $\quad$ Toxic Chemical Release Inventory Report

- 2008 Annual Polychlorinated Biphenyls Report

\section{Environmental Protection Agency Submittals}

- Delaware Basin Monitoring Annual Report

- WIPP Subsidence Monument Leveling Survey

- 2007/2008 Annual Change Report

- Toxic Chemical Release Inventory Report

- 2008 Biennial Environmental Compliance Report

Other correspondence, regulatory submittals, monitoring reports, and the results of the U.S. Environmental Protection Agency (EPA) Annual Inspection, as well as other inspections, are described in Chapters 2 and 3 of this report.

In addition, WIPP maintains an in-depth, integrated evaluation program that consists of audits, assessments, surveillances and inspections. In fiscal year (FY) 2008, 
175 evaluations were conducted that incorporated compliance checks. Over the last three years, over 60 percent of all evaluations performed incorporated a level of compliance checks. This system, coupled with the WIPP corrective action system, assures that potential compliance issues are identified, and corrective/preventive actions are tracked formally through completion.

The following compliance issues were identified in 2008. The issues have either been appropriately addressed, or formal corrective action and improvement plans are in progress and slated for completion in 2009.

- In October 2008, several rain events totaling more than 4 inches resulted in a loss of the one foot of freeboard required by the discharge permit and eventually resulted in the overtopping of the berm on the Salt Storage Extension Basin. The event was promptly reported to the NMED and corrective actions proposed that involved interim corrective actions to pump water to Evaporation Ponds B and C at the sewage treatment facility and raising the level of the berm approximately 2 feet (ft). Permanent corrective actions are being implemented in accordance with a schedule submitted to the state in a letter dated December 24, 2008.

- $\quad$ On June 5, 2008, the Permittees discovered that a drum with an open nonconformance report was disposed of at WIPP. The drum had been overpacked in a standard waste box with three other drums because of drum integrity concerns. The nonconformance report was written during visual examination of the drum when an operator detected residual liquid in the drum in excess of the volume limits in the HWFP. The HWFP requires that the conditions identified in non conformance reports be resolved before the drum is shipped to the WIPP facility. The event was self-discovered and reported to the NMED and the EPA on June 6, 2008.

Even though the overpacked drum no longer failed the liquid limits by virtue of the overpacking process, the Permittees elected to remove the standard waste box containing the drum and return it to Los Alamos for further investigation. The investigation was completed in July 2008 and the drum was remediated (i.e., residual liquid was removed, mixed with absorbent and placed back in the drum). Programmatic changes were put in place in order to avoid a recurrence of shipping a container with an open nonconformance report.

- $\quad$ On April 20, 2008, polychlorinated biphenyl (PCB) waste was disposed of at WIPP and Certificates of Disposal were not sent back to the generator site within 30 days, as required by Title 40 Code of Federal Regulations (CFR) $§ 761.218(b)$. Upon discovery, on April 2, 2009, the DOE notified the EPA by phone of this event. On that same day (April 2, 2009), Certificates of Disposal were prepared and submitted to the generator for shipment IN080131. Written notification to the EPA of this instance followed on April 8, 2009. Corrective and Preventive actions have been identified and are in progress. 


\section{Key Initiatives}

\section{Environmental Management System}

The WIPP EMS provides the mechanism for achieving the WIPP policy to maintain compliance with applicable requirements, be a good environmental steward and continually improve environmental performance. The EMS is described in the Waste Isolation Pilot Plant Environmental Management System Description (DOE/WIPP-05-3318). The EMS continued to conform to the intent of the International Organization for Standardization (ISO) 14001, Environmental Management Systems Specification with Guidance for Use (ISO, 2004). The WIPP EMS also continued to meet the requirements of DOE Order 450.1 during 2008 and remained integrated with the safety management system as described in the Integrated Safety Management System Description (DOE/CBFO-98-2276). A primary EMS effort for 2008 was to adjust the WIPP EMS to assure conformance with the new sustainability requirements of the revised DOE Orders 450.1A, Environmental Protection Program, and 430.2B, Departmental Energy, Renewal Energy and Transportation Management. In addition, significant effort was made to strengthen operational controls for compliance.

Environmental performance is monitored through the environmental data generated from implementation of WIPP major environmental programs and EMS system indicators. Monitoring results and analysis demonstrate the EMS continues to be suitable and effective for achieving the WIPP environmental policy. This conclusion was confirmed through the completion of the CBFO Annual Review of the WIPP Integrated Safety Management System of October 2008 and the WIPP Environmental Management System Annual Report for Fiscal Year 2008 (DOE/WIPP-09-3333). The annual reviews also identified opportunities for improvement of the EMS that are in the process of being implemented.

Highlights of the EMS for 2008 are as follows:

- WIPP had no reportable, unauthorized contaminant releases to the environment in 2008.

- The 2008 environmental monitoring data continue to demonstrate that there has been no adverse impact to human health or the environment from WIPP facility operations.

- The WIPP integrated evaluation system remains healthy, with 175 (62 percent of all) evaluations including one or more facets of environmental compliance or performance checks.

- $\quad$ Prudent conservation practices continue to result in energy use increases at rates significantly less than increases in waste emplacement and mining rates.

- $\quad$ Gaps identified between the WIPP EMS and the sustainability and compliance requirements initiated by Executive Order (EO)13423, Strengthening Federal 
Waste Isolation Pilot Plant Annual Site Environmental Report for 2008 DOE/WIPP-09-2225

Environmental, Energy and Transportation Management, were addressed through adjustments to the EMS.

- The EMS was prepared for certification to the ISO 14001:2004(E) standard.

\section{Summary of Releases and Radiological Doses to the Public}

Doses to the Public and the Environment

The radiation dose to members of the public from WIPP facility operations has been calculated from WIPP facility effluent monitoring results and demonstrates compliance with federal regulations.

\section{Dose Limits}

The regulatory limit for the WIPP facility is established in 10 CFR Part 191, Subpart A, "Environmental Standards for Management and Storage." The referenced standard requires that the combined annual dose equivalent to any member of the public in the general environment resulting from discharges of radioactive material and direct radiation from such management and storage shall not exceed 25 millirem (mrem) ("rem" is roentgen equivalent man) to the whole body and 75 mrem to any critical organ. In addition, in a 1995 memorandum of understanding (MOU) between the EPA and the DOE, the DOE agreed that the WIPP facility would comply with 40 CFR Part 61, Subpart H, "National Emission Standards for Emissions of Radionuclides Other Than Radon from Department of Energy Facilities," hereafter referred to as the NESHAP (National Emissions Standards for Hazardous Air Pollutants). The NESHAP standard for radionuclides requires that the emissions of radionuclides to the ambient air from DOE facilities shall not exceed those amounts that would cause any member of the public to receive in any year an effective dose equivalent (EDE) of 10 mrem per year.

\section{Background Radiation}

There are several sources of naturally occurring radiation: cosmic and cosmogenic radiation (from outer space and the earth's atmosphere), terrestrial radiation (from the earth's crust), and internal radiation (naturally occurring radioactive material in our bodies). In addition to natural radioactivity, small amounts of radioactivity from aboveground nuclear weapons tests and from the 1986 Chernobyl nuclear accident are present in the environment. A potential source of radiation in the environment near and at the WIPP site is the result of Project Gnome. Under Project Gnome, a nuclear device was detonated in bedded salt on December 10, 1961, approximately 9 kilometers $(\mathrm{km})$ (5.4 miles [mi]) from the WIPP site. The Project Gnome shot vented into the atmosphere; therefore, environmental samples taken at the WIPP site may contain residual contamination from this occurrence. Together, natural radiation and residual fallout are called "background" radiation. Exposure to radioactivity from weapons testing fallout is quite small compared to natural radioactivity. Site-specific background gamma measurements on the surface, conducted by Sandia National Laboratories, showed an average dose rate of $7.65 \mathrm{microR} /$ hour (Minnema and Brewer, 1983), which 
would equate to the background gamma radiation dose of $0.67 \mathrm{mSv}$ (67.0 mrem) per year. A comprehensive radiological baseline study before WIPP facility disposal operations began was also documented in Statistical Summary of the Radiological Baseline Program for the Waste Isolation Pilot Plant (DOE/WIPP-92-037), which provides the basis for environmental background comparison after WIPP facility disposal operations commenced.

\section{Dose From Air Emissions}

WIPP personnel have identified air emissions as the major pathway of concern for radionuclide transport during the receipt and emplacement of waste at the WIPP facility. To determine the radiation dose received by members of the public from WIPP facility operations, WIPP personnel used the emission monitoring and test procedure for DOE facilities (40 CFR §61.93, "Emission Monitoring and Test Procedure"), which requires the use of the EPA-approved CAP88-PC (computer code for calculating both dose and risk from radionuclide emissions) to calculate the EDE to members of the public.

CAP88-PC dose calculations are based on the assumption that exposed people remain at home during the entire year and all vegetables, milk, and meat consumed are homeproduced. Thus, this dose calculation is a maximum dose that encompasses dose from inhalation, plume immersion, deposition, and ingestion of air-emitted radionuclides.

\section{Total Dose From WIPP Facility Operations}

The dose to an individual from the ingestion of WIPP facility-managed radionuclides transported in water is nonexistent because drinking water for communities near the WIPP site comes from groundwater sources that are too far away to be affected by WIPP facility operations.

Game animals sampled during 2008 were deer, quail, fish, javelina, and rabbit. The radionuclides detected were not different from baseline levels. By extrapolation, no dose from WIPP facility-related radionuclides has been received by any individual from this pathway (e.g., the ingestion of meat from game animals) during 2008.

Based on the results of the WIPP effluent monitoring program, concentrations of radionuclides in air emissions did not exceed regulatory dose limits set by 40 CFR Part 191, Subpart A, or by 40 CFR Part 61, Subpart H. The results indicate that the hypothetical maximally exposed individual (MEI) who resides year-round at the fence line, 350 meters $(\mathrm{m})$ from the exhaust shaft, receives a dose that is less than 7.14E-06 mSv (7.14E-04 mrem) per year for the whole body and less than 7.81E-05 mSv (7.81E-03 mrem) per year to the critical organ. These values are in compliance with the Subpart A requirements specified in 40 CFR §191.03(b). For NESHAP (40 CFR §61.92) standards, the EDE potentially received by the MEI residing $7.5 \mathrm{~km}(4.66 \mathrm{mi})$ west-northwest of WIPP was calculated to be less than $9.05 \mathrm{E}-08 \mathrm{mSv}$ ( $9.05 \mathrm{E}-06 \mathrm{mrem})$ per year for the whole body. This value is in compliance with the 40 CFR $\S 61.92$ requirements. 
Chapter 4 of this report presents figures and tables that provide the EDE values from calendar years (CYs) 1999 through 2008. These EDE values are below the EPA limit specified in 40 CFR Part 191, Subpart A, and 40 CFR Part 61, Subpart H.

\section{Dose to Nonhuman Biota}

Dose limits that cause no deleterious effects on populations of aquatic and terrestrial organisms have been suggested by the National Council on Radiation Protection and Measurements (NCRP) and the International Atomic Energy Agency. These absorbed dose limits are:

- $\quad$ Aquatic Animals

- Terrestrial Plants

- Terrestrial Animals
10 milligray/day (mGy/d) (1 radiation absorbed dose per day $[\mathrm{rad} / \mathrm{d}])$

$10 \mathrm{mGy} / \mathrm{d}(1 \mathrm{rad} / \mathrm{d})$

$1 \mathrm{mGy} / \mathrm{d}(0.1 \mathrm{rad} / \mathrm{d})$

The DOE requires discussion of radiation doses to nonhuman biota in the ASER using the DOE Technical Standard, DOE-STD-1153-2002, A Graded Approach for Evaluating Radiation Doses to Aquatic and Terrestrial Biota. This standard requires an initial screening phase using conservative assumptions. This guidance was used to screen radionuclide concentrations observed around the WIPP site during 2008. The screening results indicate that radiation in the environment surrounding the WIPP site does not have a deleterious effect on populations of plants and animals.

\section{Release of Property Containing Residual Radioactive Material}

There was no release of radiologically contaminated materials or property in 2008 . 
Waste Isolation Pilot Plant Annual Site Environmental Report for 2008

DOE/WIPP-09-2225

This page intentionally left blank 


\section{CHAPTER 1 - INTRODUCTION}

The purpose of this report is to provide information needed by the DOE to assess WIPP facility environmental performance and to make WIPP Project environmental information available to members of the public. This report has been prepared in accordance with DOE Order 231.1A, Environment, Safety, and Health Reporting. This report documents the WIPP facility environmental monitoring and results for CY 2008.

The WIPP facility is authorized by the DOE National Security and Military Applications of Nuclear Energy Authorization Act of 1980 (Public Law [Pub. L.] 96-164). After more than twenty years of scientific study and public input, the WIPP facility received its first shipment of waste on March 26, 1999.

Located in southeastern New Mexico, the WIPP facility is the nation's first underground repository permitted to safely and permanently dispose of TRU radioactive and mixed waste generated through defense activities and programs. TRU waste is defined in the WIPP LWA (Pub. L. 102-579) as radioactive waste containing more than 100 nanocuries $(3,700$ becquerels $[\mathrm{Bq}])$ of alpha-emitting TRU isotopes per gram of waste, with half-lives greater than twenty years except for high-level waste; waste that has been determined not to require the degree of isolation required by the disposal regulations; and waste the U.S. Nuclear Regulatory Commission has approved for disposal. Most TRU waste is contaminated industrial trash, such as rags and old tools; sludges from solidified liquids; glass; metal; and other materials. The waste must also meet the criteria in Transuranic Waste Acceptance Criteria for the Waste Isolation Pilot Plant (DOE/WIPP-02-3122).

TRU waste is disposed of $655 \mathrm{~m}(2,150 \mathrm{ft})$ below the surface in excavated disposal rooms in the Salado Formation, which is a thick sequence of Permian Age evaporite salt beds. At the conclusion of the WIPP disposal phase, seals will be placed in the shafts. One of the main attributes of salt, as a rock formation in which to isolate radioactive waste, is the ability of the salt to creep, that is, to deform continuously over time. Excavations into which the waste-filled drums are placed will close eventually and the surrounding salt will flow around the drums and seal them within the Salado Formation. A detailed description of the WIPP geology and hydrology may be found in Chapter 2 of Title 40 CFR Part 191 Subparts B and C Compliance Recertification Application 2004 (DOE/WIPP-04-3231, CRA-2).

\subsection{WIPP Mission}

The WIPP mission is to provide for the safe, environmentally sound disposal of defense TRU radioactive waste left from research, development, and production of nuclear weapons.

\subsection{WIPP History}

Government officials and scientists initiated the WIPP site selection process in the 1950s. At that time, the National Academy of Sciences initiated an evaluation of stable 
geological formations to contain radioactive wastes for thousands of years. In 1955, after extensive study, salt deposits were recommended as a promising medium for the disposal of radioactive waste.

Salt deposits were selected as the host for the disposal of nuclear waste for several reasons. Most deposits of salt are found in stable geological areas with very little earthquake activity, assuring the stability of a waste repository. Salt deposits also demonstrate the absence of water that could move waste to the surface. Water, if it had been or were present, would have dissolved the salt beds. In addition, salt is relatively easy to mine. Finally, rock salt heals its own fractures because it is relatively plastic. This means salt formations will slowly and progressively move in to fill mined areas and will safely seal radioactive waste from the biosphere.

Government scientists searched for an appropriate site for the disposal of radioactive waste throughout the 1960s, and finally tested the area of southeastern New Mexico in the early 1970s. Salt formations at the WIPP site were deposited in thick beds during the evaporation of the Permian Sea. These geologic formations consist mainly of sodium chloride, the same substance as table salt. However, the salt is not granular, but in the form of solid rock. The main salt formation is approximately $610 \mathrm{~m}(2,000 \mathrm{ft})$ thick, and begins $259 \mathrm{~m}$ ( $850 \mathrm{ft}$ ) below the earth's surface. Formed during the Permian Age, the large expanses of uninterrupted salt beds provide a geologic environment that is stable.

In 1979, Congress authorized the construction of the WIPP facility, and the DOE constructed the facility during the 1980s. In late 1993, the DOE created the Carlsbad Area Office (CAO), subsequently redesignated as the CBFO, to lead the TRU waste disposal effort. The CBFO coordinates the TRU program at waste-generating sites and national laboratories.

In 1999, the WIPP facility received its first waste shipment. On March 25, the first waste bound for the WIPP facility departed Los Alamos National Laboratory in New Mexico; it arrived at the WIPP facility the following morning, and the first wastes were placed underground later that day. On April 27, the first out-of-state shipment arrived at the WIPP site from the Idaho National Engineering and Environmental Laboratory. Later in the year, on October 27, the Secretary of the NMED issued the WIPP HWFP (NM4890139088-TSDF), which allowed CH TRU mixed waste to be managed, stored, and disposed at the WIPP facility. Mixed waste is waste that contains both hazardous and radioactive waste. $\mathrm{CH}$ TRU mixed waste is TRU mixed waste with a maximum surface dose rate of $200 \mathrm{mrem}$ per hour. The surface dose rate is the measurable amount of radioactivity from neutrons and gamma rays at the external surface of the container.

On October 16, 2006, the Secretary of the NMED issued a revised HWFP allowing the WIPP facility to receive RH TRU mixed waste. RH TRU waste allowable at the WIPP facility has a surface dose rate greater than or equal to $200 \mathrm{mrem}$ per hour and up to 1,000 rem per hour. 


\subsection{Site Description}

Located in Eddy County in the Chihuahuan Desert of southeastern New Mexico (Figure 1.1), the WIPP site encompasses $41.4 \mathrm{~km}^{2}$, or $16 \mathrm{mi}^{2}$. This part of New Mexico is relatively flat and is sparsely inhabited, with little surface water. The site is $42 \mathrm{~km}$ (26 mi) east of Carlsbad in a region known as Los Medaños (the Dunes).

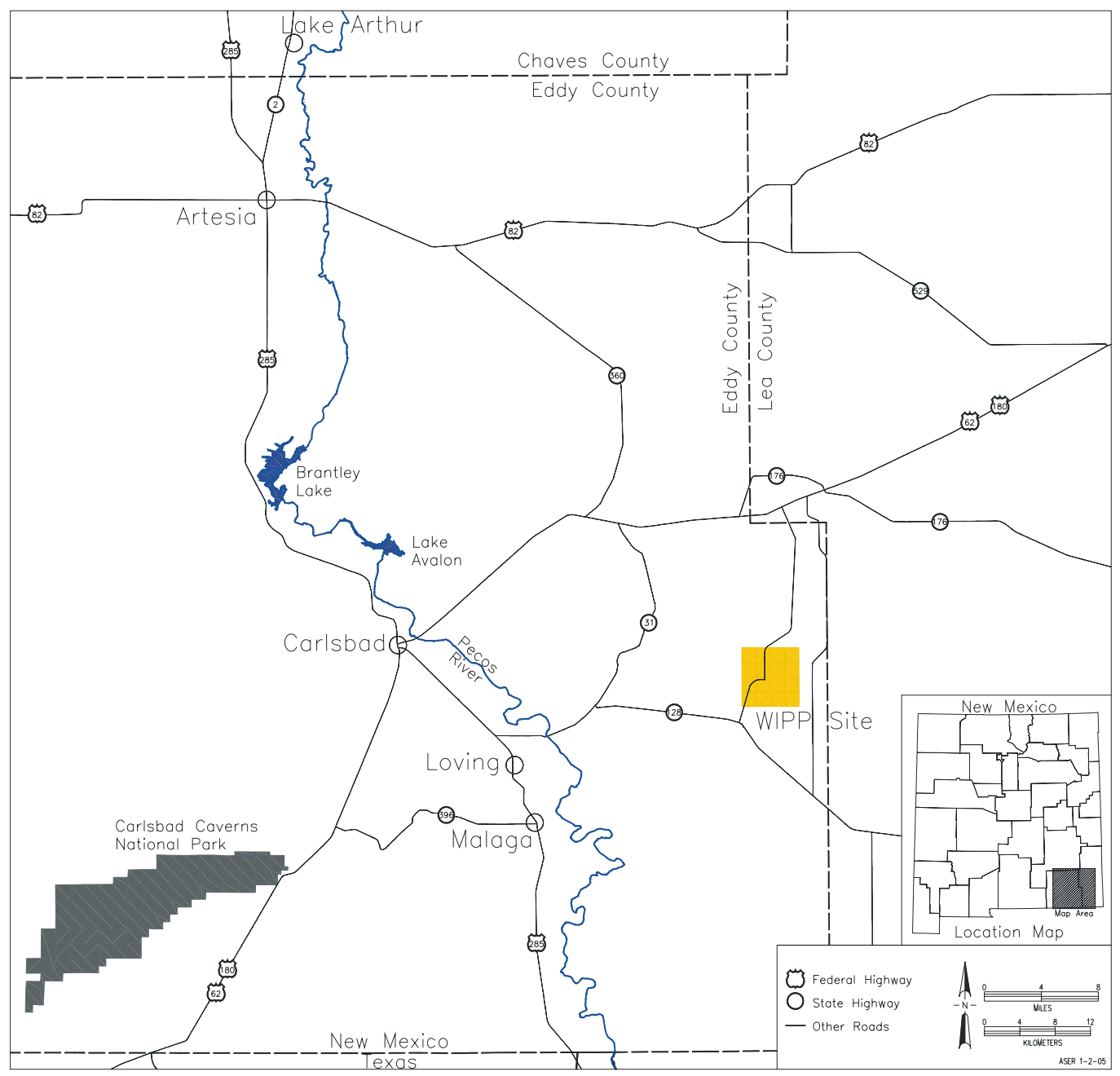

Figure 1.1 - WIPP Location

The WIPP LWA was signed into law on October 30, 1992, transferring the administration of federal land from the U.S. Department of the Interior to the DOE. With the exception of facilities within the boundaries of the posted $1.2 \mathrm{~km}^{2}\left(0.463 \mathrm{mi}^{2}\right)$ Exclusive Use Area, the surface land uses remain largely unchanged from pre-1992 uses, and are managed in accordance with accepted practices for multiple land use. However, mining and drilling for purposes other than those which support the WIPP Project are prohibited within the WIPP site, with the exception of two mineral leases. 
The majority of the lands in the immediate vicinity of the WIPP site are managed by the U.S. Department of the Interior Bureau of Land Management (BLM). Land uses in the surrounding area include livestock grazing; potash mining; oil and gas exploration and production; and recreational activities such as hunting, camping, hiking, and bird watching. The region is home to diverse populations of animals and plants.

\subsubsection{WIPP Property Areas}

Four property areas are defined within the WIPP site boundary (Figure 1.2).

\section{Property Protection Area}

The interior core of the facility encompasses $0.14 \mathrm{~km}^{2}\left(0.05 \mathrm{mi}^{2}\right)$ (35 acres) surrounded by a chain link fence. Security is provided for this area 24 hours a day.

\section{Exclusive Use Area}

The Exclusive Use Area is comprised of $1.1 \mathrm{~km}^{2}\left(.43 \mathrm{mi}^{2}\right)(277$ acres). It is surrounded by a barbed wire fence and is restricted exclusively for the use of the DOE and its contractors and subcontractors in support of the project. This area is marked by DOE warning (e.g., "no trespassing") signs and is patrolled by WIPP facility security personnel to prevent unauthorized activities or uses.

\section{Off-Limits Area}

The Off-Limits Area is an area where unauthorized entry and introduction of weapons and/or dangerous materials are prohibited. The Off-Limits Area includes $5.9 \mathrm{~km}^{2}$ $\left(2.3 \mathrm{mi}^{2}\right)(1,454$ acres$)$. Pertinent prohibitions are posted along the perimeter. Grazing and public thoroughfare will continue in this area unless these activities present a threat to the security, safety, or environmental quality of the WIPP site. This area is patrolled by WIPP facility security personnel to prevent unauthorized activities or use.

\section{WIPP Land Withdrawal Area}

The WIPP site boundary delineates the perimeter of the $41.4 \mathrm{~km}^{2}\left(16 \mathrm{mi}^{2}\right)$ $(10,240$ acres) WIPP Land Withdrawal Area. This tract includes the Property Protection Area, the Exclusive Use Area, and the Off-Limits Area, as well as outlying areas. 


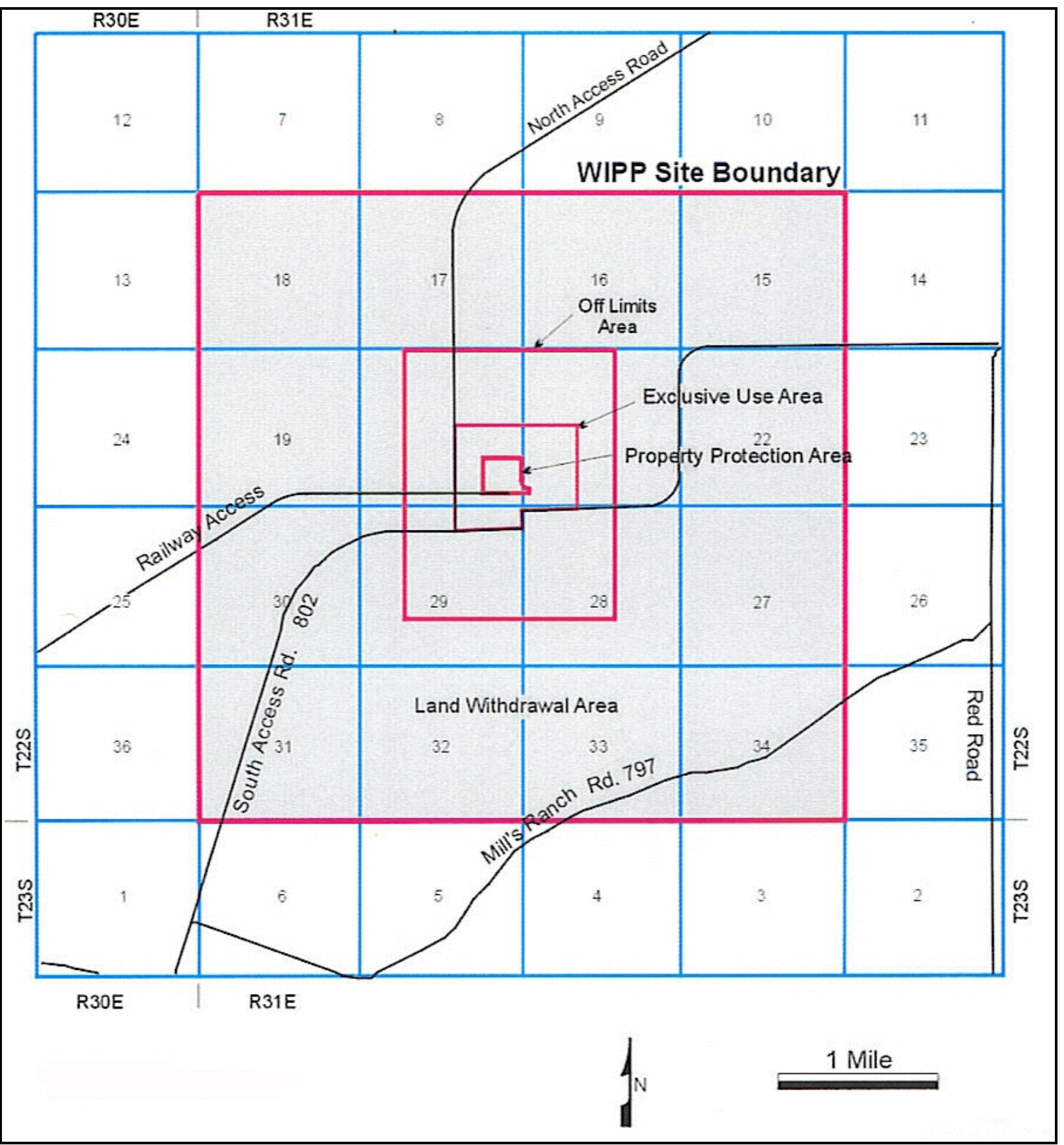

Figure 1.2 - WIPP Property Areas

\section{Special Management Areas}

Certain properties used in the execution of the WIPP Project (e.g., reclamation sites, well pads, roads) are, or may be, identified as Special Management Areas in accordance with the WIPP LMP (DOE/WIPP-93-004), which is described further in Section 5.2. A Special Management Area designation is made due to values, resources, and/or circumstances that meet criteria for protection and management under special management designations. Unique resources of value that are in danger 
of being lost or damaged, areas where ongoing construction is occurring, fragile plant and/or animal communities, sites of archaeological significance, locations containing safety hazards, or sectors that may receive an unanticipated elevated security status would be suitable for designation as a Special Management Area. In 2008, there were no areas designated as Special Management Areas.

\subsubsection{Population}

There are 25 permanent residents living within $16 \mathrm{~km}(10 \mathrm{mi})$ of the WIPP site (DOE/WIPP-93-004). The population within $16 \mathrm{~km}$ (10 mi) of WIPP is associated with ranching, oil and gas exploration/production, and potash mining.

The majority of the local population within $80.5 \mathrm{~km}$ (50 mi) of WIPP is concentrated in and around the communities of Carlsbad, Hobbs, Eunice, Loving, Jal, Lovington, and Artesia, New Mexico. According to 2000 census data, the estimated population within this radius is 100,944 . The nearest community is the village of Loving (estimated population 1,326), $29 \mathrm{~km}(18 \mathrm{mi})$ west-southwest of the WIPP site. The nearest major populated area is Carlsbad, $42 \mathrm{~km}(26 \mathrm{mi})$ west of the WIPP site. The 2000 census reported the population of Carlsbad as 25,675.

\subsection{WIPP Environmental Stewardship}

The DOE policy is to conduct its operations in compliance with applicable environmental laws and regulations, and to safeguard the integrity of the southeastern New Mexico environment. The DOE conducts effluent monitoring, environmental surveillance, land management, and assessments to verify that these objectives are met. Environmental monitoring includes collecting and analyzing environmental samples from various media and evaluating whether WIPP facility operations have caused any adverse environmental impacts.

\subsubsection{Environmental Monitoring Plan}

The Waste Isolation Pilot Plant Environmental Monitoring Plan (DOE/WIPP-99-2194) outlines the program for monitoring the environment at and around the WIPP site, including the major environmental monitoring and surveillance activities at the WIPP facility. The plan also discusses the WIPP Project QA/QC program as it relates to environmental monitoring. The purpose of the plan is to specify how the effects of WIPP facility operations on the local ecosystem are to be determined. Effluent and environmental monitoring data are necessary to demonstrate compliance with applicable environmental protection regulations. The frequency of 2008 sampling is provided in Table 1.1. 
Waste Isolation Pilot Plant Annual Site Environmental Report for 2008 DOE/WIPP-09-2225

\begin{tabular}{|c|c|c|c|}
\hline Program & Type of Sample & $\begin{array}{l}\text { Number of } \\
\text { Sampling } \\
\text { Locations }\end{array}$ & Sampling Frequency \\
\hline \multirow[t]{11}{*}{ Radiological } & Airborne effluent & 3 & Periodic/confirmatory \\
\hline & Airborne particulate & 7 & Weekly \\
\hline & $\begin{array}{l}\text { Sewage treatment system } \\
(\mathrm{DP}-831)^{2}\end{array}$ & 3 & Semiannual \\
\hline & $\mathrm{H}-19(\mathrm{DP}-831)^{2}$ & 1 & Semiannual \\
\hline & Liquid effluent & 1 (WHB sump) & If needed \\
\hline & \multicolumn{3}{|l|}{ Biotic } \\
\hline & $\begin{array}{l}\text { - } \text { Quail } \\
\text { - Rabbits } \\
\text { - Beef/Deer } \\
\text { - Javelina } \\
\text { - Fish } \\
\text { - Vegetation }\end{array}$ & $\begin{array}{c}\text { WIPP vicinity } \\
\text { WIPP vicinity } \\
\text { WIPP vicinity } \\
\text { WIPP vicinity } \\
3 \\
6\end{array}$ & $\begin{array}{l}\text { Annual } \\
\text { As available } \\
\text { As available } \\
\text { As available } \\
\text { Annual } \\
\text { Annual }\end{array}$ \\
\hline & Soil & 6 & Annual \\
\hline & Surface water & Maximum of 14 & Annual \\
\hline & Sediment & $\begin{array}{l}\text { Maximum of } 12 ; \\
13 \text { if sediment is } \\
\text { present at sewage } \\
\text { lagoon outfall }\end{array}$ & Annual \\
\hline & Groundwater & 7 & Semiannual \\
\hline \multirow[t]{7}{*}{ Nonradiological } & Meteorology & 1 & Continuous \\
\hline & \multicolumn{3}{|l|}{ Volatile organic compounds (VOCs) } \\
\hline & $\begin{array}{l}\text { - VOCs - Repository } \\
\text { - VOCs - Disposal Room }\end{array}$ & $\begin{array}{c}2 \\
\text { \# of active panel } \\
\text { disposal rooms }\end{array}$ & $\begin{array}{l}\text { Semiweekly } \\
\text { Bi-weekly }\end{array}$ \\
\hline & Hydrogen and methane & $\begin{array}{l}18 \text { per closed } \\
\text { panel }\end{array}$ & Monthly \\
\hline & Groundwater & 7 & Semiannual \\
\hline & Shallow subsurface water (SSW) & 11 & Semiannual \\
\hline & Surface water (DP-831) & 5 & $\begin{array}{l}\text { After a major storm event } \\
\text { or annually, whichever is } \\
\text { more frequent }\end{array}$ \\
\hline
\end{tabular}

1 The number of certain types of samples taken can be driven by site conditions. For example, during dry periods there may be no surface water or sediment to sample at certain locations. Likewise, the number of samples for biota will also vary. For example, the number of rabbits available as samples of opportunity will vary as will fishing conditions that are affected by weather and algae levels in the water.

2 Includes a nonradiological program component. 
The plan describes the monitoring of naturally occurring and specific anthropogenic (human-made) radionuclides. The geographic scope of radiological sampling is based on projections of potential release pathways from the waste disposed at the WIPP facility. The plan also describes monitoring of VOCs, groundwater chemistry, and other nonradiological environmental parameters, and collection of meteorological data.

\subsubsection{WIPP Facility Environmental Monitoring Program and Surveillance Activities}

Employees of the WIPP facility monitor air, surface water, groundwater, sediments, soils, and biota (e.g., vegetation, select mammals, quail, and fish). Environmental monitoring activities are performed in accordance with procedures that govern how samples are to be taken, preserved, and transferred. Procedures also direct the verification and validation of environmental sampling data.

The atmospheric pathway, which can lead to the inhalation of radionuclides, has been determined to be the most likely exposure pathway to the public from the WIPP facility. Therefore, airborne particulate sampling for alpha-emitting radionuclides is emphasized. Air sampling results are used to trend environmental radiological levels and determine if there has been a deviation from established baseline concentrations. The geographic scope of radiological sampling is based on projections of potential release pathways and nearby populations for the types of radionuclides in TRU wastes that are managed at the WIPP facility, and includes Carlsbad, New Mexico, and nearby ranches.

Nonradiological environmental monitoring activities at the WIPP site consist of sampling and analyses designed to detect and quantify impacts of construction and operational activities, and verify compliance with applicable requirements.

\subsection{Environmental Performance}

DOE Order 450.1A, Environmental Protection Program, describes the DOE commitment to environmental protection and pledges to implement sound stewardship practices that are protective of the air, water, land, and other natural and cultural resources. The provisions of DOE Order $450.1 \mathrm{~A}$ are implemented by the WIPP Project environmental policy and EMS.

In 2008, WIPP maintained compliance with applicable environmental laws, regulations, and permit conditions, except as noted in Sections 2.2 and 2.9. Furthermore, analyses of the WIPP environmental monitoring data have demonstrated that WIPP operations have not had an adverse impact on the environment. Implementation of the WIPP Environmental Monitoring Plan fulfills the environmental monitoring requirements of DOE Order 450.1A. Detailed information on WIPP programs are contained in the remaining chapters. 


\subsection{Organization of this Annual Site Environmental Report}

This ASER is organized as follows:

- Chapter 2 is the Compliance Summary.

- $\quad$ Chapter 3 presents the WIPP Project Environmental Management System.

- $\quad$ Chapter 4 presents the WIPP Facility Environmental Radiological Protection Program and Dose Assessment.

- $\quad$ Chapter 5 presents the WIPP Facility Environmental Nonradiological Program information and results.

- $\quad$ Chapter 6 presents the WIPP Facility Groundwater Protection Program and results.

- $\quad$ Chapter 7 contains information on Quality Assurance and results. 
Waste Isolation Pilot Plant Annual Site Environmental Report for 2008

DOE/WIPP-09-2225

This page intentionally left blank 


\section{CHAPTER 2 - COMPLIANCE SUMMARY}

The WIPP facility is required to comply with the applicable regulations promulgated pursuant to federal and state statutes, DOE orders, and Executive Orders (EOs). Compliance with regulatory requirements is incorporated into facility plans and implementing procedures. Methods for maintaining compliance with environmental requirements include the use of engineered controls and written procedures, routine training of facility personnel, ongoing self-assessments, and personnel accountability. The following sections list the environmental statutes/regulations applicable to WIPP, and describe significant accomplishments and ongoing compliance activities. A detailed breakdown of WIPP Project compliance with environmental laws is available in the Waste Isolation Pilot Plant Biennial Environmental Compliance Report (DOE/WIPP-08-2171).

A summary of WIPP Project compliance with major environmental regulations is presented below. A list of active WIPP Project environmental permits appears in Appendix B.

\subsection{Comprehensive Environmental Response, Compensation, and Liability Act}

The Comprehensive Environmental Response, Compensation, and Liability Act (CERCLA) (42 U.S.C. §§9601, et seq.), or Superfund, establishes a comprehensive federal strategy for responding to, and establishing liability for, releases of hazardous substances from a facility to the environment. Any spills of hazardous substances that exceed a reportable quantity must be reported to the National Response Center under the provisions of CERCLA and 40 CFR Part 302, "Designation, Reportable Quantities, and Notification." Hazardous substance cleanup procedures are specified in 40 CFR Part 300, "National Oil and Hazardous Substances Pollution Contingency Plan."

\section{Superfund Amendments and Reauthorization Act of 1986}

The WIPP facility is required by the Superfund Amendments and Reauthorization Act of 1986 Title III (42 U.S.C. §11101) (also known as the Emergency Planning and Community Right-to-Know Act [EPCRA], which is implemented by

40 CFR Parts 302-313) to submit (1) a list of hazardous chemicals present at the facility in excess of 10,000 pounds for which Material Safety Data Sheets are required, (2) an Emergency and Hazardous Chemical Inventory Form (Tier II Form) that identifies the inventory of hazardous chemicals present during the preceding year, and (3) notification to the State Emergency Response Commission (SERC) and the Local Emergency Planning Committee (LEPC) of any accidental releases of hazardous chemicals in excess of reportable quantities. The list of hazardous chemicals and the Tier II Form are also submitted to the regional fire departments.

The list of chemicals provides external emergency responders with information they may need when responding to a hazardous chemical emergency at WIPP. The list of chemicals is a one-time notification unless new chemicals in excess of 10,000 pounds, 
or new information on existing chemicals, are received. The last notification was made in 1999.

The LEPC and the SERC are notified whenever a new chemical is received on-site in excess of 10,000 pounds at any one time. The chemical is reported to the LEPC and the SERC within thirty days of receipt of the chemical.

The Tier II Form, due on March 1 of each year, provides information for the public about hazardous chemicals above threshold planning quantities that a facility has on-site at any time during the year. The Tier II Form is submitted annually to each fire department with which the CBFO maintains a memorandum of understanding and to the LEPC and the SERC.

Title 40 CFR Part 313, "Toxics Release Inventory," identifies requirements for facilities to submit a toxic chemical release report to the EPA and the resident state if toxic chemicals are used at the facility in excess of established threshold amounts. The Toxic Chemical Release Report was submitted to the EPA and to the SERC prior to the July 1, 2008, reporting deadline. Table 2.1 presents the 2008 EPCRA reporting status. $A$ response of "yes" indicates that the report was required and submitted.

Table 2.1 - Status of EPCRA Reporting

\begin{tabular}{|l|l|c|}
\hline $\begin{array}{c}\text { EPCRA Regulations } \\
\text { 40 CFR Parts }\end{array}$ & \multicolumn{1}{|c|}{ Description of Reporting } & \multicolumn{1}{c|}{ Status } \\
\hline $302-303$ & Planning Notification & Further Notification Not Required \\
\hline 304 & $\begin{array}{l}\text { Extremely Hazardous Substance Release } \\
\text { Notification }\end{array}$ & Not Required \\
\hline $311-312$ & $\begin{array}{l}\text { Material Safety Data Sheet/Chemical } \\
\text { Inventory (Tier II Form) }\end{array}$ & Yes \\
\hline 313 & Toxics Release Inventory Reporting & \multicolumn{1}{|c|}{ Yes } \\
\hline
\end{tabular}

Accidental Releases of Reportable Quantities of Hazardous Substances

During 2008, there were no releases of hazardous substances exceeding the reportable quantity limits.

\subsection{Resource Conservation and Recovery Act}

The Resource Conservation and Recovery Act (RCRA) (42 U.S.C. $\$ \$ 6901$, et seq.) was enacted in 1976. Implementing regulations were promulgated in May 1980. This body of regulations ensures that hazardous waste is managed and disposed of in a way that protects human health and the environment. The Hazardous and Solid Waste Amendments of 1984 prohibit land disposal of hazardous waste unless treatment standards are met or specific exemptions apply. The amendments also emphasize waste minimization. 
The NMED is authorized by the EPA to implement the hazardous waste program in New Mexico pursuant to the New Mexico Hazardous Waste Act (New Mexico Statutes Annotated [NMSA] §§74-4-1, et seq., 1978). The technical standards for hazardous waste treatment, storage, and disposal facilities in New Mexico are outlined in 20.4.1.500 New Mexico Administrative Code (NMAC), which adopts, by reference, 40 CFR Part 264, "Standards for Owners and Operators of Hazardous Waste Treatment, Storage, and Disposal Facilities." The hazardous waste management permitting program is administered through 20.4.1.900 NMAC, which adopts, by reference, 40 CFR Part 270, "EPA Administered Permit Programs: The Hazardous Waste Permit Program."

\section{Hazardous Waste Facility Permit}

The NMED issued the WIPP HWFP on October 27, 1999, and it became effective November 26, 1999. The HWFP authorized the WIPP facility to receive, store, and dispose of CH TRU mixed waste. The NMED modified the HWFP on October 16, 2006, to also allow receipt, storage, and disposal of RH TRU mixed waste. Two storage units (the parking area container storage unit and the Waste Handling Building container storage unit) are permitted for storage of TRU mixed waste. Seven underground hazardous waste disposal units are currently permitted for the disposal of $\mathrm{CH}$ and RH TRU mixed waste.

On June 5, 2008, the Permittees discovered that a drum with an open nonconformance report was disposed of at WIPP. The drum had been overpacked in a standard waste box with three other drums because of drum integrity concerns. The nonconformance report was written during visual examination of the drum when an operator detected residual liquid in the drum in excess of the volume limits in the HWFP. The HWFP requires that the conditions identified in non conformance reports be resolved before the drum is shipped to the WIPP facility. The event was self-discovered and reported to the NMED and the EPA on June 6, 2008.

Even though the overpacked drum no longer failed the liquid limits by virtue of the overpacking process, the Permittees elected to remove the standard waste box containing the drum and return it to Los Alamos for further investigation. The investigation was completed in July 2008 and the drum was remediated (i.e., residual liquid was removed, mixed with absorbent and placed back in the drum). Programmatic changes were put in place in order to avoid a recurrence of shipping a container with an open nonconformance report.

On November 14, 2008, a Notice of Violation (NOV) was issued to the Permittees from the NMED Hazardous Waste Bureau for the disposal of brine water containing lead above the regulatory levels in an evaporation pond. The NOV contained two violations: (1) disposing of hazardous waste in the evaporation pond without a hazardous waste disposal permit, and (2) land disposal of hazardous waste without meeting the appropriate treatment standards. The NOV requested specific information regarding the disposal of hazardous brine water. The information was sent to the NMED. 


\section{Modification Requests}

In 2008, the Permittees submitted two HWFP modification notification/requests to the NMED. These submittals consisted of two Class 1 change notifications. Class 1 changes may be implemented upon submittal to the regulator. Table 2.2 provides details on the modification requests submitted to NMED in 2008.

\begin{tabular}{|c|c|c|}
\hline Class & Description & Date Submitted \\
\hline 1 & $\begin{array}{l}\text { Permit Modification Notifications consisting of: } \\
\text { - } \quad \text { Revise Attachment B6 Checklist } \\
\text { - } \quad \text { Revise Working Days to Calendar Days } \\
\text { - } \quad \text { Correct Table B1-3 } \\
\text { - } \quad \text { Correct Storage Capacity in Attachment F }\end{array}$ & January 2008 \\
\hline 1 & $\begin{array}{l}\text { Various Class } 1 \text { Modifications Consisting of: } \\
\text { - Update SW-846 and EPA Methods } \\
\text { - } \quad \text { Revise Attachment H to Update the Organization responsible for the } \\
\text { List of Personnel Assignments } \\
\text { - } \quad \text { Revise Attachment H1 Regarding Job Title } \\
\text { - Revise Two Facility Descriptions } \\
\text { - } \quad \text { Revise Language in Table B-5 to be Consistent with Permit Text } \\
\text { - Revise Reference to Table B3-3 } \\
\text { - } \quad \text { Update Underground and Surface Figures to be Consistent with } \\
\quad \text { Current Configurations } \\
\text { - } \quad \text { Revise Final Waste Volume for Panel } 3\end{array}$ & July 2008 \\
\hline
\end{tabular}

\section{Underground Storage Tanks}

Title 40 CFR Part 280, "Technical Standards and Corrective Action Requirements for Owners and Operators of Underground Storage Tanks (UST)," addresses USTs containing petroleum products or hazardous chemicals. Requirements for UST management pertain to the design, construction, installation, and operation of USTs, as well as notification and corrective action requirements in the event of a release and actions required for out-of-service USTs. The NMED has been authorized by the EPA to regulate USTs, and implements the EPA program through 20.5 NMAC, "Petroleum Storage Tanks." The WIPP facility maintains two petroleum USTs registered with the NMED.

The NMED conducted an inspection of the USTs on March 18, 2008. The tanks were determined to be maintained in compliance with the applicable regulations.

\section{Hazardous Waste Generator Compliance}

Nonradioactive hazardous waste is currently generated through routine facility operations, and is managed in satellite accumulation areas, a "less-than-90-day" accumulation area on the surface, and a "less-than-90-day" accumulation area underground. 
Hazardous waste generated at the WIPP facility is accumulated, characterized, packaged, labeled, and manifested to off-site treatment, storage, and disposal facilities in accordance with the requirements codified in 20.4.1.300 NMAC, which adopts, by reference, 40 CFR Part 262, "Standards Applicable to Generators of Hazardous Waste."

On January 18,2008 , the NMED requested information and supporting documentation associated with a discharge of 150 gallons of leaded water into Evaporation Pond $\mathrm{H}-19$ on November 9, 2007. The requested information was received by the NMED on February 25, 2008. On November 14, 2008, a Notice of Violation (NOV) was issued to the Permittees from the NMED Hazardous Waste Bureau for the disposal of brine water containing lead above the regulatory levels in an evaporation pond. The NOV contained two violations: (1) disposing of hazardous waste in the evaporation pond without a hazardous waste disposal permit, and (2) land disposal of hazardous waste without meeting the appropriate treatment standards.

In 2007, a leaking cesium-137 $\left({ }^{137} \mathrm{Cs}\right)$ source contaminated some lead shot that was previously used as shielding. This mixed waste that was generated from the cleanup operations of this leaking source was disposed of at an off-site disposal facility permitted for the disposal of mixed waste. The leaking source with the lead shielding was shipped for disposal in August 2009.

\section{WIPP Solid Waste Management Units and Areas of Concern}

A no further action report and petition was submitted to the NMED in October 2002 for the purpose of removing the fifteen SWMUs and eight areas of concern (AOCs) from the requirement for further remediation. On April 20, 2007, the NMED reviewed and approved the WIPP no further action petition for SWMUs and AOCs. Public meetings were held in Santa Fe and Carlsbad and no comments were forthcoming. The Class 3 HWFP modification request was submitted to the NMED on August 27, 2007, and the modification was issued by the NMED on October 23, 2008.

\section{Program Deliverables and Schedule}

WIPP is in compliance with the HWFP conditions related to reporting as noted below:

- $\quad$ The annual Waste Minimization Certification Statement was completed and placed in the operating record as of November 2008 and was transmitted to the NMED.

- $\quad$ HWFP Module IV, Section F, Maintenance and Monitoring, requires annual reports evaluating the geomechanical monitoring program and the mine ventilation rate monitoring. The WIPP facility continued to comply with these requirements by preparation and submission of annual reports in October 2008, representing results for July 1, 2007, through June 30, 2008. 
Semiannual reports are required describing the implementation and results (data and analysis) of the confirmatory VOC monitoring. The WIPP facility continued to comply with these requirements by preparation and submission of semiannual reports in April 2008, representing results for July 1, 2007, through December 31, 2007, and another semiannual report in October 2008 representing results for January 1, 2008, through June 30, 2008. Reporting of hydrogen and methane program data was not required during 2008.

HWFP Module V, Section V.J.2.a, requires reports of the analytical results for semiannual detection monitoring program (DMP) well samples and duplicates, as well as results of the statistical analysis of the samples from which the determination was made that there is or is no statistically significant evidence of contamination. These reports for Sampling Rounds 26 and 27 were submitted to the NMED in 2008. Sampling results are also summarized in Appendices $E$ and $F$ of this ASER.

- $\quad$ HWFP Module V, Section V.J.2.b. requires monthly submittal of groundwater surface elevation results. This includes groundwater surface elevations calculated from field measurements and fresh-water head elevations calculated as specified in Permit Attachment L, Section L-4c(1). Twelve monthly reports were submitted to the NMED in 2008 as required.

HWFP Module V, Section V.J.2.c. requires that radionuclide sampling results and groundwater flow rate and direction be included in the ASER by October 1 of each year. These 2008 data are presented in Chapter 4, Environmental Radiological Program Information; and Chapter 6, Site Hydrology, Groundwater Monitoring, and Public Drinking Water Protection, of this ASER, respectively.

\subsection{National Environmental Policy Act}

The National Environmental Policy Act (NEPA) (42 U.S.C. §§4321, et seq.) requires the federal government to use all practicable means to consider potential environmental impacts of proposed projects as part of the decision-making process. The NEPA also dictates that the public shall be allowed to review and comment on proposed projects that have the potential to significantly affect the environment.

NEPA requirements are detailed in the Council on Environmental Quality regulations in 40 CFR Parts 1500-1508. The DOE codified its requirements for implementing the council's regulations in 10 CFR Part 1021, "National Environmental Policy Act Implementing Procedures." Title 10 CFR §1021.331 requires that, following completion of each environmental impact statement (EIS) and its associated record of decision, the DOE prepare a mitigation action plan that addresses mitigation commitments expressed in the record of decision. The first WIPP mitigation action plan was prepared in 1991. Additionally, the CBFO tracks the performance of mitigation commitments in the WIPP annual mitigation report. This report is issued in July of each year. 
Day-to-day operational compliance with the NEPA at the WIPP facility is achieved through implementation of a NEPA compliance plan and procedure. Seventy-eight projects were reviewed and approved by the CBFO NEPA Compliance Officer through the NEPA screening and approval process in 2008 . These projects were primarily upgrades to the facilities and equipment at the WIPP site. These approvals were in addition to routine activities which have been predetermined to be bounded by existing NEPA documentation and which do not require additional evaluation by the CBFO NEPA Compliance Officer. The CBFO NEPA Compliance Officer also routinely participates in the development of NEPA documents from the DOE and other federal agencies for actions that may have environmental impacts on WIPP.

\section{$2.4 \quad$ Clean Air Act}

The Clean Air Act (42 U.S.C. $\S \S 7401$, et seq.) provides for the preservation, protection, and enhancement of air quality. Both the state of New Mexico and the EPA have authority for regulating compliance with portions of the Clean Air Act. Radiological effluent monitoring in compliance with EPA standards is discussed in Chapter 4.

The Clean Air Act established National Ambient Air Quality Standards for six "criteria" pollutants: sulfur oxides, particulate matter, carbon monoxide, ozone, nitrogen dioxide, and lead. The initial 1993 WIPP air emissions inventory was developed as a baseline document to calculate maximum potential hourly and annual emissions of both hazardous and criteria pollutants. Based on the current air emissions inventory, WIPP facility operations do not exceed the 10-ton-per-year emission limit for any individual hazardous air pollutant, the 25-ton-per-year limit for any combination of hazardous air pollutant emissions, or the 10-ton-per-year emission limit for criteria pollutants except for total suspended particulate matter and particulate matter less than 10 microns in diameter. Particulate matter is produced from fugitive sources related to the management of salt tailings extracted from the underground. Consultation with the NMED Air Quality Bureau resulted in a March 2006 determination that a permit is not required for fugitive emissions of particulate matter that result from salt management at the WIPP facility. Proposed facility modifications are reviewed to determine if they will create new air emission sources and require permit applications.

Based on the initial 1993 air emissions inventory, the WIPP site is not required to obtain Clean Air Act permits. In 1993, the DOE did obtain a New Mexico Air Quality Control Regulation 702, Operating Permit (recodified in 2001 as 20.2.72 NMAC, "Construction Permits") for two backup diesel generators at the WIPP facility. There have been no activities or modifications to the operating conditions of the diesel generators that would require reporting under the conditions of the permit in 2008.

\subsection{Clean Water Act}

The Clean Water Act (33 U.S.C. §§1251, et seq.) establishes provisions for the issuance of permits for discharges into waters of the United States. The regulation defining the scope of the permitting process is contained in 40 CFR §122.1(b), "Scope of the NPDES [National Pollutant Discharge Elimination System] Permit Requirement," 
which states that "The NPDES program requires permits for the discharge of 'pollutants' from any 'point source' into 'waters of the United States."'

The WIPP facility does not have any discharges of waste water or storm water runoff into waters of the United States and is not subject to regulation under the NPDES program. Waste waters generated at the WIPP facility are either disposed of off-site or managed in on-site, lined evaporation ponds. Storm water runoff is also collected in lined detention basins. The management of waste water and storm water runoff is regulated under New Mexico Water Quality Act (NMSA 1978, §§74-6-1, et seq.) and those permits are discussed further in Section 2.6.

\subsection{New Mexico Water Quality Act}

The New Mexico Water Quality Act created the New Mexico Water Quality Control Commission and tasked the commission with the development of regulations to protect New Mexico ground and surface water. New Mexico water quality regulations for ground and surface water protection are contained in 20.6.2 NMAC, "Ground and Surface Water Protection." The WIPP facility does not have any discharges to surface water, but does have a discharge permit designed to prevent impacts to groundwater.

The DOE was issued a discharge permit (DP-831) from the NMED Ground Water Quality Bureau for the operation of the WIPP sewage treatment facility in January 1992. The discharge permit was renewed and modified to include the H-19 Evaporation Pond in July 1997. The H-19 Evaporation Pond is used for the treatment of wastewater generated during groundwater monitoring activities, water removed from sumps in the underground, and condensation from the mine ventilation system's duct work. The discharge permit was modified in December 2003 and December 2006.

The discharge permit was renewed on September 9, 2008. The discharge permit now authorizes the following activities:

- $\quad$ The discharge of up to 23,000 gallons per day of domestic effluent and nonhazardous industrial wastewater to the waste water treatment facility which consists of seven lined ponds (two settling ponds, two polishing ponds and three evaporation ponds).

- The discharge of up to 50,000 gallons per day of brine, purge waters and miscellaneous nonhazardous waste waters to the $\mathrm{H}-19$ Evaporation Pond.

- $\quad$ The discharge of up to 50,000 gallons per day of brine, purge waters and miscellaneous nonhazardous wastewaters to Evaporation Pond $B$ and $C$ up to the capacity of the pond while maintaining one foot of freeboard.

- The collection of storm water runoff from the inactive Salt Pile that has been covered with high-density polyethylene in the Salt Pile Evaporation Pond. 
The collection of storm water runoff from the Salt Storage Extension Area in the Salt Storage Extension Basin.

- $\quad$ Authorization to place mined salt and associated minerals from the repository's excavations in the Salt Storage Extension Area.

The Ground Water Quality Bureau conducted an inspection on July 8, 2008, and found the DOE to be in compliance with the conditions of the discharge permit. The Ground Water Quality Bureau did note a concern due to erosion on the earthen cover of the Salt Pile. This concern was addressed in the Discharge Permit Renewal and Modification approval on September 9, 2008, by requiring the DOE to submit a plan for controlling storm water and minimizing erosion. A plan was submitted to the NMED to install additional runoff chutes and conducting grading of the salt pile surface to direct storm water to the runoff chutes.

The previously discussed discharge of 150 gallons of lead contaminated brine into the $\mathrm{H}-19$ Evaporation Pond resulted in an NOV being jointly issued that incorporated alleged violation of 20.6.2.3104 NMAC, the discharge permit and the Water Quality Act. A final settlement agreement is pending with the NMED.

In October 2008, rain events totaling more than 4 inches resulted in a loss of the one foot of freeboard required by the discharge permit and eventually resulted in the overtopping of the berm on the Salt Storage Extension Basin. The event was promptly reported to the NMED and corrective actions proposed that involved interim corrective actions to pump water to Evaporation Ponds $B$ and $C$ at the sewage treatment facility and raising the level of the berm approximately 2 feet. Permanent corrective actions are being developed in accordance with a schedule submitted to the state in a letter dated December 24, 2008.

\section{7 $\quad$ Safe Drinking Water Act}

The Safe Drinking Water Act (42 U.S.C. §§300f, et seq.) provides the regulatory strategy for protecting public water supply systems and underground sources of drinking water. New Mexico's drinking water regulations are contained in 20.7.10 NMAC, "Drinking Water," which adopts, by reference, 40 CFR Part 141, "National Primary Drinking Water Regulations," and 40 CFR Part 143, "National Secondary Drinking Water Regulations." Water is supplied to the WIPP facility by the city of Carlsbad; however, the WIPP facility is classified as a nontransient, noncommunity water system subject to the New Mexico drinking water regulations.

The WIPP facility qualifies for a reduced monitoring schedule under 40 CFR $\S 141.86(d)(4)$, and is required to sample for lead and copper every three years. Lead and copper in drinking water were last sampled in August 2008. All samples were below action levels as specified by New Mexico monitoring requirements for lead and copper in tap water. The next lead and copper samples will be collected between June and September 2011. 
Bacterial samples are collected and residual chlorine levels tested monthly. Chlorine levels are reported to the NMED monthly. All bacteriological analytical results have been below the Safe Drinking Water Act regulatory limits. Disinfectant byproducts testing per 40 CFR $\S 141.132$ is conducted annually by the state of New Mexico. All results have been below regulatory limits.

\subsection{National Historic Preservation Act}

The National Historic Preservation Act (16 U.S.C. $\$ \$ 470$, et seq.) was enacted to protect the nation's cultural resources and establish the National Register of Historic Places. No archaeological investigations were required to support the WIPP Project in 2008.

\section{$2.9 \quad$ Toxic Substances Control Act}

The Toxic Substances Control Act (TSCA) (15 U.S.C. §§2601, et seq.) was enacted to provide information about all chemicals and to control the production of new chemicals that might present an unreasonable risk of injury to health or the environment. The TSCA authorizes the EPA to require testing of old and new chemical substances. The TSCA also provides the EPA authority to regulate the manufacturing, processing, import, use, and disposal of chemicals.

Polychlorinated biphenyls (PCBs) are one of the compounds regulated by the TSCA. The PCB storage and disposal regulations are listed in the applicable subparts of 40 CFR Part 761, "Polychlorinated Biphenyls (PCBs) Manufacturing, Processing, Distribution in Commerce, and Use Prohibitions." On May 15, 2003, EPA Region VI approved the disposal of waste containing PCBs at the WIPP facility. The WIPP facility began receiving PCB-contaminated waste on February 5, 2005.

On April 2, 2009, the DOE notified the EPA by phone of an instance in which PCB waste was disposed at the WIPP facility on April 20,2008, without Certificates of Disposal being sent back to the generator site within 30 days as required by 40 CFR $\S 761.218(b)$. On that same day (April 2, 2009), Certificates of Disposal were prepared and submitted to the generator for Shipment IN080131. Written notification to the EPA of this instance followed on April 8, 2009.

The required PCB annual report, containing information on PCB waste received and disposed of at the WIPP facility in 2007, was submitted to EPA Region VI on June 30 , 2008.

\subsection{Federal Insecticide, Fungicide, and Rodenticide Act}

The Federal Insecticide, Fungicide, and Rodenticide Act (7 U.S.C. §§136, et seq.) authorizes the EPA to regulate the registration, certification, use, storage, disposal, transportation, and recall of pesticides (40 CFR Parts 150-189). 
All applications of restricted-use pesticides at the WIPP facility are conducted by commercial pesticide contractors who are required to meet federal and state standards. General-use pesticides are stored according to label instructions. Used, empty cans are discarded by WIPP facility personnel into satellite accumulation area containers and managed as hazardous waste.

\subsection{Endangered Species Act}

The Endangered Species Act (16 U.S.C. §§1531, et seq.) was enacted in 1973 to prevent the extinction of certain species of animals and plants. This act provides strong measures to help alleviate the loss of species and their habitats, and places restrictions on activities that may affect endangered and threatened animals and plants to help ensure their continued survival. With limited exceptions, this act prohibits activities that could impact protected species, unless a permit is granted from the U.S. Fish and Wildlife Service (USFWS). A biological assessment and "formal consultation," followed by the issuance of a "biological opinion" by the USFWS, may be required for any species that is determined to be in potential jeopardy.

There are no known species of plants or animals at the WIPP site that are protected by the Endangered Species Act. The Lesser Prairie Chicken, which is a candidate for listing under the act, does have favorable habitat within the WIPP LWA and surrounding areas impacted by WIPP Project operational activities (e.g., drilling boreholes).

Therefore, the DOE, in consultation with the BLM, has instituted measures to protect the Lesser Prairie Chicken and its habitat. During the Lesser Prairie Chicken's breeding season, there are BLM-established time periods in effect for the WIPP Project during which off-site well drilling and well plugging activities may not be performed. In 2008, there were no instances associated with WIPP Project activities that had any adverse implications associated with the act.

\subsection{Migratory Bird Treaty Act}

The Migratory Bird Treaty Act (16 U.S.C. $\$ \S 703$, et seq.) is intended to protect birds that have common migratory flyways between the United States, Canada, Mexico, Japan, and Russia. The act makes it unlawful "at any time, by any means or in any manner, to pursue, hunt, take, capture, kill, or attempt to take, capture, or kill . . . any migratory bird, any part, nest, or eggs of any such bird" unless specifically authorized by the Secretary of the Interior by direction or through regulations permitting and governing these actions (50 CFR Part 20, "Migratory Bird Hunting").

The WIPP facility holds a migratory bird permit that allows for the relocation of certain bird species which are found nesting on equipment and which could be in danger due to routine operations. In December 2008, WIPP reported one unintentional take of a roadrunner on-site. The take was verbally reported to the USFWS within 48 hours of the occurrence as required by the permit and was reported on the Migratory Bird Annual Report to the USFWS for 2008. No other activities involving migratory birds took place at the WIPP facility during the reporting period. 


\subsection{Federal Land Policy and Management Act}

The objective of the Federal Land Policy and Management Act (43 U.S.C. §§1701, et seq.) is to ensure that:

... public lands be managed in a manner that will protect the quality of scientific, scenic, historical, ecological, environmental, air and atmospheric, water resource, and archeological values; that, where appropriate, will preserve and protect certain public lands in their natural condition; that will provide food and habitat for fish and wildlife and domestic animals; and that will provide for outdoor recreation and human occupancy and use.

Title II under the act, Land Use Planning; Land Acquisition and Disposition, directs the Secretary of the Interior to prepare and maintain an inventory of all public lands and to develop and maintain, with public involvement, land-use plans regardless of whether subject public lands have been classified as withdrawn, set aside, or otherwise designated. The DOE developed, and operates in accordance with, the WIPP LMP, which is described in further detail in Section 5.2.

Under Title V, Rights-of-Way, the Secretary of the Interior is authorized to grant, issue, or renew rights-of-way over, upon, under, or through public lands. To date, several right-of-way reservations and land-use permits have been granted to the DOE. Examples of right-of-way permits include those obtained for a water pipeline, an access road, a caliche borrow pit, and a sampling station. Each "facility" (road, pipeline, railroad, etc.) is maintained and operated in accordance with the stipulations provided in the respective right-of-way reservation. Areas that are the subject of a right-of-way reservation are reclaimed and revegetated consistent with the terms of the right-of-way. A list of WIPP Project active environmental permits, including rights-of-way, is in Appendix B of this report.

\subsection{Atomic Energy Act}

The Atomic Energy Act of 1954, as amended (42 U.S.C. $§ \S 2011$, et seq.), initiated a national program with responsibility for the development and production of nuclear weapons and the development and the safety regulation for the civilian use of nuclear materials. The Act split these functions between the DOE, which is responsible for the development and production of nuclear weapons, promotion of nuclear power, and other energy-related work, and the U.S. Nuclear Regulatory Commission (NRC), which regulates the use of nuclear energy for domestic civilian purposes.

The statutory authority for the EPA to establish and implement the regulatory standards applicable to the operation, closure, and long-term performance of the WIPP facility can be found in the Atomic Energy Act of 1954, Reorganization Plan Number 3 of 1970, and in the Nuclear Waste Policy Act of 1982. The regulations affecting the radioactive waste disposal operations that will occur at the WIPP are found in 40 CFR Part 191. The EPA's final rule, 40 CFR Part 191, was first published on September 19, 1985. 
This standard was vacated and remanded to the EPA by a Federal Court of Appeals in 1987. The Land Withdrawal Act (LWA), Public Law 102-579, as amended, reinstated the 1985 disposal standard except for the aspects of the standard that were specifically questioned by the court (that is, 40 CFR $\S 191.15$, Individual Protection Requirements, and 40 CFR §191.16, Ground Water Protection Requirements). On December 20, 1993, the EPA promulgated, effective January 19, 1994, final disposal standards that corrected deficiencies associated with the individual and groundwater protection requirements. The resulting standards of 40 CFR Part 191 consist of three subparts: Subpart A, Environmental Standards for Management and Storage; Subpart B, Environmental Standards for Disposal; and Subpart C, Environmental Standards for Ground-Water Protection.

The results of monitoring and dose calculations have confirmed that there have been no releases of radionuclides that may adversely impact the public. WIPP personnel have conducted periodic confirmatory monitoring since receipt of waste began in March 1999. Results of the monitoring program demonstrate compliance with the dose limits discussed above and are addressed in further detail in Chapter 4.

WIPP is subject to EPA inspections in accordance with 40 CFR §194.21, "Inspections." During the Week of July 21, 2008, the EPA conducted an inspection to assess the implementation of monitoring programs developed by the DOE to monitor geomechanical, hydrological, waste activity, drilling-related, and subsidence parameters. The EPA did not have any findings or concerns resulting from this inspection. Additional information concerning this inspection can be found in EPA Docket A-98-49, Item II-B3-108.

The LWA also establishes the regulatory authority of the EPA by specifying that the underground emplacement of TRU waste for disposal at WIPP could not commence until the DOE submitted a Compliance Certification Application (CCA) demonstrating compliance with the EPA radioactive waste disposal standards found in Subparts B and $\mathrm{C}$ of 40 CFR Part 191. The LWA further requires the EPA to conduct periodic recertification of continued compliance beginning five years after the initial receipt of TRU waste for disposal and at five-year intervals thereafter until the end of the decommissioning phase. The second Recertification Application for the WIPP facility was submitted to the EPA on March 26, 2009 (DOE/WIPP-04-3231).

\subsection{DOE Orders}

DOE orders are used to direct and guide project participants in the performance of their work and establish the standards of operations at WIPP. The DOE orders documented in this report require that emission, effluent, and environmental monitoring programs be conducted to ensure that the WIPP mission can be accomplished while protecting the public, the worker, and the environment. The list of DOE orders identified for the WIPP Project are reviewed and updated annually. 


\subsubsection{DOE Order 151.1C, Comprehensive Emergency Management System}

This order establishes requirements for emergency planning hazards assessment, categorization, classification, preparedness, response, notification, coordination control, public protection, and readiness assurance activities. The applicable requirements of this order are implemented through the WIPP emergency management program, the emergency response program, the training program, the emergency readiness program, the records management program, and the RCRA Contingency Plan. Chapter 3 , Environmental Management System, provides details on the WIPP emergency management system.

\subsubsection{DOE Order 231.1A, Chg. 1, Environment, Safety and Health Reporting}

This order specifies collection and reporting of information on environment, safety, and health that are required by law or regulation, or that are essential for evaluating DOE operations and identifying opportunities for improvement needed for planning purposes within the DOE. The order specifies the reports that must be filed, the persons or organizations responsible for filing the reports, the recipients of the reports, the format in which the reports must be prepared, and the schedule for filing the reports. This order is implemented in part at the WIPP Project through National Environmental Policy Act (NEPA) reporting, annual site environmental reports, environmental protection program reports, occupational injury and illness reports, the radiation safety manual, the dosimetry program, the fire protection program, and WIPP facility procedures.

\subsubsection{DOE Order 414.1C, Quality Assurance}

This order provides the criteria for establishing, implementing, and maintaining programs, plans, and actions to ensure quality achievement in DOE programs. This order is implemented at WIPP through the CBFO Quality Assurance Program Document (DOE/CBFO-94-1012) which establishes QA program requirements for all quality-affecting programs, projects, and activities sponsored by the CBFO. Chapter 7, Quality Assurance, of this ASER provides additional details on the WIPP QA programs.

\subsubsection{DOE Order 435.1, Radioactive Waste Management}

The objective of this order is to ensure that all DOE radioactive waste, including TRU waste that is disposed of at the WIPP site, is managed in a manner that is protective of workers and the public. In the event that a conflict exists between any requirements of this order and the WIPP LWA regarding their application to the WIPP Project, the requirements of the LWA prevail. The DOE implements the requirements of this order through the Waste Acceptance Criteria, and procedures governing the management and disposal off-site-generated TRU radioactive waste.

\subsubsection{DOE Order 450.1A , Environmental Protection Program}

This order was issued on June 4, 2008, replacing DOE Order 450.1, dated January 15, 2003. The order requires that each DOE site develop and implement an EMS that is 
integrated into the site integrated safety management system. The system must also reflect the elements and framework of the ISO 14001:2004(3) standard for EMS; contribute to DOE sustainable environmental stewardship goals; and assure compliance with environmental legal requirements. The scope of the EMS must address sustainable practices for energy and transportation functions and promote the long-term stewardship of a site's natural and cultural resources.

A declaration of conformance with requirements must be provided to the DOE every three years, beginning with June 30,2009 . To be fully implemented, systems must undergo a formal audit by a qualified and independent qualified party every three years. During 2008, the DOE maintained compliance with the original requirements while adjusting the EMS to meet the new sustainability requirements and to prepare for certification of the WIPP EMS to the ISO 14001:2004(3) standard. The certification audit will become the basis a DOE declaration of conformance with the order. Chapter 3 provides the detailed discussion of the WIPP EMS.

\subsubsection{DOE Order 451.1B, Chg. 1, National Environmental Policy Act Compliance Program}

This order establishes DOE requirements and responsibilities for implementing the NEPA, the Council on Environmental Quality Regulations Implementing the Procedural Provisions of NEPA (40 CFR Parts 1500-1508), and the DOE NEPA implementing procedures (10 CFR Part 1021). This order is implemented by the DOE for the WIPP Project through compliance plans and a screening procedure. These tools are used to evaluate environmental impacts associated with proposed activities and to determine if additional analyses are required. Section 2.1.3 of the National Environmental Policy Act; and Section 3.2.7, Communication, of this ASER provide additional details on the WIPP Project NEPA programs.

\subsubsection{DOE Order 5400.5, Chg 2, Radiation Protection of the Public and the Environment}

This order, along with portions of DOE Order 231.1A, establishes standards and requirements for operations of the DOE and its contractors with respect to protecting members of the public and the environment against undue risk from radiation. Activities and analyses describing compliance with the applicable requirements of the order are contained in the Waste Isolation Pilot Plant Documented Safety Analysis (DOE/WIPP-07-3372). Monitoring activities to document compliance with the order are described in the WIPP ALARA (as low as reasonably achievable) program manual, the records management program, and the radiation safety manual.

\subsection{Executive Orders}

Executive Orders generally are used to direct federal agencies and officials in their execution of congressionally established laws or policies. Compliance with the EOs in this section is accomplished through the WIPP Project programs, plans, and procedures 
that comply with the EOs implementing DOE order. Compliance is confirmed through the WIPP Project assessment process.

\subsubsection{Executive Order 13423, Strengthening Federal Environmental, Energy, and Transportation Management}

In January 2007, EO 13423 was issued, replacing five prior EOs that established requirements for greening the government (EOs 13101,13123, 13134, 13148, and 13149) relative to waste prevention, recycling, federal acquisition, energy management, use of biobased products and energy, fleet and transportation efficiency and EMSs. Requirements from the EO are mapped out in the WIPP EMS and are implemented into operations through energy management, fleet and vehicle management, affirmative procurement, and pollution prevention (P2) programs. Annual EMS goals have been established in one or more of these areas and are discussed in Chapter 3. 


\section{CHAPTER 3 - ENVIRONMENTAL MANAGEMENT SYSTEM}

\subsection{Introduction}

Environmental management systems are widely recognized by both government and industry as effective mechanisms for achieving an organization's policy commitments for environmental performance. In January 2007, EO 13423 was issued requiring that an EMS be used as the primary management approach for addressing environmental aspects of operations and activities, including those related to energy and transportation functions, and as a means to further federal agencies implementation of sustainable practices. Subsequently, the DOE issued revisions to DOE Orders to flow down the requirements of the EO into DOE operations. These orders, $430.2 \mathrm{~B}$, Departmental Energy, Renewable Energy and Transportation Management; and 450.1A, Environmental Protection Program; were issued on February 27, 2008, and June 4, 2008, respectively.

During FY 2008, DOE efforts were focused on making necessary adjustments to the WIPP EMS to assure conformance with the requirements of the revised DOE Orders, preparing for certification of the WIPP EMS to the ISO 14001:2004(3) standard in 2009, and strengthening compliance through improvements in operational controls.

\subsection{WIPP EMS Continuous Improvement Cycle}

The WIPP EMS is structured using the International Organization for Standardization (ISO) 14001:2004(3) continuous improvement cycle. Each phase of the cycle is accomplished through implementation of one or more of the system elements. These elements and their relationship to the continuous improvement cycle are represented in Figure 3.1.

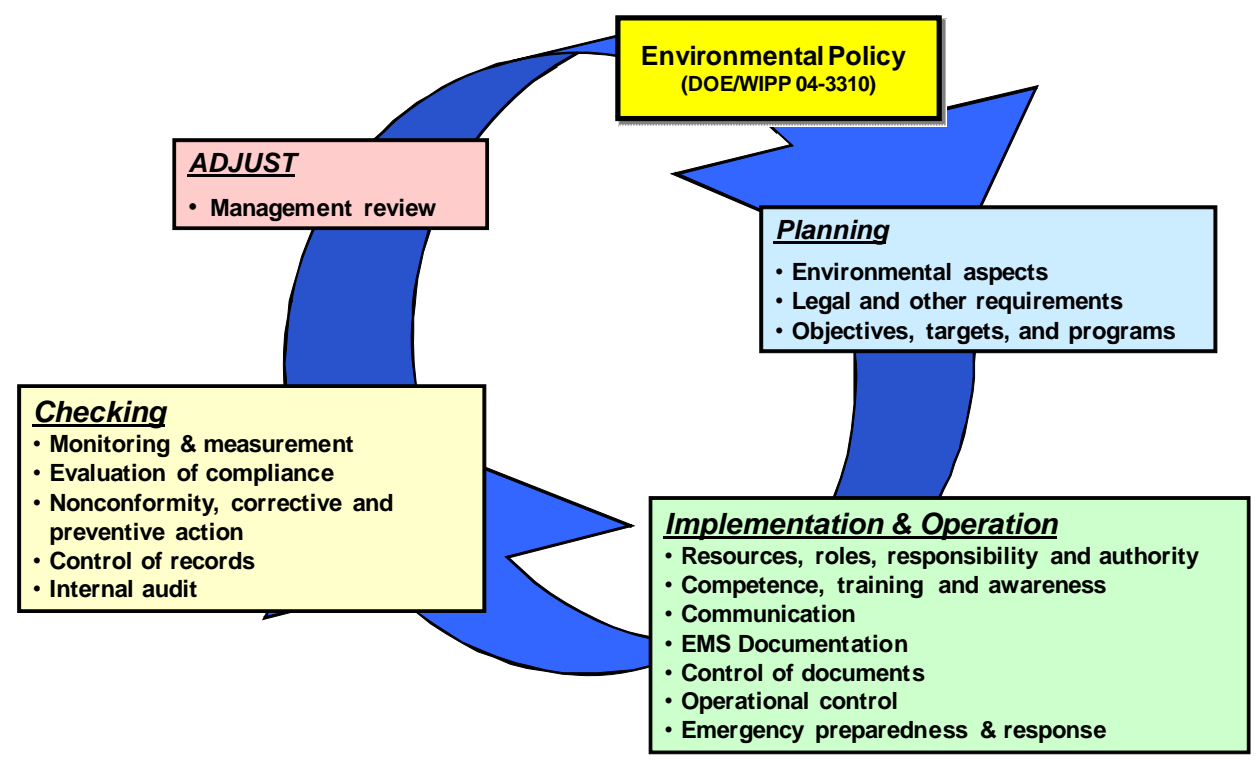

Figure 3.1 - WIPP EMS Continuous Improvement Cycle 


\subsubsection{Environmental Policy}

The WIPP environmental policy recognizes protection of workers, the public and the environment as the highest priority in carrying out the WIPP mission. The environmental policy is jointly issued by the CBFO and WTS senior managers and commits WIPP to:

- $\quad$ Comply with requirements applicable to the WIPP Project.

- $\quad$ Be a good environmental steward by working with stakeholders, correcting incidents, minimizing harm to environmental resources, and using safe, responsible, and cost-effective P2 measures.

- $\quad$ Seek continual improvement in environmental performance.

\subsubsection{Environmental Aspects}

Environmental aspects are elements of an organization's activities, products or services that can interact with the environment and result in an impact or change in the environment, either adverse or beneficial. If the potential impact could be significant, the EMS leads to implementing measures to appropriately manage the aspect. Potentially significant impacts associated with the operation of the WIPP facility have remained relatively constant over time. Following are the aspects and potentially significant impacts associated with WIPP facility operations.

- $\quad$ Safe management of TRU waste resulting in decreased risk to people and the environment both at the WIPP site and the various sites generating TRU waste.

- $\quad$ Managing TRU and TRU mixed wastes, hazardous materials, site generated hazardous and nonhazardous wastes and the wastewater treatment system with the potential for contamination of soil, water, air or biota.

- $\quad$ Use of energy to successfully complete the WIPP mission presents potential for loss of use of natural resources.

- $\quad$ Storm water runoff from the operation presents a potential for contamination of soil, water, or biota.

- $\quad$ Land management activities potentially could result in compromised stewardship of wildlife (fauna and flora), habitat, and/or historically or culturally significant sites.

The WIPP Project aspects and impacts are reviewed annually, and project-specific impacts are reviewed through the project review process. Significance is determined by considering potential environmental impact, probability of occurrence, the scale and severity of the potential impact, associated regulatory and legal requirements and 
issues, and concerns of interested parties. During 2008, fifteen SWMUs and eight areas of concern (AOCs) were removed as a WIPP Project aspect after the NMED approved an HWFP modification recognizing that the SWMUs and AOCs identified required no further action.

\subsubsection{Legal and Other Requirements}

Environmental requirements are identified as they are issued as draft and proposed rules and orders and are monitored until they are finalized. Identification is accomplished through monthly review of the environmental-related notices in the Federal Register and the New Mexico Administrative Code, and new and proposed changes to existing DOE orders. Subject matter experts are consulted to confirm applicability and assess potential impacts. Plans, procedures, and training are then modified to institutionalize compliance with the new or revised requirements as appropriate. During 2008, the most significant revisions to environmental requirements applicable to the WIPP Project were the revisions to DOE Order 450.1A and a new requirement by the NMED that required a written underground storage tank operations and maintenance plan. The DOE modified its EMS to meet the requirements of the revised DOE Order and has established a plan to meet the NMED requirement and will be revising the plan as requested by the NMED.

Examples of programs and procedures maintained for implementation of requirements include those for natural resources protection, P2, affirmative procurement, waste management, management of mined materials and environmental monitoring.

Environmental requirements and compliance status are summarized for the WIPP Project and are available to the public in the Waste Isolation Pilot Plant Biennial Environmental Compliance Report (DOE/WIPP-08-2171) and Chapter 2 of this report.

\subsubsection{Objectives, Targets, and Programs}

The DOE and WTS develop current and out-year plans to meet legal, regulatory, and contractual requirements, as well as to address significant environmental aspects and impacts. Objectives and targets are established for these plans during the annual fiscal year programmatic planning process. The environmental program is implemented as approved objectives and targets are achieved. The objectives and targets are incorporated into the Complex-Wide Integration Tool, where progress is tracked throughout the year.

Sitewide environmental goals (objectives) related to sustainable practices are also set each fiscal year. Six goals were jointly established by the CBFO and WTS for FY 2008 (see Table 3.1). These goals directly supported DOE department-level performancebased goals for P2 and sustainable environmental stewardship, as delineated in DOE Order 450.1A. At the WIPP Project, the DOE fully achieved three goals with the remaining three goals being 50 percent complete. The partially completed goals will be carried over for completion into FY 2009. 
Waste Isolation Pilot Plant Annual Site Environmental Report for 2008 DOE/WIPP-09-2225

\begin{tabular}{|c|c|c|}
\hline \multicolumn{3}{|c|}{ Table 3.1 - Site Environmental P2 Goals Scorecard - FY 2008} \\
\hline DOE Goal Category & Goal & Status \\
\hline \multirow[t]{2}{*}{$\begin{array}{l}\text { Environmentally } \\
\text { Preferred } \\
\text { Purchasing }\end{array}$} & $\begin{array}{l}\text { 1. Complete implementation of the } \\
\text { reporting system for use of } \\
\text { environmentally preferred products for } \\
\text { Constructors Inc. and office supply } \\
\text { vendors. }\end{array}$ & $\begin{array}{l}\text { Fifty percent complete. } \\
\text { Implementation with office supply } \\
\text { vendors is complete with routine } \\
\text { quarterly reports received beginning } \\
\text { in January 2008. Reporting guidance } \\
\text { has been prepared for Constructors, } \\
\text { Inc. and the system will be } \\
\text { implemented in FY2009. }\end{array}$ \\
\hline & $\begin{array}{l}\text { 2. Complete evaluation and negotiate, if } \\
\text { practical, an Energy Savings } \\
\text { Performance Contract (ESPC). }\end{array}$ & $\begin{array}{l}\text { Achieved. Evaluation indicated } \\
\text { ESPC not feasible for the WIPP } \\
\text { Project. }\end{array}$ \\
\hline Alternative Fuels & $\begin{array}{l}\text { 3. Initiate biodiesel fueling station for use } \\
\text { of biodiesel in WRES EM\&H field } \\
\text { tractor. }\end{array}$ & $\begin{array}{l}\text { Fifty percent complete. Fueling } \\
\text { equipment is available at the site. } \\
\text { Completion of goal is carried forward } \\
\text { as an FY } 2009 \text { goal. }\end{array}$ \\
\hline $\begin{array}{l}\text { Toxic Chemical } \\
\text { Reduction }\end{array}$ & $\begin{array}{l}\text { 4. Set up a general user interface for the } \\
\text { chemical inventory system on the WIPP } \\
\text { Project intranet and train users to } \\
\text { enable use of partially used materials } \\
\text { rather than new supplies. }\end{array}$ & $\begin{array}{l}\text { Fifty percent complete. Training } \\
\text { users on the interface will be carried } \\
\text { forward for FY } 2009 .\end{array}$ \\
\hline \multirow[t]{2}{*}{$\begin{array}{l}\text { Environmental } \\
\text { Stewardship (water, } \\
\text { energy, and fuel } \\
\text { efficiency; resource } \\
\text { conservation) }\end{array}$} & $\begin{array}{l}\text { 5. Maintain employee environmental } \\
\text { awareness. }\end{array}$ & $\begin{array}{l}\text { Achieved. Completed through Earth } \\
\text { Day booth at Safety Fair, publishing } \\
\text { P2 News, and updated P2 road } \\
\text { signs. }\end{array}$ \\
\hline & $\begin{array}{l}\text { 6. Zero reportable, unauthorized } \\
\text { contaminant releases. }\end{array}$ & $\begin{array}{l}\text { Achieved. There were no reportable } \\
\text { or unauthorized contaminant } \\
\text { releases in FY } 2008 .\end{array}$ \\
\hline
\end{tabular}

\subsubsection{Resources, Roles, Responsibility, and Authority}

Management's role is to provide the resources essential to implement the EMS. These resources include training, funding, human resources, specialized skills, and technology. To help facilitate this for the WIPP Project, management has designated EMS Coordinators in both the CBFO and WTS organizations. The coordinators are responsible for maintaining the EMS in accordance with the principles of ISO 14001 and DOE requirements, as well as for monitoring and reporting to management on the effectiveness of the system. Roles and responsibilities related to meeting environmental policy commitments while carrying out specific activities or programs are integrated into work procedures.

\subsubsection{Competence, Training, and Awareness}

Competence is assured for personnel at the WIPP facility through successful completion of specific training and qualification requirements for personnel whose work has the potential to result in significant environmental impact. Examples of personnel with specific qualification requirements include waste handling, waste management, mining, and maintenance staffs. Frequency of the training required for qualification for 
specific jobs is established and WTS Technical Training initiates and carries out the training.

All employees participate in General Employee Training (GET) annually. This training includes fundamentals of the Environmental Policy and EMS. In addition, several other mechanisms are used throughout the year to maintain awareness of environmental performance and issues, including the Pollution Prevention News (a newsletter focused on facets of sustainable practices including pollution prevention, resource conservation, recycling and reuse, energy and water conservation).

\subsubsection{Communication}

Internal communication related to the EMS, including compliance and P2, is accomplished via multiple mechanisms. The primary way the DOE and WTS communicate requirements and expectations is through the programs, plans, and procedures that integrate environmental requirements into daily work. Other methods include meetings, employee performance reviews, internal newsletters, the WIPP Project Intranet, and awareness posters, signs and banners. The WIPP Plan of the Day meeting is another communication tool that allows operating and support staff to understand each day's work plan and the interactions necessary to execute the plan in a safe, environmentally sound manner.

Communication with the public occurs as the DOE invites review and input on draft NEPA documents. The process for implementing the NEPA also assures that information is provided to the public related to significant environmental activities. DOE NEPA documents are found at www.gc.energy.gov/NEPA. The DOE maintains an internet site specially developed for communication with stakeholders regarding WIPP Project activities. This easily accessed site describes HWFP activities, communicates meeting dates and solicits stakeholder input. This site is maintained at www.wipp.energy.gov/stakeholders/notice.aspx. A toll-free information line (800-336-9477) is maintained and made available to the public for inquiries regarding any topic or issue. Additionally, documents such as this report and the biennial environmental compliance report, reports submitted to regulatory agencies, and selected information contained in the WIPP Waste Information System are available to the public.

\subsubsection{EMS Documentation}

The WIPP EMS is documented through the Waste Isolation Pilot Plant Environmental Management System Description (DOE/WIPP-05-3318). This document is reviewed for needed improvements during preparation of the EMS annual report. The EMS description is updated, as needed, after the annual management review. In 2008, the EMS description document was revised to incorporate changes for compliance with new requirements of EO 13423 and DOE O 450.1A. 


\subsubsection{Control of Documents and Control of Records}

The DOE has mature systems in these areas as established through its document control and records management programs. The DOE maintains an electronic document control system to manage the development, review, approval and revision of documents. This enables systematic review and input by affected organizations, with documentation for each step of the review and approval process.

\subsubsection{Operating Control}

The EMS Aspects and Impacts Table identifies the organizations that are associated with managing activities with potentially significant impacts. The WIPP Project has three core programs (design, operation and maintenance) that implement actions to minimize risk by assuring the integrity of work performance, facilities, and assets. The documents implementing these programs are Engineering Conduct of Operations (WP 09), Conduct of Operations (WP 04-CO), and Maintenance Operations Instruction Manual (WP 10-2), with their supporting procedures and work instructions. During 2008, a major focus throughout the WIPP Project was to strengthen Conduct of Operations implementation and performance.

\subsubsection{Emergency Preparedness and Response}

Emergency preparedness and response capabilities at the WIPP facility are maintained through an extensive emergency management program that includes hazard analysis, preplanning for potential incidents, training, drills, and implementing improvement actions. This program involves the many organizations and individuals that would play a part in responding to an incident at the WIPP site or from incidents/accidents that may occur with transportation of TRU waste from the TRU waste sites to the WIPP facility. The program is implemented through the numerous procedures for planning and responding to specific types of emergencies identified through the WIPP emergency planning hazards assessment. These encompass mine rescue, surface and underground fires, hazardous material spill response, severe weather, and security and medical emergencies. Ancillary procedures related to event recovery, categorization of operational incidents, and reporting occurrences are also in place.

Training and practicing response skills are a high priority for the WIPP Project. Emergency Services coordinates drills and exercises according to an annual drill and exercise plan. Members of the emergency response organization are required to participate in a minimum of one drill each year to demonstrate proficiency in their assigned role. A full-participation exercise is conducted each year to test integrated capabilities. Performance during the exercise is critiqued by an independent group and any findings are addressed and managed through the commitment tracking system.

\subsubsection{Measuring and Monitoring Environmental Performance}

Environmental performance is extensively monitored to assure that the WIPP Project mission is carried out in accordance with its environmental policy. This includes 
monitoring environmental conditions, monitoring for sustainability and monitoring for EMS effectiveness. Analysis of these data, along with evaluations of compliance (Section 3.2.13) and EMS Internal Audits (Section 3.2.15), become the basis for determining the effectiveness of the EMS.

\section{Monitoring Environmental Conditions}

Initial implementation of the WIPP Environmental Monitoring Plan during the planning and preoperational phases of the project established the WIPP site baseline environmental conditions. Continuing implementation monitors for environmental effects during the site operations phase. The plan directs the programs for monitoring of radiological and nonradiological effects and land management, as well as providing the criteria and methods for data analysis and QA. Data from the radiological, nonradiological, and land management monitoring programs for 2008 indicate that there has been no impact to human health or the environment from WIPP facility operations. Detailed analyses and summaries of the monitoring results are included in Chapters 4 , 5 , and 6.

\section{Monitoring for Environmental Sustainability}

Personnel at the WIPP facility monitor progress in many environmental sustainability areas including the areas of energy and water use, renewable energy, material recycled versus disposed, petroleum use, sustainability improvements in buildings, alternative fuel use and electronics management improvements. Key highlights from sustainability progress are included in the following paragraphs.

Figure 3-2 provides energy use in the context of the number of waste packages emplaced each year. As indicated in the graph, the WIPP facility energy use, although increasing, has not increased at the same pace as waste emplacement. Conservation practices and improvements in building efficiencies have been implemented. Also in the energy arena in 2008, WIPP purchased 7.5 percent of total energy used from wind generated sources and provided support for pursuing and evaluating the potential for a commercial photovoltaic project on WIPP LWA property. This project was in the early stages of evaluation at the end of 2008. 


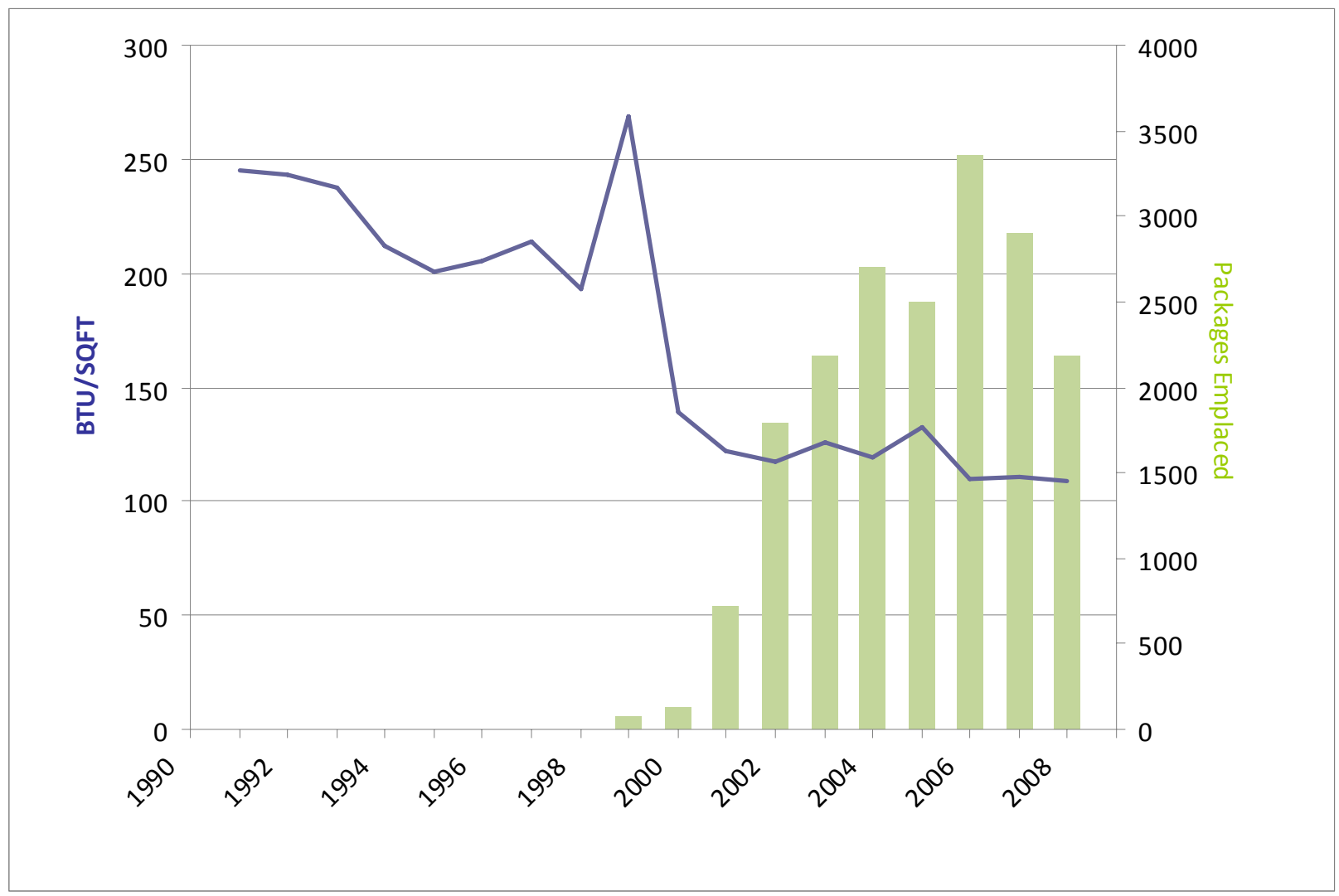

Figure 3.2 - WIPP BTUs/Building Square Footage

During FY 2008, the percentage of materials recycled versus the total amount of materials generated decreased to 48 percent. The decrease in materials recycled is attributable to redirection of internal resources to focus on regulatory compliance improvement actions beginning in the first quarter of FY 2008. Maintaining the recycling program at the WIPP facility remote location requires routine hauling of recyclables to the recycling center in Carlsbad in order for there to be collection capacity available for people to use. During the first half of FY 2008, trips to haul recyclables were reduced as personnel focused on compliance improvements. Although the overall recycling rate did decrease, the rate of recycling for hazardous materials increased from 79 percent in FY 2007 to 87 percent in FY 2008 indicating that for the highest hazard materials, recycling remained a strong focus. It is also important to note that during FY 2008, overall waste generated was 20 percent less than FY 2007 (see Figure 3.3). 


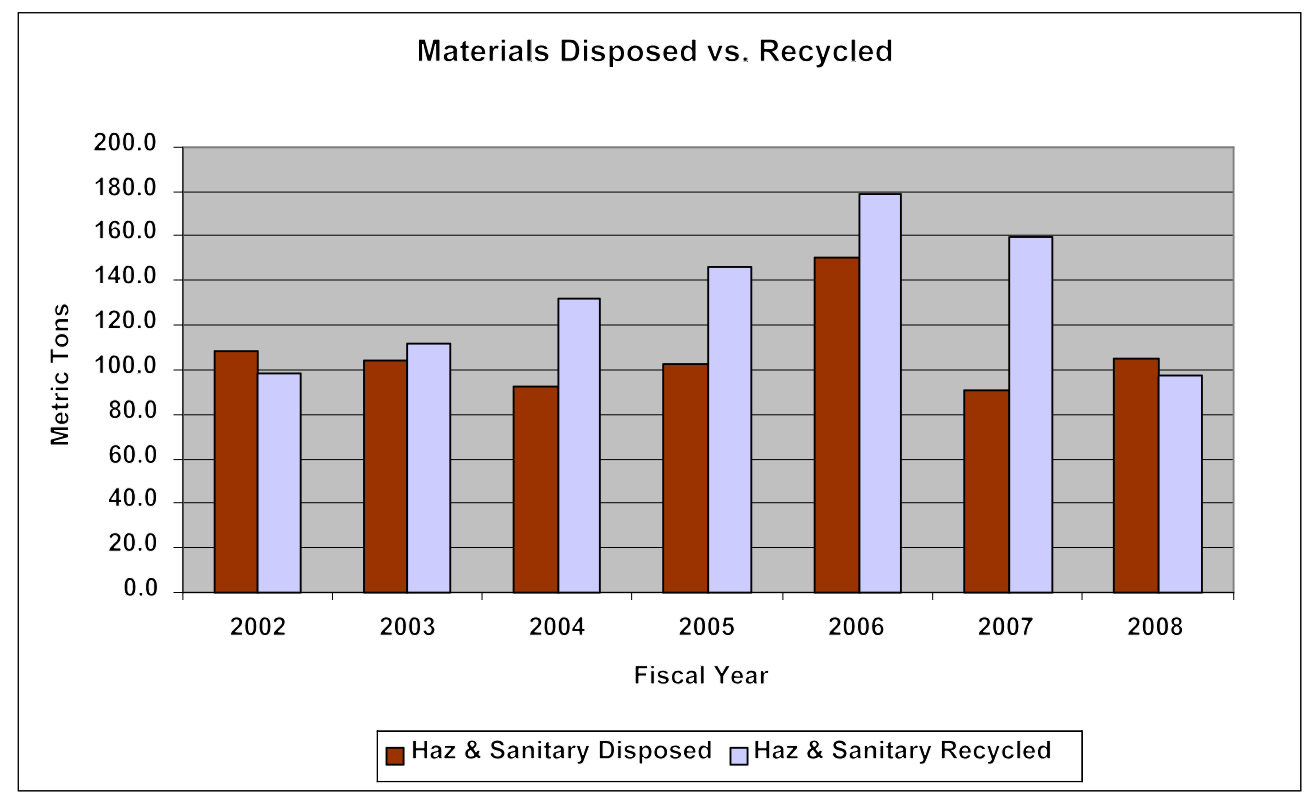

Figure 3.3 - FY 2008 WIPP Disposed Versus Recycled Materials

The WIPP Project implemented water saving practices resulting in decreased water use every year from FY 2003 to FY 2007. However, water use increased from 3.1 million gallons in FY 2007 to 4.3 million gallons in FY 2008. The unexpected increase in FY 2008 can be attributed to a substantial leak in a water line and the associated repair work. Repairs will continue into 2009.

The EO 13423 water reduction goal of 2 percent per year through FY 2015, or 16 percent total by the end of FY 2015, uses the FY 2007 water use as the baseline. Water use is currently lower than the previous 2003 baseline, and steadily decreased until FY 2007 despite increases in TRU waste throughput (see Figure 3.4). Given the improvements already made that resulted in reductions in both process and domestic use of fresh water, further improvement opportunities are limited, and it is not anticipated that the WIPP facility can achieve this goal. However, the WIPP facility plan for sustainability improvements includes replacement of some plumbing fixtures which will result in additional water reductions. 
Waste Isolation Pilot Plant Annual Site Environmental Report for 2008 DOE/WIPP-09-2225

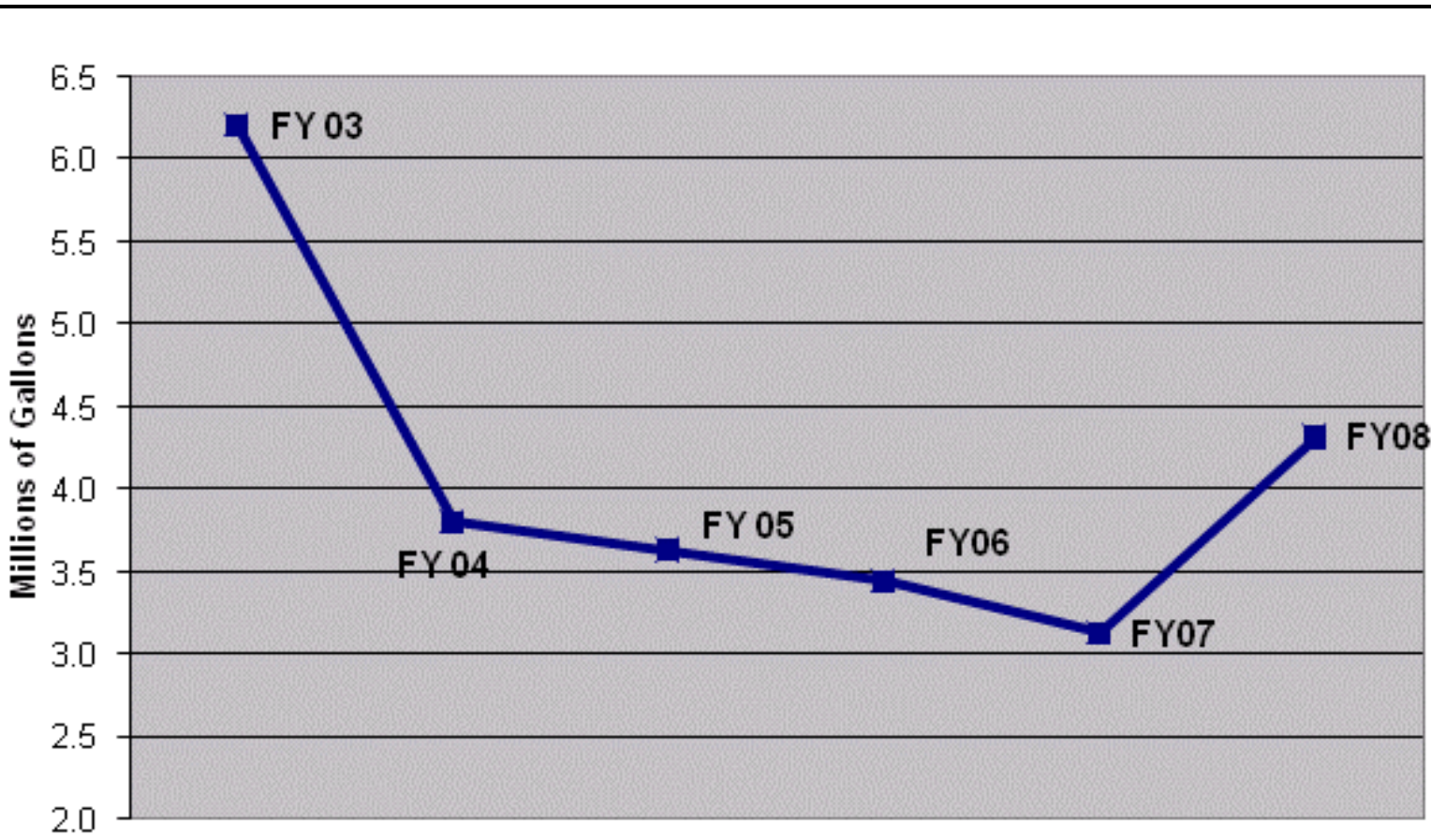

Fiscal Year

Figure 3-4 - Yearly Water Usage at WIPP

Monitoring EMS Effectiveness and Continual Improvement

The results of the extensive, ongoing monitoring of environmental conditions and sustainability progress, along with the system indicators summarized in Table 3.2 are the basis for evaluating the effectiveness of the EMS for Fiscal Year 2008.

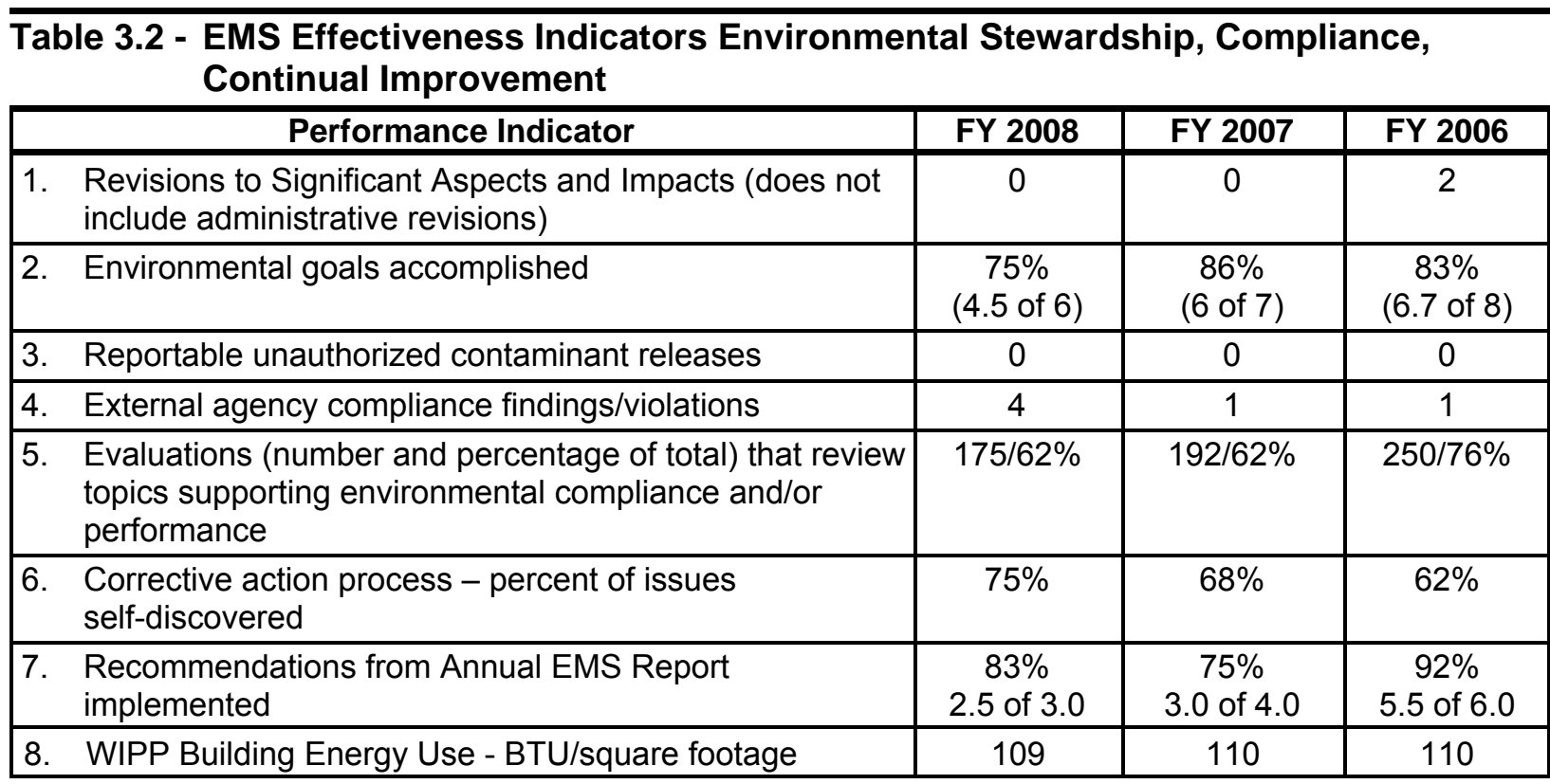


Waste Isolation Pilot Plant Annual Site Environmental Report for 2008 DOE/WIPP-09-2225

Table 3.2 - EMS Effectiveness Indicators Environmental Stewardship, Compliance, Continual Improvement

\begin{tabular}{|l|c|c|c|}
\hline \multicolumn{1}{|c|}{ Performance Indicator } & FY 2008 & FY 2007 & FY 2006 \\
\hline 9. $\quad$ Fresh Water Used, thousands gallons per year & 4,319 & 3,132 & 3,444 \\
\hline 10. Materials Recycled versus Generated & $48 \%$ & $64 \%$ & $54 \%$ \\
\hline
\end{tabular}

Indicator 1. This indicator shows whether changes were necessary to assure that significant aspects associated with the WIPP mission and potential impacts are identified. There were no changes to significant aspects and impacts in FY 2008.

Indicator 2. This indicator demonstrates that the WIPP Project has integrated sustainability, including P2, into the EMS and is actively working to minimize its environmental footprint through progress toward sustainable practices goals.

Indicator 3. This indicator demonstrates that the WIPP facility had zero reportable, unauthorized contaminant releases in FY 2008. A reportable, unauthorized contaminant release is a release to the environment of a hazardous substance that exceeds a reportable quantity $(R Q)$.

Indicator 4. This system indicator demonstrates the WIPP facility compliance performance and includes findings, issues, and NOVs from any external agency, including the NMED, the EPA, and the U.S. Nuclear Regulatory Commission. All of these occurrences were in November 2007 and included a CO for the acceptance of a drum of waste containing liquid from INL, and another for alleging the WIPP did not ensure that certain shipments from LANL met permit requirements. Also included is the NOV for alleged deficiencies to the GW Program and the incident of disposal of brine water containing lead in excess of the RCRA threshold in the lined $\mathrm{H}-19$ pond which resulted in an NOV in November 2008. Because the four incidents were experienced in the fourth quarter of 2007 and this is part of the 2008 fiscal year period, the incidents were included in the WIPP Environmental Management System Annual Report for FY 2008 (DOE/WIPP-09-3333) (2008 EMS Annual Report). They were also in the last quarter of the 2007 calendar year; therefore, they also were discussed fully in the 2007 ASER.

Indicator 5. This indicator demonstrates that the WIPP Project system for checking environmental performance compliance continues to be healthy. This is reflected by the 62 percent of all evaluations performed in FY 2008 containing varying levels of environmental checks.

Indicator 6. This indicator illustrates that the WIPP Project corrective and preventive action process is thorough. The WIPP Project self-discovered 75 percent of the total issues identified, corrected, and tracked through the WIPP Project issues management program. Issues self-discovered are those issues which WIPP departments identify versus issues that are identified from an assessment, surveillance, or audit external to the department. 
Indicator 7. The WIPP Project continues to improve the EMS with two of three recommendations for system improvements identified in the annual management review completed at the end of FY 2008 and the third in progress and on schedule to be completed in early 2009.

Indicators 8, 9, and 10. These indicators were incorporated into the effectiveness indicators in the 2008 EMS Annual Report to consolidate all indicators in one location. These indicators align with the energy, water, and waste reduction goals found in EO 13423 and DOE Orders 450.1A and 430.2B.

\subsubsection{Evaluation of Compliance}

The WIPP Project compliance with requirements is evaluated through a multitiered evaluation system that includes inspections, assessments, surveillances, and audits with scopes including one or more facets of compliance. These include self-evaluations performed by various WTS departments and Washington Regulatory and Environmental Services (WRES), and those performed by external entities (independent). Independent evaluations are performed by the CBFO QA Department, the Carlsbad Technical Assistance Contractor (CTAC), DOE Headquarters, the NMED, and the EPA. Evaluations performed are listed in each fiscal year's WIPP Integrated Evaluation Plan.

Evaluations examine implementation of WIPP Project policies, programs, procedures, and controls that assure compliance with applicable requirements. Findings identified through these evaluations are incorporated into the WIPP Project issues management program and corrective action is tracked through completion (see Section 3.2.14).

This system continues to be robust, with 175 evaluations conducted in FY 2008 incorporating varying levels of environmental compliance or performance check. Of these there were ten evaluations focused solely on environmental programs including the site generated water management program (two evaluations), the groundwater detection program (two evaluations), VOC monitoring program, National Emissions Standards for Hazardous Air Pollutants (NESHAP) compliance, Discharge Permit 831 (DP-831) compliance, and the effluent monitoring program. There were over 100 evaluations that focused on the myriad of programs that also support environmental compliance. Examples include evaluations performed for waste handling operations, the ventilation system, operational logbooks, visual examination, transportation, and generator site audits. The remaining evaluations include a few (less than ten) inspections performed by regulatory agencies and over fifty evaluations focused on programs related to system elements (e.g., Issues Management, Documents and Records, Inspection and Testing, Emergency Preparedness and Response).

\subsubsection{Nonconformity, Corrective and Preventive Action}

The WIPP Project has a thorough, mature process for managing nonconformity, corrective and preventive action that is the issues management program. Issues that are managed through this process include environmental issues that may be raised by employees or identified through evaluations, as well as actions identified through the 
WIPP incident investigation processes. The Issues Management Committee reviews and verifies concerns, and directs the appropriate level of causal analysis be performed and that corrective/preventive action plans be developed and implemented. Completion of action plans is tracked through the commitment tracking system and monitored through closure.

The DOE takes its commitment to compliance very seriously. For example, compliance incidents were experienced in 2007 that resulted in extensive and rigorous actions to improve performance in 2008. The compliance incidents were NOVs for alleged deficiencies in the WIPP groundwater monitoring program and for the self-identified incident of disposal of approximately 150 gallons of water with lead in excess of the $5.0 \mathrm{mg} / \mathrm{l}$ toxicity characteristic regulatory threshold of 40 CFR $\S 261.24$ in the $\mathrm{H}-19$ evaporation pond. Actions to understand the extent, impact and root cause of the issues were extensive and performed in a timely manner. At the end of the fiscal year, 77 of 86 (90 percent) of corrective and/or preventive actions related to these two compliance issues had been completed. The remaining actions are on schedule for completion in FY 2009.

\subsubsection{EMS Internal Audit}

The integrated safety management system (ISMS) reviews are performed each year. Both the WTS and CBFO FY 2008 ISMS annual reviews were conducted during July and October 2008, respectively. These confirmed the EMS to be effectively integrated into the WIPP ISMS and implemented at the WIPP Project. There were two EMS areas for improvement in the FY 2008 reviews. The first was to strengthen focus on compliance with regulatory requirements through conduct of operations. The second was to complete the process of rescinding Management Policy 5.5 as it is duplicative of the jointly issued CBFO/WTS Environmental Policy.

\subsubsection{Management Review}

Senior management reviews the effectiveness of the system through the EMS annual report, which is prepared by the CBFO and WTS EMS Coordinators. Management directs improvements to the system for the upcoming fiscal year as a result of this review. The 2008 EMS Annual Report documented the management review for FY 2008.

The 2008 EMS Annual Report concluded that the EMS remains suitable and effective for achieving environmental policy. There were two recommendations for improvement to the EMS during the FY 2009 continuous improvement cycle. These are to continue to strengthen compliance assurance programs and to successfully complete an ISO 14001:2004 registration audit and declare conformance with DOE Order 450.1A by June 30, 2009. 


\subsubsection{Status of EMS Implementation}

In 2008, modifications were made to the EMS to address the sustainability requirements added to DOE Orders $430.2 \mathrm{~b}$ and $450.1 \mathrm{~A}$. Significant efforts were also made on compliance improvement through conduct of operations as noted in Section 3.2.14.

The WIPP EMS is rated as being in the continuous improvement stage of implementation in the DOE EMS Scorecard. This scorecard is submitted to DOE headquarters each year and provides a summary of the results of implementing the system in relation to 22 programmatic and performance criteria. These criteria include areas such as reduced risk to facility mission, greater understanding of environmental issues, improved community relations, improved P2, and improved water and energy conservation. The WIPP EMS is rated as having a significant positive impact for the majority of the criteria.

Benefits, successes, and best practices associated with implementing and maintaining the system during FY 2008 are highlighted as follows:

- $\quad$ No reportable, unauthorized contaminates released to the environment since implementation of the EMS.

- No adverse impact to human health or the environment as demonstrated by monitoring data.

- Improved ability to work with stakeholders and regulators to secure permit modifications and compliance recertification.

- $\quad$ An improved process to track quantities of environmentally preferred office products purchased was implemented successfully.

- $\quad$ Compliance matrices for environmental requirements were developed. These matrices provide an excellent tool for assuring all compliance requirements are consolidated in one source, with the intent to facilitate sustained compliance across organization changes.

A challenge for implementation of the WIPP EMS is to maintain the visibility of the EMS in light of extensive emphasis in 2008 placed on Conduct of Operations, ISMS, Voluntary Protection Program and the new Documented Safety Analysis and Technical Safety Requirements. The key is to communicate effectively how the environment and EMS are linked with these other fundamental business processes. 


\section{CHAPTER 4 - ENVIRONMENTAL RADIOLOGICAL PROGRAM INFORMATION}

DOE Order 450.1 states that the DOE must "conduct environmental monitoring, as appropriate, to support the site's ISMS; to detect, characterize, and respond to releases from DOE activities; assess impacts; estimate dispersal patterns in the environment; characterize the pathways of exposures and doses to members of the public; characterize the exposures and doses to individuals and to the population; and evaluate the potential impacts to biota in the vicinity of the DOE activity."

Radionuclides present in the environment, whether naturally occurring or anthropogenic (human-made), may contribute to radiation doses to humans. Therefore, environmental monitoring around nuclear facilities is imperative to characterize radiological baseline conditions, identify any releases, and determine their effects, should they occur.

Personnel at the WIPP facility sample air, groundwater, surface water, soils, sediments, and biota to monitor the radiological environment around the WIPP facility. This monitoring is carried out in accordance with the WIPP Environmental Monitoring Plan. The radiological effluent monitoring portion of this plan meets the requirements contained in DOE/EH-0173T, Environmental Regulatory Guide for Radiological Effluent Monitoring and Environmental Surveillance.

WIPP is regulated under 40 CFR $\S 191.03$, Subpart A, which applies to management and storage of radioactive waste at disposal facilities operated by the DOE. The standards in 40 CFR $\$ 191.03(\mathrm{~b})$ state that management and storage of transuranic waste at the DOE facilities shall be conducted in such a manner as to provide reasonable assurance that the annual radiation to any member of the public in the general environment resulting from discharges of radioactive material and direct radiation from such management and storage shall not exceed specified limits. Based on analysis of WIPP facility operations, the DOE has identified air emissions as the major pathway of concern. For that reason, the EPA concluded that the only plausible pathway for radionuclide transport during receipt and emplacement of waste at the WIPP facility is by air emissions.

The regulatory limits for the WIPP effluent monitoring program can be found in 40 CFR Part 191, Subpart A. Radionuclides being released from WIPP operations, including the underground TRU waste disposal areas and the Waste Handling Building, are monitored through the WIPP effluent monitoring program. The referenced standard specifies that the combined annual dose equivalent to any member of the public in the general environment resulting from discharges of radioactive material and direct radiation from such management and storage shall not exceed 25 mrem to the whole body and 75 mrem to any critical organ. In addition, in a 1995 memorandum of understanding (MOU) between the EPA and the DOE, the DOE agreed that the WIPP facility would comply with 40 CFR Part 61, "National Emissions Standards for Hazardous Air Pollutants" (NESHAP), Subpart H, "National Emissions Standards for Hazardous Air Pollutants Other than Radon from Department of Energy Facilities." The NESHAP standard (40 CFR §61.92) states that the emissions of radionuclides to the ambient air from DOE facilities shall not exceed those amounts which would cause any 
member of the public to receive in any year an effective dose equivalent (EDE) of 10 mrem per year.

The radiological environment near the WIPP site includes natural radioactivity, global fallout and, potentially, radioactive contamination remaining from Project Gnome. Under Project Gnome, a nuclear device was detonated underground in bedded salt on December 10, 1961. The test site for Project Gnome is located $9 \mathrm{~km}$ (5.4 mi) southwest of the WIPP site. The Project Gnome detonation vented into the atmosphere. Therefore, environmental samples in the vicinity of the WIPP site may contain small amounts of fission products from fallout and residual contamination from Project Gnome, in addition to natural radioactivity.

Natural background radiation, global fallout, and remaining radioactive contamination from Project Gnome together comprise the radiological baseline for the WIPP site. A report titled Statistical Summary of the Radiological Baseline Program for the Waste Isolation Pilot Plant (DOE/WIPP-92-037) summarizes the radiological baseline data obtained at and near the WIPP site during the period from 1985 through 1989, prior to the time that the WIPP facility became operational. Radioisotope concentrations in environmental media sampled under the current ongoing monitoring program are compared with this baseline to gain information regarding annual fluctuations. Appendix $\mathrm{H}$ presents data that compare the highest concentrations of radionuclides detected from the WIPP environmental monitoring program to the baseline data.

The sampling media for the environmental monitoring program include airborne particulates, soil, surface water, groundwater, sediments, and biota (vegetable and animals). These samples are analyzed for ten radionuclides, including natural uranium $\left({ }^{233 / 234} \mathrm{U},{ }^{235} \mathrm{U}\right.$, and $\left.{ }^{238} \mathrm{U}\right)$; potassium-40 $\left({ }^{40} \mathrm{~K}\right)$; transuranic actinides expected to be present in the waste (plutonium $\left[{ }^{238} \mathrm{Pu}\right],{ }^{239 / 240} \mathrm{Pu}$, and americium $\left[{ }^{241} \mathrm{Am}\right]$ ), and major fission products (cesium $\left[{ }^{137} \mathrm{Cs}\right]$, cobalt $\left[{ }^{60} \mathrm{Co}\right.$, and strontium $\left[{ }^{90} \mathrm{Sr}\right]$ ). Environmental levels of these radionuclides could provide corroborating information on which to base conclusions regarding releases from WIPP facility operations.

Table 4.1 summarizes the list of target radionuclides along with their type of radiation, method of detection, and reason for monitoring at the WIPP site. The WIPP effluent monitoring program also monitors for these same radionuclides with the exception of ${ }^{235} \mathrm{U},{ }^{40} \mathrm{~K}$, and ${ }^{60} \mathrm{Co}$. 
Waste Isolation Pilot Plant Annual Site Environmental Report for 2008 DOE/WIPP-09-2225

Table 4.1 - Radioactive Nuclides Monitored at the WIPP Site

\begin{tabular}{|c|l|l|l|}
\hline Radionuclide & Radiation & Detection Method & Reason for Monitoring \\
\hline${ }^{233 / 234} \mathrm{U}$ & Alpha & Alpha spectroscopy & Naturally occurring \\
\hline${ }^{235} \mathrm{U}$ & Alpha & Alpha spectroscopy & Naturally occurring \\
\hline${ }^{238} \mathrm{U}$ & Alpha & Alpha spectroscopy & Naturally occurring \\
\hline${ }^{40} \mathrm{~K}$ & Gamma & Gamma spectroscopy & Ubiquitous in nature \\
\hline${ }^{238} \mathrm{Pu}$ & Alpha & Alpha spectroscopy & Component of waste \\
\hline${ }^{239 / 240} \mathrm{Pu}$ & Alpha & Alpha spectroscopy & Component of waste \\
\hline${ }^{241} \mathrm{Am}$ & Alpha & Alpha spectroscopy & Component of waste \\
\hline${ }^{137} \mathrm{Cs}$ & Gamma & Gamma spectroscopy & Fission product/potential component of waste \\
\hline${ }^{60} \mathrm{Co}$ & Gamma & Gamma spectrometry & Fission product/potential component of waste \\
\hline${ }^{90} \mathrm{Sr}$ & Beta & $\begin{array}{l}\text { Gas Proportional Counting } \\
\text { (GPC) }\end{array}$ & Fission product/potential component of waste \\
\hline
\end{tabular}

Note: The radionuclides ${ }^{243} \mathrm{Am},{ }^{242} \mathrm{Pu}$, and ${ }^{232} \mathrm{U}$ are used as tracers in the WIPP Laboratories.

Radionuclides are considered "detected" in a sample if the measured concentration or activity is greater than the total propagated uncertainty (TPU) at the 2 sigma $(2 \times$ TPU) level, and greater than the minimum detectable concentration (MDC). This methodology was patterned after that described in Hanford Decision Level for Alpha Spectrometry Bioassay Analyses Based on the Sample-Specific Total Propagated Uncertainty (MacLellan, 1999). The MDC is determined by the analytical laboratories based on the natural background radiation, the analytical technique, and inherent characteristics of the analytical equipment. The MDC represents the minimum concentration of a radionuclide detectable in a given sample using the given equipment and techniques with a specific statistical confidence (usually 95 percent). The TPU is an estimate of the uncertainty in the measurement due to all sources, including counting error, measurement error, chemical recovery error, detector efficiency, randomness of radioactive decay, and any other sources of uncertainty.

Measurements of radioactivity are actually probabilities due to the random nature of the disintegration process. A sample is decaying as it is being measured, so no finite value can be assigned. Instead, the ranges of possible activities are reported by incorporating the TPUs of the method. For radionuclides determined by gamma spectroscopy $\left({ }^{137} \mathrm{Cs}\right.$, ${ }^{60} \mathrm{Co}$, and ${ }^{40} \mathrm{~K}$ ), an additional factor considered in the determination of detectability is the identification (ID) confidence with which the peak or peaks associated with the particular radionuclide can be identified by the gamma spectroscopy software. In accordance with the statement of work (SOW) for the laboratory analyses, gamma spectroscopy samples with ID confidence less than 90 percent $(<0.90)$ are not considered "detects," regardless of their magnitudes compared to the TPU and MDC. Sample results are also normalized with the instrument background and/or the method blank. If either of those measurements have greater activity ranges than the actual sample, it is possible to get negative values on one end of the reported range of activities. Additional information on the equations used is in Appendix D. 
WIPP Laboratories performed the analyses for the 10 target radionuclides in all radiological samples. Highly sensitive radiochemical analysis and detection techniques were used that resulted in very low detection limits. This allowed detection of radionuclides at concentration levels far below those of environmental and human health concern. The MDCs attained by WIPP Laboratories were below the recommended MDCs specified in American National Standards Institute (ANSI) Standard N13.30, Performance Criteria for Radiobioassay.

Comparisons of radionuclide concentrations were made between years and locations using the statistical procedure, ANOVA (analysis of variance) for those data sets containing sufficient "detects" to make such comparisons statistically meaningful. When this or other statistical tests were used, the $p$ value was reported. The $p$ value is the significance level for ANOVA calculations. A $p$ value $>0.05$ indicates no significant difference in the values from a data set, and a $p$ value $<0.05$ indicates a significant difference in the values from a data set.

The $p$ value is the probability under the null hypothesis of observing a value as unlikely or more unlikely than the value of the test statistic. In many cases, scientists have accepted a value of $p<0.05$ as indicative of a difference between samples. Interpretation of $p$ values requires some judgment on the part of the reader, and individual readers may choose to defend a higher or lower value of $p$ as their cutoff value. However, for this report, a $p$ value of 0.05 was used.

The air monitoring for radionuclides is divided between two program: the WIPP effluent monitoring program and the environmental monitoring program. Descriptions of these two programs are provided in the sections below.

\section{Effluent Monitoring}

The WIPP effluent monitoring program has three effluent air monitoring stations, known as Effluent Monitoring Stations A, B, and C. Each station employs one or more fixed air samplers, collecting particulate from the effluent air stream using a Versapor ${ }^{\circledR}$ filter. Instruments at Station A sample the unfiltered underground exhaust air. Samples collected at Station B represent the underground exhaust air after HEPA (highefficiency particulate air) filtration and, sometimes, nonfiltered air during ventilation fan maintenance. Samples collected at Station $\mathrm{C}$ represent the air from the Waste Handling Building after HEPA filtration. For each sampling event, chain-of-custody forms are initiated to track and maintain an accurate written record of filter sample handling and treatment from the time of sample collection through laboratory procedures to disposal. During 2008, filter samples from all three effluent air monitoring stations were analyzed for ${ }^{238} \mathrm{Pu},{ }^{239 / 240} \mathrm{Pu},{ }^{241} \mathrm{Am},{ }^{90} \mathrm{Sr},{ }^{137} \mathrm{Cs},{ }^{233 / 234} \mathrm{U}$, and ${ }^{238} \mathrm{U}$.

In June 2009, Annual Periodic Confirmatory Measurement Compliance Report for Calendar Year 2008, was submitted to the EPA as required by 40 CFR Part 61, Subpart H (NESHAP). The report provided descriptions of the ongoing $\mathrm{CH}$ and RH TRU and TRU mixed waste receipt and emplacement. For CY 2008, the CAP88-PC 
dose assessment computer model was used to calculate the EDE value of 9.05E-06 mrem/year to the maximally exposed individual.

\section{Environmental Monitoring}

The purpose of the radiological environmental monitoring program is to measure radionuclides in the ambient environmental media. This allows for a comparison of sample data to results from previous years and to baseline data, to determine what, if any, impact WIPP is having on the surrounding environment. Radiological monitoring at the WIPP site includes sampling and analysis of air, groundwater, surface water, sediment, soil, and biota for all ten of the target radionuclides listed in Table 4.1. For each sampling event, chain-of-custody forms were initiated to track and maintain an accurate written record of sample handling and treatment from the time of sample collection through delivery to the laboratory. Internal chain of custody forms are used by the laboratory to track and maintain custody while samples are being analyzed.

The radionuclides analyzed were ${ }^{238} \mathrm{Pu},{ }^{239 / 240} \mathrm{Pu},{ }^{241} \mathrm{Am},{ }^{233 / 234} \mathrm{U},{ }^{235} \mathrm{U},{ }^{238} \mathrm{U},{ }^{137} \mathrm{Cs},{ }^{60} \mathrm{Co}$, ${ }^{40} \mathrm{~K}$, and ${ }^{90} \mathrm{Sr}$. Isotopes of plutonium and americium were analyzed because they are the most significant alpha-emitting radionuclides among the constituents of TRU wastes received at the WIPP site. Uranium isotopes were analyzed because they are prominent alpha-emitting radionuclides in the natural environment.

Strontium-90, ${ }^{60} \mathrm{Co}$, and ${ }^{137} \mathrm{Cs}$ were analyzed to demonstrate the ability to quantify these beta and gamma-emitting contaminants should they appear in the TRU waste stream. Potassium-40, a natural gamma-emitting radionuclide which is ubiquitous in the earth's crust, was also monitored.

\subsection{Effluent Monitoring}

\subsubsection{Sample Collection}

Stations $A, B$, and $C$ use skid-mounted fixed air samplers at each effluent air monitoring station. The volume of air sampled at each location varied depending on the sampling location and configuration. Each system is designed to provide a representative sample using a $3.0 \mu \mathrm{m}, 47-\mathrm{mm}$ diameter Versapor $^{\circledR}$ membrane filter.

Daily (24-hour) filter samples were collected from Station A from the unfiltered underground exhaust stream. Each day at Station A, approximately $79 \mathrm{~m}^{3}$ $\left(2,791\right.$ cubic feet $\left.\left[\mathrm{ft}^{3}\right]\right)$ of air was filtered through the Versapor ${ }^{\circledR}$ filter.

Weekly (24 hours/seven days per week) filter samples were collected at Stations B and $C$. Station B represents the underground exhaust air after HEPA filtration and, sometimes, nonfiltered air during maintenance. Each week at Station B, approximately $566 \mathrm{~m}^{3}\left(19,973 \mathrm{ft}^{3}\right)$ of air were filtered through the Versapor ${ }^{\circledR}$ filter. Weekly filter samples were also collected at Station $C$, which represents the air from the Waste Handling Building after HEPA filtration. Each week at Station C, approximately $213 \mathrm{~m}^{3}$ $\left(7,484 \mathrm{ft}^{3}\right)$ of air were filtered through the Versapor ${ }^{\circledR}$ filter. Based on the specified 
sampling periods, these air volumes were within \pm 10 percent of the volume derived using the flow rate set point of $0.057 \mathrm{~m}^{3} / \mathrm{min}\left(2 \mathrm{ft}^{3} / \mathrm{min}\right)$ for Stations A and B. The air volume for Station $C$ was within \pm 10 percent of the volume derived using the flow rate required for isokinetic sampling conditions and the specified sampling period. The sample flow rate for Station $C$ varied according to the exhaust air flow in the Waste Handling Building in order to maintain isokinetic sampling conditions.

The filter samples for Stations $B$ and $C$ were composited each quarter. Because of the large number of samples from Station $A$, these samples were composited monthly. All filter samples were analyzed radiochemically for ${ }^{241} \mathrm{Am},{ }^{238} \mathrm{Pu},{ }^{239 / 240} \mathrm{Pu}$, and ${ }^{90} \mathrm{Sr},{ }^{233 / 234} \mathrm{U}$, ${ }^{238} \mathrm{U}$, and ${ }^{137} \mathrm{Cs}$.

\subsubsection{Sample Preparation}

The monthly and quarterly filter samples were composited. The composites were transferred to a Pyrex beaker, spiked with appropriate tracers $\left({ }^{232} \mathrm{U},{ }^{243} \mathrm{Am}\right.$, and $\left.{ }^{242} \mathrm{Pu}\right)$, and heated in a Muffle furnace at $250^{\circ} \mathrm{C}\left(482^{\circ} \mathrm{F}\right)$ for two hours, followed by two hours of heating at $375^{\circ} \mathrm{C}\left(707^{\circ} \mathrm{F}\right)$ and six hours of heating at $525^{\circ} \mathrm{C}\left(977^{\circ} \mathrm{F}\right)$.

The filters were ashed and cooled, and then transferred into Teflon beakers by rinsing with concentrated nitric acid and heated with concentrated hydrofluoric acid until completely dissolved. Hydrofluoric acid was removed by evaporating to dryness. Approximately 25 milliliters $(\mathrm{mL})(0.845$ fluid ounce [oz] $)$ of concentrated nitric acid and one gram ( $0.0353 \mathrm{oz}$ ) of boric acid were added (to remove residual HF), and the samples were heated and evaporated to dryness. The sample residues were dissolved in 8 molar nitric acid for gamma spectroscopy and measurement of ${ }^{90} \mathrm{Sr}$ and the alpha-emitting radionuclides.

\subsubsection{Determination of Individual Radionuclides}

Gamma-emitting radionuclides were measured in the air filters by gamma spectroscopy. Strontium- 90 and alpha-emitting radionuclides were measured by sequential separation and counting. Strontium-90 was counted on a gas proportional counter. The actinides were co-precipitated, separated on an anion exchange column, and analyzed by alpha spectroscopy.

\subsubsection{Results and Discussion}

For 2008, out of 20 total composite samples, there were 140 analyses, as shown in Table 4.2. These analytes comprised of the following radionuclides: ${ }^{241} \mathrm{Am},{ }^{238} \mathrm{Pu}$, ${ }^{239 / 240} \mathrm{Pu},{ }^{90} \mathrm{Sr},{ }^{233 / 234} \mathrm{U},{ }^{238} \mathrm{U}$ and ${ }^{137} \mathrm{Cs}$.

Radionuclides are considered detected in a sample if the measured activity is greater than the $2 \times$ TPU and MDC. The detected radionuclides that meets this definition were selected as the nuclide data for the CAP88-PC dataset report, as shown in Table 4.2. Another criteria was to have the $2 \times$ TPU added to the activity value. The final result is 
compared to the MDC. The highest result of the two is also selected for the nuclide data in the CAP88-PC dataset report.

Sampling was routinely performed in the underground using fixed air samplers and continuous air monitors. Evaluation of the filter sample results indicate that there were no detectable releases that exceeded 25 mrem to the whole body and 75 mrem to any critical organ in accordance with the provisions of 40 CFR $\S 191.03(b)$, from the WIPP facility. In addition, there were no detectable releases that exceeded the 10 mrem per year limit, as specified in 40 CFR $\$ 61.92$, and the 0.1 mrem per year limit for periodic confirmatory sampling required by 40 CFR $\S 61.93(b)(4)(i)$, from the WIPP facility.

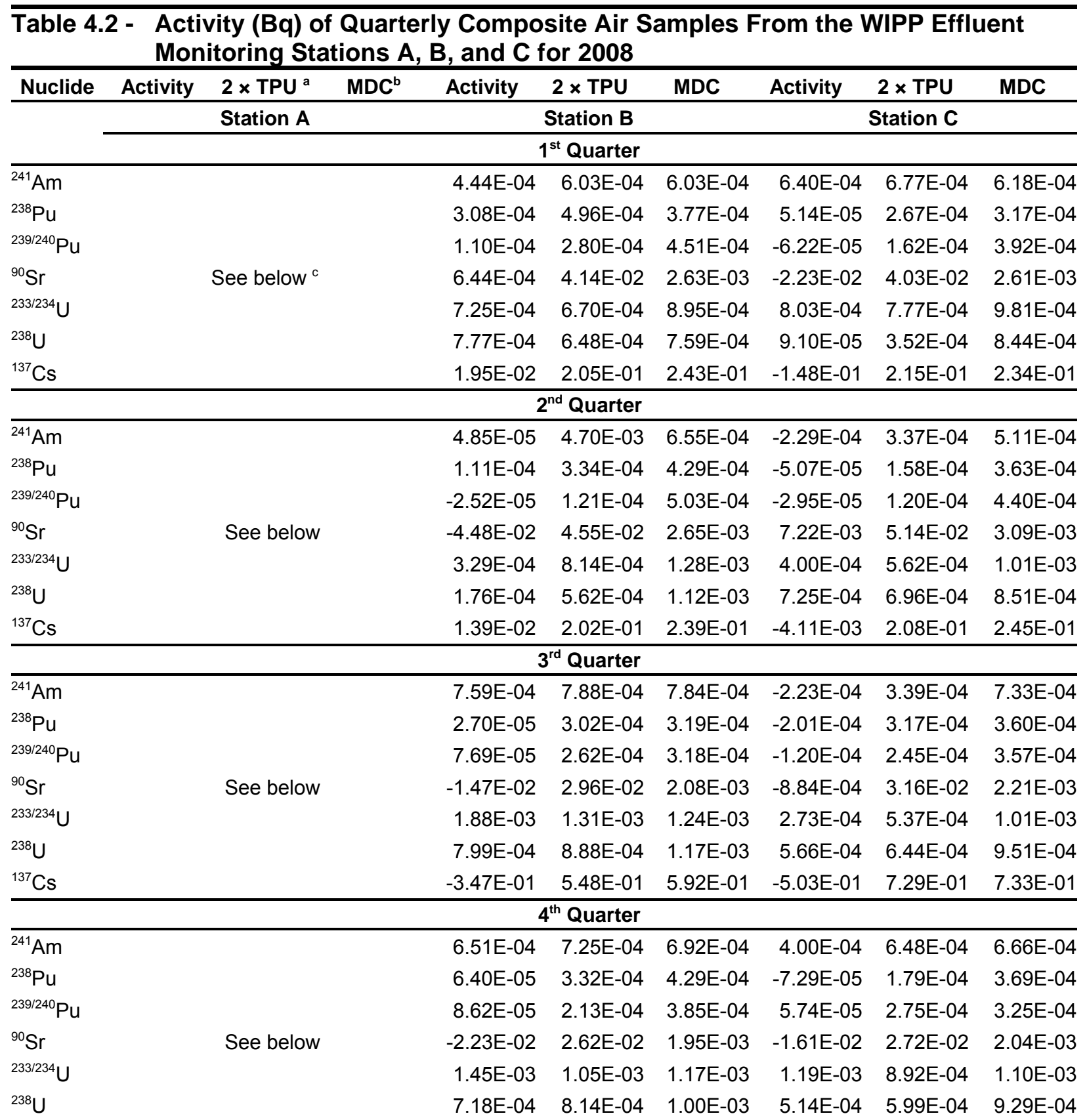


Waste Isolation Pilot Plant Annual Site Environmental Report for 2008 DOE/WIPP-09-2225

Table 4.2 - Activity (Bq) of Quarterly Composite Air Samples From the WIPP Effluent Monitoring Stations A, B, and C for 2008

\begin{tabular}{|c|c|c|c|c|c|c|c|c|c|}
\hline Nuclide & Activity & $2 \times$ TPU $^{a}$ & MDC $^{b}$ & Activity & $2 \times$ TPU & MDC & Activity & $2 \times$ TPU & MDC \\
\hline \multirow[t]{3}{*}{${ }^{137} \mathrm{Cs}$} & & & & $-4.33 \mathrm{E}-01$ & $5.03 \mathrm{E}-02$ & $1.52 \mathrm{E}+00$ & 4.07E-01 & 7.92E-01 & $9.69 \mathrm{E}-01$ \\
\hline & \multicolumn{3}{|r|}{ Station A } & \multicolumn{2}{|c|}{$\mathbf{1}^{\text {st }}$ Quarter } & Monthlyc & & & \\
\hline & \multicolumn{3}{|c|}{ January } & \multicolumn{3}{|c|}{ February } & \multicolumn{3}{|c|}{ March } \\
\hline${ }^{241} \mathrm{Am}$ & 1.86E-04 & 9.99E-04 & 7.77E-04 & 4.00E-03 & $2.53 \mathrm{E}-03$ & 1.97E-03 & 9.32E-05 & 2.73E-04 & 5.96E-04 \\
\hline${ }^{238} \mathrm{Pu}$ & $-2.21 \mathrm{E}-04$ & 3.54E-04 & 4.63E-04 & 1.12E-03 & 1.93E-03 & 1.60E-03 & 2.23E-04 & 5.74E-04 & 5.37E-04 \\
\hline${ }^{239 / 240} \mathrm{Pu}$ & 9.32E-05 & 5.29E-04 & 4.07E-04 & 2.20E-02 & 5.17E-03 & 1.60E-03 & 2.87E-04 & 5.33E-04 & 5.85E-04 \\
\hline${ }^{90} \mathrm{Sr}$ & $-8.33 E-03$ & 4.18E-02 & $3.25 \mathrm{E}-03$ & $-1.18 \mathrm{E}-02$ & $1.07 E-01$ & 7.91E-03 & 8.14E-03 & 4.40E-02 & 2.76E-03 \\
\hline${ }^{233 / 234} U$ & $5.48 \mathrm{E}-03$ & 2.35E-03 & $1.33 \mathrm{E}-03$ & 8.06E-03 & 4.44E-03 & $3.52 \mathrm{E}-03$ & 8.81E-04 & $6.62 E-04$ & $9.21 \mathrm{E}-04$ \\
\hline${ }^{238} \mathrm{U}$ & 1.32E-03 & 1.23E-03 & 9.58E-04 & $7.28 \mathrm{E}-03$ & $4.21 \mathrm{E}-03$ & 2.62E-03 & 4.22E-04 & 4.74E-04 & 7.36E-04 \\
\hline \multirow[t]{3}{*}{${ }^{137} \mathrm{Cs}$} & $-1.34 \mathrm{E}-01$ & $2.20 \mathrm{E}-01$ & $2.43 \mathrm{E}-01$ & $-3.34 \mathrm{E}-01$ & $6.95 \mathrm{E}-01$ & 8.16E-01 & 8.33E-02 & 2.05E-01 & $2.48 \mathrm{E}-01$ \\
\hline & \multicolumn{3}{|c|}{ Station A } & \multicolumn{2}{|c|}{$2^{\text {nd }}$ Quarter } & Monthly & & & \\
\hline & & April & & & May & & \multicolumn{3}{|c|}{ June } \\
\hline${ }^{241} \mathrm{Am}$ & 4.88E-05 & 4.70E-04 & 7.81E-04 & $6.14 \mathrm{E}-04$ & 8.25E-04 & 8.47E-04 & 6.95E-04 & $2.14 \mathrm{E}-03$ & 2.67E-03 \\
\hline${ }^{238} \mathrm{Pu}$ & $-1.23 E-04$ & $2.41 \mathrm{E}-04$ & 3.92E-04 & $-7.81 E-05$ & $1.98 \mathrm{E}-04$ & 3.70E-04 & 4.33E-04 & $1.66 \mathrm{E}-03$ & 1.60E-03 \\
\hline${ }^{239 / 240} \mathrm{Pu}$ & 1.64E-04 & 3.92E-04 & 4.48E-04 & $-4.77 \mathrm{E}-05$ & $1.54 \mathrm{E}-04$ & 4.48E-04 & 4.91E-04 & $1.56 \mathrm{E}-03$ & 1.79E-03 \\
\hline${ }^{90} \mathrm{Sr}$ & $-2.71 \mathrm{E}-02$ & 4.70E-02 & $3.11 \mathrm{E}-03$ & $-3.81 E-02$ & 4.00E-02 & $2.72 \mathrm{E}-03$ & $-7.04 \mathrm{E}-02$ & 1.91E-01 & 1.35E-02 \\
\hline${ }^{233 / 234} U$ & 2.06E-03 & $1.28 \mathrm{E}-03$ & $1.08 \mathrm{E}-03$ & 4.88E-04 & $5.81 \mathrm{E}-04$ & 9.47E-04 & $2.52 \mathrm{E}-03$ & $3.24 \mathrm{E}-03$ & $5.14 \mathrm{E}-03$ \\
\hline${ }^{238} \mathrm{U}$ & 9.99E-04 & 9.14E-04 & $9.29 \mathrm{E}-04$ & $1.05 \mathrm{E}-03$ & 7.92E-04 & 8.10E-04 & 2.59E-03 & 3.32E-03 & 4.66E-03 \\
\hline \multirow[t]{3}{*}{${ }^{137} \mathrm{Cs}$} & $2.98 \mathrm{E}-01$ & $1.86 \mathrm{E}-01$ & 2.43E-01 & $1.31 \mathrm{E}-01$ & 2.07E-01 & 2.54E-01 & $-3.26 \mathrm{E}-01$ & 8.59E-01 & 9.71E-01 \\
\hline & \multicolumn{3}{|c|}{ Station A } & \multicolumn{2}{|c|}{$3^{\text {rd }}$ Quarter } & \multirow[t]{2}{*}{ Monthly } & & & \\
\hline & \multicolumn{3}{|c|}{ July } & \multicolumn{2}{|r|}{ August } & & \multicolumn{3}{|c|}{ September } \\
\hline${ }^{241} \mathrm{Am}$ & 9.41E-04 & 1.16E-03 & 1.14E-03 & 7.25E-04 & $8.14 \mathrm{E}-04$ & 6.88E-04 & 3.31E-04 & 7.25E-04 & 7.84E-04 \\
\hline${ }^{238} \mathrm{Pu}$ & $-1.06 E-04$ & $6.25 E-04$ & 8.00E-04 & -8.07E-05 & 1.99E-04 & 3.50E-04 & $-5.40 \mathrm{E}-05$ & $4.22 \mathrm{E}-04$ & 3.85E-04 \\
\hline${ }^{239 / 240} \mathrm{Pu}$ & 1.71E-04 & 6.97E-04 & 8.10E-04 & 2.04E-04 & 3.85E-04 & 3.50E-04 & 3.23E-05 & 3.64E-04 & $3.85 E-04$ \\
\hline${ }^{90} \mathrm{Sr}$ & $-3.50 \mathrm{E}-02$ & 8.18E-02 & $6.06 \mathrm{E}-03$ & $1.48 \mathrm{E}-02$ & 5.03E-02 & 3.70E-03 & 1.49E-03 & 2.94E-02 & 1.97E-03 \\
\hline${ }^{233 / 234} U$ & $2.42 \mathrm{E}-03$ & $1.68 \mathrm{E}-03$ & $1.84 \mathrm{E}-03$ & $1.03 \mathrm{E}-03$ & $9.58 \mathrm{E}-04$ & $9.62 \mathrm{E}-04$ & 5.11E-04 & $6.59 \mathrm{E}-04$ & $1.06 \mathrm{E}-03$ \\
\hline${ }^{238} U$ & 1.74E-03 & 1.37E-03 & 1.69E-03 & 3.96E-04 & 5.77E-04 & 9.47E-04 & 5.33E-04 & $6.44 \mathrm{E}-04$ & 9.99E-04 \\
\hline \multirow[t]{3}{*}{${ }^{137} \mathrm{Cs}$} & $1.43 \mathrm{E}-01$ & 4.11E-01 & 2.60E-01 & $-4.96 \mathrm{E}-01$ & $5.18 \mathrm{E}-01$ & 5.59E-01 & 1.13E-01 & 4.14E-01 & $5.22 \mathrm{E}-01$ \\
\hline & \multicolumn{3}{|r|}{ Station A } & \multicolumn{2}{|c|}{$4^{\text {th }}$ Quarter } & \multirow[t]{2}{*}{ Monthly } & & & \\
\hline & \multicolumn{3}{|c|}{ October } & \multicolumn{2}{|c|}{ November } & & \multicolumn{3}{|c|}{ December } \\
\hline${ }^{241} \mathrm{Am}$ & $6.18 \mathrm{E}-04$ & $9.44 \mathrm{E}-04$ & 8.07E-04 & $-1.43 E-05$ & $4.88 \mathrm{E}-04$ & 8.33E-04 & $-1.92 \mathrm{E}-04$ & $3.60 \mathrm{E}-04$ & 7.62E-04 \\
\hline${ }^{238} \mathrm{Pu}$ & $-2.99 E-05$ & 4.37E-04 & 4.11E-04 & $-1.71 E-04$ & 3.06E-04 & 4.00E-04 & -1.57E-04 & 2.75E-04 & 3.74E-04 \\
\hline${ }^{239 / 240} \mathrm{Pu}$ & -8.95E-05 & 2.27E-04 & 4.11E-04 & $-1.47 E-04$ & 2.83E-04 & 3.89E-04 & $3.55 \mathrm{E}-04$ & 5.59E-04 & 3.49E-04 \\
\hline${ }^{90} \mathrm{Sr}$ & $-7.55 E-03$ & 8.95E-02 & 7.22E-03 & $-7.70 \mathrm{E}-02$ & $6.40 \mathrm{E}-02$ & 3.89E-03 & $-1.92 \mathrm{E}-02$ & $3.48 \mathrm{E}-02$ & $2.51 \mathrm{E}-03$ \\
\hline${ }^{233 / 234} U$ & $1.26 \mathrm{E}-03$ & $9.62 \mathrm{E}-04$ & 2.97E-02 & 3.96E-04 & 7.14E-04 & 1.19E-03 & $1.56 \mathrm{E}-03$ & 1.21E-03 & $1.26 \mathrm{E}-03$ \\
\hline${ }^{238} \mathrm{U}$ & $9.25 \mathrm{E}-04$ & 8.36E-04 & $1.02 \mathrm{E}-03$ & $6.40 \mathrm{E}-04$ & 7.70E-04 & 1.07E-03 & $1.08 \mathrm{E}-03$ & $1.08 \mathrm{E}-03$ & 1.12E-03 \\
\hline${ }^{137} \mathrm{Cs}$ & 6.59E-01 & 7.14E-01 & 9.07E-01 & $-1.15 E+00$ & $1.35 \mathrm{E}+00$ & $1.44 \mathrm{E}+00$ & 2.01E-01 & 7.70E-01 & 9.25E-01 \\
\hline
\end{tabular}




\subsection{Airborne Particulates}

\subsubsection{Sample Collection}

Weekly airborne particulate samples are collected from seven locations on or near the WIPP site (Figure 4.1) using low-volume air samplers. Locations were selected based on the prevailing wind direction. Location codes are shown in Appendix C. Each week at each sampling location, approximately $600 \mathrm{~m}^{3}\left(21,187 \mathrm{ft}^{3}\right)$ of air were filtered through a 4.7 -centimeter $(\mathrm{cm})(1.85$-inch [in.]) diameter glass microfiber filter using a continuous low-volume air sampler.

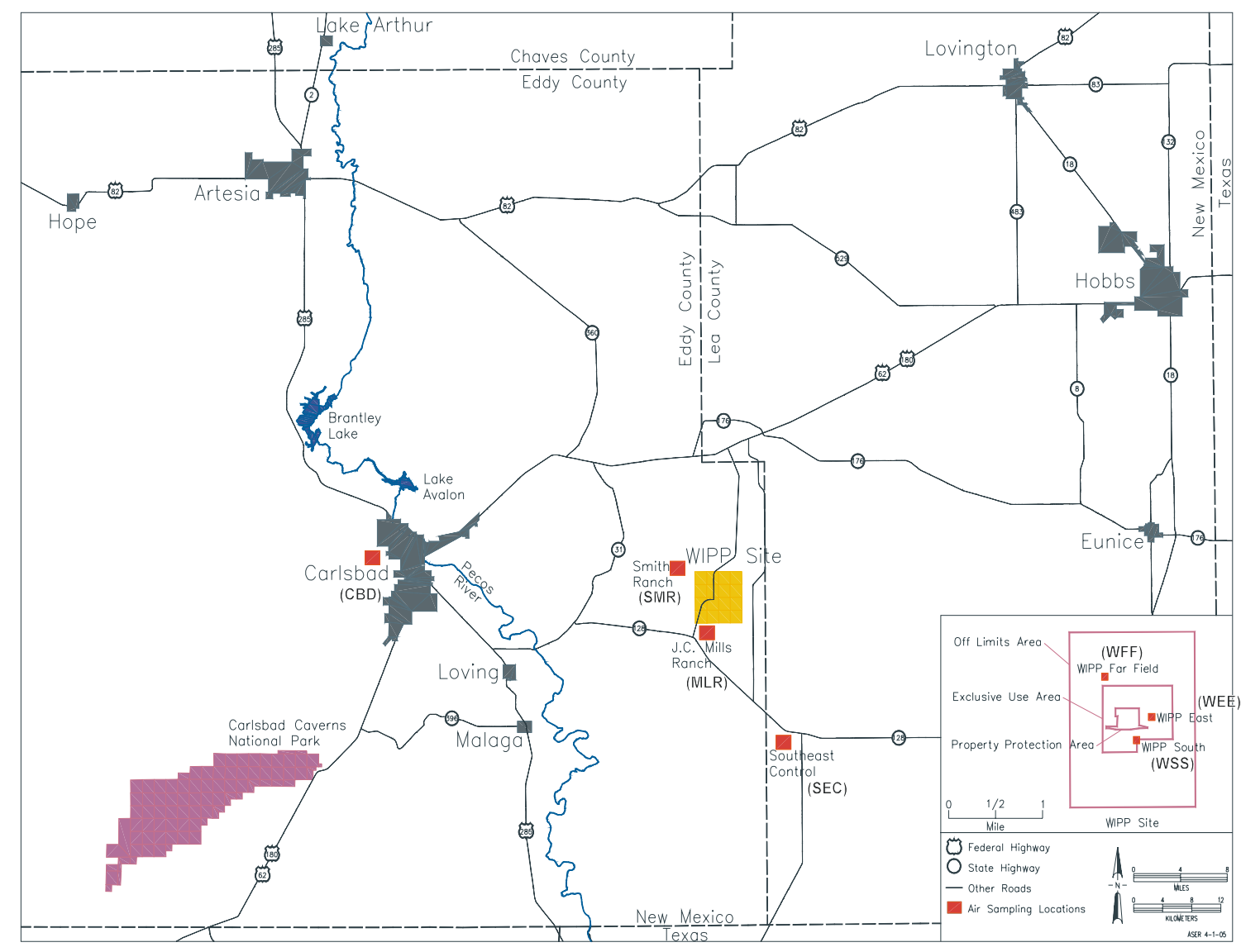

Figure 4.1 - Air Sampling Locations on and Near the WIPP Site

\subsubsection{Sample Preparation}

Weekly air particulate samples were composited for each quarter. The composite samples were transferred into a Pyrex beaker, spiked with appropriate tracers $\left({ }^{232} \mathrm{U}\right.$, ${ }^{243} \mathrm{Am}$ and ${ }^{242} \mathrm{Pu}$ ), and heated in a Muffle furnace at $250^{\circ} \mathrm{C}$ for two hours, followed by heating for two hours at $375^{\circ} \mathrm{C}$, and heating for six hours at $525^{\circ} \mathrm{C}$.

The filters were ashed and cooled, and then transferred into Teflon beakers by rinsing with concentrated nitric acid, and the mixture was heated with concentrated hydrofluoric 
acid until completely dissolved. Hydrofluoric acid was removed by evaporating to dryness.

Approximately $25 \mathrm{~mL}$ of concentrated nitric acid and one gram of boric acid were added, and the samples were heated and finally evaporated to dryness. The residues were dissolved in $8 \mathrm{M}$ nitric acid for gamma spectroscopy and for determinations of ${ }^{90} \mathrm{Sr}$ and alpha-emitting radionuclides.

\subsubsection{Determination of Individual Radionuclides}

Gamma-emitting radionuclides were measured in the air filter samples by gamma spectroscopy. Strontium-90 and alpha-emitting radionuclides were measured by sequential separation and counting. Strontium- 90 was counted with a gas proportional counter. Actinides were measured by alpha spectroscopy following the necessary separation steps involving co-precipitation and ion exchange.

\subsubsection{Results and Discussion}

The combined average, minimum, and maximum concentrations (becquerels per cubic meter $\left[\mathrm{Bq} / \mathrm{m}^{3}\right]$ ) of target nuclides for all air sampling locations are reported in Table 4.3. Detailed sample data for each station are reported in Appendix G (Table G.1).

Whenever the word "sample" is used for air filter samples, it should be taken to mean "composite sample" and does not include blanks. Individual minimum and maximum sample concentrations are highlighted in Appendix G. The average concentrations are reported for those locations where duplicate samples were collected.

Natural uranium isotopes consisting of ${ }^{233 / 234} \mathrm{U},{ }^{235} \mathrm{U}$, and ${ }^{238} \mathrm{U}$ were not detected in any of the 2008 composite samples (Table G.1). Since these isotopes were not detected, Analysis of Variance (ANOVA) comparisons between years and among locations were not performed.

Plutonium-238, ${ }^{239 / 240} \mathrm{Pu}$, and ${ }^{241} \mathrm{Am}$ were also not detected in any 2008 low-volume air samples. Since these isotopes were not detected, ANOVA comparisons between years and among locations were not performed.

Measurable concentrations of ${ }^{40} \mathrm{~K},{ }^{37} \mathrm{Cs}$, and ${ }^{60} \mathrm{Co}$ were also not detected in any of the 2008 air particulate samples. Thus no ANOVA comparisons could be performed between years or among locations for these gamma radionuclides. 


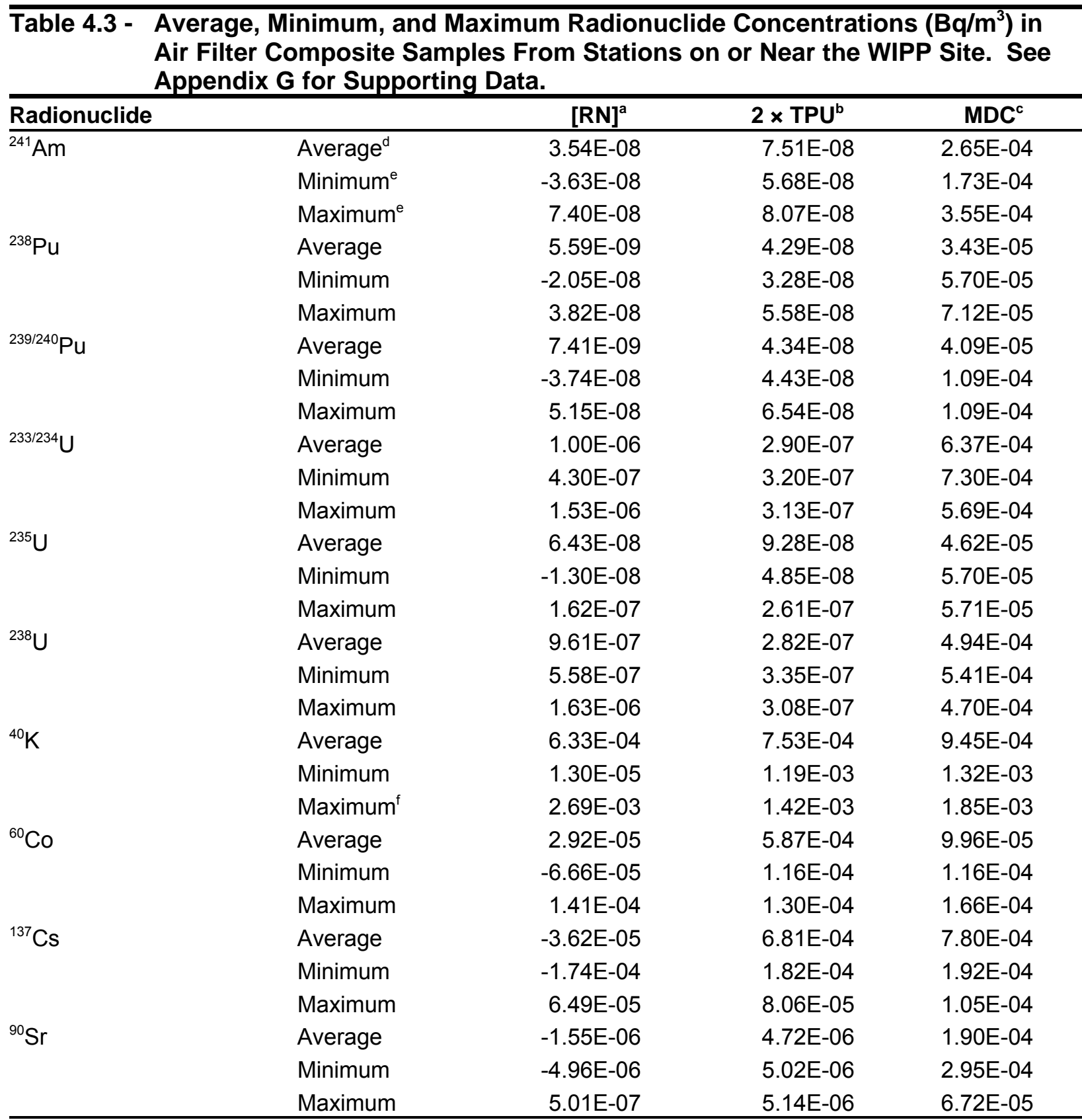

a Radionuclide concentration. Only radionuclides with activities greater than the $2 \times$ TPU and MDC are "detects." Values are for seven locations and four quarterly composites (Appendix G).

b Total propagated uncertainty

c Minimum detectable concentration

d Arithmetic average for concentration, $2 \times$ TPU and MDC

e Minimum and maximum reported concentrations for each radionuclide are based on [RN], while the associated $2 \mathrm{x}$ TPU and MDC are inherited with the specific [RN].

f ID confidence was zero even though the activity was greater than the $2 \times$ TPU and MDC.

During 2008, duplicate samples were taken from four locations. There were no detects in any of the samples, and thus analysis precision, as measured by the relative error ratio (RER) could not be measured for any of the 2008 air filter composite samples. 


\subsection{Groundwater}

\subsubsection{Sample Collection}

Groundwater samples were collected twice in 2008 from seven different WIPP groundwater quality sampling program (WQSP) wells around the WIPP site, as shown in Figure 6.1. During each of the resulting 14 sampling episodes, a primary sample and a duplicate sample were simultaneously collected from each well. Six of these wells are completed in the Culebra Member of the Rustler Formation (wells WQSP-1 through WQSP-6) and the seventh (well WQSP-6A) is completed in the Dewey Lake Redbeds Formation. Approximately three bore volumes of water were pumped out of each well before collecting approximately 38 liters $(\mathrm{L})$ (10 gallons) of water samples. The water samples were collected from depths ranging from 180-270 $\mathrm{m}(591-886 \mathrm{ft})$ from the six wells (WQSP-1 to WQSP-6), and from a depth of $69 \mathrm{~m}$ (226 ft) from WQSP-6A. Approximately $8 \mathrm{~L}$ (2 gallons) of water were sent to the laboratory for the measurement of the target radionuclides. The remaining portions of the samples were used to analyze for nonradiological parameters or were placed in storage. The radiological samples were filtered during collection and acidified to $\mathrm{pH} \leq 2$ with concentrated nitric acid.

\subsubsection{Sample Preparation}

The acidified groundwater sample containers were shaken to distribute any suspended material evenly, and sample aliquots were measured into glass beakers. The first $0.5-\mathrm{L}$ portion was used directly for gamma spectroscopy analysis and the second $0.5-\mathrm{L}$ portion was used for uranium and transuranic target isotopes and ${ }^{90} \mathrm{Sr}$. Tracers $\left({ }^{232} \mathrm{U}\right.$, ${ }^{243} \mathrm{Am}$, and ${ }^{242} \mathrm{Pu}$ ) and carriers (strontium nitrate and barium nitrate) were added to the second portion, and the samples were then digested using concentrated nitric acid and hydrofluoric acid. The samples were then heated to dryness and wet-ashed using concentrated nitric acid and hydrogen peroxide. Finally, the samples were heated to dryness again, and the isotopic separation process was initiated.

\subsubsection{Determination of Individual Radionuclides}

The first portion of water sample was used directly for the measurement of the gamma-emitting radionuclides ${ }^{40} \mathrm{~K},{ }^{60} \mathrm{Co}$, and ${ }^{137} \mathrm{Cs}$, by gamma spectroscopy. The second 0.5 -L portion of the water was used for the sequential determination of ${ }^{90} \mathrm{Sr}$ using a gas proportional counter and the uranium isotopes, the plutonium isotopes, and ${ }^{241} \mathrm{Am}$ by alpha spectroscopy. The samples were prepared for counting by co-precipitating the target isotopes and corresponding tracers with an iron carrier, performing ion exchange and chromatographic separations of the individual radionuclides, and micro-precipitating the separated radionuclides onto planchets for counting by alpha spectroscopy. 


\subsubsection{Results and Discussion}

Isotopes of naturally occurring uranium $\left({ }^{233 / 234} \mathrm{U},{ }^{235} \mathrm{U}\right.$, and $\left.{ }^{238} \mathrm{U}\right)$ were detected in all the groundwater well samples in 2008 except for ${ }^{233 / 234} U$ and ${ }^{235} U$ in WQSP-6, as shown in Table 4.3. The concentrations in Table 4.3 are from the primary samples collected from each WQSP well. A duplicate sample from each well was analyzed during each sampling episode. The data from the duplicate samples were used for the precision determinations as described later in this section. The radionuclide is considered detected if the activity is greater than the $2 \times$ TPU and MDC.

The 2008 groundwater concentrations in the WQSP wells were compared with the concentrations from the same locations in 2007 using ANOVA. ANOVA calculations were performed using the average uranium concentrations from the spring and fall sampling (Rounds 26 and 27). Uranium-233/234 and ${ }^{235} U$ were not detected in the 2008 Round 26 (spring) sampling at WQSP-6. Thus, the WQSP-6 ${ }^{233 / 234} \mathrm{U}$ concentrations are not included in the ANOVA calculation.

The concentrations of the uranium isotopes measured in 2008 did not vary significantly from the concentrations measured in the same wells in 2007 , as demonstrated by the combined ANOVA of all the wells with detects for both Rounds 26 and 27 (spring and fall sampling) with ANOVA, ${ }^{233 / 234} U p=0.204 ;{ }^{235} U p=0.799$; and ${ }^{238} U p=0.177$.

The concentrations of the uranium isotopes measured in 2008 were also compared to the 2007 concentrations by location. There was significant variation by location between 2008 and 2007 as shown by the combined ANOVA results of ${ }^{233 / 234} U p=0.00349 ;{ }^{235} U p=0.00307$; and ${ }^{238} U p=0.0248$, with all $p$ values below the significance level of 0.05 .

Concentrations of uranium isotopes were also compared with baseline concentrations measured between 1985 and 1989 (baseline values: ${ }^{233 / 234} \mathrm{U}=1.30 \mathrm{~Bq} / \mathrm{L}$,

$\left.{ }^{235} \mathrm{U}=3.10 \mathrm{E}-02 \mathrm{~Bq} / \mathrm{L},{ }^{238} \mathrm{U}=3.20 \mathrm{E}-01 \mathrm{~Bq} / \mathrm{L}\right)$. For 2008 , the concentrations of ${ }^{234} \mathrm{U},{ }^{235} \mathrm{U}$, and ${ }^{238} \mathrm{U}$ were all well within the 99 percent confidence interval ranges of baseline levels (DOE/WIPP-92-037). Therefore, it is concluded that WIPP operations have not resulted in changes in the radiological background in the vicinity of the WIPP site.

The other alpha spectroscopy radionuclides, ${ }^{238} \mathrm{Pu},{ }^{239 / 240} \mathrm{Pu}$, and ${ }^{241} \mathrm{Am}$ were also analyzed for in the groundwater samples (Table 4.3). These isotopes were not detected in any of the groundwater samples, so ANOVA comparisons between years and among locations could not be performed.

The beta emitter, ${ }^{90} \mathrm{Sr}$, was not detected in any of the groundwater samples, and thus no ANOVA comparisons between years or among locations could be performed. With respect to the gamma isotopes, ${ }^{137} \mathrm{Cs}$ and ${ }^{60} \mathrm{Co}$ were also not detected in any of the groundwater samples and ANOVA comparisons were not performed.

The gamma isotope ${ }^{40} \mathrm{~K}$ was detected in both the spring and fall rounds only at wells WQSP-1, WQSP-4, and WQSP-5 as shown by activities greater than the TPU and MDC 
in Table 4-3. Potassium-40 was not detected in some wells even though the activity was greater than the $2 \times$ TPU and MDC. The reason was that the ID confidence was $<0.90$. These cases are noted with an asterisk. It was detected in all the primary samples except WQSP-6A in the spring sampling (Round 26), but only in WQSP-1, WQSP-4, and WQSP-6 in the fall sampling round. For the gamma analytes, the ID confidence needs to be $\geq 0.90$ (equal to or greater than) to be considered a detect, although the author used one value for ${ }^{40} \mathrm{~K}$ where the ID confidence was $\geq 0.88$, and ${ }^{40} \mathrm{~K}$ was also detected in the duplicate sample (WQSP-3, Round 26).

ANOVA calculations were performed using a single concentration in those cases when ${ }^{40} \mathrm{~K}$ was detected in the primary sample. There were only five instances in which ${ }^{40} \mathrm{~K}$ was detected in a 2008 sampling round primary sample and the corresponding sample from 2007.

There was no difference in the ${ }^{40} \mathrm{~K}$ concentrations between years (ANOVA $p=0.934$ ), but significant difference among sampling locations (ANOVA $p=9.13 \mathrm{E}-05$ ). These ANOVA values are very similar to those in the last ASER comparing 2006 and 2007. The differences in ${ }^{40} \mathrm{~K}$ concentrations at the various wells (locations) are likely due to the differences in the abundance of this naturally occurring isotope in the earth's crust. The concentrations of ${ }^{40} \mathrm{~K}$ confirmed during 2008 fall within the 99 percent confidence interval range of the baseline concentrations (baseline concentration: $6.30 \mathrm{E}+01 \mathrm{~Bq} / \mathrm{L}$ ).

\begin{tabular}{|c|c|c|c|c|c|c|c|c|c|c|}
\hline & \multicolumn{9}{|c|}{$\begin{array}{l}\text { Radionuclide Concentrations (Bq/L) of Groundwater From Wells at the } \\
\text { WIPP Site. See Chapter } 6 \text { for Sampling Locations. }\end{array}$} \\
\hline \multirow{4}{*}{$\begin{array}{l}\text { Location } \\
\text { WQSP-1 }\end{array}$} & Round & {$[\mathrm{RN}]^{\mathrm{a}}$} & $2 \times T^{2} U^{b}$ & $\mathrm{MDC}^{\mathrm{C}}$ & {$[\mathrm{RN}]^{\mathrm{a}}$} & $2 \times T^{2} U^{b}$ & $\mathrm{MDC}^{\mathrm{c}}$ & {$[\mathrm{RN}]^{\mathrm{a}}$} & $2 \times T^{2} U^{b}$ & $\mathrm{MDC}^{\mathrm{C}}$ \\
\hline & & \multicolumn{3}{|c|}{${ }^{241} \mathrm{Am}$} & \multicolumn{3}{|c|}{${ }^{238} \mathrm{Pu}$} & \multicolumn{3}{|c|}{${ }^{2391 / 240} \mathrm{Pu}$} \\
\hline & 26 & & $6.97 \mathrm{E}-04$ & & & $5.04 \mathrm{E}-04$ & & & $2.78 \mathrm{E}-04$ & .20E-04 \\
\hline & 27 & & & & & & $0 \mathrm{E}-04$ & & & \\
\hline \multirow[t]{2}{*}{ WQSP-2 } & 26 & & & & & 4.24E-04 & $31 \mathrm{E}-04$ & & & \\
\hline & 27 & 3. & 4 & 33E-04 & 20E-04 & $2.35 \mathrm{E}-04$ & 40E-04 & & & $.40 \mathrm{E}-04$ \\
\hline \multirow[t]{2}{*}{ WQSP-3 } & 26 & 3.24E-04 & $8.64 \mathrm{E}$ & 1E-04 & $-1.75 E-05$ & 4.87E-04 & 78E-04 & & E-04 & 1.50E-04 \\
\hline & 27 & $3.48 \mathrm{E}-$ & $5.31 \mathrm{E}$ & $5 \mathrm{E}-04$ & $25 \mathrm{E}-05$ & $2.75 \mathrm{E}-04$ & 34E-04 & & & $.04 \mathrm{E}-04$ \\
\hline \multirow[t]{2}{*}{ WQSP-4 } & 26 & $-3.40 E-04$ & $4.56 \mathrm{E}$ & 57E-04 & $-1.36 \mathrm{E}-04$ & 4.12E-04 & 73E-04 & & & 4.35E-04 \\
\hline & 27 & +00 & $54 \mathrm{E}$ & $6 \mathrm{E}-04$ & $-4.74 \mathrm{E}-05$ & $2.94 \mathrm{E}-04$ & 63E-04 & & & $2.62 \mathrm{E}-04$ \\
\hline \multirow[t]{2}{*}{ WQSP-5 } & 26 & $=-04$ & $5.04 \mathrm{E}-$ & $3 \mathrm{E}-04$ & 3.69E-04 & $6.83 E-04$ & 28E-04 & & & 4.17E-04 \\
\hline & 27 & 2.70 & $4.26 \mathrm{E}$ & E-04 & $1.38 \mathrm{E}-04$ & 4.04E-04 & $35 \mathrm{E}-04$ & & & $35 \mathrm{E}-04$ \\
\hline \multirow[t]{2}{*}{ WQSP-6 } & 26 & $-1.07 E-04$ & 4.10E-04 & 7E-04 & $-1.52 \mathrm{E}-04$ & 2.43E-04 & 11E-04 & & & 3.35E-04 \\
\hline & 27 & 7.44 & $6.04 \mathrm{E}$ & $E-04$ & $37 E-05$ & 4.68E-04 & 38E-04 & & & $.38 \mathrm{E}-04$ \\
\hline \multirow[t]{3}{*}{ WQSP-6A } & 26 & 3.41 & $8.19 \mathrm{E}-04$ & $E-04$ & 2.09E-04 & $5.80 \mathrm{E}-04$ & 53E-04 & & & $.01 \mathrm{E}-04$ \\
\hline & 27 & $95 \mathrm{E}-04$ & $6.05 \mathrm{E}-04$ & $.72 \mathrm{E}-04$ & $53 \mathrm{E}-04$ & $5.88 \mathrm{E}-04$ & 3.11E-04 & $E-05$ & 2.00E-04 & 3.11E-04 \\
\hline & & & ${ }^{233 / 234} U$ & & & ${ }^{235} \mathrm{U}$ & & & ${ }^{238} \mathrm{U}$ & \\
\hline \multirow[t]{2}{*}{ WQSP-1 } & 26 & $6.74 \mathrm{E}$ & $2.99 \mathrm{E}-02$ & & $1.02 \mathrm{E}-02$ & $2.59 \mathrm{E}-03$ & 32E-04 & & & $.83 \mathrm{E}-04$ \\
\hline & 27 & 5.33E-01 & $2.40 \mathrm{E}-02$ & $9.96 \mathrm{E}-04$ & $2.42 \mathrm{E}-02$ & $3.80 \mathrm{E}-03$ & 4.63E-04 & $8 \mathrm{E}-02$ & & $.92 \mathrm{E}-04$ \\
\hline \multirow[t]{2}{*}{ WQSP-2 } & 26 & $6.04 \mathrm{E}-01$ & $2.78 \mathrm{E}-02$ & 9.57E-04 & $8.43 \mathrm{E}-03$ & $2.30 \mathrm{E}-03$ & 4.66E-04 & & & 7.70E-04 \\
\hline & 27 & $5.24 \mathrm{E}-$ & $2.45 \mathrm{E}-$ & $3 \mathrm{E}-03$ & $1.03 E-02$ & $2.72 \mathrm{E}-03$ & 50E-04 & & & E-04 \\
\hline \multirow[t]{2}{*}{ WQSP-3 } & 26 & 39E-01 & $1.03 \mathrm{E}$ & & $1.96 \mathrm{E}-03$ & $1.21 \mathrm{E}-03$ & 29E-04 & & & E-04 \\
\hline & 27 & 1.27E-01 & $8.65 \mathrm{E}$ & & 3.43E-03 & $1.41 \mathrm{E}-03$ & $56 \mathrm{E}-04$ & & & 7E-04 \\
\hline \multirow[t]{2}{*}{ WQSP-4 } & 26 & $1.99 \mathrm{E}-01$ & 1.19E- & & & $1.39 \mathrm{E}-03$ & 4E-04 & & & $.03 E-04$ \\
\hline & 27 & $3.25 \mathrm{E}-01$ & $1.76 \mathrm{E}-02$ & 1.07E-03 & 1.10E-02 & 2.73E-03 & $5.23 \mathrm{E}-04$ & $5.83 \mathrm{E}-02$ & $5.94 \mathrm{E}-03$ & $9.29 \mathrm{E}-04$ \\
\hline
\end{tabular}


Waste Isolation Pilot Plant Annual Site Environmental Report for 2008 DOE/WIPP-09-2225

\begin{tabular}{|c|c|c|c|c|c|c|c|c|c|c|}
\hline \multicolumn{2}{|c|}{ Table 4.4 - } & \multicolumn{9}{|c|}{$\begin{array}{l}\text { Radionuclide Concentrations (Bq/L) of Groundwater From Wells at the } \\
\text { WIPP Site. See Chapter } 6 \text { for Sampling Locations. }\end{array}$} \\
\hline Location & Round & {$[\mathrm{RN}]^{\mathrm{a}}$} & $2 \times$ TPU $^{b}$ & $\mathrm{MDC}^{\mathrm{C}}$ & {$[\mathrm{RN}]^{\mathrm{a}}$} & $2 \times T_{P U}^{b}$ & $\mathrm{MDC}^{\mathrm{c}}$ & {$[R N]^{a}$} & $2 \times$ TPU $^{b}$ & $M C^{c}$ \\
\hline \multirow[t]{2}{*}{ WQSP-5 } & 26 & $2.80 \mathrm{E}-01$ & $52 \mathrm{E}-02$ & 9.66E-04 & $2.72 \mathrm{E}-03$ & $1.28 \mathrm{E}-03$ & 4.75E-04 & 3.59E-02 & $4.32 \mathrm{E}-03$ & $6.18 \mathrm{E}-04$ \\
\hline & 27 & $3.24 \mathrm{E}$ & 82E-02 & 05E-03 & $.02 \mathrm{E}-02$ & $2.75 \mathrm{E}-03$ & $.93 \mathrm{E}-04$ & -02 & & $E-04$ \\
\hline \multirow[t]{2}{*}{ WQSP-6 } & 26 & $2.72 \mathrm{E}$ & 02 & & 2.23E-03 & $1.21 \mathrm{E}-03$ & & & & \\
\hline & 27 & & & & 8.60E-05 & 5.33E-04 & & & & \\
\hline \multirow[t]{3}{*}{ WQSP-6A } & 26 & $1.10 \mathrm{E}$ & $36 \mathrm{E}-$ & $1.66 \mathrm{E}-03$ & $6.50 \mathrm{E}$ & $3.38 \mathrm{E}-03$ & $1.25 \mathrm{E}-03$ & 5.73 & & -03 \\
\hline & 27 & 1.09E-01 & 15E-03 & $12 \mathrm{E}-04$ & $.65 E-03$ & 1.84E-03 & 4.46E-04 & 02 & $5.59 \mathrm{E}-03$ & 8.49E-04 \\
\hline & & & ${ }^{40} \mathrm{~K}$ & & & ${ }^{60} \mathrm{Co}$ & & & & \\
\hline \multirow[t]{2}{*}{ WQSP-1 } & 26 & $1.75 E+01$ & $4.15 \mathrm{E}+$ & & & 3.83E-01 & & & & \\
\hline & 27 & $1.50 \mathrm{E}+01$ & $5.35 \mathrm{E}+00$ & $5.97 \mathrm{E}+00$ & $-5.63 E-02$ & $5.78 \mathrm{E}-01$ & $6.68 \mathrm{E}-01$ & -3.15 & & $E-01$ \\
\hline \multirow[t]{2}{*}{ WQSP-2 } & 26 & $1.64 \mathrm{E}+01$ & $4.31 \mathrm{E}+00$ & $4.45 \mathrm{E}+00$ & 5.57E-02 & $3.48 \mathrm{E}-01$ & 4.04E-01 & -1.5 & & $E-01$ \\
\hline & 27 & *1.65E+01 & *8.88E+00 & $1.35 \mathrm{E}+01$ & 5.66E-02 & $6.86 \mathrm{E}-01$ & E-01 & & & -01 \\
\hline \multirow[t]{2}{*}{ WQSP-3 } & 26 & $5.01 \mathrm{E}+01$ & $7.47 \mathrm{E}+00$ & $3.00 \mathrm{E}+00$ & $0.00 \mathrm{E}+00$ & $0.00 \mathrm{E}+00$ & & & & \\
\hline & 27 & *4.63E+01 & *1.07E+01 & $1.61 \mathrm{E}+01$ & 3.94E-01 & 5.74E-01 & $69 \mathrm{E}-01$ & & & \\
\hline \multirow[t]{2}{*}{ WQSP-4 } & 26 & $2.72 E+01$ & $5.39 \mathrm{E}+00$ & $3.45 \mathrm{E}+00$ & $9.59 \mathrm{E}-02$ & $3.82 \mathrm{E}-01$ & 4.38E-01 & 1.03E-01 & & E-01 \\
\hline & 27 & $2.20 \mathrm{E}+01$ & $6.27 \mathrm{E}+00$ & $5.92 \mathrm{E}+00$ & 5.53E-01 & 5.98E-01 & 8.23E-01 & & & \\
\hline \multirow[t]{2}{*}{ WQSP-5 } & 26 & $1.20 \mathrm{E}+01$ & $3.25 \mathrm{E}+00$ & $3.25 \mathrm{E}+00$ & 1.21E-01 & $3.52 \mathrm{E}-01$ & $4.08 \mathrm{E}-01$ & & & E-01 \\
\hline & 27 & $1.09 \mathrm{E}+01$ & $4.05 E+00$ & $4.06 \mathrm{E}+00$ & 3.44E-03 & 5.74E-01 & $6.79 \mathrm{E}-01$ & & & E-01 \\
\hline \multirow[t]{2}{*}{ WQSP-6 } & 26 & $5.38 \mathrm{E}+00$ & $2.37 E+00$ & $3.11 \mathrm{E}+00$ & 3.04E-01 & 3.64E-01 & 4.43E-01 & & & 3.39E-01 \\
\hline & 27 & $4.74 \mathrm{E}+00$ & $3.84 \mathrm{E}+00$ & $6.04 \mathrm{E}+00$ & $1.38 \mathrm{E}-01$ & 4.86E-01 & 5.52E-01 & $-5.52 \mathrm{E}-01$ & & $5.54 \mathrm{E}-01$ \\
\hline \multirow[t]{2}{*}{ WQSP-6A } & 26 & $1.29 \mathrm{E}+00$ & $2.74 \mathrm{E}+00$ & $3.28 \mathrm{E}+00$ & 1.47E-01 & $2.40 \mathrm{E}-01$ & 2.93E-01 & & & $2.58 \mathrm{E}-01$ \\
\hline & 27 & *4.89E+00 & $* 2.40 \mathrm{E}+00$ & $3.30 \mathrm{E}+00$ & 7.28E-02 & 2.47E-01 & 2.93E-01 & $-2.56 \mathrm{E}-02$ & 2.19E-01 & $2.55 \mathrm{E}-01$ \\
\hline
\end{tabular}

\begin{tabular}{lllll} 
& & \multicolumn{3}{c}{${ }^{90} \mathrm{Sr}$} \\
\cline { 3 - 5 } WQSP-1 & 26 & $-4.63 \mathrm{E}-03$ & $3.34 \mathrm{E}-02$ & $2.07 \mathrm{E}-03$ \\
WQSP-2 & 27 & $-2.15 \mathrm{E}-02$ & $3.07 \mathrm{E}-02$ & $2.13 \mathrm{E}-03$ \\
& 26 & $-3.72 \mathrm{E}-04$ & $3.33 \mathrm{E}-02$ & $2.02 \mathrm{E}-03$ \\
WQSP-3 & 26 & $-4.40 \mathrm{E}-03$ & $3.24 \mathrm{E}-02$ & $2.09 \mathrm{E}-03$ \\
& 27 & $-7.27 \mathrm{E}-03$ & $3.45 \mathrm{E}-02$ & $2.35 \mathrm{E}-03$ \\
WQSP-4 & 26 & $-1.67 \mathrm{E}-02$ & $5.31 \mathrm{E}-02$ & $3.31 \mathrm{E}-03$ \\
& 27 & $2.00 \mathrm{E}-03$ & $4.04 \mathrm{E}-02$ & $2.57 \mathrm{E}-03$ \\
WQSP-5 & 26 & $-6.26 \mathrm{E}-03$ & $3.40 \mathrm{E}-02$ & $2.48 \mathrm{E}-03$ \\
& 27 & $-2.24 \mathrm{E}-03$ & $4.72 \mathrm{E}-02$ & $3.05 \mathrm{E}-03$ \\
WQSP-6 & 26 & $-1.52 \mathrm{E}-03$ & $3.42 \mathrm{E}-02$ & $2.47 \mathrm{E}-03$ \\
& 27 & $-1.96 \mathrm{E}-02$ & $3.34 \mathrm{E}-02$ & $2.59 \mathrm{E}-03$ \\
WQSP-6A & 26 & $-9.83 \mathrm{E}-03$ & $4.36 \mathrm{E}-02$ & $3.61 \mathrm{E}-03$ \\
& 27 & $-1.51 \mathrm{E}-02$ & $3.06 \mathrm{E}-02$ & $2.57 \mathrm{E}-03$ \\
\hline
\end{tabular}

a Radionuclide concentration. Only radionuclides with activities greater than the $2 \times$ TPU and MDC are "detects."

b Total propagated uncertainty

${ }^{c}$ Minimum detectable concentration

* Gamma spectroscopy, samples with ID confidence $<0.90$ - not considered "detects."

This ASER reports the RERs only for the radionuclides that were detected during analysis of the primary and duplicate samples collected at each WQSP well. The detected radionuclides included the uranium isotopes and ${ }^{40} \mathrm{~K}$. The analysis data and resulting RERs are shown in Table 4.5 for Sampling Round 26 and in Table 4.6 for Sampling Round 27. 
The Round 26 RERs in Table 4.5 show that three values were $>1$ including ${ }^{238} \mathrm{U}$ in WQSP-3 (1.018) and WQSP-4 (1.954), and ${ }^{235} U$ in WQSP-6A (1.135).

The Round 27 RERs in Table 4.6 shows that seven RER values were $>1$ including ${ }^{233 / 234} U$ in WQSP-1 (2.513), WQSP-3 (1.559), WQSP-5 (1.339), and WQSP-6 (18.225); ${ }^{235} \mathrm{U}$ in WQSP-1 (1.396), and WQSP-6 (3.767); and ${ }^{238} \mathrm{U}$ in WQSP-6A (.1.83), and ${ }^{40} \mathrm{~K}$ in WQSP-6A (1.143).

In theory, the primary and duplicate samples should be identical to each other since the sample containers are filled simultaneously. However, these results show that the precision objective was not met for some of the alpha spectroscopy analysis procedures for field duplicates even though the objective was met for laboratory duplicates. The alpha spectroscopy sample preparation requires many different laboratory procedures, and all the steps combined can contribute to some lack of precision. The laboratory reanalyzed some batches of samples because of spectral interferences, and some samples contained relatively weak alpha spectra as evidenced by low tracer recoveries although the laboratory's QA/QC criteria were met.

The greater imprecision of field duplicates suggests that the imprecision is associated more with the samples than wit the analyses and may reflect actual differences in the composition of samples.

Table 4.5 - Results of Duplicate Groundwater Sample Analyses for Sampling Round 26. Units are in Bq/L. See Chapter 6 for Sampling Locations.

\begin{tabular}{|c|c|c|c|c|c|c|c|c|}
\hline \multirow[t]{2}{*}{ Location } & & \multicolumn{3}{|c|}{ Sample } & \multicolumn{3}{|c|}{ Duplicate } & \multirow[b]{2}{*}{ RER $^{d}$} \\
\hline & & {$[\mathrm{RN}]^{\mathrm{a}}$} & $2 \times$ TPU $^{b}$ & MDC $^{c}$ & {$[\mathrm{RN}]^{\mathrm{a}}$} & $2 \times T^{T} U^{b}$ & MDC $^{c}$ & \\
\hline \multirow[t]{4}{*}{ WQSP-1 } & ${ }^{233 / 234} U$ & $6.74 \mathrm{E}-01$ & 2.99E-02 & 9.70E-04 & 6.36E-01 & $2.86 \mathrm{E}-02$ & $9.40 \mathrm{E}-04$ & 0.920 \\
\hline & ${ }^{235} \mathrm{U}$ & $1.02 \mathrm{E}-02$ & 2.59E-03 & 4.82E-04 & 1.13E-02 & 2.62E-03 & 4.45E-04 & 0.303 \\
\hline & ${ }^{238} \mathrm{U}$ & 1.12E-01 & 8.54E-03 & 7.83E-04 & $1.05 \mathrm{E}-01$ & 7.96E-03 & 7.53E-04 & 0.649 \\
\hline & ${ }^{40} \mathrm{~K}$ & $1.75 \mathrm{E}+01$ & $4.15 \mathrm{E}+00$ & $3.74 \mathrm{E}+00$ & $1.46 \mathrm{E}+01$ & $4.06 \mathrm{E}+00$ & $4.39 \mathrm{E}+00$ & 0.500 \\
\hline \multirow[t]{4}{*}{ WQSP-2 } & ${ }^{233 / 234} U$ & 6.04E-01 & 2.78E-02 & 9.57E-04 & 6.39E-01 & 2.93E-02 & 9.66E-04 & 0.867 \\
\hline & ${ }^{235} U$ & 8.43E-03 & $2.30 \mathrm{E}-03$ & 4.66E-04 & $1.02 \mathrm{E}-02$ & 2.62E-03 & 4.77E-04 & 0.508 \\
\hline & ${ }^{238} \mathrm{U}$ & 9.84E-02 & 7.83E-03 & 7.70E-04 & 1.04E-01 & 8.19E-03 & 7.79E-04 & 0.494 \\
\hline & ${ }^{40} \mathrm{~K}$ & $1.64 \mathrm{E}+01$ & $4.31 \mathrm{E}+00$ & $4.45 \mathrm{E}+00$ & $1.98 E+01$ & $5.36 \mathrm{E}+00$ & $6.46 \mathrm{E}+00$ & 0.494 \\
\hline \multirow[t]{4}{*}{ WQSP-3 } & ${ }^{233 / 234} U$ & 1.39E-01 & 1.03E-02 & 9.71E-04 & 1.34E-01 & $9.42 \mathrm{E}-03$ & $9.13 \mathrm{E}-04$ & 0.358 \\
\hline & ${ }^{235} U$ & 1.96E-03 & $1.21 \mathrm{E}-03$ & 5.29E-04 & 1.39E-03 & $9.29 \mathrm{E}-04$ & 4.58E-04 & 0.374 \\
\hline & ${ }^{238} \mathrm{U}$ & 1.49E-02 & 2.96E-03 & 7.46E-04 & 1.93E-02 & $3.15 \mathrm{E}-03$ & 6.89E-04 & 1.018 \\
\hline & ${ }^{40} \mathrm{~K}$ & $5.01 \mathrm{E}+01$ & $7.47 \mathrm{E}+00$ & $3.00 \mathrm{E}+00$ & $5.13 E+01$ & $8.33 E+00$ & $6.21 \mathrm{E}+00$ & 0.107 \\
\hline \multirow[t]{4}{*}{ WQSP-4 } & ${ }^{233 / 234} U$ & 1.99E-01 & 1.19E-02 & 9.03E-04 & 1.85E-01 & 1.51E-02 & $1.20 \mathrm{E}-03$ & 0.728 \\
\hline & ${ }^{235} U$ & 3.29E-03 & $1.39 \mathrm{E}-03$ & 4.34E-04 & 4.04E-03 & 2.17E-03 & 8.46E-04 & 0.291 \\
\hline & ${ }^{238} U$ & 3.77E-02 & 4.35E-03 & 7.03E-04 & 2.49E-02 & 4.90E-03 & 1.05E-03 & 1.954 \\
\hline & ${ }^{40} \mathrm{~K}$ & $2.72 \mathrm{E}+01$ & $5.39 E+00$ & $3.45 \mathrm{E}+00$ & $2.43 E+01$ & $5.39 E+00$ & $4.51 \mathrm{E}+00$ & 0.380 \\
\hline
\end{tabular}




\begin{tabular}{|c|c|c|c|c|c|c|c|c|}
\hline \multirow[t]{2}{*}{ Location } & & \multicolumn{3}{|c|}{ Sample } & \multicolumn{3}{|c|}{ Duplicate } & \multirow[b]{2}{*}{ RER $^{d}$} \\
\hline & & ${\text { [RN }]^{\mathrm{a}}}$ & $2 \times$ TPU $^{b}$ & MDC $^{c}$ & [RN] $^{\mathrm{a}}$ & $2 \times \operatorname{TPU}^{\mathrm{b}}$ & MDC $^{c}$ & \\
\hline \multirow[t]{4}{*}{ WQSP-5 } & ${ }^{233 / 234} U$ & $2.80 \mathrm{E}-01$ & 1.52E-02 & $9.66 \mathrm{E}-04$ & $2.92 \mathrm{E}-01$ & $1.56 \mathrm{E}-02$ & $9.73 \mathrm{E}-04$ & 0.551 \\
\hline & ${ }^{235} \mathrm{U}$ & 2.72E-03 & $1.28 \mathrm{E}-03$ & 4.75E-04 & $3.24 \mathrm{E}-03$ & $1.41 \mathrm{E}-03$ & 4.83E-04 & 0.273 \\
\hline & ${ }^{238} \mathrm{U}$ & 3.59E-02 & 4.32E-03 & $6.18 \mathrm{E}-04$ & 4.03E-02 & 4.62E-03 & $6.25 \mathrm{E}-04$ & 0.696 \\
\hline & ${ }^{40} \mathrm{~K}$ & $1.20 \mathrm{E}+01$ & $3.25 \mathrm{E}+00$ & $3.25 E+00$ & $1.02 \mathrm{E}+01$ & $3.31 E+00$ & $3.92 E+00$ & 0.388 \\
\hline \multirow[t]{4}{*}{ WQSP-6 } & ${ }^{233 / 234} U$ & 2.72E-01 & $1.50 \mathrm{E}-02$ & 9.90E-04 & 2.70E-01 & 1.52E-02 & 9.85E-04 & 0.094 \\
\hline & ${ }^{235} \mathrm{U}$ & 2.23E-03 & $1.21 \mathrm{E}-03$ & 5.04E-04 & $1.53 \mathrm{E}-03$ & $1.02 \mathrm{E}-03$ & 4.99E-04 & 0.442 \\
\hline & ${ }^{238} \mathrm{U}$ & 3.70E-02 & 4.52E-03 & 6.42E-04 & $3.29 E-02$ & 4.24E-03 & 6.37E-04 & 0.662 \\
\hline & ${ }^{40} \mathrm{~K}$ & $5.38 \mathrm{E}+00$ & $2.37 E+00$ & $3.11 \mathrm{E}+00$ & $4.15 E+00$ & $2.52 \mathrm{E}+00$ & $3.69 E+00$ & 0.356 \\
\hline \multirow[t]{4}{*}{ WQSP-6A } & ${ }^{233 / 234} U$ & 1.10E-01 & 1.36E-02 & 1.66E-03 & 1.10E-01 & 8.34E-03 & $1.04 \mathrm{E}-03$ & 0.000 \\
\hline & ${ }^{235} \mathrm{U}$ & $6.50 \mathrm{E}-03$ & 3.38E-03 & 1.25E-03 & 2.38E-03 & $1.32 \mathrm{E}-03$ & 4.84E-04 & 1.135 \\
\hline & ${ }^{238} \mathrm{U}$ & 5.73E-02 & 9.37E-03 & 1.27E-03 & $6.00 \mathrm{E}-02$ & 5.83E-03 & $6.50 \mathrm{E}-04$ & 0.245 \\
\hline & ${ }^{40} \mathrm{~K}$ & ND & & & ND & & & NA \\
\hline
\end{tabular}

a Radionuclide concentration. Only radionuclides with activities greater than the $2 \times$ TPU and MDC are "detects."

b Total propagated uncertainty

c Minimum detectable concentration

d Relative error ratio

\begin{tabular}{|c|c|c|c|c|c|c|c|c|}
\hline \multirow{2}{*}{ Location } & & \multicolumn{3}{|c|}{ Sample } & \multicolumn{3}{|c|}{ Duplicate } & \multirow[b]{2}{*}{ RER $^{d}$} \\
\hline & & {$[\mathrm{RN}]^{\mathrm{a}}$} & $2 \times$ TPU $^{b}$ & $M^{\prime} C^{c}$ & {$[\mathrm{RN}]^{\mathrm{a}}$} & $2 \times$ TPU $^{b}$ & $M D C^{c}$ & \\
\hline \multirow[t]{4}{*}{ WQSP-1 } & ${ }^{233 / 234} U$ & 5.33E-01 & $2.40 \mathrm{E}-02$ & 9.96E-04 & 4.54E-01 & 2.03E-02 & 9.38E-04 & 2.513 \\
\hline & ${ }^{235} U$ & 2.42E-02 & 3.80E-03 & 4.63E-04 & $3.22 \mathrm{E}-02$ & $4.29 E-03$ & 4.40E-04 & 1.396 \\
\hline & ${ }^{238} \mathrm{U}$ & 9.08E-02 & 7.42E-03 & 8.92E-04 & 8.26E-02 & 6.54E-03 & 8.38E-04 & 0.829 \\
\hline & ${ }^{40} \mathrm{~K}$ & $1.50 \mathrm{E}+01$ & $5.35 E+00$ & $5.97 E+00$ & $1.03 E+01$ & $5.28 E+00$ & $6.70 \mathrm{E}+00$ & 0.625 \\
\hline \multirow[t]{4}{*}{ WQSP-2 } & ${ }^{233 / 234} U$ & $5.24 \mathrm{E}-01$ & $2.45 \mathrm{E}-02$ & 1.03E-03 & 5.57E-01 & $2.50 \mathrm{E}-02$ & $1.05 E-03$ & 0.943 \\
\hline & ${ }^{235} U$ & 1.03E-02 & $2.72 \mathrm{E}-03$ & 5.50E-04 & 1.23E-02 & 3.04E-03 & 5.83E-04 & 0.490 \\
\hline & ${ }^{238} \mathrm{U}$ & 8.50E-02 & 7.45E-03 & $9.75 \mathrm{E}-04$ & 8.86E-02 & 7.76E-03 & 1.00E-03 & 0.335 \\
\hline & ${ }^{40} \mathrm{~K}$ & *1.65E+01 & $8.88 \mathrm{E}+00$ & $1.35 E+01$ & $1.66 \mathrm{E}+01$ & $5.25 \mathrm{E}+00$ & $5.09 \mathrm{E}+00$ & 0.010 \\
\hline \multirow[t]{4}{*}{ WQSP-3 } & ${ }^{233 / 234} U$ & 1.27E-01 & 8.65E-03 & 9.63E-04 & $1.46 \mathrm{E}-01$ & 8.58E-03 & $9.40 \mathrm{E}-04$ & 1.559 \\
\hline & ${ }^{235} U$ & 3.43E-03 & 1.41E-03 & 4.56E-04 & $2.11 \mathrm{E}-03$ & 1.07E-03 & 4.27E-04 & 0.746 \\
\hline & ${ }^{238} \mathrm{U}$ & 1.76E-02 & 2.86E-03 & 8.87E-04 & 2.09E-02 & 2.89E-03 & 8.64E-04 & 0.812 \\
\hline & ${ }^{40} \mathrm{~K}$ & ND & & & $5.08 \mathrm{E}+01$ & $1.11 \mathrm{E}+01$ & $1.02 \mathrm{E}+01$ & NA \\
\hline \multirow[t]{4}{*}{ WQSP-4 } & ${ }^{233 / 234} U$ & $3.25 E-01$ & 1.76E-02 & 1.07E-03 & 3.09E-01 & $1.74 \mathrm{E}-02$ & 1.13E-03 & 0.646 \\
\hline & ${ }^{235} \mathrm{U}$ & 1.10E-02 & 2.73E-03 & 5.23E-04 & 9.57E-03 & $2.74 \mathrm{E}-03$ & 6.04E-04 & 0.370 \\
\hline & ${ }^{238} \mathrm{U}$ & 5.83E-02 & 5.94E-03 & $9.29 \mathrm{E}-04$ & 5.83E-02 & 6.33E-03 & 9.95E-04 & 0.000 \\
\hline & ${ }^{40} \mathrm{~K}$ & $2.20 \mathrm{E}+01$ & $6.27 E+00$ & $5.92 E+00$ & $2.21 \mathrm{E}+01$ & $6.21 E+00$ & $5.68 \mathrm{E}+00$ & 0.011 \\
\hline
\end{tabular}


Waste Isolation Pilot Plant Annual Site Environmental Report for 2008 DOE/WIPP-09-2225

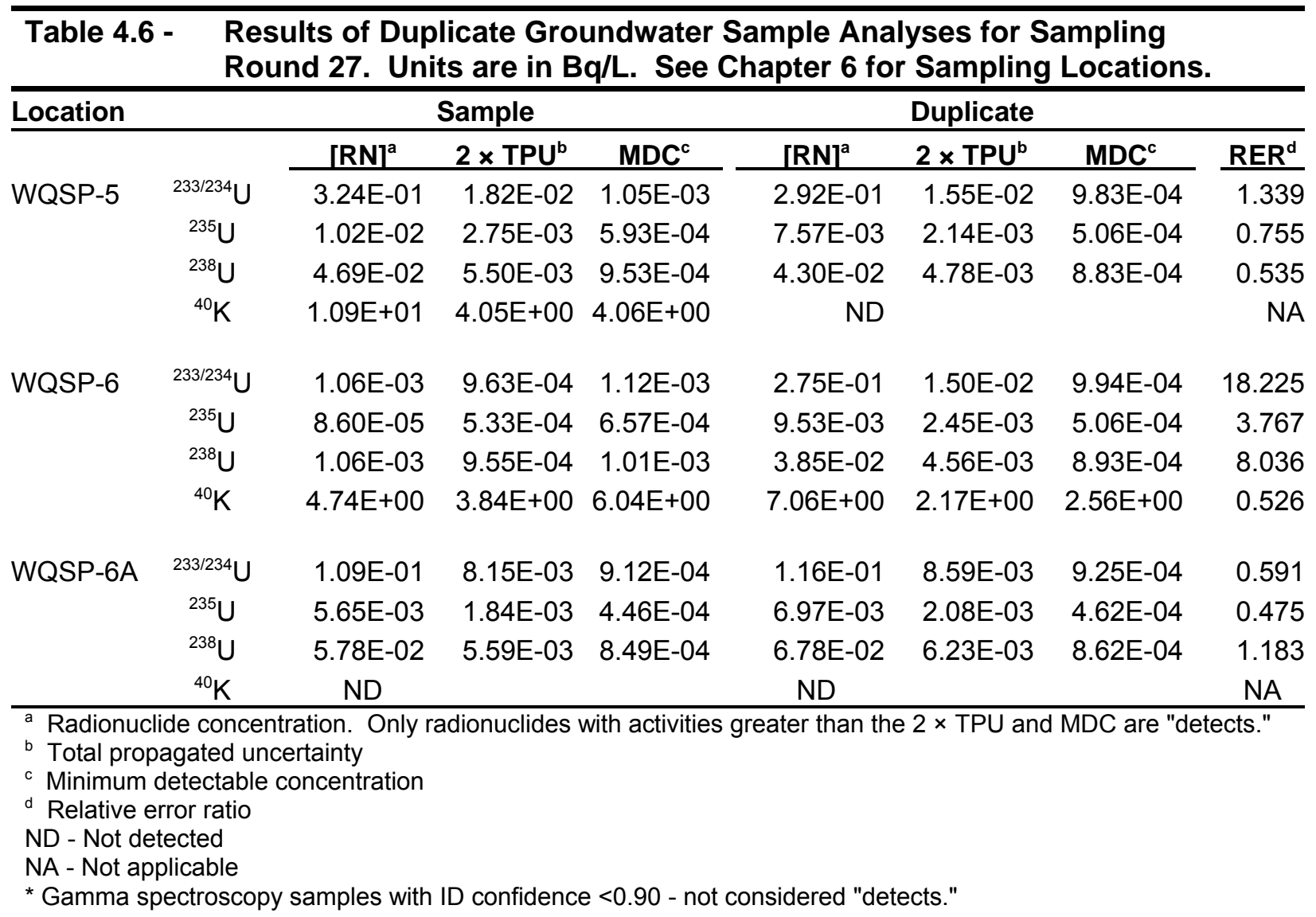

\subsection{Surface Water}

\subsubsection{Sample Collection}

Surface water samples were collected from various locations around the WIPP site, as shown in Figure 4.2 (see Appendix $C$ for location codes). If a particular surface water collection location was dry, only the sediment was collected. Sediment sample analysis results are discussed in Section 4.5.

Water from each sampling location was used to rinse 3.78-L (1-gallon) polyethylene containers at least three times prior to taking the sample. Approximately $3.78 \mathrm{~L}$ (1 gallon) of water was collected from each location. The samples were acidified to $\mathrm{pH} \leq 2$ immediately after collection with concentrated nitric acid. Later, the samples were transferred to WIPP Laboratories for analysis. Chain of custody was maintained throughout the process. 


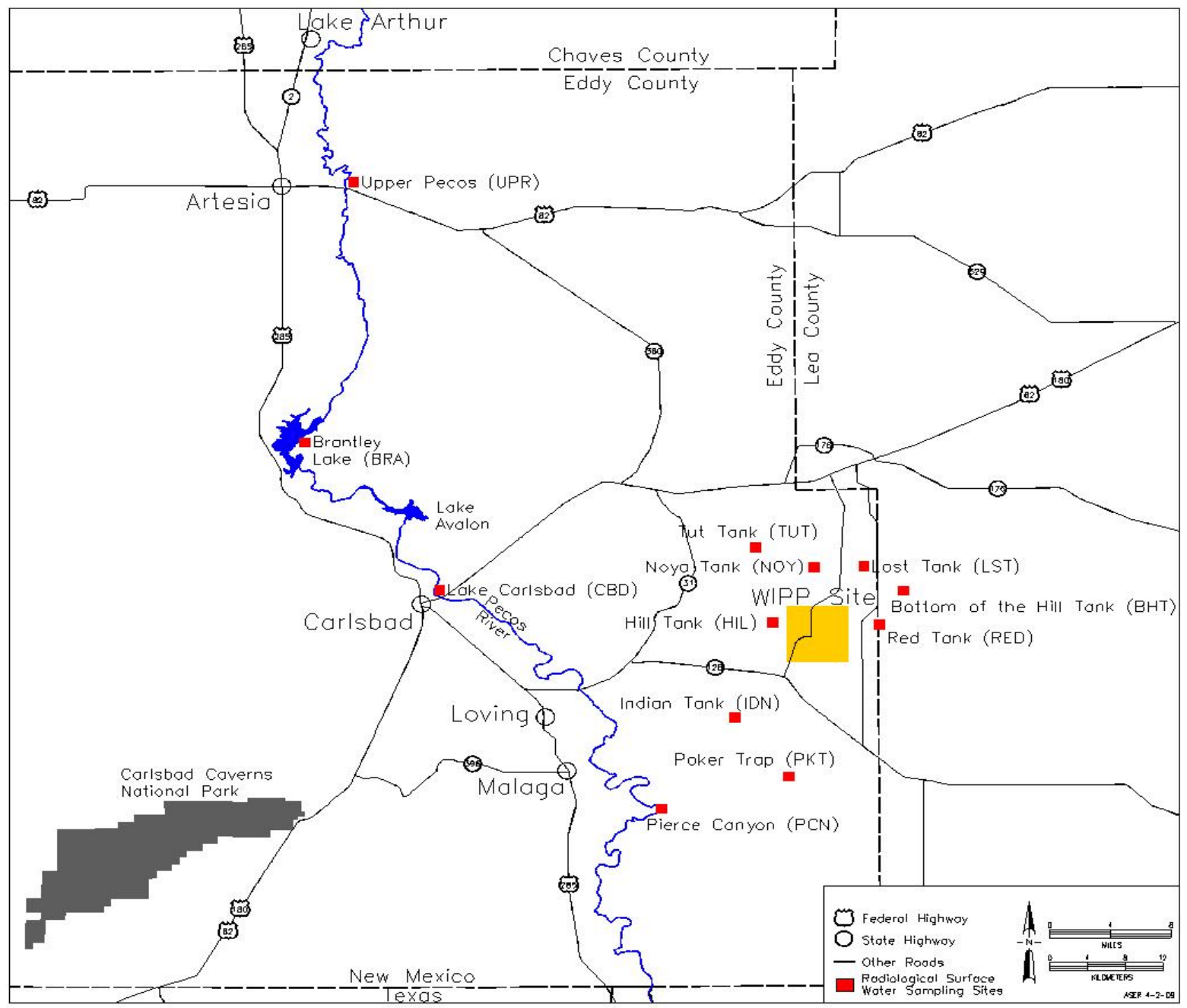

Figure 4.2 - Routine Surface Water Sampling Locations

\subsubsection{Sample Preparation}

Surface water sample containers were shaken to distribute suspended material evenly, and sample aliquots were measured into glass beakers. One 0.5-L portion was used for gamma spectroscopy and another 0.5 -L portion was used for sequential analysis of the other isotopes. Tracers $\left({ }^{232} \mathrm{U},{ }^{243} \mathrm{Am}\right.$, and ${ }^{242} \mathrm{Pu}$ ) and carriers (strontium nitrate and barium nitrate) were added to the second portion, and the samples were then digested using concentrated nitric acid and hydrofluoric acid. The samples were heated to dryness and wet-ashed using concentrated nitric acid and hydrogen peroxide. Finally, the samples were heated to dryness again, and the isotopic separation steps were initiated.

\subsubsection{Determination of Individual Radionuclides}

A 0.5-L portion of the acidified water sample was used directly for the measurement of the gamma-emitting radionuclides ${ }^{40} \mathrm{~K},{ }^{60} \mathrm{Co}$, and ${ }^{137} \mathrm{Cs}$, by gamma spectroscopy and 
${ }^{90} \mathrm{Sr}$ using a gas proportional counter. Another 0.5-L portion of the water was used for the sequential determination of the uranium isotopes, the plutonium isotopes, and ${ }^{241} \mathrm{Am}$ by alpha spectroscopy. The samples were prepared for counting by co-precipitating the target isotopes and corresponding tracers with an iron carrier, performing ion exchange and chromatographic separations of the individual radionuclides, and micro-precipitating the separated radionuclides onto planchets for counting by alpha spectroscopy.

\subsubsection{Results and Discussion}

Uranium isotopes were detected in most of the surface water samples, which included 14 separate samples, 2 duplicate samples, and a distilled water field blank (COW). The field blank sample (sample location $\mathrm{COW}$ ) was submitted to the laboratory with the surface water samples as a "blind" QC sample. No radionuclides were detected in the field blank, while ${ }^{233 / 234} U$ was detected in all the samples; ${ }^{235} U$ was detected in four of the samples; and ${ }^{238} \mathrm{U}$ was detected in all the samples (Table 4.7).

The concentrations of uranium isotopes were compared between 2007 and 2008 and also among sampling locations using ANOVA for those locations where the uranium isotopes were detected both years, and using the average concentration of duplicate samples when available. The ${ }^{233 / 234} U$ was detected in 13 common locations in 2007 and $2008 ;{ }^{235} U$ was detected in four common locations in 2007 and 2008 ; and ${ }^{238} U$ was detected in 13 common locations.

There was no significant variation in the concentrations of the uranium isotopes between 2007 and 2008 (ANOVA, ${ }^{233 / 234} U p=0.146,{ }^{235} U p=0.118$, and ${ }^{238} U p=0.117$ ).

Significant variability was observed among sampling locations in 2008 for ${ }^{233 / 234} U$ and ${ }^{238} \mathrm{U}$ but not for ${ }^{235} \mathrm{U}$ (ANOVA, ${ }^{233 / 234} \mathrm{U} p=6.96 \mathrm{E}-02 ;{ }^{235} \mathrm{U} p=0.230$, and

$\left.{ }^{238} \mathrm{U} p=2.15 \mathrm{E}-02\right)$. The same patterns were observed with the 2007 uranium isotope data. Some variability among sampling locations is expected since natural concentrations of uranium varies widely in the earth's crust, and this variation is reflected in the amounts of uranium dissolved in surface water. 
Table 4.7 - Uranium Concentrations (Bq/L) in Surface Water Taken Near the WIPP Site. See Appendix C for Sampling Location Codes

\begin{tabular}{|c|c|c|c|c|c|c|c|c|c|}
\hline Location & {$[\mathrm{RN}]^{\mathrm{a}}$} & $2 \times$ TPU $^{b}$ & MDC $^{c}$ & {$[\mathrm{RN}]^{\mathrm{a}}$} & $2 \times T_{P U}^{b}$ & $\mathrm{MDC}^{\mathrm{c}}$ & {$[\mathrm{RN}]^{\mathrm{a}}$} & $2 \times T^{T} U^{b}$ & $\mathrm{MDC}^{\mathrm{C}}$ \\
\hline & & ${ }^{233 / 234} \mathrm{U}$ & & & ${ }^{235} U$ & & & ${ }^{238} \mathrm{U}$ & \\
\hline RED & $8.67 \mathrm{E}-03$ & $2.55 \mathrm{E}-03$ & 1.14E-03 & $-7.58 \mathrm{E}-05$ & 2.57E-04 & $6.78 \mathrm{E}-04$ & $5.39 \mathrm{E}-03$ & $2.00 \mathrm{E}-03$ & $7.82 \mathrm{E}-04$ \\
\hline NOY & $2.59 \mathrm{E}-03$ & $1.24 \mathrm{E}-03$ & $1.03 E-03$ & 4.50E-04 & 6.37E-04 & 5.37E-04 & 3.62E-03 & $1.43 \mathrm{E}-03$ & $6.68 \mathrm{E}-04$ \\
\hline HIL & 5.93E-03 & 2.02E-03 & 1.10E-03 & 1.53E-04 & 4.59E-04 & 6.26E-04 & 4.13E-03 & 1.67E-03 & 7.40E-04 \\
\hline TUT & 1.23E-02 & 3.47E-03 & 1.31E-03 & $1.52 \mathrm{E}-03$ & $1.58 \mathrm{E}-03$ & 8.87E-04 & 6.96E-03 & $2.64 \mathrm{E}-03$ & $9.51 \mathrm{E}-04$ \\
\hline TUT Dup & 5.68E-03 & 1.92E-03 & 1.09E-03 & $0.00 \mathrm{E}+00$ & 5.61E-04 & 6.10E-04 & 7.89E-03 & $2.28 \mathrm{E}-03$ & 7.27E-04 \\
\hline FWT & 3.04E-02 & $4.20 \mathrm{E}-03$ & $1.02 \mathrm{E}-03$ & $4.74 \mathrm{E}-04$ & $6.10 \mathrm{E}-04$ & $5.29 \mathrm{E}-04$ & 1.10E-02 & $2.46 \mathrm{E}-03$ & $6.62 \mathrm{E}-04$ \\
\hline $\operatorname{cow}^{d}$ & 8.64E-04 & 7.86E-04 & 1.07E-03 & $-9.69 \mathrm{E}-05$ & $2.69 \mathrm{E}-04$ & 5.87E-04 & 7.12E-04 & 7.17E-04 & 7.09E-04 \\
\hline PKT & 7.23E-03 & $2.45 \mathrm{E}-03$ & $1.22 \mathrm{E}-03$ & $7.00 \mathrm{E}-04$ & $9.39 \mathrm{E}-04$ & 7.73E-04 & $6.43 \mathrm{E}-03$ & 2.35E-03 & $8.59 \mathrm{E}-04$ \\
\hline IDN & 1.34E-02 & $2.70 \mathrm{E}-03$ & 9.96E-04 & 1.60E-04 & 3.14E-04 & 4.96E-04 & 1.13E-02 & 2.43E-03 & 6.35E-04 \\
\hline $\mathrm{PCN}$ & 1.07E-01 & 8.62E-03 & 1.03E-03 & $3.59 \mathrm{E}-03$ & 1.60E-03 & 5.37E-04 & 5.54E-02 & 5.86E-03 & $6.68 \mathrm{E}-04$ \\
\hline SWL & $5.72 \mathrm{E}-03$ & $2.13 \mathrm{E}-03$ & 1.15E-03 & $5.04 \mathrm{E}-04$ & $6.98 \mathrm{E}-04$ & 7.01E-04 & 2.17E-03 & $1.34 \mathrm{E}-03$ & 8.73E-04 \\
\hline CBD & 4.49E-02 & 5.18E-03 & $9.78 \mathrm{E}-04$ & 8.17E-04 & 7.92E-04 & 4.93E-04 & 2.32E-02 & 3.64E-03 & 7.05E-04 \\
\hline $\mathrm{COY}^{\mathrm{e}}$ & 3.11E-02 & $5.09 \mathrm{E}-03$ & 1.15E-03 & $-8.41 \mathrm{E}-05$ & 1.03E-03 & 7.03E-04 & 1.05E-02 & $2.92 \mathrm{E}-03$ & $8.74 \mathrm{E}-04$ \\
\hline BRA & 1.05E-01 & $1.08 \mathrm{E}-02$ & $1.26 \mathrm{E}-03$ & 3.93E-03 & $2.14 \mathrm{E}-03$ & 8.37E-04 & 4.20E-02 & $6.52 \mathrm{E}-03$ & $9.83 \mathrm{E}-04$ \\
\hline UPR & 5.44E-02 & 6.38E-03 & 1.07E-03 & $2.30 \mathrm{E}-03$ & 1.43E-03 & 6.04E-04 & 3.09E-02 & 4.70E-03 & 7.94E-04 \\
\hline LST & 4.04E-03 & 1.49E-03 & 9.33E-04 & $-7.17 \mathrm{E}-05$ & $2.14 \mathrm{E}-04$ & 4.77E-04 & 3.23E-03 & 1.34E-03 & 8.45E-04 \\
\hline BHT & $3.26 \mathrm{E}-03$ & 1.37E-03 & 9.49E-04 & $6.22 \mathrm{E}-04$ & 7.11E-04 & 4.97E-04 & $2.59 \mathrm{E}-03$ & 1.21E-03 & $8.61 \mathrm{E}-04$ \\
\hline
\end{tabular}

a Radionuclide concentration. Only radionuclides with activities greater than the $2 \times$ TPU and MDC are "detects."

b Total propagated uncertainty

c Minimum detectable concentration

d COW - Field blank sample

e COY - CBD Dup

The 2008 uranium isotope surface water concentrations were also compared with baseline levels observed between 1985 and 1989 (DOE/WIPP-92-037). The highest concentrations detected for ${ }^{233 / 234} \mathrm{U},{ }^{235} \mathrm{U}$, and ${ }^{238} \mathrm{U}$ in the Pecos River and associated bodies of water (BRA, CBD, PCN) were within the 99 percent confidence interval ranges of baseline levels (baseline levels: ${ }^{233 / 234} \mathrm{U}=3.30 \mathrm{E}-01 \mathrm{~Bq} / \mathrm{L},{ }^{235} \mathrm{U}=1.40 \mathrm{E}-02$ $\mathrm{Bq} / \mathrm{L}$, and $\left.{ }^{238} \mathrm{U}=1.10 \mathrm{E}-01 \mathrm{~Bq} / \mathrm{L}\right)$.

Likewise, the highest concentrations of all three uranium isotopes for samples taken from tanks and tank-like structures (BHT, HIL, PKT, RED, FWT, IDN, LST, NOY, and TUT) fell within the 99 percent confidence interval ranges of baseline levels (baseline levels: ${ }^{233 / 234} \mathrm{U}=1.00 \mathrm{E}-01 \mathrm{~Bq} / \mathrm{L},{ }^{235} \mathrm{U}=5.20 \mathrm{E}-03 \mathrm{~Bq} / \mathrm{L}$, and ${ }^{238} \mathrm{U}=3.20 \mathrm{E}-02 \mathrm{~Bq} / \mathrm{L}$ ).

The surface water samples were also analyzed for ${ }^{238} \mathrm{Pu},{ }^{239 / 240} \mathrm{Pu}$, and ${ }^{241} \mathrm{Am}$ (Table 4.8). Plutonium-238 and ${ }^{239 / 240} \mathrm{Pu}$ were not detected in any of the samples. Americium-241 was detected in one sample at location, UPR. In $2007{ }^{241} \mathrm{Am}$ was detected at one location, TUT. Thus no ANOVA comparisons between years and among locations could be performed. Also, there were no baseline data relative to ${ }^{241} \mathrm{Am}$ in surface water so no comparison to the baseline could be made. 
Waste Isolation Pilot Plant Annual Site Environmental Report for 2008 DOE/WIPP-09-2225

Table 4.8 - Americium and Plutonium Concentrations in Surface Water Taken Near the WIPP Site. See Appendix C for Sampling Location Codes

\begin{tabular}{|c|c|c|c|c|c|c|c|c|c|}
\hline Location & {$[\mathrm{RN}]^{\mathrm{a}}$} & $2 \times \mathrm{TPU}^{\mathrm{b}}$ & $\mathrm{MDC}^{\mathrm{c}}$ & {$[\mathrm{RN}]^{\mathrm{a}}$} & $2 \times \mathrm{TPU}^{\mathrm{b}}$ & $\mathrm{MDC}^{\mathrm{c}}$ & {$[\mathrm{RN}]^{\mathrm{a}}$} & $2 \times \mathrm{TPU}^{\mathrm{b}}$ & MDC $^{c}$ \\
\hline & & ${ }^{241} \mathrm{Am}$ & & & ${ }^{238} \mathrm{Pu}$ & & & ${ }^{239 / 240} \mathrm{Pu}$ & \\
\hline RED & $3.96 \mathrm{E}-04$ & $5.17 \mathrm{E}-04$ & $5.39 \mathrm{E}-04$ & $-6.27 \mathrm{E}-05$ & 3.89E-04 & $4.02 \mathrm{E}-04$ & $-4.60 \mathrm{E}-05$ & $3.78 E-04$ & $4.06 \mathrm{E}-04$ \\
\hline NOY & 5.06E-04 & 5.23E-04 & 5.17E-04 & $-2.43 E-04$ & 3.52E-04 & 4.21E-04 & $-5.30 E-05$ & $1.64 \mathrm{E}-04$ & 4.26E-04 \\
\hline HIL & 1.77E-04 & 3.89E-04 & 5.46E-04 & $-2.30 \mathrm{E}-05$ & 3.97E-04 & 4.35E-04 & 1.60E-04 & 4.54E-04 & 4.39E-04 \\
\hline TUT & 1.19E-04 & 4.05E-04 & 5.34E-04 & -2.76E-05 & 3.06E-04 & 3.42E-04 & -5.51E-05 & $1.48 \mathrm{E}-04$ & 3.47E-04 \\
\hline TUT Dup & 3.12E-04 & 4.19E-04 & $5.28 \mathrm{E}-04$ & $-1.55 E-04$ & $2.48 \mathrm{E}-04$ & 3.42E-04 & $-2.76 \mathrm{E}-05$ & 3.05E-04 & 3.46E-04 \\
\hline FWT & $3.41 \mathrm{E}-04$ & $5.01 \mathrm{E}-04$ & $5.81 \mathrm{E}-04$ & 6.57E-05 & 3.15E-04 & 4.18E-04 & -8.75E-05 & 2.10E-04 & 4.23E-04 \\
\hline $\mathrm{COW}^{\mathrm{d}}$ & $6.72 \mathrm{E}-05$ & 3.65E-04 & $6.15 \mathrm{E}-04$ & 2.31E-04 & 5.66E-04 & 4.42E-04 & $3.23 \mathrm{E}-04$ & $5.20 \mathrm{E}-04$ & 4.43E-04 \\
\hline PKT & 4.19E-05 & 4.72E-04 & 5.51E-04 & $9.23 \mathrm{E}-05$ & 4.94E-04 & 3.68E-04 & -1.11E-04 & 2.17E-04 & 3.68E-04 \\
\hline IDN & 7.35E-05 & 2.49E-04 & 5.09E-04 & $-1.35 E-04$ & 2.36E-04 & 3.52E-04 & 1.78E-05 & 2.83E-04 & 3.56E-04 \\
\hline $\mathrm{PCN}$ & 1.59E-04 & 4.36E-04 & 5.70E-04 & 4.21E-05 & $3.20 \mathrm{E}-04$ & 4.05E-04 & 2.11E-04 & 3.79E-04 & 4.09E-04 \\
\hline SWL & $-4.15 E-05$ & $1.41 \mathrm{E}-04$ & 5.48E-04 & $6.23 \mathrm{E}-05$ & 2.99E-04 & 3.80E-04 & $-8.30 \mathrm{E}-05$ & 1.99E-04 & 4.05E-04 \\
\hline CBD & 1.47E-04 & 4.03E-04 & 5.43E-04 & $-3.73 E-05$ & 3.35E-04 & 3.49E-04 & 3.73E-05 & 2.83E-04 & 3.71E-04 \\
\hline $\mathrm{COY}^{\mathrm{e}}$ & 1.87E-04 & 3.87E-04 & $5.49 \mathrm{E}-04$ & -1.94E-05 & 4.66E-04 & 3.67E-04 & 1.16E-04 & 3.95E-04 & 3.84E-04 \\
\hline BRA & 2.64E-05 & $3.47 \mathrm{E}-04$ & $5.68 \mathrm{E}-04$ & $-3.29 E-05$ & $3.64 \mathrm{E}-04$ & 3.76E-04 & $2.06 \mathrm{E}-05$ & $3.27 \mathrm{E}-04$ & $4.01 \mathrm{E}-04$ \\
\hline UPR & 7.66E-04 & 7.04E-04 & $5.90 \mathrm{E}-04$ & 3.52E-05 & 2.67E-04 & 3.29E-04 & -3.52E-05 & 1.19E-04 & 3.53E-04 \\
\hline LST & 5.21E-04 & $6.29 \mathrm{E}-04$ & 5.93E-04 & $-6.41 E-05$ & $1.59 \mathrm{E}-04$ & 2.83E-04 & $1.54 \mathrm{E}-04$ & 3.18E-04 & 3.16E-04 \\
\hline BHT & 1.36E-05 & 3.67E-04 & 5.54E-04 & 3.07E-04 & 4.71E-04 & 3.49E-04 & $-6.34 \mathrm{E}-05$ & 1.76E-04 & 3.82E-04 \\
\hline
\end{tabular}

Potassium-40 was detected in seven of the surface water samples, including BHT, RED, HIL, TUT (Dup), PKT, IDN, and SWL as shown in Table 4.9. The ${ }^{40} \mathrm{~K}$ was also detected in the primary TUT sample but the ID confidence was $<0.90$. The only common location where ${ }^{40} \mathrm{~K}$ was detected in 2007 and 2008 was SWL so there were not enough data to perform ANOVA comparisons. Potassium is ubiquitous throughout the earth's crust, so it would be expected to be found in some surface water samples due to leaching from sediments. Comparison of the maximum detected ${ }^{40} \mathrm{~K}(2.91 \mathrm{E}+01 \mathrm{~Bq} / \mathrm{L})$ in the TUT sample duplicate with the baseline data (baseline value: $7.60 \mathrm{E}+01 \mathrm{~Bq} / \mathrm{L}$ ) shows that the concentration is within the 99 percent confidence interval range of the baseline concentrations (DOE/WIPP-92-037).

Cesium-137, ${ }^{60} \mathrm{Co}$, and ${ }^{90} \mathrm{Sr}$, were not detected in any of the surface water samples (Table 4.9). Since these isotopes were not detected, ANOVA comparisons between years and among locations were not performed. 
Table 4.9 - Selected Radionuclide Concentrations (Bq/L) in Surface Water Near the WIPP Site. See Appendix $C$ for sampling location codes.

\begin{tabular}{|c|c|c|c|c|c|c|}
\hline Location & [RN $^{\mathrm{a}}$ & $2 \times$ TPU $^{b}$ & $M^{\prime} C^{c}$ & {$[\mathrm{RN}]^{\mathrm{a}}$} & $2 \times \mathrm{TPU}^{\mathrm{b}}$ & $\mathrm{MDC}^{\mathrm{c}}$ \\
\hline & \multicolumn{3}{|c|}{${ }^{40} \mathrm{~K}$} & \multicolumn{3}{|c|}{${ }^{60} \mathrm{Co}$} \\
\hline RED & $4.71 \mathrm{E}+00$ & $2.00 \mathrm{E}+00$ & $2.51 \mathrm{E}+00$ & $3.25 E-01$ & 3.27E-01 & 4.06E-01 \\
\hline NOY & *5.30E+00 & $3.29 E+00$ & $4.24 \mathrm{E}+00$ & 2.85E-01 & 3.17E-01 & 3.95E-01 \\
\hline $\mathrm{HIL}$ & $3.48 \mathrm{E}+00$ & $1.82 E+00$ & $2.46 \mathrm{E}+00$ & 4.02E-01 & 3.09E-01 & 4.03E-01 \\
\hline TUT & *1.21E+01 & $3.57 \mathrm{E}+00$ & $3.99 \mathrm{E}+00$ & $2.29 \mathrm{E}-01$ & 3.10E-01 & 3.83E-01 \\
\hline TUT Dup & $2.91 E+01$ & $6.51 \mathrm{E}+00$ & $6.39 \mathrm{E}+00$ & ${ }^{*} 9.67 \mathrm{E}-01$ & 5.09E-01 & 5.99E-01 \\
\hline FWT & *5.24E+00 & $3.02 E+00$ & $4.06 \mathrm{E}+00$ & 2.71E-01 & 3.17E-01 & 3.94E-01 \\
\hline $\mathrm{COW}^{\mathrm{d}}$ & 2.33E-01 & $3.47 \mathrm{E}+00$ & $3.92 \mathrm{E}+00$ & 2.74E-01 & 3.38E-01 & 4.15E-01 \\
\hline PKT & $6.36 \mathrm{E}+00$ & $4.13 E+00$ & $6.30 \mathrm{E}+00$ & *1.05E+00 & 5.10E-01 & 6.01E-01 \\
\hline IDN & $3.53 E+00$ & $2.08 \mathrm{E}+00$ & $2.96 \mathrm{E}+00$ & 2.78E-01 & 3.35E-01 & 4.11E-01 \\
\hline PCN & $2.01 \mathrm{E}+00$ & $2.37 \mathrm{E}+00$ & $3.79 \mathrm{E}+00$ & 6.85E-02 & $3.28 \mathrm{E}-01$ & $3.84 \mathrm{E}-01$ \\
\hline SWL & $1.94 \mathrm{E}+01$ & $5.05 \mathrm{E}+00$ & $6.26 \mathrm{E}+00$ & ${ }^{*} 6.99 \mathrm{E}-01$ & 4.83E-01 & 5.69E-01 \\
\hline CBD & ${ }^{*} 9.91 \mathrm{E}+00$ & $4.95 \mathrm{E}+00$ & $5.82 \mathrm{E}+00$ & $-2.61 \mathrm{E}-01$ & 5.08E-01 & $5.44 \mathrm{E}-01$ \\
\hline $\mathrm{COY}^{\mathrm{e}}$ & 9.49E-01 & $2.77 \mathrm{E}+00$ & $3.27 E+00$ & 1.16E-02 & 2.73E-01 & $3.14 \mathrm{E}-01$ \\
\hline BRA & $2.45 \mathrm{E}+00$ & $2.52 \mathrm{E}+00$ & $3.17 \mathrm{E}+00$ & $-1.04 \mathrm{E}-01$ & 2.80E-01 & 2.99E-01 \\
\hline UPR & *8.64E+00 & $5.04 \mathrm{E}+00$ & $5.87 \mathrm{E}+00$ & 3.62E-01 & 4.80E-01 & 5.55E-01 \\
\hline LST & ${ }^{*} 8.03 \mathrm{E}+00$ & $5.04 \mathrm{E}+00$ & $5.86 \mathrm{E}+00$ & 3.19E-01 & 4.97E-01 & 5.71E-01 \\
\hline \multirow[t]{2}{*}{$\mathrm{BHT}$} & $2.31 E+00$ & $1.39 \mathrm{E}+00$ & $2.00 \mathrm{E}+00$ & *3.64E-02 & 2.64E-01 & 3.06E-01 \\
\hline & \multicolumn{3}{|c|}{${ }^{137} \mathrm{Cs}$} & \multicolumn{3}{|c|}{${ }^{90} \mathrm{Sr}$} \\
\hline RED & 1.63E-01 & $2.63 E-01$ & 3.23E-01 & $-6.24 \mathrm{E}-03$ & $3.41 \mathrm{E}-02$ & $2.34 \mathrm{E}-03$ \\
\hline NOY & 1.86E-01 & 2.69E-01 & 3.13E-01 & $-2.42 \mathrm{E}-03$ & 3.59E-02 & $2.52 \mathrm{E}-03$ \\
\hline HIL & $-1.39 E-01$ & 2.77E-01 & 3.06E-01 & 7.12E-03 & 3.60E-02 & 2.47E-03 \\
\hline TUT & $-5.16 E-02$ & $2.90 \mathrm{E}-01$ & 3.16E-01 & 5.66E-04 & $3.45 \mathrm{E}-02$ & 2.36E-03 \\
\hline TUT Dup & $-1.57 \mathrm{E}-01$ & 4.95E-01 & 5.25E-01 & $-4.87 \mathrm{E}-03$ & 3.59E-02 & $2.54 \mathrm{E}-03$ \\
\hline FWT & -1.67E-01 & 2.86E-01 & $3.18 \mathrm{E}-01$ & 7.66E-04 & $3.56 \mathrm{E}-02$ & 2.47E-03 \\
\hline $\operatorname{COW}^{\mathrm{d}}$ & $-8.10 \mathrm{E}-02$ & 2.87E-01 & 3.10E-01 & $-4.00 E-03$ & 3.52E-02 & $2.44 \mathrm{E}-03$ \\
\hline PKT & $-8.51 \mathrm{E}-01$ & 5.58E-01 & 5.30E-01 & -7.83E-03 & 3.43E-02 & 2.39E-03 \\
\hline IDN & 2.03E-01 & 2.71E-01 & 3.35E-01 & $-1.04 \mathrm{E}-02$ & 3.49E-02 & $2.46 \mathrm{E}-03$ \\
\hline $\mathrm{PCN}$ & $-2.53 E-01$ & $2.95 \mathrm{E}-01$ & 2.96E-01 & $-7.40 \mathrm{E}-03$ & 3.60E-02 & $2.58 \mathrm{E}-03$ \\
\hline SWL & $-2.83 E-01$ & 5.30E-01 & 5.86E-01 & $-1.27 \mathrm{E}-02$ & 3.65E-02 & 2.57E-03 \\
\hline CBD & $-2.69 \mathrm{E}-01$ & 4.84E-01 & $5.72 \mathrm{E}-01$ & 1.08E-02 & 3.71E-02 & $2.51 \mathrm{E}-03$ \\
\hline coYe $^{e}$ & 7.38E-02 & 2.01E-01 & 2.44E-01 & $-1.23 E-02$ & 3.59E-02 & 2.49E-03 \\
\hline BRA & $-1.06 \mathrm{E}-01$ & 2.18E-01 & 2.44E-01 & -1.77E-02 & 3.72E-02 & 2.67E-03 \\
\hline UPR & $-5.82 E-01$ & 5.39E-01 & 5.74E-01 & -8.57E-03 & 3.67E-02 & 2.59E-03 \\
\hline LST & $-5.45 E-01$ & 5.32E-01 & 5.68E-01 & 4.52E-03 & 4.36E-02 & 3.08E-03 \\
\hline $\mathrm{BHT}$ & $1.29 \mathrm{E}-01$ & 2.03E-01 & 2.49E-01 & $-7.56 \mathrm{E}-03$ & 4.26E-02 & 2.97E-03 \\
\hline $\begin{array}{ll}\text { a } & \text { Radionucl } \\
\text { b } & \text { Total prop } \\
\text { c } & \text { Minimum c } \\
\text { d } & \text { COW - Fie } \\
\text { e COY - CB }\end{array}$ & $\begin{array}{l}\text { centration. } \\
\text { uncertainty } \\
\text { ble concentr } \\
\text { k sample }\end{array}$ & radionuclide & a activities $\mathrm{g}$ & nan the $2 \times T$ & and MDC are & etects." \\
\hline
\end{tabular}

The reproducibility of the sampling and analysis procedures was assessed by collecting and analyzing duplicate samples from two locations (TUT, CBD). The CBD duplicate 
was blind to the laboratory and labeled "COY." Relative error ratios were calculated for the isotopes with measurable concentrations of the target radionuclides in both the primary and duplicate samples. The RERs for the analysis results are presented in Table 4.10. The RERs for ${ }^{233 / 234} \mathrm{U}$ and ${ }^{40} \mathrm{~K}$ were $>1$ in the TUT duplicates and $>1$ for ${ }^{233 / 234} U$ and ${ }^{238} U$ in the CBD duplicates. In addition, ${ }^{235} U$ was detected in the CBD sample but not in the blind COY duplicate. Thus, the sampling and analysis precision objective was not met for most of the detected radionuclides in the duplicate surface water samples.

\begin{tabular}{|c|c|c|c|c|c|c|c|c|}
\hline \multirow{3}{*}{$\begin{array}{l}\text { Table } 4.10 \text { - } \\
\text { Location } \\
\end{array}$} & \multicolumn{8}{|c|}{$\begin{array}{c}\text { Results of Duplicate Surface Water Sample Analyses Taken in } 2008 . \\
\text { Units are in Bq/L. See Chapter } 6 \text { for Sampling Locations. }\end{array}$} \\
\hline & & & Sample & & & Duplicate & & \\
\hline & & $\left.{ }_{[\mathrm{RN}}\right]^{\mathrm{a}}$ & $2 \times T^{T} U^{b}$ & $M^{\prime} C^{c}$ & {$[\mathrm{RN}]^{\mathrm{a}}$} & $2 \times$ TPU $^{b}$ & MDC $^{c}$ & RER $^{d}$ \\
\hline \multirow[t]{3}{*}{ TUT } & ${ }^{233 / 234} \mathrm{U}$ & $1.23 \mathrm{E}-02$ & $3.47 \mathrm{E}-03$ & 1.31E-03 & $5.68 E-03$ & $1.92 \mathrm{E}-03$ & 1.09E-03 & 1.669 \\
\hline & ${ }^{238} \mathrm{U}$ & 6.96E-03 & $2.64 \mathrm{E}-03$ & $9.51 \mathrm{E}-04$ & 7.89E-03 & $2.28 \mathrm{E}-03$ & 7.27E-04 & 0.267 \\
\hline & ${ }^{40} \mathrm{~K}$ & $1.21 \mathrm{E}+01$ & $3.57 \mathrm{E}+00$ & $3.99 \mathrm{E}+00$ & $2.91 \mathrm{E}+01$ & $6.51 \mathrm{E}+00$ & $6.39 \mathrm{E}+00$ & 2.290 \\
\hline CBD & ${ }^{233 / 234} U$ & 4.49E-02 & $5.18 \mathrm{E}-03$ & 9.78E-04 & 3.11E-02 & $5.09 \mathrm{E}-03$ & 1.15E-03 & 1.900 \\
\hline $\begin{array}{l}\text { (Blind dup } \\
\text { labeled "COY") }\end{array}$ & ${ }^{238} U$ & 2.32E-02 & 3.64E-03 & 7.05E-04 & 1.05E-02 & $2.92 \mathrm{E}-03$ & 8.74E-04 & 2.722 \\
\hline \multicolumn{9}{|c|}{ 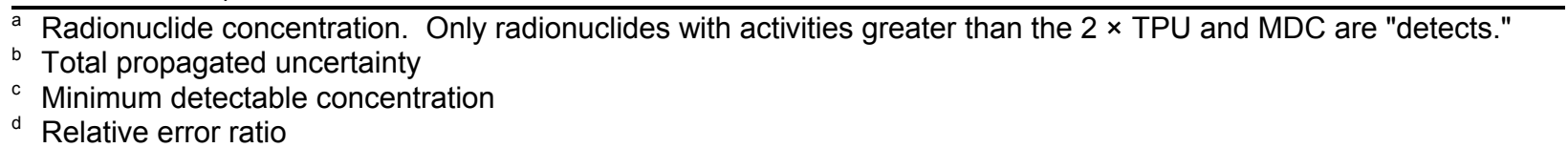 } \\
\hline \multicolumn{9}{|c|}{$\begin{array}{l}\text { The laboratory used the blind field duplicate sample COY for the laboratory duplicate sample in this batch. Relative } \\
\text { error ratios were reported for all the target radionuclides, including those which were not "detects." All of the RERs } \\
\text { were }<1.0 \text {, although the RER for }{ }^{235} \mathrm{U} \text { was } 0.995 \text {. Since the laboratory RERs met the precision objective and the field } \\
\text { RERs did not, based on this limited amount of data, the imprecision appears to be related to the field samples and } \\
\text { possibly the presence of particulates with a nonhomogeneous distribution of radionuclides. Surface water sampling } \\
\text { and preservation procedures could be a factor in the lack of precision, but an actual difference in the samples seems } \\
\text { more likely. }\end{array}$} \\
\hline
\end{tabular}

\subsection{Sediments}

\subsubsection{Sample Collection}

Sediment samples were collected from 14 locations around the WIPP site. The sites included all the same sites as for surface water except for FWT, SWL, and the COW blank (see Figure 4.3, see Appendix $C$ for location codes). The samples were collected in 1-L plastic containers from the top $15 \mathrm{~cm}$ (6 in.) of the sediments of the water bodies and transferred to WIPP Laboratories for determination of individual radionuclides.

\subsubsection{Sample Preparation}

Sediment samples were dried at $110^{\circ} \mathrm{C}\left(230^{\circ} \mathrm{F}\right)$ for several hours and homogenized by grinding into smaller particle sizes. A 2-gram (0.08 oz) aliquot of each of the dried and homogenized sediment samples was dissolved by heating with a mixture of nitric, hydrochloric, and hydrofluoric acids. The sample residues were heated with nitric and 
boric acids to remove hydrofluoric acid. Finally, the residues were dissolved in hydrochloric acid for the measurement of the individual radionuclide concentrations.

\subsubsection{Determination of Individual Radionuclides}

The hydrochloric acid digestates of the sediment samples were split into two fractions. One acid fraction was analyzed by gamma spectroscopy for ${ }^{40} \mathrm{~K},{ }^{60} \mathrm{Co}$, and ${ }^{137} \mathrm{Cs}$. The other fraction was analyzed sequentially for the uranium/transuranic radioisotopes and ${ }^{90} \mathrm{Sr}$ by employing a series of chemical, physical, and ion exchange separations followed by mounting on a planchet for counting. The uranium/transuranic isotopes were measured by alpha spectroscopy and the ${ }^{90} \mathrm{Sr}$ by gas proportional counting.

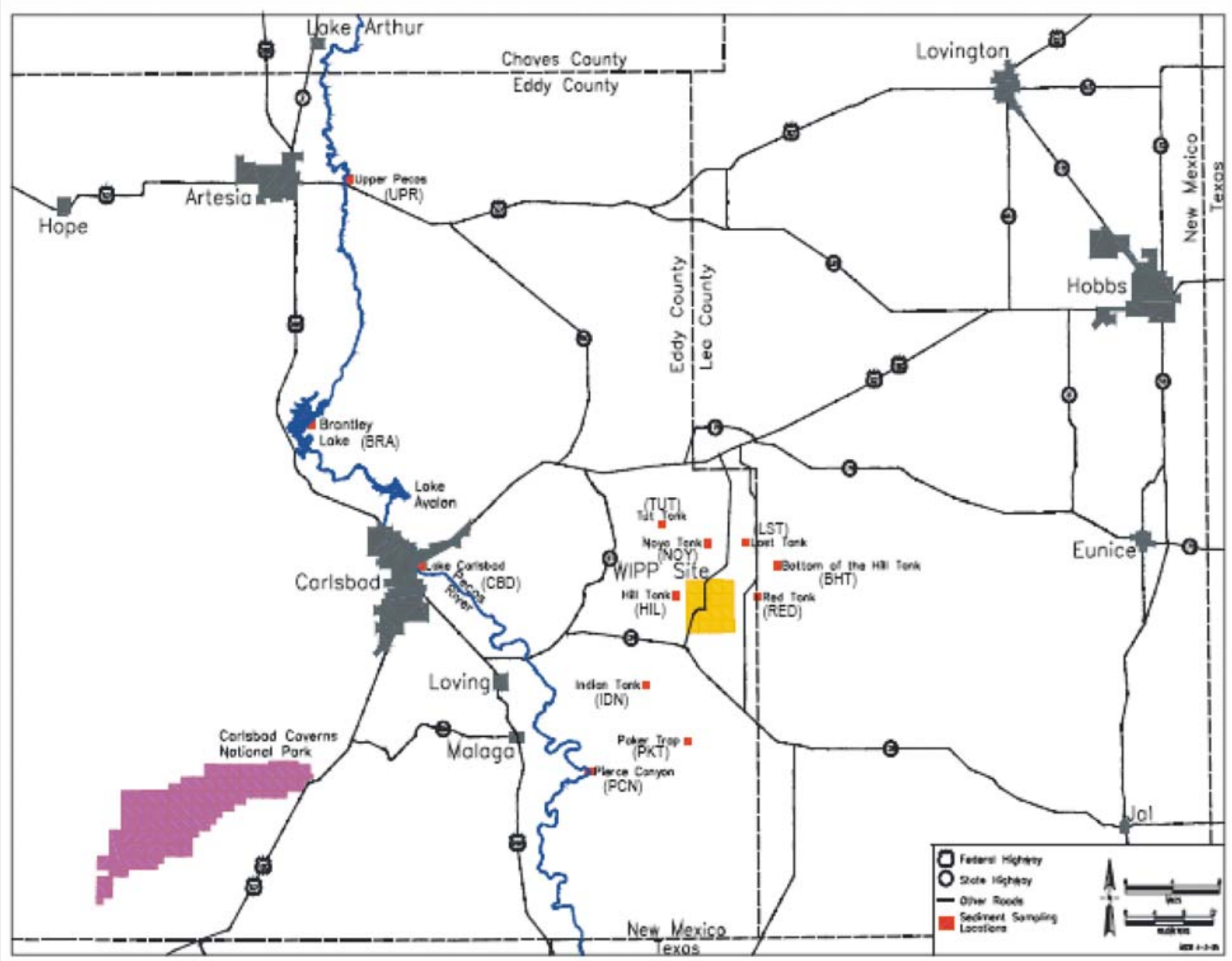

Figure 4.3 - Sediment Sampling Sites

\subsubsection{Results and Discussion}

Uranium-233/234, ${ }^{235} \mathrm{U}$, and ${ }^{238} \mathrm{U}$ were detected in every sediment sample with the exception of ${ }^{235} \mathrm{U}$, which was not detected at the NOY, BRA, and LST locations (Table 4.11). The concentrations of the uranium isotopes were compared between 
2007 and 2008 and also among sampling locations using ANOVA. Average concentrations were used for TUT and CBD in 2008. There were 12 locations with detections in both 2007 and 2008 for ${ }^{233 / 234} U$ and ${ }^{238} U$ and 10 common locations for ${ }^{235} U$.

In contrast to last year's data, there was a significant difference in the concentrations of the uranium isotopes between 2007 and 2008 (ANOVA, ${ }^{233 / 234} \mathrm{U} p=3.82 \mathrm{E}-04$;

${ }^{235} \mathrm{U} p=6.05 \mathrm{E}-03$; and $\left.{ }^{238} \mathrm{U} p=5.78 \mathrm{E}-04\right)$. The significant difference between years appears to be due to the 2008 concentrations being generally lower than the 2007 concentrations. The lower uranium isotope concentrations in 2008 may be due to the settling of sediment with lower concentrations of uranium isotopes due to rainfall. However, there was no significant variation in uranium isotope concentrations among sampling locations (ANOVA ${ }^{233 / 234} U p=0.953,{ }^{235} U p=0.844,{ }^{238} U p=0.953$ ).

Concentrations of all three uranium isotopes fell within the 99 percent confidence interval ranges of the baseline data $\left({ }^{233 / 234} \mathrm{U}: 1.10 \mathrm{E}-01 \mathrm{~Bq} / \mathrm{g} ;{ }^{235} \mathrm{U}: 3.20 \mathrm{E}-03 \mathrm{~Bq} / \mathrm{g}\right.$; $\left.{ }^{238} \mathrm{U}: 5.00 \mathrm{E}-02 \mathrm{~Bq} / \mathrm{g}\right)$.

Table 4.11 - $\quad$ Uranium Concentrations (Bq/g) in Sediment Samples Taken Near the WIPP Site. See Appendix C for Sampling Location Codes

\begin{tabular}{|c|c|c|c|c|c|c|c|c|c|}
\hline Location & {$[\mathrm{RN}]^{\mathrm{a}}$} & $2 \times T^{T P U^{b}}$ & MDC $^{c}$ & {$[\mathrm{RN}]^{\mathrm{a}}$} & $2 \times T^{T P U^{b}}$ & $\mathrm{MDC}^{\mathrm{c}}$ & {$[\mathrm{RN}]^{\mathrm{a}}$} & $2 \times T^{T P U^{b}}$ & MDC $^{c}$ \\
\hline & \multicolumn{3}{|c|}{${ }^{233 / 234} U$} & \multicolumn{3}{|c|}{${ }^{235} \mathrm{U}$} & \multicolumn{3}{|c|}{${ }^{238} \mathrm{U}$} \\
\hline RED & 1.17E-02 & 1.76E-03 & 8.13E-04 & $3.71 \mathrm{E}-04$ & 3.47E-04 & $2.72 \mathrm{E}-04$ & 1.13E-02 & $1.73 \mathrm{E}-03$ & $4.54 \mathrm{E}-04$ \\
\hline NOY & $8.65 \mathrm{E}-03$ & 1.39E-03 & $7.86 \mathrm{E}-04$ & 3.48E-04 & $3.75 \mathrm{E}-04$ & $2.38 \mathrm{E}-04$ & $9.46 \mathrm{E}-03$ & $1.45 \mathrm{E}-03$ & $4.27 \mathrm{E}-04$ \\
\hline HIL & $7.69 \mathrm{E}-03$ & $1.08 \mathrm{E}-03$ & $7.42 \mathrm{E}-04$ & 4.32E-04 & $2.83 \mathrm{E}-04$ & $1.83 \mathrm{E}-04$ & $8.20 \mathrm{E}-03$ & $1.11 \mathrm{E}-03$ & $3.83 \mathrm{E}-04$ \\
\hline TUT & 8.68E-03 & 1.13E-03 & 7.38E-04 & $5.02 \mathrm{E}-04$ & 2.98E-04 & 1.79E-04 & 8.62E-03 & 1.12E-03 & $3.79 \mathrm{E}-04$ \\
\hline TUT Dup & 7.80E-03 & 1.06E-03 & 7.37E-04 & 5.35E-04 & 3.08E-04 & 1.78E-04 & 8.11E-03 & $1.08 \mathrm{E}-03$ & 3.78E-04 \\
\hline PKT & 1.06E-02 & $1.45 \mathrm{E}-03$ & 7.71E-04 & $6.24 \mathrm{E}-04$ & 3.83E-04 & $2.19 \mathrm{E}-04$ & $1.30 \mathrm{E}-02$ & $1.61 \mathrm{E}-03$ & $4.12 \mathrm{E}-04$ \\
\hline IDN & $9.46 \mathrm{E}-03$ & 1.23E-03 & 7.47E-04 & $8.25 \mathrm{E}-04$ & 3.98E-04 & 1.89E-04 & $1.28 \mathrm{E}-02$ & $1.45 \mathrm{E}-03$ & 3.88E-04 \\
\hline PCN & 1.36E-02 & 1.33E-03 & $7.25 \mathrm{E}-04$ & $6.66 \mathrm{E}-04$ & 3.09E-04 & 1.62E-04 & 1.13E-02 & $1.21 \mathrm{E}-03$ & 3.66E-04 \\
\hline CBD & 8.44E-03 & $9.86 \mathrm{E}-04$ & 7.05E-04 & 2.61E-04 & $1.88 \mathrm{E}-04$ & $1.53 \mathrm{E}-04$ & 7.93E-03 & $9.50 \mathrm{E}-04$ & $3.45 \mathrm{E}-04$ \\
\hline $\mathrm{COY}^{*}$ & $1.24 \mathrm{E}-02$ & $1.68 \mathrm{E}-03$ & 7.73E-04 & 4.11E-04 & $3.94 \mathrm{E}-04$ & $2.37 \mathrm{E}-04$ & $9.46 \mathrm{E}-03$ & $1.45 \mathrm{E}-03$ & 4.14E-04 \\
\hline BRA & 6.76E-03 & 9.97E-04 & $7.28 \mathrm{E}-04$ & $1.61 \mathrm{E}-04$ & $1.81 \mathrm{E}-04$ & 1.82E-04 & $6.20 \mathrm{E}-03$ & 9.51E-04 & 3.69E-04 \\
\hline UPR & 7.37E-03 & $9.41 \mathrm{E}-04$ & 7.09E-04 & 3.42E-04 & 2.25E-04 & $1.58 \mathrm{E}-04$ & $6.55 \mathrm{E}-03$ & 8.84E-04 & $3.50 \mathrm{E}-04$ \\
\hline LST & 5.91E-03 & 1.30E-03 & 7.22E-04 & $1.78 \mathrm{E}-04$ & 2.24E-04 & 2.01E-04 & 6.06E-03 & 1.12E-03 & $5.60 \mathrm{E}-04$ \\
\hline BHT & $1.28 \mathrm{E}-02$ & $1.65 \mathrm{E}-03$ & 7.16E-04 & 7.03E-04 & $4.24 \mathrm{E}-04$ & $1.94 \mathrm{E}-04$ & $1.28 \mathrm{E}-02$ & $1.64 \mathrm{E}-03$ & $5.54 \mathrm{E}-04$ \\
\hline
\end{tabular}

${ }^{a}$ Radionuclide concentration. Only radionuclides with activities greater than the $2 \times$ TPU and MDC are "detects."

${ }^{\mathrm{b}}$ Total propagated uncertainty

${ }^{\mathrm{C}}$ Minimum detectable concentration

${ }^{*}$ COY - CBD Dup

Sediment samples were also analyzed for ${ }^{241} \mathrm{Am},{ }^{238} \mathrm{Pu}$, and ${ }^{239 / 240} \mathrm{Pu}$ by alpha spectroscopy, with the results reported in Table 4.12. However, none of these isotopes were detected in any of the sediment samples, and no ANOVA comparisons could be made with 2007 data, and no baseline concentrations were exceeded. 


\begin{tabular}{|c|c|c|c|c|c|c|c|c|c|}
\hline \multicolumn{2}{|c|}{ Table 4.12 - } & \multicolumn{8}{|c|}{$\begin{array}{l}\text { Americium and Plutonium Concentrations (Bq/g) in Sediment Samples } \\
\text { Taken Near the WIPP Site. See Appendix C for Sampling Location } \\
\text { Codes }\end{array}$} \\
\hline 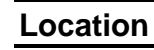 & {$[\mathrm{RN}]^{\mathrm{a}}$} & $2 \times T_{P U^{b}}$ & $M^{\prime} C^{c}$ & {$[\mathrm{RN}]^{\mathrm{a}}$} & $2 \times$ TPU $^{b}$ & $\mathrm{MDC}^{\mathrm{C}}$ & {$[\mathrm{RN}]^{\mathrm{a}}$} & $2 \times$ TPU $^{b}$ & $\mathrm{MDC}^{\mathrm{C}}$ \\
\hline & & ${ }^{241} \mathrm{Am}$ & & & ${ }^{238} \mathrm{Pu}$ & & & ${ }^{239 / 240} \mathrm{Pu}$ & \\
\hline ED & 1.63E-04 & $1.60 \mathrm{E}-04$ & & E-05 & $17 \mathrm{E}-04$ & & & 2.06E-04 & $F_{-}-0<>$ \\
\hline oY & 5.05E-05 & 1.34 & & $E-05$ & & & & & \\
\hline $\mathrm{IL}$ & $1.90 \mathrm{E}-04$ & 1.95E- & & E-05 & & & & & $E-04$ \\
\hline JT & $1.75 \mathrm{E}-04$ & $1.93 \mathrm{E}-$ & & E-05 & & & & & $2 \mathrm{E}-04$ \\
\hline JT Dup & 1.12E-04 & $1.71 \mathrm{E}-\mathrm{C}$ & & 3E-05 & & & 5 & & 52E-04 \\
\hline $\mathrm{KT}$ & 2.01E-04 & 1.77E-04 & & $7 E-05$ & & & 5 & & 47E-04 \\
\hline DN & $1.45 \mathrm{E}-04$ & $1.55 \mathrm{E}-04$ & & EE-05 & & & 57 & & $55 \mathrm{E}-04$ \\
\hline $\mathrm{CN}$ & $1.28 \mathrm{E}-04$ & 1.56E-04 & 2 & $6 \mathrm{E}-05$ & & 4 & -1.06 & & $.09 E-04$ \\
\hline 3D & 2.06E-06 & 8.39E-C & & 2E-05 & & & & & 15E-04 \\
\hline$\partial Y^{*}$ & 1.80E-04 & $1.74 \mathrm{E}-\mathrm{C}$ & & E-05 & & & 5 & & 4E-04 \\
\hline RA & $1.51 \mathrm{E}-05$ & 7.72E-05 & & 4E-05 & & & & & 37E-04 \\
\hline JPR & 2.56E-04 & 1.97E-04 & 2.75E-04 & 7.20E-06 & & 97E-04 & $-2.30 \mathrm{E}-05$ & 6.17E-05 & $1.59 \mathrm{E}-04$ \\
\hline ST & $-3.10 E-05$ & 7.84E-05 & 3.25E-04 & 2.95E-05 & 1.67E-04 & 1.90E-04 & 3.18E-05 & $1.65 E-04$ & 2.80E-04 \\
\hline BHT & $5.81 \mathrm{E}-05$ & 1.64E-04 & $3.20 \mathrm{E}-04$ & 7.23E-05 & 1.31E-04 & 9.68E-05 & 1.11E-04 & 1.45E-04 & 1.87E-04 \\
\hline
\end{tabular}

${ }^{a}$ Radionuclide concentration. Only radionuclides with activities greater than the $2 \times$ TPU and MDC are "detects."

b Total propagated uncertainty

${ }^{c}$ Minimum detectable concentration

${ }^{*} \mathrm{COY}$ - CBD Dup

Potassium-40 was detected in all sediment samples as presented in Table 4.13. For samples BHT and LST, the lab had reported the ${ }^{40} \mathrm{~K}$ as undetected. However, in both cases the activity was significantly greater than the $2 \times$ TPU and MDC, and the ID confidence was 0.895 , which would round to 0.90 and meet the ID confidence criteria. The values were considered as detects for this report.

When data from 2007 and 2008 were compared for all locations with ${ }^{40} \mathrm{~K}$ detections, there was no statistical difference in the concentration between the years (ANOVA, $p=0.890$ ) or among locations (ANOVA, $p=0.361$ ).

All detected concentrations of ${ }^{40} \mathrm{~K}$ observed in the sediment samples associated with the tanks and tank-like structures were within the 99 percent confidence interval range of baseline concentrations (baseline concentration: 1.20E+00 Bq/g).

One detected concentration of ${ }^{40} \mathrm{~K}$ at sediment locations associated with the Pecos River and associated bodies of water exceeded the baseline concentration for sediments (baseline concentration of $4.00 \mathrm{E}-01 \mathrm{~Bq} / \mathrm{g}$ ), and that was the concentration of 4.12E-01 Bq/g at the UPR location. Potassium is ubiquitous throughout the earth's crust and therefore would be expected to be present in the sediment samples.

Cesium-137 was detected in 11 of 14 samples as shown in Table 4.13. It was not detected at locations TUT, CBD, and BRA. However, it was detected in the TUT field duplicate and in the blind CBD field duplicate (COY). In 2007, ${ }^{137} \mathrm{Cs}$ was detected in all the samples except LST and PCN, but was detected in the duplicate of sample from the PCN location. 
For nine locations where ${ }^{137} \mathrm{Cs}$ was detected in the primary samples, there was no significant difference in the concentrations between 2007 and 2008 (ANOVA, $p=0.549$ ). However, there was a significant difference in the concentrations by sampling location (ANOVA, $p=2.95 \mathrm{E}-03$ ), with about half of the concentrations higher and half lower than in 2007.

All the measured ${ }^{137} \mathrm{Cs}$ concentrations in the sediments associated with tanks and tank-like structures were within the 99 percent confidence interval range of the baseline concentration $(3.50 \mathrm{E}-02 \mathrm{~Bq} / \mathrm{g})$. In addition, all the measured ${ }^{137} \mathrm{Cs}$ concentrations in sediments from the Pecos River were within the 99 percent confidence interval range of the baseline concentration (baseline concentration: $5.00 \mathrm{E}-03 \mathrm{~Bq} / \mathrm{g}$ ). Cesium-137 is a fission product and is ubiquitous in sediment and soil because of global fallout from atmospheric nuclear weapons testing (Beck and Bennett, 2002; and UNSCEAR [United Nations Scientific Committee on the Effects of Atomic Radiation], 2000).

Strontium-90 and ${ }^{60} \mathrm{Co}$ were not detected in any of the sediment samples as shown in Table 4.13. Thus, no ANOVA among sampling locations or between years could be calculated.

Table 4.13 -

Gamma Radionuclides and ${ }^{90} \mathrm{Sr}$ Concentrations (Bq/g) in Sediment Samples Taken Near the WIPP Site. See Appendix C for Sampling Location Codes

\begin{tabular}{|c|c|c|c|c|c|c|}
\hline Location & {$[\mathrm{RN}]^{\mathrm{a}}$} & $2 \times \mathrm{TPU}^{\mathrm{b}}$ & $M^{\prime} C^{c}$ & {$[\mathrm{RN}]^{\mathrm{a}}$} & $2 \times T^{\prime b} U^{b}$ & $\mathrm{MDC}^{\mathrm{c}}$ \\
\hline & \multicolumn{3}{|c|}{${ }^{40} \mathrm{~K}$} & \multicolumn{3}{|c|}{${ }^{60} \mathrm{Co}$} \\
\hline RED & 6.83E-01 & 9.99E-02 & 1.20E-02 & *1.49E-03 & $1.25 \mathrm{E}-03$ & 1.47E-03 \\
\hline NOY & 7.48E-01 & $1.04 \mathrm{E}-04$ & 9.27E-03 & $-2.51 \mathrm{E}-04$ & 8.68E-04 & 9.49E-04 \\
\hline $\mathrm{HIL}$ & 7.32E-01 & 1.08E-01 & 4.11E-03 & 3.84E-04 & 4.25E-04 & 4.76E-04 \\
\hline TUT & 7.26E-01 & $1.05 \mathrm{E}-01$ & 8.98E-03 & 6.46E-06 & 1.07E-03 & 1.18E-03 \\
\hline TUT Dup & 6.95E-01 & 9.69E-02 & $1.02 \mathrm{E}-02$ & 4.15E-04 & 7.94E-04 & $9.13 \mathrm{E}-04$ \\
\hline PKT & 6.75E-01 & 9.95E-02 & 4.70E-03 & 5.51E-04 & 4.93E-04 & $5.52 \mathrm{E}-04$ \\
\hline IDN & 6.98E-01 & $9.75 \mathrm{E}-02$ & 9.85E-03 & 2.08E-04 & 8.38E-04 & $9.55 \mathrm{E}-04$ \\
\hline $\mathrm{PCN}$ & 5.30E-01 & 6.86E-02 & 4.29E-03 & *8.74E-04 & 4.13E-04 & 4.65E-04 \\
\hline CBD & 2.88E-01 & $3.90 \mathrm{E}-02$ & $6.45 \mathrm{E}-03$ & 5.60E-04 & 6.92E-04 & 8.04E-04 \\
\hline $\mathrm{COY}^{d}$ & 2.99E-01 & 4.09E-02 & 6.64E-03 & $5.60 \mathrm{E}-04$ & 5.49E-04 & $6.56 \mathrm{E}-04$ \\
\hline BRA & 2.18E-01 & 3.23E-02 & 3.28E-03 & $1.82 \mathrm{E}-04$ & 3.04E-04 & $3.43 E-04$ \\
\hline UPR & 4.12E-01 & 5.52E-02 & 8.89E-03 & 4.07E-04 & 8.88E-04 & 1.00E-03 \\
\hline LST & 5.10E-01 & 6.90E-02 & 8.70E-03 & $-3.54 \mathrm{E}-04$ & 8.23E-04 & 8.88E-04 \\
\hline \multirow[t]{2}{*}{ BHT } & $5.88 \mathrm{E}-01$ & 7.81E-02 & 1.13E-02 & $-6.87 \mathrm{E}-04$ & 1.12E-03 & 1.16E-03 \\
\hline & \multicolumn{3}{|c|}{${ }^{137} \mathrm{Cs}$} & \multicolumn{3}{|c|}{${ }^{90} \mathrm{Sr}$} \\
\hline RED & 3.07E-03 & 7.84E-04 & $9.46 \mathrm{E}-04$ & $1.84 \mathrm{E}-03$ & 1.10E-02 & $1.30 \mathrm{E}-03$ \\
\hline NOY & $1.40 \mathrm{E}-03$ & 4.15E-04 & 5.40E-04 & $-3.17 \mathrm{E}-03$ & 1.06E-02 & 1.27E-03 \\
\hline HIL & 2.15E-03 & $3.11 \mathrm{E}-04$ & $2.51 \mathrm{E}-04$ & 2.94E-03 & 1.09E-02 & 1.27E-03 \\
\hline TUT & 8.25E-04 & 8.07E-04 & 9.57E-04 & 2.11E-03 & 1.12E-02 & 1.31E-03 \\
\hline TUT Dup & $1.27 \mathrm{E}-03$ & 4.24E-04 & 5.81E-04 & $-4.52 \mathrm{E}-03$ & 1.06E-02 & $1.29 \mathrm{E}-03$ \\
\hline PKT & 8.82E-03 & 1.13E-03 & 3.10E-04 & $-2.49 \mathrm{E}-03$ & $1.08 \mathrm{E}-02$ & $1.29 \mathrm{E}-03$ \\
\hline IDN & 2.82E-03 & 5.41E-04 & 5.10E-04 & $-9.74 E-04$ & 1.07E-02 & 1.27E-03 \\
\hline
\end{tabular}


Table 4.13 - $\quad$ Gamma Radionuclides and ${ }^{90} \mathrm{Sr}$ Concentrations (Bq/g) in Sediment Samples Taken Near the WIPP Site. See Appendix C for Sampling Location Codes

\begin{tabular}{|c|c|c|c|c|c|c|}
\hline Location & {$[\mathrm{RN}]^{\mathrm{a}}$} & $2 \times T_{P U}^{b}$ & MDC $^{c}$ & {$[\mathrm{RN}]^{\mathrm{a}}$} & $2 \times \mathrm{TPU}^{\mathrm{b}}$ & $\mathrm{MDC}^{\mathrm{c}}$ \\
\hline $\mathrm{PCN}$ & 1.16E-03 & 1.95E-04 & $2.46 \mathrm{E}-04$ & $1.01 \mathrm{E}-04$ & 1.12E-02 & $1.33 \mathrm{E}-03$ \\
\hline CBD & 4.07E-04 & 6.27E-04 & 7.46E-04 & $-1.08 \mathrm{E}-03$ & 1.15E-02 & $1.28 \mathrm{E}-03$ \\
\hline $\mathrm{COY}^{*}$ & 5.73E-04 & 2.83E-04 & 4.17E-04 & 1.08E-03 & $1.20 \mathrm{E}-02$ & 1.29E-03 \\
\hline BRA & 2.93E-04 & 3.00E-04 & $3.28 \mathrm{E}-04$ & 2.06E-03 & 1.22E-02 & 1.35E-03 \\
\hline UPR & 5.24E-04 & $2.16 \mathrm{E}-04$ & 4.89E-04 & $-2.77 \mathrm{E}-04$ & 1.16E-02 & 1.26E-03 \\
\hline LST & 2.87E-03 & 5.89E-04 & $6.16 \mathrm{E}-04$ & $-2.75 \mathrm{E}-03$ & 9.47E-03 & 7.12E-04 \\
\hline BHT & 6.57E-03 & 1.13E-03 & $1.00 \mathrm{E}-03$ & -1.27E-03 & 8.85E-03 & $6.66 \mathrm{E}-04$ \\
\hline
\end{tabular}

a Radionuclide concentration. Only radionuclides with activities greater than the $2 \times$ TPU and MDC are "detects."

b Total propagated uncertainty

c Minimum detectable concentration

d COY - CBD Dup

* Gamma spectroscopy samples with ID confidence < 0.90 - not considered "detects."

Duplicate analyses were performed for all the target radionuclides in sediment samples from sampling location TUT and CBD as shown in Table 4.14. The CBD duplicate was blind to the laboratory and labeled "COY." Relative error ratios were calculated for the isotopes for which measurable concentrations were detected in both the primary and the duplicate samples $\left({ }^{137} \mathrm{Cs}\right.$ was not detected in the primary sample of either location). The RERs were $<1.0$ for all isotopes detected in the duplicate samples, indicating that the precision objective was met for the reproducibility of the combined sampling and analysis procedures.

Table 4.14 - Results of 2008 Duplicate Sediment Sampling and Analysis. Units are in $\mathrm{Bq} / \mathrm{g}$. See Chapter 6 for Sampling Locations.

\begin{tabular}{|c|c|c|c|c|c|c|c|c|}
\hline \multicolumn{2}{|l|}{ Location } & \multicolumn{3}{|c|}{ Sample } & \multicolumn{3}{|c|}{ Duplicate } & \multirow[b]{2}{*}{ RER $^{\mathrm{d}}$} \\
\hline & & {$[\mathrm{RN}]^{\mathrm{a}}$} & $2 \times$ TPU $^{b}$ & $\mathrm{MDC}^{\mathrm{c}}$ & [RN] $^{\mathrm{a}}$ & $2 \times T^{\prime b} U^{b}$ & $\mathrm{MDC}^{\mathrm{c}}$ & \\
\hline \multirow[t]{4}{*}{ TUT } & ${ }^{233 / 234} \mathrm{U}$ & 8.68E-03 & 1.13E-03 & 7.38E-04 & 7.80E-03 & 1.06E-03 & 7.37E-04 & 0.568 \\
\hline & ${ }^{235} U$ & 5.02E-04 & 2.98E-04 & 1.79E-04 & 5.35E-04 & 3.08E-04 & $1.78 \mathrm{E}-04$ & 0.077 \\
\hline & ${ }^{238} \mathrm{U}$ & 8.62E-03 & 1.12E-03 & 3.79E-04 & 8.11E-03 & 1.08E-03 & 3.78E-04 & 0.328 \\
\hline & ${ }^{40} \mathrm{~K}$ & 7.26E-01 & 1.05E-01 & 8.98E-03 & $6.95 \mathrm{E}-01$ & 9.69E-02 & 1.02E-02 & 0.217 \\
\hline \multirow{4}{*}{$\begin{array}{l}\text { CARLSBAD } \\
\text { (Blind dup } \\
\text { labeled "COY") }\end{array}$} & ${ }^{233 / 234} U$ & 8.44E-03 & $9.86 \mathrm{E}-04$ & 7.05E-04 & $1.24 \mathrm{E}-02$ & 1.68E-03 & 7.73E-04 & 0.316 \\
\hline & ${ }^{235} U$ & 2.61E-04 & 1.88E-04 & 1.53E-04 & 4.11E-04 & 3.94E-04 & 2.37E-04 & 0.263 \\
\hline & ${ }^{238} \mathrm{U}$ & 7.93E-03 & 9.50E-04 & $3.45 \mathrm{E}-04$ & $9.46 \mathrm{E}-03$ & $1.45 \mathrm{E}-03$ & 4.14E-04 & 0.160 \\
\hline & ${ }^{40} \mathrm{~K}$ & 2.88E-01 & $3.90 \mathrm{E}-02$ & $6.45 \mathrm{E}-03$ & 2.99E-01 & 4.09E-02 & $6.64 \mathrm{E}-03$ & 0.036 \\
\hline
\end{tabular}

a Radionuclide concentration. Only radionuclides with activities greater than the $2 \times$ TPU and MDC are "detects."

b Total propagated uncertainty

c Minimum detectable concentration

d Relative error ratio 


\subsection{Soil Samples}

\subsubsection{Sample Collection}

Soil samples were collected from near six of the locations where the low-volume air samplers are stationed around the WIPP site: MLR, SEC, SMR, WEE, WFF, and WSS (Figure 4.4). Samples were collected from each location in three incremental profiles: surface soil (0-2 cm [0-0.8 in.]), intermediate soil (2-5 cm [0.8-2 in.]), and deep soil (5-10 cm [2-4 in.]). Measurements of radionuclides in depth profiles may provide information about their vertical movements in the soil systems.

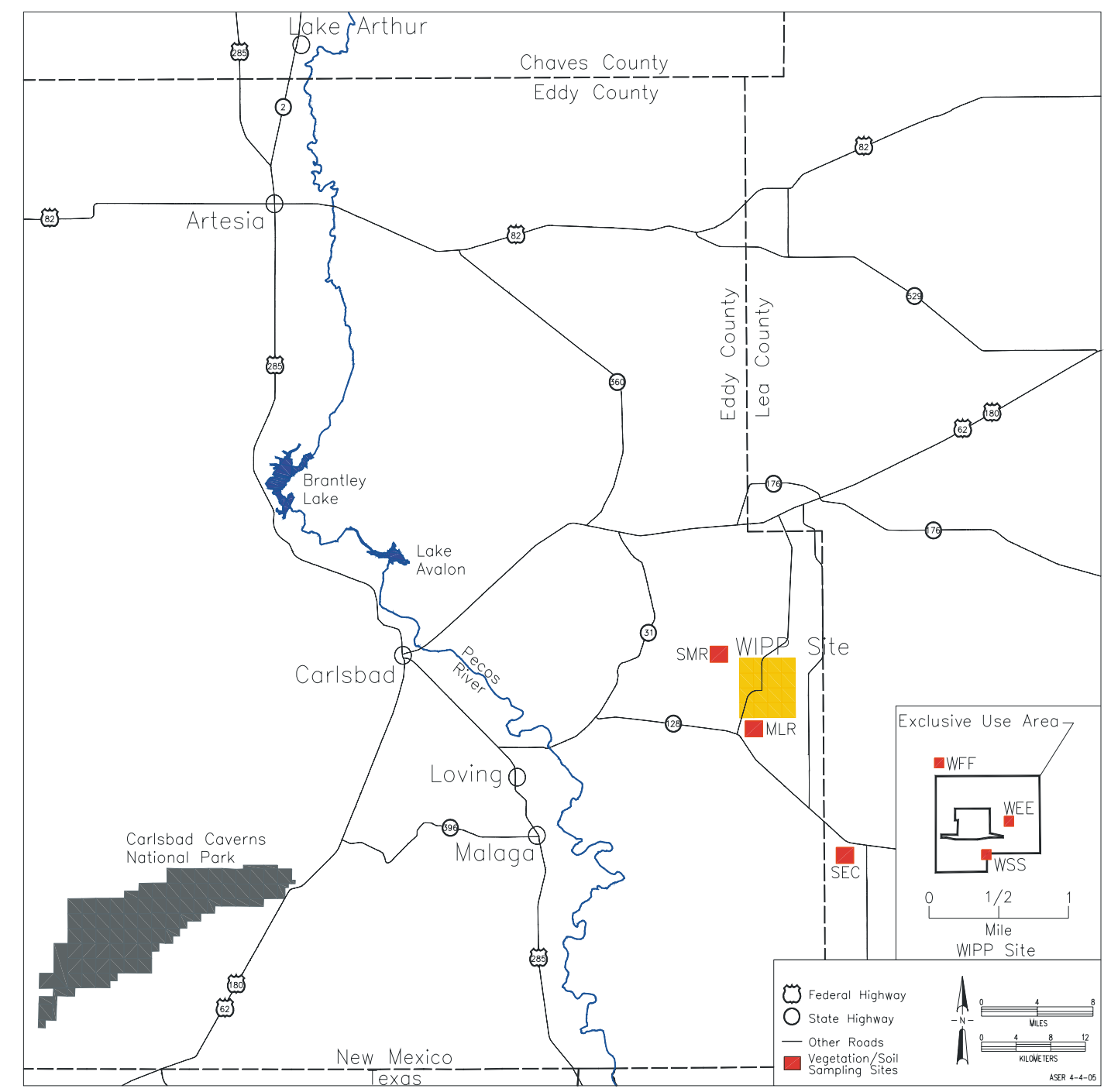

Figure 4.4 - Routine Soil and Vegetation Sampling Areas

\subsubsection{Sample Preparation}

Soil samples were dried at $110^{\circ} \mathrm{C}\left(230^{\circ} \mathrm{F}\right)$ for several hours and homogenized by grinding to small particle sizes. A 2-g aliquot of each of the dried and homogenized soil 
samples was dissolved by heating with a mixture of nitric, hydrochloric, and hydrofluoric acids. The sample residues were heated with nitric and boric acids to remove hydrofluoric acid. Finally, the residues were dissolved in nitric acid for the measurement of the individual radionuclide concentrations.

\subsubsection{Determination of Individual Radionuclides}

The nitric acid digestates of the soil samples were split into two fractions. One acid fraction was analyzed by gamma spectroscopy for ${ }^{40} \mathrm{~K},{ }^{60} \mathrm{Co}$, and ${ }^{137} \mathrm{Cs}$. The other fraction was analyzed sequentially for the uranium/transuranic radioisotopes and ${ }^{90} \mathrm{Sr}$ by employing a series of chemical, physical, and ion exchange separations followed by mounting on a planchet for counting. The uranium/transuranic isotopes were measured by alpha spectroscopy and the ${ }^{90} \mathrm{Sr}$ by gas proportional counting.

\subsubsection{Results and Discussion}

Uranium-233/234, ${ }^{235} \mathrm{U}$, and ${ }^{238} \mathrm{U}$ were detected in every soil sample analyzed with just one exception, the $2-5 \mathrm{~cm}$ core of SEC $\left({ }^{235} \mathrm{U}\right.$ was not detected in the sample). A total of ten non-detects were among these three constituents in the samples analyzed in 2007.

There was no significant difference between detected uranium isotope concentrations between 2007 and 2008 using the average concentration for WSS (ANOVA, ${ }^{233 / 234} \mathrm{U} p=0.544 . ;{ }^{235} \mathrm{U} p=0.0967 ;{ }^{238} \mathrm{U} p=0.350$ ). There was also no significant variation in uranium isotope concentrations among sampling locations using the combined analysis results from all three depths to yield a single ANOVA for each isotope (ANOVA, ${ }^{233 / 234} \mathrm{U} p=0.938 ;{ }^{235} \mathrm{U} p=0.755$; and ${ }^{238} \mathrm{U} p=0.839$ ).

The highest concentrations of ${ }^{233 / 234} \mathrm{U}$ measured in $2008(1.43 \mathrm{E}-02 \mathrm{~Bq} / \mathrm{g})$ fell within the 99 percent confidence interval range of baseline concentrations (baseline $=$ $2.20 \mathrm{E}-02 \mathrm{~Bq} / \mathrm{g})$. The highest concentration of ${ }^{235} \mathrm{U}$ at $8.76 \mathrm{E}-04 \mathrm{~Bq} / \mathrm{g}$ fell with the 99 percent confidence interval of $1.70 \mathrm{E}-03 \mathrm{~Bq} / \mathrm{g}$. The highest concentration of ${ }^{238} \mathrm{U}$ at $1.32 \mathrm{E}-02 \mathrm{~Bq} / \mathrm{g}$ was just slightly above the ${ }^{238} \mathrm{U}$ baseline concentration of $1.30 \mathrm{E}-02 \mathrm{~Bq} / \mathrm{g}$ ) (DOE/WIPP-92-037).

These detected concentrations are similar to the range of natural concentrations of uranium found in soils throughout the world. The average concentration of ${ }^{238} \mathrm{U}$ in the earth's soil (upper crust) is 3.60E-02 Bq/g (NCRP Report No. 94, 1987a). The agreement of the measured uranium concentrations with natural uranium in soils throughout the world, and the fact that none of the actinides, which would be expected to be released along with uranium, were detected in concentrations in excess of baseline quantities, suggests that these soil concentrations follow a pattern of natural variability consistent with the existence of natural uranium. 
Table 4.15 - Uranium Concentrations (Bq/g) in Soil Samples Taken Near the WIPP Site. See Appendix C for Sampling Location Codes

\begin{tabular}{|c|c|c|c|c|c|c|c|c|c|c|}
\hline Location & $\begin{array}{c}\text { Depth } \\
\text { (cm) }\end{array}$ & {$[\mathrm{RN}]^{\mathrm{a}}$} & $2 \times$ TPU $^{b}$ & $M^{\prime} C^{c}$ & {$[\mathrm{RN}]^{\mathrm{a}}$} & $2 \times \mathrm{TPU}^{\mathrm{b}}$ & $M C^{c}$ & {$[\mathrm{RN}]^{\mathrm{a}}$} & $2 \times \operatorname{TPU}^{\mathrm{b}}$ & $M^{\prime} C^{c}$ \\
\hline & & & ${ }^{233 / 234} U$ & & & ${ }^{235} U$ & & & ${ }^{238} U$ & \\
\hline WFF & $0-2$ & 1.06E-02 & $1.41 \mathrm{E}-03$ & 8.63E-04 & $5.44 \mathrm{E}-04$ & 3.43E-04 & 1.86E-04 & $1.05 E-02$ & 1.39E-03 & $4.42 \mathrm{E}-04$ \\
\hline WFF & $2-5$ & 1.03E-02 & $1.25 \mathrm{E}-03$ & 8.38E-04 & 4.70E-04 & 2.87E-04 & $1.55 \mathrm{E}-04$ & 1.06E-02 & $1.26 \mathrm{E}-03$ & 4.17E-04 \\
\hline WFF & $5-10$ & 1.14E-02 & $1.50 \mathrm{E}-03$ & 8.69E-04 & 7.96E-04 & 4.24E-04 & 1.93E-04 & 1.01E-02 & $1.40 \mathrm{E}-03$ & 4.47E-04 \\
\hline WEE & $0-2$ & 1.43E-02 & $2.38 \mathrm{E}-03$ & 9.91E-04 & 8.76E-04 & $6.40 \mathrm{E}-04$ & $3.44 \mathrm{E}-04$ & 1.32E-02 & $2.28 \mathrm{E}-03$ & 5.70E-04 \\
\hline WEE & $2-5$ & 1.20E-02 & $1.45 \mathrm{E}-03$ & 8.55E-04 & 4.04E-04 & 2.86E-04 & 1.76E-04 & 1.26E-02 & 1.49E-03 & 4.34E-04 \\
\hline WEE & $5-10$ & 1.07E-02 & $1.43 E-03$ & 8.64E-04 & 4.72E-04 & 3.34E-04 & $1.87 \mathrm{E}-04$ & 1.09E-02 & $1.43 E-03$ & 4.43E-04 \\
\hline WSS & $0-2$ & 1.39E-02 & $1.51 \mathrm{E}-03$ & $8.21 \mathrm{E}-04$ & $6.88 \mathrm{E}-04$ & 3.61E-04 & $1.64 \mathrm{E}-04$ & 1.46E-02 & $1.55 \mathrm{E}-03$ & 4.00E-04 \\
\hline WSS & $2-5$ & 1.16E-02 & 1.61E-03 & 8.62E-04 & 7.72E-04 & 4.52E-04 & $2.16 \mathrm{E}-04$ & 1.26E-02 & 1.69E-03 & $4.41 \mathrm{E}-04$ \\
\hline WSS & $5-10$ & $1.01 \mathrm{E}-02$ & $1.28 \mathrm{E}-03$ & $8.22 \mathrm{E}-04$ & 5.57E-04 & 3.26E-04 & $1.66 \mathrm{E}-04$ & 1.04E-02 & 1.30E-03 & $4.01 \mathrm{E}-04$ \\
\hline WSS DUP & $0-2$ & 8.58E-03 & 1.15E-03 & $8.18 \mathrm{E}-04$ & $5.02 \mathrm{E}-04$ & 2.97E-04 & $1.61 \mathrm{E}-04$ & $9.49 \mathrm{E}-03$ & $1.21 \mathrm{E}-03$ & 3.97E-04 \\
\hline WSS DUP & $2-5$ & $1.09 \mathrm{E}-02$ & $1.24 \mathrm{E}-03$ & 8.08E-04 & $3.20 \mathrm{E}-04$ & 2.29E-04 & $1.48 \mathrm{E}-04$ & 1.12E-02 & $1.25 \mathrm{E}-03$ & 3.86E-04 \\
\hline WSS DUP & $5-10$ & 1.02E-02 & $1.27 \mathrm{E}-03$ & 8.19E-04 & $6.38 \mathrm{E}-04$ & $3.40 \mathrm{E}-04$ & 1.62E-04 & $9.82 \mathrm{E}-03$ & $1.24 \mathrm{E}-03$ & $3.98 \mathrm{E}-04$ \\
\hline MLR & $0-2$ & 5.79E-03 & 8.83E-04 & 8.31E-04 & $2.75 \mathrm{E}-04$ & 2.14E-04 & $1.47 \mathrm{E}-04$ & $6.23 \mathrm{E}-03$ & $9.16 \mathrm{E}-04$ & 3.98E-04 \\
\hline MLR & $2-5$ & 2.64E-03 & 5.83E-04 & 8.25E-04 & 2.36E-04 & 2.31E-04 & $1.40 \mathrm{E}-04$ & 2.69E-03 & 5.88E-04 & $3.92 \mathrm{E}-04$ \\
\hline MLR & $5-10$ & $6.06 \mathrm{E}-03$ & $9.09 \mathrm{E}-04$ & 8.33E-04 & 3.13E-04 & 2.34E-04 & 1.49E-04 & 5.63E-03 & 8.73E-04 & 3.99E-04 \\
\hline SEC & $0-2$ & 4.88E-03 & 8.91E-04 & 8.51E-04 & $3.76 \mathrm{E}-04$ & 2.80E-04 & 1.71E-04 & 4.48E-03 & 8.55E-04 & 4.17E-04 \\
\hline SEC & $2-5$ & 4.77E-03 & $1.11 \mathrm{E}-03$ & $9.16 \mathrm{E}-04$ & $1.98 \mathrm{E}-04$ & 2.90E-04 & $2.51 \mathrm{E}-04$ & 4.62E-03 & $1.09 E-03$ & 4.82E-04 \\
\hline SEC & $5-10$ & 7.05E-03 & $1.28 \mathrm{E}-03$ & 8.96E-04 & 4.69E-04 & 3.71E-04 & 2.27E-04 & $9.47 \mathrm{E}-03$ & 1.49E-03 & 4.63E-04 \\
\hline SMR & $0-2$ & 5.57E-03 & $9.50 \mathrm{E}-04$ & 8.51E-04 & $2.72 \mathrm{E}-04$ & 2.47E-04 & $1.71 \mathrm{E}-04$ & $5.70 \mathrm{E}-03$ & $9.60 \mathrm{E}-04$ & 4.18E-04 \\
\hline SMR & $2-5$ & 7.44E-03 & 9.94E-04 & 8.30E-04 & 2.76E-04 & 2.06E-04 & 1.45E-04 & 8.09E-03 & 1.04E-03 & 3.96E-04 \\
\hline SMR & $5-10$ & 5.87E-03 & 9.51E-04 & 8.44E-04 & $3.49 E-04$ & 2.65E-04 & 1.63E-04 & $5.74 \mathrm{E}-03$ & 9.37E-04 & 4.11E-04 \\
\hline
\end{tabular}

Plutonium-238, ${ }^{239 / 240} \mathrm{Pu}$, and ${ }^{241} \mathrm{Am}$ were analyzed for in all the soil samples (Table 4.16). Americium-241 and ${ }^{238}$ Pu were not detected in any of the soil samples.

Plutonium-239/240 was detected in five different samples, including the $0-2 \mathrm{~cm}$ depth of WFF; the $0-2 \mathrm{~cm}$ depth of $2-5 \mathrm{~cm}$ depth of MLR; the $2-5 \mathrm{~cm}$ depth at MLR; the 2-5 cm depth of SMR; and the 5-10 cm depth of SMR. The detected concentrations of ${ }^{239 / 240} \mathrm{Pu}$ were low and not much higher than the TPU.

There were insufficient detections of ${ }^{239 / 240} \mathrm{Pu}$ (only one common location between 2007 and 2008) to permit ANOVA between years or among sampling locations. The detected concentrations of ${ }^{239 / 240} \mathrm{Pu}$ fell within the 99 percent confidence interval range of the baseline concentration of 1.90E-03 Bq/g (DOE/WIPP-92-037). 
Table 4.16 - Americium and Plutonium Concentrations (Bq/g) in Soil Samples Taken Near the WIPP Site. See Appendix C for Sampling Location Codes

\begin{tabular}{|c|c|c|c|c|c|c|c|c|c|c|}
\hline Location & $\begin{array}{c}\text { Depth( } \\
\mathbf{c m})\end{array}$ & [RN] $^{\mathrm{a}}$ & $2 \times \operatorname{TPU}^{\mathrm{b}}$ & $M C^{c}$ & {$[\mathrm{RN}]^{\mathrm{a}}$} & $2 \times \mathrm{TPU}^{\mathrm{b}}$ & $\mathrm{MDC}^{\mathrm{c}}$ & {$[\mathrm{RN}]^{\mathrm{a}}$} & $2 \times$ TPU $^{b}$ & $M^{\prime} C^{c}$ \\
\hline & & & ${ }^{241} \mathrm{Am}$ & & & ${ }^{238} \mathrm{Pu}$ & & & ${ }^{2391240} \mathrm{Pu}$ & \\
\hline WFF & $0-2$ & $2.04 \mathrm{E}-04$ & $2.44 \mathrm{E}-04$ & $3.09 E-04$ & $-2.02 \mathrm{E}-05$ & $1.25 \mathrm{E}-04$ & $1.71 \mathrm{E}-04$ & $3.72 \mathrm{E}-04$ & $2.60 \mathrm{E}-04$ & $1.14 \mathrm{E}-04$ \\
\hline WFF & $2-5$ & 1.46E-04 & $1.92 \mathrm{E}-04$ & $3.08 \mathrm{E}-04$ & $1.29 \mathrm{E}-04$ & 2.46E-04 & $2.06 \mathrm{E}-04$ & $2.32 \mathrm{E}-04$ & 2.47E-04 & $1.49 \mathrm{E}-04$ \\
\hline WFF & $5-10$ & $2.78 \mathrm{E}-04$ & 3.09E-04 & 3.46E-04 & 1.12E-04 & 2.07E-04 & $1.84 \mathrm{E}-04$ & 1.63E-04 & 2.22E-04 & 1.27E-04 \\
\hline WEE & $0-2$ & $2.73 \mathrm{E}-04$ & 4.73E-04 & $4.41 \mathrm{E}-04$ & $9.07 \mathrm{E}-05$ & 3.35E-04 & $2.72 \mathrm{E}-04$ & $2.74 \mathrm{E}-04$ & $3.22 \mathrm{E}-04$ & $2.15 \mathrm{E}-04$ \\
\hline WEE & $2-5$ & $1.62 \mathrm{E}-04$ & $2.21 \mathrm{E}-04$ & 3.06E-04 & $-5.79 \mathrm{E}-05$ & $1.08 \mathrm{E}-04$ & 2.04E-04 & 1.77E-04 & 2.22E-04 & 1.47E-04 \\
\hline WEE & $5-10$ & 2.70E-04 & 2.13E-04 & $2.85 \mathrm{E}-04$ & $-5.59 \mathrm{E}-05$ & $1.06 \mathrm{E}-04$ & 2.04E-04 & $7.68 \mathrm{E}-05$ & 1.63E-04 & 1.47E-04 \\
\hline WSS & $0-2$ & $2.18 \mathrm{E}-05$ & $1.24 \mathrm{E}-04$ & $2.79 \mathrm{E}-04$ & $5.06 \mathrm{E}-05$ & $1.44 \mathrm{E}-04$ & $1.60 \mathrm{E}-04$ & $1.31 \mathrm{E}-04$ & $1.68 \mathrm{E}-04$ & $9.84 \mathrm{E}-05$ \\
\hline WSS & $2-5$ & $8.41 \mathrm{E}-05$ & $1.35 \mathrm{E}-04$ & 2.83E-04 & $1.04 \mathrm{E}-05$ & $1.08 \mathrm{E}-04$ & $1.80 \mathrm{E}-04$ & $-4.15 \mathrm{E}-05$ & $8.14 \mathrm{E}-05$ & $1.26 \mathrm{E}-04$ \\
\hline WSS & $5-10$ & 2.12E-04 & 2.07E-04 & 2.96E-04 & $-1.01 \mathrm{E}-05$ & 1.18E-04 & $1.78 \mathrm{E}-04$ & $1.01 \mathrm{E}-05$ & $1.04 \mathrm{E}-04$ & $1.20 \mathrm{E}-04$ \\
\hline WSS DUP & $0-2$ & $7.39 \mathrm{E}-05$ & $1.28 \mathrm{E}-04$ & $2.77 \mathrm{E}-04$ & 8.60E-06 & $1.31 \mathrm{E}-04$ & 1.63E-04 & 4.30E-05 & $1.12 \mathrm{E}-04$ & $1.03 \mathrm{E}-04$ \\
\hline WSS DUP & $2-5$ & 3.36E-05 & $1.02 \mathrm{E}-04$ & $2.68 \mathrm{E}-04$ & $5.35 \mathrm{E}-05$ & $1.31 \mathrm{E}-04$ & $1.54 \mathrm{E}-04$ & 1.35E-04 & $1.51 \mathrm{E}-04$ & $9.18 \mathrm{E}-05$ \\
\hline WSS DUP & $5-10$ & $9.30 \mathrm{E}-05$ & $1.50 \mathrm{E}-04$ & $2.94 \mathrm{E}-04$ & $1.28 \mathrm{E}-05$ & $1.09 \mathrm{E}-04$ & $1.82 \mathrm{E}-04$ & 1.14E-04 & $1.53 \mathrm{E}-04$ & $1.20 \mathrm{E}-04$ \\
\hline MLR & $0-2$ & 7.33E-05 & $1.08 \mathrm{E}-04$ & $2.53 \mathrm{E}-04$ & $1.52 \mathrm{E}-05$ & $1.12 \mathrm{E}-04$ & $1.63 \mathrm{E}-04$ & 2.03E-04 & $1.82 \mathrm{E}-04$ & $8.73 \mathrm{E}-05$ \\
\hline MLR & $2-5$ & 4.45E-05 & 1.14E-04 & $2.68 \mathrm{E}-04$ & $-3.77 \mathrm{E}-06$ & $8.12 \mathrm{E}-05$ & $1.57 \mathrm{E}-04$ & 2.06E-04 & $1.64 \mathrm{E}-04$ & $8.18 \mathrm{E}-05$ \\
\hline MLR & $5-10$ & 1.79E-05 & 7.97E-05 & 2.64E-04 & $-3.71 \mathrm{E}-06$ & $7.98 \mathrm{E}-05$ & $1.56 \mathrm{E}-04$ & $1.21 \mathrm{E}-05$ & $6.84 \mathrm{E}-05$ & $8.05 \mathrm{E}-05$ \\
\hline SEC & $0-2$ & $4.22 \mathrm{E}-05$ & $1.12 \mathrm{E}-04$ & $2.66 \mathrm{E}-04$ & $1.37 \mathrm{E}-05$ & $1.00 \mathrm{E}-04$ & $1.55 \mathrm{E}-04$ & 1.03E-04 & $1.34 \mathrm{E}-04$ & $7.90 \mathrm{E}-05$ \\
\hline SEC & $2-5$ & $1.73 \mathrm{E}-04$ & $2.11 \mathrm{E}-04$ & 3.09E-04 & $-2.66 \mathrm{E}-05$ & $6.73 \mathrm{E}-05$ & 2.01E-04 & $1.42 \mathrm{E}-04$ & $1.90 \mathrm{E}-04$ & $1.28 \mathrm{E}-04$ \\
\hline SEC & $5-10$ & $2.36 \mathrm{E}-05$ & $8.54 \mathrm{E}-05$ & $2.74 \mathrm{E}-04$ & $-1.03 \mathrm{E}-05$ & $7.85 \mathrm{E}-05$ & $1.51 \mathrm{E}-04$ & 8.27E-05 & $1.11 \mathrm{E}-04$ & 7.63E-05 \\
\hline SMR & $0-2$ & $1.36 \mathrm{E}-04$ & $1.45 \mathrm{E}-04$ & $2.58 \mathrm{E}-04$ & $-2.19 \mathrm{E}-05$ & 8.97E-05 & $1.55 \mathrm{E}-04$ & $8.74 \mathrm{E}-05$ & $1.17 \mathrm{E}-04$ & $8.04 \mathrm{E}-05$ \\
\hline SMR & $2-5$ & $1.55 \mathrm{E}-05$ & $8.80 \mathrm{E}-05$ & $2.70 \mathrm{E}-04$ & $-8.31 \mathrm{E}-06$ & $8.23 \mathrm{E}-05$ & $1.56 \mathrm{E}-04$ & 1.43E-04 & $1.42 \mathrm{E}-04$ & $8.00 \mathrm{E}-05$ \\
\hline SMR & $5-10$ & 4.96E-05 & 1.15E-04 & 2.72E-04 & $1.04 \mathrm{E}-04$ & 1.32E-04 & $1.65 \mathrm{E}-04$ & 2.39E-04 & $1.77 \mathrm{E}-04$ & $8.94 \mathrm{E}-05$ \\
\hline
\end{tabular}

The sample data in Table 4.17 show that ${ }^{137} \mathrm{Cs}$ and ${ }^{40} \mathrm{~K}$ were detected in all of the soil samples, while ${ }^{60} \mathrm{Co}$ and ${ }^{90} \mathrm{Sr}$ were not detected in any of the soil samples. (The same situation applied in 2007.)

Statistical analyses of ${ }^{137} \mathrm{Cs}$ using the average concentration for WSS data show that there was no statistical difference between the concentrations in 2007 and 2008 (ANOVA, $p=0.971$ ). In contrast to 2007, there was a significant difference in the concentrations of ${ }^{137} \mathrm{Cs}$ among locations (ANOVA, $p=9.22 \mathrm{E}-08$ ).

Cesium-137 concentrations for 2008 fell within the 99 percent confidence interval range of the baseline concentration $(4.00 \mathrm{E}-02 \mathrm{~Bq} / \mathrm{g})$. Cesium-137 is a fission product and is ubiquitous in soils because of global fallout from atmospheric nuclear weapons testing (Beck and Bennett, 2002; and UNSCEAR, 2000).

Potassium-40 is a naturally occurring gamma-emitting radionuclide that is ubiquitous in soils. There was no significant variation in the ${ }^{40} \mathrm{~K}$ concentrations between 2007 and 2008 (ANOVA, $p=0.625$ ). However, there was a significant variation in the concentrations among locations, including the soil depths (ANOVA, $p=1.12 E-09$ ).

The highest ${ }^{40} \mathrm{~K}$ concentration of $6.92 \mathrm{E}-01 \mathrm{~Bq} / \mathrm{g}$ at the $5-10 \mathrm{~cm}$ depth at location SMR was higher than the 99 percent confidence interval range of baseline levels 
(3.40E-01 Bq/g) (DOE/WIPP-92-037). The samples at 0-2 cm and 2-5 cm depths at SMR were also higher than the baseline with very similar concentrations to the $5-10 \mathrm{~cm}$ depth of $6.88 \mathrm{E}-01 \mathrm{~Bq} / \mathrm{g}$ and $6.75 \mathrm{~Bq} / \mathrm{g}$, respectively. All three samples taken at location MLR also had concentrations higher than the 99 percent confidence interval range of the baseline with concentrations of $4.69 \mathrm{E}-01,3.97 \mathrm{E}-01$, and $3.91 \mathrm{E}-01 \mathrm{~Bq} / \mathrm{g}$ for the $0-2 \mathrm{~cm}, 2-5 \mathrm{~cm}$, and $5-10 \mathrm{~cm}$ depths, respectively.

Since ${ }^{90} \mathrm{Sr}$ and ${ }^{60} \mathrm{Co}$ were not detected at any sampling locations (Table 4.17), there are insufficient data to permit any kind of variance analysis between years or among sampling locations.

\begin{tabular}{|c|c|c|c|c|c|c|c|}
\hline Table 4.1 & $\begin{array}{l}\text { Sel } \\
\text { the }\end{array}$ & $\begin{array}{l}\text { Radio } \\
\text { Site. }\end{array}$ & $\begin{array}{l}\text { le Co } \\
\text { pper }\end{array}$ & for $S$ & in So & $\begin{array}{l}\text { nples T } \\
\text { odes }\end{array}$ & Vear \\
\hline Location & $\begin{array}{l}\text { Depth } \\
(\mathrm{cm})\end{array}$ & {$[\mathrm{RN}]^{\mathrm{a}}$} & $2 \times \operatorname{TPU}^{\mathrm{b}}$ & $M^{\prime} C^{c}$ & {$[\mathrm{RN}]^{\mathrm{a}}$} & $2 \times$ TPU $^{b}$ & $\mathrm{MDC}^{\mathrm{c}}$ \\
\hline & & & ${ }^{40} \mathrm{~K}$ & & & ${ }^{60} \mathrm{Co}$ & \\
\hline WFF & $0-2$ & 1.80E-01 & $2.76 \mathrm{E}-02$ & 6.18E-03 & 5.18E-04 & 6.79E-04 & $8.01 \mathrm{E}-04$ \\
\hline WFF & $2-5$ & $1.75 \mathrm{E}-01$ & $2.56 \mathrm{E}-02$ & 5.16E-03 & 4.44E-04 & 4.96E-04 & $6.02 \mathrm{E}-04$ \\
\hline WFF & $5-10$ & $1.90 \mathrm{E}-01$ & 2.49E-02 & 3.88E-03 & 3.41E-04 & 3.16E-04 & 3.61E-04 \\
\hline WEE & $0-2$ & 2.45E-01 & 3.69E-02 & 6.90E-03 & $-4.91 E-05$ & 2.15E-03 & 2.38E-03 \\
\hline WEE & $2-5$ & 2.03E-01 & 2.67E-02 & 3.90E-03 & $2.35 \mathrm{E}-04$ & 3.16E-04 & 3.59E-04 \\
\hline WEE & $5-10$ & 1.96E-01 & $2.85 \mathrm{E}-02$ & 5.55E-03 & $-2.32 \mathrm{E}-05$ & 5.62E-04 & 6.34E-04 \\
\hline WSS & $0-2$ & 2.36E-01 & $3.41 \mathrm{E}-02$ & 6.57E-03 & -1.06E-04 & 6.27E-04 & 6.96E-04 \\
\hline WSS & $2-5$ & 2.05E-01 & 2.68E-02 & 4.01E-03 & 4.60E-04 & 3.20E-04 & 3.67E-04 \\
\hline WSS & $5-10$ & 2.35E-01 & 3.55E-02 & $6.12 \mathrm{E}-03$ & 2.94E-04 & 7.17E-04 & 8.26E-04 \\
\hline WSS DUP & $0-2$ & 2.18E-01 & 3.13E-02 & 5.70E-03 & $-3.13 E-04$ & 5.61E-04 & 5.94E-04 \\
\hline WSS DUP & $2-5$ & 2.12E-01 & 2.77E-02 & 3.84E-03 & 3.01E-04 & $3.10 \mathrm{E}-04$ & 3.53E-04 \\
\hline WSS DUP & $5-10$ & 2.10E-01 & $3.20 \mathrm{E}-02$ & 7.40E-03 & $-3.03 E-04$ & 7.91E-04 & 8.24E-04 \\
\hline MLR & $0-2$ & 4.69E-01 & 6.88E-02 & 8.02E-03 & $-4.24 \mathrm{E}-04$ & 9.90E-04 & 1.04E-03 \\
\hline MLR & $2-5$ & 3.97E-01 & 5.15E-02 & 5.88E-03 & 2.89E-04 & $3.45 E-04$ & 3.89E-04 \\
\hline MLR & $5-10$ & 3.91E-01 & 5.77E-02 & 7.75E-03 & 5.55E-04 & $9.00 \mathrm{E}-04$ & $1.03 \mathrm{E}-03$ \\
\hline SEC & $0-2$ & 2.38E-01 & $3.41 \mathrm{E}-02$ & $6.28 \mathrm{E}-03$ & $-5.53 E-05$ & 5.82E-04 & 6.52E-04 \\
\hline SEC & $2-5$ & 2.47E-01 & 3.23E-02 & 3.64E-03 & 3.01E-04 & $3.10 \mathrm{E}-04$ & 3.52E-04 \\
\hline SEC & $5-10$ & $2.71 \mathrm{E}-01$ & 4.06E-02 & 8.26E-03 & $-4.47 \mathrm{E}-04$ & 8.28E-04 & 8.58E-04 \\
\hline SMR & $0-2$ & $6.88 \mathrm{E}-01$ & $9.61 \mathrm{E}-02$ & 8.34E-03 & $-2.40 \mathrm{E}-04$ & 8.78E-04 & $9.62 \mathrm{E}-04$ \\
\hline SMR & $2-5$ & $6.75 \mathrm{E}-01$ & 8.73E-02 & 4.85E-03 & 5.43E-04 & 4.42E-04 & 4.98E-04 \\
\hline SMR & $5-10$ & $6.92 \mathrm{E}-01$ & 8.96E-02 & $5.62 E-03$ & 4.80E-04 & 5.00E-04 & 5.62E-04 \\
\hline & & & ${ }^{137} \mathrm{Cs}$ & & & ${ }^{90} \mathrm{Sr}$ & \\
\hline WFF & $0-2$ & 1.59E-03 & $3.26 \mathrm{E}-04$ & 3.94E-04 & 5.14E-03 & $8.22 \mathrm{E}-03$ & $1.81 \mathrm{E}-03$ \\
\hline WFF & $2-5$ & $1.68 \mathrm{E}-03$ & 3.75E-04 & 4.06E-04 & $-3.20 \mathrm{E}-04$ & $8.22 E-03$ & 1.82E-03 \\
\hline WFF & $5-10$ & $2.24 \mathrm{E}-03$ & $3.48 \mathrm{E}-04$ & 2.61E-04 & $-2.28 \mathrm{E}-03$ & 8.29E-03 & 1.84E-03 \\
\hline WEE & $0-2$ & 3.05E-03 & 6.66E-04 & 7.02E-04 & 5.83E-03 & 8.68E-03 & 1.85E-03 \\
\hline WEE & $2-5$ & 2.09E-03 & 2.97E-04 & 2.01E-04 & 7.74E-03 & 7.94E-03 & 1.77E-03 \\
\hline WEE & $5-10$ & 1.19E-03 & 3.27E-04 & 4.03E-04 & 8.11E-03 & 8.46E-03 & 1.82E-03 \\
\hline WSS & $0-2$ & $1.20 \mathrm{E}-03$ & $3.28 \mathrm{E}-04$ & 4.00E-04 & $-6.50 \mathrm{E}-04$ & 9.89E-03 & 1.83E-03 \\
\hline WSS & $2-5$ & $1.61 \mathrm{E}-03$ & 3.16E-04 & 3.44E-04 & $-4.40 E-04$ & $9.75 E-03$ & $1.80 \mathrm{E}-03$ \\
\hline
\end{tabular}


Table 4.17 - Selected Radionuclide Concentrations (Bq/g) in Soil Samples Taken Near the WIPP Site. See Appendix C for Sampling Location Codes

\begin{tabular}{|c|c|c|c|c|c|c|c|}
\hline Location & $\begin{array}{l}\text { Depth } \\
(\mathrm{cm})\end{array}$ & [RN $^{\mathrm{a}}$ & $2 \times \operatorname{TPU}^{\mathrm{b}}$ & $M C^{c}$ & {$[\mathrm{RN}]^{\mathrm{a}}$} & $2 \times \operatorname{TPU}^{\mathrm{b}}$ & $M^{\prime} C^{c}$ \\
\hline & & \multicolumn{3}{|c|}{${ }^{40} \mathrm{~K}$} & \multicolumn{3}{|c|}{${ }^{60} \mathrm{Co}$} \\
\hline WSS & $5-10$ & 9.55E-04 & 3.33E-04 & 4.38E-04 & $-6.50 \mathrm{E}-04$ & 9.40E-03 & 1.76E-03 \\
\hline WSS DUP & $0-2$ & 9.66E-04 & 2.81E-04 & 3.51E-04 & $-6.50 \mathrm{E}-04$ & 9.73E-03 & 1.78E-03 \\
\hline WSS DUP & $2-5$ & 1.69E-03 & $2.90 \mathrm{E}-04$ & 2.62E-04 & $-6.50 \mathrm{E}-04$ & 1.01E-02 & 1.86E-03 \\
\hline WSS DUP & $5-10$ & 1.06E-03 & 3.80E-04 & 5.13E-04 & $-6.50 E-04$ & 9.66E-03 & 1.79E-03 \\
\hline MLR & $0-2$ & 8.80E-03 & 1.35E-03 & 8.60E-04 & 7.78E-04 & 7.58E-03 & 1.61E-03 \\
\hline MLR & $2-5$ & 3.07E-03 & 4.16E-04 & 2.24E-04 & $-1.81 \mathrm{E}-03$ & 7.17E-03 & $1.58 \mathrm{E}-03$ \\
\hline MLR & $5-10$ & 7.84E-04 & 3.86E-04 & 5.67E-04 & 2.77E-03 & 8.00E-03 & 1.64E-03 \\
\hline SEC & $0-2$ & 3.75E-03 & 5.61E-04 & $3.40 \mathrm{E}-04$ & $-5.62 E-03$ & 7.04E-03 & $1.58 \mathrm{E}-03$ \\
\hline SEC & $2-5$ & 4.43E-03 & 6.03E-04 & 2.90E-04 & 4.81E-04 & 7.64E-03 & $1.62 \mathrm{E}-03$ \\
\hline SEC & $5-10$ & 1.66E-03 & 4.13E-04 & 4.71E-04 & $-4.30 \mathrm{E}-04$ & 7.49E-03 & $1.61 \mathrm{E}-03$ \\
\hline SMR & $0-2$ & 1.90E-03 & 5.03E-04 & 6.30E-04 & $-3.54 \mathrm{E}-03$ & 7.03E-03 & 1.56E-03 \\
\hline SMR & $2-5$ & 3.63E-03 & 4.93E-04 & 2.73E-04 & -1.67E-03 & 7.41E-03 & $1.59 \mathrm{E}-03$ \\
\hline SMR & $5-10$ & 4.45E-03 & 6.00E-04 & $3.09 E-04$ & $-1.88 \mathrm{E}-03$ & $7.50 \mathrm{E}-03$ & 1.62E-03 \\
\hline
\end{tabular}

Duplicate soil samples were collected and analyzed separately from location WSS. The analysis results are shown in Table 4.18. Relative error ratios were calculated for ${ }^{233 / 234} \mathrm{U},{ }^{235} \mathrm{U},{ }^{238} \mathrm{U},{ }^{40} \mathrm{~K}$, and ${ }^{137} \mathrm{Cs}$, since these radionuclides were detected in all the duplicate samples.

All but one of the 15 calculated RERs readily met the precision objective of RER $<1.0$, demonstrating good reproducibility for the sampling and analysis procedures. The one RER that did not meet the objective was for the shallow ${ }^{233 / 234} \mathrm{U}$ samples. The high RER may reflect some inhomogeneity in the prepared samples.

\begin{tabular}{|c|c|c|c|c|c|c|c|c|c|}
\hline \multirow[t]{2}{*}{ Location } & \multirow[t]{2}{*}{$\begin{array}{c}\text { Depth } \\
\text { (cm) }\end{array}$} & & \multicolumn{3}{|c|}{ Sample } & \multicolumn{3}{|c|}{ Duplicate } & \multirow[b]{2}{*}{ RER $^{d}$} \\
\hline & & & {$[\mathrm{RN}]^{\mathrm{a}}$} & $2 \times$ TPU $^{b}$ & MDC $^{c}$ & {$[\mathrm{RN}]^{\mathrm{a}}$} & $2 \times$ TPU $^{b}$ & MDC $^{c}$ & \\
\hline WSS & $0-2$ & ${ }^{233 / 234} U$ & 1.39E-02 & $1.51 \mathrm{E}-03$ & 8.21E-04 & 8.58E-03 & 1.15E-03 & 8.18E-04 & 2.803 \\
\hline WSS & $2-5$ & ${ }^{233 / 234} \mathrm{U}$ & 1.16E-02 & 1.61E-03 & 8.62E-04 & 1.09E-02 & $1.24 \mathrm{E}-03$ & 8.08E-04 & 0.344 \\
\hline WSS & $5-10$ & ${ }^{233 / 234} \mathrm{U}$ & $1.01 \mathrm{E}-02$ & $1.28 \mathrm{E}-03$ & $8.22 \mathrm{E}-04$ & $1.02 \mathrm{E}-02$ & 1.27E-03 & 8.19E-04 & 0.055 \\
\hline WSS & $0-2$ & ${ }^{235} \mathrm{U}$ & $6.88 \mathrm{E}-04$ & $3.61 \mathrm{E}-04$ & 1.64E-04 & $5.02 \mathrm{E}-04$ & 2.97E-04 & $1.61 \mathrm{E}-04$ & 0.398 \\
\hline WSS & $2-5$ & ${ }^{235} \mathrm{U}$ & 7.72E-04 & 4.52E-04 & 2.16E-04 & 3.20E-04 & 2.29E-04 & $1.48 \mathrm{E}-04$ & 0.892 \\
\hline WSS & $5-10$ & ${ }^{235} \mathrm{U}$ & 5.57E-04 & $3.26 \mathrm{E}-04$ & 1.66E-04 & $6.38 \mathrm{E}-04$ & $3.40 \mathrm{E}-04$ & 1.62E-04 & 0.172 \\
\hline WSS & $0-2$ & ${ }^{238} \mathrm{U}$ & 1.46E-02 & $1.55 \mathrm{E}-03$ & 4.00E-04 & $9.49 \mathrm{E}-03$ & $1.21 \mathrm{E}-03$ & 3.97E-04 & 2.599 \\
\hline WSS & $2-5$ & ${ }^{238} \mathrm{U}$ & 1.26E-02 & 1.69E-03 & 4.41E-04 & 1.12E-02 & $1.25 \mathrm{E}-03$ & 3.86E-04 & 0.666 \\
\hline WSS & $5-10$ & ${ }^{238} \mathrm{U}$ & 1.04E-02 & 1.30E-03 & 4.01E-04 & $9.82 \mathrm{E}-03$ & $1.24 \mathrm{E}-03$ & $3.98 \mathrm{E}-04$ & 0.323 \\
\hline WSS & $0-2$ & ${ }^{40} \mathrm{~K}$ & 2.36E-01 & 3.41E-02 & 6.57E-03 & $2.18 \mathrm{E}-01$ & 3.13E-02 & 5.70E-03 & 0.389 \\
\hline
\end{tabular}




\begin{tabular}{|c|c|c|c|c|c|c|c|c|c|}
\hline \multirow[t]{2}{*}{ Location } & \multirow[t]{2}{*}{$\begin{array}{c}\text { Depth } \\
\text { (cm) }\end{array}$} & & \multicolumn{3}{|c|}{ Sample } & \multicolumn{3}{|c|}{ Duplicate } & \multirow[b]{2}{*}{ RER $^{d}$} \\
\hline & & & {$[\mathrm{RN}]^{\mathrm{a}}$} & $2 \times \operatorname{TPU}^{\mathrm{b}}$ & MDC $^{c}$ & {$[\mathrm{RN}]^{\mathrm{a}}$} & $2 \times \mathrm{TPU}^{\mathrm{b}}$ & $\mathrm{MDC}^{\mathrm{c}}$ & \\
\hline WSS & $2-5$ & ${ }^{40} \mathrm{~K}$ & 2.05E-01 & $2.68 \mathrm{E}-02$ & $4.01 \mathrm{E}-03$ & 2.12E-01 & $2.77 \mathrm{E}-02$ & 3.84E-03 & 0.182 \\
\hline WSS & $5-10$ & ${ }^{40} \mathrm{~K}$ & 2.35E-01 & $3.55 \mathrm{E}-02$ & $6.12 \mathrm{E}-03$ & 2.10E-01 & $3.20 \mathrm{E}-02$ & $7.40 \mathrm{E}-03$ & 0.523 \\
\hline WSS & $0-2$ & ${ }^{137} \mathrm{Cs}$ & 1.20E-03 & 3.28E-04 & 4.00E-04 & $9.66 \mathrm{E}-04$ & 2.81E-04 & 3.51E-04 & 0.542 \\
\hline WSS & $2-5$ & ${ }^{137} \mathrm{Cs}$ & $1.61 \mathrm{E}-03$ & $3.16 \mathrm{E}-04$ & $3.44 \mathrm{E}-04$ & 1.69E-03 & $2.90 \mathrm{E}-04$ & $2.62 \mathrm{E}-04$ & 0.187 \\
\hline WSS & $5-10$ & ${ }^{137} \mathrm{Cs}$ & $9.55 \mathrm{E}-04$ & 3.33E-04 & 4.38E-04 & 1.06E-03 & 3.80E-04 & 5.13E-04 & 0.208 \\
\hline
\end{tabular}

\subsection{Biota}

\subsubsection{Sample Collection}

Rangeland vegetation samples were collected from the same six locations from which the soil samples were collected (Figure 4.4). Fauna samples were also collected when available. All biota samples were analyzed for the target radionuclides.

\subsubsection{Sample Preparation}

\section{Vegetation}

The vegetation samples were chopped into 2.5-to-5-cm (1-to-2-in.) pieces, mixed together well, and air dried at room temperature. Weighed aliquots were spiked with tracers and carriers and heated in a muffle furnace to burn off organic matter.

The samples were digested with concentrated nitric acid, hydrochloric acid, hydrofluoric acid and hydrogen peroxide. The samples were dried and heated in a muffle furnace. The remaining residue was repetitively wet ashed with concentrated acids until only a white or pale yellow residue remained. The residue was dissolved in nitric acid for the measurement of the individual radionuclide concentrations.

\section{$\underline{\text { Animals }}$}

The tissue samples were spiked with tracers and carriers and dried in a muffle furnace. The samples were then digested with concentrated acids and hydrogen peroxide in the same manner as the vegetation samples and dissolved in nitric acid for the measurement of the individual radionuclide concentrations.

\subsubsection{Determination of Individual Radionuclides}

The nitric acid digestates of the biota samples were split into two fractions. One acid fraction was analyzed by gamma spectroscopy for ${ }^{40} \mathrm{~K},{ }^{60} \mathrm{Co}$, and ${ }^{137} \mathrm{Cs}$. The other 
fraction was analyzed sequentially for the uranium/transuranic radioisotopes and ${ }^{90} \mathrm{Sr}$ by employing a series of chemical, physical and ion exchange separations followed by mounting on a planchet for counting. The uranium/transuranics were measured by alpha spectroscopy and the ${ }^{90} \mathrm{Sr}$ by gas proportional counting.

\subsubsection{Results and Discussion}

\section{$\underline{\text { Vegetation }}$}

Table 4.19 shows that ${ }^{238} \mathrm{U},{ }^{233 / 234} \mathrm{U}$, and ${ }^{235} \mathrm{U}$ were not detected in any of the vegetation samples. There also were no uranium radionuclide detections in vegetation in 2007. Thus, no ANOVA comparisons were able to be performed. Americium-241, ${ }^{238} \mathrm{Pu}$, and ${ }^{239 / 240} \mathrm{Pu}$ were not detected in any of the vegetation samples. Cesium $-137,{ }^{60} \mathrm{Co}$, and ${ }^{90} \mathrm{Sr}$ were also not detected in any vegetation samples and no statistical comparisons between years or among locations could be performed on any of these undetected radionuclides.

Potassium-40 was detected in every vegetation sample analyzed (Table 4.19) as it was in 2007. There was no statistical difference in ${ }^{40} \mathrm{~K}$ vegetation concentrations between 2007 and 2008 (ANOVA, $p=0.480$ ). However, the detected concentrations varied significantly at the different locations where the vegetation was collected (ANOVA, $p=0.00514$ ) due to the natural variability of this naturally occurring radionuclide in the soil. The concentrations of ${ }^{40} \mathrm{~K}$ all fell within the 99 percent ID confidence range of the average baseline concentration of $3.2 \mathrm{~Bq} / \mathrm{g}$.

\begin{tabular}{|c|c|c|c|c|c|c|c|c|c|}
\hline \multirow[t]{2}{*}{ Location } & {$[\mathrm{RN}]^{\mathrm{a}}$} & $2 \times T^{T P U^{b}}$ & MDC $^{c}$ & {$[\mathrm{RN}]^{\mathrm{a}}$} & $2 \times T^{T P U^{b}}$ & $\mathrm{MDC}^{\mathrm{c}}$ & {$[\mathrm{RN}]^{\mathrm{a}}$} & $2 \times T^{T} U^{b}$ & $\mathrm{MDC}^{\mathrm{c}}$ \\
\hline & \multicolumn{3}{|c|}{${ }^{233 / 234} \mathrm{U}$} & \multicolumn{3}{|c|}{${ }^{235} U$} & \multicolumn{3}{|c|}{${ }^{238} \mathrm{U}$} \\
\hline WFF & $2.75 \mathrm{E}-04$ & $1.44 \mathrm{E}-04$ & 5.95E-04 & $-1.10 \mathrm{E}-05$ & $3.13 \mathrm{E}-05$ & 8.12E-05 & 1.26E-04 & 9.87E-05 & 4.96E-04 \\
\hline WEE & 2.12E-04 & 2.05E-04 & 6.53E-04 & 3.47E-05 & 1.11E-04 & 1.53E-04 & $2.20 \mathrm{E}-04$ & 2.01E-04 & 5.54E-04 \\
\hline WSS & 2.02E-04 & 1.23E-04 & 5.92E-04 & $-8.75 E-06$ & 3.32E-05 & 1.07E-04 & 1.20E-04 & 1.21E-04 & 5.17E-04 \\
\hline MLR & -2.57E-05 & 7.12E-05 & 6.96E-04 & 5.70E-05 & 1.30E-04 & 1.85E-04 & 4.09E-05 & 1.10E-04 & 5.97E-04 \\
\hline SEC & 1.70E-04 & 1.20E-04 & 6.11E-04 & -5.72E-06 & 2.32E-05 & 8.01E-05 & 1.06E-04 & 1.00E-04 & 5.12E-04 \\
\hline \multirow[t]{2}{*}{ SMR } & 3.02E-04 & 1.43E-04 & 6.03E-04 & 3.79E-05 & $6.12 \mathrm{E}-05$ & 7.06E-05 & 4.04E-04 & 1.64E-04 & 5.04E-04 \\
\hline & \multicolumn{3}{|c|}{${ }^{241} \mathrm{Am}$} & \multicolumn{3}{|c|}{${ }^{238} \mathrm{Pu}$} & \multicolumn{3}{|c|}{${ }^{239 / 240} \mathrm{Pu}$} \\
\hline WFF & 1.03E-04 & $1.02 \mathrm{E}-04$ & $2.22 \mathrm{E}-04$ & $1.85 \mathrm{E}-05$ & $5.41 \mathrm{E}-05$ & 4.91E-05 & 2.06E-05 & $5.28 \mathrm{E}-05$ & 8.25E-05 \\
\hline WEE & 6.87E-05 & 7.61E-05 & $2.12 \mathrm{E}-04$ & $-8.55 E-06$ & 2.11E-05 & 4.16E-05 & 3.15E-05 & 5.07E-05 & 7.50E-05 \\
\hline WSS & 4.63E-05 & 6.04E-05 & 2.12E-04 & $-6.74 E-06$ & 1.87E-05 & 4.15E-05 & $-2.70 \mathrm{E}-05$ & 3.74E-05 & 7.49E-05 \\
\hline MLR & 4.37E-05 & 5.96E-05 & 2.23E-04 & $-2.42 \mathrm{E}-05$ & 3.68E-05 & 4.43E-05 & $1.21 \mathrm{E}-05$ & 5.07E-05 & 7.77E-05 \\
\hline SEC & 5.92E-05 & $6.25 \mathrm{E}-05$ & $2.22 \mathrm{E}-04$ & 1.31E-04 & 1.61E-04 & 1.09E-04 & 1.64E-05 & $9.38 \mathrm{E}-05$ & $1.42 \mathrm{E}-04$ \\
\hline \multirow[t]{2}{*}{ SMR } & $3.08 \mathrm{E}-05$ & 4.86E-05 & 2.21E-04 & $-1.05 E-05$ & 4.47E-05 & 4.21E-05 & $-5.03 E-06$ & 1.63E-05 & $7.55 \mathrm{E}-05$ \\
\hline & \multicolumn{3}{|c|}{${ }^{40} \mathrm{~K}$} & \multicolumn{3}{|c|}{${ }^{60} \mathrm{Co}$} & \multicolumn{3}{|c|}{${ }^{137} \mathrm{Cs}$} \\
\hline WFF & 3.17E-01 & $5.80 \mathrm{E}-02$ & $2.48 \mathrm{E}-02$ & $-6.68 \mathrm{E}-05$ & 2.60E-03 & 2.96E-03 & 5.54E-04 & 1.93E-03 & 2.32E-03 \\
\hline WEE & $5.68 \mathrm{E}-01$ & 9.89E-02 & 2.67E-02 & $-6.19 E-04$ & $3.29 \mathrm{E}-03$ & 3.66E-03 & $-6.24 \mathrm{E}-04$ & 2.57E-03 & 2.96E-03 \\
\hline WSS & 4.12E-01 & 6.37E-02 & $3.21 \mathrm{E}-02$ & -1.08E-05 & 2.48E-03 & 2.78E-03 & 4.32E-04 & 1.96E-03 & 2.47E-03 \\
\hline MLR & $7.86 \mathrm{E}-01$ & 1.31E-01 & $2.49 \mathrm{E}-02$ & $-1.87 \mathrm{E}-03$ & $3.01 \mathrm{E}-03$ & $3.13 \mathrm{E}-03$ & $-1.38 \mathrm{E}-03$ & $2.21 \mathrm{E}-03$ & $2.44 \mathrm{E}-03$ \\
\hline
\end{tabular}


Table 4.19 - $\quad$ Radionuclide Concentrations (Bq/g Wet Mass) in Vegetation Samples Taken Near the WIPP Site. See Appendix C for Sampling Location Codes.

\begin{tabular}{|c|c|c|c|c|c|c|c|c|c|}
\hline Location & {$[\mathrm{RN}]^{\mathrm{a}}$} & $2 \times T^{2} U^{b}$ & MDC $^{c}$ & {$[\mathrm{RN}]^{\mathrm{a}}$} & $2 \times T^{2} U^{b}$ & $\mathrm{MDC}^{\mathrm{c}}$ & {$[\mathrm{RN}]^{\mathrm{a}}$} & $2 \times$ TPU $^{b}$ & $\mathrm{MDC}^{\mathrm{c}}$ \\
\hline SEC & 5.39E-01 & $8.18 \mathrm{E}-02$ & $3.69 \mathrm{E}-02$ & $8.20 \mathrm{E}-04$ & $2.82 \mathrm{E}-03$ & $3.19 \mathrm{E}-03$ & $-4.18 \mathrm{E}-03$ & $2.81 \mathrm{E}-03$ & $2.89 \mathrm{E}-03$ \\
\hline \multirow[t]{2}{*}{ SMR } & $1.20 \mathrm{E}+00$ & 1.95E-01 & 2.43E-02 & 7.62E-04 & $2.52 \mathrm{E}-03$ & $2.94 \mathrm{E}-03$ & 1.69E-03 & $1.89 \mathrm{E}-03$ & 2.32E-03 \\
\hline & & ${ }^{90} \mathrm{Sr}$ & & & & & & & \\
\hline WFF & $-5.25 E-04$ & 3.97E-03 & $5.16 \mathrm{E}-04$ & & & & & & \\
\hline WEE & $-1.42 \mathrm{E}-03$ & 3.80E-03 & 5.03E-04 & & & & & & \\
\hline WSS & $-9.58 \mathrm{E}-04$ & $3.76 \mathrm{E}-03$ & 4.97E-04 & & & & & & \\
\hline MLR & $9.65 \mathrm{E}-04$ & 4.39E-03 & $6.02 \mathrm{E}-04$ & & & & & & \\
\hline SEC & $-2.73 E-03$ & 4.33E-03 & $5.98 \mathrm{E}-04$ & & & & & & \\
\hline SMR & $-2.76 \mathrm{E}-04$ & 4.30E-03 & $6.02 \mathrm{E}-04$ & & & & & & \\
\hline
\end{tabular}

${ }^{a}$ Radionuclide concentration. Only radionuclides with activities greater than the $2 \times$ TPU and MDC are "detects."

${ }^{\mathrm{b}}$ Total propagated uncertainty

A duplicate analysis of the vegetation sample from sampling location WFF was performed for all the radionuclides of interest. An RER was calculated for ${ }^{40} \mathrm{~K}$, the only target radionuclide detected. The RER was less one indicating that the precision objective was met for the duplicate analysis.

Table 4.20 - Results of Duplicate Vegetation Sample Analysis. Units are Bq/g. See Appendix $\mathrm{C}$ for sampling location codes.

\begin{tabular}{|c|c|c|c|c|c|c|c|c|}
\hline \multirow[t]{2}{*}{ Location } & & \multicolumn{3}{|c|}{ Sample } & \multicolumn{3}{|c|}{ Duplicate } & \\
\hline & & {$[\mathrm{RN}]^{\mathrm{a}}$} & $2 \times$ TPU $^{b}$ & MDC $^{c}$ & [RN] & $2 \times$ TPU & MDC & RER $^{d}$ \\
\hline WFF & ${ }^{40} \mathrm{~K}$ & 3.17E-01 & $5.80 \mathrm{E}-02$ & $2.48 \mathrm{E}-02$ & $3.41 \mathrm{E}-01$ & $5.23 \mathrm{E}-02$ & $2.39 \mathrm{E}-02$ & 0.307 \\
\hline
\end{tabular}

a Radionuclide concentration. Only radionuclides with activities greater than the $2 \times$ TPU and MDC are "detects."

B Total propagated uncertainty

C Minimum detectable concentration

D Relative error ratio

\section{Animals}

Table 4.21 shows that the only radionuclide to be detected in any of the animal samples was ${ }^{40} \mathrm{~K}$, and that it was detected in all the samples. Uranium-233/234, ${ }^{235} \mathrm{U},{ }^{238} \mathrm{U},{ }^{241} \mathrm{Am}$, ${ }^{238} \mathrm{Pu},{ }^{239 / 240} \mathrm{Pu},{ }^{137} \mathrm{Cs},{ }^{60} \mathrm{Co}$, and ${ }^{90} \mathrm{Sr}$, were not detected in any of the animal samples. No statistical comparisons between locations or years could be performed for any of these undetected radionuclides.

Potassium-40 was detected in all of the biota samples including quail, three fish, rabbit, javelina, and a deer sample. However, there were too few samples to allow statistical comparison between years. The detected ${ }^{40} \mathrm{~K}$ concentrations were within the baseline analysis results, including $0.39 \mathrm{~Bq} / \mathrm{g}$ for rabbit (dry); $0.41 \mathrm{~Bq} / \mathrm{g}$ for quail (dry); $0.61 \mathrm{~Bq} / \mathrm{g}$ for fish (dry); and 0.34 Bq/g for beef muscle (dry) (DOE/WIPP-92-037).

These results can only be used as a gross indication of uptake by the animals, since the sample sizes are too small to provide a thorough analysis. Within this limitation, the data do not suggest any contribution to animal uptake of the radionuclides at the WIPP facility. 
Precision data for animal samples were limited to laboratory duplicate from the same sample since duplicate animal samples were not collected.

Table 4.21 - Radionuclide Concentrations (Bq/g Wet Mass) in Quail, Fish, Rabbit, Javelina, and Deer Samples Taken Near the WIPP Site. See Appendix C for Sampling Location Codes.

\begin{tabular}{|c|c|c|c|c|c|c|c|c|c|}
\hline $\begin{array}{c}\text { Biota } \\
\text { (Location) } \\
\end{array}$ & {$[\mathrm{RN}]^{\mathrm{a}}$} & $2 \times$ TPU $^{\mathrm{b}}$ & $\mathrm{MDC}^{\mathrm{c}}$ & {$[\mathrm{RN}]^{\mathrm{a}}$} & $2 \times \mathrm{TPU}^{\mathrm{b}}$ & $M^{\prime} C^{c}$ & {$[\mathrm{RN}]^{\mathrm{a}}$} & $2 \times$ TPU $^{\mathrm{b}}$ & $\mathrm{MDC}^{\mathrm{c}}$ \\
\hline & \multicolumn{3}{|c|}{${ }^{233 / 234} \mathrm{U}$} & \multicolumn{3}{|c|}{${ }^{235} U$} & \multicolumn{3}{|c|}{${ }^{238} U$} \\
\hline Quail (WEE) & 5.14E-05 & $8.28 \mathrm{E}-06$ & $6.44 \mathrm{E}-04$ & 2.67E-06 & $2.13 \mathrm{E}-06$ & 5.06E-05 & 4.19E-05 & 7.42E-06 & $2.85 \mathrm{E}-04$ \\
\hline Fish (PCN) & 3.37E-04 & 2.81E-05 & $5.58 \mathrm{E}-04$ & 5.80E-06 & $3.71 \mathrm{E}-06$ & 4.37E-05 & $1.83 \mathrm{E}-04$ & 1.97E-05 & 4.34E-04 \\
\hline Fish (BRA) & 1.10E-04 & 1.67E-05 & $5.58 \mathrm{E}-04$ & 2.10E-06 & $2.61 \mathrm{E}-06$ & 3.54E-05 & 5.27E-05 & 1.13E-05 & 4.59E-04 \\
\hline Fish (CBD) & 8.69E-05 & $1.83 \mathrm{E}-05$ & 5.72E-04 & 5.29E-06 & 5.37E-06 & 2.17E-05 & $5.45 \mathrm{E}-05$ & 1.44E-05 & 4.48E-04 \\
\hline Rabbit (SOO) & $5.61 \mathrm{E}-06$ & 5.17E-06 & $5.47 \mathrm{E}-04$ & $-2.31 \mathrm{E}-07$ & $1.06 \mathrm{E}-06$ & 1.71E-05 & 4.61E-06 & $4.72 \mathrm{E}-06$ & 4.36E-04 \\
\hline Javelina (SOO) & 5.36E-06 & 3.22E-06 & 5.83E-04 & 3.08E-07 & $1.27 \mathrm{E}-06$ & 3.98E-05 & $1.48 \mathrm{E}-06$ & $1.85 \mathrm{E}-06$ & 4.59E-04 \\
\hline \multirow[t]{2}{*}{ Deer (SOO) } & $9.53 \mathrm{E}-07$ & $1.24 \mathrm{E}-06$ & $5.83 \mathrm{E}-04$ & $3.44 \mathrm{E}-07$ & $9.24 \mathrm{E}-07$ & 2.47E-05 & 1.99E-06 & 1.71E-06 & 4.34E-04 \\
\hline & \multicolumn{3}{|c|}{${ }^{241} \mathrm{Am}$} & \multicolumn{3}{|c|}{${ }^{238} \mathrm{Pu}$} & \multicolumn{3}{|c|}{${ }^{239 / 240} \mathrm{Pu}$} \\
\hline Quail (WEE) & 1.33E-06 & $1.25 \mathrm{E}-06$ & 1.99E-04 & $1.53 \mathrm{E}-07$ & $7.35 \mathrm{E}-07$ & $9.12 \mathrm{E}-05$ & 1.63E-06 & $1.55 \mathrm{E}-06$ & 4.29E-05 \\
\hline Fish (PCN) & 1.83E-06 & 2.30E-06 & 2.61E-04 & $-3.50 \mathrm{E}-07$ & $1.61 \mathrm{E}-06$ & 5.33E-05 & $3.66 \mathrm{E}-07$ & 1.77E-06 & 1.15E-04 \\
\hline Fish (BRA) & 2.88E-06 & 4.32E-06 & 2.74E-04 & 7.20E-08 & 9.47E-07 & 3.93E-05 & $-2.04 \mathrm{E}-07$ & 5.31E-07 & 1.20E-04 \\
\hline Fish (CBD) & 9.19E-08 & $1.46 \mathrm{E}-06$ & 1.75E-04 & 7.31E-08 & $1.47 \mathrm{E}-06$ & 2.01E-05 & $-4.03 \mathrm{E}-07$ & $9.22 \mathrm{E}-07$ & 8.69E-05 \\
\hline Rabbit (SOO) & 1.18E-06 & 1.57E-06 & $2.48 \mathrm{E}-04$ & $-4.50 \mathrm{E}-07$ & $1.81 \mathrm{E}-06$ & 3.45E-05 & 1.44E-06 & 1.70E-06 & 1.25E-04 \\
\hline Javelina (SOO) & 4.90E-07 & 1.25E-06 & 2.61E-04 & 5.79E-07 & $1.14 \mathrm{E}-06$ & 4.29E-05 & $3.86 \mathrm{E}-07$ & $9.27 \mathrm{E}-07$ & 1.15E-04 \\
\hline \multirow[t]{2}{*}{ Deer (SOO) } & $-9.91 \mathrm{E}-07$ & 4.56E-06 & 2.02E-04 & $0.00 \mathrm{E}+00$ & $1.85 \mathrm{E}-06$ & 1.17E-05 & 8.89E-07 & $2.14 \mathrm{E}-06$ & 1.06E-04 \\
\hline & \multicolumn{3}{|c|}{${ }^{40} \mathrm{~K}$} & \multicolumn{3}{|c|}{${ }^{60} \mathrm{Co}$} & \multicolumn{3}{|c|}{${ }^{137} \mathrm{Cs}$} \\
\hline Quail (WEE) & 7.19E-02 & 1.17E-02 & 1.08E-02 & $-7.64 \mathrm{E}-04$ & 1.06E-03 & 1.12E-03 & $9.29 \mathrm{E}-04$ & $9.81 \mathrm{E}-04$ & 1.16E-03 \\
\hline Fish (PCN) & 3.23E-02 & 8.62E-03 & $1.00 \mathrm{E}-02$ & 1.64E-04 & 1.01E-03 & 1.16E-03 & 2.42E-05 & $9.21 \mathrm{E}-04$ & 1.08E-03 \\
\hline Fish (BRA) & 2.31E-02 & $1.46 \mathrm{E}-02$ & 2.26E-02 & 1.19E-03 & $2.50 \mathrm{E}-03$ & 2.79E-03 & $-3.99 \mathrm{E}-03$ & $3.78 \mathrm{E}-03$ & 4.10E-03 \\
\hline Fish (CBD) & 6.47E-02 & $1.28 \mathrm{E}-02$ & 1.10E-02 & $1.29 \mathrm{E}-03$ & $1.33 \mathrm{E}-03$ & $1.58 \mathrm{E}-03$ & $-2.79 E-04$ & $1.33 \mathrm{E}-03$ & 1.52E-03 \\
\hline Rabbit (SOO) & 2.67E-02 & 1.13E-02 & $1.64 \mathrm{E}-02$ & 2.06E-03 & $1.31 \mathrm{E}-03$ & $1.54 \mathrm{E}-03$ & $-3.00 \mathrm{E}-03$ & $1.72 \mathrm{E}-03$ & $1.75 \mathrm{E}-03$ \\
\hline Javelina (SOO) & 8.75E-02 & 1.59E-02 & $1.48 \mathrm{E}-02$ & 5.22E-04 & - $1.29 \mathrm{E}-03$ & $1.46 \mathrm{E}-03$ & $-1.64 \mathrm{E}-05$ & $1.52 \mathrm{E}-03$ & 1.74E-03 \\
\hline \multirow[t]{2}{*}{ Deer (SOO) } & 1.16E-01 & 1.77E-02 & 8.77E-03 & 7.48E-05 & $9.73 \mathrm{E}-04$ & $1.10 \mathrm{E}-03$ & 1.87E-04 & $1.01 \mathrm{E}-03$ & $1.18 \mathrm{E}-03$ \\
\hline & & ${ }^{90} \mathrm{Sr}$ & & & & & & & \\
\hline Quail (WEE) & $-6.21 \mathrm{E}-06$ & 8.92E-05 & 5.38E-04 & & & & & & \\
\hline Fish (PCN) & $-3.71 \mathrm{E}-05$ & 1.10E-04 & $1.91 \mathrm{E}-04$ & & & & & & \\
\hline Fish (BRA) & $-1.73 E-05$ & $1.21 \mathrm{E}-04$ & 1.69E-04 & & & & & & \\
\hline Fish (CBD) & $-2.91 \mathrm{E}-06$ & $1.39 \mathrm{E}-04$ & $1.46 \mathrm{E}-04$ & & & & & & \\
\hline Rabbit (SOO) & $-4.15 E-05$ & $1.24 \mathrm{E}-04$ & 3.10E-04 & & & & & & \\
\hline Javelina (SOO) & 3.04E-05 & $1.08 \mathrm{E}-04$ & $1.54 \mathrm{E}-04$ & & & & & & \\
\hline Deer (SOO) & 1.35E-05 & 1.04E-04 & 1.10E-04 & & & & & & \\
\hline
\end{tabular}




\subsection{Potential Dose From WIPP Operations}

\subsubsection{Dose Limits}

Compliance with the regulatory standards is determined by comparing annual radiation doses to the regulatory standards. The regulatory standards can be found in 40 CFR Part 191, Subpart A. The referenced standard specifies that the combined annual dose equivalent to any member of the public in the general environment resulting from discharges of radioactive material and direct radiation from such management and storage shall not exceed $25 \mathrm{mrem}$ to the whole body and $75 \mathrm{mrem}$ to any critical organ. In addition, in a 1995 MOU between the EPA and the DOE, the DOE agreed that the WIPP facility would comply with the applicable NESHAP for radionuclides. The NESHAP standard states that the emissions of radionuclides to the ambient air from DOE facilities shall not exceed those amounts that would cause any member of the public to receive in any year an EDE of 10 mrem per year. The EDE is the weighted sum of the doses to the individual organs of the body. The dose to each organ is weighted according to the risk that dose represents. These organ doses are then added together, and that total is the EDE. In this manner, the risk from different sources of radiation can be controlled by a single standard.

Compliance with applicable regulatory requirements is determined by monitoring, extracting, and calculating the EDE. Calculating the EDE to members of the public requires the use of CAP88-PC or other EPA-approved computer models and procedures. The WIPP effluent monitoring program generally uses CAP88-PC, which is a set of computer programs, datasets and associated utility programs for estimating dose and risk from radionuclide air emissions. CAP88-PC uses a Gaussian Plume dispersion model, which predicts air concentrations, deposition rates, concentrations in food, and intake rates for people. CAP88-PC estimates dose and risk to individuals and populations from multiple pathways. Dose and risk is calculated for ingestion, inhalation, ground-level air immersion, and ground-surface irradiation exposure pathways.

The Safe Drinking Water Act (40 CFR §141.66, "Maximum Contaminant Levels for Radionuclides") states that average annual concentrations for beta- and gamma-emitting human-made radionuclides in drinking water shall not result in an annual dose equivalent $>0.04$ millisieverts ( $\mathrm{mSv})(4 \mathrm{mrem})$. It is important to note that all of these dose equivalent limits are set for radionuclides released to the environment from DOE operations. They do not include, but are limits in addition to, doses from natural background radiation or from medical procedures.

\subsubsection{Background Radiation}

There are several sources of natural radiation: cosmic and cosmogenic radiation (from outer space and the earth's atmosphere), terrestrial radiation (from the earth's crust), and internal radiation (naturally occurring radiation in our bodies, such as ${ }^{40} \mathrm{~K}$ ). The most common sources of terrestrial radiation are uranium, thorium, and their decay products. Potassium-40 is another source of terrestrial radiation. While not a major 
radiation source, ${ }^{40} \mathrm{~K}$ in the southeastern New Mexico environment may be due to the deposition of tailings from local potash mining. Radon gas, a decay product of uranium, is a widely known naturally occurring terrestrial radionuclide. In addition to natural radioactivity, small amounts of radioactivity from aboveground nuclear weapons tests that occurred from 1945 through 1980, and the 1986 Chernobyl nuclear accident are also present in the environment. Together, these sources of radiation are called "background" radiation.

Naturally occurring radiation in our environment can deliver both internal and external doses. Internal dose is received as a result of the intake of radionuclides. The routes of intake of radionuclides for members of the public are ingestion and inhalation. Ingestion includes eating and drinking food or drink containing radionuclides. Inhalation includes the intake of radionuclides through breathing radioactive particulates. External dose can occur from immersion in contaminated air or deposition of contaminants on surfaces. The average annual dose received by a member of the public from naturally occurring radionuclides is approximately $3 \mathrm{mSv}$ (300 mrem) (Table 4.22).

\begin{tabular}{lcc}
\hline Table 4.22 - $\begin{array}{l}\text { Annual Estimated Average Radiation Dose Received by a Member of the } \\
\text { Population of the United States From Naturally Occurring Radiation Sources } \\
\text { (adapted from NCRP, 1987a) }\end{array}$ & \multicolumn{2}{c}{ Average Annual EDE } \\
\multicolumn{1}{c}{ Source } & (mSv) & (mrem) \\
\hline Inhaled (Radon and Decay Products) & 2 & 200 \\
Internal Radionuclides & 0.39 & 39 \\
Terrestrial Radiation & 0.28 & 28 \\
Cosmic Radiation & 0.27 & 27 \\
Cosmogenic Radioactivity & 0.01 & 1 \\
Rounded Total from Natural Sources & 3 & 300 \\
\hline
\end{tabular}

\subsubsection{Dose From Air Emissions}

The 40 CFR Part 191, Subpart A, standard limits radiation doses to members of the public in the general environment. The DOE has identified air emissions as the major pathway of concern for the WIPP facility.

Compliance with Subpart A (40 CFR §191.03[b]) and the NESHAP standard (40 CFR §61.92) is determined by comparing annual radiation doses to the maximally exposed individual (MEI) to the regulatory standards. As recommended by the EPA, the DOE uses computer modeling to calculate radiation doses for compliance with the Subpart A and NESHAP standards. Compliance procedures for DOE facilities (40 CFR §61.93[a]) require the use of CAP88-PC or AIRDOS-PC computer models, or equivalent, to calculate dose to members of the public. Source term input for CAP88-PC was determined by radiochemical analyses of filter air samples taken from Stations A, B, and C. Air filter samples were analyzed for ${ }^{241} \mathrm{Am},{ }^{239 / 240} \mathrm{Pu},{ }^{238} \mathrm{Pu},{ }^{90} \mathrm{Sr}$, ${ }^{233 / 234} \mathrm{U},{ }^{238} \mathrm{U}$, and ${ }^{137} \mathrm{Cs}$ because these radionuclides constitute over 98 percent of the 
dose potential from $\mathrm{CH}$ and $\mathrm{RH}$ waste. A combination of measured concentration or activity results, the $2 \times$ TPU and MDC, were used as input nuclide data in the CAP88-PC computer model to calculate the EDEs to members of the public (see Section 4.1.4 for more information on the results and discussion of the effluent monitoring data).

CAP88-PC dose calculations are based on the assumption that exposed persons remain at home during the entire year and all vegetables, milk, and meat consumed are home produced. Thus, this dose calculation is a maximum potential dose which encompasses dose from inhalation, submersion, deposition, and ingestion of radionuclides emitted via the air pathway from the WIPP facility.

\subsubsection{Total Potential Dose From WIPP Operations}

The radiation dose equivalent received by members of the public as a result of the management and storage of TRU radioactive wastes at any disposal facility operated by the DOE is regulated under 40 CFR Part 191, Subpart A. Specific standards state that the combined annual dose equivalent to any member of the public in the general environment resulting from the discharges of radioactive material and direct radiation from management and storage shall not exceed $0.25 \mathrm{mSv}(25 \mathrm{mrem})$ to the whole body and $0.75 \mathrm{mSv}(75 \mathrm{mrem})$ to any other critical organ. Section 4.8.4.3 discusses the potential dose equivalent received from radionuclides released to the air from WIPP. The following sections discuss the potential dose equivalent through other pathways and the total potential dose equivalent a member of the public may have received from the WIPP facility during 2008.

\subsubsection{Potential Dose From Water Ingestion Pathway}

The potential dose to individuals from the ingestion of WIPP facility-related radionuclides transported in water is determined to be zero for several reasons. Drinking water for communities near the WIPP facility comes from groundwater sources that are not expected to be affected by WIPP facility contaminants based on current radionuclide transport scenarios summarized in the Waste Isolation Pilot Plant Documented Safety Analysis (DOE/WIPP-08-3372). The only credible pathway for contaminants from the WIPP facility to accessible groundwater is through the Culebra Member of the Rustler Formation as stated in Title 40 CFR Part 191 Compliance Certification Application for the Waste Isolation Pilot Plant 2004 (DOE/CAO-96-2194). Water from the Culebra is naturally not potable due to high levels of total dissolved solids (TDS). Water from the Dewey Lake Redbeds Formation is suitable for livestock consumption, having TDS values below 10,000 milligrams per liter (mg/L).

Groundwater samples collected around the WIPP facility during 2008 did not contain radionuclide concentrations discernable from those in samples collected prior to the WIPP facility receiving waste. 


\subsubsection{Potential Dose From Wild Game Ingestion}

Game animals sampled during 2008 were mule deer, rabbit, fish, javelina, and quail. The only radionuclides detected were not different from baseline levels measured prior to commencement of waste shipments to the WIPP facility. Therefore, no dose from WIPP facility-related radionuclides could have been received by any individual from this pathway during 2008.

\subsubsection{Total Potential Dose From All Pathways}

The only credible pathway from the WIPP facility to humans is through air emissions and, therefore, this is the only pathway for which a dose is calculated. The total radiological dose and atmospheric release at WIPP in 2008 is summarized in Table 4.23 for the regulations in both 40 CFR $\$ 61.92$ and 40 CFR $§ 191.03(b)$.

In compliance with 40 CFR Part 191, Subpart A, the receptor selected is assumed to reside year-round at the fence line in the northwest sector. For 2008, the dose to this receptor was estimated to be $<7.14 \mathrm{E}-06 \mathrm{mSv}$ (7.14E-04 mrem) per year for the whole body and <1.46E-05 mSv (1.46E-03 mrem) per year to the critical organ. These values are in compliance with the requirements specified in 40 CFR $§ 191.03(b)$.

For the NESHAP standard (40 CFR §61.92), the EDE potentially received by the MEI in 2007 assumed to be residing $7.5 \mathrm{~km}$ (4.66 mi) west-northwest of WIPP is calculated to be $<9.05 \mathrm{E}-08 \mathrm{mSv}(9.05 \mathrm{E}-06 \mathrm{mrem})$ per year for the whole body. This value is in compliance with 40 CFR $\S 61.92$ requirements.

As required by DOE Order 5400.5, Chapter II, Section 6.b, the collective dose to the public within $80 \mathrm{~km}$ (50 mi) of the WIPP facility has been evaluated, and is 2.72E-07 person Sv (2.72E-05 person rem) in 2008. The collective dose to the public is a factor considered in developing the field program for the ALARA process, as required by DOE Order 5400.5, Chapter II, Section 2.a(2). 
Waste Isolation Pilot Plant Annual Site Environmental Report for 2008 DOE/WIPP-09-2225

Table 4.23 - WIPP Radiological Dose and Release Summary

\begin{tabular}{|c|c|c|c|}
\hline \multicolumn{3}{|c|}{ WIPP Radiological Atmospheric Releases ${ }^{\text {a }}$ During 2008} \\
\hline${ }^{238} \mathrm{Pu}$ & ${ }^{239 / 240} \mathrm{Pu}$ & ${ }^{241} \mathrm{Am}$ & ${ }^{90} \mathrm{Sr}$ \\
\hline $6.27 \mathrm{E}-08 \mathrm{Ci}$ & $2.02 \mathrm{E}-07 \mathrm{Ci}$ & $1.61 \mathrm{E}-07 \mathrm{Ci}$ & $1.73 \mathrm{E}-06 \mathrm{Ci}$ \\
$2,319.9 \mathrm{~Bq}$ & $7,474 \mathrm{~Bq}$ & $5,957 \mathrm{~Bq}$ & $610 \mathrm{~Bq}$ \\
\hline${ }^{233 / 234} \mathrm{U}$ & ${ }^{238} \mathrm{U}$ & ${ }^{137} \mathrm{Cs}$ & \\
\hline $2.36 \mathrm{E}-07 \mathrm{Ci}$ & $1.87 \mathrm{E}-07 \mathrm{Ci}$ & $5.85 \mathrm{E}-05 \mathrm{Ci}$ & \\
\hline $8,732 \mathrm{~Bq}$ & $6,919 \mathrm{~Bq}$ & $2,164,500 \mathrm{~Bq}$ & \\
\hline
\end{tabular}

\begin{tabular}{|c|c|c|c|c|c|c|c|}
\hline \multicolumn{8}{|c|}{ WIPP Radiological Dose Reporting Table in 2008} \\
\hline \multirow{2}{*}{ Pathway } & \multicolumn{2}{|c|}{$\begin{array}{l}\text { EDE to the Maximally } \\
\text { Exposed Individual } \\
\text { at } 7,500 \text { Meters WNW }\end{array}$} & \multirow{2}{*}{$\begin{array}{l}\text { Percent of } \\
\text { EPA } \\
\text { 10-mrem/ } \\
\text { Year Limit to } \\
\text { Member of } \\
\text { the Public }\end{array}$} & \multicolumn{2}{|c|}{$\begin{array}{l}\text { Estimated Population Dose } \\
\text { Within } 50 \text { Miles }\end{array}$} & \multirow{2}{*}{$\begin{array}{c}\text { Estimated } \\
\text { Population } \\
\text { Within } \\
50 \text { Miles }^{\mathrm{b}}\end{array}$} & \multirow{2}{*}{$\begin{array}{c}\text { Estimated } \\
\text { Natural } \\
\text { Radiation } \\
\text { Population } \text { Dose }^{\mathrm{c}} \\
\\
\text { (person-rem) }\end{array}$} \\
\hline & (mrem/year) & (mSv/year) & & $\begin{array}{c}\text { (person-re } \\
\text { m/year) }\end{array}$ & $\begin{array}{l}\text { (person-Sv/ } \\
\text { year) }\end{array}$ & & \\
\hline Air & 9.05E-06 & $9.05 \mathrm{E}-08$ & 9.05E-05 & 2.72E-05 & $2.72 \mathrm{E}-07$ & 101,017 & 30,305 \\
\hline Water & $N / A^{d}$ & $N / A$ & N/A & N/A & $\mathrm{N} / \mathrm{A}$ & $\mathrm{N} / \mathrm{A}$ & $\mathrm{N} / \mathrm{A}$ \\
\hline $\begin{array}{c}\text { Other } \\
\text { Pathways }\end{array}$ & N/A & $\mathrm{N} / \mathrm{A}$ & $\mathrm{N} / \mathrm{A}$ & N/A & $N / A$ & N/A & N/A \\
\hline
\end{tabular}

\begin{tabular}{|c|c|c|c|c|c|c|}
\hline \multicolumn{7}{|c|}{ WIPP Radiological Dose Reporting Table in 2008} \\
\hline \multirow[t]{2}{*}{ Pathway } & \multicolumn{2}{|c|}{$\begin{array}{l}\text { Dose equivalent to the whole } \\
\text { body of the receptor who } \\
\text { resides year-round at WIPP } \\
\text { fence line } 350 \text { meters NW }\end{array}$} & \multirow{2}{*}{$\begin{array}{c}\text { Percent of } \\
\text { EPA } \\
\text { 25-mrem/Year } \\
\text { Whole Body } \\
\text { Limit }\end{array}$} & \multicolumn{2}{|c|}{$\begin{array}{l}\text { Dose equivalent to the critical } \\
\text { organ of the receptor who } \\
\text { resides year-round at WIPP } \\
\text { fence line } 350 \text { meters NW }\end{array}$} & \multirow{2}{*}{$\begin{array}{c}\text { Percent of EPA } \\
\text { 75-mrem/Year } \\
\text { Critical Organ } \\
\text { Limit }\end{array}$} \\
\hline & (mrem/year) & (mSv/year) & & (mrem/year) & (mSv/year) & \\
\hline Air & 7.14E-04 & 7.14E-06 & 2.86E-03 & 7.81E-03 & 7.81E-05 & 1.04E-02 \\
\hline Water & $\mathrm{N} / \mathrm{A}$ & N/A & $\mathrm{N} / \mathrm{A}$ & $\mathrm{N} / \mathrm{A}$ & $\mathrm{N} / \mathrm{A}$ & $\mathrm{N} / \mathrm{A}$ \\
\hline $\begin{array}{c}\text { Other } \\
\text { Pathways }\end{array}$ & $\mathrm{N} / \mathrm{A}$ & $\mathrm{N} / \mathrm{A}$ & $\mathrm{N} / \mathrm{A}$ & $\mathrm{N} / \mathrm{A}$ & $\mathrm{N} / \mathrm{A}$ & $\mathrm{N} / \mathrm{A}$ \\
\hline
\end{tabular}

a Total releases from the combination of Stations A, B, and C. Values are calculated from detected activities or either the $2 \times$ TPU or MDC, whichever are greater (where activities were less than the $2 \times$ TPU and MDC) and multiplied by the ratio of flow to stack flow volumes.

Source: 2000 Census Data

Estimated natural radiation populations dose $=($ estimated population within $50 \mathrm{mi}) \times(300 \mathrm{mrem} / \mathrm{year})$

Not applicable at WIPP 


\subsubsection{Dose to Nonhuman Biota}

Dose limits for populations of aquatic and terrestrial organisms are discussed in NCRP Report No. 109, Effects of Ionizing Radiation on Aquatic Organisms (NCRP, 1991), and the International Atomic Energy Agency (IAEA) Technical Report Series No. 332, Effects of lonizing Radiation on Plants and Animals at Levels Implied by Current Radiation Protection Standards. Those dose limits are:

- $\quad$ Aquatic animals $-10 \mathrm{mGy} / \mathrm{d}(1 \mathrm{rad} / \mathrm{d})$

- $\quad$ Terrestrial plants $-10 \mathrm{mGy} / \mathrm{d}(1 \mathrm{rad} / \mathrm{d})$

- Terrestrial animals $-1 \mathrm{mGy} / \mathrm{d}(0.1 \mathrm{rad} / \mathrm{d})$

The DOE has considered establishing these dose standards for aquatic and terrestrial biota in proposed rule 10 CFR Part 834, "Radiation Protection of the Public and the Environment," but has delayed finalizing this rule until guidance for demonstrating compliance was developed. A Graded Approach for Evaluating Radiation Doses to Aquatic and Terrestrial Biota (DOE-STD-1153-2002) was developed to meet this need.

The DOE requires reporting of radiation doses to nonhuman biota in the ASER using DOE-STD-1153-2002. DOE-STD-1153-2002 requires an initial general screening using conservative assumptions. In the initial screen, biota concentration guides (BCGs) are derived using conservative assumptions for a variety of generic organisms. Maximum concentrations of radionuclides detected in soil, sediment, and water during environmental monitoring are divided by the BCGs and the results are summed for each organism. If the sum of these fractions is $<1.0$, the site is deemed to have passed the screen and no further action is required. This screening evaluation is intended to provide a very conservative evaluation of the site in relation to the recommended limits. This guidance was used to screen radionuclide concentrations observed around WIPP during 2008 using the maximum radionuclide concentrations listed in Table 4.24, and the sum of fractions was $<1.0$ for all media. The element ${ }^{40} \mathrm{~K}$ is not included in Table 4.24 since it is a natural component of the earth's crust and is not part of TRU-waste-related radionuclides. 
Waste Isolation Pilot Plant Annual Site Environmental Report for 2008 DOE/WIPP-09-2225

Table 4.24 - General Screening Results for Potential Radiation Dose to Nonhuman Biota From Radionuclide Concentrations in Surface Water (Bq/L), Sediment (Bq/g), and Soil (Bq/g) Near the WIPP Site in 2008

\begin{tabular}{|c|c|c|c|c|}
\hline Medium & Radionuclide & $\begin{array}{l}\text { Maximum Detected } \\
\text { Concentration }\end{array}$ & $\mathrm{BCG}^{\mathrm{a}}$ & Concentration/BCG \\
\hline \multicolumn{5}{|c|}{ Aquatic System Evaluation } \\
\hline \multirow[t]{9}{*}{ Sediment (Bq/g) } & ${ }^{60} \mathrm{Co}$ & $\mathrm{ND}^{\mathrm{c}}$ & $5.00 \mathrm{E}+01$ & $N / A^{d}$ \\
\hline & ${ }^{90} \mathrm{Sr}$ & ND & $2.00 \mathrm{E}+01$ & N/A \\
\hline & ${ }^{137} \mathrm{Cs}$ & 8.82E-03 & $1.00 \mathrm{E}+02$ & 8.82E-05 \\
\hline & ${ }^{233 / 234} U$ & 1.36E-02 & $2.00 \mathrm{E}+02$ & 6.80E-05 \\
\hline & ${ }^{235} U$ & 8.25E-04 & $1.00 \mathrm{E}+02$ & 8.25E-06 \\
\hline & ${ }^{238} \mathrm{U}$ & $1.30 \mathrm{E}-02$ & $9.00 \mathrm{E}+01$ & $1.44 \mathrm{E}-04$ \\
\hline & ${ }^{238} \mathrm{Pu}$ & ND & $2.00 \mathrm{E}+02$ & N/A \\
\hline & ${ }^{239} \mathrm{Pu}$ & ND & $2.00 \mathrm{E}+02$ & $\mathrm{~N} / \mathrm{A}$ \\
\hline & ${ }^{241} \mathrm{Am}$ & ND & $2.00 \mathrm{E}+02$ & $\mathrm{~N} / \mathrm{A}$ \\
\hline \multirow[t]{10}{*}{ Water $^{\mathrm{b}}(\mathrm{Bq} / \mathrm{L})$} & ${ }^{60} \mathrm{Co}$ & ND & $1.00 \mathrm{E}+02$ & $\mathrm{~N} / \mathrm{A}$ \\
\hline & ${ }^{90} \mathrm{Sr}$ & ND & $1.00 \mathrm{E}+01$ & $\mathrm{~N} / \mathrm{A}$ \\
\hline & ${ }^{137} \mathrm{Cs}$ & ND & $2.00 \mathrm{E}+00$ & $\mathrm{~N} / \mathrm{A}$ \\
\hline & ${ }^{233 / 234} \mathrm{U}$ & $1.07 E-01$ & $7.00 \mathrm{E}+00$ & 1.53E-02 \\
\hline & ${ }^{235} U$ & 3.93E-03 & $8.00 \mathrm{E}+00$ & 4.91E-04 \\
\hline & ${ }^{238} U$ & $5.54 \mathrm{E}-02$ & $8.00 \mathrm{E}+00$ & 6.93E-03 \\
\hline & ${ }^{238} \mathrm{Pu}$ & ND & $7.00 \mathrm{E}+00$ & N/A \\
\hline & ${ }^{239} \mathrm{Pu}$ & ND & $7.00 \mathrm{E}+00$ & $\mathrm{~N} / \mathrm{A}$ \\
\hline & \multirow[t]{2}{*}{${ }^{241} \mathrm{Am}$} & \multirow[t]{2}{*}{ ND } & $2.00 \mathrm{E}+01$ & $\mathrm{~N} / \mathrm{A}$ \\
\hline & & & SUM OF FRACTIONS & 2.30E-02 \\
\hline \multicolumn{5}{|c|}{ Terrestrial System Evaluation } \\
\hline \multirow[t]{9}{*}{ Soil (Bq/g) } & ${ }^{60} \mathrm{Co}$ & ND & $3.00 \mathrm{E}+01$ & $\mathrm{~N} / \mathrm{A}$ \\
\hline & ${ }^{90} \mathrm{Sr}$ & ND & 8.00E-01 & N/A \\
\hline & ${ }^{137} \mathrm{Cs}$ & 8.80E-03 & 8.00E-01 & 1.10E-02 \\
\hline & ${ }^{233 / 234} U$ & 1.43E-02 & $2.00 \mathrm{E}+02$ & 7.15E-05 \\
\hline & ${ }^{235} U$ & 8.76E-04 & $1.00 \mathrm{E}+02$ & 8.76E-06 \\
\hline & ${ }^{238} U$ & 1.46E-02 & $6.00 \mathrm{E}+01$ & 2.43E-04 \\
\hline & ${ }^{238} \mathrm{Pu}$ & ND & $2.00 \mathrm{E}+02$ & N/A \\
\hline & ${ }^{239} \mathrm{Pu}$ & $3.72 E-04$ & $2.00 \mathrm{E}+02$ & $1.86 \mathrm{E}-06$ \\
\hline & ${ }^{241} \mathrm{Am}$ & ND & $1.00 \mathrm{E}+02$ & N/A \\
\hline \multirow[t]{10}{*}{ Water $(\mathrm{Bq} / \mathrm{L})$} & ${ }^{60} \mathrm{Co}$ & ND & $4.00 \mathrm{E}+04$ & $\mathrm{~N} / \mathrm{A}$ \\
\hline & ${ }^{90} \mathrm{Sr}$ & ND & $2.00 \mathrm{E}+04$ & $\mathrm{~N} / \mathrm{A}$ \\
\hline & ${ }^{137} \mathrm{Cs}$ & ND & $2.00 \mathrm{E}+04$ & N/A \\
\hline & ${ }^{233 / 234} U$ & $1.07 E-01$ & $1.00 \mathrm{E}+04$ & 1.07E-05 \\
\hline & ${ }^{235} U$ & 3.93E-03 & $2.00 \mathrm{E}+04$ & $1.97 \mathrm{E}-07$ \\
\hline & ${ }^{238} U$ & $5.54 \mathrm{E}-02$ & $2.00 \mathrm{E}+04$ & 2.77E-06 \\
\hline & ${ }^{238} \mathrm{Pu}$ & ND & $7.00 \mathrm{E}+03$ & N/A \\
\hline & ${ }^{239} \mathrm{Pu}$ & ND & $7.00 \mathrm{E}+03$ & $\mathrm{~N} / \mathrm{A}$ \\
\hline & ${ }^{241} \mathrm{Am}$ & ND & 7.00E+03 & $\mathrm{N} / \mathrm{A}$ \\
\hline & & & SUM OF FRACTIONS & 1.13E-02 \\
\hline
\end{tabular}

The radionuclide concentration in the medium that would produce a radiation dose in the organism equal to the dose limit under the conservative assumptions in the model.

b Sediment and water sample were assumed to be co-located

c Not detected in all sampling locations for a given medium

d Not available for calculation

Note: Maximum detected concentrations were compared with BCG values to assess potential dose to biota. As long as the sum of the ratios between detected maximum concentrations and the associated BCG is below 1.0, no adverse effects on plant or animal populations are expected (DOE-STD-1153-2002). 


\subsubsection{Release of Property Containing Residual Radioactive Material}

There was no release of radiologically contaminated materials or property from the WIPP facility in 2008. The criteria used for release of potentially radioactive materials are specified in DOE Order 5400.5, Radiation Protection of the Public and the Environment, Figure IV-1, Allowable Total Residual Surface Contamination. The primary isotopes of concern for unrestricted release of potentially contaminated materials are transuranic. The values for transuranic isotopes are very low and close to minimum detectable activity for instruments used for the assessments of removable and total contamination levels on items being released. The values in Order 5400.5 for transuranics are $<20$ percent of the values in ANSI/HPS [Health Physics Society] N13.12-1999, Surface and Volume Radioactivity Standards for Clearance.

\subsection{Radiological Program Conclusions}

\section{Effluent Monitoring}

For 2008, the EDE to the receptor (hypothetical MEI) who resides year-round at the fence line is $<7.14 \mathrm{E}-06 \mathrm{mSv}$ (7.14E-04 mrem) per year for the whole body, and is $<7.81 \mathrm{E}-05 \mathrm{mSv}$ (7.81E-03 mrem) per year for the critical organ. For the WIPP effluent monitoring program, Figure 4.5 and Table 4.25 show the dose to the whole body for the hypothetical MEI for CY 1999 to CY 2008. In addition, Figure 4.6 and Table 4.27 show the dose to the critical organ for the hypothetical MEI for CY 1999 to CY 2008. These dose equivalent values are below the $25 \mathrm{mrem}$ to the whole body and $75 \mathrm{mrem}$ to any critical organ, in accordance with the provisions of 40 CFR §191.03(b). 


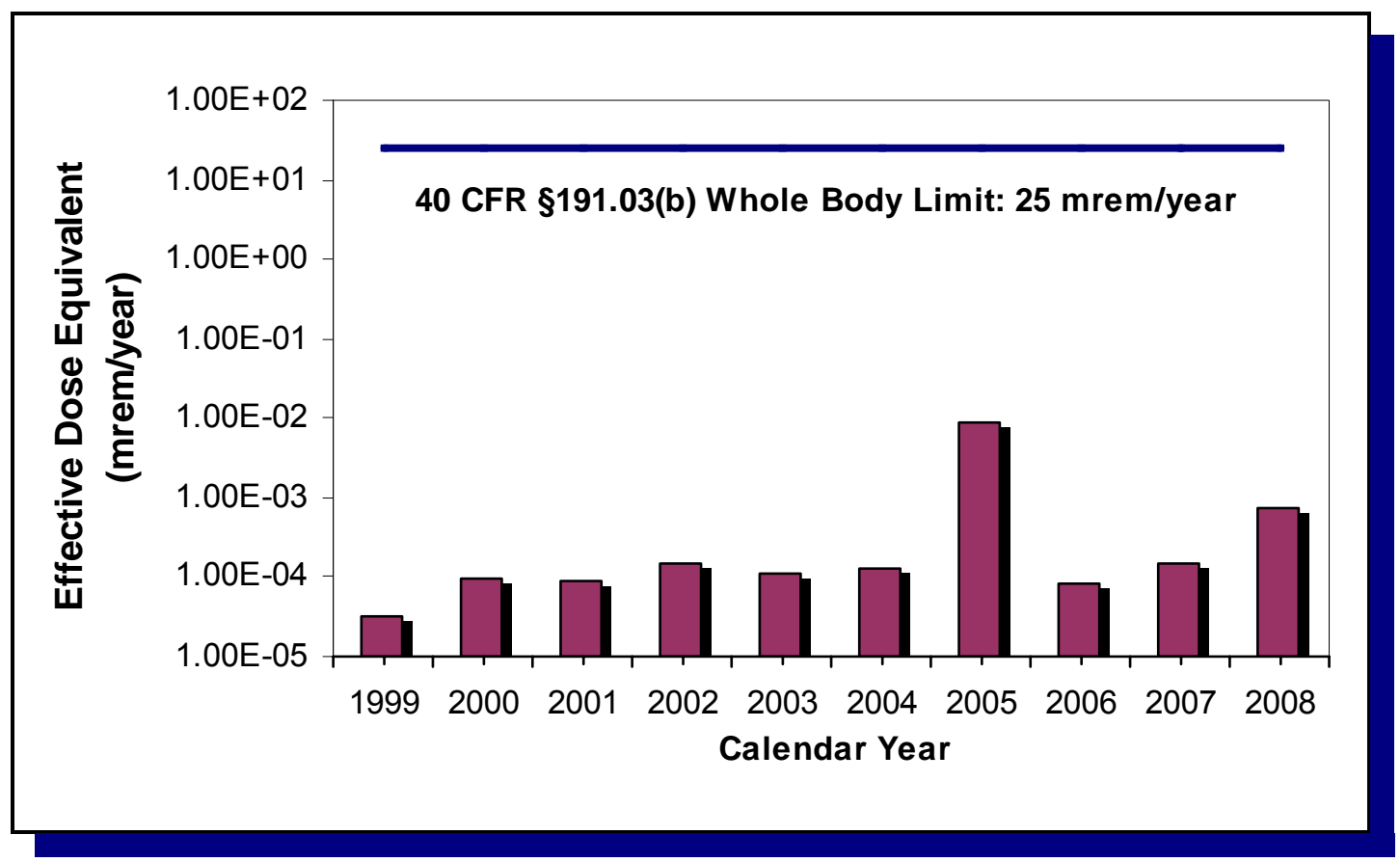

Figure 4.5 - Dose to the Whole Body for the Hypothetical Maximally Exposed Individual at the WIPP Fence Line

Table 4.25 - Comparison of Dose to the Whole Body to EPA Limit of $25 \mathrm{mrem} /$ Year per 40 CFR §191.03(b)

\begin{tabular}{|c|c|c|}
\hline Year & Annual Dose (mrem/yr) & Percent of EPA Limit \\
\hline 1999 & $3.10 \mathrm{E}-05$ & 0.00012 \\
\hline 2000 & $9.35 \mathrm{E}-05$ & 0.00037 \\
\hline 2001 & $8.99 \mathrm{E}-05$ & 0.00036 \\
\hline 2002 & $1.51 \mathrm{E}-04$ & 0.0006 \\
\hline 2003 & $1.15 \mathrm{E}-04$ & 0.00046 \\
\hline 2004 & $1.27 \mathrm{E}-04$ & 0.00051 \\
\hline 2005 & $8.86 \mathrm{E}-05$ & 0.00035 \\
\hline 2006 & $8.16 \mathrm{E}-05$ & 0.00033 \\
\hline 2007 & $1.52 \mathrm{E}-04$ & 0.00061 \\
\hline 2008 & $7.14 \mathrm{E}-04$ & 0.0029 \\
\hline 40 CFR §191.03(b) & 25 & \\
Whole Body Limit & & \\
\hline
\end{tabular}




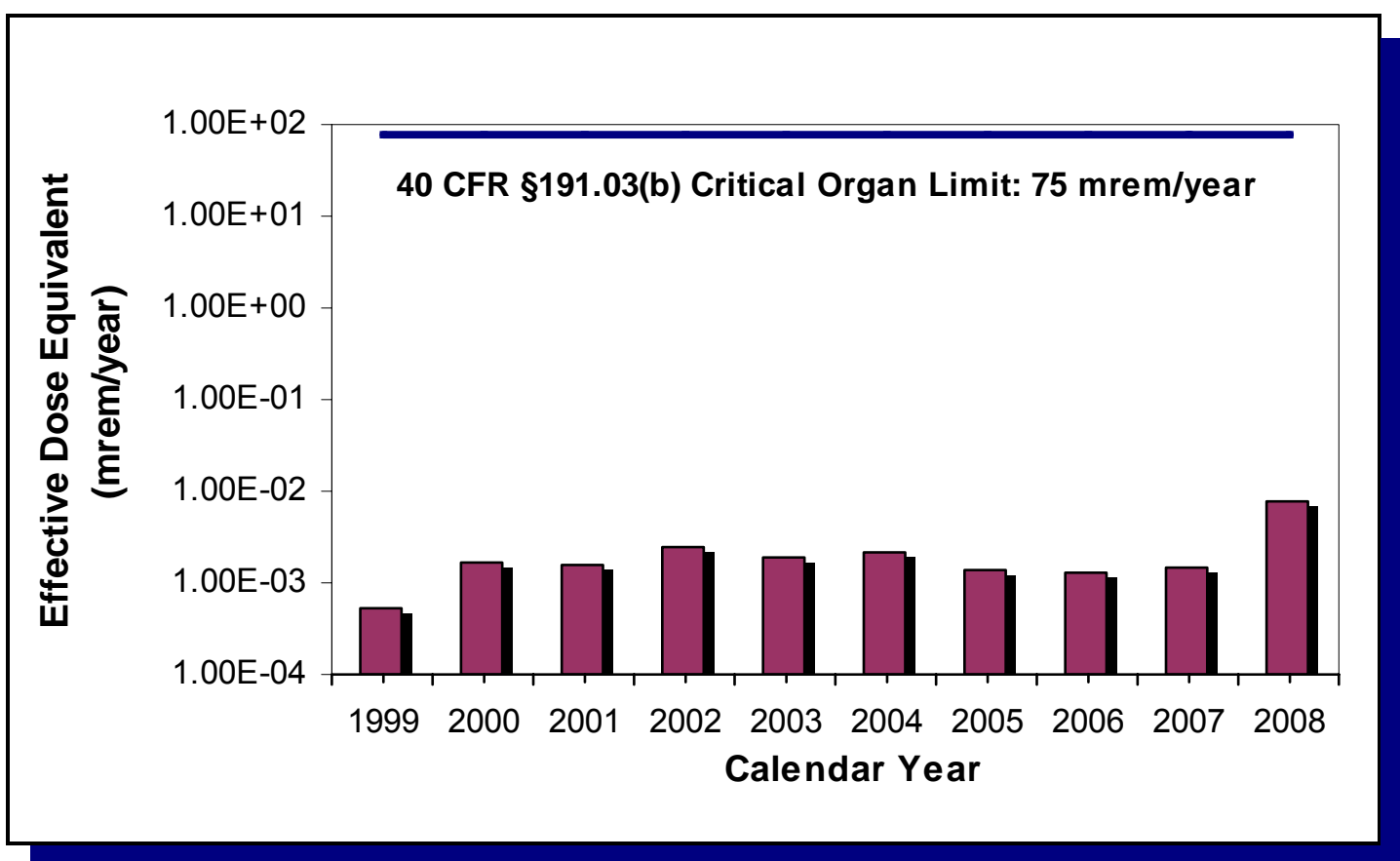

Figure 4.6 - Dose to the Critical Organ for Hypothetical Maximally Exposed individual at the WIPP Fence Line

Table 4.26 - Comparison of Dose to the Critical Organ to EPA Limit of $75 \mathrm{mrem} /$ Year per 40 CFR §191.03(b)

\begin{tabular}{|c|c|c|}
\hline Year & Annual Dose (mrem/yr) & Percent of EPA Limit \\
\hline 1999 & $5.30 \mathrm{E}-04$ & 0.00071 \\
\hline 2000 & $1.63 \mathrm{E}-03$ & 0.0022 \\
\hline 2001 & $1.56 \mathrm{E}-03$ & 0.0021 \\
\hline 2002 & $2.46 \mathrm{E}-03$ & 0.0033 \\
\hline 2003 & $1.85 \mathrm{E}-03$ & 0.0025 \\
\hline 2004 & $2.11 \mathrm{E}-03$ & 0.0028 \\
\hline 2005 & $1.41 \mathrm{E}-03$ & 0.0019 \\
\hline 2006 & $1.30 \mathrm{E}-03$ & 0.0017 \\
\hline 2007 & $1.46 \mathrm{E}-03$ & 0.0019 \\
\hline 2008 & $7.81 \mathrm{E}-03$ & 0.0014 \\
\hline 40 CFR §191.03(b) & 75 & \\
\hline Critical Organ Limit & & \\
\hline
\end{tabular}

In addition, for 2008, the EDE to the MEI from normal operations conducted at the WIPP facility is <7.81E-03 mSv (7.81E-05 mrem) - no new numbers given in markup per year. For the WIPP effluent monitoring program, Figure 4.7 and Table 4.27 show the EDE to the MEI for CY 1999 to CY 2008. These EDE values are more than six orders of magnitude below the EPA NESHAP standard of 10 mrem per year, as specified in 40 CFR $\$ 61.92$. 
Waste Isolation Pilot Plant Annual Site Environmental Report for 2008 DOE/WIPP-09-2225

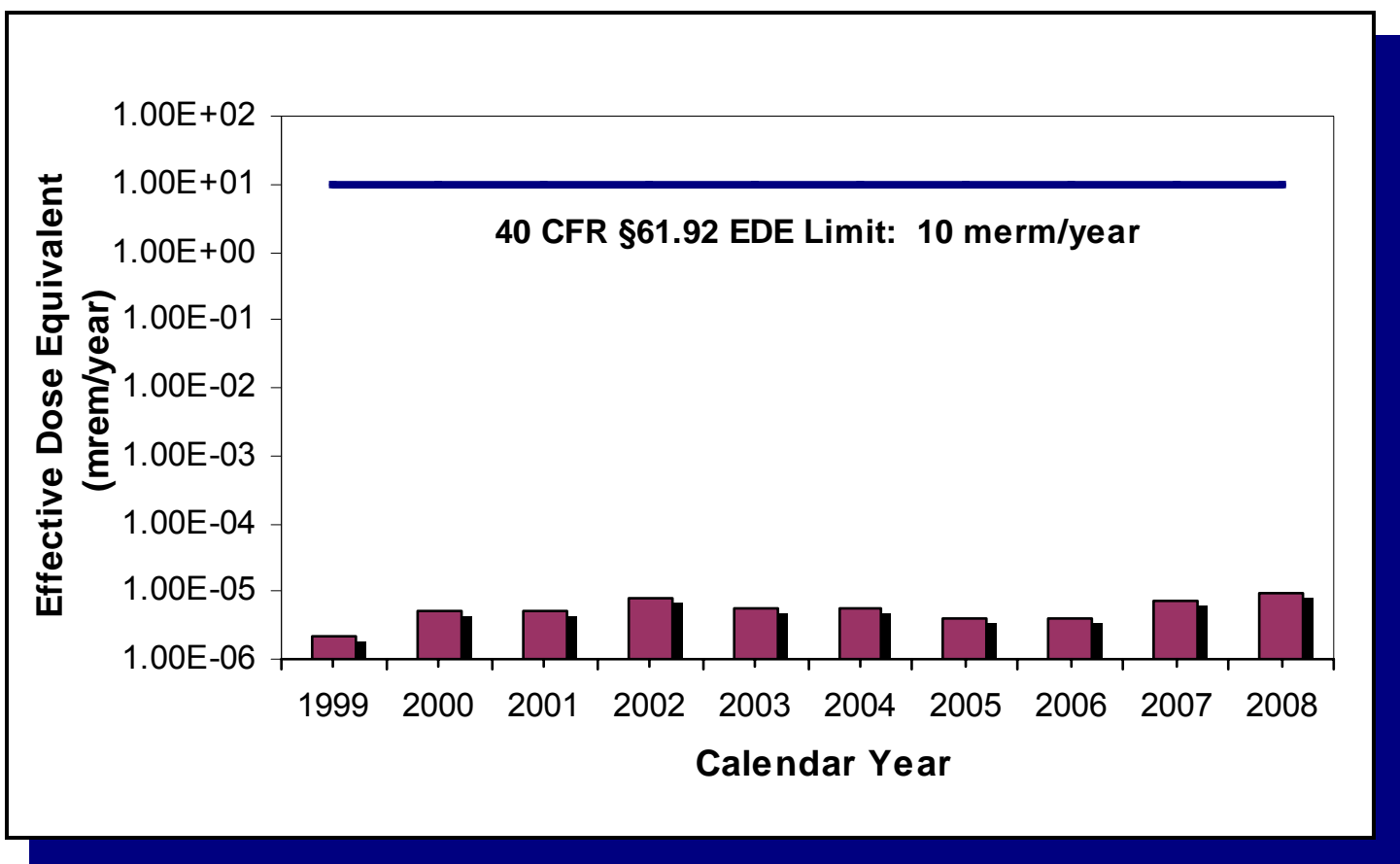

Figure 4.7 - WIPP EDE to the Off-Site MEI

Table 4.27 - Comparison of EDEs to EPA Limit of $10 \mathrm{mrem} /$ Year per 40 CFR $\$ 61.92$

\begin{tabular}{|c|c|c|}
\hline Year & Annual Dose (mrem/yr) & Percent of EPA Limit \\
\hline 1999 & $2.23 \mathrm{E}-06$ & 0.000022 \\
\hline 2000 & $5.18 \mathrm{E}-06$ & 0.000051 \\
\hline 2001 & $4.96 \mathrm{E}-06$ & 0.000050 \\
\hline 2002 & $7.61 \mathrm{E}-06$ & 0.000076 \\
\hline 2003 & $5.43 \mathrm{E}-06$ & 0.000054 \\
\hline 2004 & $5.69 \mathrm{E}-06$ & 0.000057 \\
\hline 2005 & $3.85 \mathrm{E}-06$ & 0.000039 \\
\hline 2006 & $3.93 \mathrm{E}-06$ & 0.000039 \\
\hline 2007 & $7.01 \mathrm{E}-06$ & 0.000070 \\
\hline 2008 & $9.05 \mathrm{E}-06$ & 0.000091 \\
\hline
\end{tabular}

\section{Environmental Monitoring}

Radionuclide concentrations observed in environmental monitoring were extremely small and comparable to radiological baseline levels. Appendix $\mathrm{H}$ contains graphs comparing detected radionuclide concentrations to their respective baseline values. In cases where the radionuclide concentrations slightly exceeded baseline levels (uranium isotopes and ${ }^{40} \mathrm{~K}$ in some samples), these differences are most likely due to natural spatial variability, and they are so far below the regulatory limit as to be nonimpactive. 


\section{CHAPTER 5 - ENVIRONMENTAL NONRADIOLOGICAL PROGRAM INFORMATION}

Nonradiological programs at the WIPP facility include land management, meteorological monitoring, VOC monitoring, hydrogen and methane monitoring, seismic monitoring, certain aspects of liquid effluent, and groundwater monitoring. The monitoring is performed to comply with the provisions of the WIPP HWFP. Surface water monitoring is performed in accordance with DP-831. Radiological and nonradiological groundwater monitoring is discussed in Chapters 4 and 6, respectively.

\subsection{Principal Functions of Nonradiological Sampling}

The principal functions of the nonradiological environmental surveillance program are to:

- $\quad$ Assess the impacts of WIPP facility operations on the surrounding ecosystem.

- $\quad$ Monitor ecological conditions in the Los Medaños region.

- $\quad$ Provide environmental data which are important to the mission of the WIPP project, but which have not or will not be acquired by other programs.

- $\quad$ Comply with applicable commitments (e.g., BLM/DOE Memorandum of Understanding and Interagency Agreements).

\subsection{Land Management Programs}

On October 30, 1992, the WIPP LWA was approved by Congress. This act transferred the responsibility for the management of the WIPP Land Withdrawal Area from the Secretary of the Interior to the Secretary of Energy. In accordance with Sections 3(a)(1) and (3) of the Act, these lands:

. . . are withdrawn from all forms of entry, appropriation, and disposal under the public land laws ... are reserved for the use of the Secretary ... for the construction, experimentation, operation, repair and maintenance, disposal, shutdown, monitoring, decommissioning, and other authorized activities associated with the purposes of WIPP as set forth in Section 213 of the Department of Energy National Security and Military Application of the Nuclear Energy Authorization Act of 1980 (Pub. L. 96-164; 93 Stat. 1259, 1265), and this Act.

The DOE developed the LMP as required by Section 4 of the WIPP LWA. The LMP identifies resource values, promotes multiple-use management, and identifies long-term goals for the management of WIPP lands until the culmination of the decommissioning phase. The LMP was developed in consultation and cooperation with the BLM and the state of New Mexico.

The LMP sets forth cooperative arrangements and protocols for addressing WIPP-related land management actions. Commitments contained in current permits, 
agreements, or concurrent Memoranda of Understanding with other agencies will be respected when addressing and evaluating land use management activities and future amendments that affect the management of WIPP lands.

\subsubsection{Land Use Requests}

Parties who wish to conduct activities that may impact lands under the jurisdiction of the DOE, but outside the Property Protection Area, are required by the LMP to prepare a land use request. A land use request consists of a narrative description of the project, a completed environmental review, and a map depicting the location of the proposed activity. This documentation is used to determine if applicable regulatory requirements have been met prior to the approval of a proposed project. A land use request may be submitted to the Land Use Coordinator by any organization wishing to complete any construction, right-of-way, pipeline easement, or similar action within the WIPP Land Withdrawal Area or on lands used in the operation of the WIPP facility, under the jurisdiction of the DOE. In 2008, three land use requests were submitted to, and approved by, the Land Use Coordinator.

\subsubsection{Wildlife Population Monitoring}

In 1995, the USFWS provided an updated list of threatened and endangered species for Eddy and Lea Counties, New Mexico. Included were 18 species that may be present on DOE lands. A comprehensive evaluation in support of the SEIS-II (Waste Isolation Pilot Plant Disposal Phase Final Supplemental Environmental Impact Statement, DOE/EIS-0026-S-2) was conducted in 1996 to determine the presence or absence of threatened or endangered species in the vicinity of the WIPP site and the effect of WIPP facility operations on these species. Results indicated that activities associated with the operation of the WIPP facility had no impact on any threatened or endangered species.

Employees of the WIPP facility continue to consider resident species when planning activities that may impact their habitat, in accordance with the DOE/BLM MOU, the Joint Powers Agreement with the state of New Mexico, and 50 CFR Part 17, "Endangered and Threatened Plants and Wildlife." An example of this is protection is the Lesser Prairie Chicken (a candidate for listing under the Endangered Species Act) and its habitat in accordance with BLM guidance. Favorable habitat for the Lesser Prairie Chicken has been observed within the WIPP Land Withdrawal Area and areas affected by WIPP operational activities.

\subsubsection{Reclamation of Disturbed Lands}

Reclamation serves to mitigate the effects of WIPP-related activities on affected plant and animal communities. The objective of the reclamation program is to restore lands used in the operation of the WIPP facility that are no longer needed for those activities. Reclamation is intended to reduce soil erosion, increase the rate of plant colonization and succession, and provide habitat for wildlife in disturbed areas. 
The DOE follows a reclamation program and a long-range reclamation plan in accordance with the LMP and specified permit conditions. As locations are identified for reclamation, WIPP personnel reclaim these areas by using the best acceptable reclamation practices. Seed mixes used reflect those species indigenous to the area, with priority given to those plant species which are conducive to soil stabilization, wildlife, and livestock needs. Additionally, special seed mixes identified by the BLM are used where necessary to preserve the habitat of the Lesser Prairie Chicken.

\subsubsection{Oil and Gas Surveillance}

Oil and gas activities within $1.6 \mathrm{~km}(1 \mathrm{mi})$ of the WIPP site boundary are routinely monitored in accordance with the LMP to identify new activities associated with oil and gas exploration and production, including:

$\begin{array}{ll}\text { - } & \text { Survey staking } \\ \text { - } & \text { Geophysical exploration } \\ \text { - } & \text { Pipeline construction } \\ \text { - } & \text { Changes in well status } \\ & \text { Anomalous occurrences (e.g., leaks, spills, accidents) }\end{array}$

During 2008, WIPP surveillance teams conducted weekly surveillances and field inspections.

Proposed new well locations, staked within one mile of the WIPP site, are field-verified. This ensures that the proposed location is of sufficient distance from the WIPP boundary to protect the WIPP site from potential trespass. One new well was drilled and completed in 2008. If a well is within $330 \mathrm{ft}$ of the WIPP site boundary, the driller is required to submit daily deviation surveys to the WIPP Land Use Coordinator to assess the horizontal drift of the well bore during drilling. Deviation calculations showed that there were no trespass conditions.

\subsection{Meteorological Monitoring}

The WIPP facility meteorological station is located $600 \mathrm{~m}(1,970 \mathrm{ft})$ northeast of the Waste Handling Building. The main function of the station is to provide data for atmospheric dispersion modeling. The station measures and records wind speed, wind direction, and temperature at elevations of 2,10 , and $50 \mathrm{~m}(6.5,33$, and $165 \mathrm{ft})$.

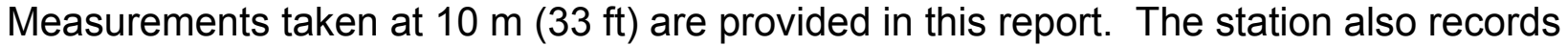
ground-level measurements of barometric pressure, relative humidity, precipitation, and solar radiation. 


\subsubsection{Climatic Data}

The precipitation at the WIPP site for 2008 was $294.6 \mathrm{~mm}$ (11.6 in.). Figure 5.1 displays the monthly precipitation at the WIPP site. Snow at the WIPP site was minimal in 2008.

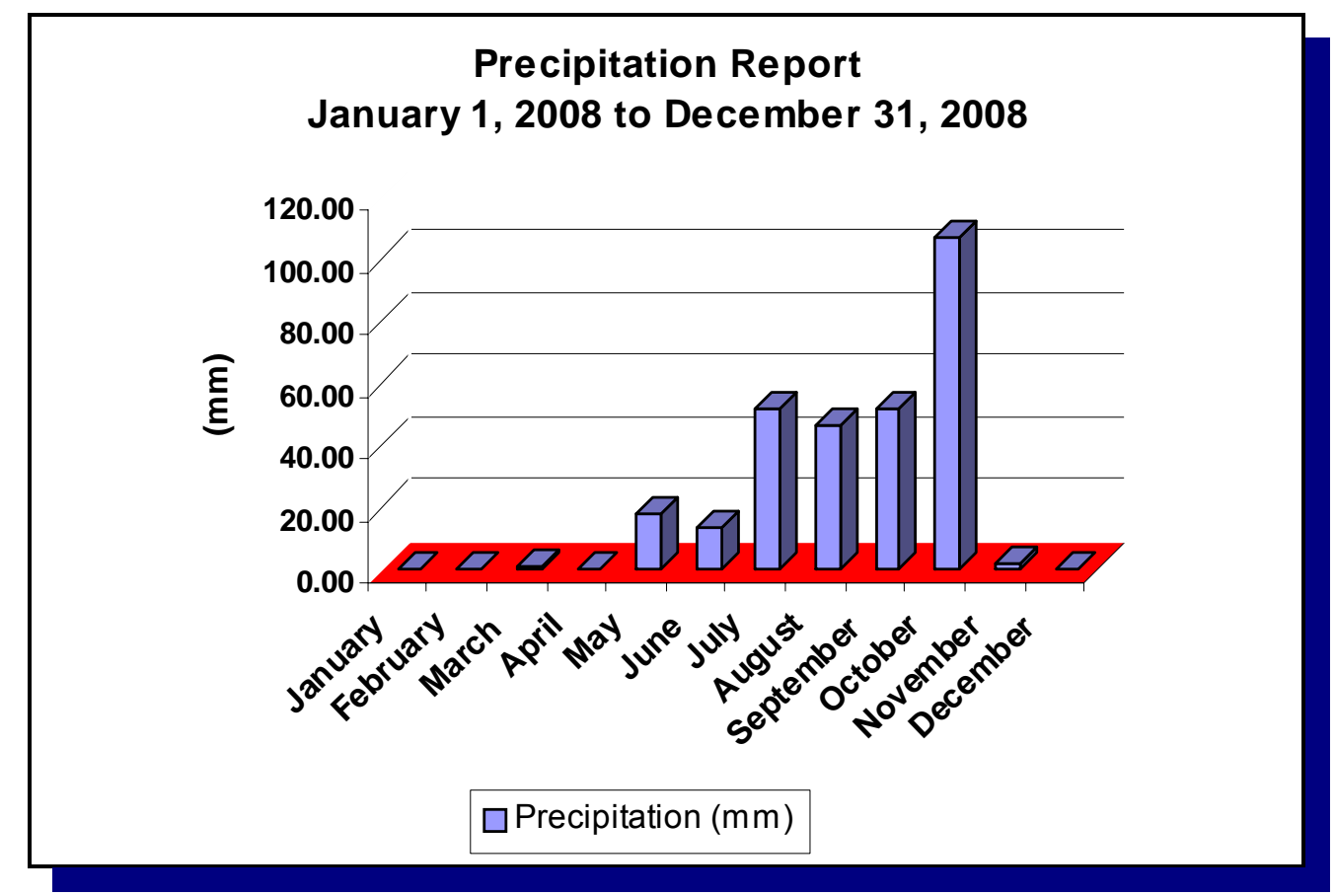

Figure 5.1 - WIPP Precipitation Report for 2008

The maximum recorded temperature at the WIPP site in 2008 was $40.56^{\circ} \mathrm{C}\left(105.0^{\circ} \mathrm{F}\right)$ in June (Figure 5.2). Monthly temperatures are illustrated in Figures 5.2, 5.3, and 5.4. The mean temperature at the WIPP site in 2008 was $17.7^{\circ} \mathrm{C}\left(63.9^{\circ} \mathrm{F}\right)$. The mean monthly temperatures for the WIPP area ranged from $28.3^{\circ} \mathrm{C}\left(83^{\circ} \mathrm{F}\right)$ during June to $6.5^{\circ} \mathrm{C}\left(43.7^{\circ} \mathrm{F}\right)$ in January (Figure 5.3). The lowest recorded temperature was $-8.57^{\circ} \mathrm{C}$ $\left(16.6^{\circ} \mathrm{F}\right)$ in January (Figure 5.4). 


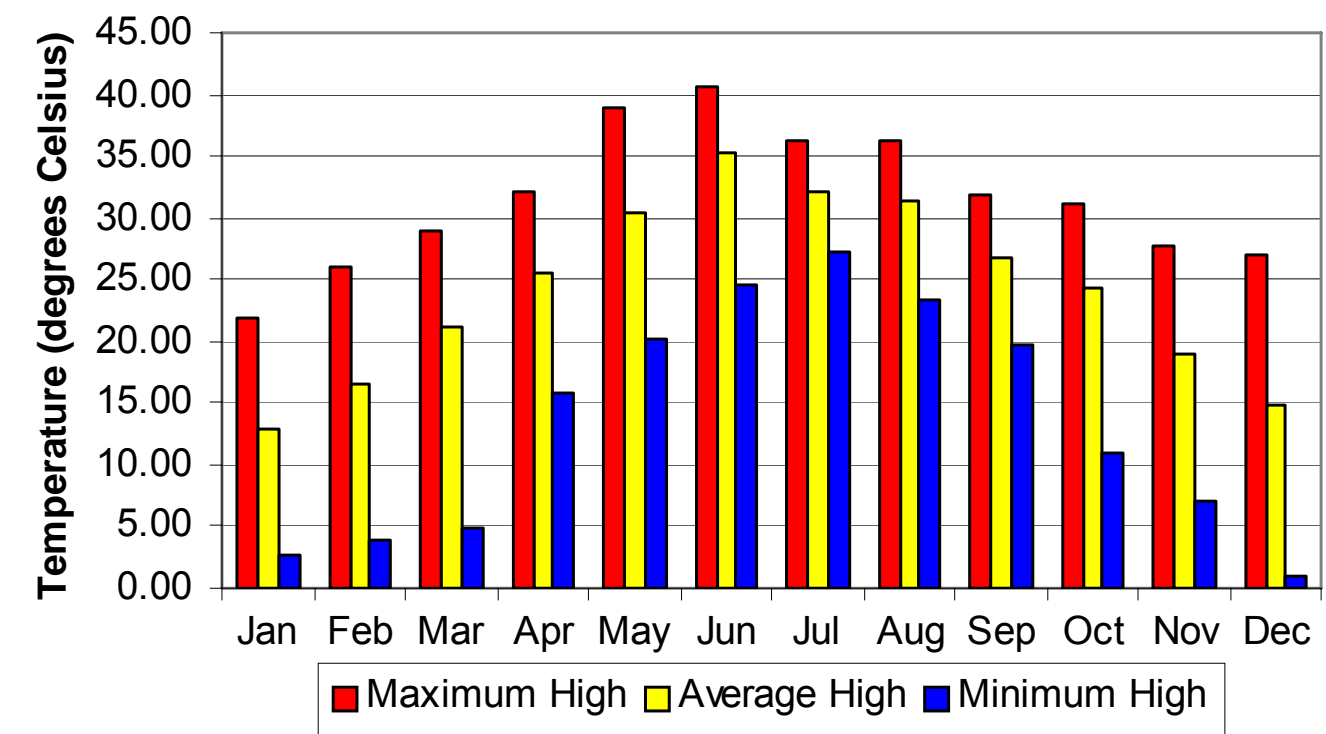

Figure 5.2 - WIPP High Temperatures for 2008

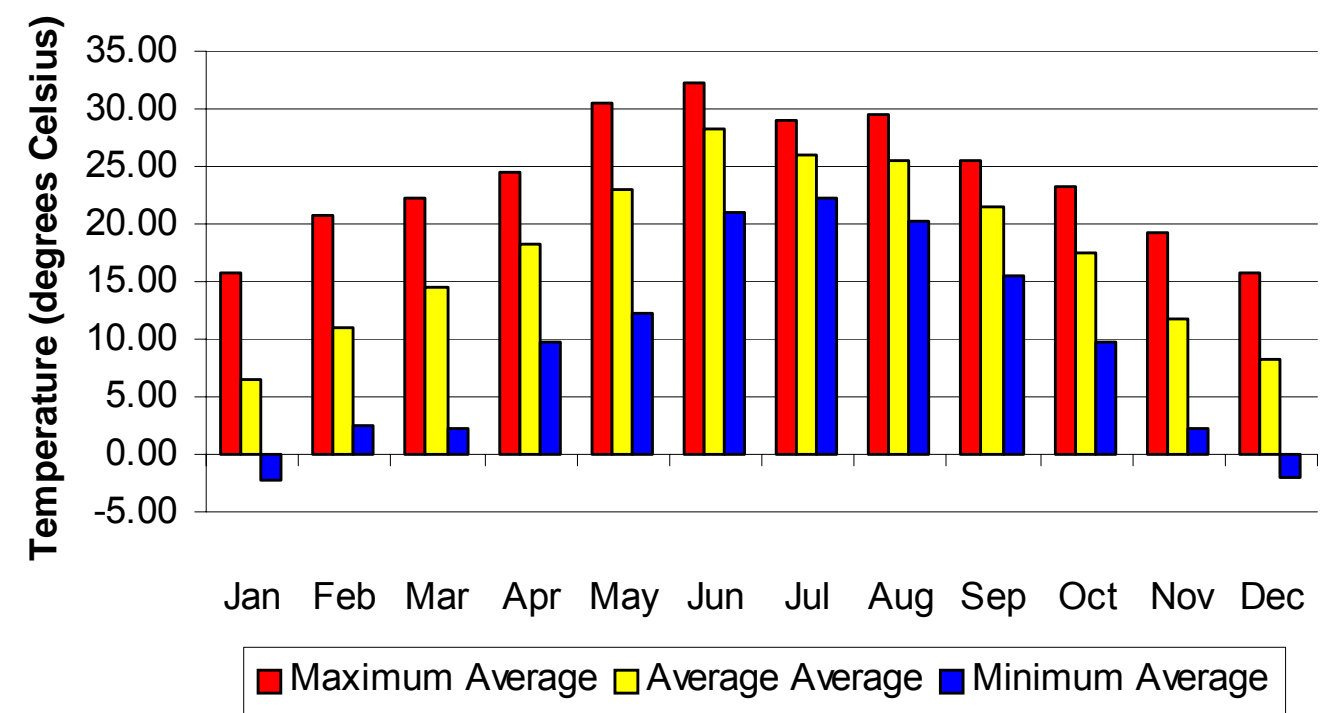

Figure 5.3 - WIPP Average Temperatures for 2008 


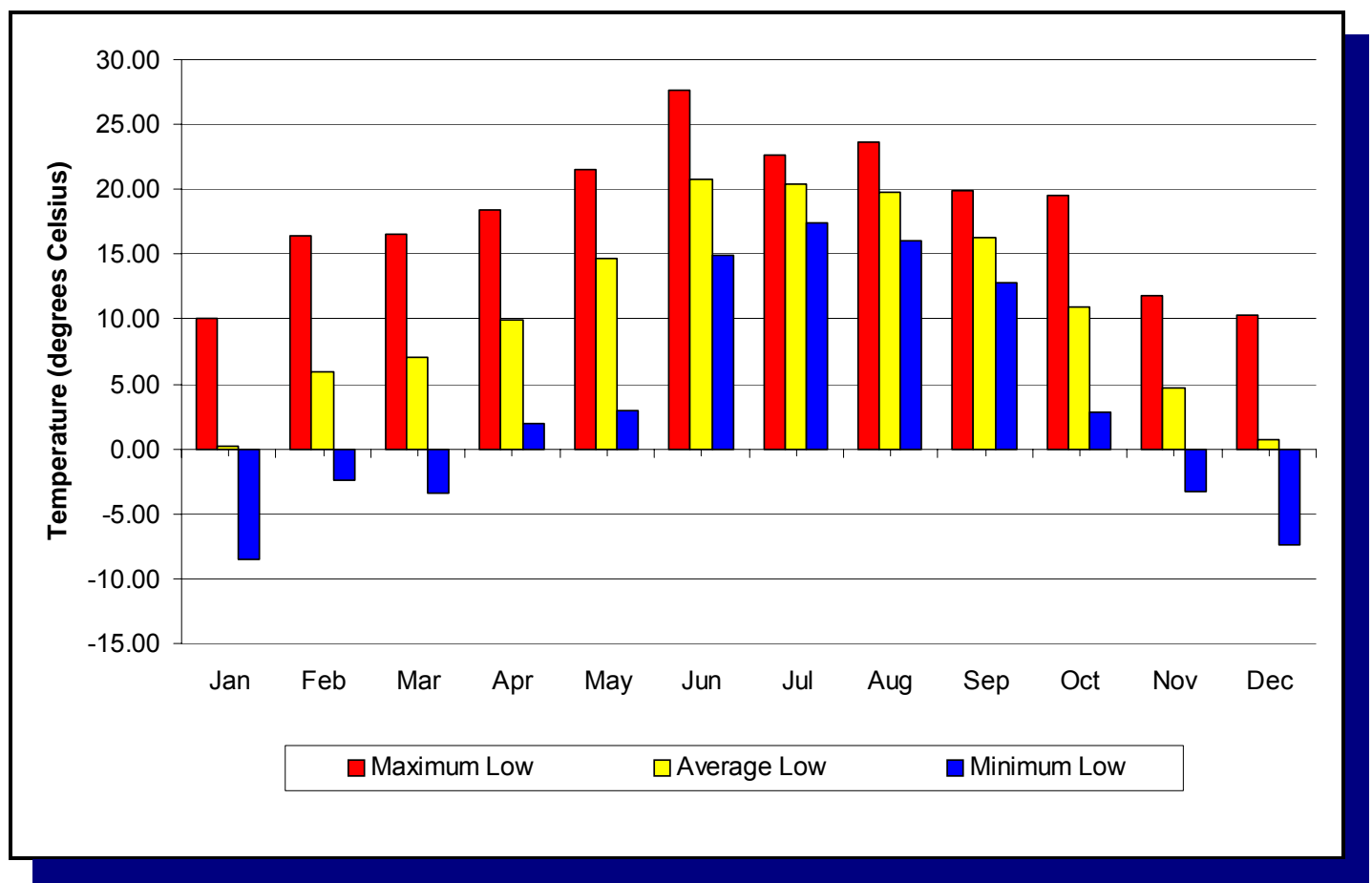

Figure 5.4 - WIPP Average Low Temperatures for 2008

\subsubsection{Wind Direction and Wind Speed}

Winds in the WIPP area are predominantly from the southeast. In 2008, wind speed measured at the $10-\mathrm{m}$ (33-ft) level was calm (less than 0.5 meters per second $[\mathrm{m} / \mathrm{s}]$ ) (1.1 miles per hour [mph]) approximately 0.6 percent of the time. Winds of 3.71 to $6.30 \mathrm{~m} / \mathrm{s}$ (8.30 to $14.09 \mathrm{mph}$ ) were the most prevalent over 2008, occurring approximately 36 percent of the time. There were no tornadoes at the WIPP site in 2008; the strongest wind recorded at WIPP was $19.18 \mathrm{~m} / \mathrm{s}(42.9 \mathrm{mph})$. Figure 5.5 displays the annual wind data at WIPP for 2008. 

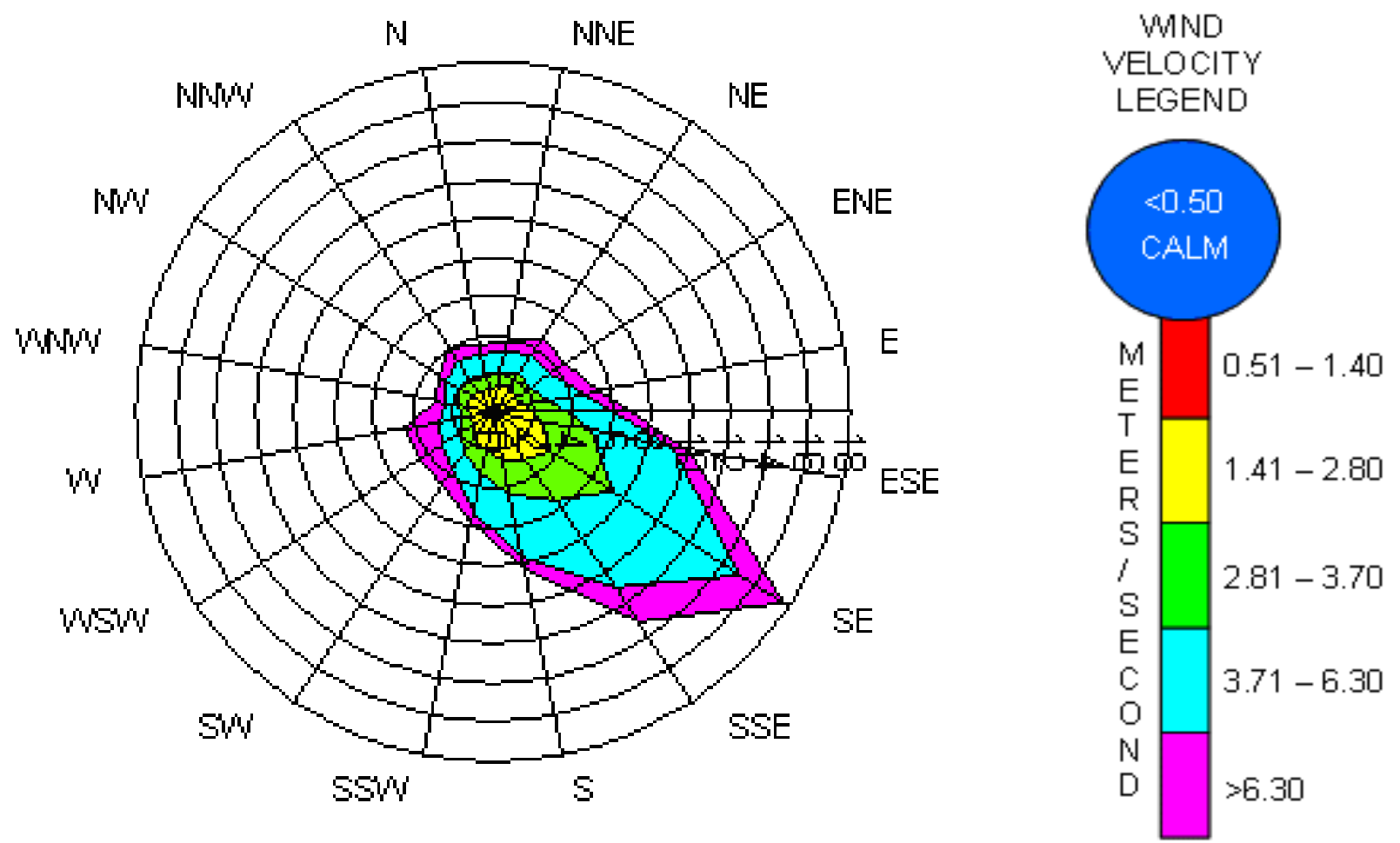

Figure 5.5 - Wind Speed Report for 2008

Wind Speed Report (Meters/Second)

January 1, 2008, to December 31, 2008 - Elevation 10.0 Meters

\begin{tabular}{|c|c|c|c|c|c|c|c|}
\hline $\begin{array}{l}\text { Wind } \\
\text { Direction }\end{array}$ & $0.0-0.50$ & $0.51-1.40$ & $1.41-2.80$ & $2.81-3.70$ & $3.71-6.30$ & $>6.30$ & $\begin{array}{c}\text { Total Percent Occurrence } \\
\text { by Direction }\end{array}$ \\
\hline$E$ & 0.03 & 0.37 & 1.28 & 1.20 & 1.82 & 0.77 & 5.46 \\
\hline ENE & 0.04 & 0.32 & 1.07 & 0.83 & 1.28 & 0.84 & 4.37 \\
\hline NE & 0.05 & 0.40 & 1.14 & 0.82 & 1.11 & 0.95 & 4.48 \\
\hline NNE & 0.03 & 0.31 & 1.02 & 0.72 & 1.08 & 0.51 & 3.65 \\
\hline $\mathrm{N}$ & 0.03 & 0.27 & 0.94 & 0.66 & 1.16 & 0.50 & 3.55 \\
\hline NNW & 0.03 & 0.25 & 0.89 & 0.73 & 1.36 & 0.70 & 3.96 \\
\hline NW & 0.03 & 0.32 & 1.08 & 0.61 & 0.78 & 0.38 & 3.21 \\
\hline WNW & 0.04 & 0.35 & 0.97 & 0.39 & 0.73 & 0.47 & 2.95 \\
\hline W & 0.03 & 0.30 & 0.76 & 0.47 & 1.13 & 1.89 & 4.58 \\
\hline WSW & 0.03 & 0.26 & 0.92 & 0.64 & 1.24 & 1.38 & 4.46 \\
\hline SW & 0.05 & 0.28 & 1.31 & 0.92 & 1.10 & 0.81 & 4.46 \\
\hline SSW & 0.03 & 0.35 & 1.63 & 1.18 & 2.15 & 0.51 & 5.84 \\
\hline $\mathrm{S}$ & 0.05 & 0.46 & 2.01 & 1.73 & 3.39 & 0.63 & 8.27 \\
\hline SSE & 0.05 & 0.42 & 2.50 & 2.60 & 5.42 & 2.02 & 13.01 \\
\hline SE & 0.02 & 0.49 & 2.96 & 3.87 & 7.75 & 2.56 & 17.65 \\
\hline \multirow[t]{2}{*}{ ESE } & 0.02 & 0.51 & 2.02 & 2.40 & 4.29 & 0.85 & 10.10 \\
\hline & $0.56 \%$ & $5.64 \%$ & $22.51 \%$ & $19.75 \%$ & $35.80 \%$ & $15.75 \%$ & $100.00 \%$ \\
\hline
\end{tabular}




\subsection{Volatile Organic Compound Monitoring}

VOC monitoring was implemented on April 21, 1997, in accordance with WP 12-VC.01, Confirmatory Volatile Organic Compound Monitoring Program. This program is a requirement of the Permit. VOC monitoring is performed to verify that VOCs emitted by the waste are within the concentration limits specified by the Permit.

Nine target compounds, which contribute approximately 99 percent of the calculated human health risks from RCRA constituents, were chosen for monitoring. These target compounds are shown in Table 5.1.

On November 16, 2006, additional Permit conditions were implemented requiring the addition of disposal room VOC monitoring to the program. This new requirement included the addition of sampling locations within active hazardous waste facility units. Within each active unit, two sampling locations are required for each filled room, one at the exhaust side of the room and one at the inlet side of the room. In addition, each room actively receiving waste is required to be sampled at the exhaust side of the room. The sampling frequency for disposal room sampling is once every two weeks. Typical disposal room VOC sampling locations are shown in Figure 5.6.

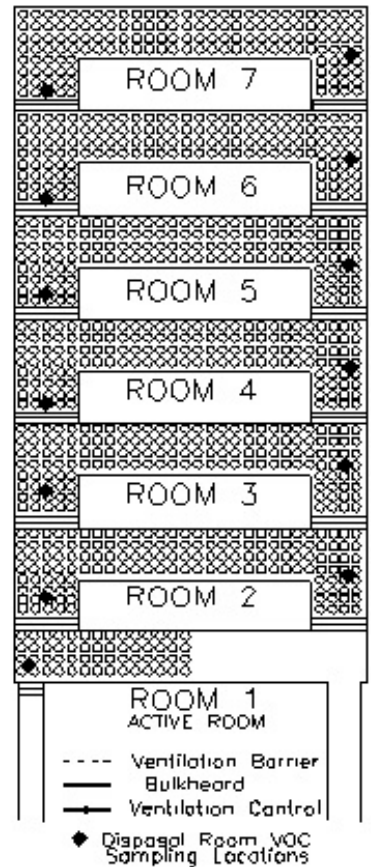

Figure 5.6 - Typical Disposal Room VOC Sampling Locations

For Panel 3, sampling locations included two locations in Rooms 7 through 2 and one location at the exhaust side of Room 1. Sampling in Panel 4 included two locations in Rooms 7 through 3 and one location at the exhaust side of both Rooms 2 and 1 . 
On March 25, 2008, new permit conditions were added requiring ongoing disposal room VOC monitoring in "filled" panels (panels in which waste emplacement is complete), thus reducing the number of VOC sampling locations in Panel 3 . Ongoing disposal room VOC monitoring included the continued monitoring of VOCs in Room 1 of the filled panel. The sampling frequency for ongoing disposal room monitoring is once per month. For 2008, ongoing disposal room monitoring was conducted in Panel 3.

Repository VOC sampling for target compounds is performed semiweekly at two ambient air monitoring stations. The stations are identified as VOC-A, located downstream from hazardous waste disposal unit Panel 1 in Drift E300, and VOC-B, located upstream from the active panel. As waste is placed in new panels, VOC-B will be relocated to ensure that it samples underground air before it passes the waste panels. The location of VOC-A is not anticipated to change.

Target compounds found in VOC-B are not attributable to open or closed panels. The VOC concentrations measured at this location are VOCs entering the mine through the air intake shaft and VOCs contributed by facility operations upstream of the waste panels. Differences measured between the two stations represent any VOC contributions from the waste panels. Any positive concentration differences in the annual averages between the two stations must be less than the concentrations of concern listed in the HWFP (Table 5.1).

Table 5.1 - Concentrations of Concern for Volatile Organic Compounds, From Module IV of the Permit (No. NM4890139088-TSDF)

\begin{tabular}{lcc}
\hline \multicolumn{1}{c}{ Compound } & $\begin{array}{c}\text { Concentration of } \\
\text { Concern ppbv }^{\mathbf{a}}\end{array}$ & $\begin{array}{c}\text { Room Based Limits } \\
\text { ppmv }^{\mathbf{b}}\end{array}$ \\
\hline 1,1,1-Trichloroethane & 590 & 33,700 \\
1,1,2,2-Tetrachloroethane & 50 & 2,960 \\
1,1-Dichloroethylene & 100 & 5,490 \\
1,2-Dichloroethane & 45 & 2,400 \\
Carbon tetrachloride & 165 & 9,625 \\
Chlorobenzene & 220 & 13,000 \\
Chloroform & 180 & 9,930 \\
Methylene chloride & 1,930 & 100,000 \\
Toluene & 190 & 11,000 \\
\hline
\end{tabular}

${ }^{a}$ Parts per billion by volume

${ }^{\mathrm{b}}$ Parts per million by volume

VOC sampling reported in this section was performed using guidance included in Compendium Method TO-15, Determination of Volatile Organic Compounds (VOCs) in Air Collected in Specially-Prepared Canisters and Analysis By Gas Chromatography/ Mass Spectrometry (GC/MS) (EPA, 1999), as a basis. The samples were analyzed using gas chromatography/mass spectrometry under an established QA/QC program. Laboratory analytical procedures were developed based on the concepts contained in both TO-15 and the draft EPA Contract Laboratory Program Volatile Organics Analysis of Ambient Air in Canisters (EPA, 1994). 
For repository VOC sampling, the routine method reporting limits (MRLs) and maximum concentrations detected (MCDs) are shown in Table 5.2. It should be noted that the MRLs are between 20 times and 386 times lower than the respective concentrations of concern for the nine target compounds.

The results of 2008 repository VOC monitoring, compared to 2007, indicated an increase in the maximum and average concentration of each detected target compound in air downstream of Panel 1. Although the sample results for 2008 showed an overall increase in the concentration of detections, the annual average for repository VOC sample results were well below the concentrations of concern listed in Table 5.1.

\begin{tabular}{|lccc}
\hline \multicolumn{1}{c}{ Table 5.2 - Repository Air VOC MRLs and MCDs } \\
\hline Compound & $\begin{array}{c}\text { MRL } \\
\text { (ppbv) }\end{array}$ & $\begin{array}{c}\text { Annual } \\
\text { Average } \\
\text { (ppbv) }\end{array}$ & $\begin{array}{c}\text { MCD } \\
\text { (ppbv) }\end{array}$ \\
\hline 1,1,1-Trichloroethane & 5 & 19 & 105.55 \\
1,1,2,2-Tetrachloroethane & 2 & $<\mathrm{MRL}$ & $<\mathrm{MRL}$ \\
1,1-Dichloroethylene & 5 & $<\mathrm{MRL}$ & $<\mathrm{MRL}$ \\
1,2-Dichloroethane & 2 & $<\mathrm{MRL}$ & $<\mathrm{MRL}$ \\
Carbon Tetrachloride & 2 & 38.9 & 315.06 \\
Chlorobenzene & 2 & $<\mathrm{MRL}$ & $<\mathrm{MRL}$ \\
Chloroform & 2 & $<\mathrm{MRL}$ & 15.72 \\
Methylene chloride & 5 & $<\mathrm{MRL}$ & 27.89 \\
Toluene & 5 & $<\mathrm{MRL}$ & $<\mathrm{MRL}$ \\
\hline
\end{tabular}

For disposal room VOC monitoring, 393 samples were collected during 2008 (including field duplicates). The routine MRLs and MCDs are shown in Table 5.3. Four of the nine target compounds were detected above the MRL. The sample results indicated an increase in maximum concentrations detected in disposal rooms for chloroform at $0.8 \mathrm{ppmv}$ (less than 0.01 percent of room-based limits [RBL]), and methylene chloride at $6.2 \mathrm{ppmv}$ (less than 0.01 percent of RBL). The sample results showed a decrease in maximum concentrations detected for 1,1,1-trichloroethane at $15.7 \mathrm{ppmv}(0.05$ percent of RBLs shown in Table 5.1), and carbon tetrachloride at 21.8 ppmv (0.23 percent of $\mathrm{RBL})$. 


\begin{tabular}{lcc}
\hline \multicolumn{3}{c}{ Table 5.3 - Disposal Room VOC MRLs and MCDs } \\
\hline \multicolumn{1}{c}{ Compound } & $\begin{array}{c}\text { MRL } \\
(\mathbf{p p m v})^{*}\end{array}$ & $\begin{array}{c}\text { MCD } \\
(\mathbf{p p m v})^{*}\end{array}$ \\
\hline 1,1,1-Trichloroethane & 0.5 & 15.7 \\
1,1,2,2-Tetrachloroethane & 0.5 & $<\mathrm{MRL}$ \\
1,1-Dichloroethylene & 0.5 & $<\mathrm{MRL}$ \\
1,2-Dichloroethane & 0.5 & $<\mathrm{MRL}$ \\
Carbon Tetrachloride & 0.5 & 21.8 \\
Chlorobenzene & 0.5 & $<\mathrm{MRL}$ \\
Chloroform & 0.5 & 0.8 \\
Methylene chloride & 0.5 & 6.2 \\
Toluene & 0.5 & $<\mathrm{MRL}$ \\
\hline
\end{tabular}

* ppmv = parts per million by volume

\subsection{Hydrogen and Methane Monitoring}

Hydrogen and methane monitoring in "filled" Panels 3 through 7 was included as new permit conditions on March 25, 2008. Hydrogen and methane are required to be monitored at two locations in each room and at four additional bulkhead locations in the panel area upon the completion of waste emplacement in each panel. Monitoring is required for each location on a monthly basis. In April of 2008, this permit condition was implemented. For 2008, hydrogen and methane monitoring was conducted in Panel 3.

Hydrogen and methane samples are analyzed using gas chromatography with thermal conductivity detection under an established QA/QC program. Specialized laboratory analytical procedures were developed based on standard laboratory techniques and approved through established QA processes.

A total of 149 samples were collected between April 1, 2008, and December 31, 2008. Out of the 149 samples, 80 yielded hydrogen detections with only 14 detections over the MRL. The maximum detected value of $353 \mathrm{ppmv}$ was considerably lower than the action levels (less than 9 percent of Action Level 1 and less than 4.5 percent of Action Level 2 shown in Table 5.4). None of the samples contained methane. 
Waste Isolation Pilot Plant Annual Site Environmental Report for 2008 DOE/WIPP-09-2225

\begin{tabular}{lcrrrrr}
\hline \multicolumn{1}{c}{ Table 5.4 - Hydrogen and Methane MRLs Action Levels and MCDs } & \\
\hline & Compound & $\begin{array}{c}\text { MRL } \\
(\mathbf{p p m v}) *\end{array}$ & $\begin{array}{c}\text { Action } \\
\text { Level 1 }\end{array}$ & $\begin{array}{c}\text { Action } \\
\text { Level 2 }\end{array}$ & $\begin{array}{c}\text { MCD } \\
(\mathbf{p p m v})\end{array}$ \\
\hline Hydrogen & 0.5 & 4,000 & 8,000 & 353 \\
\hline Methane & & 0.5 & 5,000 & 10,000 & N/A \\
\hline
\end{tabular}

${ }^{*}$ ppmv $=$ parts per million by volume

\subsection{Seismic Activity}

Currently, seismicity within $300 \mathrm{~km}$ (186 mi) of the WIPP site is being monitored by the New Mexico Institute of Mining and Technology (NMIMT) using data from a nine-station network approximately centered on the site (Figure 5.7). Station signals are transmitted to the NMIMT Seismological Observatory in Socorro. When appropriate, readings from the WIPP network stations are combined with readings from an additional NMIMT network in the central Rio Grande Rift. Occasionally, data are also exchanged with the University of Texas at El Paso and Texas Tech University in Lubbock, both of which operate stations in West Texas.

The mean operational efficiency of the WIPP seismic monitoring stations during 2008 was approximately 84.9 percent. From January 1 through December 31, 2008, locations for 45 seismic events were recorded within $300 \mathrm{~km}$ (186 mi) of WIPP. These data included origin times, epicenter coordinates, and magnitudes. The strongest recorded event (magnitude 2.6) occurred on July 15, 2008, and was located approximately $278 \mathrm{~km}(173 \mathrm{mi})$ east of the site. The closest event to the site was located approximately $20 \mathrm{~km}(12 \mathrm{mi})$ west and had a magnitude of -0.6 . These events had no effect on WIPP structures. 


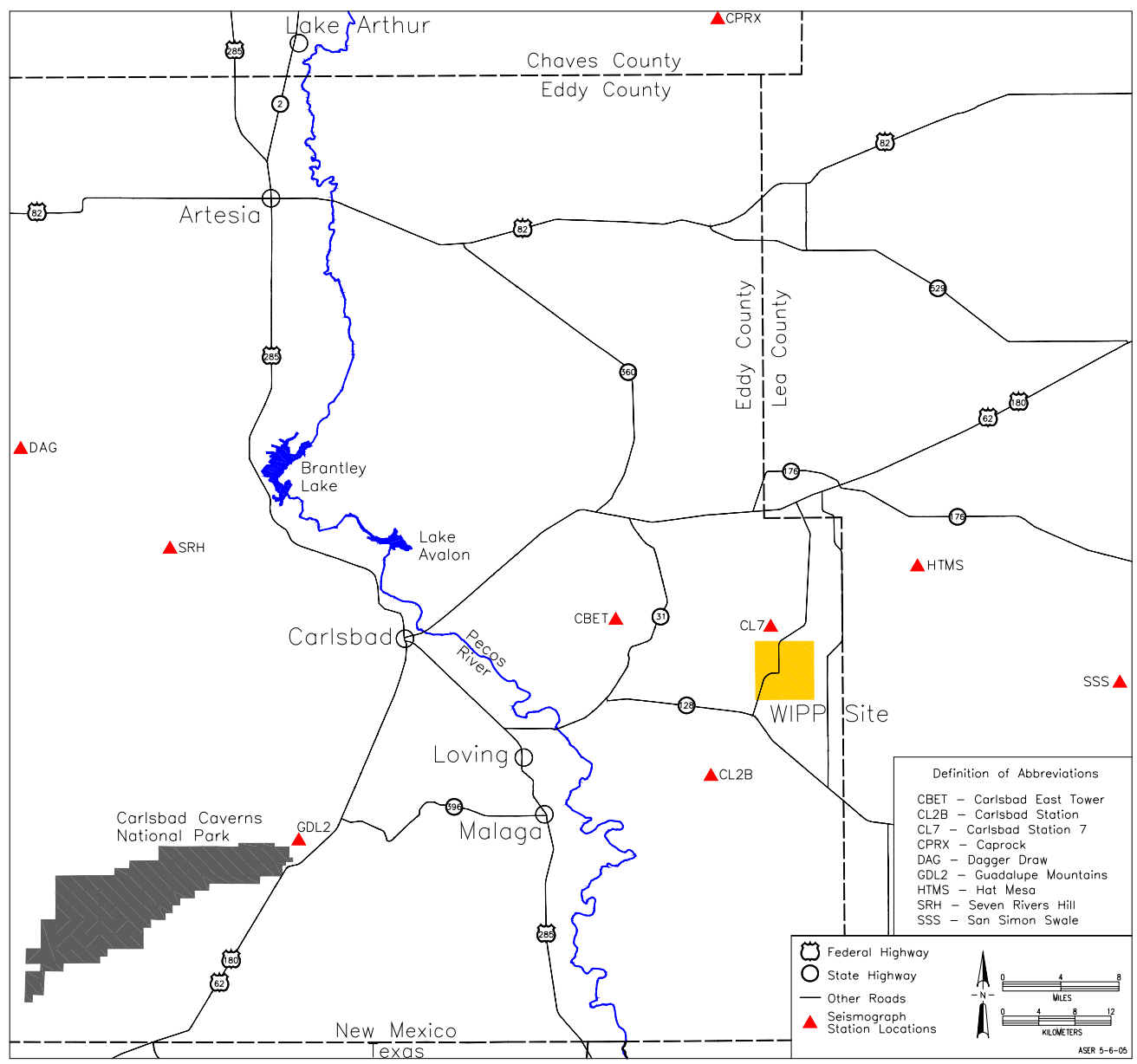

Figure 5.7 - Seismograph Station Locations in the Vicinity of the WIPP Site

\subsection{Liquid Effluent Monitoring}

The NMED Ground and Surface Water Protection regulations set forth in 20.6.2 NMAC regulate discharges that could impact surface water or groundwater. DOE compliance with the Ground and Surface Water Protection Regulations is discussed in Chapter 2, Section 2.6. The WIPP site has no discharges that could impact surface water. The WIPP facility does have DP-831 (a discharge permit) for discharges to the facultative sewage lagoon system and the $\mathrm{H}-19$ Evaporation Pond, and for the control of rainwater infiltration from active and inactive salt piles.

The WIPP facility facultative sewage system consists of lined ponds that allow for the evaporation of liquids. The sewage treatment facility is permitted for the disposal of up to $87,064 \mathrm{~L}(23,000$ gallons) per day of sewage effluent and up to $189,270 \mathrm{~L}$ $(50,000$ gallons $)$ of nonhazardous brine water per day to the north evaporation pond.

The H-19 Evaporation Pond is permitted for the treatment of up to $189,270 \mathrm{~L}$ (50,000 gallons) per day of nonhazardous brine waters from groundwater monitoring and observation wells, mine dewatering and condensate collected from the mine ventilation system. 
A DP-831 modification approved on December 22, 2003, addressed infiltration of rainwater from a 16-acre mine tailings pile accumulated from mining activities. In accordance with the DP-831 modification, a new salt storage area with a 60-mil synthetic liner and an associated double-lined evaporation pond with leak detection was constructed to contain and evaporate rainwater runoff. Additionally, the tailings pile evaporation pond and three storm water evaporation ponds were lined with 60-mil high-density polyethylene liners to collect storm water runoff for evaporation and minimize infiltration. Another discharge permit modification was approved on December 29,2006 , which incorporated the site and preliminary design validation (SPDV) material pile into the discharge permit.

Discharge monitoring reports are submitted semiannually to the NMED to demonstrate compliance with the inspection, monitoring, and reporting requirements identified in DP-831. The permit requires semiannual sampling of the sewage lagoons and the $\mathrm{H}-19$ Evaporation Pond and annual sampling of the storm water infiltration control ponds. There are no regulatory limits associated with the analytes. Detection limits vary with each analytical event based on the required sample dilutions. Analytical data from the discharge monitoring reports are summarized in Tables 5.5 and 5.6, respectively. Note that the discharge permit renewal and modification issued on September 9, 2008 resulted in changes in the required parameters beginning in the July 1 through December 31 discharge monitoring period. Chloride and sulfate were added as analytes for all surface impoundments, and radionuclides were eliminated. Chromium and selenium were removed as analytes from what are commonly known as the infiltration control ponds (Pond A, Pond 1, Pond 2, Salt Pile Evaporation Pond, and Salt Storage Extension Evaporation Basin). Subsurface shallow water monitoring results are outlined in Chapter 6. 
Waste Isolation Pilot Plant Annual Site Environmental Report for 2008 DOE/WIPP-09-2225

Table 5.5 - Sewage Lagoon and H-19 Analytical Results for January Through June 2008

\begin{tabular}{|c|c|c|c|c|c|c|c|c|}
\hline \multirow{2}{*}{$\begin{array}{c}\text { Analyte } \\
\text { Nitrate }(\mathrm{mg} / \mathrm{L})\end{array}$} & \multicolumn{2}{|c|}{$\begin{array}{c}\text { Influent to Facultative } \\
\text { Lagoon System }\end{array}$} & \multicolumn{2}{|c|}{ Evaporation Pond B } & \multicolumn{2}{|c|}{ Evaporation Pond C } & \multicolumn{2}{|c|}{$\begin{array}{l}\text { H-19 Evaporation } \\
\text { Pond }\end{array}$} \\
\hline & $<1.00$ & & $\mathrm{~N} / \mathrm{A}$ & & $N / A^{a}$ & & $\mathrm{~N} / \mathrm{A}$ & \\
\hline $\mathrm{TKN}^{\mathrm{b}}(\mathrm{mg} / \mathrm{L})$ & 70.28 & & $\mathrm{~N} / \mathrm{A}$ & & $\mathrm{N} / \mathrm{A}$ & & $\mathrm{N} / \mathrm{A}$ & \\
\hline \multirow[t]{2}{*}{$\mathrm{TDS}^{\mathrm{c}}(\mathrm{mg} / \mathrm{L})$} & 655 & & 27,800 & & 38,800 & & 364,500 & \\
\hline & Activity & $2 \times T_{P U^{d}}$ & Activity & $2 \times$ TPU & Activity & $2 \times$ TPU & Activity & $2 \times \mathrm{TPU}$ \\
\hline $\mathrm{U}^{233 / 234}(\mathrm{~Bq} / \mathrm{L})^{\mathrm{e}}$ & 6.63E-03 & 2.51E-03 & 8.97E-03 & 2.97E-03 & 1.27E-02 & $5.15 \mathrm{E}-03$ & $N S^{f}$ & NS \\
\hline $\mathrm{U}^{235}(\mathrm{~Bq} / \mathrm{L})$ & 4.51E-04 & 8.55E-04 & 2.29E-04 & 6.49E-04 & 9.95E-04 & 1.94E-03 & NS & NS \\
\hline $\mathrm{U}^{238}(\mathrm{~Bq} / \mathrm{L})$ & 5.37E-03 & $2.21 \mathrm{E}-03$ & $3.22 \mathrm{E}-03$ & 1.81E-03 & $4.41 \mathrm{E}-03$ & 3.09E-03 & NS & NS \\
\hline $\mathrm{Pu}^{238}(\mathrm{~Bq} / \mathrm{L})$ & $-1.54 \mathrm{E}-04$ & 2.47E-04 & $-1.45 \mathrm{E}-04$ & 2.46E-04 & $-2.04 \mathrm{E}-05$ & $4.90 \mathrm{E}-04$ & NS & NS \\
\hline $\mathrm{Pu}^{239 / 240}(\mathrm{~Bq} / \mathrm{L})$ & $-1.30 \mathrm{E}-04$ & 2.27E-04 & 3.62E-04 & 4.60E-04 & $1.22 \mathrm{E}-04$ & 4.15E-04 & NS & NS \\
\hline $\mathrm{Am}^{241}(\mathrm{~Bq} / \mathrm{L})$ & 3.60E-04 & 4.84E-04 & 5.07E-04 & 6.04E-04 & 2.73E-05 & $3.59 E-04$ & NS & NS \\
\hline $\mathrm{Sr}^{90}(\mathrm{~Bq} / \mathrm{L})$ & $-9.49 \mathrm{E}-03$ & 2.85E-02 & $-2.10 \mathrm{E}-02$ & 2.79E-02 & $-7.04 \mathrm{E}-03$ & $3.02 E-02$ & NS & NS \\
\hline
\end{tabular}

${ }^{a} \mathrm{~N} / \mathrm{A}$ - The analytical parameter not required

b Total Kjeldahl Nitrogen (as N)

c Total dissolved solids

d Total propagated uncertainty

e Becquerel per liter

F NS - Not sampled

Table 5.6 - Sewage Lagoon, H-19, and Infiltration Control Pond Analytical Results for July Through December $2008^{\mathrm{a}}$

\begin{tabular}{|l|c|c|c|c|c|}
\hline \multicolumn{1}{|c|}{ Location } & Nitrate $(\mathbf{m g} / \mathbf{l})$ & TKN $^{\mathbf{b}}(\mathbf{m g} / \mathbf{l})$ & TDS $^{\mathbf{~}(\mathbf{m g} / \mathbf{l})}$ & Sulfate (mg/l) & Chloride $(\mathbf{m g} / \mathbf{l})$ \\
\hline Influent Pond 2A & 0.1 & 93.5 & 536 & 61.4 & 103 \\
\hline Evaporation Pond B & N/A & N/A & 95,000 & 4,810 & 49,000 \\
\hline Evaporation Pond C & N/A & N/A & 119,000 & 6,040 & 65,900 \\
\hline H-19 Evaporation Pond & N/A & N/A & 210,000 & 1,210 & 119,000 \\
\hline Salt Pile Evaporation Pond & N/A & N/A & 19,900 & 104 & 11,100 \\
\hline $\begin{array}{l}\text { Salt Storage Extension } \\
\text { Evaporation Basin }\end{array}$ & N/A & N/A & 326,000 & 13,900 & 185,000 \\
\hline Pond 1 & N/A & N/A & 229 & 25.6 & 54.6 \\
\hline Pond 2 & N/A & N/A & 430 & 9.64 & 217 \\
\hline Pond A & N/A & N/A & 234 & 26.4 & 252 \\
\hline
\end{tabular}

September 9, 2008, modification and renewal of DP-381 eliminated radionuclides and added sulfate and chloride

Total Kjeldahl Nitrogen (as N)

Total dissolved solids

N/A - The analytical parameter not required 
Waste Isolation Pilot Plant Annual Site Environmental Report for 2008

DOE/WIPP-09-2225

This page intentionally left blank 


\section{CHAPTER 6 - SITE HYDROLOGY, GROUNDWATER MONITORING, AND PUBLIC DRINKING WATER PROTECTION}

Current groundwater monitoring activities for the WIPP facility are outlined in the WIPP Groundwater Monitoring Program Plan (WP 02-1). In addition, the WIPP facility has detailed procedures for performing specific activities, such as pumping system installations, field parameter analyses and documentation, and QA records management. Groundwater monitoring activities are also included in the Waste Isolation Pilot Plant Environmental Monitoring Plan (DOE/WIPP-99-2194, Rev. 4, 2008).

\subsection{Site Hydrology}

The hydrology at and surrounding the WIPP site has been studied extensively over the last 30 years. A summary of the hydrology in this area is contained in the following sections. Figure 6.1 presents the WIPP stratigraphy.

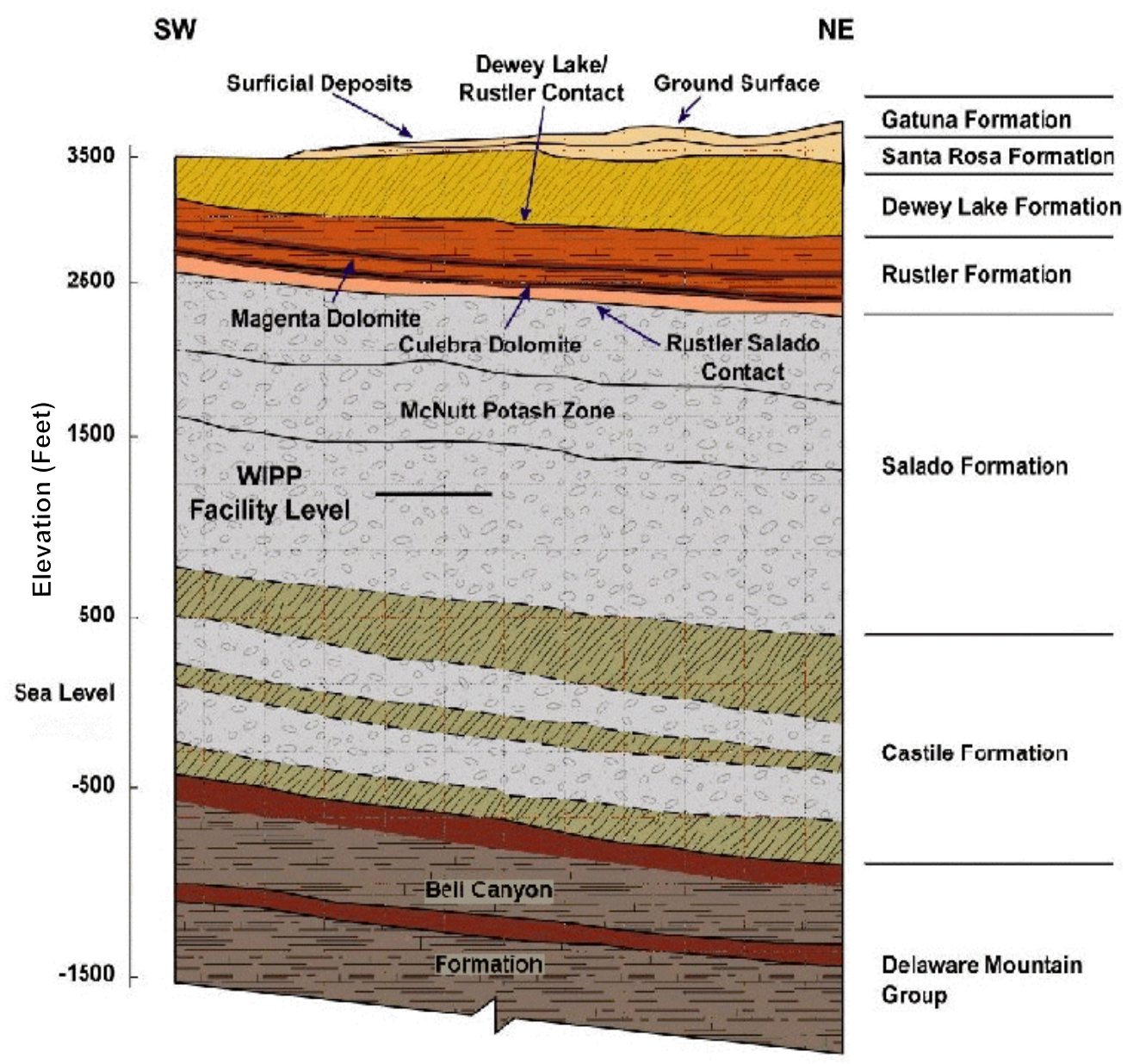

Figure 6.1 - WIPP Stratigraphy 


\subsubsection{Surface Hydrology}

Surface water is absent at the WIPP site. The nearest significant surface water body, Laguna Grande de la Sal, is $13 \mathrm{~km}(8 \mathrm{mi})$ west-southwest of the center of the WIPP site in Nash Draw, where shallow brine ponds occur. Small, manmade livestock watering holes ("tanks") occur several kilometers from the WIPP site, but are not hydrologically connected to the formations overlying the WIPP repository.

\subsubsection{Subsurface Hydrology}

Several water-bearing zones have been identified and extensively studied at and near the WIPP site. Limited amounts of potable water are found in the middle Dewey Lake Redbeds Formation (Dewey Lake) and the overlying Triassic Dockum group in the southern part of the WIPP Land Withdrawal Area. Two water-bearing units, the Culebra Dolomite Member (Culebra) and Magenta Dolomite Member (Magenta), occur in the Rustler Formation (Rustler) and produce brackish to saline water at and in the vicinity of the site. Another very low transmissivity, saline water-bearing zone is the Rustler-Salado contact.

\subsubsection{Hydrology of the Castile Formation}

The Castile Formation (Castile) is composed of a sequence of three thick anhydrite beds separated by two thick halite beds. This formation acts as an aquitard, separating the Salado Formation (Salado) from the underlying water-bearing sandstones of the Bell Canyon Formation. In the halite zones, the occurrence of circulating groundwater is restricted because halite at these depths does not readily maintain secondary porosity, open fractures, or solution channels.

No regional groundwater flow system appears to be present in the Castile in the vicinity of the WIPP site. The only significant water present in the formation occurs in isolated brine reservoirs in fractured anhydrite. Wells have encountered pressurized brine reservoirs in the upper anhydrite unit of the Castile in the vicinity of the WIPP site. Two such encounters have been made by boreholes drilled for the WIPP Project:

(1) ERDA-6, located northeast of the current WIPP site, encountered a pressurized brine reservoir in 1975; and (2) borehole WIPP-12, one mile north of the center of the WIPP site encountered a brine reservoir in 1981. Both encounters were hydrologically and chemically tested in 1981 and determined to be not connected with each other.

\subsubsection{Hydrology of the Salado Formation}

The massive halite beds within the Salado host the WIPP facility horizon. The Salado represents a regional aquiclude due to the hydraulic properties of the bedded halite that forms most of the formation. In the halites, the presence of circulating groundwater is restricted because halites do not readily maintain primary porosity, solution channels, or open fractures. 
The results of permeability testing, both within the facility and from the surface, are generally consistent with a hydraulic conductivity of the undisturbed salt mass of less than $6.5 \mathrm{E}-09 \mathrm{~m}$ per day $(\mathrm{m} / \mathrm{d})(2.1 \mathrm{E}-08 \mathrm{ft} / \mathrm{d})$, with the more pure (less argillaceous) halites having even lower permeability. Anhydrite interbeds typically have hydraulic conductivities ranging from $6.5 \mathrm{E}-09 \mathrm{~m} / \mathrm{d}$ to $6.5 \mathrm{E}-07 \mathrm{~m} / \mathrm{d}(2.1 \mathrm{E}-08$ to $2.1 \mathrm{E}-06 \mathrm{ft} / \mathrm{d})$ (Beauheim and Roberts, 2002). The only significant variation to these extremely low permeabilities occurs in the immediate vicinity of the underground workings (Stormont et al., 1991). This increase is believed to be a result of near-field fracturing due to the excavation.

Small quantities of brine have been observed to collect in boreholes drilled into Marker Bed 139 a few feet below the floor of the WIPP underground repository rooms and have also been observed to seep out of the excavated walls. The long-term performance assessment for the WIPP disposal system assumes that small quantities of brine will be present in the WIPP repository.

\subsubsection{Hydrology of the Rustler-Salado Contact}

In Nash Draw and areas immediately west of the site, the Rustler-Salado contact exists as a dissolution residue capable of transmitting water. Eastward from Nash Draw toward the WIPP site, the amount of dissolution decreases and the transmissivity of this interval decreases (Mercer, 1983). Small quantities of brine were found in this zone at the WIPP site in the WIPP Project test holes (Mercer and Orr, 1977).

\subsubsection{Hydrology of the Culebra Member}

The Culebra is the most transmissive hydrologic unit in the WIPP site area and is considered the most significant potential hydrologic pathway for a radiologic release to the accessible environment.

Tests show that the Culebra is a fractured, heterogeneous system with varying local anisotropic characteristics (Mercer and Orr, 1977; Mercer, 1983; Beauheim, 1986, 1987; Beauheim and Ruskauff, 1998). Calculated transmissivities for the Culebra within the WIPP site boundary have a wide range, with values between $1.2 \mathrm{E}-08 \mathrm{~m}^{2} / \mathrm{d}$ to approximately $112 \mathrm{~m}^{2} / \mathrm{d}\left(1.03-07\right.$ to approximately $\left.336 \mathrm{ft}^{2} / \mathrm{d}\right)$; the majority of the values are less than 9.3E-02 $\mathrm{m}^{2} / \mathrm{d}\left(1 \mathrm{ft}^{2} / \mathrm{d}\right.$ ) (Beauheim, 1987; Compliance Recertification Application Appendix HYDRO, 2009). Transmissivities generally decrease from west to east across the site area, with a relatively high transmissivity zone trending southeast from the center of the WIPP site to the site boundary. The regional flow direction of groundwater in the Culebra is generally south.

\subsubsection{Hydrology of the Magenta Member}

The Magenta is situated above the Culebra and, though not the water-bearing zone of interest for monitoring of a facility release, is of interest in understanding water-level changes that occur in the Culebra. The Magenta has been tested in 18 cased and open holes at and around the WIPP site. Magenta transmissivities within the WIPP site range 
from 2.0E-04 to $3.5 \mathrm{E}-02 \mathrm{~m}^{2} / \mathrm{d}$ (2.1E-03 to $3.8 \mathrm{E}-01 \mathrm{ft}^{2} / \mathrm{d}$ ) (Beauheim et al., 1991; Beauheim and Ruskauff, 1998; Sandia National Laboratories [SNL], the Scientific Advisor, 2003; Bowman and Roberts, 2009).

\subsubsection{Hydrology of the Dewey Lake Redbeds Formation}

The Dewey Lake at the WIPP site is approximately $152 \mathrm{~m}$ (500 ft) thick and consists of alternating thin beds of siltstone and fine-grained sandstone. The upper Dewey Lake consists of a thick, generally unsaturated section. The middle Dewey Lake is the interval immediately above a cementation change, from carbonate (above) to sulfate (below), where saturated conditions and a natural water table have been identified in limited areas. An anthropogenic saturated zone has been observed in the overlying Santa Rosa Formation (Santa Rosa) and in the upper part of the Dewey Lake since 1995. This is described in Section 6.6. The lower Dewey Lake is below the sulfate cementation change, with much lower permeabilities.

WIPP monitoring well WQSP-6A (see Figure 6.2) intersects natural water in the Dewey Lake. At this location, the saturated horizon is within the middle portion of the formation. The saturated zone at well WQSP-6A is both vertically and laterally distinct from the water at C-2811 (see Section 6.6 for a full discussion of Shallow Subsurface Water [SSW]). Well C-2811 is located approximately one mile $(1.61 \mathrm{~km})$ to the northeast on the C-2737 well pad (see Figure 6.2). Approximately one mile south of the WIPP site, domestic and stock supply wells produce water from the middle Dewey Lake.

\subsubsection{Hydrology of the Santa Rosa and Gatuña Formations}

Within the WIPP site boundary, the Santa Rosa is relatively thin to absent. At the Air Intake Shaft, $0.6 \mathrm{~m}(2 \mathrm{ft})$ of rock is classified as the Santa Rosa. The Santa Rosa is a maximum of $78 \mathrm{~m}(255 \mathrm{ft})$ thick in exploratory potash holes drilled for WIPP, east of the site boundary. The Santa Rosa is thicker to the east. The geologic data from design studies have been incorporated with data from drilling to investigate SSW in the Santa Rosa to provide structure and thickness maps of the Santa Rosa in the vicinity of the WIPP surface structures area. These results are consistent with the broader regional distribution of the Santa Rosa (DOE/WIPP-04-3231).

Water in the Santa Rosa has been found in the center part of the WIPP site since 1995 and because no water was found in this zone during the mapping of the shafts in 1980s, this water is deemed to be anthropogenic (Daniel B. Stephens \& Associates, Inc., 2003). To assess the quantity and quality of this water, piezometers PZ-1 to PZ-12 were installed in the area between the WIPP shafts. Also, wells C-2505, C-2506, and C-2507 were drilled and tested in 1996 and 1997 (Exhaust Shaft Hydraulic Assessment Data Report, DOE/WIPP-97-2219). These wells are shown in Figure 6.16 of this report. During October 2007, three additional piezometers were installed around the SPDV tailings pile to evaluate the nature and extent of SSW around this area. 
The Gatuña Formation (Gatuña) unconformably overlies the Santa Rosa at the WIPP site. This formation ranges in thickness from approximately 6 to $9 \mathrm{~m}(19$ to $31 \mathrm{ft})$ at the WIPP site and consists of silt, sand, and clay, with deposits formed in localized depressions.

The Gatuña is water-bearing in some areas, with saturation occurring in discontinuous perched zones. However, because of its erratic distribution, the Gatuña has no known continuous saturation zone. Drilling at the WIPP site, including 30 exploration borings drilled between 1978 and 1979, did not identify any saturated zones in the Gatuña (Daniel B. Stephens \& Associates, Inc., 2003).

\subsection{Groundwater Monitoring}

\subsubsection{Program Objectives}

The objectives of the groundwater monitoring program are to:

- $\quad$ Monitor the physical and chemical characteristics of groundwater;

- Maintain surveillance of groundwater levels surrounding the WIPP facility throughout the operational lifetime of the facility; and

- Document and identify effects, if any, of WIPP operations on groundwater parameters throughout the operational lifetime (including closure) and post-closure of the facility.

Data obtained by the WIPP Project groundwater monitoring program support two major programs: (1) the RCRA detection monitoring program supporting the Permit in compliance with 20.4.1.500 NMAC (incorporating 40 CFR Part 264, Subparts F and X), and (2) performance assessment supporting the Compliance Certification Application (DOE/CAO-96-2184) and five-year recertification applications.

Baseline water chemistry data were collected from 1995 through 1997 and reported in the Waste Isolation Pilot Plant RCRA Background Groundwater Quality Baseline Report (DOE/WIPP-98-2285). The baseline data were expanded in 2000 to include ten rounds of sampling instead of five. The data were published in Addendum 1, Waste Isolation Pilot Plant RCRA Background Groundwater Quality Baseline Update Report (IT Corporation, 2000). These baseline data are compared to water quality data collected semiannually.

\subsubsection{Summary of 2008 Activities}

Routine groundwater monitoring activities include groundwater quality sampling, groundwater level monitoring, and the pressure density survey, as described in this section. These annual programs are required by the Permit. Supporting activities during 2008 included hydraulic testing and non-Permit groundwater quality sampling (Section 6.4), and well maintenance (Section 6.5). Table 6.1 presents a summary of 
WIPP groundwater monitoring activities at the end of 2008. Wells are classified as environmental surveillance wells. The WIPP Project does not have wells required for remediation, waste management, or other requirements. Appendix F, Table F.8, lists active groundwater monitoring wells used by the DOE for the WIPP Project at the end of 2008.

Radiological data for 2008 from the groundwater monitoring program are summarized in Chapter 4. The remainder of the results from the groundwater monitoring program are contained in this chapter.

Table 6.1 - Summary of 2008 DOE WIPP Region Groundwater Monitoring Program

\begin{tabular}{|l|c|}
\hline & Environmental Surveillance \\
\hline Number of Active Wells & 84 \\
\hline Number of Samples Taken & $28^{*}$ \\
\hline Number of Water Level Measurements & 787 \\
\hline Number of Analyses Performed & 1,708 \\
\hline$\%$ of Analyses that are Non-Detects & $79 \%^{* *}$ \\
\hline
\end{tabular}

* Primary and duplicate samples taken from seven wells, twice per year. Sixty-one constituents analyzed per sample.

** All VOCs, SVOCs (semivolatile organic compounds), and the majority of trace metals were nondetect. Most detections are the routine major water chemistry parameters.

Regular monthly groundwater level data were gathered from 77 wells across the WIPP region (Figure 6.2), three of which were equipped with production-injection packers (PIPs) to allow groundwater level surveillance of more than one hydrologic zone in the same well. The count excludes six redundant wells on the $\mathrm{H}-19$ pad that were measured quarterly, and H-3D which was dry (for "SR/DL" [Santa Rosa/Dewey Lake Contact] listed in Appendix F, Table F.8, quarterly measurement is the norm). Table F.9 shows the water level data. Water levels were not taken where access was poor, or in certain wells whenever testing equipment was present. 


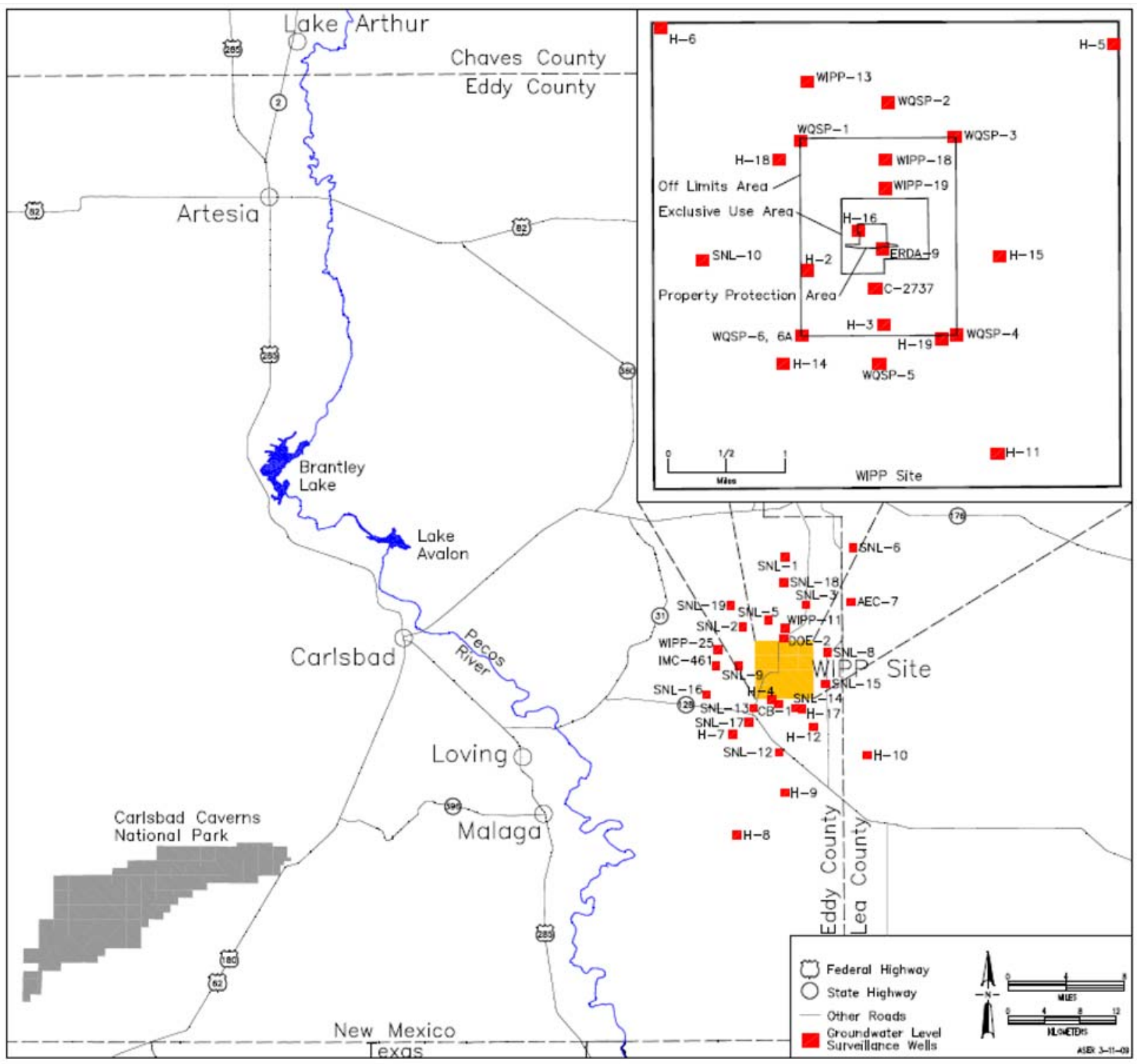

Figure 6.2 - Groundwater Level Surveillance Wells (insert represents the groundwater surveillance wells in WIPP Land Withdrawal Area)

\subsubsection{Groundwater Quality Sampling}

The Permit Module $\mathrm{V}$ requires groundwater quality sampling twice a year, from March through May (Round 26 for 2008), and again from September through November (Round 27 for 2008). Sampling for groundwater quality was performed at seven well sites (Figure 6.3). Field analyses for oxygen-reduction potential, $\mathrm{pH}$, specific gravity, specific conductance, temperature, acidity or alkalinity, chloride, divalent cations, and total iron were performed periodically during the sampling. 


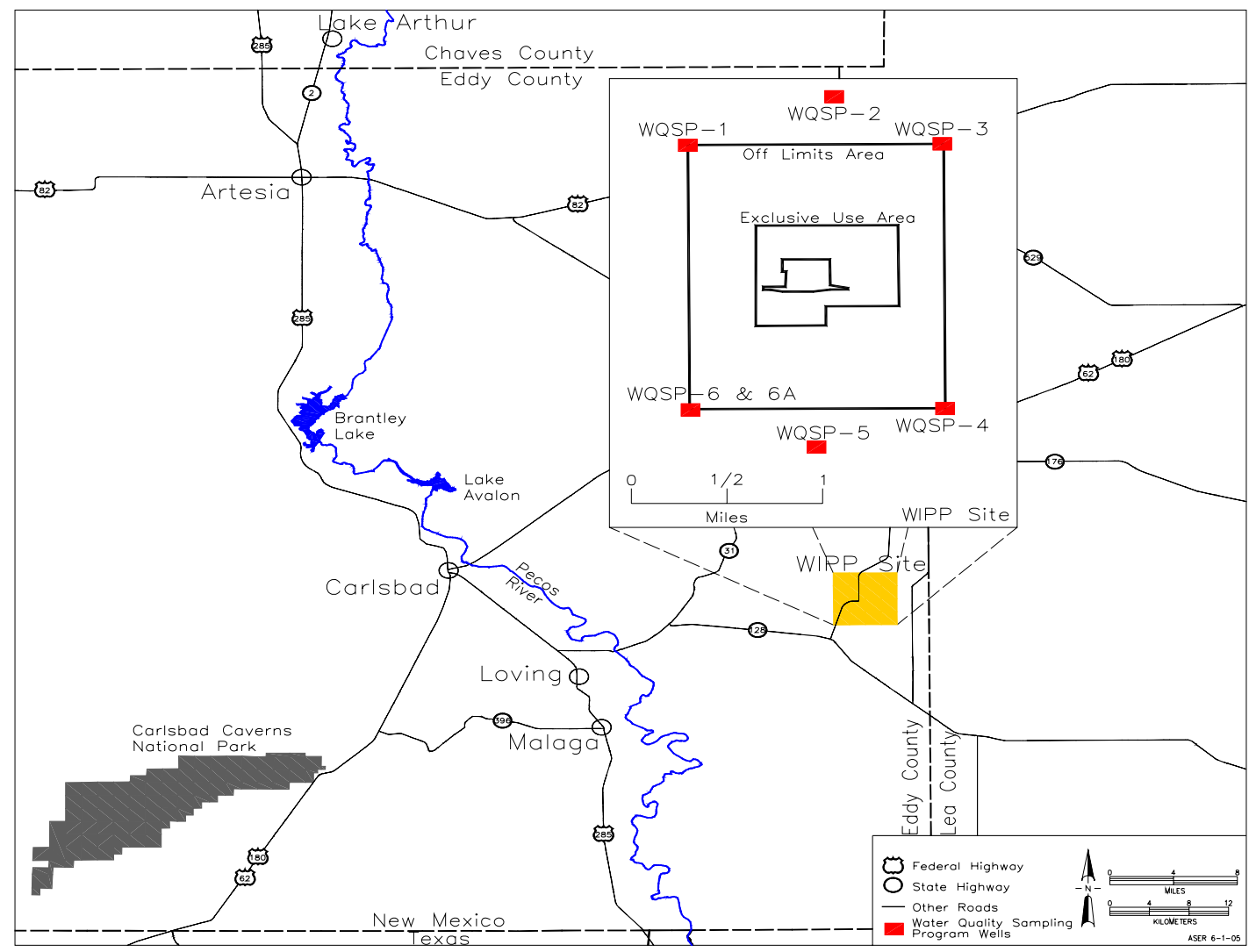

Figure 6.3 - Water Quality Sampling Program Wells

Primary and duplicate samples for groundwater quality were taken in each of the seven wells: six wells completed in the Culebra (WQSP-1 through WQSP-6) and one well completed in the Dewey Lake (WQSP-6A), for a total of 14 samples analyzed per sampling round.

Wells WQSP-1, WQSP-2, and WQSP-3 are located upgradient of the WIPP shaft area. The locations of the three upgradient wells were selected to be representative of the groundwater moving downgradient onto the WIPP site. Wells WQSP-4, WQSP-5, and WQSP-6 were located downgradient of the WIPP shaft area. WQSP-4 was also specifically located to monitor a zone of higher transmissivity. WQSP-6A was installed in the Dewey Lake at the WQSP-6 well pad to assess shallower groundwater conditions at this location.

The difference between the depth of the WIPP repository and the depth of the WQSP wells completed in the Culebra varies from $387 \mathrm{~m}$ to $587 \mathrm{~m}(1,271 \mathrm{ft}$ to $1925 \mathrm{ft})$. The DOE does not anticipate finding WIPP-related contamination in the groundwater because a release along the pathway from the repository to the Culebra is highly unlikely. In order for contaminated liquid to move from the repository to the Culebra, three conditions must be met. First, sufficient brine has to accumulate in the waste disposal areas to leach contaminants from the disposed waste. Second, sufficient pressure would have to build up in the disposal area to overcome the hydrostatic head 
between the repository and the Culebra. Third, a pathway must exist and remain open for the contaminated brine to flow from the repository to the Culebra. Since the times required for the brine accumulation and repository pressurization are on the order of thousands of years, and current plans call for the sealing of the shafts and boreholes that could become such a pathway at the closure of the facility, WIPP-related contamination in the groundwater is highly unlikely.

Table 6.2 lists the analytical parameters included in the 2008 groundwater sampling program.

\begin{tabular}{|c|c|c|c|c|c|}
\hline CAS No. ${ }^{a}$ & Parameter & $\begin{array}{c}\text { EPA } \\
\text { Method } \\
\text { Number }\end{array}$ & CAS No. & Parameter & $\begin{array}{c}\text { EPA } \\
\text { Method } \\
\text { Number }\end{array}$ \\
\hline $71-55-6$ & 1,1,1-Trichloroethane & $8260 \mathrm{~B}$ & $7782-50-5$ & Chloride & 300 \\
\hline $79-34-5$ & $1,1,2,2$-Tetrachloroethane & $8260 B$ & & Density ${ }^{b}$ & \\
\hline $79-00-5$ & 1,1,2-Trichloroethane & $8260 \mathrm{~B}$ & $7727-37-9$ & Nitrate (as N) & $300 / 353.3$ \\
\hline $75-34-3$ & 1,1-Dichloroethane & $8260 \mathrm{~B}$ & & $\mathrm{pH}$ & 150.1 \\
\hline $75-35-4$ & 1,1-Dichloroethylene & $8260 B$ & & Specific conductance & 120.1 \\
\hline $107-06-2$ & 1,2-Dichloroethane & $8260 \mathrm{~B}$ & & Sulfate & 300 \\
\hline $56-23-5$ & Carbon tetrachloride & $8260 B$ & & Total dissolved solids & 160.1 \\
\hline $108-90-7$ & Chlorobenzene & $8260 \mathrm{~B}$ & & Total organic carbon & 415.1 \\
\hline $67-66-3$ & Chloroform & $8260 B$ & & Total organic halogen & $9020 \mathrm{~B}$ \\
\hline $540-59-0$ & cis-1,2-Dichloroethylene & $8260 B$ & & Total suspended solids & 160.2 \\
\hline $540-59-0$ & trans-1, 2-Dichloroethylene & $8260 B$ & & & \\
\hline $78-93-3$ & Methyl ethyl ketone & $8260 B$ & & & \\
\hline 75-09-2 & Methylene chloride & $8260 B$ & & & \\
\hline $127-18-4$ & Tetrachloroethylene & $8260 \mathrm{~B}$ & $7440-36-0$ & Alkalinity & 310.1 \\
\hline $108-88-3$ & Toluene & $8260 \mathrm{~B}$ & $7440-38-2$ & Antimony & $6010 \mathrm{~B}$ \\
\hline $79-01-6$ & Trichloroethylene & $8260 B$ & $7440-39-3$ & Arsenic & $6010 \mathrm{~B}$ \\
\hline $75-69-4$ & Trichlorofluoromethane & $8260 B$ & $7440-41-7$ & Barium & $6010 B$ \\
\hline $75-01-4$ & Vinyl chloride & $8260 B$ & $7440-43-9$ & Beryllium & $6010 \mathrm{~B}$ \\
\hline $1330-20-7$ & Xylene & $8260 B$ & $7440-70-2$ & Cadmium & $6010 B$ \\
\hline $95-50-1$ & 1,2-Dichlorobenzene & $8270 \mathrm{C}$ & $7440-47-3$ & Calcium & $6010 \mathrm{~B}$ \\
\hline $106-46-7$ & 1,4-Dichlorobenzene & $8270 \mathrm{C}$ & $7439-89-6$ & Chromium & $6010 B$ \\
\hline $51-28-5$ & 2,4-Dinitrophenol & $8270 \mathrm{C}$ & $7439-92-1$ & Iron & $6010 B$ \\
\hline $121-14-2$ & 2,4-Dinitrotoluene & $8270 \mathrm{C}$ & $7439-95-4$ & Lead & $6010 B$ \\
\hline $95-48-7$ & 2-Methylphenol & $8270 \mathrm{C}$ & $7439-97-6$ & Magnesium & $6010 \mathrm{~B}$ \\
\hline \multirow{2}{*}{$\begin{array}{l}108-39-4 / \\
106-44-5\end{array}$} & 3-Methylphenol/ & $8270 \mathrm{C}$ & $7439-97-6$ & Mercury & $7470 \mathrm{~A}$ \\
\hline & 4-Methylphenol & & $7440-02-0$ & Nickel & $6010 \mathrm{~B}$ \\
\hline $118-74-1$ & Hexachlorobenzene & $8270 \mathrm{C}$ & $7782-49-2$ & Potassium & $6010 B$ \\
\hline $67-72-1$ & Hexachloroethane & $8270 \mathrm{C}$ & $7440-22-4$ & Selenium & $6010 B$ \\
\hline $98-95-3$ & Nitrobenzene & $8270 \mathrm{C}$ & $7440-23-5$ & Silver & $6010 B$ \\
\hline $87-86-5$ & Pentachlorophenol & $8270 \mathrm{C}$ & $7440-28-0$ & Sodium & $6010 B$ \\
\hline $110-86-1$ & Pyridine & $8270 \mathrm{C}$ & $7440-62-2$ & Thallium & $6010 B$ \\
\hline $78-83-1$ & Isobutanol & $8260 \mathrm{~B}$ & $7440-66-6$ & Vanadium & $6010 \mathrm{~B}$ \\
\hline
\end{tabular}




\subsubsection{Evaluation of Groundwater Quality}

The quality of the Culebra water sampled at the WIPP site is naturally poor and not suitable for human consumption or for agricultural purposes, because the TDS concentrations are generally above $10,000 \mathrm{mg} / \mathrm{L}$. In 2008, average TDS concentrations in the Culebra (as measured in WQSP wells) varied from a low of $15,200 \mathrm{mg} / \mathrm{L}$ (WQSP-6) to a high of $227,000 \mathrm{mg} / \mathrm{L}$ (WQSP-3). The groundwater of the Culebra is considered to be Class III water (non-potable) by EPA guidelines.

Water quality measurements performed in the Dewey Lake indicate that the water is considerably better quality than that from the Culebra. In 2008, the TDS values in water from the well WQSP-6A, obtained from the Dewey Lake, averaged $3,450 \mathrm{mg} / \mathrm{L}$. This water is suitable for livestock consumption, and is classified as Class II water by EPA guidelines. Saturation of the Dewey Lake in the area of the WIPP facility is discontinuous. In addition to this naturally occurring groundwater, anthropogenic SSW has been encountered in the upper Dewey Lake at the Santa Rosa contact (see Section 6.6).

Because of the highly variable TDS values within the Culebra, baseline groundwater quality was defined for each individual well. The analytical results for detectable constituents are plotted as Time Trend Plots compared to the baseline (Appendix E, Figures E.1 through E.98). The results of analyses for each parameter or constituent for the two sampling sessions in 2008 (Rounds 26 and 27) are summarized in Appendix F, Tables F.1 through F.7.

In these tables, either the $95^{\text {th }}$ upper tolerance limit value (UTLV) or the $95^{\text {th }}$ percentile value (as calculated for the background sampling rounds) is presented for each parameter depending on the type of distribution exhibited by the parameter or constituent. Both values represent the value beneath which 95 percent of the values in a population are expected to occur. The UTLVs were calculated for data that exhibited a normal or a lognormal distribution. The $95^{\text {th }}$ percentile was determined for data that were considered nonparametric (i.e., having neither a normal nor a lognormal distribution). Due to the large number of nondetectable concentrations of organic compounds, the limits for organic compounds were considered nonparametric and based on the contract-required reporting limit for the contract laboratory. These values have been recomputed after baseline sampling was completed in 2000 , and were used for sampling Rounds 26 and 27 to evaluate potential contamination of the local groundwater. None of the constituents of interest exceeded baseline values.

\subsubsection{Groundwater Level Surveillance}

Well bores were used to perform surveillance of the groundwater surface elevation of five water-bearing zones in the vicinity of the WIPP facility:

$\begin{array}{ll}\text { - } & \text { SSW (SR/DL Contact) } \\ \text { - } & \text { Dewey Lake } \\ & \text { Magenta }\end{array}$


- Culebra

- Bell Canyon

The two zones of most interest are the Culebra and Magenta (see Figure 6.1). Throughout 2008, water levels in up to 50 Culebra wells were measured (includes the Culebra zone of dual completion wells) and 14 wells in the Magenta (includes the Magenta zone of dual completion wells). One Dewey Lake well and two Bell Canyon wells were monitored. Nineteen wells in the shallow zone of the SR/DL Contact were monitored. Groundwater level measurements were taken monthly in at least one accessible well bore at each well site for each available formation (Figure 6.2). Water levels in redundant well bores (well bores located on well pads with multiple wells completed in the same formation) at each well site were measured on a quarterly basis (Appendix F, Table F.9). Water levels at SSW wells and piezometers were measured on a quarterly basis.

A breakout of the groundwater zone(s) intercepted by each well measured at least once in 2008 is given in Appendix F, Table F.8. Note that three existing wells (Culebra/Magenta; C-2737, Culebra/Magenta; WIPP-25, Culebra/Magenta; H-9c, Culebra/Magenta) are completed at multiple depths. By using PIPs, these wells monitor more than one formation.

Water elevation trend analysis was performed for 36 of 50 wells completed or isolated in the Culebra. The subset of wells analyzed were those which had a sufficient period of record to analyze through CY 2008, did not display anomalous levels or trends, and were representative of more than one well at a given well pad (Appendix F, Table F.8). Excluded from trend analysis were C-2737 (anomalous water level due to density variation from packer adjustment); $\mathrm{H}-6 \mathrm{bR}$, replacement for $\mathrm{H}-6 \mathrm{~b}$ (insufficient data for trending); $\mathrm{H}-12$ (water level variation from bailing); $\mathrm{H}-15 \mathrm{R}$, replacement for $\mathrm{H}-15$ (PIP) (insufficient data for trending); $\mathrm{H}-16$ (insufficient data for trending); SNL-6 (in long-term water level recovery); SNL-8 (in long-term water level recovery), and SNL-15 (in long-term water level recovery).

The dominant trend through 2008 was a spatially uniform, decreasing freshwater equivalent level in the Culebra, with a slight increase during the last three months of the year. By "dominant," it is meant that (1) water levels were neutral or fell in 28 of 36 wells from January through December (or shorter periods in wells that still had a discernable trend), (2) the average water level decrease was 1.39 feet $(0.42 \mathrm{~m})$, and (3) the general water level fall is best indicated by sixteen measured water levels falling in the zero (neutral) to 1.0 foot range, and all but one decline being less than 2.9 feet.

Water levels in the Culebra, and to a lesser extent in the Magenta, have generally been rising since the completion of site characterization activities in 1989. The rise was not recognized as having a regional extent for many years because well drilling and testing, shaft sinking, and other human activities disturbed water levels. Since these activities were completed, a rise in water levels over the monitored area has become evident. However, 2008 trends indicate a decrease in water levels regionally. 
The water-level rise is not monotonic, but shows variations related to factors both known and hypothesized. Water levels in the Culebra in Nash Draw, west of the WIPP site, respond to major rainfall events within a few days (Hillesheim et al., 2007). It is hypothesized that the change in head in Nash Draw then propagates under Livingston Ridge to the WIPP site in the succeeding weeks or months. It is also hypothesized that the Culebra may be receiving leakage through poorly plugged and abandoned drillholes, or through fractures in Nash Draw, from higher hydrologic units and/or potash tailings piles north of the WIPP site. For example, the observed long-term rise in water levels might be caused by the leakage into the Culebra of approximately 74 acre-ft/yr of brine discharged onto the Intrepid East tailings pile north of the WIPP site, and/or by the leakage of a similar volume through 26 potash exploration holes north, west, and south of the WIPP site that may not have been properly plugged through the Culebra (Lowry and Beauheim, 2004; 2005). Likewise, a number of plugged and abandoned oil or gas wells have been identified, mostly to the east and south of the WIPP site, that may not be plugged through the Culebra with cement and could, hypothetically, be sources of leakage that affects the head in the Culebra (Powers, 2004).

Because of the wide areal distribution of the rise, it does not result in significant changes in the hydraulic gradient in the Culebra, which controls the rate and direction of groundwater flow. The DOE uses updated heads in calculating potential radionuclide releases through the Culebra in the performance assessments that are part of each Compliance Recertification Application.

Figures 6.4 through 6.10 provide hydrographs of wells WQSP-1 to WQSP-6A for CY 2008. The six Culebra wells (Figures 6.4 through 6.9; WQSP-6A is Dewey Lake) are typical of the hydrographs of the 36 wells analyzed for Culebra water level trends. Temporary declines from spring and fall water quality sampling are evident in some wells such as WQSP-3 and WQSP-5. The Permit requires that the NMED be notified if a cumulative groundwater surface elevation change of more than two feet is detected in wells WQSP-1 to WQSP-6A over the course of one year that is not attributable to site tests or natural stabilization of the site hydrologic system. There was no abnormal or unexplained rise in the DMP wells outside the regional trend. Wells WQSP-1, -2 , and -3 had cumulative decreases in water level in excess of two feet during the course of the year from January to December. The reason for the decreased water elevations can be attributed to 8 inches less rainfall in 2008 than the average annual rainfall for the first time in four years. 


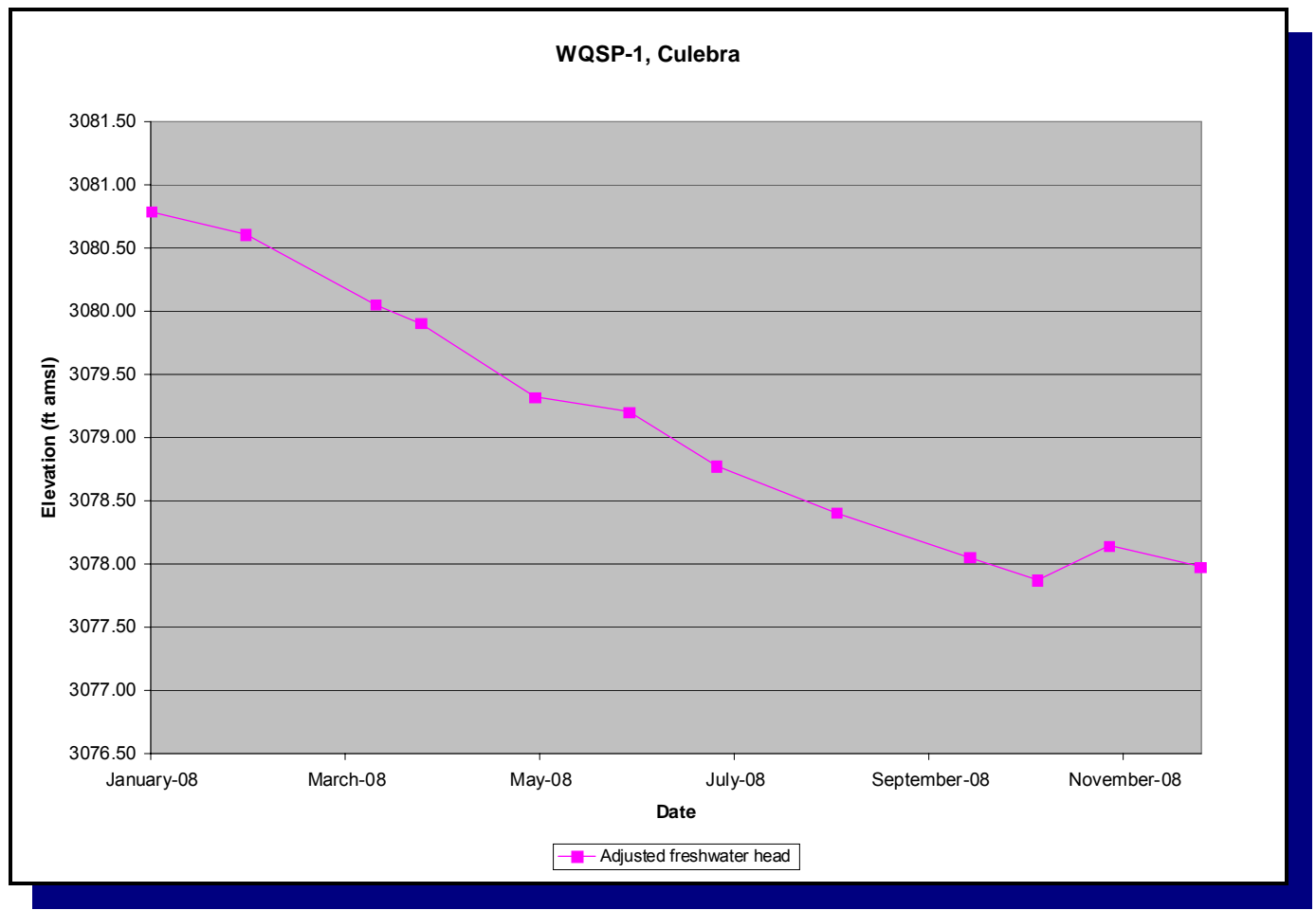

Figure 6.4 - Hydrograph of WQSP-1

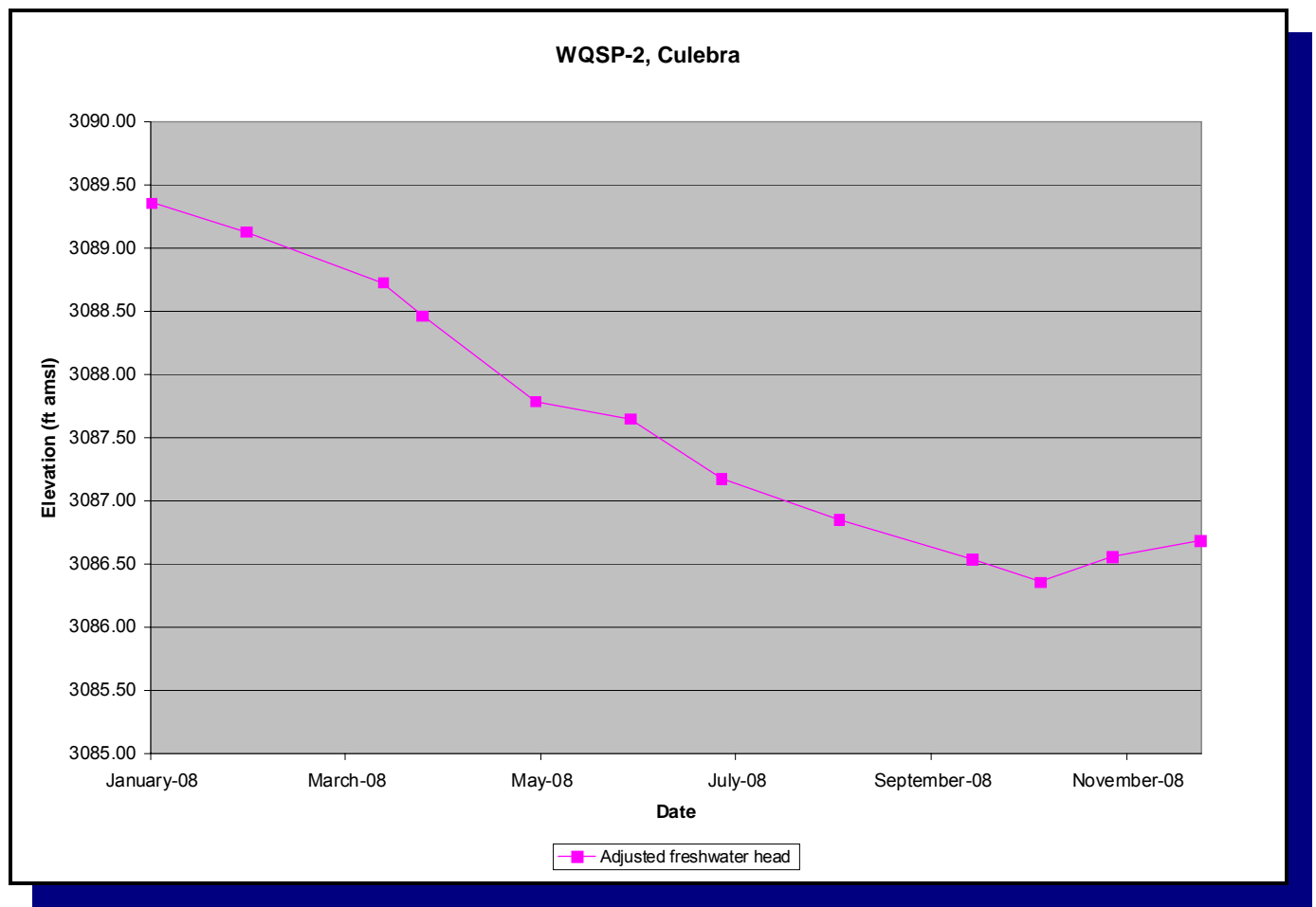

Figure 6.5 - Hydrograph of WQSP-2 


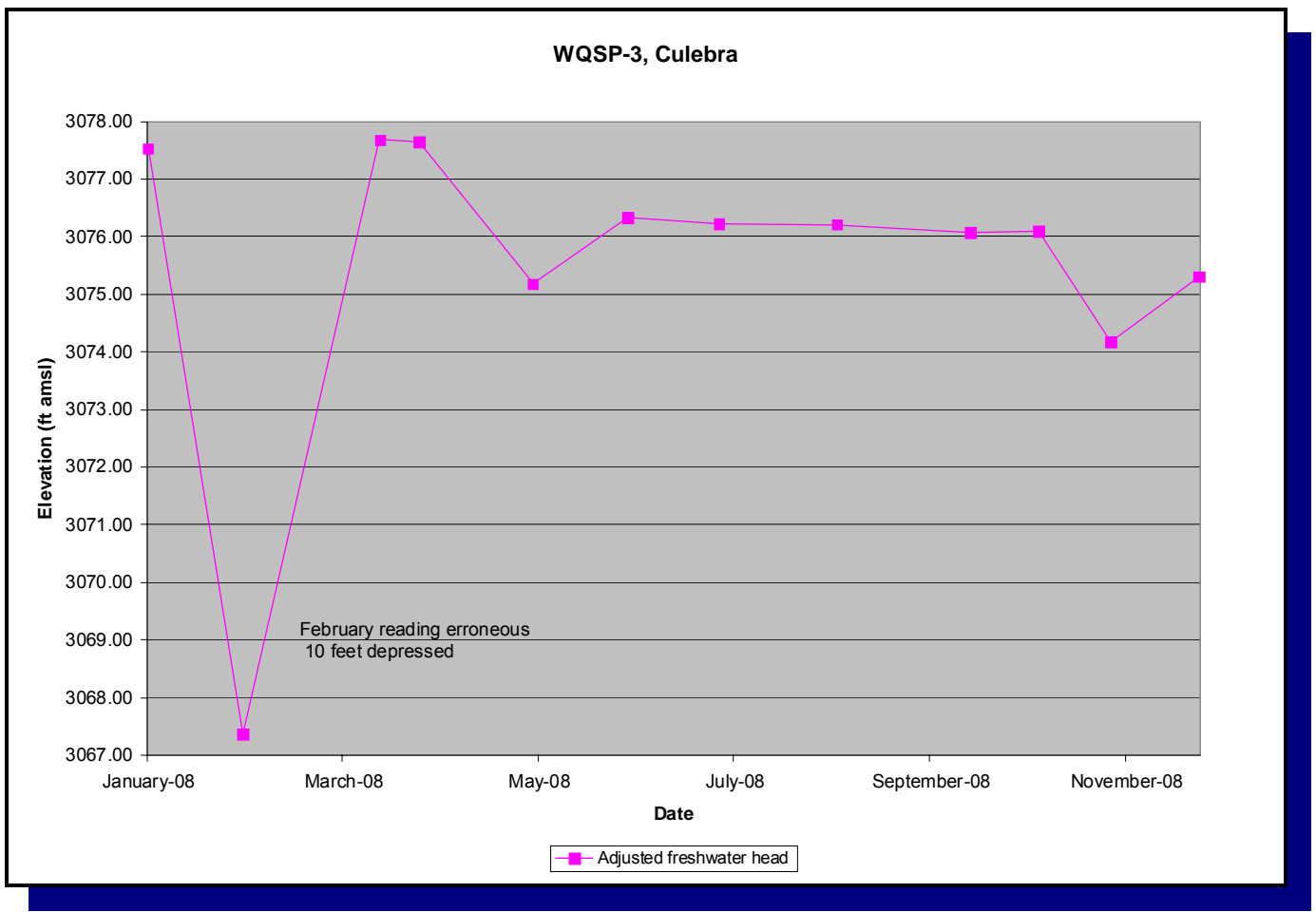

Figure 6.6 - Hydrograph of WQSP-3

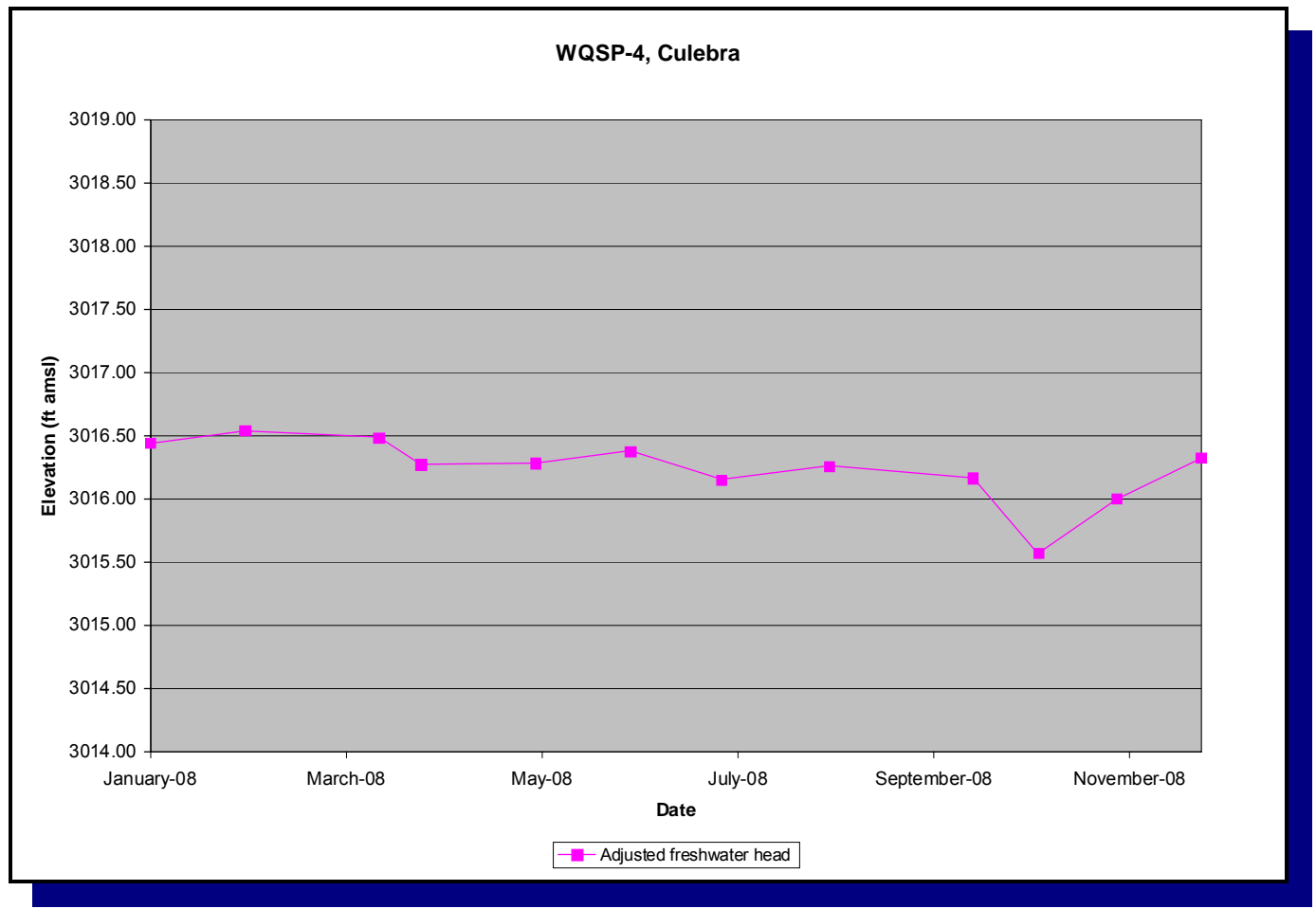

Figure 6.7 - Hydrograph of WQSP-4 


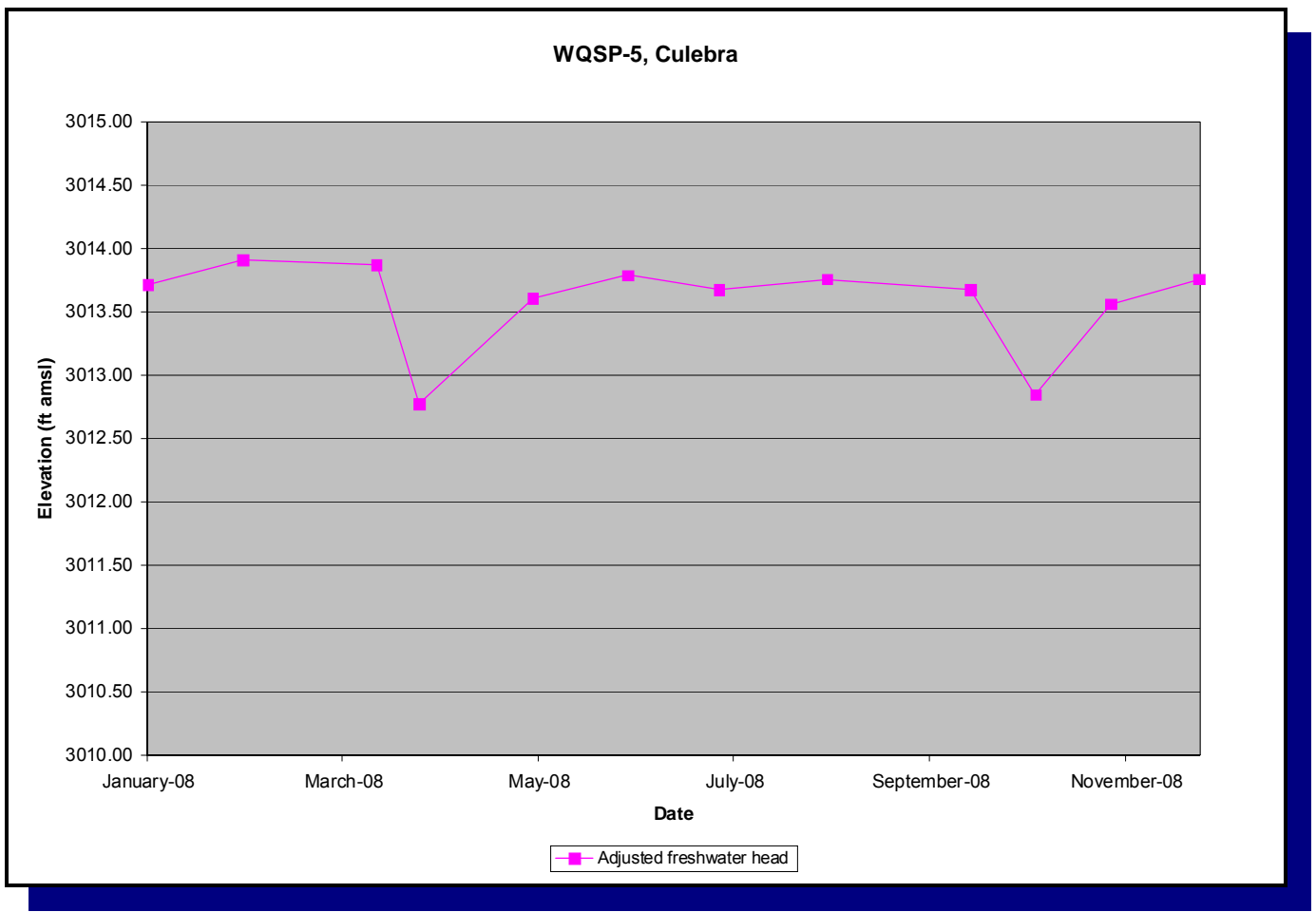

Figure 6.8 - Hydrograph of WQSP-5

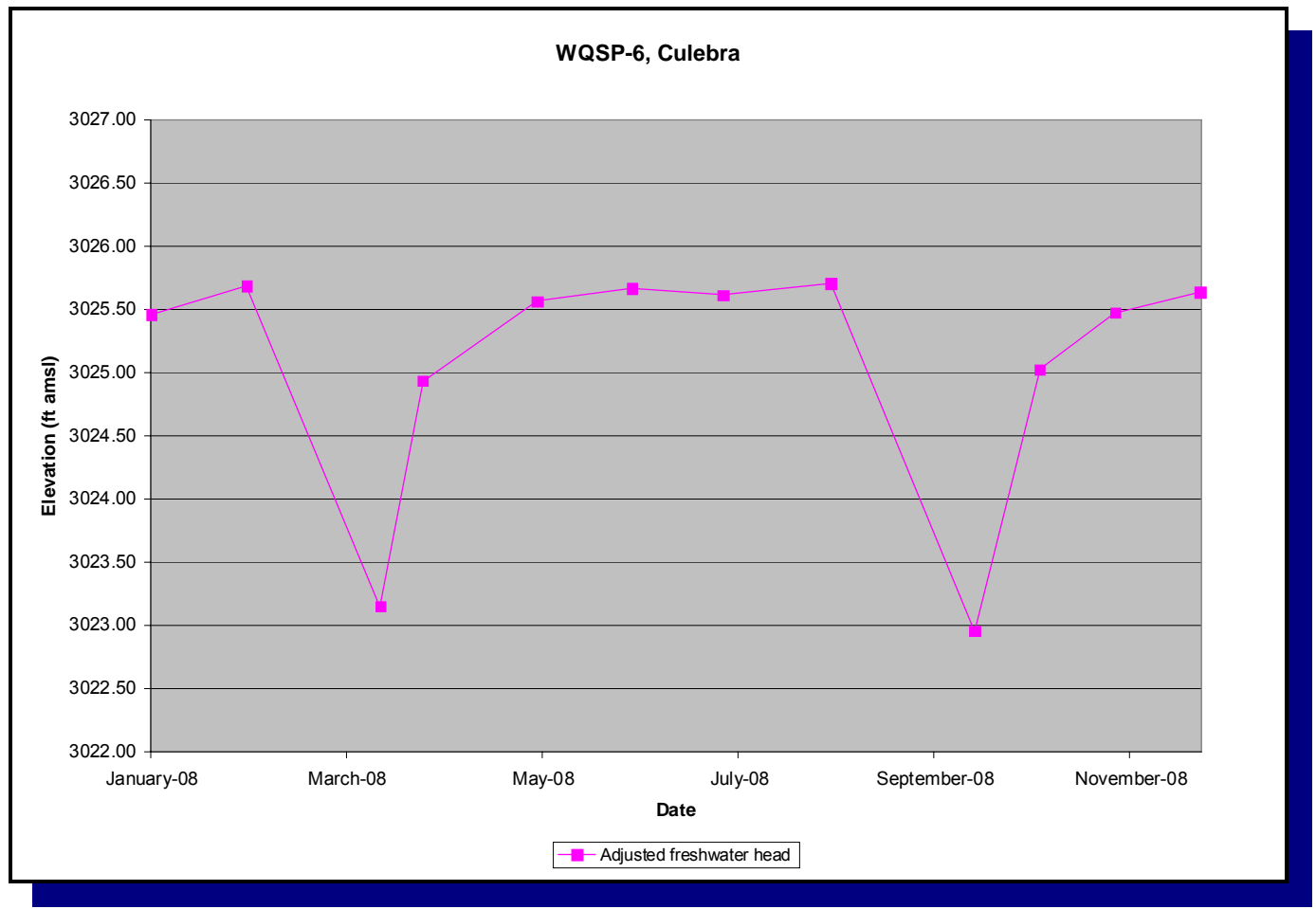

Figure 6.9 - Hydrograph of WQSP-6 


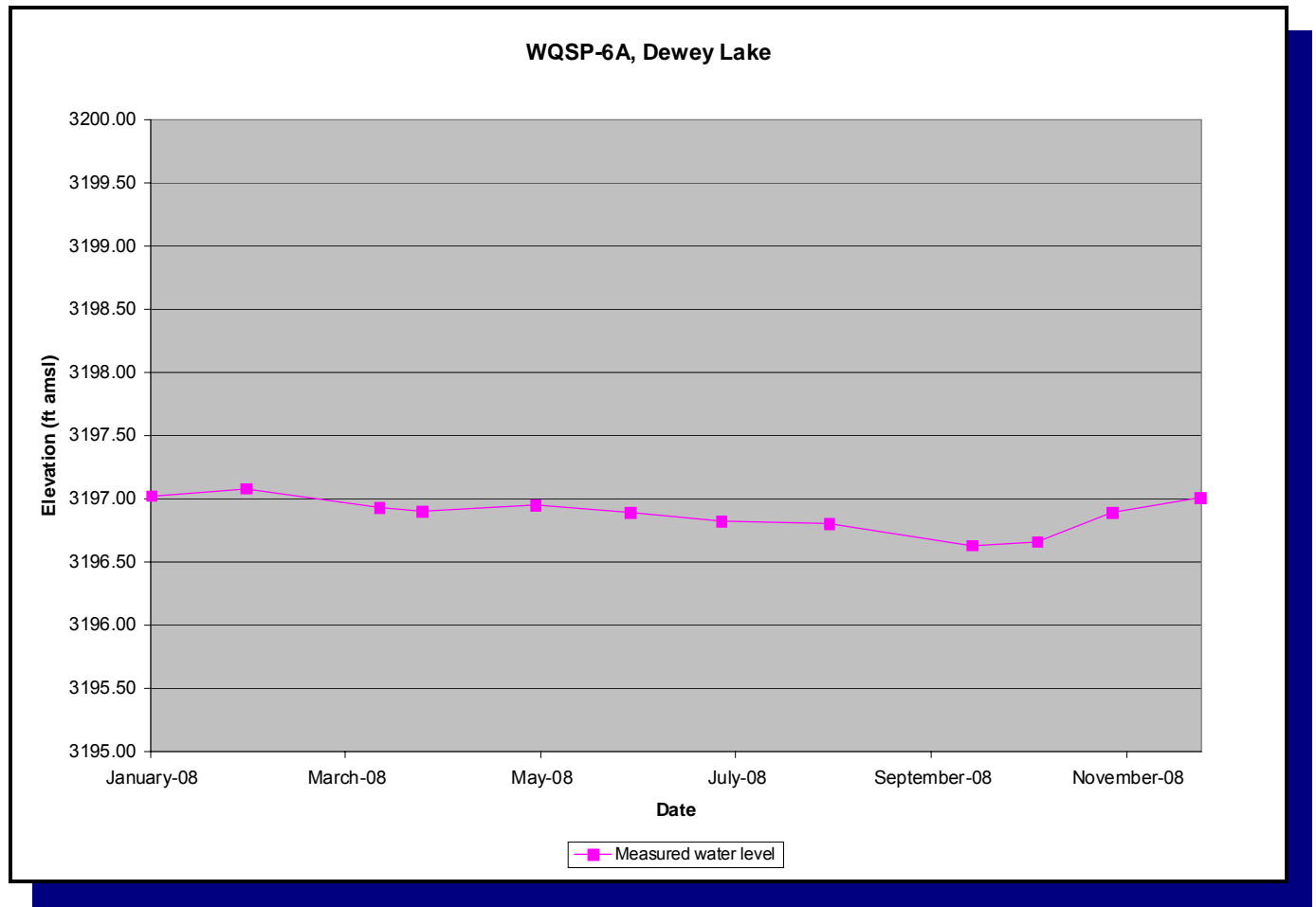

Figure 6.10 - Hydrograph of WQSP-6A

Groundwater level data were transmitted on a monthly basis to the NMED, SNL, and the CBFO. A copy of the data was placed in the operating record for inspection.

For the Culebra wells in the vicinity of the WIPP site, equivalent freshwater heads for September 2008 were used to calibrate a model of the potentiometric surface. This month was judged to have a large number of Culebra water levels available, few wells affected by pumping events, and all wells in quasi-steady state with few individual wells contrary to the general water level trend. Table 6.3 shows the water level data set. Adjusted freshwater heads are typically accurate to \pm 1.5 feet given the density measurement error. Density measurement error is less than 0.019 specific gravity units (WP 02-1).

Table 6.3 - Water Level Elevations for the September 2008 Potentiometric Surface Calibration, Culebra Hydraulic Unit

\begin{tabular}{|l|c|c|r|l|}
\hline \multicolumn{1}{|c|}{ Well I.D. } & $\begin{array}{c}\text { Date of } \\
\text { Measurement }\end{array}$ & $\begin{array}{c}\text { Adjusted } \\
\text { Freshwater } \\
\text { Head } \\
\text { (feet, } \text { msl) }\end{array}$ & $\begin{array}{c}\text { Density } \\
\text { Used } \\
\text { (grams/cc) }\end{array}$ & Notes \\
\hline AEC-7 & $09 / 22 / 08$ & $3,064.06$ & 1.078 & Density effective 06/18/08 \\
\hline C-2737 (PIP) & $09 / 24 / 08$ & $3,023.61$ & 1.029 & Density effective 06/26/08 \\
\hline ERDA-9 & $09 / 24 / 08$ & $3,033.97$ & 1.067 & Density from Johnson, 2007, 2008 \\
\hline H-02b2 & $09 / 24 / 08$ & $3,050.51$ & 1.014 & \\
\hline H-03b2 & $09 / 24 / 08$ & $3,015.20$ & 1.042 & \\
\hline
\end{tabular}




\section{Waste Isolation Pilot Plant Annual Site Environmental Report for 2008 DOE/WIPP-09-2225}

\section{Table 6.3 - Water Level Elevations for the September 2008 Potentiometric Surface}

Calibration, Culebra Hydraulic Unit

\begin{tabular}{|c|c|c|c|c|}
\hline Well I.D. & $\begin{array}{c}\text { Date of } \\
\text { Measurement }\end{array}$ & $\begin{array}{c}\text { Adjusted } \\
\text { Freshwater } \\
\text { Head } \\
\text { (feet, msl) }\end{array}$ & $\begin{array}{l}\text { Density } \\
\text { Used } \\
\text { (grams/cc) }\end{array}$ & Notes \\
\hline $\mathrm{H}-04 \mathrm{~b}$ & 09/24/08 & $3,006.82$ & 1.015 & \\
\hline $\mathrm{H}-05 \mathrm{~b}$ & $09 / 22 / 08$ & $3,081.33$ & 1.095 & Density from Johnson, 2007, 2008 \\
\hline $\mathrm{H}-06 \mathrm{bR}$ & $09 / 23 / 08$ & $3,074.22$ & 1.033 & Do not use. Replacement well insufficient data \\
\hline $\mathrm{H}-07 \mathrm{~b} 1$ & $09 / 23 / 08$ & $2,999.24$ & 1.002 & \\
\hline $\mathrm{H}-09 \mathrm{c}(\mathrm{PIP})$ & 09/23/08 & $2,997.25$ & 1.001 & \\
\hline $\mathrm{H}-10 \mathrm{c}$ & $09 / 23 / 08$ & $3,024.16$ & 1.001 & Density from Johnson, 2007, 2008 \\
\hline $\mathrm{H}-11 \mathrm{~b} 4$ & 09/22/08 & $3,009.92$ & 1.070 & \\
\hline $\mathrm{H}-12$ & $09 / 23 / 08$ & $3,007.71$ & 1.097 & \\
\hline $\mathrm{H}-15 \mathrm{R}$ & 08/15/08 & $3,020.01$ & 1.130 & $\begin{array}{l}\text { Do not use. Replacement well insufficient data (no } \\
\text { Sept. meas.) }\end{array}$ \\
\hline $\mathrm{H}-16$ & $09 / 25 / 08$ & $3,050.45$ & 1.039 & New well; insufficient data for trend, okay for map \\
\hline $\mathrm{H}-17$ & $09 / 22 / 08$ & $3,007.52$ & 1.133 & \\
\hline $\mathrm{H}-19 \mathrm{~b} 0$ & $09 / 24 / 08$ & $3,015.69$ & 1.068 & \\
\hline $\mathrm{I}-461$ & $09 / 23 / 08$ & $3,046.33$ & 1.005 & \\
\hline SNL-01 & $09 / 23 / 08$ & $3,085.69$ & 1.033 & \\
\hline SNL-02 & $09 / 23 / 08$ & $3,074.57$ & 1.012 & \\
\hline SNL-03 & $09 / 23 / 08$ & $3,081.17$ & 1.023 & \\
\hline SNL-05 & $09 / 23 / 08$ & $3,077.77$ & 1.010 & \\
\hline SNL-06 & $09 / 22 / 08$ & $2,892.05$ & 1.246 & Do not use. Depressed and recovering from testing \\
\hline SNL-08 & $09 / 22 / 08$ & $3,055.32$ & 1.103 & Do not use. Depressed and recovering from testing \\
\hline SNL-09 & $09 / 22 / 08$ & $3,057.49$ & 1.024 & \\
\hline SNL-10 & $09 / 22 / 08$ & $3,056.14$ & 1.011 & \\
\hline SNL-12 & $09 / 23 / 08$ & $3,003.45$ & 1.005 & \\
\hline SNL-13 & $09 / 22 / 08$ & $3,012.72$ & 1.027 & \\
\hline SNL-14 & 09/22/08 & $3,006.17$ & 1.048 & \\
\hline SNL-15 & $09 / 23 / 08$ & $2,911.00$ & 1.228 & Do not use. Depressed and recovering from testing \\
\hline SNL-16 & $09 / 22 / 08$ & $3,010.72$ & 1.010 & \\
\hline SNL-17 & $09 / 23 / 08$ & $3,007.36$ & 1.006 & \\
\hline SNL-18 & 09/23/08 & $3,082.59$ & 1.028 & \\
\hline SNL-19 & $09 / 23 / 08$ & $3,073.61$ & 1.003 & \\
\hline WIPP-11 & $09 / 22 / 08$ & $3,084.85$ & 1.038 & \\
\hline WIPP-13 & $09 / 22 / 08$ & $3,081.86$ & 1.053 & \\
\hline WIPP-19 & $09 / 24 / 08$ & $3,063.27$ & 1.044 & \\
\hline WIPP-25 (PIP) & $09 / 23 / 08$ & $3,069.43$ & 1.011 & \\
\hline WQSP-1 & $09 / 24 / 08$ & $3,078.05$ & 1.048 & \\
\hline WQSP-2 & $09 / 24 / 08$ & $3,086.54$ & 1.048 & \\
\hline WQSP-3 & $09 / 24 / 08$ & $3,076.08$ & 1.146 & \\
\hline WQSP-4 & $09 / 24 / 08$ & $3,016.16$ & 1.075 & \\
\hline WQSP-5 & $09 / 24 / 08$ & $3,013.67$ & 1.025 & \\
\hline WQSP-6 & $09 / 24 / 08$ & $3,022.96$ & 1.014 & \\
\hline
\end{tabular}

Modeled freshwater head contours for September 2008 for the model domain are shown in Figure 6.11. These contours were generated using MODFLOW 2K (Harbaugh 
et al., 2000) results for the Culebra using ensemble average distributed aquifer parameters from the SNL Culebra flow model, calibrated as part of the performance assessment baseline calculation for the 2009 Compliance Recertification Application (DOE, 2009). Because that model was calibrated to both a snapshot of assumed steady-state water levels (May 2007), and to transient multi-well responses observed during large-scale pumping tests throughout the domain, the boundary conditions were then adjusted to improve the match between the model and the observed September 2008 Culebra freshwater heads presented in this report. The portion of the flow domain of interest to the site is extracted on Figure 6.12. The freshwater head values for September 2008 were estimated using densities computed from 2007 data except for wells ERDA-9, $\mathrm{H}-5 \mathrm{~b}$, and $\mathrm{H}-10 \mathrm{c}$. Freshwater head calculations for these three wells use density values, obtained in the 2008 density survey, based on improved data collected from downhole Troll sensors, which were recently relocated to Culebra mid-formation depths (Johnson, 2009).

The base $\mathrm{T}$ fields and the 100 calibrated model realizations derived from them for the performance assessment baseline calculation (PABC) essentially embody the hydrologic and geologic understanding of the Culebra behavior in the vicinity surrounding the WIPP site, as presented to the peer review panel by SNL (Burgess et al., 2008). Using the ensemble average of these 100 realizations, therefore, captures the mean flow behavior of the system, and allows straightforward contouring of results from a single flow model.

The Culebra flow model is a single-layer groundwater flow model. The boundary conditions of the flow model are of two types. First are the geologic or hydrologic-type boundary conditions, which include the specified head along the eastern boundary, and the no-flow boundary along the northwestern boundary of the domain. The second type of boundary condition is specified head. The northern and southern boundaries are of this type, along with the southern portion of the west boundary. The no-flow constant head boundary defined in Figure 6.12 is due to the low transmissivity for this area defined by such wells as SNL-15 and SNL-8.

These boundary conditions were determined using a calculational code called PEST (Doherty, 2002) as part of this modeling effort. PEST is used to systematically adjust the boundary conditions to maximize the fit between modeled and observed heads at wells.

The particle track shown on Figure 6.12 as a solid blue line is computed from the MODFLOW 2K flow results using DTRKMF (Rudeen, 2003). The release point corresponds to the waste handling shaft. Since the flow model has the ensemble hydraulic conductivity and anisotropy fields as inputs, the freshwater head contours and particle tracks take into account the variability of known aquifer conditions across the site.

The illustrated particle takes 5,715 years to travel from the waste handling shaft to the WIPP LWB assuming porous-medium flow with a porosity of 16 percent. The path has a length of $4,079 \mathrm{~m}$, indicating a mean travel velocity of $0.71 \mathrm{~m} /$ year. 
Figure 6.13 shows the modeled versus observed heads for all wells in the flow domain. The central diagonal line in Figure 6.13 represents a perfect model fit (45-degree line); the two lines on either side of this represent a 1-m misfit above or below the perfect fit.

Another way to observe model fit is by frequency at which the residual (i.e., measured less modeled) head occurs. The residuals are shown in Figure 6.14 as a combined histogram; one for the wells inside and near the WIPP LWB, and the other shows all the wells. The residuals are shown by well in Figure 6.15, with the wells again grouped by geographic proximity to the WIPP facility. Well AEC-7 has a large misfit for two reasons. First, this well historically has had an anomalously low freshwater head elevation lower than wells around it in all directions. Second, it did not have a May 2007 observation (due to well reconfiguration activities) and therefore was not included as a calibration target in the PABC MODFLOW model calibration. Aside from AEC-7, the model fit to the September 2008 observations is very good. The average model captures the average Culebra behavior, while the PEST calibration improved the model fit to the specific September 2008 observations. 


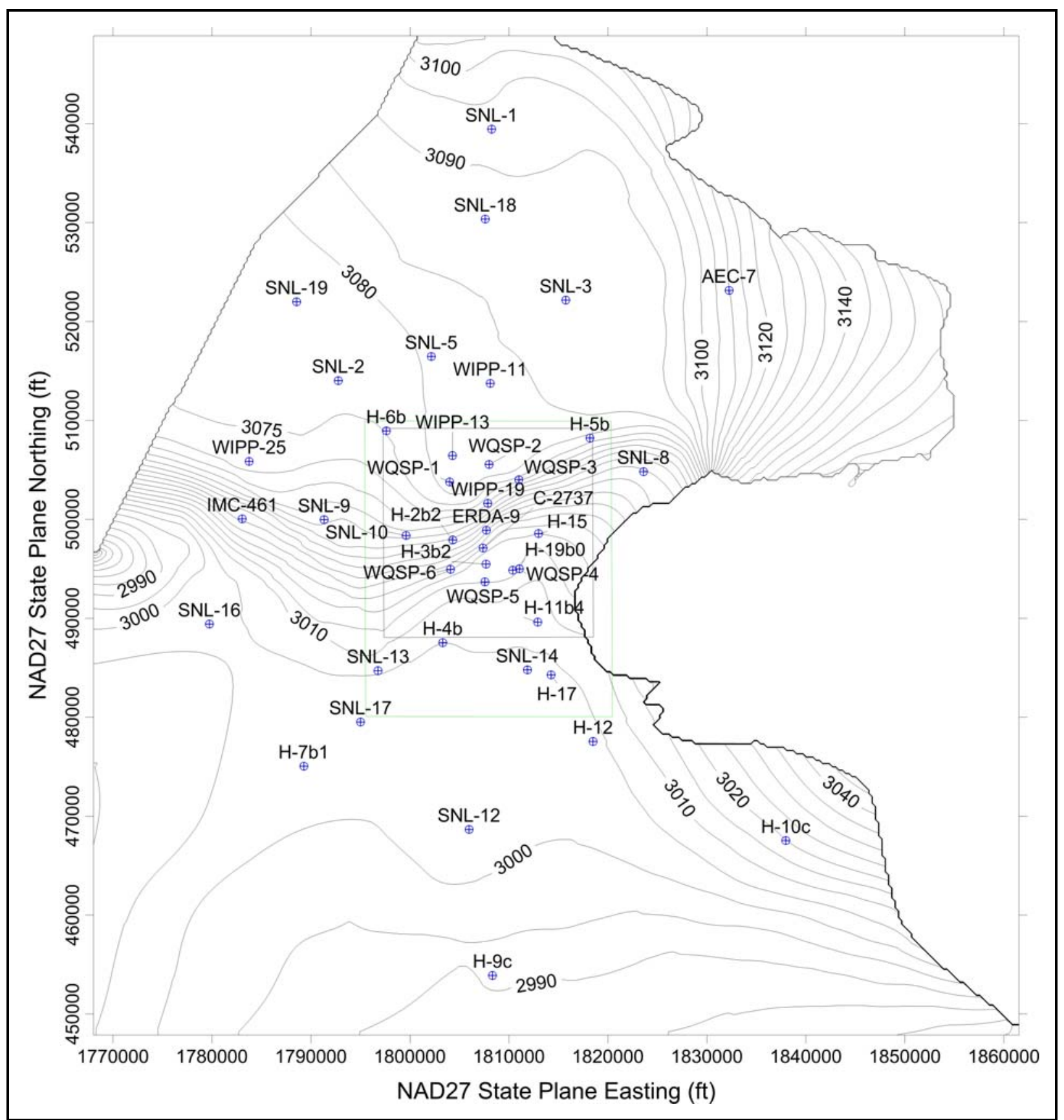

Figure 6.11 - Model-Generated September 2008 Freshwater Head Contours in the Model Domain 


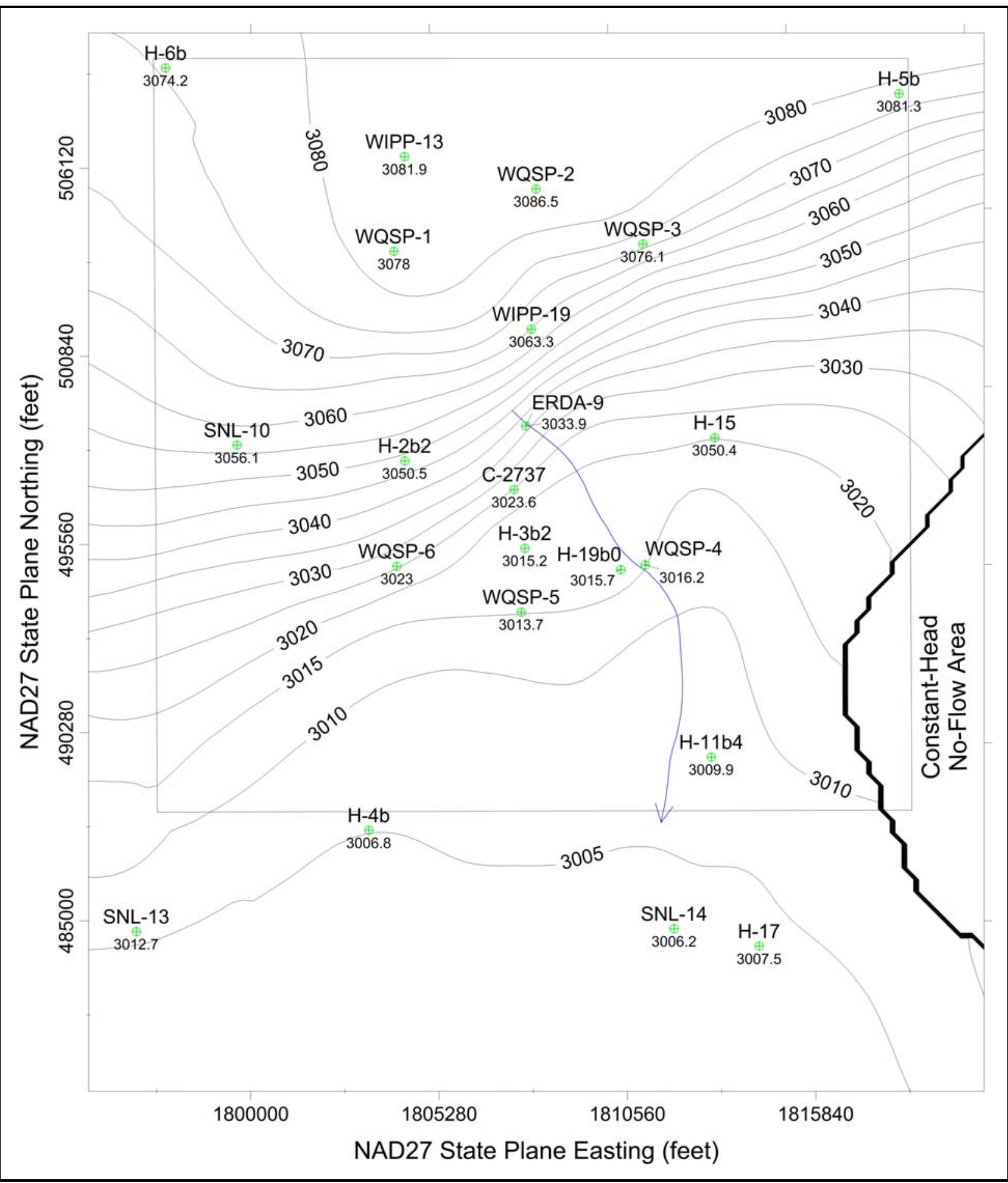

Figure 6.12 - Model-Generated September 2008 Freshwater Head Contours (5-Foot Contour Interval) in the WIPP Vicinity with Blue Water Particle Track From Waste Handling Shaft to WIPP LWB 
Waste Isolation Pilot Plant Annual Site Environmental Report for 2008 DOE/WIPP-09-2225

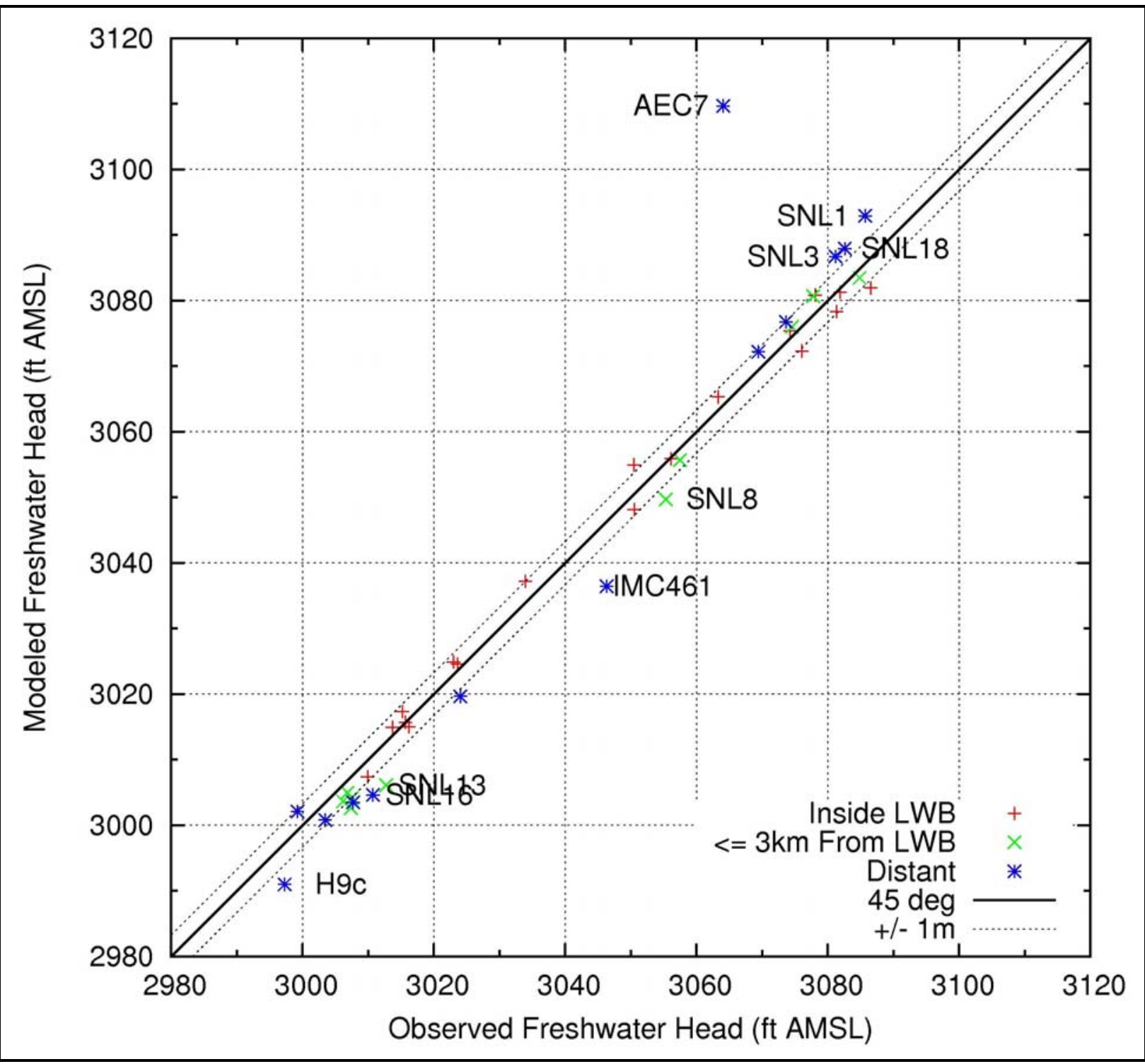

Figure 6.13 - Measured Versus Modeled Scatter Plot for PEST-Calibrated MODFLOW-2000 Generated Heads and September 2008 Observed Freshwater Heads 


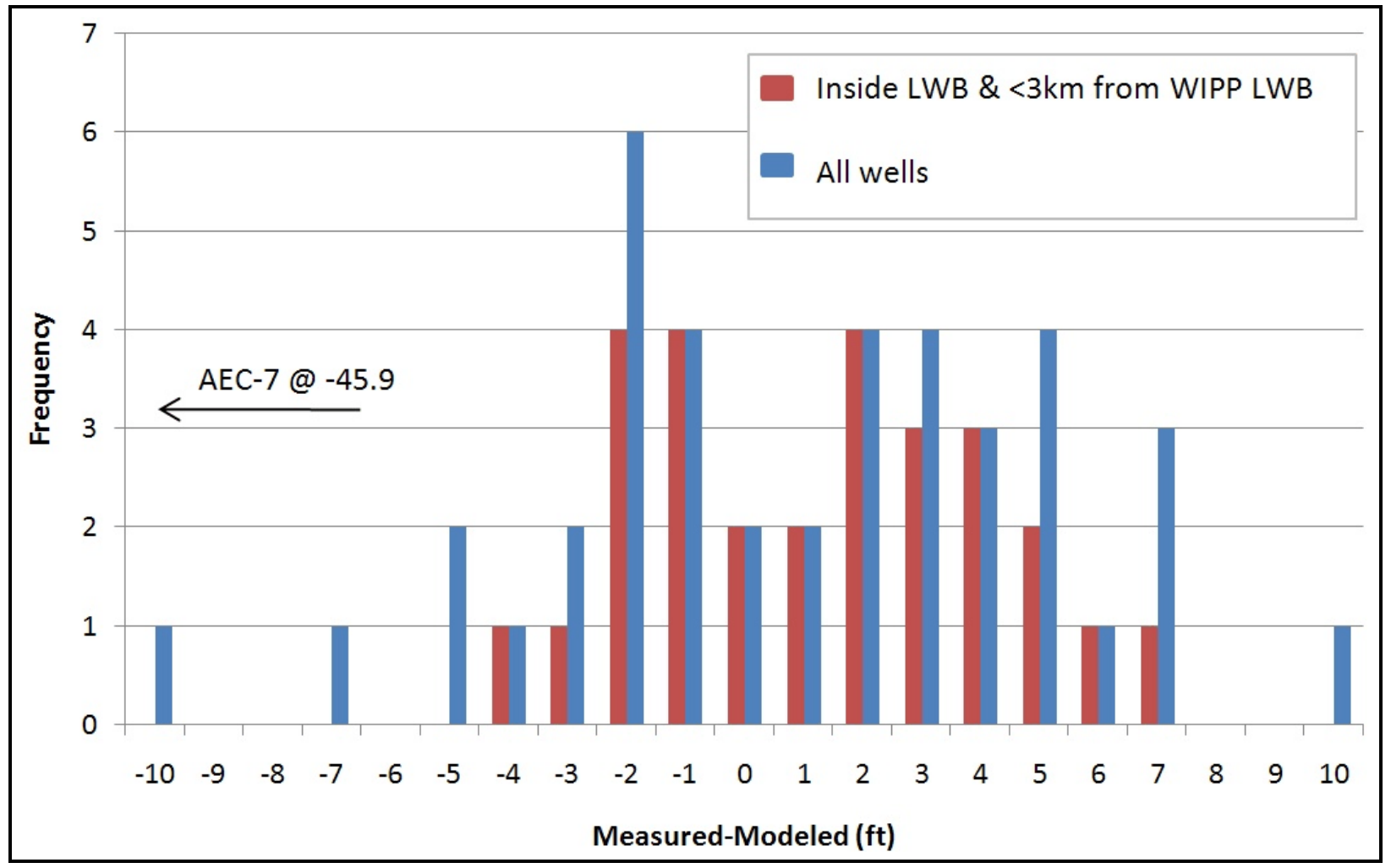

Figure 6.14 - Frequency of Modeled Freshwater Head Residuals

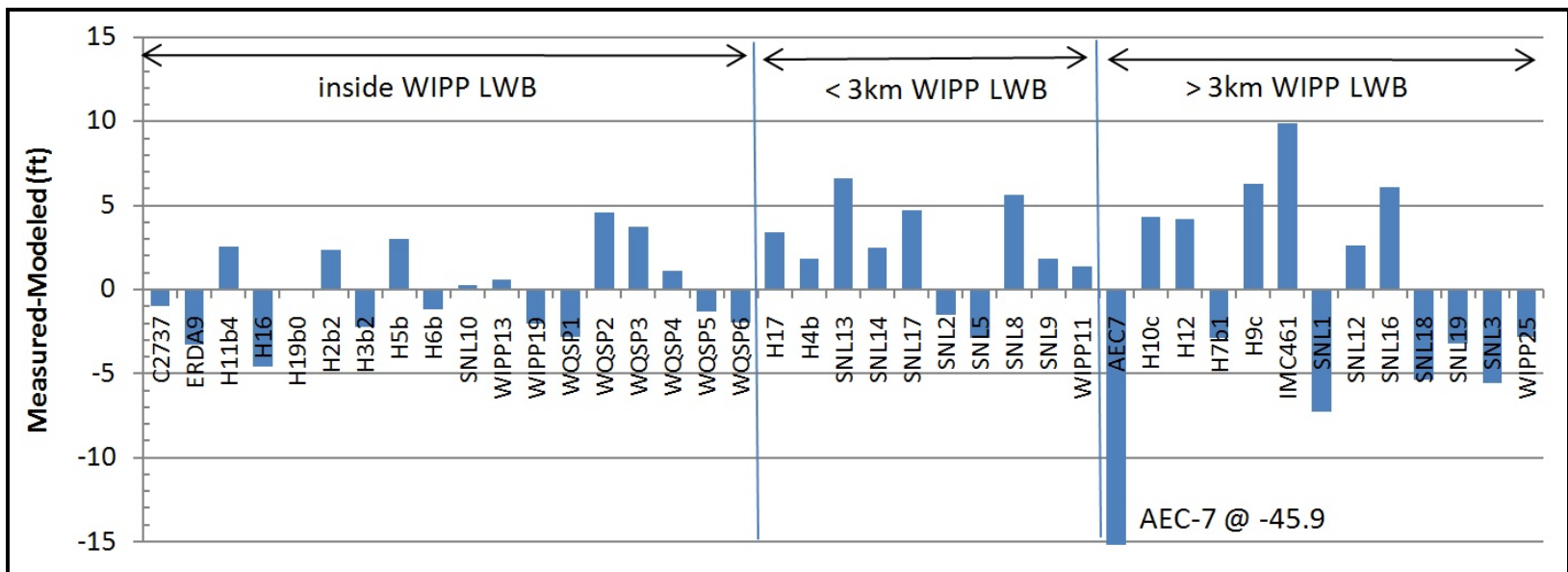

Figure 6.15 - Modeled Residual Freshwater Head at Each Well 


\subsubsection{Pressure Density Surveys}

At the WIPP site, variable TDS concentrations result in variability in groundwater density. WIPP measures the density of well-bore fluids in water level monitoring wells to adjust water levels to their equivalent freshwater head values. This allows more accurate determination of relative heads between wells. Pressure density surveys have been performed by two different methods during the past three years. In 2006 (and prior years), pressure density was obtained by a mobile trailer mounted system that obtained data at each well. In 2007 the process changed in which each well contained a dedicated pressure transducer installed by SNL.

In 2008, density measurements were derived from 44 wells, as shown in Table 6.4, from Mini Trolls installed by SNL. This approach employed several calibrated pressure-measuring transducers dedicated to given wells at times during the year. For the WQSP wells, field hydrometer measurements are always used. For comparison, 2006 and 2007 density data are shown. All year-to-year density differences are within the error as described in WP 02-1.

\begin{tabular}{|c|c|c|c|c|}
\hline Well I.D. & $\begin{array}{l}2006 \text { Pressure } \\
\text { Density Survey } \\
\text { Result }\end{array}$ & $\begin{array}{l}2007 \text { Pressure } \\
\text { Density Surve } \\
\text { Result }\end{array}$ & $\begin{array}{l}2008 \text { Pressure } \\
\text { Density Survey } \\
\text { Result }\end{array}$ & $\begin{array}{c}\text { Notes for } 2008 \text { Pressure Density } \\
\text { Survey }\end{array}$ \\
\hline & $\begin{array}{c}\text { Density } \\
\text { (grams/cc) }\end{array}$ & $\begin{array}{c}\text { Density } \\
\text { (grams/cc) }\end{array}$ & $\begin{array}{c}\text { Density } \\
\text { (grams/cc) }\end{array}$ & \\
\hline AEC-7 & 1.211 & 1.211 & 1.078 & $\begin{array}{l}\text { Re-perforated and reconfigured in } 2008 \text {; } \\
\text { value effective } 6 / 18 / 08\end{array}$ \\
\hline C-2737 & 1.027 & 1.010 & 1.029 & $\begin{array}{l}\text { PIP tubing swabbed restoring density } \\
\text { after resetting packer; value effective } \\
6 / 26 / 08\end{array}$ \\
\hline ERDA-9 & Obstructed & 1.047 & 1.067 & \\
\hline $\mathrm{H}-02 \mathrm{~b} 2$ & 1.000 & 1.014 & 1.000 & Rounded up \\
\hline $\mathrm{H}-03 \mathrm{~b} 2$ & 1.009 & 1.042 & 1.038 & \\
\hline $\mathrm{H}-04 \mathrm{~b}$ & 1.021 & 1.015 & 1.013 & \\
\hline $\mathrm{H}-05 \mathrm{~b}$ & 1.099 & 1.091 & 1.093 & \\
\hline $\mathrm{H}-06 \mathrm{~b}$ & 1.043 & 1.034 & & H-6b Plugged and Abandoned in 2008 \\
\hline $\mathrm{H}-06 \mathrm{bR}$ & & & 1.033 & $\begin{array}{l}\text { Replacement well for } \mathrm{H}-6 \mathrm{~b} \text { drilled in } \\
2008\end{array}$ \\
\hline $\mathrm{H}-07 \mathrm{~b} 1$ & 1.006 & 1.002 & 1.000 & Rounded up \\
\hline $\mathrm{H}-09 \mathrm{c}$ & 1.007 & 1.001 & 1.003 & \\
\hline $\mathrm{H}-10 \mathrm{c}$ & 1.005 & 1.008 & 1.001 & \\
\hline $\mathrm{H}-11 \mathrm{~b} 4$ & 1.071 & 1.070 & 1.062 & \\
\hline $\mathrm{H}-12$ & 1.108 & 1.097 & 1.096 & \\
\hline $\mathrm{H}-15$ & $\begin{array}{l}\text { Testing in } \\
\text { progress }\end{array}$ & 1.053 & & Converted to Magenta Well in 2008 \\
\hline $\mathrm{H}-15 \mathrm{R}$ & & & 1.130 & $\mathrm{H}-15$ replacement well drilled in 2008 \\
\hline $\mathrm{H}-16$ & & & 1.039 & $\begin{array}{l}\text { New in 2008; formerly multi-packer } \\
\text { transducer well }\end{array}$ \\
\hline $\mathrm{H}-17$ & 1.134 & 1.133 & 1.120 & \\
\hline
\end{tabular}


Waste Isolation Pilot Plant Annual Site Environmental Report for 2008 DOE/WIPP-09-2225

\begin{tabular}{|c|c|c|c|c|}
\hline \multicolumn{5}{|c|}{ Table 6.4 - Pressure Density Survey for 2008} \\
\hline Well I.D. & $\begin{array}{c}2006 \text { Pressure } \\
\text { Density Survey } \\
\text { Result }\end{array}$ & $\begin{array}{l}2007 \text { Pressure } \\
\text { Density Surve } \\
\text { Result }\end{array}$ & $\begin{array}{l}2008 \text { Pressure } \\
\text { Density Survey } \\
\text { Result }\end{array}$ & $\begin{array}{c}\text { Notes for } 2008 \text { Pressure Density } \\
\text { Survey }\end{array}$ \\
\hline & $\begin{array}{c}\text { Density } \\
\text { (grams/cc) }\end{array}$ & $\begin{array}{c}\text { Density } \\
\text { (grams/cc) }\end{array}$ & $\begin{array}{c}\text { Density } \\
\text { (grams/cc) }\end{array}$ & \\
\hline$\overline{\mathrm{H}-19 \mathrm{~b} 0}$ & 1.071 & 1.068 & 1.075 & \\
\hline |-461 & 1.017 & 1.005 & 1.019 & \\
\hline SNL-01 & 1.027 & 1.033 & 1.032 & \\
\hline SNL-02 & 1.017 & 1.012 & 1.015 & \\
\hline SNL-03 & 1.028 & 1.023 & 1.029 & \\
\hline SNL-05 & 1.010 & 1.010 & 1.012 & \\
\hline SNL-06 & No measurement & 1.246 & 1.253 & \\
\hline SNL-08 & 1.051 & 1.103 & 1.104 & \\
\hline SNL-09 & 1.024 & 1.024 & 1.026 & \\
\hline SNL-10 & 1.004 & 1.011 & 1.013 & \\
\hline SNL-12 & 1.006 & 1.005 & 1.011 & \\
\hline SNL-13 & 1.008 & 1.027 & 1.028 & \\
\hline SNL-14 & 1.038 & 1.048 & 1.048 & \\
\hline SNL-15 & 1.221 & 1.228 & 1.232 & \\
\hline SNL-16 & 1.000 & 1.010 & 1.023 & \\
\hline SNL-17 & $\begin{array}{l}\text { Testing in } \\
\text { progress }\end{array}$ & 1.006 & 1.007 & \\
\hline SNL-18 & $\begin{array}{l}\text { Testing in } \\
\text { progress }\end{array}$ & 1.028 & 1.011 & \\
\hline SNL-19 & $\begin{array}{l}\text { Testing in } \\
\text { progress }\end{array}$ & 1.003 & 1.008 & \\
\hline WIPP-11 & 1.039 & 1.038 & 1.035 & \\
\hline WIPP-13 & 1.041 & 1.053 & 1.055 & \\
\hline WIPP-19 & 1.055 & 1.044 & 1.046 & \\
\hline WIPP-25 & $\begin{array}{l}\text { Testing in } \\
\text { progress }\end{array}$ & 1.011 & 1.010 & \\
\hline WIPP-30 & 1.007 & 1.000 & & Plugged in 2008 \\
\hline WQSP-1 & 1.048 & 1.048 & 1.048 & $\begin{array}{l}\text { Average Rounds } 26 \text { and } 27 \text {, field } \\
\text { hydrometer }\end{array}$ \\
\hline WQSP-2 & 1.047 & 1.048 & 1.048 & $\begin{array}{l}\text { Average Rounds } 26 \text { and } 27 \text {, field } \\
\text { hydrometer }\end{array}$ \\
\hline WQSP-3 & 1.145 & 1.146 & 1.144 & $\begin{array}{l}\text { Average Rounds } 26 \text { and } 27 \text {, field } \\
\text { hydrometer }\end{array}$ \\
\hline WQSP-4 & 1.074 & 1.075 & 1.074 & $\begin{array}{l}\text { Average Rounds } 26 \text { and } 27 \text {, field } \\
\text { hydrometer }\end{array}$ \\
\hline WQSP-5 & 1.025 & 1.025 & 1.025 & $\begin{array}{l}\text { Average Rounds } 26 \text { and } 27 \text {, field } \\
\text { hydrometer }\end{array}$ \\
\hline WQSP-6 & 1.014 & 1.014 & 1.015 & $\begin{array}{l}\text { Average Rounds } 26 \text { and } 27 \text {, field } \\
\text { hydrometer }\end{array}$ \\
\hline
\end{tabular}




\subsection{Drilling Activities}

Two Culebra monitoring wells were installed in 2008 to replace wells that were either plugged or reconfigured. Well $\mathrm{H}-15 \mathrm{R}$ was drilled as a replacement well for $\mathrm{H}-15$ that was reconfigured as a Magenta monitoring well. Well $\mathrm{H}-6 \mathrm{bR}$ was drilled as a replacement well for $\mathrm{H}-6 \mathrm{~b}$ that was plugged and abandoned (Basic Data Report for Well Plugging and Abandonment, Reconfiguration, and New Well Drilling Activities for Fiscal Year 2008, DOE/WIPP 08-3326).

\subsection{Hydraulic Testing and Other Water Quality Sampling}

Hydrologic testing was performed by SNL throughout 2008 for basic water chemistry. Table 6.5 presents the wells tested by SNL and type of testing performed.

\begin{tabular}{|l|l|l|}
\hline \multicolumn{1}{c|}{ Table 6.5 - 2008 SNL Well and Water Quality Sampling Testing Activities } \\
\hline WNL-6, Culebra & \multicolumn{1}{c|}{ Dates } & \multicolumn{1}{c|}{ Activity $^{1}$} \\
\hline H-11b2, Magenta & January 2008 & Water Chemistry \\
\hline H-15, Magenta & January - June 2008 & Water Chemistry \\
\hline AEC-7, Culebra & March 2008 & Water Chemistry \\
\hline H-15R, Culebra & March, April, June 2008 & Water Chemistry \\
\hline H-6bR, Culebra & September, October, November 2008 & Water Chemistry \\
\hline
\end{tabular}

\subsection{Well Maintenance}

Well maintenance activities for 2008 included plugging and abandonment of two wells, reconfiguration of two wells (DOE/WIPP 08-3326), development of seven wells and surveying of seven wells that were either reconfigured or were new.

Well AEC-7 was reconfigured due to seepage from the Salado Formation into the well, artificially raising fluid density. A cement plug was placed into this well to a point in which the casing intersecting the Culebra Member could be perforated. After perforation the well was developed to restore Culebra fluid density (DOE/WIPP-08-3326).

Well $\mathrm{H}-15$ was previously a dual completion well where the Magenta Member was separated from the Culebra Member with a production-injection packer (PIP). The PIP was removed and the well was cemented to the perforations of the Magenta Member. A Magenta well was installed inside the older well casing (DOE/WIPP-08-3326).

Well $\mathrm{H}-16$ was previously an open borehole with a multi-level packer and transducer completion. The well historically had not been accessible to obtain water level 
measurements until it was reconfigured in 2008 to a single screened interval well completed in the Culebra Member (DOE/WIPP-08-3326).

Seven wells were developed in 2008 to either restore fluid density, clear an obstruction, or bail debris from the bottom of the well.

Wells Cabin Baby-1 (CB-1) and DOE-2 were reconfigured as Bell Canyon Formation wells in 2004. During this reconfiguration it appeared some fresh water remained in the PIP after inflation of the packers, thus affecting fluid density. In 2008 these wells were swabbed using a pulling unit due to the depth requirements $(>4,000$ feet) to remove the water and restore fluid density.

Well C-2737 had its PIP reset in late 2007 and during this process retained some freshwater while inflating the packer. The PIP was swabbed and this restored the fluid density.

Wells $\mathrm{H}-3 \mathrm{~b} 2, \mathrm{H}-12$, and $\mathrm{H}-17$ were bailed in late 2008 to remove oxidation spall from the steel casing and other debris from the bottom of the wells that had collected over the years.

The wells that were newly drilled or reconfigured were also resurveyed. Additionally, CB-1 and DOE-2 were resurveyed due to the top of casing being altered for fittings during development. The survey was performed by Real-Time Kinematic (RTK) GPS methods. Table 6.6 lists the surveyed wells, coordinates, and elevations.

Table 6.6 - 2008 Survey Data

\begin{tabular}{|c|c|c|c|c|}
\hline Well & $\begin{array}{c}\text { Northing } \\
\text { NAD27(ft) }\end{array}$ & $\begin{array}{c}\text { Easting } \\
\text { NAD27(ft) }\end{array}$ & $\begin{array}{c}\text { Top of Casing } \\
\text { (TOC)(ft) }\end{array}$ & $\begin{array}{c}\text { Ground } \\
\text { Elevation(ft) }\end{array}$ \\
\hline CB-1 & 486062 & 665522 & 3329.12 & 3327.10 \\
\hline AEC-7 & 523115 & 691844 & 3657.06 & 3656.11 \\
\hline DOE-2 & 509872 & 667287 & 3419.18 & 3417.45 \\
\hline $\mathrm{H}-6 \mathrm{bR}$ & 508904 & 657138 & 3349.22 & 3346.59 \\
\hline $\mathrm{H}-15$ & 498559 & 672588 & 3483.50 & 3480.24 \\
\hline $\mathrm{H}-15 \mathrm{R}$ & 498510 & 672592 & 3482.02 & 3479.98 \\
\hline $\mathrm{H}-16$ & 499725 & 666232 & 3410.06 & 3409.08 \\
\hline
\end{tabular}

Note: Coordinates are New Mexico State Plane (feet)

\subsection{Shallow Subsurface Water Monitoring Program}

Shallow subsurface water occurs beneath the WIPP site at a depth of less than $100 \mathrm{ft}$ below ground level at the contact between the Santa Rosa and the Dewey Lake (Figure 6.1). Water yields are generally less than one gallon per minute in monitoring wells and piezometers and the water contains varying concentrations of TDS (968 mg/L to $245,500 \mathrm{mg} / \mathrm{L}$ ) and chloride (186 mg/L to $150,000 \mathrm{mg} / \mathrm{L})$; to the south, yields are greater. The origin of the high TDS in this water is believed to be primarily from anthropogenic sources, with some contribution from natural sources. The SSW occurs not only under the WIPP site surface facilities but also to the south as indicated by 
shallow water in drill hole C-2811, about one half mile south of the waste handling shaft (Figure 6.16). Additionally, drilling in 2007 around the SPDV salt pile tailings revealed shallow water in three piezometers (PZ-13, PZ-14, and PZ-15, shown in Figure 6.14). Natural shallow groundwater occurs in the middle part of the Dewey Lake at the southern portion of the WIPP site (WQSP-6A) and to the south of the WIPP site (J. C. Mills Ranch). To date, there is no indication that the anthropogenic SSW has affected the naturally occurring groundwater in the Dewey Lake.

In order to investigate the SSW, 15 piezometers (PZ-1 to PZ-15) and four wells (C-2505, C-2506, C-2507, and C-2811) have been drilled as part of a monitoring program to measure spatial and temporal changes in SSW levels and water quality. Monitoring activities during 2008 included SSW level surveillance at these 19 locations (Figure 6.16).

On September 9, 2008, the NMED GWQB issued a DP-831 modification to bring the original permit of December 2003 into its current form. SSW is monitored per the conditions of this permit modification. 
Waste Isolation Pilot Plant Annual Site Environmental Report for 2008 DOE/WIPP-09-2225

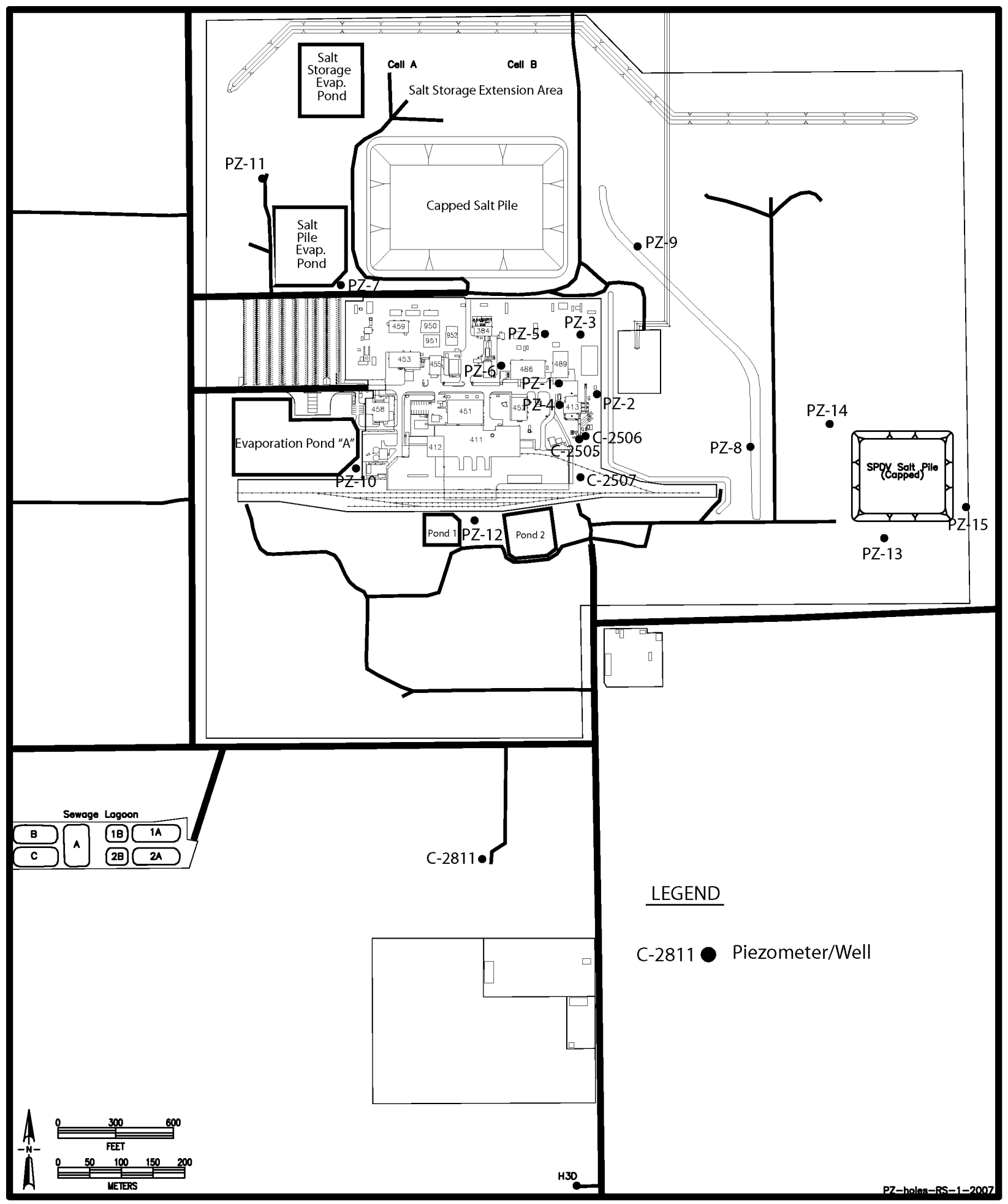

Figure 6.16 - Location of SSW Wells (Piezometers PZ-01 through 15, C-2811, C-2505, C-2506, C-2507) 


\subsubsection{Shallow Subsurface Water Quality Sampling}

DP-831, as modified, requires 11 SSW wells to be sampled on a semiannual basis. Wells PZ-1, PZ-5, PZ-6, PZ-7, PZ-9, PZ-10, PZ-11, PZ-12, PZ-13, C-2811, and C-2507 are sampled for this program. These wells were sampled in June and October 2008 and laboratory analyzed for the parameters presented in Table 6.7

\begin{tabular}{|c|c|c|c|c|c|c|c|}
\hline \multirow[b]{2}{*}{$\begin{array}{l}\text { Monitoring } \\
\text { Site }\end{array}$} & \multicolumn{5}{|c|}{ General Chemistry Parameters } & \multicolumn{2}{|c|}{ Trace Metals } \\
\hline & $\begin{array}{c}\text { Sample } \\
\text { Date }\end{array}$ & $\begin{array}{l}\text { Nitrate } \\
\text { (mg/L) }\end{array}$ & $\begin{array}{l}\text { Sulfate } \\
\text { (mg/L) }\end{array}$ & $\begin{array}{c}\text { Chloride } \\
\text { (mg/L) }\end{array}$ & $\begin{array}{c}\text { TDS } \\
(\mathrm{mg} / \mathrm{L})\end{array}$ & $\begin{array}{c}\text { Selenium } \\
\text { (mg/L) }\end{array}$ & $\begin{array}{c}\text { Chromium } \\
\text { (mg/L) }\end{array}$ \\
\hline PZ-1 & $6 / 5 / 08$ & $<2.0$ & 2,100 & 57,000 & 98,000 & 0.667 & 0.00218 \\
\hline PZ-1 & $10 / 14 / 08$ & NS & 2,200 & 59,000 & 94,000 & NS & NS \\
\hline PZ-5 & $6 / 5 / 08$ & 5.7 & 1,500 & 19,000 & 33,000 & 0.0801 & 0.00317 \\
\hline $\mathrm{PZ}-5$ & $10 / 14 / 08$ & NS & 1,400 & 13,000 & 25,000 & NS & NS \\
\hline PZ-6 & $6 / 5 / 08$ & 6.1 & 2,100 & 47,000 & 81,000 & 0.0412 & 0.00259 \\
\hline$\overline{P Z-6}$ & $10 / 14 / 08$ & NS & 2,500 & 58,000 & 87,000 & NS & NS \\
\hline PZ-7 & $6 / 4 / 08$ & 5.0 & 2,300 & 49,000 & 86,000 & 0.0635 & 0.00257 \\
\hline PZ-7 & $10 / 13 / 08$ & NS & 1,700 & 27,000 & 42,000 & NS & NS \\
\hline $\mathrm{PZ}-8^{1}$ & $6 / 6 / 08$ & 1.8 & 630 & 11,000 & 16,000 & 0.0655 & $<0.001$ \\
\hline PZ-9 & $6 / 5 / 08$ & 2.2 & 4,400 & 87,000 & 150,000 & 0.0351 & 0.00492 \\
\hline PZ-9 & $10 / 14 / 08$ & NS & 4,100 & 96,000 & 140,000 & NS & NS \\
\hline PZ-10 & $6 / 4 / 08$ & 4.5 & 390 & 300 & 1,500 & 0.0144 & 0.00119 \\
\hline PZ-10 & $10 / 13 / 08$ & NS & 380 & 290 & 1,400 & NS & NS \\
\hline PZ-11 & $6 / 4 / 08$ & 3.9 & 2,100 & 65,000 & 110,000 & 0.0149 & 0.00216 \\
\hline PZ-11 & $10 / 13 / 08$ & NS & 3,000 & 79,000 & 110,000 & NS & NS \\
\hline PZ-12 & $6 / 4 / 08$ & 11 & 760 & 3,300 & 6,800 & 0.0291 & 0.00132 \\
\hline $\mathrm{PZ}-12$ & $10 / 13 / 08$ & NS & 850 & 3,300 & 7,000 & NS & NS \\
\hline PZ-13 & $10 / 10 / 07$ & 12.4 & 2,670 & 150,000 & 245,500 & $<0.100$ & $<0.00500$ \\
\hline PZ-13 & $6 / 6 / 08$ & $<200$ & 2,600 & 170,000 & 240,000 & 0.0118 & 0.00316 \\
\hline $\mathrm{PZ}-14^{1}$ & $6 / 6 / 08$ & $<100$ & 3,300 & 130,000 & 180,000 & 0.0201 & 0.00168 \\
\hline$P Z-15^{1}$ & $6 / 6 / 08$ & 12 & 160 & 460 & 1,600 & 0.00372 & $<0.001$ \\
\hline C-2811 & $6 / 4 / 08$ & 5.7 & 390 & 1,300 & 2,800 & 0.00170 & 0.0350 \\
\hline C-2811 & $10 / 13 / 08$ & NS & 320 & 1,000 & 2,100 & NS & NS \\
\hline C-2507 & $6 / 5 / 08$ & 6.9 & 990 & 2,800 & 5,800 & 0.0637 & 0.00493 \\
\hline C-2507 & $10 / 14 / 08$ & NS & 940 & 2,200 & 5,100 & NS & NS \\
\hline
\end{tabular}

${ }^{1}$ Sampled for baseline. DP-831 does not require further sampling.

\subsubsection{Shallow Subsurface Water Level Surveillance}

Nineteen wells were used to perform surveillance of the SSW-bearing horizon in the Santa Rosa Formation and the upper portion of the Dewey Lake Redbeds Formation. Water levels were collected quarterly at all the piezometers and wells shown in Figure 6.16. 
The potentiometric surface for the SSW using December 2008 data is presented in Figure 6.17. The contours were generated using SURFER version 8.06 .39 surface mapping software by Golden Software. Sixteen data points were used in the contour development, whereas the contours around the SPDV salt pile were estimated by hand.

Groundwater elevation measurements in the SSW indicate that flow is to the east and south away from a potentiometric high located near PZ-7 adjacent to the Salt Pile Evaporation Pond (Figure 6.17). At this time, it appears that the water identified in PZ-13 and PZ-14 is separate and distinct from the SSW in the other wells at the WIPP facilities area (DOE/WIPP-08-3375, Basic Data Report for Piezometers PZ-13, PZ-14. And PZ-15 and SSW). Piezometer-13 and PZ-14 were completed at the contact of the Santa Rosa and Dewey Lake. PZ-15 was completed much shallower in the Gatuña Formation where it appears rainwater has accumulated from a localized recharge source. Geochemically, the PZ-wells around the SPDV salt pile are distinct from the SSW wells located on the WIPP facilities area. Because of the recharge influence from a localized depression near PZ-15, this is a geochemically distinct area from the piezometers around the SPDV salt pile and the WIPP facilities area. 
Waste Isolation Pilot Plant Annual Site Environmental Report for 2008 DOE/WIPP-09-2225

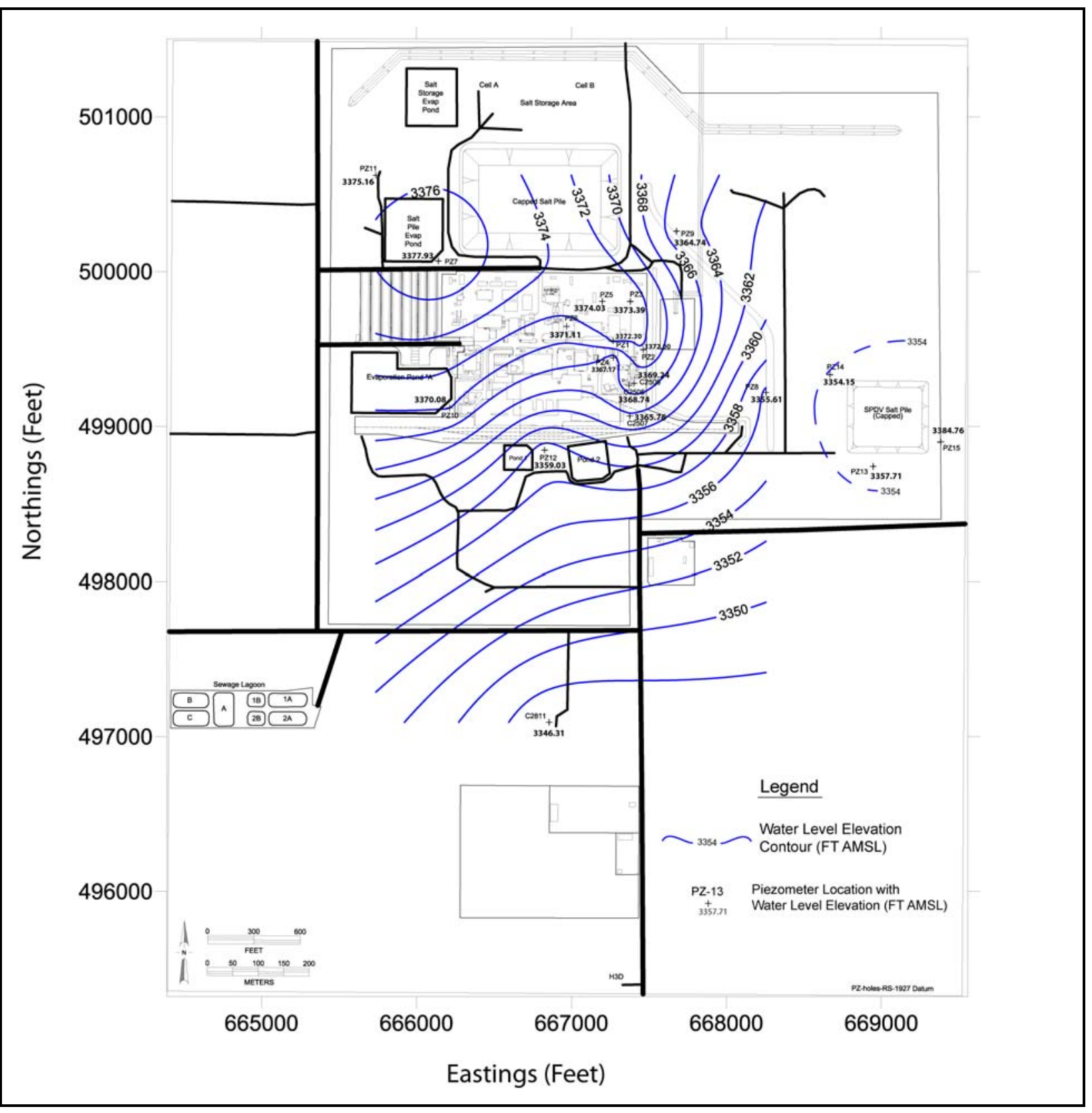

Figure 6.17 - SSW Potentiometric Surface

\subsection{Public Drinking Water Protection}

The water wells nearest the WIPP site that use the natural shallow groundwater for domestic use are the Barn Well and Ranch Well located on the J. C. Mills Ranch. These wells are located approximately 3 mi south-southwest of the WIPP surface facilities, and about $1.75 \mathrm{mi}$ south of WQSP-6A (see Figure 6.3 for location of WQSP-6A). Total dissolved solids concentrations in the Barn Well have ranged from 630 to $720 \mathrm{mg} / \mathrm{L}$, and TDS concentrations in the Ranch Well have ranged from 2,800 to $3,300 \mathrm{mg} / \mathrm{L}$ (DOE, 1996). 
A water budget analysis in 2003 indicated that seepage from five primary sources (salt pile and four surface water detention basins) provided sufficient recharge to account for the observed SSW saturated lens and that the lens is expected to spread.

The potential extent for long-term SSW migration was examined by expanding the saturated flow model domain to include the 16-square-mile WIPP Land Withdrawal Area. The long-term migration model simulations indicated that the engineered seepage controls that are now in place will substantially reduce the extent of migration. 
Waste Isolation Pilot Plant Annual Site Environmental Report for 2008

DOE/WIPP-09-2225

This page intentionally left blank 


\section{CHAPTER 7 - QUALITY ASSURANCE}

The fundamental objective of the environmental QA program is to obtain accurate and precise analytical data that is technically and legally defensible. This is accomplished through a series of management activities that plan, implement, review, assess, and correct as necessary. Samples are collected and analyzed using standardized and proven methods. The resulting sample and associated QC data are reviewed, verified, validated, and incorporated into succinct and informative reports.

In 2008, WIPP Laboratories performed the radiological analyses of environmental samples from the WIPP site, while several contract laboratories including the Carlsbad Environmental Monitoring and Research Center (CEMRC), in Carlsbad, New Mexico; TraceAnalysis, Inc. (Trace), in Lubbock, Texas, and Hall Environmental Analysis Laboratory (HEAL), in Albuquerque, New Mexico, performed the nonradiological analyses. These laboratories were required contractually to have documented QA programs, including an established QA plan along with laboratory-specific standard operating procedures (SOPs) based on published standard methods to perform the work.

The WIPP Laboratories, Trace, and HEAL were required to participate in inter-comparison programs with such entities as the National Institute of Standards and Technology Radiochemistry Inter-comparison Program (NRIP), the Mixed Analyte Performance Evaluation Program (MAPEP), the Environmental Resource Associates ${ }^{\circledR}$ (ERA) interlaboratory assessment, the National Environmental Laboratory Accreditation Conference (NELAC), and/or other reputable interlaboratory comparison programs. Laboratories used by the WIPP program are required to meet the applicable requirements of the CBFO Quality Assurance Program Document (DOE/CBFO-94-1012), as flowed down through the Washington TRU Solutions LLC Quality Assurance Program Description (WP 13-1). CEMRC was not required to participate in inter-comparison programs during 2008.

The WIPP sampling program and the subcontracted analytical laboratories operate in accordance with $Q A$ plans and QA project plans that incorporate $Q A$ requirements from the WTS Quality Assurance Program Description. These plans contain such elements as:

- Management and organization

- Quality system and description

- $\quad$ Personnel qualification and training

- $\quad$ Procurement of products and services

- Documents and records

- $\quad$ Computer hardware and software 


\section{- $\quad$ Planning}

- $\quad$ Management of work process (SOPs)

- $\quad$ Assessment and response

- $\quad$ Quality improvement

To ensure that the quality of the systems, processes, and deliverables are maintained or improved, three layers of assessments and audits are performed:

- $\quad$ DOE/CBFO performs assessments and audits of the WTS QA program.

- WTS performs internal assessments and audits of their own QA program.

- WTS performs assessments and audits of subcontractor QA programs as applied to WTS contract work.

The QA objectives for the sampling and analysis program are completeness, precision, accuracy, comparability, and representativeness.

Sections 7.1, 7.2, 7.3, and 7.4 discuss the QC results for the WIPP Laboratories, CEMRC, Trace, and HEAL, in terms of how they met the QA objectives.

\subsection{WIPP Laboratories}

Samples for analysis of radionuclides were collected using approved procedures based on generally accepted methodologies for environmental sampling, ensuring that the samples were representative of the media sampled. The samples were analyzed for natural radioactivity, fallout radioactivity from nuclear weapons tests, and other anthropogenic radionuclides. The reported concentrations at various locations are representative of the baseline information for radionuclides of interest at the WIPP facility.

\subsubsection{Completeness}

The SOW for analyses performed by WIPP Laboratories states that "analytical completeness, as measured by the amount of valid data collected versus the amount of data expected or needed, shall be greater than 90 percent for WTS sampling programs." For radiological sampling and analysis programs, this contract requirement translates into the following quantitative definition. 
Completeness is expressed as the number of samples analyzed with valid results as a percent of the total number of samples submitted for analysis, or

$$
\% C=\frac{V}{n} \times 100
$$

Where:

$\% \mathrm{C}=$ Percent Completeness

$V=$ Number of Samples with Valid Results

$\mathrm{n}=$ Number of Samples Submitted for Analysis

Samples and measurements for all environmental media (air particulate composites, groundwater, surface water, soil, sediment, and animal and plant tissues) were 100 percent complete for 2008.

\subsubsection{Precision}

The SOW states that analytical precision (as evaluated through replicate measurements) will meet or surpass control criteria or guidelines established in the industry-standard methods used for sample analysis. To ensure overall quality of analysis of environmental samples, precision was evaluated for both sample collection and sample analysis procedures combined as well as the sample analysis procedures alone. At least one pair of field duplicates should be collected and analyzed for each matrix type. The precision of field duplicates and laboratory duplicates can be calculated for non-detected as well as detected radionuclide analytes, but only the precision of detected radionuclides is presented in this report.

The measure of precision for radionuclide sample analyses is the Relative Error Ratio, RER. The RER is expressed as follows:

$$
R E R=\frac{\mid(\text { MeanActivity })_{\text {ori }}-(\text { MeanActivity })_{\text {dup }} \mid}{\sqrt{(2 \times S D)^{2} \text { ori }+(2 \times S D)^{2} \text { dup }}}
$$

Where:
(Mean Activity) $)_{\text {ori }}=$
Mean Activity of the Original or Primary Sample
(Mean Activity $)_{\text {dup }}$
$=\quad$ Mean Activity of the Duplicate Sample
SD
$=\quad$ Standard Deviation of Original and Duplicate Samples 
The QA objective for the RER results is a value less than or equal to $1(\leq 1)$. Relative error ratio values $\leq 1$ demonstrate adequate to good reproducibility.

Comparison of analytical results for duplicate samples collected in the field provides a measure of precision of the entire measurement system, including the heterogeneity of the media being sampled.

Precision or reproducibility in sample collection and analysis combined was evaluated through comparison of analytical results for duplicate samples collected in the field.

In the case of the air particulate filters, a portable low-volume air sampler was moved from location to location in each quarter, and was operated along with routine stationary air particulate samplers. No RER precision determinations were reported for the 2008 air particulate filter data since there were no instances in which both the sample and the duplicate met the detection criteria.

The duplicate samples for other environmental media were collected at the same time, same place, and under similar conditions as routine samples. In the case of animals, there were no duplicate field samples, but the laboratory generated duplicate samples for analysis from the single samples.

The laboratory performed duplicate analyses on separate portions of the same homogenized sample on at least one sample from each batch for each type of sample matrix in order to generate precision data. The duplicate analyses of separate aliquots of the same sample evaluate the precision of subsampling, the heterogeneity of the media being sampled, and the precision of the analytical method. These precision data, as RERs, are not reported in the tables, but all the RERs were $\leq 1$ for the sample batches analyzed in 2008, demonstrating excellent precision for the analysis procedures.

In contrast to the single samples analyzed in duplicate, duplicate field samples of groundwater, surface water, sediments, soil, and vegetation were collected and submitted to the laboratory for analysis. Most of the field duplicate samples for multiple radiological parameters also yielded RERs $\leq 1$ indicating good reproducibility for the combination of the sampling and analysis procedures. However, a few duplicate pairs for groundwater, surface water, sediments, soil, and vegetation yielded RERs $>1$, indicating that the precision objective was not met (Tables 4.5 and 4.6, 4.10, 4.14, 4.18, and 4.20). Four of five RER values for surface water were $>1$ as shown in Table 4.10. Based on the precise analysis results for laboratory duplicates, the imprecision of some field duplicate samples suggests that the imprecision is associated more with the samples than with the analysis procedures and may reflect actual differences in the composition of the duplicate samples due to a nonhomogeneous distribution of radionuclides, perhaps due to association of radionuclides with particulates in the water. 


\subsubsection{Accuracy}

The accuracy of the radiochemical analyses was evaluated by analyzing calibration standards, method blanks, and laboratory control samples (blank spikes) as specified in the laboratory's SOPs. The radiochemistry SOW does not require the analysis of matrix spike samples. The SOW requires the measured accuracy to meet or surpass control criteria or guidelines established in the industry-standard methods used for sample analysis. Instrument accuracy was assessed and assured by using National Institute of Standards and Technology (NIST) traceable standards for instrument calibration.

NIST-traceable standards were also spiked into clean water or clean solid to prepare laboratory control samples (LCSs). Laboratory control samples are QC samples that check whether the analysis procedure is in control. Analysis of LCSs containing the isotopes of interest was performed on a minimum 10 percent basis (one per every batch of ten or fewer samples). The QA objective for the analysis results was that the measured concentration be within \pm 20 percent of the known spiked value. If this criterion was not met, the entire batch of samples was reanalyzed. LCS results for each isotope were tracked on a running basis using control charts. All radiological LCS results fell within the acceptable ranges, indicating good accuracy.

Accuracy was also ensured through participation by the laboratory in the DOE MAPEP, the DOE Laboratory Accreditation Program (DOELAP), and NRIP interlaboratory comparison programs, as discussed in more detail in Section 7.1.4. Under these programs, WIPP Laboratories analyzed blind check samples, and the analysis results were compared with the official results measured by the DOELAP, MAPEP, and NRIP laboratories. Performance was established by percent bias, calculated as shown below.

$$
\% \text { Bias }=\frac{\left(A_{m}-A_{k}\right)}{A_{k}} \times 100
$$

Where:

$\begin{array}{lll}\% \text { Bias }= & \text { Percent Bias } \\ A_{m} & = & \text { Measured Sample Activity } \\ A_{k} & = & \text { Known Sample Activity }\end{array}$

The DOELAP and NRIP programs for accuracy only include the analyses of urine and feces. Since bioassay (urine and feces) samples are not analyzed as part of the WIPP environmental program, these NRIP and DOELAP program PE analysis results are not specifically discussed in this report. However, out of a total of 78 NRIP, 12 DOELAP, and 50 MAPEP PE analysis results reported in fiscal year 2008, only one analysis result, which was for ${ }^{134} \mathrm{Cs}$, did not meet the accuracy acceptance criteria of the various agencies, and this analyte is not a WIPP analyte. The laboratory reported a concentration for ${ }^{134} \mathrm{Cs}$ when it was not present in the sample, but also reported an ID confidence factor of zero for the result that was not taken into account by the testing agency. 
Based on the number of A (Acceptable) ratings earned by WIPP Laboratories for the analysis of performance evaluation samples, the laboratory provided accurate and reliable radionuclide analysis data for the WIPP environmental samples.

\subsubsection{Comparability}

The mission of WIPP Laboratories is to produce high-quality and defensible analytical data in support of the WIPP operations. The SOW requires WIPP Laboratories to ensure consistency through the use of standard analytical methods coupled with specific procedures that govern the handling of samples and the reporting of analytical results. A key element in the WIPP Laboratories QA program is analysis of performance evaluation (PE) samples as part of interlaboratory comparison programs administered by reputable agencies. During the period September 1, 2007, to September 1, 2008, WIPP Laboratories participated in four rounds of the NIST NRIP Emergency Preparedness Program and one round of the DOE MAPEP. In addition, WIPP Laboratories hosted an on-site audit and analyzed numerous PE samples from DOELAP. DOELAP granted accreditation for in-vitro bioassay analyses on March 21, 2001, and renewed the accreditation in 2004 and 2007 as part of the three-year renewal schedule.

The DOELAP, MAPEP, and NRIP programs involve preparing QC samples containing various alpha-, beta-, and gamma-emitting radionuclides in synthetic urine, synthetic feces, air filter, water, soil, and vegetation media, and distributing the samples to the participating laboratories. The programs are interlaboratory comparisons in that results from the participants are compared with the experimentally measured results of the administering agencies. The programs assess each laboratory's analysis results as acceptable (or passing) or not acceptable (or failing), based on the accuracy of the analyses.

Table 7.1 presents the analysis results for the MAPEP soil, air filter, vegetation, and water PE samples. All MAPEP bias results met the acceptance criteria (-25 percent/ +50 percent) for all radionuclides and media of interest at the WIPP site.

Table 7.1 - Mixed Analyte Performance Evaluation Program Review for WIPP Laboratories, 2008

\begin{tabular}{|c|c|c|c|c|c|c|c|c|}
\hline \multirow[b]{2}{*}[\mathrm{RN}]{$^{\mathrm{a}}$} & \multicolumn{4}{|c|}{$\begin{array}{c}\text { MATRIX: Air Filter (Bq/Filter) } \\
\text { MAPEP-07-RdF18 }\end{array}$} & \multicolumn{4}{|c|}{$\begin{array}{l}\text { MATRIX: Water (Bq/sample) } \\
\text { MAPEP-07-MaW18 }\end{array}$} \\
\hline & $\begin{array}{l}\text { Reported } \\
\text { Value }\end{array}$ & $\begin{array}{l}\text { MAPEP }^{b} \\
\text { Value }\end{array}$ & $E^{c}$ & \% Bias & $\begin{array}{l}\text { Reported } \\
\text { Value }\end{array}$ & $\begin{array}{l}\text { MAPEP } \\
\text { Value }\end{array}$ & $E$ & $\%$ Bias \\
\hline${ }^{241} \mathrm{Am}$ & 0.147 & 0.158 & $A$ & -7.0 & 1.19 & 1.23 & $A$ & -3.3 \\
\hline${ }^{60} \mathrm{Co}$ & 1.29 & 1.31 & A & -1.5 & 8.39 & 8.40 & A & -0.1 \\
\hline${ }^{134} \mathrm{Cs}$ & 1.92 & 2.52 & $A$ & -23.8 & 1.15 & 0 & $\mathrm{~N}$ & $d$ \\
\hline${ }^{137} \mathrm{Cs}$ & 2.47 & 2.70 & A & -8.5 & -6.50 & 0 & A & $d$ \\
\hline${ }^{238} \mathrm{Pu}$ & 0.102 & 0.105 & A & -3.1 & 0.631 & 0.73 & A & -13.6 \\
\hline${ }^{239 / 240} \mathrm{Pu}$ & 0.108 & 0.114 & $A$ & -5.3 & 0.0153 & 0.0141 & A & $\mathrm{e}$ \\
\hline${ }^{90} \mathrm{Sr}$ & 1.54 & 1.548 & $A$ & -0.5 & 11.7 & 11.4 & A & 2.6 \\
\hline${ }^{233 / 234} U$ & 0.255 & 0.218 & $A$ & 17.0 & 3.61 & 3.63 & $A$ & -0.6 \\
\hline
\end{tabular}


Waste Isolation Pilot Plant Annual Site Environmental Report for 2008 DOE/WIPP-09-2225

Table 7.1 - Mixed Analyte Performance Evaluation Program Review for WIPP Laboratories, 2008

\begin{tabular}{|c|c|c|c|c|c|c|c|c|}
\hline${ }^{238} \mathrm{U}$ & 0.249 & 0.225 & A & 10.7 & 3.65 & 3.74 & A & -2.4 \\
\hline \multicolumn{5}{|c|}{$\begin{array}{l}\text { MATRIX: Soil (Bq/kg) } \\
\text { MAPEP-07-MaS18 }\end{array}$} & \multicolumn{4}{|c|}{$\begin{array}{l}\text { MATRIX: Vegetation (Bq/Sample) } \\
\text { MAPEP-07-RdV18 }\end{array}$} \\
\hline [RN] & $\begin{array}{l}\text { Reported } \\
\text { Value }\end{array}$ & $\begin{array}{l}\text { MAPEP } \\
\text { Value }\end{array}$ & E & $\%$ Bias & $\begin{array}{l}\text { Reported } \\
\text { Value }\end{array}$ & $\begin{array}{l}\text { MAPEP } \\
\text { Value }\end{array}$ & E & $\%$ Bias \\
\hline${ }^{241} \mathrm{Am}$ & 120 & 127.2 & A & -5.7 & 0.240 & 0.240 & A & 0 \\
\hline${ }^{60} \mathrm{Co}$ & 1.87 & 2.9 & $f$ & $f$ & 2.86 & 2.77 & A & 3.2 \\
\hline${ }^{134} \mathrm{Cs}$ & 860 & 854 & A & 0.7 & 6.47 & 6.28 & A & 3.0 \\
\hline${ }^{137} \mathrm{Cs}$ & 507 & 545 & A & -7.0 & 3.50 & 3.41 & A & 2.6 \\
\hline${ }^{238} \mathrm{Pu}$ & 69.9 & 72.8 & A & -4.0 & 0.137 & 0.147 & A & -6.8 \\
\hline${ }^{239 / 240} \mathrm{Pu}$ & 88.0 & 90.1 & A & -2.3 & 0.257 & 0.284 & A & -9.5 \\
\hline${ }^{90} \mathrm{Sr}$ & 504 & 493 & A & 2.2 & 1.38 & 1.273 & A & 8.4 \\
\hline${ }^{233 / 234} \mathrm{U}$ & 141 & 142 & A & -0.7 & 0.347 & 0.346 & A & 0.3 \\
\hline${ }^{238} \mathrm{U}$ & 142 & 148 & A & -4.1 & 0.362 & 0.359 & $\mathrm{~A}$ & 0.8 \\
\hline
\end{tabular}

${ }^{a}$ Radionuclide

${ }^{b}$ Mixed Analyte Performance Evaluation Program

${ }^{c}$ Evaluation Rating $(A=$ acceptable, $W=$ Acceptable with warning, $N=$ Not acceptable $)$

${ }^{d}$ Not applicable for non-detect per MAPEP

e Not applicable statistically zero result per MAPEP

${ }^{f}$ Information not provided by MAPEP

\subsubsection{Representativeness}

Representativeness is the extent to which measurements actually represent the true environmental condition or population at the time a sample was collected. The primary objective of environmental monitoring is to protect the health and safety of the population surrounding the WIPP facility. Samples of ambient air, surface water, sediment, soil, groundwater, and biota were collected from areas representative of potential pathways for intake.

According to the SOW, analytical representativeness is assured through the use of technically sound and accepted approaches for environmental investigations, including industry-standard procedures for sample collection and monitoring for potential sample cross-contamination through the analysis of field and laboratory method blank samples. These conditions were satisfied during the sample collection and analysis practices of the WIPP environmental monitoring program.

The environmental media samples (air, groundwater, surface water, soil, sediment, and biota) were collected from areas representative of potential pathways for intake of radionuclides. The samples were collected using generally accepted methodologies for environmental sampling, ensuring that they would be representative of the media sampled. Both sample collection blanks and laboratory method blanks were used to check for cross-contamination and ensure sample integrity. 


\subsection{CEMRC}

CEMRC performed the analyses of VOC and hydrogen/methane samples collected in the WIPP underground during 2008.

\subsubsection{Completeness}

Completeness is defined in WP 12-VC.01 and WP 12-VC.04 as being "the percentage of the ratio of the number of valid sample results received versus the total number of samples collected." For 2008, CEMRC was required to maintain a completeness of 95 percent.

For 2008, 603 VOC samples (including field duplicates) were submitted to CEMRC for analysis; 603 of these produced valid data. For repository and disposal room VOC monitoring, the program completion percentage was 100 percent.

For 2008, 152 hydrogen and methane samples (including field duplicates) were submitted to CEMRC for analysis (12 of these samples were also analyzed for VOCs); 152 of these produced valid data. For hydrogen, methane and ongoing disposal room VOCs, the program completion percentage was 100 percent.

\subsubsection{Precision}

Precision is evaluated by two means in both the VOC monitoring and the hydrogen and methane monitoring programs: comparing both laboratory duplicate samples and field duplicate samples. The laboratory duplicate samples consist of an LCS and laboratory control sample duplicate (LCSD). The field duplicate is a duplicate sample that is collected parallel with the original sample. Both of these duplicate samples are evaluated using the relative percent difference (RPD), as defined in WP 12-VC.01 and WP 12-VC.04. The RPD is calculated using the following equation.

$$
R P D=\frac{(A-B)}{(|A+B|) / 2} \times 100
$$

Where: $A=$ Original Sample Result

B = Duplicate Sample Result

During 2008, an LCS and an LCSD were generated and evaluated for all data packages discussed in Section 7.2.1. The result from the evaluation of the comparison resulted in 100 percent of the data within the acceptable range.

Field duplicate samples are also collected and compared for precision. The acceptable range for the RPD between measured concentrations is \pm 35 percent. For each value reported over the MRL in 2008, each field duplicate met the acceptance criteria. 


\subsubsection{Accuracy}

The VOC monitoring program evaluates both quantitative and qualitative accuracy. The quantitative evaluation includes performance verification for instrument calibrations, LCS recoveries, and sample internal standard areas. Qualitative evaluation consists of the evaluation of standard ion abundance for the instrument tune; that is, a mass calibration check performed prior to analyses of calibration curves and samples.

The hydrogen and methane monitoring program evaluates quantitative accuracy. The quantitative evaluation includes performance verification for instrument calibrations and LCS recoveries.

\subsubsection{Quantitative Accuracy}

$\underline{\text { Instrument Calibrations }}$

Instrument calibrations are required to have a relative standard deviation percentage of less than 30 percent for each analyte of the calibration. This is calculated by first calculating the relative response factor as indicated below:

Relative Response Factor $=\quad \underline{\text { (Analyte Response)(Internal Standard Concentration })}$ (Internal Standard Response)(Analyte Concentration)

Relative Standard Deviation $=\quad$ Standard Deviation of Relative Response Factor Average Relative Response Factor of Analyte $\times 100$

During 2008, 100 percent of instrument calibrations met the \pm 30 percent criteria.

\section{$\underline{\text { LCS recoveries }}$}

LCS recoveries are required to have a percent recovery of $\pm 25(75-125 \% R)$ percent. LCS recoveries are calculated as follows:

Percent Recovery $=$ Concentration Result Introduced Concentration $\times 100$

During 2008, 100 percent of the LCS recoveries met the \pm 25 percent criterion.

Internal Standard Area

For VOC analyses, internal standard areas are compared to a calibrated standard to evaluate accuracy. The acceptance criteria is \pm 40 percent.

During 2008, 100 percent of all standards met this criterion. 


\section{Sensitivity}

The method detection limit for each of the nine target compounds must be evaluated before sampling begins to meet sensitivity requirements. The initial and annual method detection limit evaluation is performed in accordance with 40 CFR Part 136, "Guidelines Establishing Test Procedures for the Analysis of Pollutants," and with EPA/530-SW-90-021, as revised and retitled, "Quality Assurance and Quality Control" (Chapter 1 of SW-846) (1996). For 2008, CEMRC completed method detection limit studies for VOC analyses in October and for hydrogen methane analysis in August.

\subsubsection{Qualitative Accuracy}

For VOC analyses, the standard ion abundance criteria for bromofluorobenzene is used to evaluate the accuracy of the analytical system in the identification of target analytes as well as unknown contaminants (qualitative accuracy). This ensures that the instrumentation is correctly identifying individual compounds during the analysis of air samples.

During 2008, all ion abundance criteria were within tolerance.

\subsubsection{Comparability}

There is no HWFP requirement for comparability in the VOC monitoring program and the hydrogen and methane monitoring program. However, comparability is maintained through the use of consistent, approved standard operating procedures for sample collection and analyses.

\subsubsection{Representativeness}

There is no HWFP requirement for representativeness in the VOC monitoring program and the hydrogen and methane monitoring program.

\subsection{TraceAnalysis, Inc.}

TraceAnalysis, Inc., of Lubbock, Texas, was subcontracted during the first part of 2008 to perform the analyses of groundwater samples collected at the WIPP site. They analyzed the groundwater samples from Round 26 taken in the spring of 2008.

\subsubsection{Completeness}

Seven monitoring wells are sampled twice each year for the WIPP groundwater detection monitoring program. During 2008, all seven wells were sampled twice for all required parameters on schedule. The Round 26 water samples were submitted to Trace, which completed all required analyses without losing any samples. The completeness objective was met, and analytical results were received for all the samples submitted (100 percent completeness). 


\subsubsection{Precision}

The groundwater samples generally contained detected concentrations for the major cations including calcium, magnesium, potassium, sodium, as well as for the general chemistry parameters including chloride, sulfate, total organic carbon (TOC), total organic halogen (TOX), density, total dissolved solids (TDS), total suspended solids (TSS), pH, conductivity, and alkalinity. For these parameters, precision was based on the analysis results of the duplicate well samples, duplicate analyses of a single well sample for some methods and the precision of the recoveries of the laboratory control sample and laboratory control sample duplicate (LCS/LCSD pairs) and the matrix spike and matrix spike duplicate pairs (MS/MSD) when analyzed. One other general chemistry parameter, TOX, was generally not detected.

Precision was measured differently for the various RCRA constituents (metals and organics) and general chemistry parameters. There were no detects for the volatile organics (VOCs) or semivolatile organics (SVOCs) in any of the groundwater samples, and thus the precision data for these parameters was based on the analysis results of the QC samples including the LCS/LCSD pairs and MS/MSD pairs. The major cations were detected in all the samples, but there were very few detects for the trace metals, and again the precision data was based on the results of the analysis of the QC samples.

The precision objective was an RPD of 20 for QC samples and duplicate samples when applicable. The precision objective was generally, but not always met for all the target analytes in Round 26. Specific instances where duplicate field samples or duplicate QC samples did not meet the precision objective are provided in Table 7.2. This is a small percentage of the total amount of precision data generated, with $>95$ percent of the precision data yielding RPDs less than 20 . In some cases where the precision objective was not met, the analysis results were at or near the reporting limit of the method where the precision would not be expected to be as good as at higher concentrations. The precision would also not be expected to be as good in the high-brine MS/MSD samples as in the LCS/LCSD samples where the matrix is clean water.

Table 7.2 shows that TSS missed the precision objective the most times. TSS is a difficult analysis for high-brine samples when specks of salt can precipitate from the samples. The only other analytes to miss the precision objective was one case each of TOC, TOX, iron, and one MS/MSD pair where five of the SVOC target compounds just missed the precision objective.

Table 7.2 - Individual Cases Where the Precision Objective Was Not Met for Round 26 Samples Analyzed by TraceAnalysis, Inc.

\begin{tabular}{ccccc}
\hline Well & Parameter & Sample & Duplicate & RPD \\
\hline WQSP-1 & TSS & $13.5 \mathrm{mg} / \mathrm{L}$ & $8.0 \mathrm{mg} / \mathrm{L}$ & 51 \\
WQSP-2 & TSS & $4.0 \mathrm{mg} / \mathrm{L}$ & $12 \mathrm{mg} / \mathrm{L}$ & 97 \\
WQSP-3 & Iron & $3.61 \mathrm{mg} / \mathrm{L}(\mathrm{MS})$ & $4.95 \mathrm{mg} / \mathrm{L}(\mathrm{MSD})$ & 31 \\
WQSP-4 & TSS & $12 \mathrm{mg} / \mathrm{L}$ & $8.5 \mathrm{mg} / \mathrm{L}$ & 30
\end{tabular}


Waste Isolation Pilot Plant Annual Site Environmental Report for 2008 DOE/WIPP-09-2225

Table 7.2 - Individual Cases Where the Precision Objective Was Not Met for Round 26 Samples Analyzed by TraceAnalysis, Inc.

\begin{tabular}{ccccc}
\hline Well & Parameter & Sample & Duplicate & RPD \\
\hline WQSP-5 & TSS & $7.0 \mathrm{mg} / \mathrm{L}$ & $5.5 \mathrm{mg} / \mathrm{L}$ & 24 \\
WQSP-6 & TOX & $0.669 \mathrm{mg} / \mathrm{L}$ & $1.16 \mathrm{mg} / \mathrm{L}$ & 54 \\
WQSP-6 & 1,4-Dichlorobenzene & $35.8 \mu \mathrm{g} / \mathrm{L}(\mathrm{MS})$ & $44.4 \mu \mathrm{g} / \mathrm{L}(\mathrm{MSD})$ & 22 \\
WQSP-6 & 1,2-Dichlorobenzene & $37.5 \mu \mathrm{g} / \mathrm{L}(\mathrm{MS})$ & $46.3 \mu \mathrm{g} / \mathrm{L}(\mathrm{MSD})$ & 21 \\
WQSP-6 & 4-+3-Methylphenol & $25.0 \mu \mathrm{g} / \mathrm{L}(\mathrm{MS})$ & $32.1 \mu \mathrm{g} / \mathrm{L}(\mathrm{MSD})$ & 24 \\
WQSP-6 & 2,4-Dinitrophenol & $35.1 \mu \mathrm{g} / \mathrm{L}(\mathrm{MS})$ & $47.7 \mu \mathrm{g} / \mathrm{L}(\mathrm{MSD})$ & 30 \\
WQSP-6 & 2,4-Dinitrotoluene & $63.8 \mu \mathrm{g} / \mathrm{L} \mathrm{(MS)}$ & $79.2 \mu \mathrm{M} / \mathrm{L}(\mathrm{MSD})$ & 22 \\
WQSP-6A & TOC & $3.9 \mathrm{mg} / \mathrm{L}$ & $\mathrm{U}(1.0) \mathrm{mg} / \mathrm{L}$ & 118 \\
\hline
\end{tabular}

$\mathrm{U}$ - Undetected at the associated method reporting limited

\subsubsection{Accuracy}

The accuracy of the groundwater sample analyses was based on the presence and/or absence of the target compounds in the method blank samples as well as the percent recovery of each constituent and applicable general chemistry parameter from the LCS and LCSD and/or MS and MSD QC samples. TraceAnalysis analyzed nitrate using a colorimetric procedure while the other anions were analyzed by ion chromatography.

The QA objective for the accuracy of the LCS/LCSD recoveries was generally 75-125 percent for the general chemistry parameters and metals and 70-130 percent for the VOCs. The QA objectives for the recoveries of the SVOCs were based on the laboratory's historical recoveries for each individual compound as recorded on control charts. The Trace control chart recovery range was wide for some SVOC parameters (e.g., from "detected" to 63 percent for pyridine; from 19-91 percent for 2-methylphenol; and from "detected" to 123 percent for pentachlorophenol).

The QA objective for the recoveries of the target analytes from the high-brine MS/MSD samples were generally wider than for the LCS/LCSD samples using clean water as the matrix. Trace randomly selected samples to use for the matrix spike samples and did not always use WQSP groundwater samples for the MS/MSD samples but instead used field blanks consisting of distilled water in which case a MS/MSD was the same as an LCS/LCSD. Although the SVOC recoveries were more variable than for the other target analytes, the analysis method ensured that the compounds would have been detected, if present, in the groundwater samples at concentrations near or above the reporting limit of $5 \mu \mathrm{g} / \mathrm{L}$.

None of the target analytes were detected in method blank samples as contaminants at concentrations above the reporting limit, and thus accuracy was not adversely affected by contamination.

Table 7.3 summarizes the QC samples for which the accuracy QA objectives, as measured by percent recovery, were not met. In some cases the samples from two WQSP wells were analyzed in the same batch, and the same QC data apply to more than one well. For example, the nitrate QC data are the same for WQSP-2 and 
WQSP-3 as well as WQSP-5 and WQSP-6. The recoveries of analytes which contained native sample concentrations greater than four times the matrix spike concentration, such as the major cations, are not included in Table 7.3. Parameters not spiked as LCS, LCSD, MS, and MSD samples and for which there is no recovery data included TSS, pH, conductivity, and alkalinity.

Table 7.3 - Individual Cases Where the Accuracy Objective Was Not Met for Round 26 Samples Analyzed by TraceAnalysis, Inc.

\begin{tabular}{|c|c|c|c|c|c|}
\hline Well & Parameter & Sample & $\% \operatorname{Rec}$ & Sample & \% Rec. \\
\hline WQSP-1 & Nitrate & MS & 0 & MSD & -14 \\
\hline WQSP-1 & TOX & MS & $84(a)$ & MSD & 66 \\
\hline WQSP-1 & Tetrachloroethylene & MS & 53 & MSD & 54 \\
\hline WQSP-1 & 1,1,2,2-Tetrachloroethane & MS & 134 & MSD & 132 \\
\hline WQSP-2 & Nitrate & MS & 239 & MSD & 231 \\
\hline WQSP-2 & Isobutyl alcohol & LCS & 61 & LSD & 60 \\
\hline WQSP-2 & Tetrachloroethylene & MS & 64 & MSD & 63 \\
\hline WQSP-2 & 1,1,2,2-Tetrachloroethane & MS & 141 & MSD & 137 \\
\hline WQSP-3 & Nitrate & MS & 239 & MSD & 231 \\
\hline WQSP-3 & Isobutyl alcohol & MS & 474 & MSD & 576 \\
\hline WQSP-3 & 2-Butanone & MS & 179 & MSD & 193 \\
\hline WQSP-3 & Tetrachloroethylene & MS & 49 & MSD & 51 \\
\hline WQSP-3 & 1,1,2,2-Tetrachloroethane & MS & 159 & MSD & 163 \\
\hline WQSP-4 & Nitrate & MS & 68 & MSD & 56 \\
\hline WQSP-4 & Antimony & MS & 65 & MSD & 66 \\
\hline WQSP-4 & Isobutyl alcohol & MS & $118(a)$ & MSD & 141 \\
\hline WQSP-4 & Tetrachloroethylene & MS & 59 & MSD & 61 \\
\hline WQSP-4 & 1,1,2,2-Tetrachloroethane & MS & 126 & MSD & 124 \\
\hline WQSP-5 & Nitrate & MS & 68 & MSD & 56 \\
\hline WASP-5 & Tetrachloroethylene & LCS & 136 & LCSD & 135 \\
\hline WQSP-5 & 2-Butanone & MS & 137 & MSD & 155 \\
\hline WQSP-5 & Tetrachloroethylene & MS & 64 & MSD & 69 \\
\hline WQSP-6 & Nitrate & MS & 68 & MSD & 56 \\
\hline WQSP-6 & TOX & MS & 26 & MSD & $76(a)$ \\
\hline WQSP-6 & Nickel & MS & 61 & MSD & 60 \\
\hline WQSP-6 & Thallium & MS & 67 & MSD & 64 \\
\hline WQSP-6 & Tetrachloroethylene & MS & 65 & MSD & 64 \\
\hline WQSP-6 & 1,1,2,2-Tetrachloroethane & MS & 132 & MSD & $124(a)$ \\
\hline WQSP-6A & Nitrate & MS & -17 & MSD & -17 \\
\hline WQSP-6A & Nickel & MS & 68 & MSD & 66 \\
\hline
\end{tabular}

(a) Recovery meets accuracy QA objective. 
Of the analytes in Table 7.3 that did not meet the QC sample accuracy objective, nitrate was detected in only one sample (WQSP-6A). TOX was detected in only one of the duplicate samples from WQSP-2 at a concentration just above the reporting limit, and nickel was detected near the reporting limit only in WQSP-6A. The 66-68 percent recovery of nickel in WQSP-6A suggests that the measured concentrations in this sample may be a little lower than the actual concentration. WQSP-6A is the only sample with detectable nitrate, but nitrate was not recovered in the MS/MSD samples and some nitrate was lost. Nitrate yielded high MS/MSD recoveries for the WQSP-2 and WQSP-3 sample batch and low MS/MSD recoveries for the WQSP-4, WQSP-5, and WQSP-6 sample batch. These results suggest a weakness with the colorimetric method for the groundwater samples. A chromatography method was used for nitrate analysis beginning with Round 27 . The colorimetric method was not used after Round 26.

The QA objectives for the VOC data were met for most VOC. The high salt concentrations affected some of the MS/MSD recoveries. The 1,1,2,2-tetrachloroethane, 2-butanone, and isobutyl alcohol recoveries were generally biased high, but the compounds were undetected in the samples. Some VOC recoveries were lower in the MS/MSD samples than in the LCS, but were not so low that detections would be compromised if present in the samples. For example, the MS/MSD results for tetrachloroethane were slightly less than the acceptance criteria, but they were consistent and provided assurance that the compound would have been detected if present in the samples. Therefore, the impact to the data usability is minimal.

For some WQSP sample sets, the MS and MSD recoveries for metals were slightly lower than the 75-125 percent recovery objective, but the recoveries were higher than 70 percent. These recoveries are not included in the Table 7.3.

The number of individual $Q C$ recoveries listed in Table 7.3 is very small compared to the total number of QC measurements made indicating that a large body of QC data was generated that met the QA objectives for accuracy. The accuracy data support the overall reliability and usability for the groundwater chemical analysis data.

\subsubsection{Comparability}

The HWFP requires that groundwater analytical results be comparable by reporting data in consistent units and collecting and analyzing samples using consistent methodology. These comparability requirements were met through the use of approved standard operating procedures for sample collection and analyses. The normal reporting units for metals and general chemistry parameters were $\mathrm{mg} / \mathrm{L}$, and the normal reporting limits for organics were ug/L.

Trace participated in an Absolute Grade PT Program interlaboratory assessment running from October to November 2007, and 97 percent of the parameters analyzed met the acceptance criteria. 


\subsubsection{Representativeness}

The groundwater monitoring program is designed so that representative groundwater samples are collected from specific monitoring well locations. During the sampling process, serial samples were collected and analyzed in the on-site mobile laboratory to help determine whether the water being pumped from the monitoring wells was stable and representative of the natural groundwater at each well. The final samples for analysis of VOCs, SVOCs, metals and general chemistry parameters submitted to Trace were collected only when it had been determined from serial sampling and analysis that the water being pumped was representative of the natural groundwater at each location.

\subsection{Hall Environmental Analysis Laboratory}

HEAL was awarded the groundwater analysis contract in February 2008 and performed the chemical analyses for the fall sampling in 2008 (Round 27). Generally, HEAL followed SOPs based on the same standard analytical methods as used by Trace. Heal used ion chromatography exclusively for nitrate analyses, while Trace had used both the colorimetric procedure (SM4500e) and ion chromatography for nitrate analysis.

The data from the two laboratories were quite comparable as demonstrated by the information in the sections below, including the nitrate analysis data from WQSP-6A.

\subsubsection{Completeness}

The seven WQSP monitoring wells were sampled during September-November 2008 for the WIPP groundwater detection monitoring program. The completeness objective was met, and analytical results were received for all the samples submitted (100 percent completeness).

\subsubsection{Precision}

The groundwater samples generally contained detected concentrations for the major cations including calcium, magnesium, potassium, sodium, as well as for chloride, sulfate, TOC, density, total dissolved solids (TDS), total suspended solids (TSS), pH, conductivity, and alkalinity. There were more detects of TOX in Round 27, but at very low concentrations. HEAL subcontracted TOX analyses to a different laboratory than used by Trace.

Precision was based on the analysis results of the duplicate well samples, duplicate analyses of a single well sample for some general chemistry parameter methods, as well as the precision of the recoveries of LCS/LCSD and MS/MSD pairs. HEAL also performed a separate LCS precision study by analyzing LCS samples twice to measure the precision of the analysis steps of each type of analysis without the sample preparation. 
As with Round 26 analyzed by Trace, there were no detects for the volatile organics or semivolatile organics in any of the samples and very few detects for trace metals, and thus the precision data for these parameters was based on the analysis results of the QC samples.

Table 7.4 shows the analysis results for which the precision objective of $\leq 20$ RPD was not met.

Table 7.4 - $\quad$ Individual Cases Where the Precision Objective Was Not Met for Round 27 Samples Analyzed by HEAL

\begin{tabular}{ccccc}
\hline Well & Parameter & Sample & Duplicate & RPD \\
\hline WQSP-1 & 2,4-dinitrophenol & $30.9(\mathrm{MS})$ & 53.7 (MSD) & 54 \\
WQSP-1 & TOX & 118 (primary) & 182 (dup) & 42 \\
\hline
\end{tabular}

As can be seen in Table 7.4, Heal's analytical data met the precision QA objectives for all groundwater and QC samples with two minor exceptions for difficult analytes including the MS and MSD recovery for 2,4-dinitrophenol and the sample analysis results for TOX. Thus $>99$ percent of the precision analysis results met the objective.

\subsubsection{Accuracy}

The accuracy of the groundwater sample analyses was based on the presence or absence of the target compounds in the method blank samples as well as the percent recovery of each constituent and applicable general chemistry parameter from the LCS and LCSD and/or MS and MSD QC samples. HEAL analyzed nitrate by ion chromatography in the same manner as chloride and sulfate.

The QA objective for the accuracy of the LCS/LCSD recoveries was generally 75-125 percent for the general chemistry parameters and metals and 70-130 percent for the VOCs. The QA objectives for the recoveries of the SVOCs were based on the laboratory's historical recoveries for each individual compound as recorded on control charts. The HEAL control chart recovery range for SVOCs was tighter than the Trace range with the low range being closer to 50 percent recovery.

The QA objective for the recoveries of the target analytes from the high-brine MS/MSD samples were generally wider than for the LCS/LCSD samples using clean water as the matrix. HEAL used WQSP well groundwater samples for all the MS/MSD samples, and thus the MS/MSD recoveries provided relevant information about the effect of the groundwater matrix on the accuracy of measuring the target analytes.

Table 7.5 summarizes the QC samples for which the accuracy QA objectives, as measured by percent recovery, were not met. None of the target analytes were detected in method blank samples as contaminants, and thus accuracy was not adversely affected by contamination. The recoveries of analytes which contained native sample concentrations greater than four times the matrix spike concentration, such as 
the major cations, are not included in Table 7.5. Parameters not spiked as LCS and LCSD or MS and MSD samples included conductivity, $\mathrm{pH}$, and total suspended solids.

Table 7.5 - Individual Cases Where the Accuracy Objective Was Not Met for Round 27 Samples Analyzed by Hall Environmental Analysis Laboratory (HEAL)

\begin{tabular}{|c|c|c|c|c|c|}
\hline Well & Parameter & Sample & \% Rec. & Sample & \% Rec. \\
\hline WQSP-2 & Nitrate & MS & 155 & MSD & 154 \\
\hline WQSP-2 & Isobutanol & MS & 228 & MSD & 231 \\
\hline WQSP-2 & 2-Butanone & MS & 147 & MSD & 138 \\
\hline WQSP-2 & 1,1,2,2-Tetrachloroethane & MS & 150 & MSD & 147 \\
\hline WQSP-3 & Mercury & MS & 63.5 & MSD & 63.6 \\
\hline WQSP-3 & Isobutanol & MS & 676 & MSD & 815 \\
\hline WQSP-3 & 2-Butanone & MS & 276 & MSD & 309 \\
\hline WQSP-3 & 1,1,2,2-Tetrachloroethane & MS & 199 & MSD & 190 \\
\hline WQSP-3 & TOX & MS & 49.4 & MSD & 12.4 \\
\hline WQSP-4 & Isobutanol & MS & 326 & MSD & 354 \\
\hline WQSP-4 & 2-Butanone & MS & 175 & MSD & 178 \\
\hline WQSP-4 & 1,1,2,2-Tetrachloroethane & MS & 138 & MSD & 138 \\
\hline WQSP-4 & TOX & MS & 274 & MSD & 265 \\
\hline WQSP-5 & Isobutanol & MS & 213 & MSD & 205 \\
\hline WQSP-5 & 2-Butanone & MS & $130(a)$ & MSD & 131 \\
\hline WQSP-6 & Nitrate & MS & 162 & MSD & 137 \\
\hline
\end{tabular}

(a) Recovery meets QA objective.

Not included in Table 7.5 are also some recoveries of SVOC target compounds from the MS and MSD samples. The recoveries were lower than the laboratory's historical control chart limits (where the lower limit recoveries were about 50 percent), but were higher than the recoveries specified in EPA guidance documents where the recovery limits are 40-140 percent for base/neutral compounds and 30-130 percent for acidic compounds. The SVOC compounds for which recoveries were affected by the groundwater matrix included the compounds 2,4-dinitrophenol, 2,4-dinitrotoluene, hexachlorobenzene, 2-methylphenol, 3+4-methylphenol, and pentachlorophenol.

The analytes listed in Table 7.6 that did not always meet the accuracy objective at Hall are generally the same analytes listed in Table 7.3 that did not meet the accuracy objective for Trace Analysis. Thus the high-brine samples were responsible for the same issues at both laboratories. In addition to the same analytes, another common feature is the WQSP well from which the QC samples were taken.

As examples of common issues with the data from the two laboratories, recoveries for isobutanol and 2-butanone were high in matrix spike samples, likely due to a higher purging efficiency in brine solution than in the aqueous calibration standards. The 1,1,2,2-tetrachloroethane recoveries appear to be high due to some degradation of another chlorinated organic with lower recoveries, such as tetrachloroethene. Nitrate 
was difficult to analyze using both the colorimetric method and ion chromatography in the brine samples when high concentrations of chloride were present. Nitrate has only been detected in the Dewey Lake WQSP-6A well, which has relatively low brine concentrations. Mercury recoveries appear to be reduced by the high ionic strength in the WQSP-3 well. Finally TOX yielded high spike recoveries in WQSP-3 and WQSP-4, the wells with the highest chloride concentrations which can interfere with TOX measurement.

Overall, the quality of the accuracy QC data was excellent with nearly all the data meeting the QA objective.

\subsubsection{Comparability}

The HWFP requires that groundwater analytical results be comparable by reporting data in consistent units and collecting and analyzing samples using consistent methodology. These comparability requirements were met through the use of consistent, approved standard operating procedures for sample collection and analyses. The normal reporting units for metals and general chemistry parameters were $\mathrm{mg} / \mathrm{L}$, and the normal reporting limits for organics were ug/L.

HEAL also participated in interlaboratory evaluation programs including on-site NELAC audits and analyzed performance evaluation samples provided by a NELAC-accredited Proficiency Standard Vendor. Of the target analytes that HEAL analyzed in proficiency testing samples, HEAL obtained acceptable results for all except total suspended solids for which the laboratory was asked to recheck their data in two consecutive rounds of testing. HEAL had no "Not Acceptable" results for any target analytes.

The groundwater sample analysis data generated by HEAL was very similar to that generated by Trace.

\subsubsection{Representativeness}

The groundwater DMP is designed so that representative groundwater samples are collected from specific monitoring well locations. During the sampling process, serial samples were collected and analyzed in the on-site mobile laboratory to help determine whether the water being pumped from the monitoring wells was stable and representative of the natural groundwater at each well. The final samples for analysis of VOCs, SVOCs, metals and general chemistry parameters by HEAL were collected only when it had been determined from serial sampling and analysis that the water being pumped was representative of the natural groundwater at each location. 


\section{Appendix A \\ References}

10 CFR Part 50, Appendix B. "Quality Assurance Criteria for Nuclear Power Plants and Fuel Reprocessing Plants." Code of Federal Regulations. Office of the Federal Register, National Archives and Records Administration, Washington, D.C.

10 CFR Part 834. "Radiation Protection of the Public and the Environment"; Proposed Rule. Code of Federal Regulations. Office of the Federal Register, National Archives and Records Administration, Washington, D.C.

10 CFR Part 1021. "National Environmental Policy Act Implementing Procedures." Code of Federal Regulations. Office of the Federal Register, National Archives and Records Administration, Washington, D.C.

40 CFR Part 61. "National Emission Standards for Hazardous Air Pollutants." Code of Federal Regulations. Office of the Federal Register, National Archives and Records Administration, Washington, D.C.

40 CFR Part 61.93. "Emission Monitoring and Test Procedure." Code of Federal Regulations. Office of the Federal Register, National Archives and Records Administration, Washington, D.C.

40 CFR Part 61, Subpart H. "National Emission Standards for Emissions of Radionuclides Other Than Radon from Department of Energy Facilities." Code of Federal Regulations. Office of the Federal Register, National Archives and Records Administration, Washington, D.C.

40 CFR Part 122.1. "Purpose and Scope." Code of Federal Regulations. Office of the Federal Register, National Archives and Records Administration, Washington, D.C.

40 CFR Part 136. "Guidelines Establishing Test Procedures for the Analysis of Pollutants." Code of Federal Regulations. Office of the Federal Register, National Archives and Records Administration, Washington, D.C.

40 CFR Part 141. "National Primary Drinking Water Regulations." Code of Federal Regulations. Office of the Federal Register, National Archives and Records Administration, Washington, D.C.

40 CFR Part 143. "National Secondary Drinking Water Regulations." Code of Federal Regulations. Office of the Federal Register, National Archives and Records Administration, Washington, D.C. 
40 CFR Parts 150-189. Federal Insecticide, Fungicide, and Rodenticide Act (FIFRA) Regulations. Code of Federal Regulations. Office of the Federal Register, National Archives and Records Administration, Washington, D.C.

40 CFR Part 191. "Environmental Radiation Protection Standards for Management and Disposal of Spent Nuclear Fuel, High-Level and Transuranic Radioactive Wastes." Code of Federal Regulations. Office of the Federal Register, National Archives and Records Administration, Washington, D.C.

40 CFR Part 191. Subpart A, "Environmental Standards for Management and Storage." Code of Federal Regulations. Office of the Federal Register, National Archives and Records Administration, Washington, D.C.

40 CFR Part 191, Subpart B. "Environmental Standards for Disposal." Code of Federal Regulations. Office of the Federal Register, National Archives and Records Administration, Washington, D.C.

40 CFR Part 191, Subpart C. "Environmental Standards for Ground-Water Protection." Code of Federal Regulations. Office of the Federal Register, National Archives and Records Administration, Washington, D.C.

40 CFR Part 194. "Criteria for the Certification and Re-Certification of the Waste Isolation Pilot Plant's Compliance With the 40 CFR Part 191 Disposal Regulations." Code of Federal Regulations. Office of the Federal Register, National Archives and Records Administration, Washington, D.C.

40 CFR §194.4. "Conditions of Compliance Certification." Code of Federal Regulations. Office of the Federal Register, National Archives and Records Administration, Washington, D.C.

40 CFR §194.21. "Inspections." Code of Federal Regulations. Office of the Federal Register, National Archives and Records Administration, Washington, D.C.

40 CFR Part 261.24. "Toxicity Characteristic." Code of Federal Regulations. Office of the Federal Register, National Archives and Records Administration, Washington, D.C.

40 CFR Part 262. "Standards Applicable to Generators of Hazardous Waste." Code of Federal Regulations. Office of the Federal Register, National Archives and Records Administration, Washington, D.C.

40 CFR Part 264. "Standards for Owners and Operators of Hazardous Waste Treatment, Storage, and Disposal Facilities." Code of Federal Regulations. Office of the Federal Register, National Archives and Records Administration, Washington, D.C. 
40 CFR Part 270. "EPA Administered Permit Programs: the Hazardous Waste Permit Program." Code of Federal Regulations. Office of the Federal Register, National Archives and Records Administration, Washington, D.C.

40 CFR Part 280. "Technical Standards and Corrective Action Requirements for Owners and Operators of Underground Storage Tanks (UST)." Code of Federal Regulations. Office of the Federal Register, National Archives and Records Administration, Washington, D.C.

40 CFR Part 300. "National Oil and Hazardous Substances Pollution Contingency Plan." Code of Federal Regulations. Office of the Federal Register, National Archives and Records Administration, Washington, D.C.

40 CFR Part 302. "Designation, Reportable Quantities, and Notification." Code of Federal Regulations. Office of the Federal Register, National Archives and Records Administration, Washington, D.C.

40 CFR Part 313. "Toxics Release Inventory." Code of Federal Regulations. Office of the Federal Register, National Archives and Records Administration, Washington, D.C.

40 CFR Part 761. "Polychlorinated Biphenyls (PCBs) Manufacturing, Processing, Distribution in Commerce, and Use Prohibitions." Code of Federal Regulations. Office of the Federal Register, National Archives and Records Administration, Washington, D.C.

40 CFR Parts 1500-1508. "Council on Environmental Quality." Code of Federal Regulations. Office of the Federal Register, National Archives and Records Administration, Washington, D.C.

50 CFR Part 17. "Endangered and Threatened Plants and Wildlife." Code of Federal Regulations. Office of the Federal Register, National Archives and Records Administration, Washington, D.C.

50 CFR Part 20. "Migratory Bird Hunting." Code of Federal Regulations. Office of the Federal Register, National Archives and Records Administration, Washington, D.C.

70 FR 61107-61111. "Notification of Completeness of the Department of Energy's Compliance Recertification Application for the Waste Isolation Pilot Plant." Federal Register. Office of the Federal Register, National Archives and Records Administration, Washington, D.C.

20.2.72 NMAC. "Construction Permits." Title 20, New Mexico Administrative Code. (Air Quality Control Regulation 702). Santa Fe, NM. 
20.4.1 NMAC. "Hazardous Waste Management." Title 20, New Mexico Administrative Code. Santa Fe, NM.

20.4.1.500 NMAC. "Adoption of 40 CFR Part 264." Title 20, New Mexico Administrative Code. Santa Fe, NM.

20.5 NMAC. "Petroleum Storage Tanks." Title 20, New Mexico Administrative Code. Sante Fe, NM.

20.6.2 NMAC. "Ground and Surface Water Protection." Title 20, New Mexico Administrative Code. Santa Fe, NM.

20.7.10 NMAC. "Drinking Water." Title 20 New Mexico Administrative Code. Santa Fe, NM.

7 U.S.C. $\S \S 136$, et seq. Federal Insecticide, Fungicide, and Rodenticide Act (FIFRA). U.S. Government Printing Office, Washington, D.C.

15 U.S.C. $\S \S 2601$, et seq. Toxic Substances Control Act. U.S. Government Printing Office, Washington, D.C.

16 U.S.C. $\S \S 470$, et seq. National Historic Preservation Act. United States Code. U.S. Government Printing Office, Washington, D.C.

16 U.S.C. §§1531, et seq. Endangered Species Act of 1973. United States Code. U.S. Government Printing Office, Washington, D.C.

16 U.S.C. $\S \S 703$, et seq. Migratory Bird Treaty Act. United States Code. U.S. Government Printing Office, Washington, D.C.

33 U.S.C. §§1251, et seq. Federal Water Pollution Control Act of 1948 (Clean Water Act), Section 402. United States Code. U.S. Government Printing Office, Washington, D.C.

42 U.S.C. $\S \S 300 f$, et seq. Safe Drinking Water Act. United States Code. U.S. Government Printing Office, Washington, D.C.

42 U.S.C. §2011, et seq. Atomic Energy Act of 1954, as amended. United States Code. U.S. Government Printing Office, Washington, D.C.

42 U.S.C. $\S \S 4321$, et seq. National Environmental Policy Act. United States Code. U.S. Government Printing Office, Washington, D.C.

42 U.S.C. $\S \S 6901$, et seq. Resource Conservation and Recovery Act. United States Code. U.S. Government Printing Office, Washington, D.C. 
42 U.S.C. §6924, et seq. Treatment Standards for Wastes Subject to Land Disposal. United States Code. U.S. Government Printing Office, Washington, D.C.

42 U.S.C. $\S \S 6912,6939 c$, and 6961. Federal Facilities Compliance Act of 1992. United States Code. U.S. Government Printing Office, Washington, D.C.

42 U.S.C. $\S \S 7401$, et seq. Clean Air Act. United States Code. U.S. Government Printing Office, Washington, D.C.

42 U.S.C. $\S \S 9601$, et seq. Comprehensive Environmental Response, Compensation, and Liability Act (including the Superfund Amendments and Reauthorization Act of 1986). United States Code. U.S. Government Printing Office, Washington, D.C.

42 U.S.C. §10101, et seq. Nuclear Waste Policy Act of 1982. United States Code. U.S. Government Printing Office, Washington, D.C.

42 U.S.C. $\S 11101$. Superfund Amendments and Reauthorization Act of 1986 (SARA) Title III. United States Code. U.S. Government Printing Office, Washington, D.C.

43 U.S.C. $\S \S 1701$, et seq. Federal Land Policy and Management Act. United States Code. U.S. Government Printing Office, Washington, D.C.

ANSI/HPS N13.12-1999, Surface and Volume Radioactivity Standards for Clearance.

ANSI N13.30. 1996. Performance Criteria for Radiobioassay. Health Physics Society, Washington, D.C.

ASME NQA-1-1989 and Supplementary Requirements, Quality Assurance Program Requirements for Nuclear Facilities.

ASME NQA-2a-1990 addenda, Part 2.7, Quality Assurance Requirements of Computer Software for Nuclear Facility Applications.

ASME NQA-3-1989 (excluding Section 2.1(b) and (c), and Section 17.1), Quality Assurance Program Requirements for the Collection of Scientific and Technical Information for Site Characterization of High-Level Nuclear Waste.

Beauheim, R. L. 1986. Analysis of Pumping Tests of the Culebra Dolomite Conducted at the H-3 Hydropad at the Waste Isolation Pilot Plant (WIPP) Site, SAND86-2311, Sandia National Laboratories, Albuquerque, NM.

Beauheim, R. L. 1987. Interpretations of Single-Well Hydraulic Tests Conducted at and Near the Waste Isolation Pilot Plant (WIPP) Site, 1983-1987. SAND 87-0039, Sandia National Laboratories, Albuquerque, NM. 
Beauheim, R. L., T. F. Dale, and J. F. Pickens. 1991. Interpretations of Single-Well Hydraulic Tests of the Rustler Formation Conducted in the Vicinity of the Waste Isolation Pilot Plant Site, 1988-1989. SAND-890869, Sandia National Laboratories, Albuquerque, NM.

Beauheim, R. L., and G. J. Ruskauff. 1998. Analysis of Hydraulic Tests of the Culebra and Magenta Dolomites and Dewey Lake Redbeds Conducted at the Waste Isolation Pilot Plant Site. SAND 98-0049, Sandia National Laboratories, Albuquerque, NM.

Beauheim, R. L., and R. M. Roberts. 2002. "Hydrology and Hydraulic Properties of a Bedded Evaporite Formation." Journal of Hydrology, v. 259, pp. 66-88.

Beck, Harold L. and Burton G. Bennet. 2002. Historical Overview of Atmospheric Nuclear Weapon Testing and Estimates of Fallout in the Continental United States. Health Phys 82:591-608.

Bowman, D. O., and R. M. Roberts. 2009. Analysis Report for AP-070: Analysis of Culebra and Magenta Hydraulic Tests Performed Between January 2005 and August 2008. ERMS \# 550906. Sandia National Laboratories. Carlsbad, NM.

Burgess, Anthony; T. Doe; and T. Lowenstein. 2008. "Waste Isolation Pilot Plant Final Report Culebra Hydrogeology Conceptual Model Peer Review." ERMS\#551513, WIPP Records Center Carlsbad NM, Sandia National Laboratories.

Clayton, Daniel J. 2009. "Analysis Plan for the CRA-2009 Performance Assessment Baseline Calculation, AP-145, Revision 0". Carlsbad, NM, Sandia National Laboratories.

Cooper, J. B., and V. M. Glanzman. 1971. "Geohydrology of Project Gnome Site, Eddy County, New Mexico." Professional Paper 712-A, U.S. Geological Survey, Washington, D.C.

Daniel B. Stephens \& Associates, Inc. 2003. Water Budget Analysis of the Shallow Subsurface Water at the Waste Isolation Pilot Plant, Carlsbad, NM.

DOE/EH-0173T. 1991. Environmental Regulatory Guide for Radiological Effluent Monitoring and Environmental Surveillance, Department of Environment, Safety, and Health, U.S. Department of Energy, Washington, D.C.

DOE Order 151.1C. 2005. Comprehensive Emergency Management System. U.S. Department of Energy, Washington, D.C.

DOE Order 231.1A. 2004. Environment, Safety, and Health Reporting. U.S. Department of Energy, Washington, D.C. 
DOE Order 414.1C. 2005. Quality Assurance. U.S. Department of Energy, Washington, D.C.

DOE Order 430.2B. 2008. Departmental Energy, Renewable Energy and Transportation Management. U.S. Department of Energy, Washington, D.C.

DOE Order 435.1. 1999. Radioactive Waste Management. U.S. Department of Energy, Washington, D.C.

DOE Order 450.1. 2003. Environmental Protection Program. U.S. Department of Energy, Washington D.C.

DOE Order 451.1B. 2001. National Environmental Compliance Policy Act Compliance Program. U.S. Department of Energy, Washington, D.C.

DOE Order 5400.5. 1993. Radiation Protection of the Public and the Environment. U.S. Department of Energy, Washington, D.C.

DOE/EIS-0026-S-2. 1997. Waste Isolation Pilot Plant Disposal Phase Final Supplemental Environmental Impact Statement (SEIS-II). Volumes 1 through 3. U.S. Department of Energy, Washington, D.C.

DOE-STD-1153-2002. 2003. A Graded Approach for Evaluating Radiation Doses to Aquatic and Terrestrial Biota. National Technical Information Service, Washington, D.C.

DOE/CAO-96-2184. 1996. Title 40 CFR Part 191 Compliance Certification Application for the Waste Isolation Pilot Plant. U.S. Department of Energy, Carlsbad Field Office. Carlsbad, NM.

DOE/CBFO-94-1012. 1994. Quality Assurance Program Document. Waste Isolation Pilot Plant, Carlsbad, NM.

DOE/CBFO-98-2276. 2003. Integrated Safety Management System Description. Waste Isolation Pilot Plant, Carlsbad, NM.

DOE/WIPP-92-037. 1992. Statistical Summary of the Radiological Baseline for the Waste Isolation Pilot Plant. Waste Isolation Pilot Plant, Carlsbad, NM.

DOE/WIPP-93-004. 2002. Waste Isolation Pilot Plant Land Management Plan. Waste Isolation Pilot Plant, Carlsbad, NM.

DOE/WIPP-97-2219. 1997. Exhaust Shaft Hydraulic Assessment Data Report. Waste Isolation Pilot Plant. Carlsbad, NM. 
DOE/WIPP-98-2285. 1998. Waste Isolation Pilot Plant RCRA Background Groundwater Quality Baseline Report. Waste Isolation Pilot Plant, Carlsbad, NM.

DOE/WIPP-99-2194. 2008. Waste Isolation Pilot Plant Environmental Monitoring Plan. Waste Isolation Pilot Plant, Carlsbad, NM.

DOE/WIPP-02-3122. 2006. Transuranic Waste Acceptance Criteria for the Waste Isolation Pilot Plant. Waste Isolation Pilot Plant, Carlsbad, NM.

DOE/WIPP-04-3231. 2004. Title 40 CFR Part 191 Subparts B and C Compliance Recertification Application 2004. Waste Isolation Pilot Plant, Carlsbad, NM.

DOE/WIPP-04-3310. 2004. CBFO/WTS Environmental Policy Statement. Waste Isolation Pilot Plant, Carlsbad, NM.

DOE/WIPP-05-3318. 2005. Waste Isolation Pilot Plant Environmental Management System Description. Waste Isolation Pilot Plant, Carlsbad, NM.

DOE/WIPP-07-2225. 2007. Waste Isolation Pilot Plant Annual Site Environmental Report for 2006. Waste Isolation Pilot Plant, Carlsbad, NM.

DOE/WIPP-07-2293. 2006. WIPP Subsidence Monument Leveling Survey 2006. Waste Isolation Pilot Plant, Carlsbad, NM.

DOE/WIPP-07-3177-Vol 1. 2007. Geotechnical Analysis Report for July 2005 - June 2006. Waste Isolation Pilot Plant, Carlsbad, NM.

DOE/WIPP-07-3177-Vol 2. 2007. Geotechnical Analysis Report for July 2005 - June 2006. Waste Isolation Pilot Plant, Carlsbad, NM.

DOE/WIPP-07-3317. 2007. Annual Change Report-2006-2007. Waste Isolation Pilot Plant, Carlsbad, NM.

DOE/WIPP-08-3372. 2009. Waste Isolated Pilot Plant Documented Safety Analysis. Waste Isolation Pilot Plant, Carlsbad, NM.

DOE/WIPP-08-2171. 2008. Waste Isolation Pilot Plant Biennial Environmental Compliance Report. Waste Isolation Pilot Plant, Carlsbad, NM.

DOE/WIPP-08-3326. 2008. Basic Data Report for Well Plugging and Abandonment, Reconfiguration, and New Well Drilling Activities for Fiscal Year 2008. Waste Isolation Pilot Plant, Carlsbad, NM.

B(OVIPP-08-3372. 2009. Waste Isolation Pllot Plant Documented Safety Analysis. Waste Isolation Pilot Plant, Carlsbad, NM. 
DOE/WIPP-08-3375, Basic Data Report for Piezometers PZ-13, PZ-14, and PZ-15 and SSW. Waste Isolation Pilot Plant. Carlsbad, NM.

DOE/WIPP-08-3378. 2008. Waste Isolation Pilot Plant Emergency Planning Hazards Assessment. Waste Isolation Pilot Plant. Carlsbad, NM.

DOE/WIPP-09-3333. 2009. WIPP Environmental Management System Annual Report for Fiscal Year 2008. Waste Isolation Pilot Plant. Carlsbad, NM.

DOE/WIPP-09-3424. 2009. Compliance Recertification Application. Waste Isolation Pilot Plant, Carlsbad, NM.

Doherty, J. 2002. PEST: Model Independent Parameter Estimation. Watermark Numerical Computing, Brisbane, Australia.

DP-831. 2003. WIPP Discharge Permit. New Mexico Environment Department, Santa Fe, NM.

EPA/530-SW-90-021. 1996. Quality Assurance and Quality Control. U.S. Environmental Protection Agency, Washington, D.C.

EPA/600 4-83-004. 1983. Interim Guidelines and Specification for Preparing Quality Assurance Project Plans. U.S. Environmental Protection Agency, Washington, D.C.

EPA. 1994. Draft Contract Laboratory Program Volatile Organics Analysis of Ambient Air in Canisters.

EPA. 2007a. Letter to David Moody (CBFO) from Juan Reyes (EPA) dated February 14, 2007.

EPA. 2007b. Letter to David Moody (CBFO) from Juan Reyes (EPA) dated December 20, 2007.

EPA Compendium Method TO-15. 1999. Determination of Volatile Organic Compounds (VOCs) in Air Collected in Specially-Prepared Canisters and Analysis By Gas Chromatography/Mass Spectrometry (GC/MS). U.S. Environmental Protection Agency, Washington, D.C.

EPA Docket A-98-49, Item II-B3-108.

Executive Order 13101. 1998. Greening the Government Through Waste Prevention, Recycling, and Federal Acquisition. Office of the President, Washington, D.C.

Executive Order 13148. 1998. Greening the Government Through Leadership in Environmental Management. Office of the President, Washington, D.C. 
Executive Order 13423. 2007. Strengthening Federal Environmental, Energy, and Transportation Management. Office of the President, Washington, D.C.

Harbaugh, A. W.; E. R. Banta; M. C. Hill; and M. G. McDonald. 2000. MODFLOW-2000, The U.S. Geological Survey Modular Ground-Water Model -- User Guide to Modularization Concepts and the Ground-Water Flow Process. U.S. Geological Survey Open-File Report 00-92.

Hillesheim, M. B., R.L. Beauheim, and R. G. Richardson. 2006. "Overview of the WIPP Groundwater Monitoring Programs with Inferences about Karst in the WIPP Vicinity," in L. Land, V. W. Lueth, W. Raatz, P. Boston, and D. L. Love, eds., Caves and Karst of Southeastern New Mexico. New Mexico Geological Society, 57th Annual Fall Field Conference Guidebook. 277-286.

International Atomic Energy Agency. 1992. Technical Report Series No. 332, Effects of Ionizing Radiation on Plants and Animals at Levels Implied by Current Radiation Protection Standards. Vienna, Austria.

ISO 14001. Environmental Management Systems - Specification with Guidance for Use. 2004. International Organizations for Standardization, Geneva, Switzerland.

ISO/IEC 17025. 2006. General Requirements for the Competence of Testing and Calibration Laboratories. International Organization for Standardization, Geneva, Switzerland.

IT Corporation. 2000. Waste Isolation Pilot Plant RCRA Background Groundwater Quality Baseline Update Report. Albuquerque, NM.

Johnson, Patricia B. 2009. Calculated Densities for Use in Deriving Equivalent Freshwater Heads of the Culebra Dolomite Member of the Rustler Formation Near the WIPP Site. January 2009. ERMS 550755. Carlsbad, NM. Sandia National Laboratories, WIPP Records Center.

Johnson, Patricia B. 2008. Calculated Densities for Use in Deriving Equivalent Freshwater Heads of the Culebra Dolomite Member of the Rustler Formation Near the WIPP Site. May 2007. ERMS 548127. Carlsbad, NM. Sandia National Laboratories, WIPP Records Center.

Lowry, T. S., and R. L. Beauheim. 2004. Analysis Report, Task 2 of AP-110, Evaluation of Water-Level Rise in the Culebra Due to Recharge from Refining Process Water Discharged onto Potash Tailings Piles. ERMS\# 536239. Carlsbad, NM: Sandia WIPP Records Center. 
Lowry, T. S., and R. L. Beauheim. 2005. Analysis Report, Task 3 of AP-110, Evaluation of Water-Level Rise in the Culebra Due to Leakage Through Poorly Plugged and Abandoned Potash Boreholes. ERMS\# 540187. Carlsbad, NM: Sandia WIPP Records Center.

MacLellan, J. A. 1999. "Hanford Decision Level for Alpha Spectrometry Bioassay Analyses Based on the Sample-Specific Total Propagated Uncertainty." Presented at the $46^{\text {th }}$ Annual Conference on Bioassay, Analytical, and Environmental Radiochemistry, Seattle, WA; November 12-17, 2000.

Mercer, J. W. 1983. Geohydrology of the Proposed Waste Isolation Pilot Plant Site, Los Medaños Area, Southeastern New Mexico. Water Resources investigations, Report 83-4016, U.S. Geological Survey.

Mercer, J. W. and B. R. Orr. 1977. Review and Analysis of Geologic Conditions Near the Site of a Potential Nuclear Waste Repository Eddy and Lea Counties, New Mexico. U.S. Geological Survey Open-File Rept., 77-123.

Minnema, D. M. and L. W. Brewer. 1983. Background Radiation Measurements at Waste Isolation Pilot Plant Site, Carlsbad, NM. SAND83-1296.

MP 1.28, Integrated Safety Management. Washington TRU Solutions LLC, Waste Isolation Pilot Plant, Carlsbad, NM.

NCRP. 1987a. Report No. 94, Exposure of the Population in the United States and Canada from Natural Background Radiation. National Council on Radiation Protection and Measurements. Bethesda, MD.

NCRP. 1987b. Report No. 087, Use of Bioassay Procedures for Assessment of Internal Radionuclide Deposition. National Council on Radiation Protection and Measurements. Bethesda, MD.

NCRP. 1991. Report No. 109, Effects of Ionizing Radiation on Aquatic Organisms. National Council on Radiation Protection and Measurements. Bethesda, MD.

NM4890139088-TSDF. 1999. Waste Isolation Pilot Plant Hazardous Waste Facility Permit. New Mexico Environment Department, Santa Fe, NM.

NMSA 1978. §74-2. New Mexico Air Quality Control Act. New Mexico Statutes Annotated 1978. State of New Mexico, Santa Fe, NM.

NMSA 1978. §74-4-1. New Mexico Hazardous Waste Act. New Mexico Statutes Annotated 1978. State of New Mexico, Santa Fe, NM.

NMSA 1978. §74-6-1. New Mexico Water Quality Act. New Mexico Statutes Annotated. State of New Mexico, Santa Fe, NM. 
Pacific Northwest National Laboratory. 1999. Hanford Decision Level for Alpha Spectrometry Bioassay Analyses Based on the Sample Specific Total Propagated Uncertainty (99352). J. A. MacLellan, Radiation and Health Technology. Richland, WA.

Powers, D. W. 2004. Analysis Report, Task 1B of AP-110, Identify Plugged and Abandoned Oil or Gas Wells Not Sealed Through the Culebra with Cement, and Units to Which the Culebra Might Be Connected. ERMS\# 538279. Carlsbad, NM: Sandia WIPP Records Center.

Public Law 96-164. National Security and Military Applications of Nuclear Energy Authorization Act of 1980.

Public Law 102-579. Waste Isolation Pilot Plant Land Withdrawal Act. October 1992, as amended October 1996 by Public Law 104-201.

Rudeen, D. K. 2003. User's Manual for DTRKMF Version 1.00. ERMS 523246. Sandia National Laboratories, Carlsbad, NM.

SNL. 2003. Sandia National Laboratories Technical Baseline Report, WBS 1.3.4.3: Compliance Monitoring, WBS 1.3.5.4: Repository Investigations, Milestone RI 03-210, January 31, 2003. ERMS\# 526049. Sandia National Laboratories. Carlsbad, NM.

Stormont, J. C., C. L. Howard, and J. J. K. Daemen. 1991. Changes in Rock Salt Permeability Due to Nearby Excavation. In: Roegiers, J. C. (Ed.), Rock Mechanics as a Multidisciplinary Science. Proceedings of the $32^{\text {nd }}$ U.S. Symposium, the University of Oklahoma, Norman, Oklahoma, July 10-12, 1991. A. A. Balkema, Brookfield, VT, pp. 899-907.

U.S. Nuclear Regulatory Commission Docket-71-9218. TRUPACT-II Safety Analysis Report for Packaging. Nuclear Regulator Commission, Washington, D.C.

UNSCEAR. 2000. Sources and Effects of lonizing Radiation. 2000 Report, Vol. 1. United Nations Scientific Committee on the Effects of Atomic Radiation.

WP 02-1, WIPP Groundwater Monitoring Program Plan. Washington TRU Solutions LLC. Waste Isolation Pilot Plant, Carlsbad, NM.

WP 02-EC.07, Waste Isolation Pilot Plant Affirmative Procurement Plan. Washington TRU Solutions LLC. Waste Isolation Pilot Plant, Carlsbad, NM.

WP 02-EC.11, Waste Isolation Pilot Plant Pollution Prevention Program Plan. Washington TRU Solutions LLC. Waste Isolation Pilot Plant, Carlsbad, NM.

WP 02-EC.13, Environmental Assessment Plan. Washington TRU Solutions LLC. Waste Isolation Pilot Plant, Carlsbad, NM. 
WP 02-EM3004, Radiological Data Verification and Validation. Washington TRU Solutions LLC. Waste Isolation Pilot Plant, Carlsbad, NM.

WP 04-CO, Maintenance Operation Instruction Manual. Washington TRU Solutions LLC. Waste Isolation Pilot Plant, Carlsbad, NM.

WP 09, Engineering Conduct of Operations. Washington TRU Solutions LLC. Waste Isolation Pilot Plant, Carlsbad, NM.

WP 10-2, Conduct of Operations. Washington TRU Solutions LLC. Waste Isolation Pilot Plant, Carlsbad, NM.

WP 12-VC.01, Confirmatory Volatile Organic Compound Monitoring Program. Washington TRU Solutions LLC. Waste Isolation Pilot Plant, Carlsbad, NM.

WP 13-1, Washington TRU Solutions LLC Quality Assurance Program Description. Washington TRU Solutions LLC. Waste Isolation Pilot Plant, Carlsbad, NM. 
Waste Isolation Pilot Plant Annual Site Environmental Report for 2008

DOE/WIPP-09-2225

This page intentionally left blank 


\section{Waste Isolation Pilot Plant Annual Site Environmental Report for 2008 DOE/WIPP-09-2225}

\section{Appendix B Active Environmental Permits}

\begin{tabular}{|c|c|c|c|c|c|}
\hline \multicolumn{6}{|c|}{$\begin{array}{l}\text { Table B.1 - Active Environmental Permits, Registration, and Rights of Way for the Waste Isolation } \\
\text { Pilot Plant - Calendar Year } 2008 \text { (Does Not Include Hazardous Waste Facility Permit or } \\
\text { DP-831) }\end{array}$} \\
\hline & Granting Agency & Type of Permit & $\begin{array}{l}\text { Permit } \\
\text { Number }\end{array}$ & Granted & Expiration \\
\hline 1 & $\begin{array}{l}\text { Department of the Interior, } \\
\text { Bureau of Land Management }\end{array}$ & Right-of-Way for Water Pipeline & NM53809 & $8 / 17 / 83$ & None \\
\hline 2 & $\begin{array}{l}\text { Department of the Interior, } \\
\text { Bureau of Land Management }\end{array}$ & Right-of-Way for the North Access Road & NM55676 & $8 / 24 / 83$ & None \\
\hline 3 & $\begin{array}{l}\text { Department of the Interior, } \\
\text { Bureau of Land Management }\end{array}$ & Right-of-Way for Railroad & NM55699 & $9 / 27 / 83$ & None \\
\hline 4 & $\begin{array}{l}\text { Department of the Interior, } \\
\text { Bureau of Land Management }\end{array}$ & $\begin{array}{l}\text { Right-of-Way for Dosimetry and Aerosol } \\
\text { Sampling Sites }\end{array}$ & NM63136 & $7 / 31 / 86$ & $7 / 31 / 11$ \\
\hline 5 & $\begin{array}{l}\text { Department of the Interior, } \\
\text { Bureau of Land Management }\end{array}$ & $\begin{array}{l}\text { Right-of-Way for Seven Subsidence } \\
\text { Monuments }\end{array}$ & NM65801 & $11 / 7 / 86$ & None \\
\hline 6 & $\begin{array}{l}\text { Department of the Interior, } \\
\text { Bureau of Land Management }\end{array}$ & Right-of-Way for Aerosol Sampling Site & NM77921 & $8 / 18 / 89$ & $8 / 18 / 19$ \\
\hline 7 & $\begin{array}{l}\text { Department of the Interior, } \\
\text { Bureau of Land Management }\end{array}$ & Right-of-Way for 2 Survey Monuments & NM82245 & $12 / 13 / 89$ & $12 / 13 / 19$ \\
\hline 8 & $\begin{array}{l}\text { Department of the Interior, } \\
\text { Bureau of Land Management }\end{array}$ & Right-of-Way for telephone cable & NM46092 & $7 / 3 / 90$ & $9 / 4 / 11$ \\
\hline 9 & $\begin{array}{l}\text { Department of the Interior, } \\
\text { Bureau of Land Management }\end{array}$ & Right-of-Way for Valor Telecon & NM113339 & $8 / 9 / 05$ & $12 / 31 / 34$ \\
\hline 10 & $\begin{array}{l}\text { Department of the Interior, } \\
\text { Bureau of Land Management }\end{array}$ & Right-of-Way for SPS Powerline & NM43203 & $2 / 20 / 96$ & $10 / 19 / 11$ \\
\hline 11 & $\begin{array}{l}\text { Department of the Interior, } \\
\text { Bureau of Land Management }\end{array}$ & Right-of-Way for South Access Road & NM46130 & $8 / 17 / 81$ & $8 / 17 / 31$ \\
\hline 12 & $\begin{array}{l}\text { Department of the Interior, } \\
\text { Bureau of Land Management }\end{array}$ & $\begin{array}{l}\text { Right-of-Way for South Access Road } \\
\text { Fence }\end{array}$ & NM94304 & $3 / 15 / 95$ & none \\
\hline 13 & $\begin{array}{l}\text { Department of the Interior, } \\
\text { Bureau of Land Management }\end{array}$ & Right-of-Way for Duval telephone line & NM60174 & $11 / 6 / 96$ & $3 / 8 / 15$ \\
\hline 14 & $\begin{array}{l}\text { Department of the Interior, } \\
\text { Bureau of Land Management }\end{array}$ & Right-of-Way for Wells AEC-7 \& AEC-8 & NM108365 & $8 / 30 / 02$ & $8 / 30 / 32$ \\
\hline 15 & $\begin{array}{l}\text { Department of the Interior, } \\
\text { Bureau of Land Management }\end{array}$ & Right-of-Way for ERDA-6 & NM108365 & $8 / 30 / 02$ & $8 / 30 / 32$ \\
\hline 16 & $\begin{array}{l}\text { Department of the Interior, } \\
\text { Bureau of Land Management }\end{array}$ & $\begin{array}{l}\text { Right-of-Way for Monitoring Well C-2756 } \\
\text { (P-18) }\end{array}$ & NM108365 & $8 / 30 / 02$ & $8 / 30 / 32$ \\
\hline 17 & $\begin{array}{l}\text { Department of the Interior, } \\
\text { Bureau of Land Management }\end{array}$ & $\begin{array}{l}\text { Right-of-way for Monitoring Well C-2664 } \\
\text { (Cabin Baby) }\end{array}$ & NM107944 & $4 / 23 / 02$ & $4 / 23 / 32$ \\
\hline 18 & $\begin{array}{l}\text { Department of the Interior, } \\
\text { Bureau of Land Management }\end{array}$ & $\begin{array}{l}\text { Right-of-Way for Seismic Monitoring } \\
\text { Station }\end{array}$ & NM120413 & $7 / 10 / 08$ & None \\
\hline 19 & $\begin{array}{l}\text { Department of the Interior, } \\
\text { Bureau of Land Management }\end{array}$ & $\begin{array}{l}\text { Right-of-Way for Wells C-2725 (H-4A), } \\
\text { C-2775 (H-4B), \& C-2776 (H-4C) }\end{array}$ & NM108365 & $8 / 30 / 02$ & $8 / 30 / 32$ \\
\hline 20 & $\begin{array}{l}\text { Department of the Interior, } \\
\text { Bureau of Land Management }\end{array}$ & $\begin{array}{l}\text { Right-of-Way for Monitoring Wells C-2723 } \\
\text { (WIPP-25), C-2724 (WIPP-26), C-2722 } \\
\text { (WIPP-27), C-2636 (WIPP-28), C-2743 } \\
\text { (WIPP-29), \& C-2727 (WIPP-30) }\end{array}$ & NM108365 & $8 / 30 / 02$ & $8 / 30 / 32$ \\
\hline 21 & $\begin{array}{l}\text { Department of the Interior, } \\
\text { Bureau of Land Management }\end{array}$ & Right-of-Way for Monitoring Well WIPP-11 & NM108365 & $9 / 15 / 04$ & $9 / 20 / 34$ \\
\hline 22 & $\begin{array}{l}\text { Department of the Interior, } \\
\text { Bureau of Land Management }\end{array}$ & $\begin{array}{l}\text { Right-of-Way easement for WIPP well } \\
\text { bore SNL-2 }\end{array}$ & 109174 & $4 / 15 / 03$ & $4 / 15 / 33$ \\
\hline 23 & $\begin{array}{l}\text { Department of the Interior, } \\
\text { Bureau of Land Management }\end{array}$ & $\begin{array}{l}\text { Right-of-Way easement for WIPP well } \\
\text { bore SNL-9 }\end{array}$ & 109175 & $4 / 15 / 03$ & $4 / 15 / 33$ \\
\hline
\end{tabular}




\section{Waste Isolation Pilot Plant Annual Site Environmental Report for 2008 DOE/WIPP-09-2225}

\begin{tabular}{|c|c|c|c|c|c|}
\hline \multicolumn{6}{|c|}{$\begin{array}{l}\text { Table B.1 - Active Environmental Permits, Registration, and Rights of Way for the Waste Isolation } \\
\text { Pilot Plant - Calendar Year } 2008 \text { (Does Not Include Hazardous Waste Facility Permit or } \\
\text { DP-831) }\end{array}$} \\
\hline & Granting Agency & Type of Permit & $\begin{array}{l}\text { Permit } \\
\text { Number }\end{array}$ & Granted & Expiration \\
\hline 24 & $\begin{array}{l}\text { Department of the Interior, } \\
\text { Bureau of Land Management }\end{array}$ & $\begin{array}{l}\text { Right-of-Way easement for WIPP well } \\
\text { bore SNL-12 }\end{array}$ & 109176 & $4 / 15 / 03$ & $4 / 15 / 33$ \\
\hline 25 & $\begin{array}{l}\text { Department of the Interior, } \\
\text { Bureau of Land Management }\end{array}$ & $\begin{array}{l}\text { Right-of-Way easement for WIPP well } \\
\text { bore SNL-1 and access road }\end{array}$ & 109177 & $6 / 17 / 03$ & $6 / 17 / 33$ \\
\hline 26 & $\begin{array}{l}\text { Department of the Interior, } \\
\text { Bureau of Land Management }\end{array}$ & $\begin{array}{l}\text { Right-of-Way easement for WIPP well } \\
\text { bore SNL-11 and access road }\end{array}$ & 110735 & $10 / 16 / 03$ & $10 / 16 / 33$ \\
\hline 27 & $\begin{array}{l}\text { Department of the Interior, } \\
\text { Bureau of Land Management }\end{array}$ & $\begin{array}{l}\text { Right-of-Way easement for WIPP well } \\
\text { bore SNL-5 and access road }\end{array}$ & 110735 & $10 / 16 / 03$ & $10 / 16 / 33$ \\
\hline 28 & $\begin{array}{l}\text { Department of the Interior, } \\
\text { Bureau of Land Management }\end{array}$ & Right-of-Way grant for SNL-16 and 17 & NM108365 & $12 / 21 / 05$ & $8 / 30 / 32$ \\
\hline 29 & $\begin{array}{l}\text { Department of the Interior, } \\
\text { Bureau of Land Management }\end{array}$ & Right-of-Way grant for SNL-18 and 10 & NM115315 & $3 / 21 / 06$ & $12 / 31 / 35$ \\
\hline 30 & $\begin{array}{l}\text { Department of the Interior, } \\
\text { Bureau of Land Management }\end{array}$ & $\begin{array}{l}\text { Right-of-way reservation amendment for } \\
\text { SNL-13 and SNL-14 }\end{array}$ & NM108365 & $1 / 25 / 05$ & $8 / 30 / 32$ \\
\hline 31 & $\begin{array}{l}\text { Department of the Interior, } \\
\text { Bureau of Land Management }\end{array}$ & $\begin{array}{l}\text { Right-of-way reservation amendment for } \\
\text { SNL-6, SNL-8, and SNL-15 }\end{array}$ & NM108365 & $3 / 15 / 05$ & $8 / 30 / 32$ \\
\hline 32 & $\begin{array}{l}\text { Department of the Interior, } \\
\text { Bureau of Land Management }\end{array}$ & $\begin{array}{l}\text { Right-of-way for } 20 \text { radiological stations, } 2 \\
\text { aerosol samplers, and } 2 \text { weather monitor } \\
\text { site. }\end{array}$ & NM063136 & $7 / 3 / 86$ & $7 / 2 / 11$ \\
\hline 33 & $\begin{array}{l}\text { U.S. Department of the Interior, } \\
\text { Fish and Wildlife Service }\end{array}$ & $\begin{array}{l}\text { Concurrence that WIPP construction } \\
\text { activities will have no significant impact on } \\
\text { federally-listed threatened or endangered } \\
\text { species }\end{array}$ & None & $5 / 29 / 80$ & None \\
\hline 34 & $\begin{array}{l}\text { New Mexico Commissioner of } \\
\text { Public Lands }\end{array}$ & Right-of-Way for High Volume Air Sampler & $\mathrm{RW}-22789$ & $10 / 3 / 85$ & $10 / 3 / 20$ \\
\hline 35 & $\begin{array}{l}\text { New Mexico Commissioner of } \\
\text { Public Lands }\end{array}$ & Monitoring Well SNL-3 & RW-28537 & $7 / 31 / 03$ & $7 / 31 / 38$ \\
\hline 36 & $\begin{array}{l}\text { New Mexico Commissioner of } \\
\text { Public Lands }\end{array}$ & Monitoring Well SNL-1 & $\mathrm{RW}-28535$ & $8 / 27 / 03$ & $8 / 27 / 38$ \\
\hline 37 & $\begin{array}{l}\text { New Mexico Commissioner of } \\
\text { Public Lands }\end{array}$ & $\begin{array}{l}\text { Right-of-Way Easement for Accessing } \\
\text { State Trust Lands in Eddy \& Lea Counties }\end{array}$ & $\mathrm{RW}-25430$ & $9 / 28 / 04$ & $9 / 28 / 14$ \\
\hline 38 & $\begin{array}{l}\text { New Mexico Environment } \\
\text { Department Air Quality Bureau }\end{array}$ & $\begin{array}{l}\text { Operating Permit for two backup diesel } \\
\text { generators }\end{array}$ & $310-\mathrm{M}-2$ & $12 / 7 / 93$ & None \\
\hline 39 & $\begin{array}{l}\text { New Mexico Department of Game } \\
\text { and Fish }\end{array}$ & $\begin{array}{l}\text { Concurrence that WIPP construction } \\
\text { activities will have no significant impact on } \\
\text { state-listed threatened or endangered } \\
\text { species }\end{array}$ & None & $5 / 26 / 89$ & None \\
\hline 40 & $\begin{array}{l}\text { New Mexico Environment } \\
\text { Department-UST Bureau }\end{array}$ & Underground Storage Tanks Registration & $\begin{array}{l}\text { Facility No. } \\
31539\end{array}$ & $7 / 1 / 08$ & $6 / 30 / 09$ \\
\hline 41 & New Mexico State Engineer Office & $\begin{array}{l}\text { Monitoring Well Exhaust Shaft Exploratory } \\
\text { Borehole }\end{array}$ & C-2801 & $2 / 23 / 01$ & None \\
\hline 42 & New Mexico State Engineer Office & Monitoring Well & C-2811 & $3 / 2 / 02$ & None \\
\hline 43 & New Mexico State Engineer Office & $\begin{array}{l}\text { Monitoring Well Exhaust Shaft Exploratory } \\
\text { Borehole }\end{array}$ & C-2802 & $2 / 23 / 01$ & None \\
\hline 44 & New Mexico State Engineer Office & $\begin{array}{l}\text { Monitoring Well Exhaust Shaft Exploratory } \\
\text { Borehole }\end{array}$ & C-2803 & $2 / 23 / 01$ & None \\
\hline 45 & New Mexico State Engineer Office & Appropriation: WQSP-1 Well & C-2413 & $10 / 21 / 96$ & None \\
\hline 46 & New Mexico State Engineer Office & Appropriation: WQSP-2 Well & C-2414 & $10 / 21 / 96$ & None \\
\hline 47 & New Mexico State Engineer Office & Appropriation: WQSP-3 Well & C-2415 & $10 / 21 / 96$ & None \\
\hline 48 & New Mexico State Engineer Office & Appropriation: WQSP-4 Well & C-2416 & $10 / 21 / 96$ & None \\
\hline 49 & New Mexico State Engineer Office & Appropriation: WQSP-5 Well & C-2417 & $10 / 21 / 96$ & None \\
\hline
\end{tabular}




\section{Waste Isolation Pilot Plant Annual Site Environmental Report for 2008 DOE/WIPP-09-2225}

\section{Table B.1 - Active Environmental Permits, Registration, and Rights of Way for the Waste Isolation Pilot Plant - Calendar Year 2008 (Does Not Include Hazardous Waste Facility Permit or DP-831)}

\begin{tabular}{|c|c|c|c|c|c|}
\hline & Granting Agency & Type of Permit & $\begin{array}{l}\text { Permit } \\
\text { Number }\end{array}$ & Granted & Expiration \\
\hline 50 & New Mexico State Engineer Office & Appropriation: WQSP-6 Well & C-2418 & $10 / 21 / 96$ & None \\
\hline 51 & New Mexico State Engineer Office & Appropriation: WQSP-6a Well & C-2419 & $10 / 21 / 96$ & None \\
\hline 52 & New Mexico State Engineer Office & Monitoring Well AEC-7 & C-2742 & $11 / 6 / 00$ & None \\
\hline 53 & New Mexico State Engineer Office & Monitoring Well AEC-8 & C-2744 & $11 / 6 / 00$ & None \\
\hline 54 & New Mexico State Engineer Office & Monitoring Well Cabin Baby & C-2664 & $7 / 30 / 99$ & None \\
\hline 55 & New Mexico State Engineer Office & Monitoring Well DOE-1 & C-2757 & $11 / 6 / 00$ & None \\
\hline 56 & New Mexico State Engineer Office & Monitoring Well DOE-2 & C-2682 & $4 / 17 / 00$ & None \\
\hline 57 & New Mexico State Engineer Office & Monitoring Well ERDA-9 & C-2752 & $11 / 6 / 00$ & None \\
\hline 58 & New Mexico State Engineer Office & Monitoring Well $\mathrm{H}-1$ & C-2765 & $11 / 6 / 00$ & None \\
\hline 59 & New Mexico State Engineer Office & Monitoring Well H-2A & C-2762 & $11 / 6 / 00$ & None \\
\hline 60 & New Mexico State Engineer Office & Monitoring Well H-2B1 & C-2758 & $11 / 6 / 00$ & None \\
\hline 61 & New Mexico State Engineer Office & Monitoring Well H-2B2 & C-2763 & $11 / 6 / 00$ & None \\
\hline 62 & New Mexico State Engineer Office & Monitoring Well $\mathrm{H}-2 \mathrm{C}$ & C-2759 & $11 / 6 / 00$ & None \\
\hline 63 & New Mexico State Engineer Office & Monitoring Well H-3B1 & C-2764 & $11 / 6 / 00$ & None \\
\hline 64 & New Mexico State Engineer Office & Monitoring Well H-3B2 & C-2760 & $11 / 6 / 00$ & None \\
\hline 65 & New Mexico State Engineer Office & Monitoring Well H-3B3 & C-2761 & $11 / 6 / 00$ & None \\
\hline 66 & New Mexico State Engineer Office & Monitoring Well H-3D & C-3207 & $11 / 6 / 00$ & None \\
\hline 67 & New Mexico State Engineer Office & Monitoring Well H-4A & C-2725 & $11 / 6 / 00$ & None \\
\hline 68 & New Mexico State Engineer Office & Monitoring Well H-4B & C-2775 & $11 / 6 / 00$ & None \\
\hline 69 & New Mexico State Engineer Office & Monitoring Well $\mathrm{H}-4 \mathrm{C}$ & C-2776 & $11 / 6 / 00$ & None \\
\hline 70 & New Mexico State Engineer Office & Monitoring Well $\mathrm{H}-5 \mathrm{~A}$ & C-2746 & $11 / 6 / 00$ & None \\
\hline 71 & New Mexico State Engineer Office & Monitoring Well H-5B & C-2745 & $11 / 6 / 00$ & None \\
\hline 72 & New Mexico State Engineer Office & Monitoring Well $\mathrm{H}-5 \mathrm{C}$ & C-2747 & $11 / 6 / 00$ & None \\
\hline 73 & New Mexico State Engineer Office & Monitoring Well H-6A & C-2751 & $11 / 6 / 00$ & None \\
\hline 74 & New Mexico State Engineer Office & Monitoring Well H-6BR & C-3362 & $12 / 27 / 07$ & None \\
\hline 75 & New Mexico State Engineer Office & Monitoring Well H-6C & C-2750 & $11 / 6 / 00$ & None \\
\hline 76 & New Mexico State Engineer Office & Monitoring Well H-7A & C-2694 & $4 / 17 / 00$ & None \\
\hline 77 & New Mexico State Engineer Office & Monitoring Well H-7B1 & C-2770 & $11 / 6 / 00$ & None \\
\hline 78 & New Mexico State Engineer Office & Monitoring Well H-7B2 & C-2771 & $11 / 6 / 00$ & None \\
\hline 79 & New Mexico State Engineer Office & Monitoring Well $\mathrm{H}-7 \mathrm{C}$ & C-2772 & $11 / 6 / 00$ & None \\
\hline 80 & New Mexico State Engineer Office & Monitoring Well $\mathrm{H}-8 \mathrm{~A}$ & C-2780 & $11 / 6 / 00$ & None \\
\hline 81 & New Mexico State Engineer Office & Monitoring Well H-8B & $\mathrm{C}-2781$ & $11 / 6 / 00$ & None \\
\hline 82 & New Mexico State Engineer Office & Monitoring Well $\mathrm{H}-8 \mathrm{C}$ & C-2782 & $11 / 6 / 00$ & None \\
\hline 83 & New Mexico State Engineer Office & Monitoring Well $\mathrm{H}-9 \mathrm{~A}$ & C-2785 & $11 / 6 / 00$ & None \\
\hline 84 & New Mexico State Engineer Office & Monitoring Well H-9B & C-2783 & $11 / 6 / 00$ & None \\
\hline 85 & New Mexico State Engineer Office & Monitoring Well H-9C & C-2784 & $11 / 6 / 00$ & None \\
\hline 86 & New Mexico State Engineer Office & Monitoring Well $\mathrm{H}-10 \mathrm{~A}$ & C-2779 & $11 / 6 / 00$ & None \\
\hline 87 & New Mexico State Engineer Office & Monitoring Well $\mathrm{H}-10 \mathrm{~B}$ & C-2778 & $11 / 6 / 00$ & None \\
\hline 88 & New Mexico State Engineer Office & Monitoring Well $\mathrm{H}-10 \mathrm{C}$ & C-2695 & $4 / 17 / 00$ & None \\
\hline 89 & New Mexico State Engineer Office & Monitoring Well H-11B1 & C-2767 & $11 / 6 / 00$ & None \\
\hline 90 & New Mexico State Engineer Office & Monitoring Well H-11B2 & C-2687 & $4 / 17 / 00$ & None \\
\hline 91 & New Mexico State Engineer Office & Monitoring Well H-11B3 & C-2768 & $11 / 6 / 00$ & None \\
\hline 92 & New Mexico State Engineer Office & Monitoring Well H-11B4 & C-2769 & $11 / 6 / 00$ & None \\
\hline
\end{tabular}




\section{Waste Isolation Pilot Plant Annual Site Environmental Report for 2008 DOE/WIPP-09-2225}

\begin{tabular}{|c|c|c|c|c|c|}
\hline \multicolumn{6}{|c|}{$\begin{array}{l}\text { Table B.1 - Active Environmental Permits, Registration, and Rights of Way for the Waste Isolation } \\
\text { Pilot Plant - Calendar Year } 2008 \text { (Does Not Include Hazardous Waste Facility Permit or } \\
\text { DP-831) }\end{array}$} \\
\hline & Granting Agency & Type of Permit & $\begin{array}{c}\text { Permit } \\
\text { Number }\end{array}$ & Granted & Expiration \\
\hline 93 & New Mexico State Engineer Office & Monitoring Well $\mathrm{H}-12$ & C-2777 & $11 / 6 / 00$ & None \\
\hline 94 & New Mexico State Engineer Office & Monitoring Well H-14 & C-2766 & $11 / 6 / 00$ & None \\
\hline 95 & New Mexico State Engineer Office & Monitoring Well H-15 & C-2685 & $4 / 17 / 00$ & None \\
\hline 96 & New Mexico State Engineer Office & Monitoring Well H-15R & C-3361 & $12 / 27 / 07$ & None \\
\hline 97 & New Mexico State Engineer Office & Monitoring Well H-16 & C-2753 & $11 / 6 / 00$ & None \\
\hline 98 & New Mexico State Engineer Office & Monitoring Well H-17 & C-2773 & $11 / 6 / 00$ & None \\
\hline 99 & New Mexico State Engineer Office & Monitoring Well H-18 & C-2683 & $4 / 17 / 00$ & None \\
\hline 100 & New Mexico State Engineer Office & Monitoring Well P-17 & C-2774 & $11 / 6 / 00$ & None \\
\hline 101 & New Mexico State Engineer Office & Monitoring Well WIPP-11 & C-3365 & $12 / 27 / 07$ & None \\
\hline 102 & New Mexico State Engineer Office & Monitoring Well WIPP-12 & C-2639 & $1 / 12 / 99$ & None \\
\hline 103 & New Mexico State Engineer Office & Monitoring Well WIPP-13 & C-2748 & $11 / 6 / 00$ & None \\
\hline 104 & New Mexico State Engineer Office & Monitoring Well WIPP-18 & C-2684 & $4 / 17 / 00$ & None \\
\hline 105 & New Mexico State Engineer Office & Monitoring Well WIPP-19 & C-2755 & $11 / 6 / 00$ & None \\
\hline 106 & New Mexico State Engineer Office & Monitoring Well WIPP-21 & C-2754 & $11 / 6 / 00$ & None \\
\hline 107 & New Mexico State Engineer Office & Monitoring Well WIPP-25 & C-2723 & $7 / 26 / 00$ & None \\
\hline 108 & New Mexico State Engineer Office & Monitoring Well WIPP-26 & C-2724 & $11 / 6 / 00$ & None \\
\hline 109 & New Mexico State Engineer Office & Monitoring Well WIPP-27 & C-2722 & $11 / 6 / 00$ & None \\
\hline 110 & New Mexico State Engineer Office & Monitoring Well WIPP-28 & C-2636 & $1 / 12 / 99$ & None \\
\hline 111 & New Mexico State Engineer Office & Monitoring Well WIPP-29 & C-2743 & $11 / 6 / 00$ & None \\
\hline 112 & New Mexico State Engineer Office & Monitoring Well WIPP-30 & C-2727 & $8 / 4 / 00$ & None \\
\hline 113 & New Mexico State Engineer Office & Monitoring Well SNL-2 & C-2948 & $2 / 14 / 03$ & None \\
\hline 114 & New Mexico State Engineer Office & Monitoring Well SNL-9 & C-2950 & $2 / 14 / 03$ & None \\
\hline 115 & New Mexico State Engineer Office & Monitoring Well SNL-12 & C-2954 & $2 / 25 / 03$ & None \\
\hline 116 & New Mexico State Engineer Office & Monitoring Well SNL-1 & C-2953 & $2 / 25 / 03$ & None \\
\hline 117 & New Mexico State Engineer Office & Monitoring Well SNL-3 & C-2949 & $2 / 14 / 03$ & None \\
\hline 118 & New Mexico State Engineer Office & Monitoring Well WTS-4 & C-2960 & $3 / 18 / 03$ & None \\
\hline 119 & New Mexico State Engineer Office & Monitoring Well SNL-5 & C-3002 & $10 / 1 / 03$ & None \\
\hline 120 & New Mexico State Engineer Office & Monitoring Well IMC-461 & C-3015 & $11 / 25 / 03$ & None \\
\hline 121 & New Mexico State Engineer Office & Monitoring Well SNL-11 & C-3003 & $10 / 1 / 03$ & None \\
\hline 122 & New Mexico State Engineer Office & Monitoring Well SNL10 & $\mathrm{C} 03221$ & $7 / 26 / 05$ & None \\
\hline 123 & New Mexico State Engineer Office & Monitoring Well SNL16 & C03220 & $7 / 26 / 05$ & None \\
\hline 124 & New Mexico State Engineer Office & Monitoring Well SNL17 & $\mathrm{C} 03222$ & $7 / 26 / 05$ & None \\
\hline 125 & New Mexico State Engineer Office & Monitoring Well SNL18 & $\mathrm{C} 03233$ & $10 / 6 / 05$ & None \\
\hline 126 & New Mexico State Engineer Office & Monitoring Well SNL19 & C03234 & $10 / 6 / 05$ & None \\
\hline 127 & U.S. Fish and Wildlife Service & Migratory Bird Special Purpose - Relocate & MB155189-0 & $7 / 10 / 07$ & $3 / 31 / 09$ \\
\hline
\end{tabular}




\section{Appendix C \\ Location Codes}

Table C.1 - Codes Used to Identify the Sites from Which Samples Were Collected

\begin{tabular}{llll}
\hline Code & \multicolumn{1}{c}{ Location } & \multicolumn{1}{c}{ Code } & \multicolumn{1}{c}{ Location } \\
\hline BHT & Bottom of the Hill Tank & RCP1 & Rainwater Catchment Pond (1) \\
BRA & Brantley Lake & RCP2 & Rainwater Catchment Pond (2) \\
CBD & Carlsbad & RED & Red Tank \\
COW & Coyote Well (distilled water blank) & SEC & South East Control \\
FWT & Fresh Water Tank & SMR & Smith Ranch \\
HIL & Hill Tank & SOO & Sample of Opportunity* \\
IDN & Indian Tank & SWL & Sewage Lagoons \\
LST & Lost Tank & TUT & Tut Tank \\
MLR & Mills Ranch & UPR & Upper Pecos River \\
NOY & Noya Tank & WAB & WIPP Air Blank \\
PCN & Pierce Canyon & WEE & WIPP East \\
PEC & Pecos River & WFF & WIPP Far Field \\
PKT & Poker Trap & WQSP & Water Quality Sampling Program \\
& & WSS & WIPP South \\
\hline
\end{tabular}

* Sample taken where found 
Waste Isolation Pilot Plant Annual Site Environmental Report for 2008

DOE/WIPP-09-2225

This page intentionally left blank 


\section{Appendix D \\ Radiochemical Equations}

\section{Detection}

All radionuclides with the exception of the gamma spectroscopy targets $\left({ }^{137} \mathrm{Cs},{ }^{60} \mathrm{Co}\right.$, and ${ }^{40} \mathrm{~K}$ ) are considered "detected" if the radionuclide activity or concentration [RN] is greater than the minimum detectable concentration and greater than the total propagated uncertainty at the 2 sigma level. The gamma radionuclides are considered detected when the above criteria are met and the gamma spectroscopy software used to identify the peak generates an associated identification confidence of 90 percent or greater (ID Confidence $\geq 0.90$ ).

\section{Minimum Detectable Concentration (MDC)}

The MDC is the smallest amount (activity or mass) of a radionuclide in a sample that will be detected with a 5 percent probability of nondetection while accepting a 5 percent probability of erroneously deciding that a positive quantity of a radionuclide is present in an appropriate blank sample. This method assures that any claimed MDC has at least a 95 percent chance of being detected. It is possible to achieve a very low level of detection by analyzing a large sample size and counting for a very long time.

The WIPP Laboratories uses the following equation for calculating the MDCs for each radionuclide in various sample matrices:

$$
M D C=\frac{4.66 \sqrt{S}}{K T}+\frac{3.00}{K T}
$$

Where:

$$
\begin{aligned}
S= & \begin{array}{l}
\text { Net method blank counts; when method blank counts }=0, \text { average } \\
\text { of the last } 30 \text { blanks analyzed are substituted }
\end{array} \\
K= & \begin{array}{l}
\text { A correction factor that includes items such as unit conversions, } \\
\text { sample volume/weight, decay correction, detector efficiency, } \\
\text { chemical recovery and abundance correction, etc. }
\end{array} \\
T= & \begin{array}{l}
\text { Counting time where the background and sample counting time are } \\
\text { identical }
\end{array}
\end{aligned}
$$

For further evaluation of the MDC, refer to ANSI N13.30, Performance Criteria for Radiobioassay.

\section{Total Propagated Uncertainty (TPU)}

The TPU is an estimate of the uncertainty in the measurement due to all sources, including counting error, measurement error, chemical recovery error, detector efficiency, randomness of radioactive decay, and any other sources of uncertainty. 
The TPU for each data point must be reported at the $2 \sigma$ level $(2 \times T P U) . T_{2 \sigma}$ is found by multiplying $\mathrm{TPU}_{1 \sigma}$ by 1.96 after using the following equation:

$$
T P U_{1 \sigma}=\frac{\sqrt{\sigma_{N C R}^{2}+(N C R)^{2} *\left(R E_{E F F}^{2}+R E_{A L I}^{2}+R E_{R}^{2}+\Sigma R E_{C F}^{2}\right)}}{2.22 * E F F * A L I * R * A B N_{S} * e^{-\lambda \Delta t} * C F}
$$

Where:

$$
\begin{aligned}
& \mathrm{EFF}=\text { Detector Efficiency } \\
& \text { ALI = Sample Aliquot Volume or Mass } \\
& \mathrm{R} \quad=\text { Sample Tracer/Carrier Recovery } \\
& \mathrm{ABN}_{\mathrm{s}}=\text { Abundance Fraction of the Emissions Used for } \\
& \text { Identification/Quantification } \\
& \sigma^{2}{ }_{\mathrm{NCR}}=\text { Variance of the Net Sample Count Rate } \\
& \text { NCR }=\text { Net Sample Count Rate } \\
& \mathrm{RE}_{\mathrm{EFF}}^{2}=\text { Square of the Relative Error of the Efficiency Term } \\
& \mathrm{RE}^{2}{ }_{\mathrm{ALI}}=\text { Square of the Relative Error of the Aliquot } \\
& \mathrm{RE}_{\mathrm{R}}^{2}=\text { Square of the Relative Error of the Sample Recovery } \\
& \mathrm{RE}_{\mathrm{CF}}^{2}=\text { Square of the Relative Error of Other Correction Factors } \\
& \lambda=\text { Radionuclide Decay Constant }=\ln 2 / \text { (half-life) (same units as the } \\
& \text { half-life used to compute } \Delta t \text { ) } \\
& \Delta \mathrm{t} \quad=\text { Time from Sample Collection to Radionuclide Separation or } \\
& \text { Mid-Point of Count Time (same units as half-life) } \\
& \mathrm{CF}=\text { Other Correction Factors as Appropriate (i.e., ingrowth factor, } \\
& \text { self-absorption factor, etc.). }
\end{aligned}
$$

For further discussion of TPU, refer to ANSI N13.30 and/or Waste Acceptance Criteria for Off-Site Generators, Fernald Environmental Management Project (DOE, 1994). 


\section{Relative Error Ratio (RER)}

The Relative Error Ratio is a method, similar to a t-test, with which to compare duplicate results (see Chapters 4 and 8; WP 02-EM3004, Radiological Data Verification and Validation).

$$
R E R=\frac{\left|x_{A}-x_{B}\right|}{\sqrt{\left(2 \sigma_{A}\right)^{2}+\left(2 \sigma_{R}\right)^{2}}}
$$

Where:

$$
\begin{array}{ll}
\overline{X_{A}} & =\text { Mean Activity of Population A } \\
\overline{X_{B}} & =\text { Mean Activity of Population B } \\
\sigma_{A} & =\text { Standard Deviation of Population A } \\
\sigma_{B} & =\text { Standard Deviation of Population B }
\end{array}
$$

\section{Percent Bias (\% Bias)}

The percent bias is a measure of the accuracy of radiochemical separation methods and counting instruments; that is, a measure of how reliable the results of analyses are when compared to the actual values.

$$
\% B I A S=\left[\frac{A_{m}-A_{k}}{A_{k}}\right] * 100 \%
$$

Where:

$$
\begin{array}{lll}
\% \text { BIAS } & =\text { Percent Bias } \\
A_{m} & =\text { Measured Sample Activity } \\
A_{k} & =\quad \text { Known Sample Activity }
\end{array}
$$


Waste Isolation Pilot Plant Annual Site Environmental Report for 2008

DOE/WIPP-09-2225

This page intentionally left blank. 


\section{Appendix E \\ Time Trend Plots for Detectable Constituents in Groundwater}

The seven WQSP wells had been sampled 25 times prior to the two sampling rounds conducted in 2008. The first 10 sampling rounds measured from 1995 through 2000 (all conducted prior to receiving mixed waste at the WIPP site) were used to establish the original baseline for groundwater chemistry at each sampling location. The baseline sample set is used to determine whether statistically significant changes have occurred at any well. The following time trend charts show the Round 26 and Round 27 results with respect to the established baseline.

The baseline was established incorporating data from three different laboratories. The wide ranges of target analyte concentrations measured during the baseline resulted from past difficulties in analyzing the high-brine groundwater from the WIPP site. The contract laboratories used variable dilution factors when analyzing the samples resulting in variable detection limits for some analytes. The analytes include constituents which are defined as the target 20 volatile and 12 semivolatile organics as well as 14 trace metals. Time trend plots are not included for these. The other analytes include the general chemistry parameters. The general chemistry parameters include the common cation metals, calcium, magnesium, potassium, and sodium; the anions chloride and sulfate; density, $\mathrm{pH}$, specific conductance, total dissolved solids, total suspended solids, total organic carbon, and total organic halogens. Time trend plots are provided below for all the general chemistry parameters with the exception of nitrate, which has periodically been detected only in WQSP-6A. These plots show the concentrations in the primary sample and the duplicate sample with respect to Sampling Round.

The current laboratory analytical results were verified and validated in accordance with WIPP procedures and U.S. Environmental Protection Agency technical guidance. Sampling Round 26 samples were taken March through May 2008 and Sampling Round 27 samples were taken September through November 2008. See Appendix F for specific concentration information on the WQSP groundwater wells.

Some notable observations from the trend plots include:

- There was no evidence of any external contamination in any of the groundwater samples.

$\bullet$

Most of the measurements reported for Rounds 26 and 27 were less than the $95^{\text {th }}$ Upper Tolerance Limit Value (UTLV) or within the range of previous measurements with a few minor exceptions as discussed below. The UTLV establishes a concentration range that contains a specified proportion of the population with a specified confidence.

With respect to the major metal cations, calcium, magnesium, and potassium concentrations were within the normal range of past values although the concentrations do fluctuate. Sodium concentrations were higher than the 
95th UTLV for both WQSP-1 and WQSP-2 in Round 26, but within the normal range in Round 27.

The high-concentration anions chloride and sulfate also fluctuate, but the concentrations were all below the $95^{\text {th }}$ UTLV.

The $\mathrm{pH}$ was just below the established range of 6.6-7.2 on one of the duplicate samples from WQSP-3 with a $\mathrm{pH}$ of 6.54. The same situation applied to one of the duplicate samples for Round 25 in 2007 and for Round 27 in 2008. In all the cases the average $\mathrm{pH}$ from both duplicates was within the range.

- $\quad$ The TDS for one of the duplicates was above the 95 ${ }^{\text {th }}$ UTLV at WQSP-3 for Round 27. However, the other duplicate was within the range, and the average of the two values was within the range.

- $\quad$ The alkalinity the samples was higher than the UTLV for WQSP-5 and WQSP-6A in Round 26. Again in both case the duplicate sample concentrations were within the range, and the averages of the duplicates for both wells were within the range.

The TSS values were both out of the established range on the high side for WQSP-6 from Round 27. One of the values is off-scale in the Time Trend Plots below. These results appear to be erroneous since TSS were not historically detected in WQSP-6 samples. The possibility that these TSS results were erroneous is corroborated by the fact that the laboratory produced some TSS performance evaluation sample data for their NELAC certification that were not within acceptance limits at the time the groundwater samples were being analyzed. The laboratory was allowed to reanalyze the samples, and acceptable data were eventually obtained. TSS analysis results will be closely monitored as part of the groundwater monitoring program.

There was only one TOX detection in Round 26, and that was in the sample from WQSP-2, and the concentration was right at the reporting limit. During Round 27 with a different laboratory, there were trace TOX detections in all the wells except WQSP-6A. TOX is a particularly difficult analysis in the high-brine samples because any chloride that does not get washed from the granular activated sorption columns is counted as TOX as a false-positive detection. The groundwater samples likely do not contain any halogenated (chlorinated or brominated) organic compounds. This is supported by the fact that no halogenated volatile or semivolatile organic compounds have been detected in the groundwater samples by GC/MS with parts-per-billion detection limits.

- $\quad$ The cation-anion balance ratios were very good and supported the quality of the cation and anion analysis results. Although cation-anion ratios less than 10 percent can be difficult to achieve in high-brine sample matrices, for the 
Round 26 samples analyzed by Trace, all the percent differences between the sum of the cations and anions were less than 10 percent with the exception of WQSP-5 where the percent difference was 10.99. For the Round 27 samples analyzed by Hall, all the percent differences were less than 10 percent with the highest difference for WQSP-3 with 8.43 percent. Several of the percent differences were less than 1 percent with WQSP-6A from Round 26 at 0.06 percent. The values for Round 27 included WQSP-2 at 0.49 percent, WQSP-4 at 0.10 percent, and WQSP-6 at 0.88 percent.

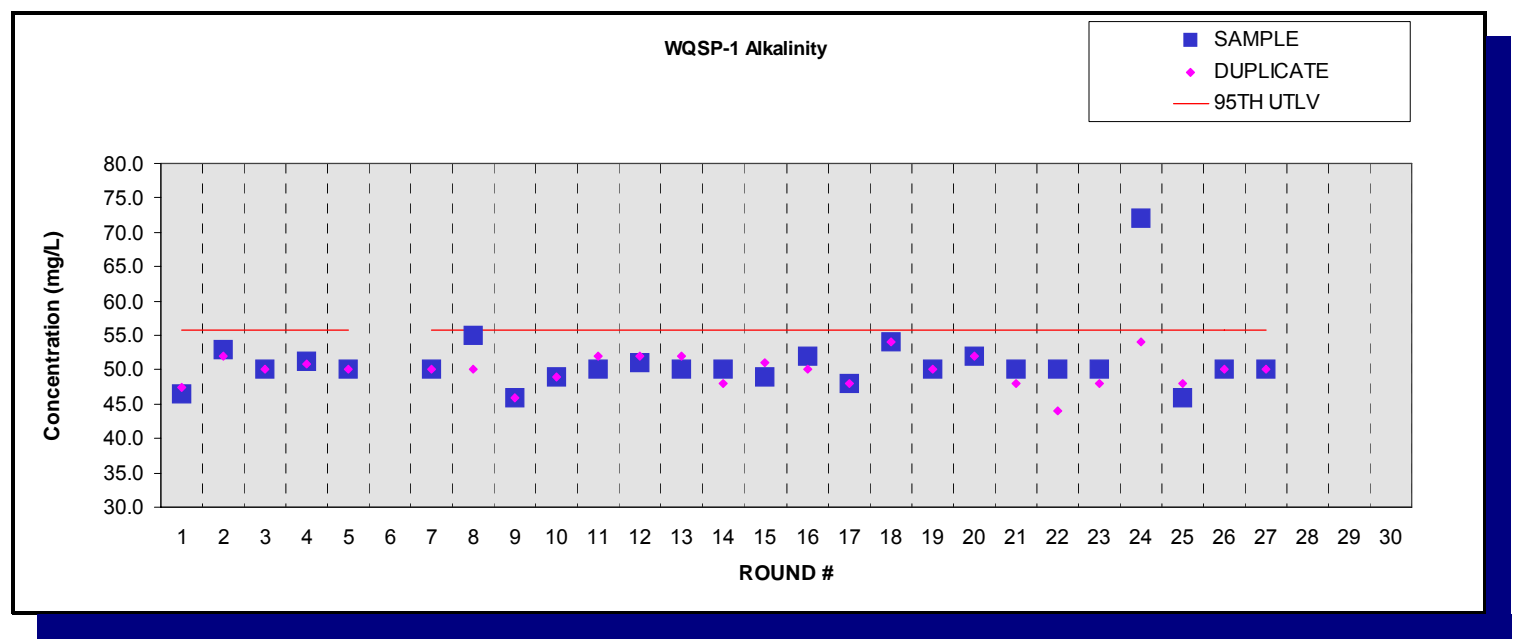

Figure E.1 - Time Trend Plot for Alkalinity at WQSP-1

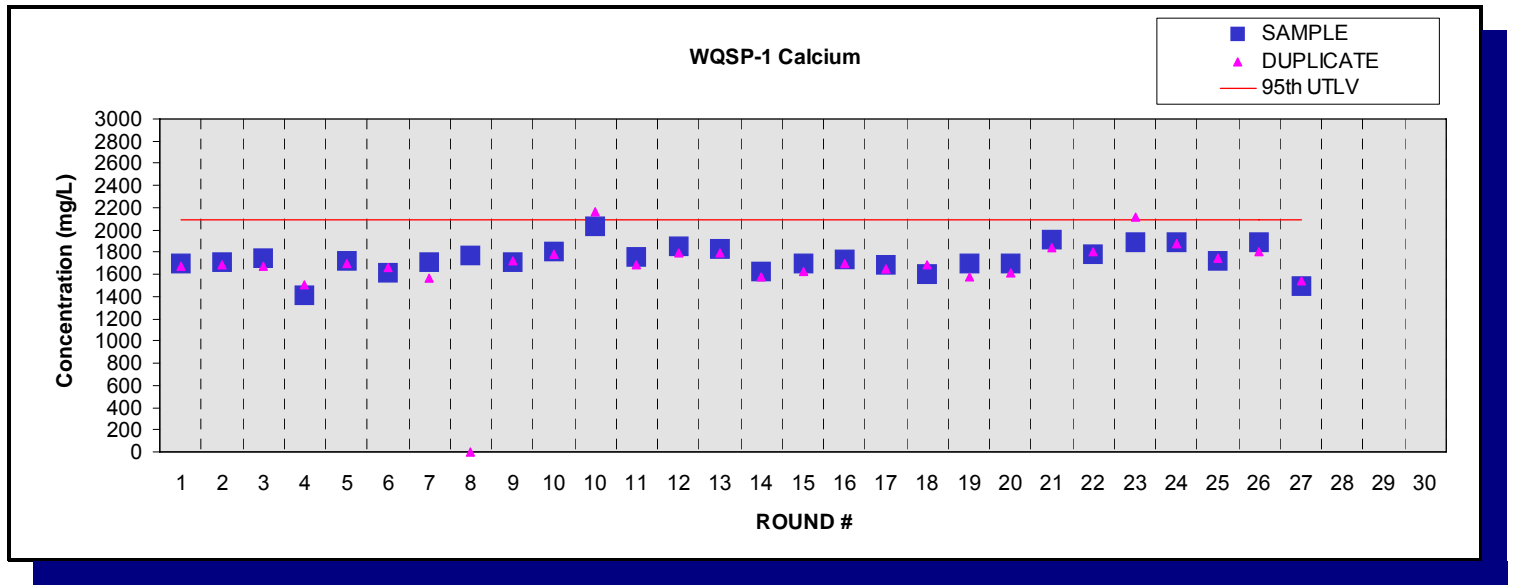

Figure E.2 - Time Trend Plot for Calcium at WQSP-1 
Waste Isolation Pilot Plant Annual Site Environmental Report for 2008 DOE/WIPP-09-2225

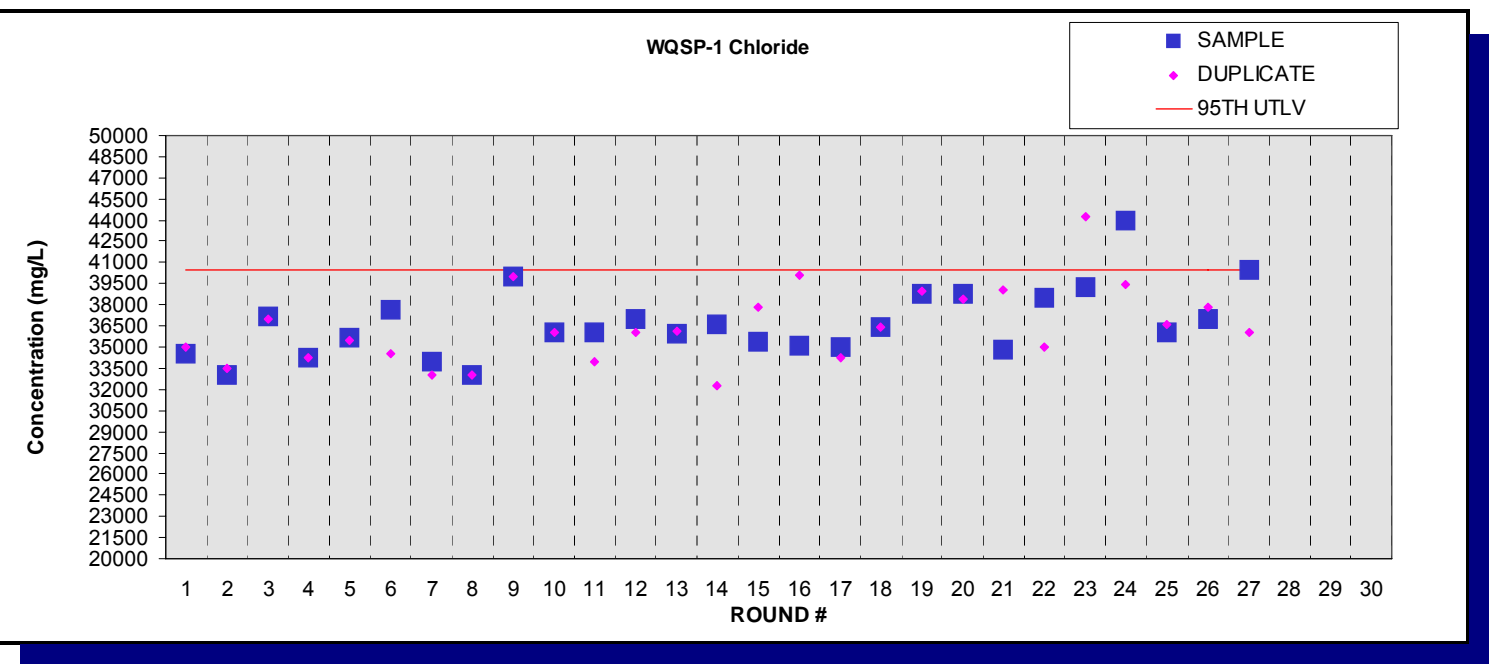

Figure E.3 - Time Trend Plot for Chloride at WQSP-1

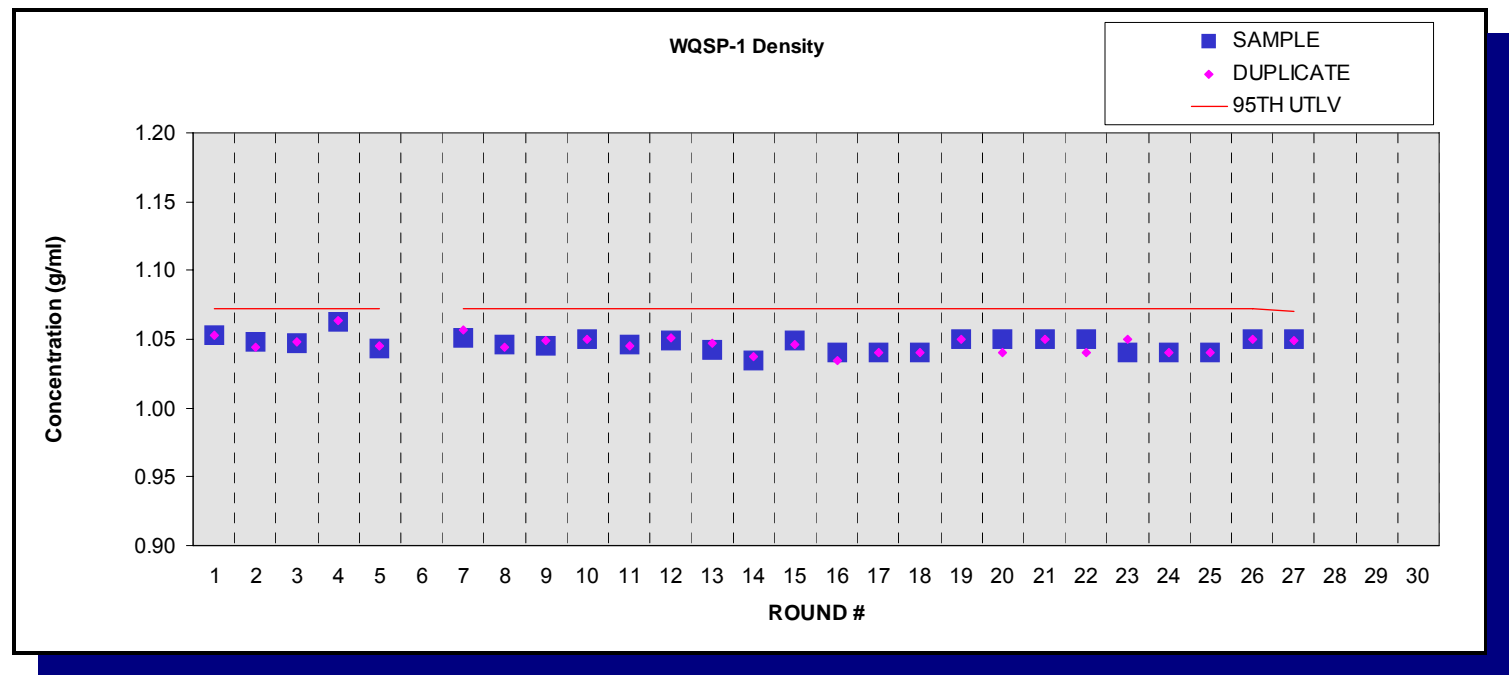

Figure E.4 - Time Trend Plot for Density at WQSP-1

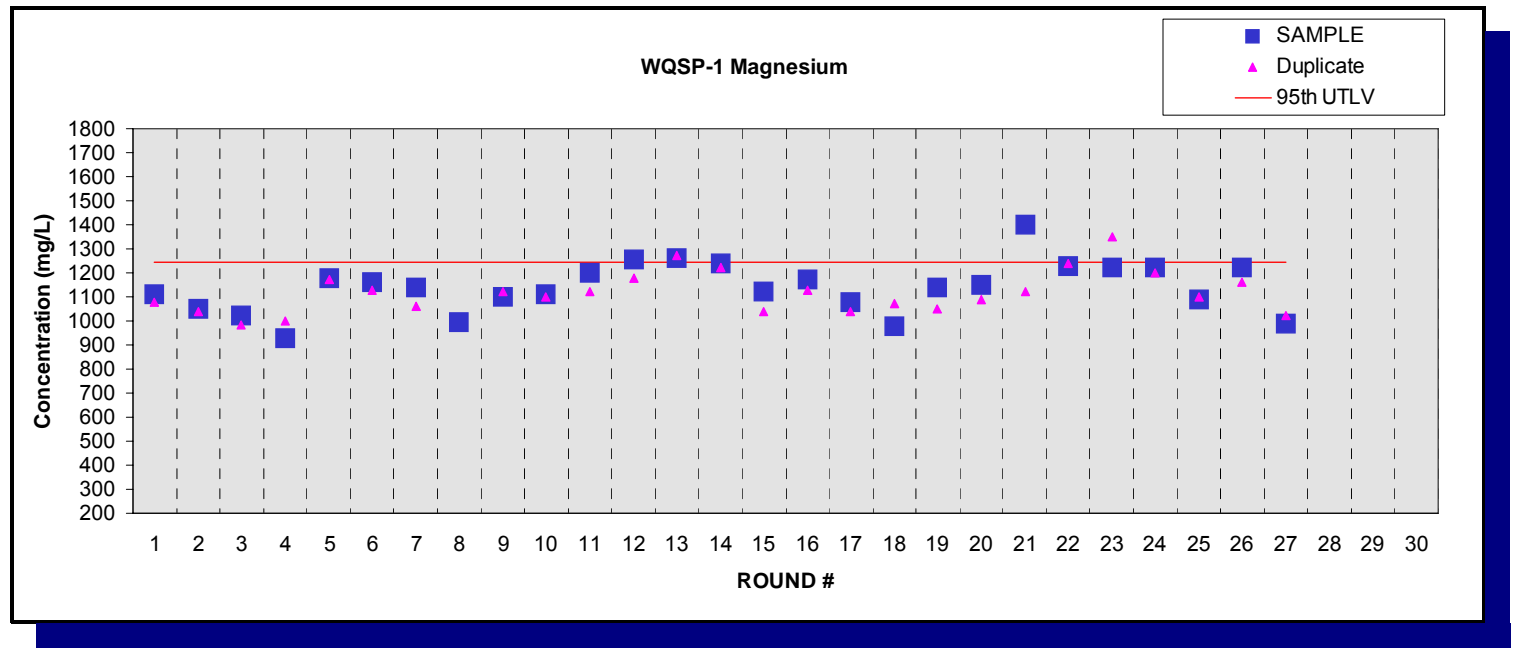

Figure E.5 - Time Trend Plot for Magnesium at WQSP-1 
Waste Isolation Pilot Plant Annual Site Environmental Report for 2008 DOE/WIPP-09-2225

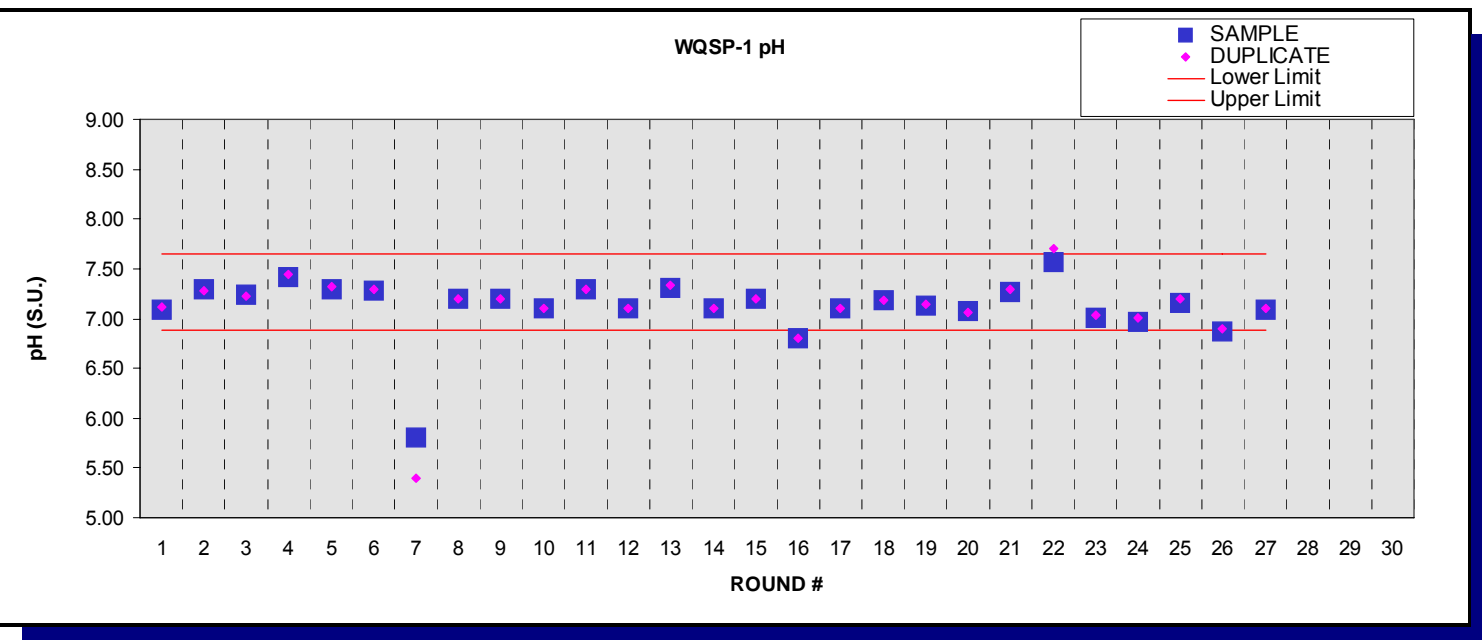

Figure E.6 - Time Trend Plot for pH at WQSP-1

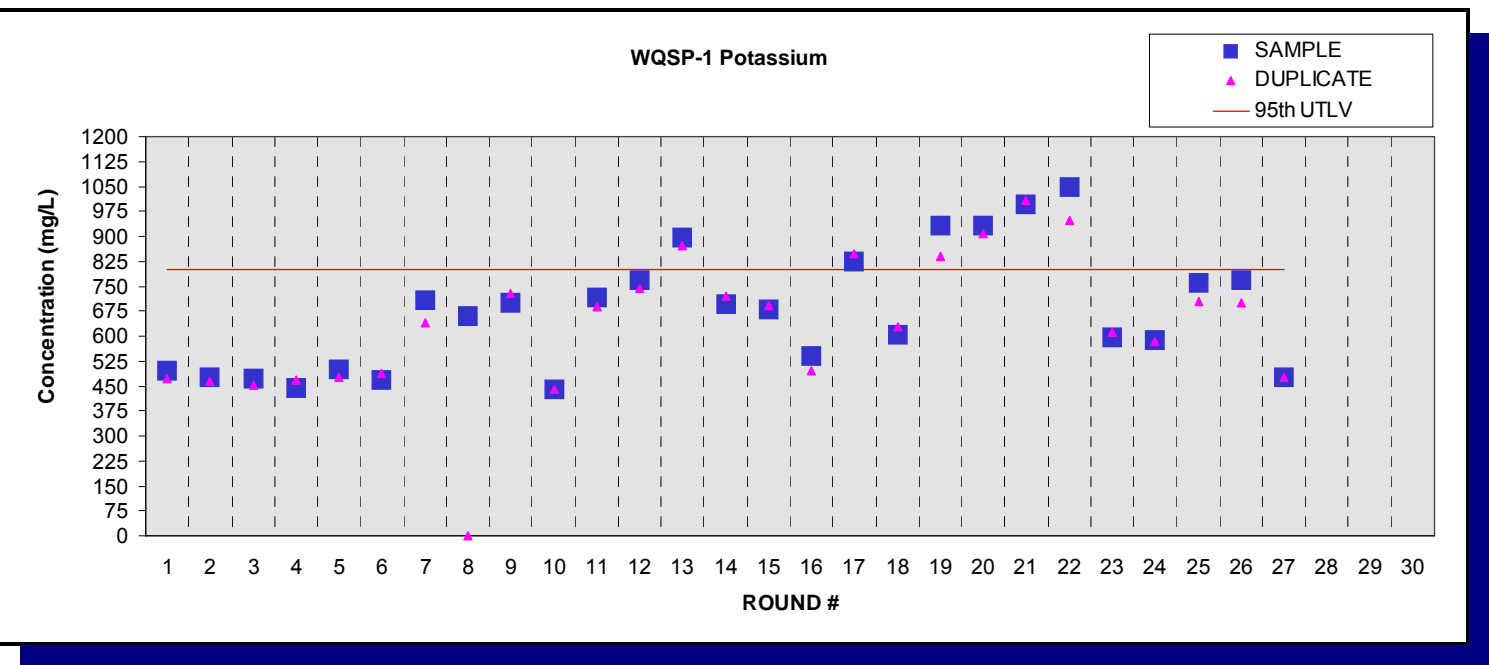

Figure E.7 - Time Trend Plot for Potassium at WQSP-1

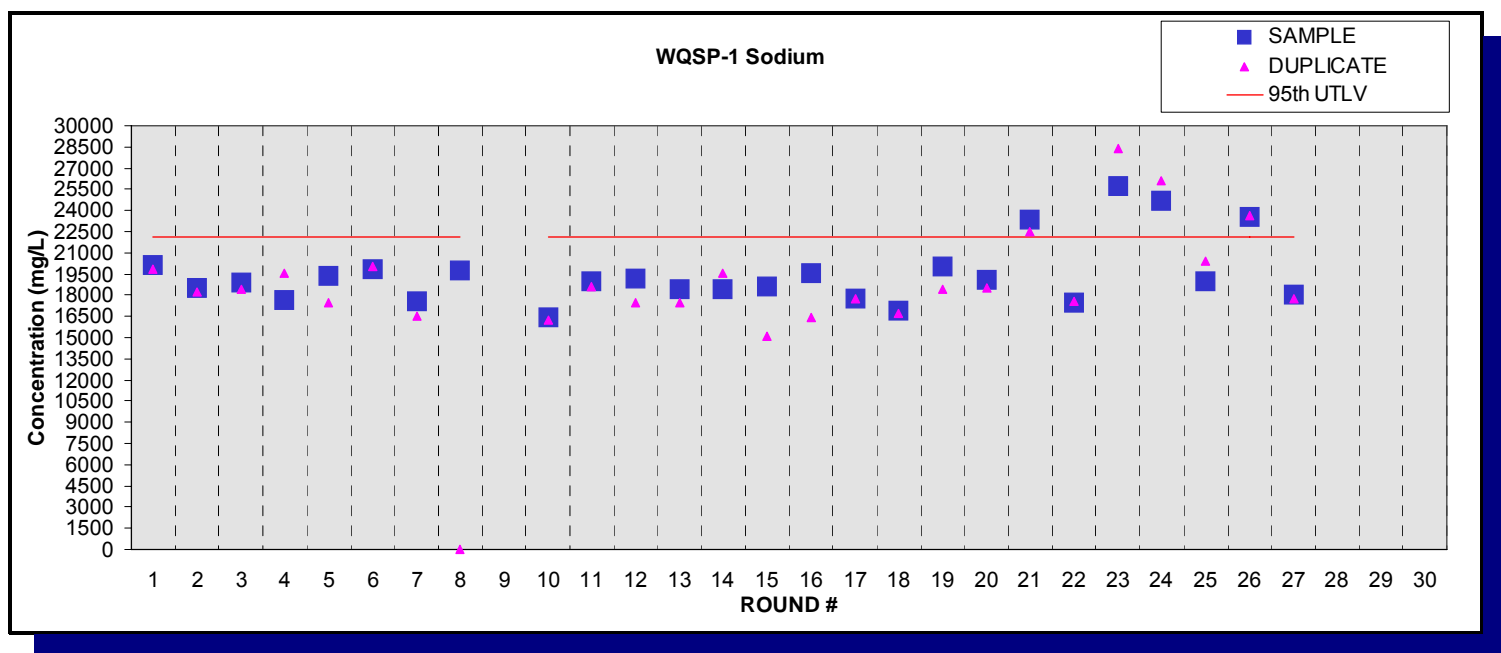

Figure E.8 - Time Trend Plot for Sodium at WQSP-1 
Waste Isolation Pilot Plant Annual Site Environmental Report for 2008 DOE/WIPP-09-2225

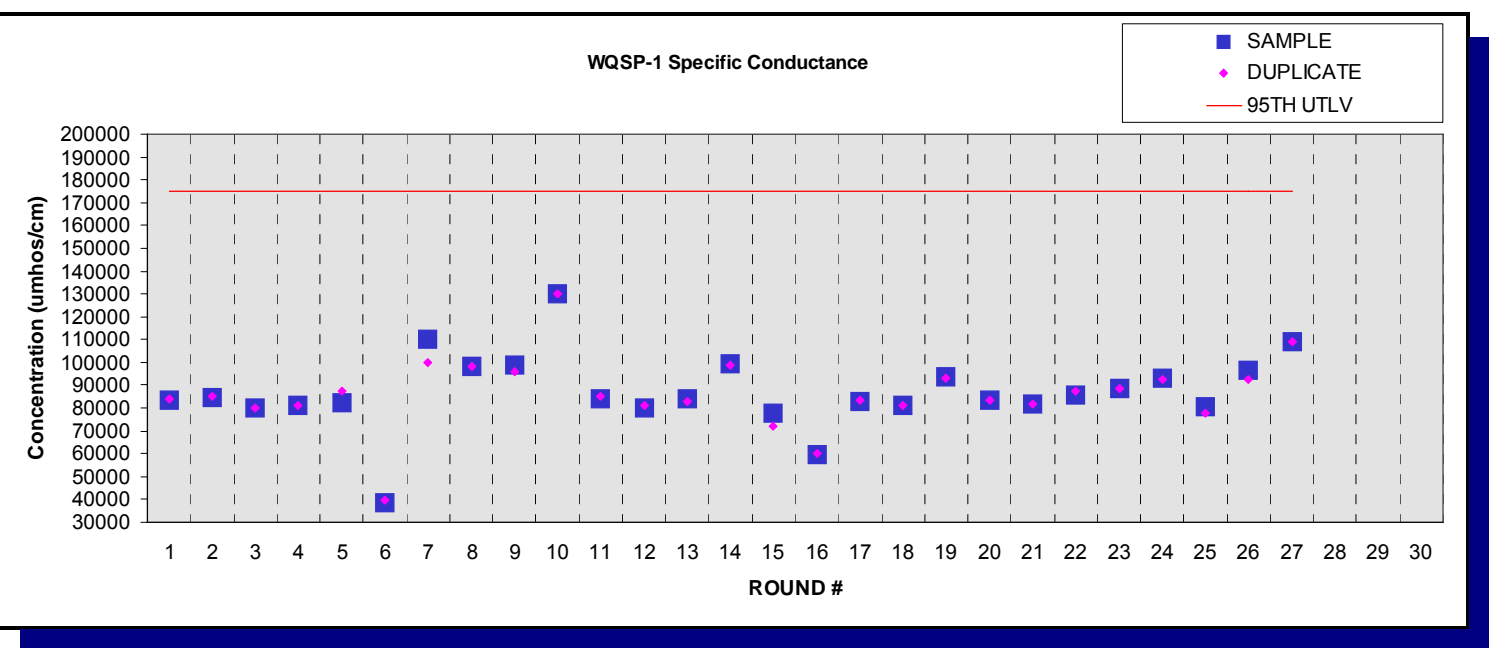

Figure E.9 - Time Trend Plot for Specific Conductance at WQSP-1

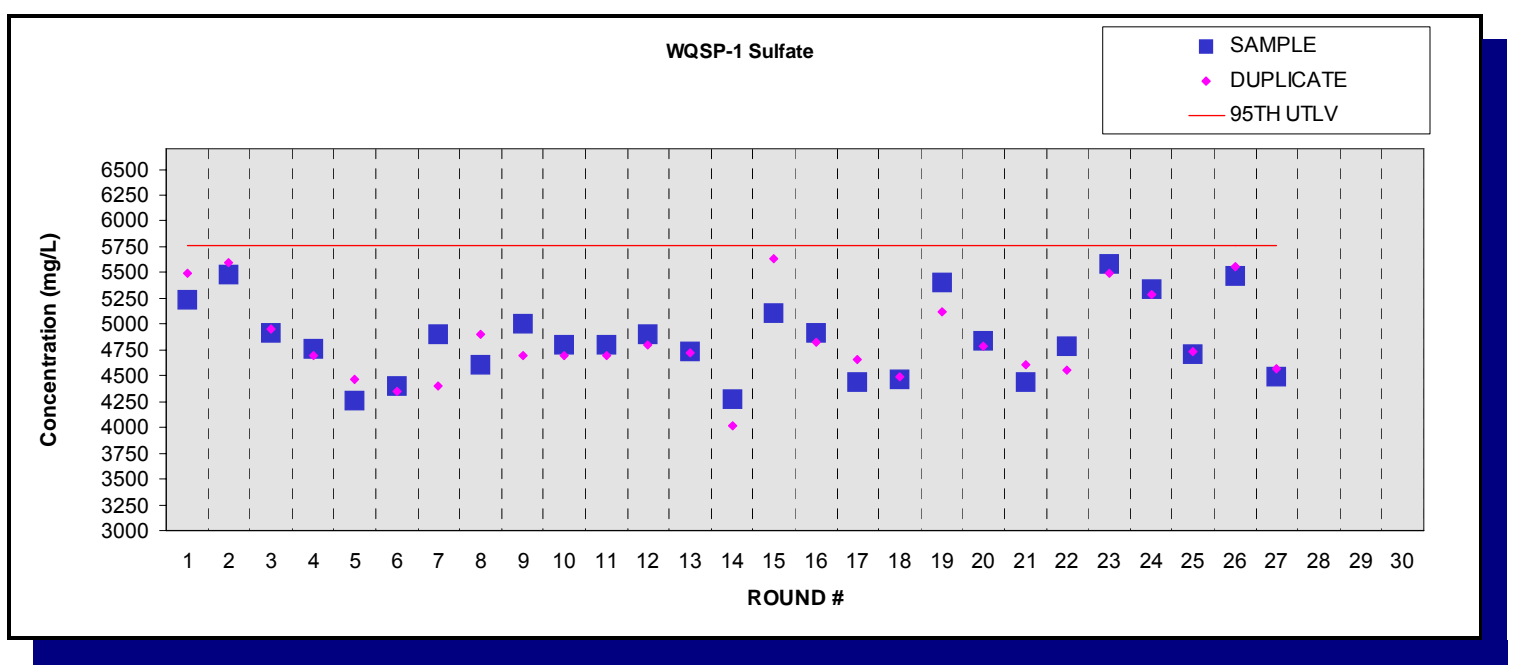

Figure E.10 - Time Trend Plot for Sulfate WQSP-1

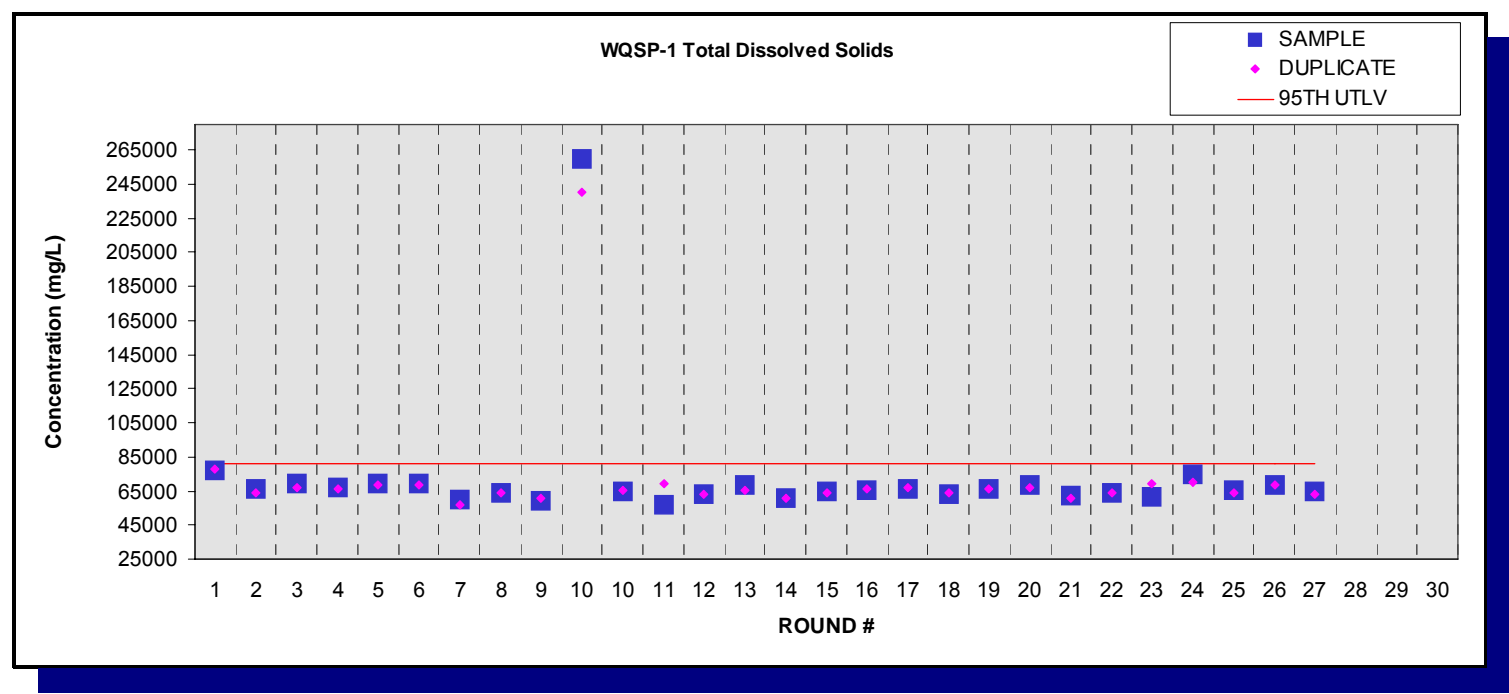

Figure E.11 - Time Trend Plot for Total Dissolved Solids at WQSP-1 


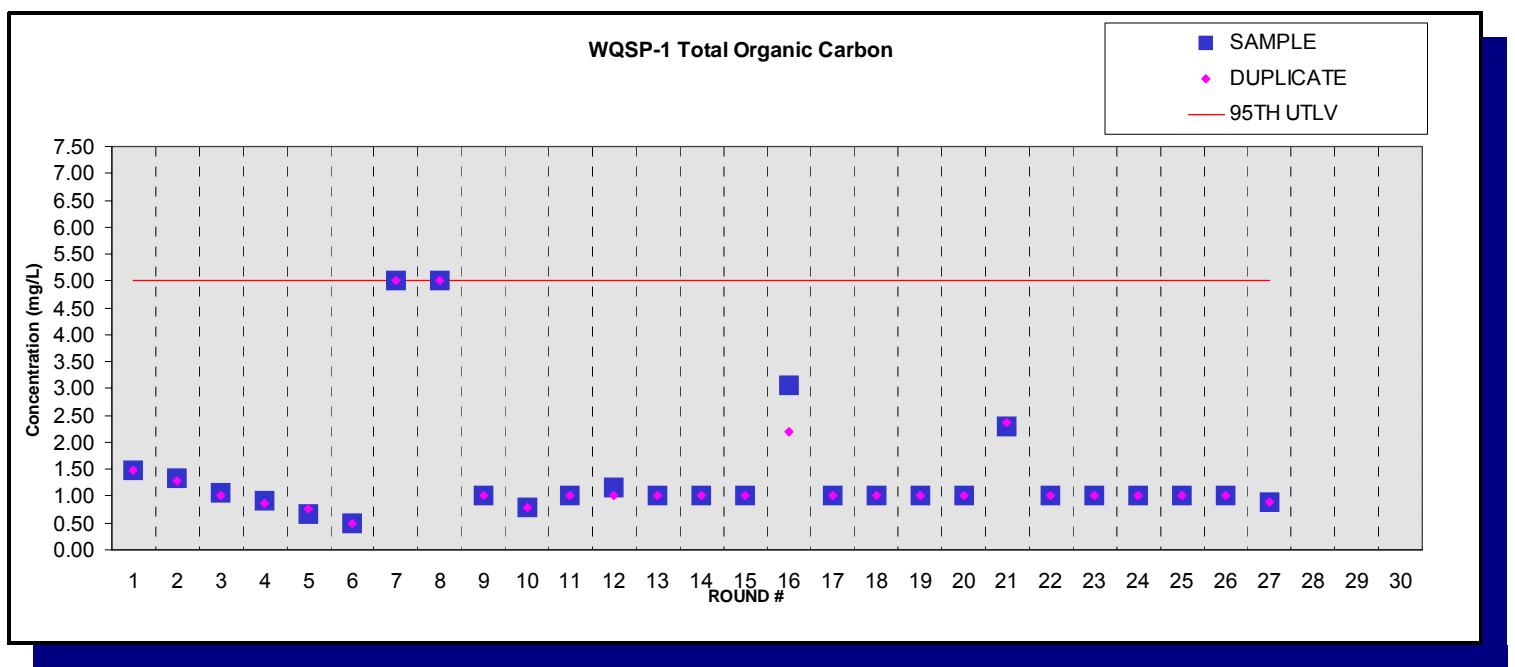

Figure E.12 - Time Trend Plot for Total Organic Carbon at WQSP-1

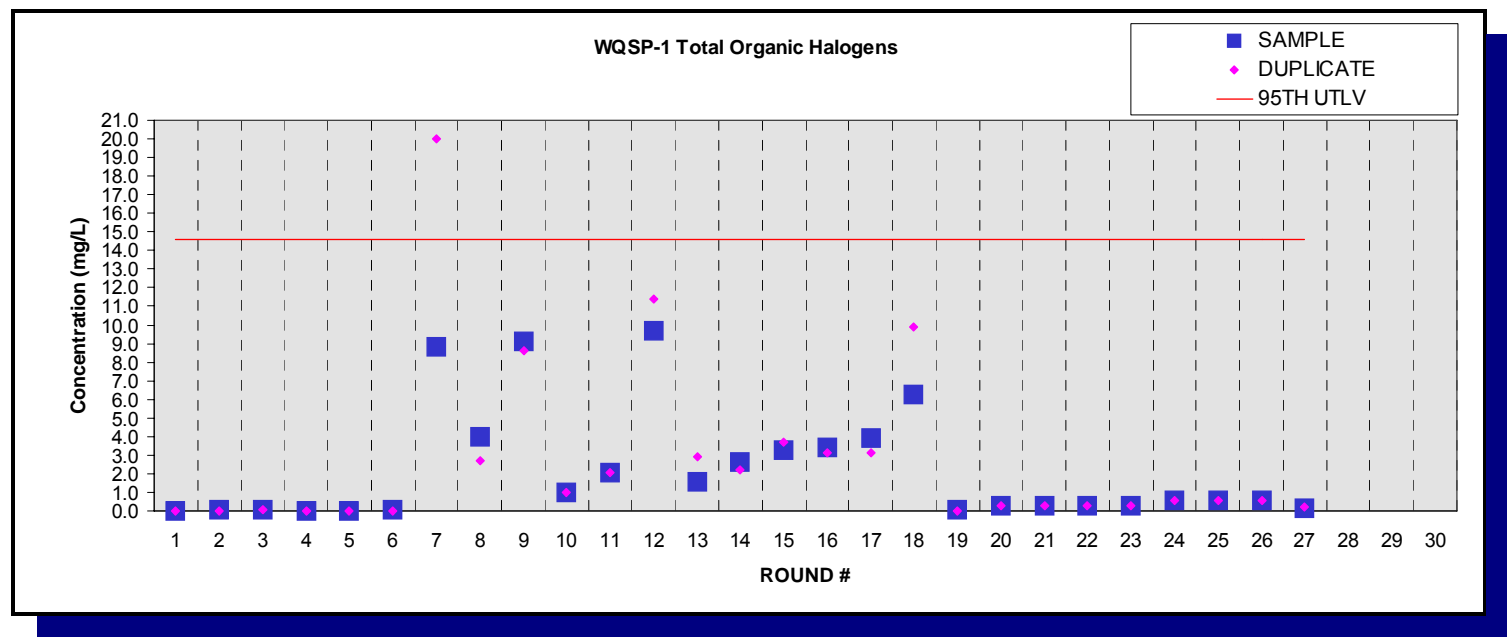

Figure E.13 - Time Trend Plot for Total Organic Halogens at WQSP-1

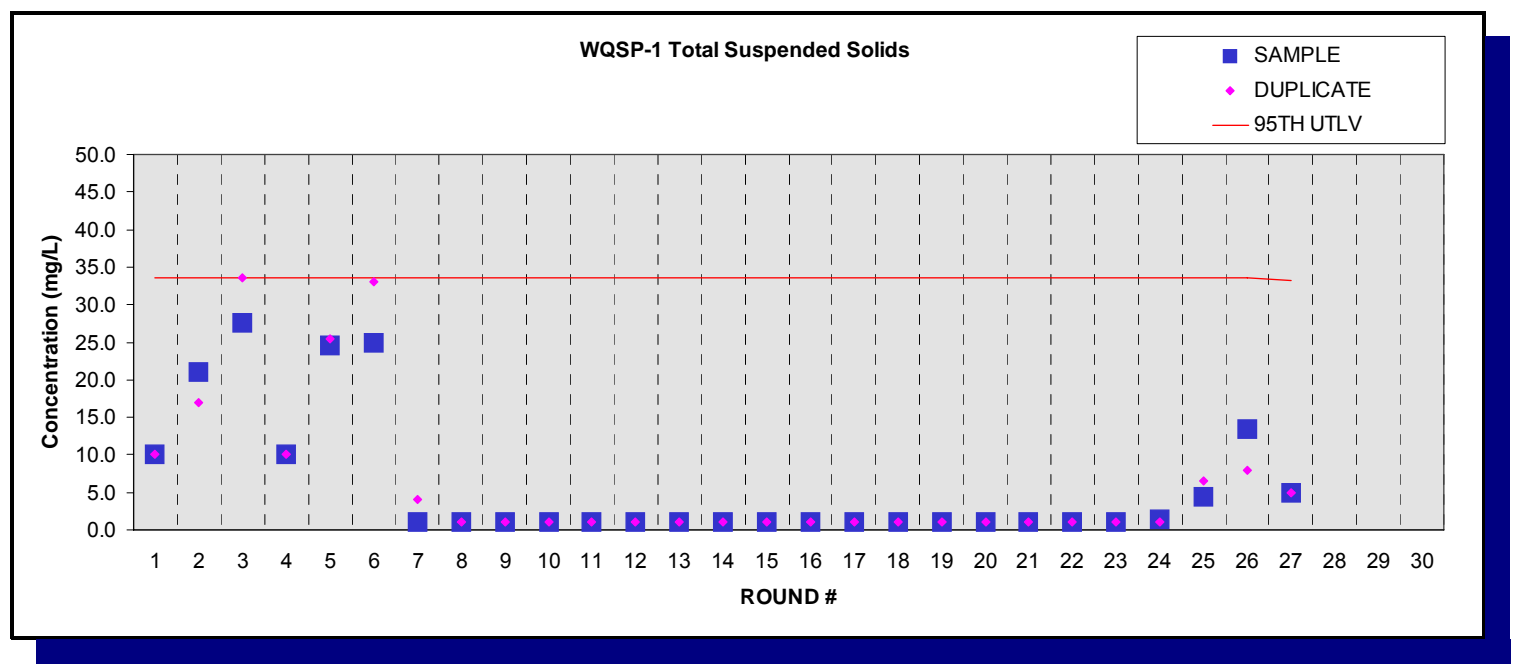

Figure E.14 - Time Trend Plot for Total Suspended Solids at WQSP-1 
Waste Isolation Pilot Plant Annual Site Environmental Report for 2008 DOE/WIPP-09-2225

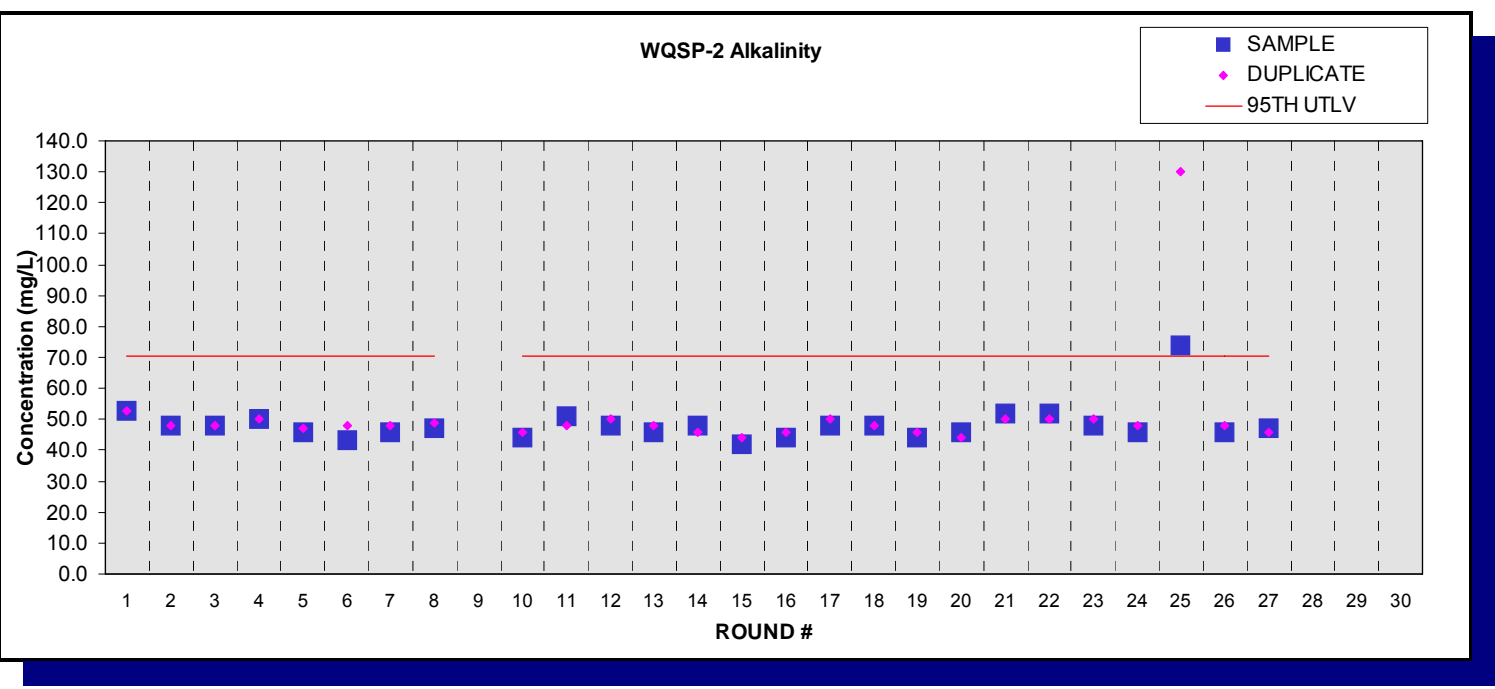

Figure E.15 - Time Trend Plot for Alkalinity at WQSP-2

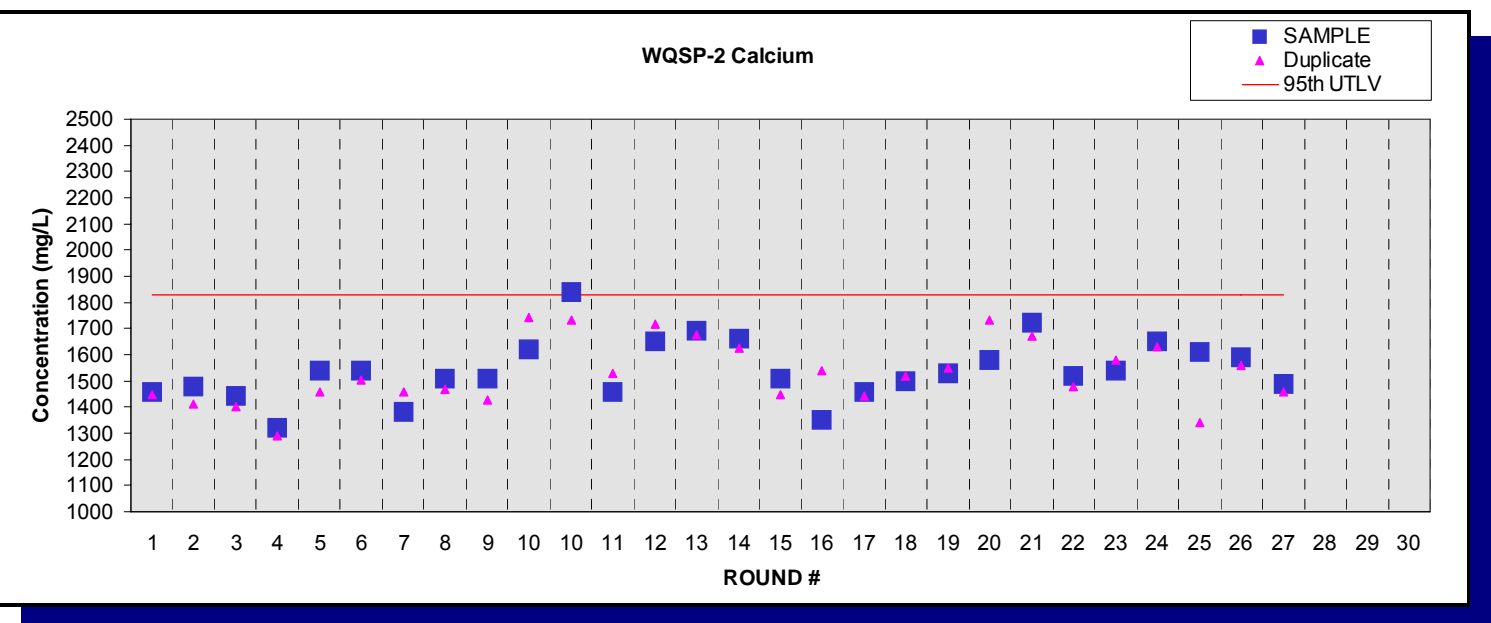

Figure E.16 - Time Trend Plot for Calcium at WQSP-2

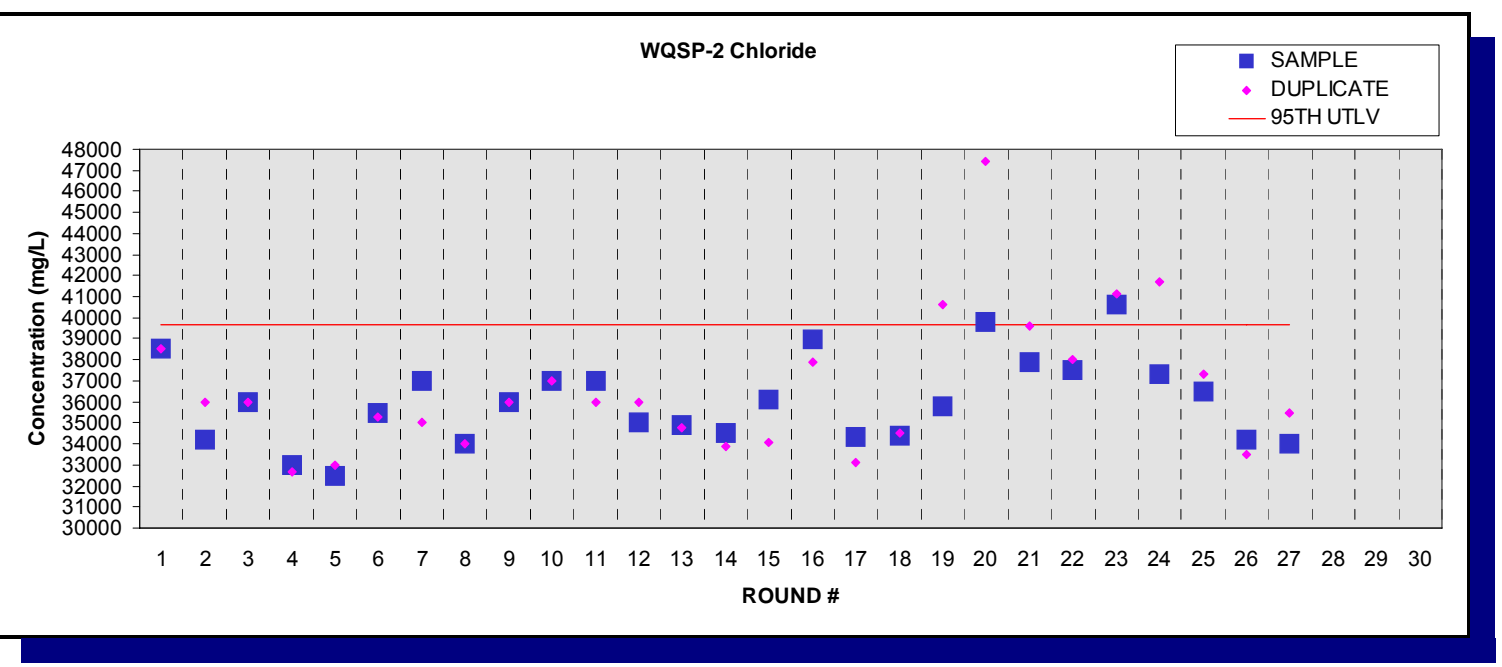

Figure E.17 - Time Trend Plot for Chloride at WQSP-2 
Waste Isolation Pilot Plant Annual Site Environmental Report for 2008 DOE/WIPP-09-2225

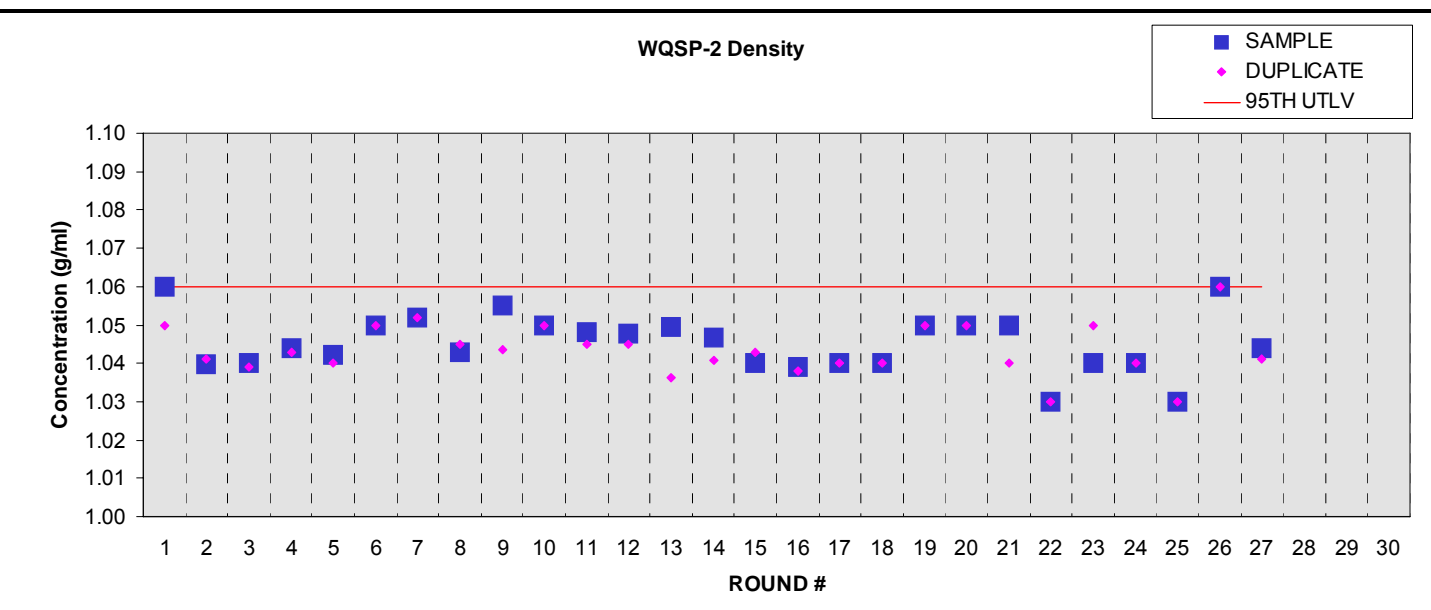

Figure E.18 - Time Trend Plot for Density at WQSP-2

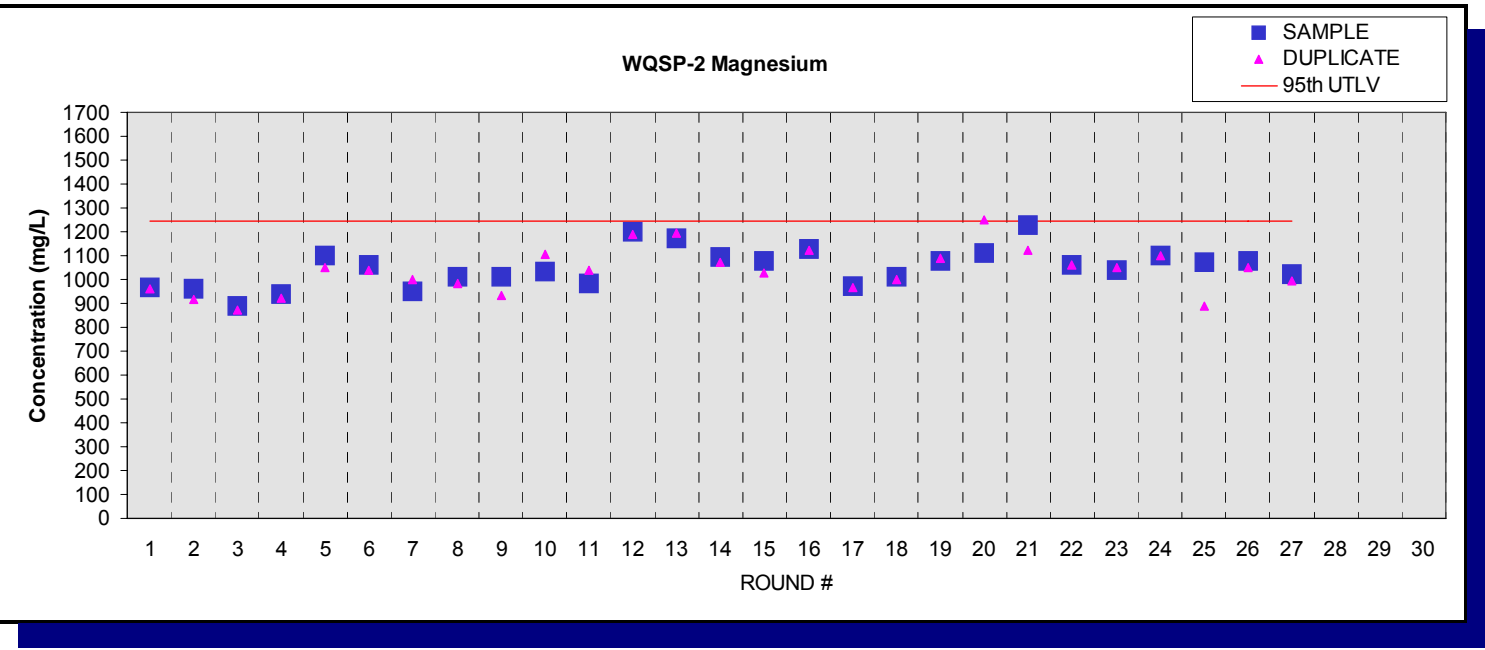

Figure E.19 - Time Trend Plot for Magnesium at WQSP-2

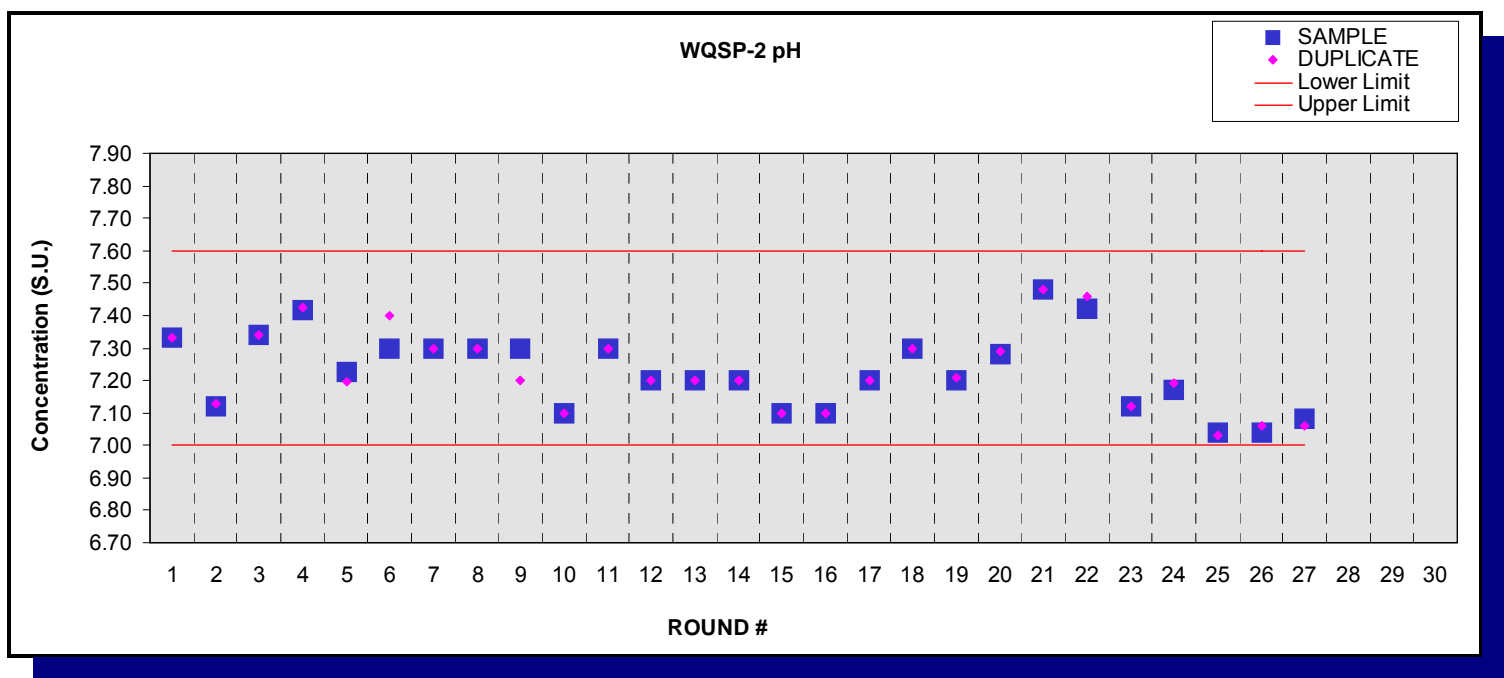

Figure E.20 - Time Trend Plot for pH at WQSP-2 
Waste Isolation Pilot Plant Annual Site Environmental Report for 2008 DOE/WIPP-09-2225

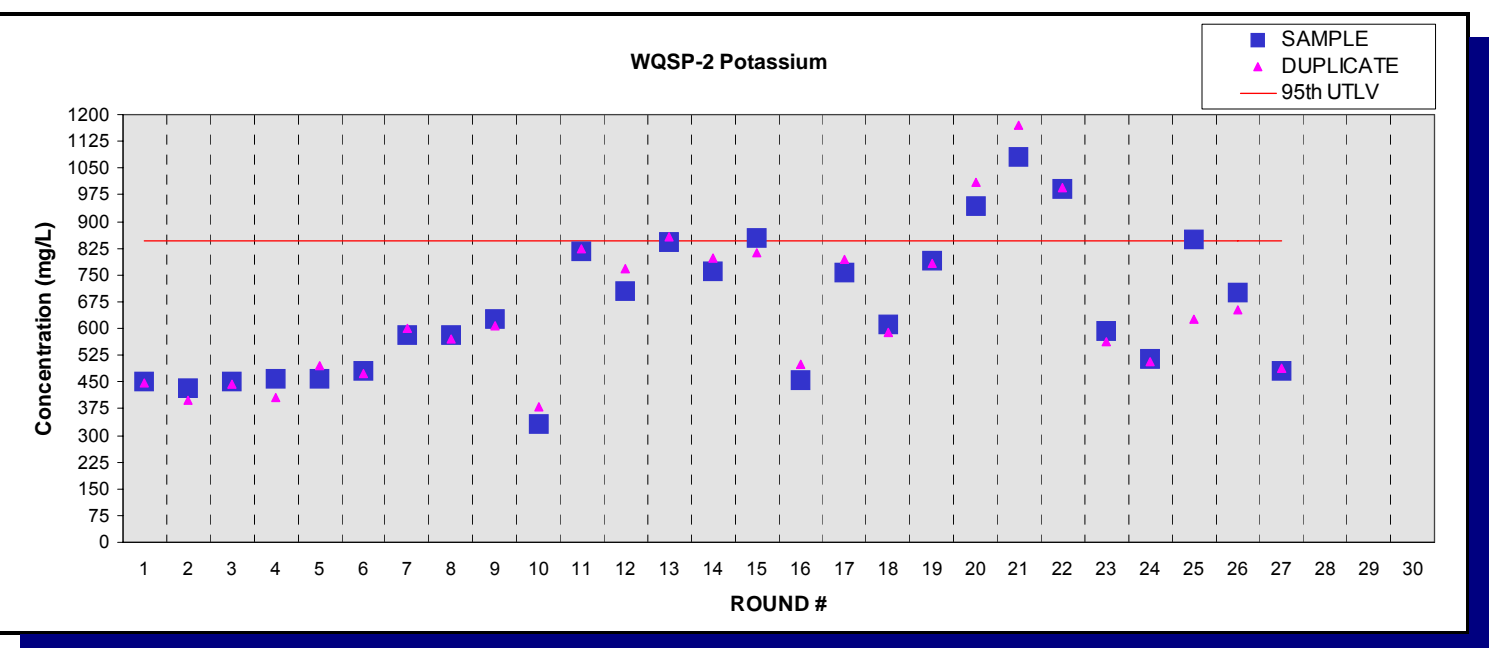

Figure E.21 - Time Trend Plot for Potassium at WQSP-2

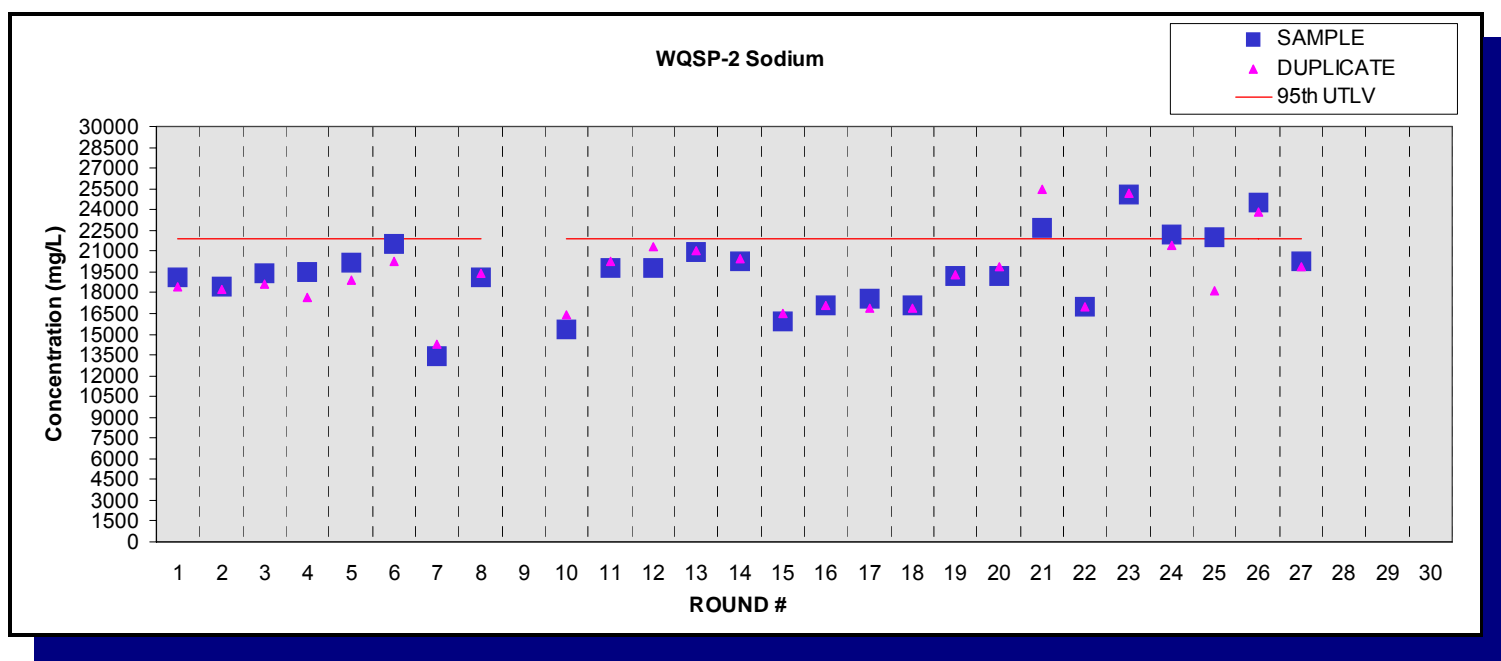

Figure E.22 - Time Trend Plot for Sodium at WQSP-2

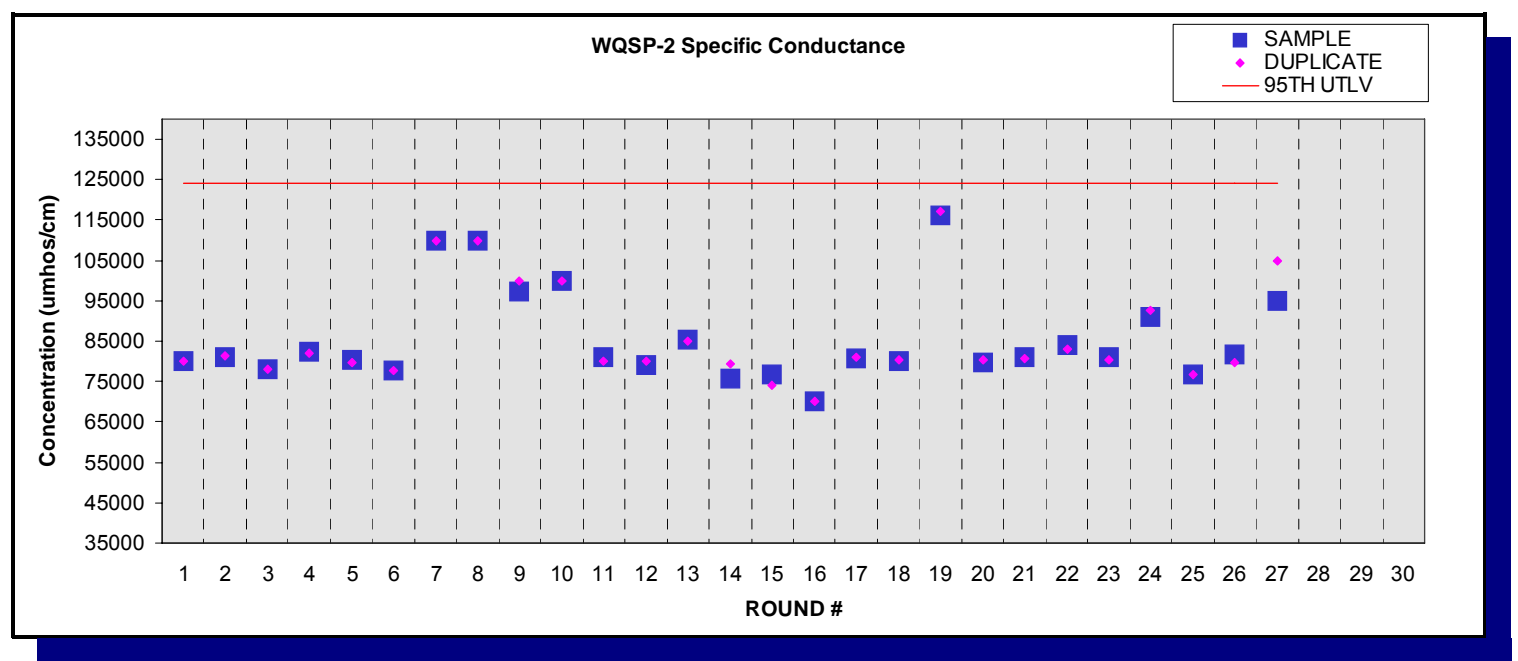

Figure E.23 - Time Trend Plot for Specific Conductance at WQSP-2 
Waste Isolation Pilot Plant Annual Site Environmental Report for 2008 DOE/WIPP-09-2225

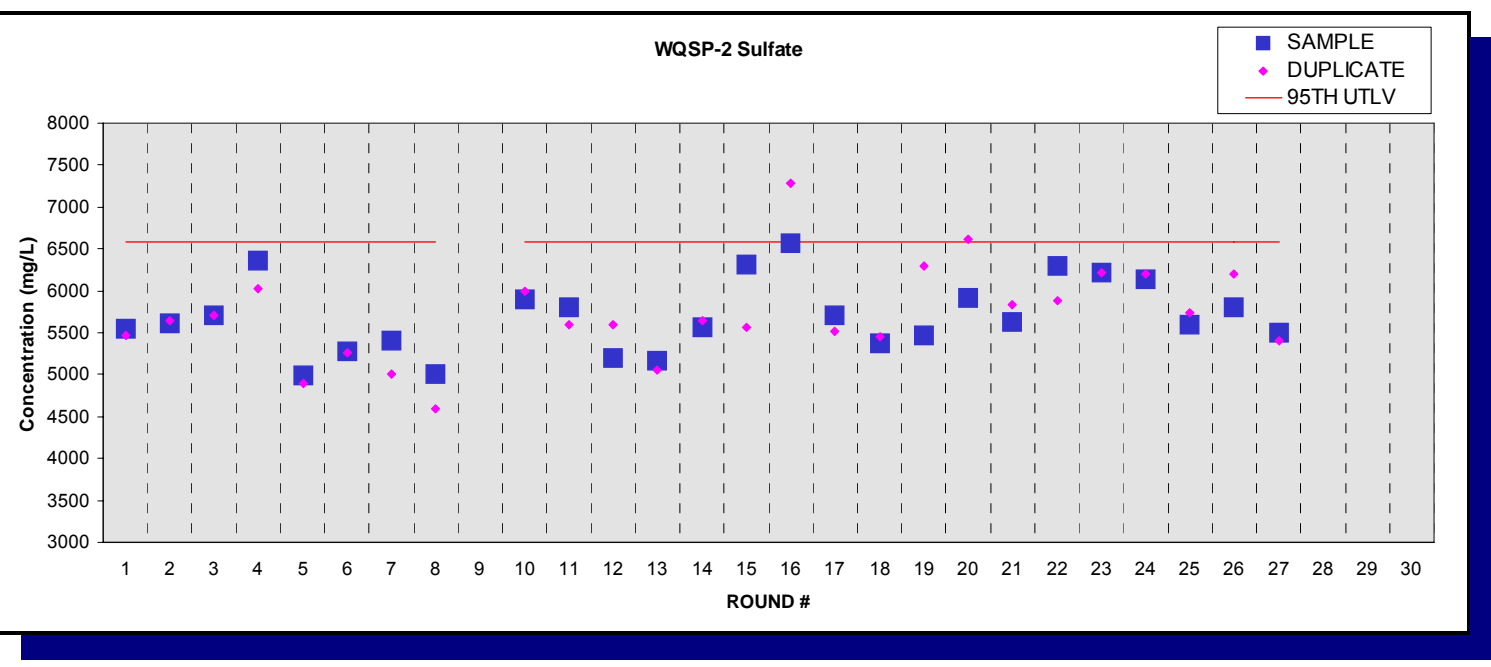

Figure E.24 - Time Trend Plot for Sulfate at WQSP-2

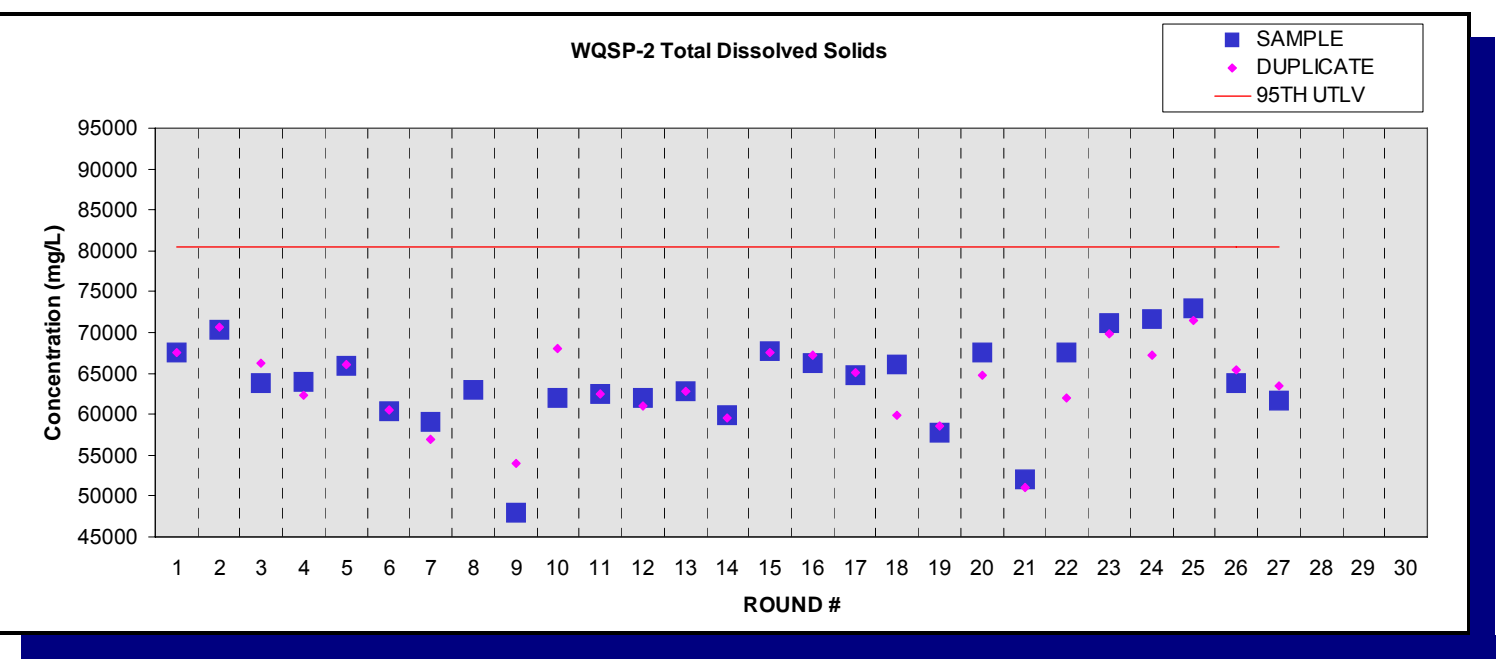

Figure E.25 - Total Trend Plot for Total Dissolved Solids at WQSP-2

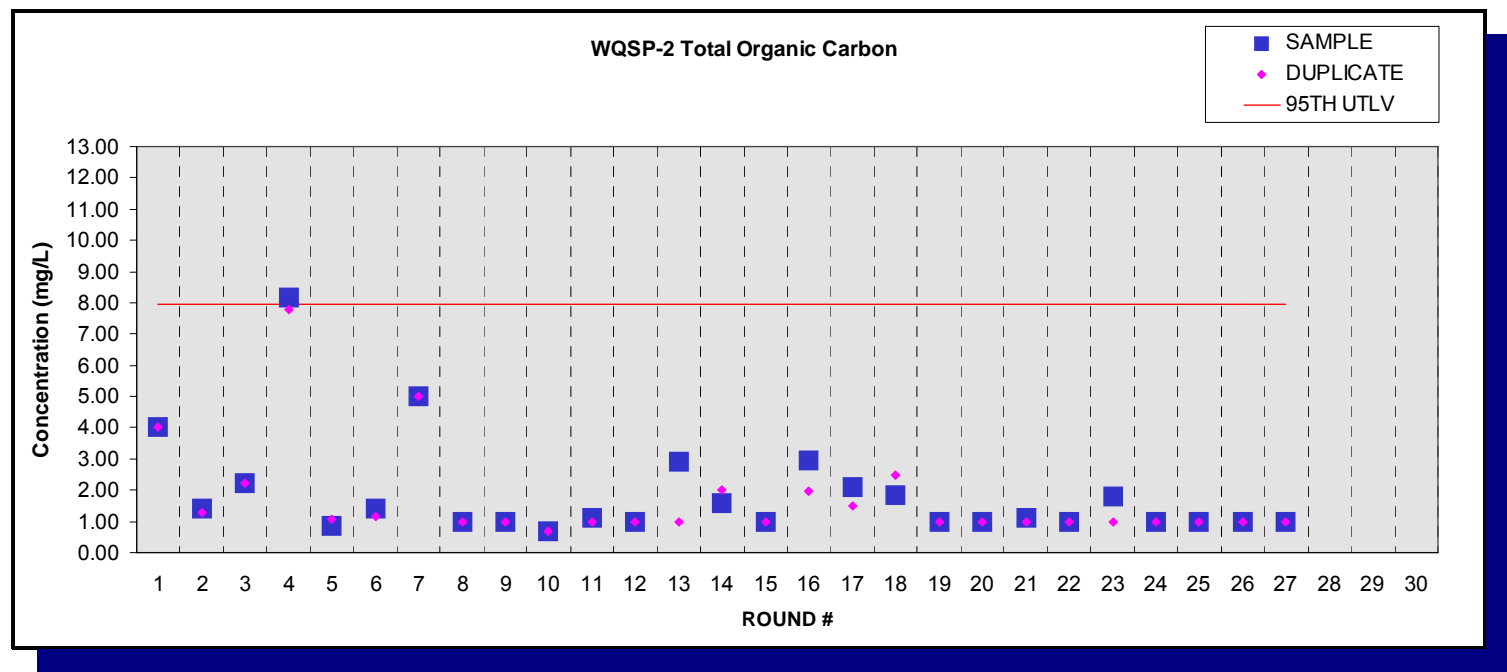

Figure E.26 - Time Trend Plot for Total Organic Carbon at WQSP-2 
Waste Isolation Pilot Plant Annual Site Environmental Report for 2008 DOE/WIPP-09-2225

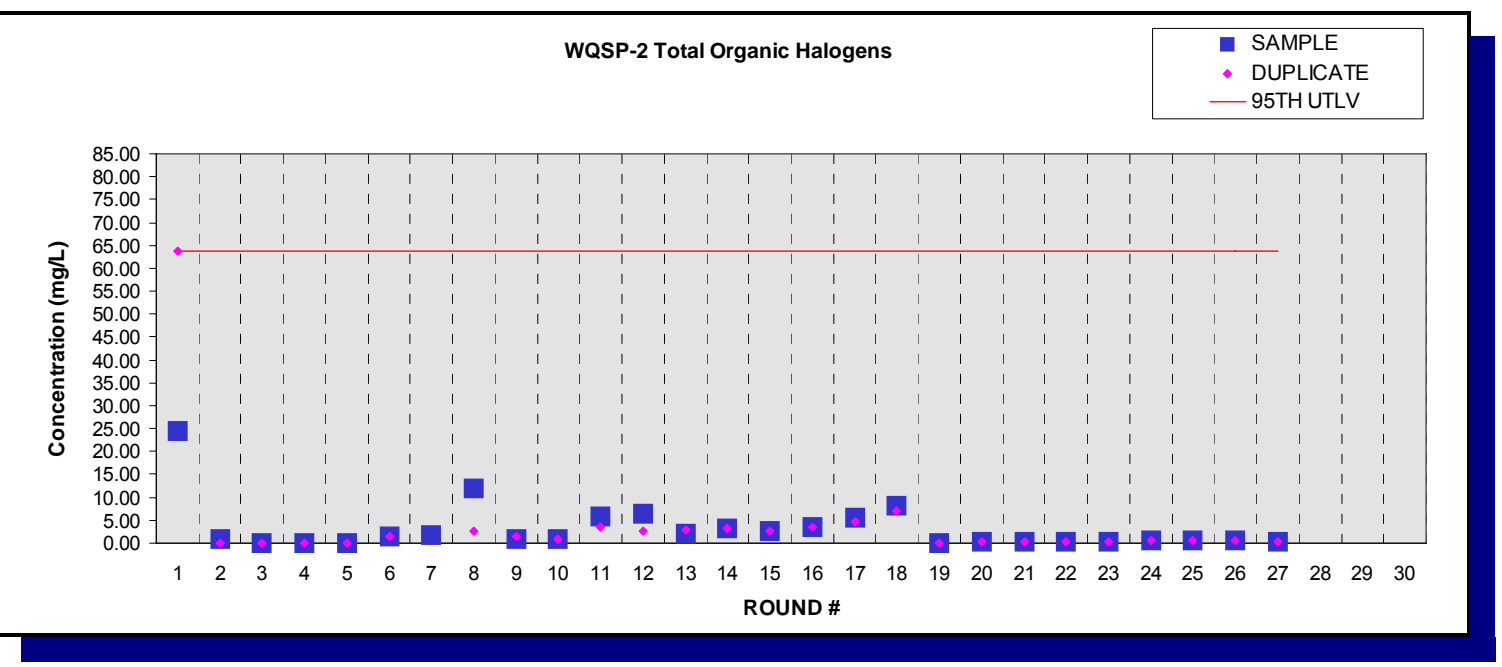

Figure E.27 - Time Trend Plot for Total Organic Halogens at WQSP-2

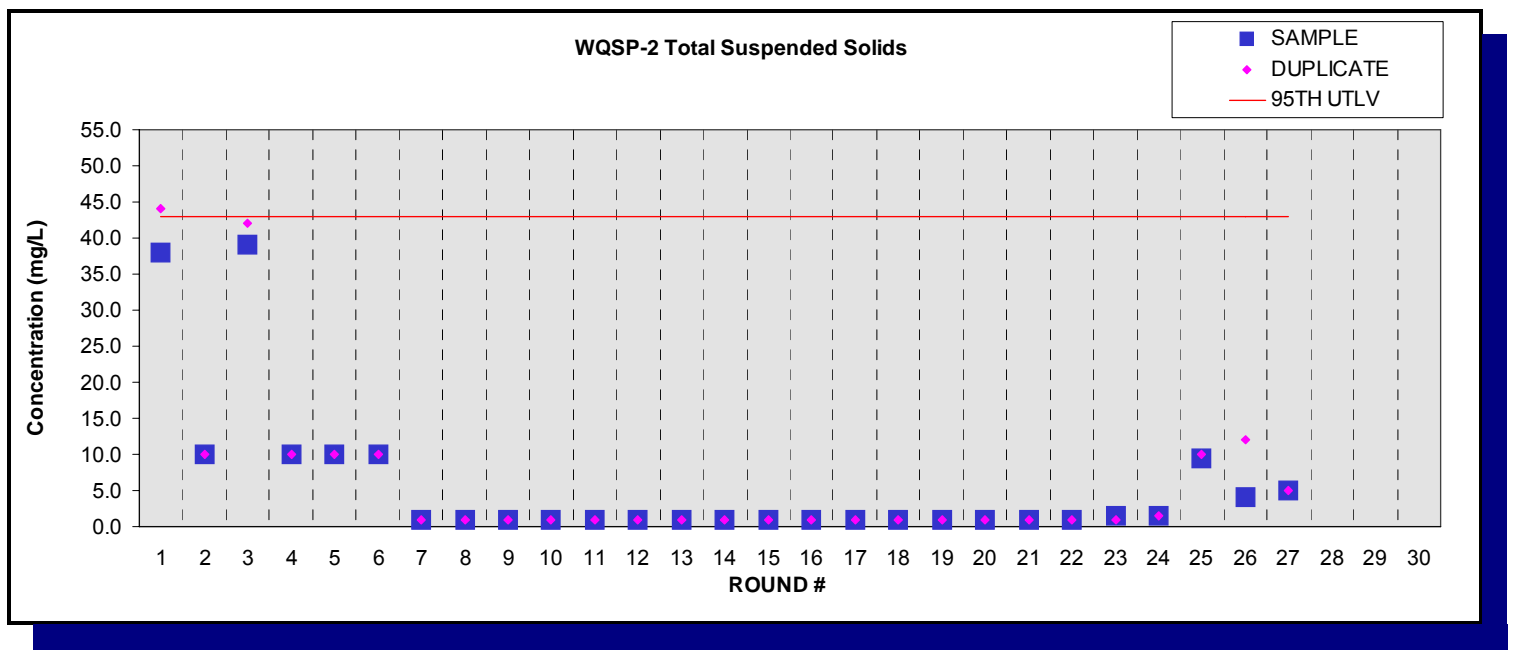

Figure E.28 - Time Trend Plot for Total Suspended Solids at WQSP-2

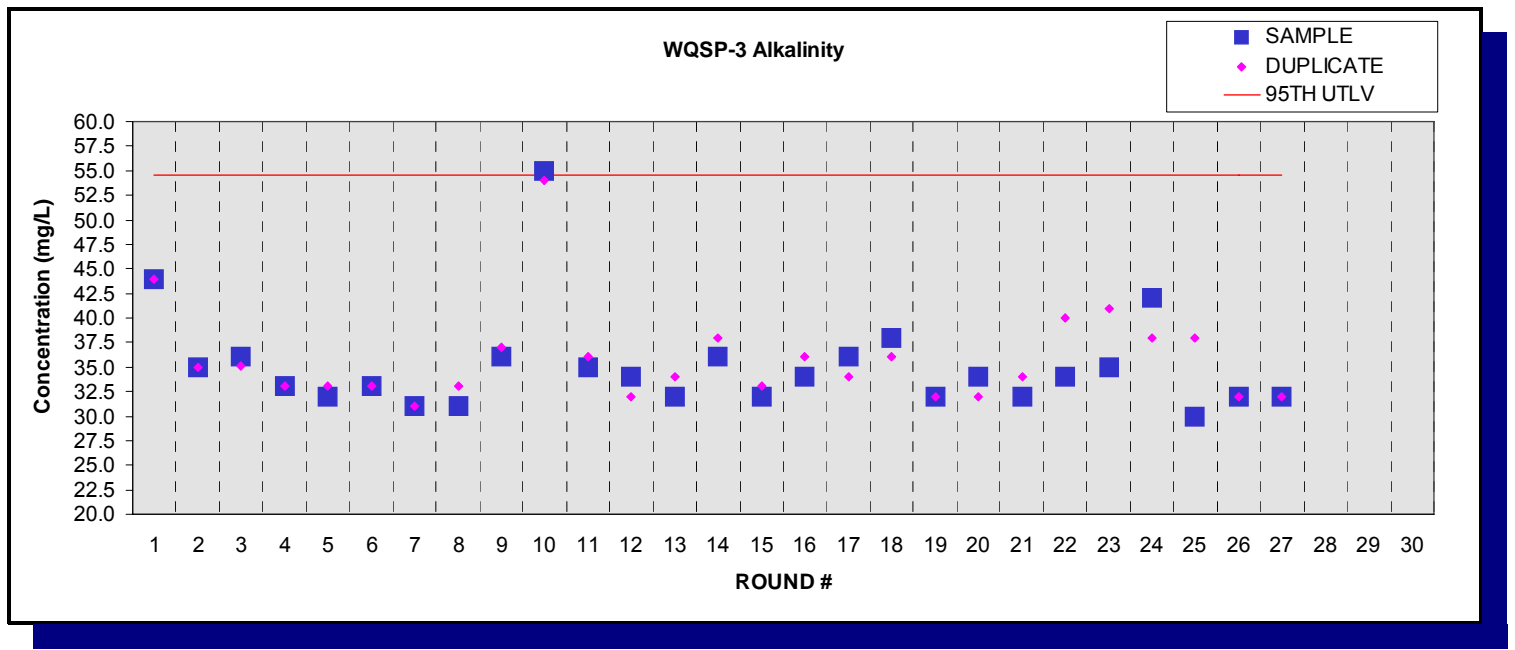

Figure E.29 - Time Trend Plot for Alkalinity at WQSP-3 
Waste Isolation Pilot Plant Annual Site Environmental Report for 2008 DOE/WIPP-09-2225

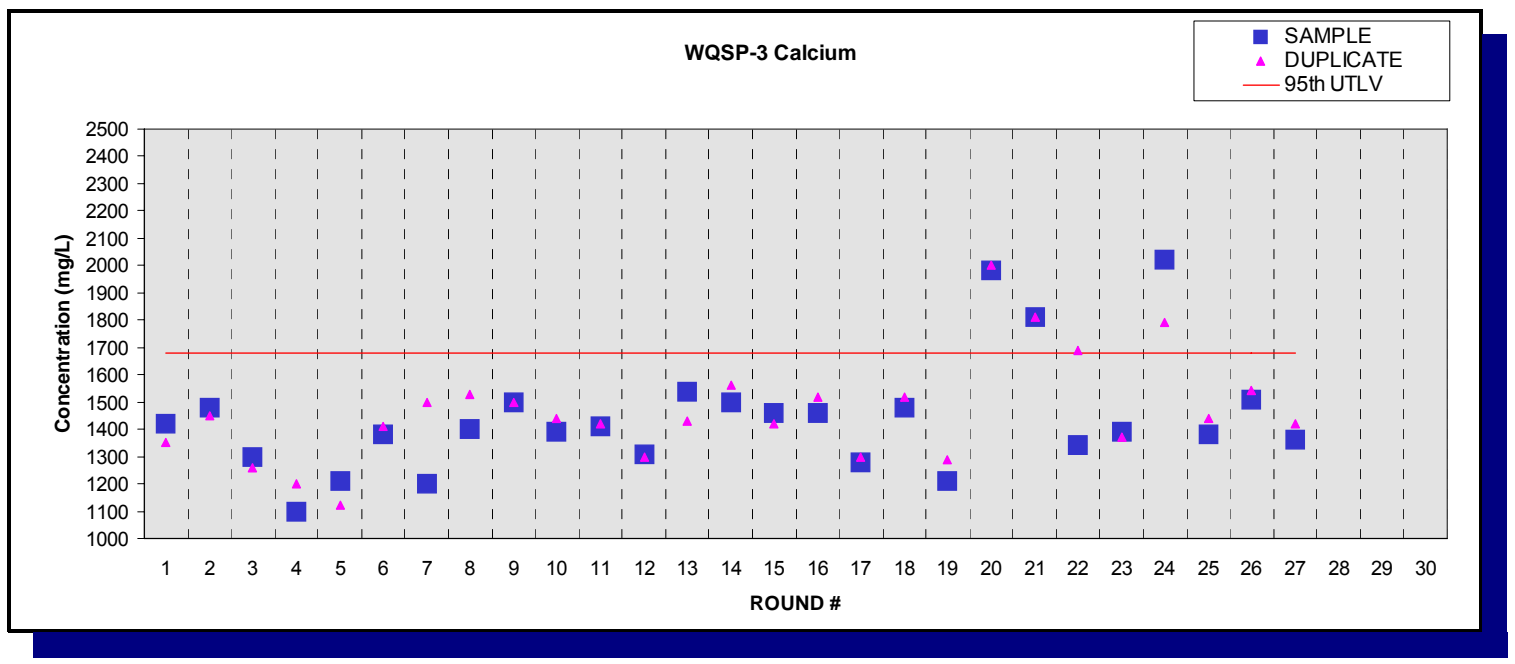

Figure E.30 - Time Trend Plot for Calcium at WQSP-3

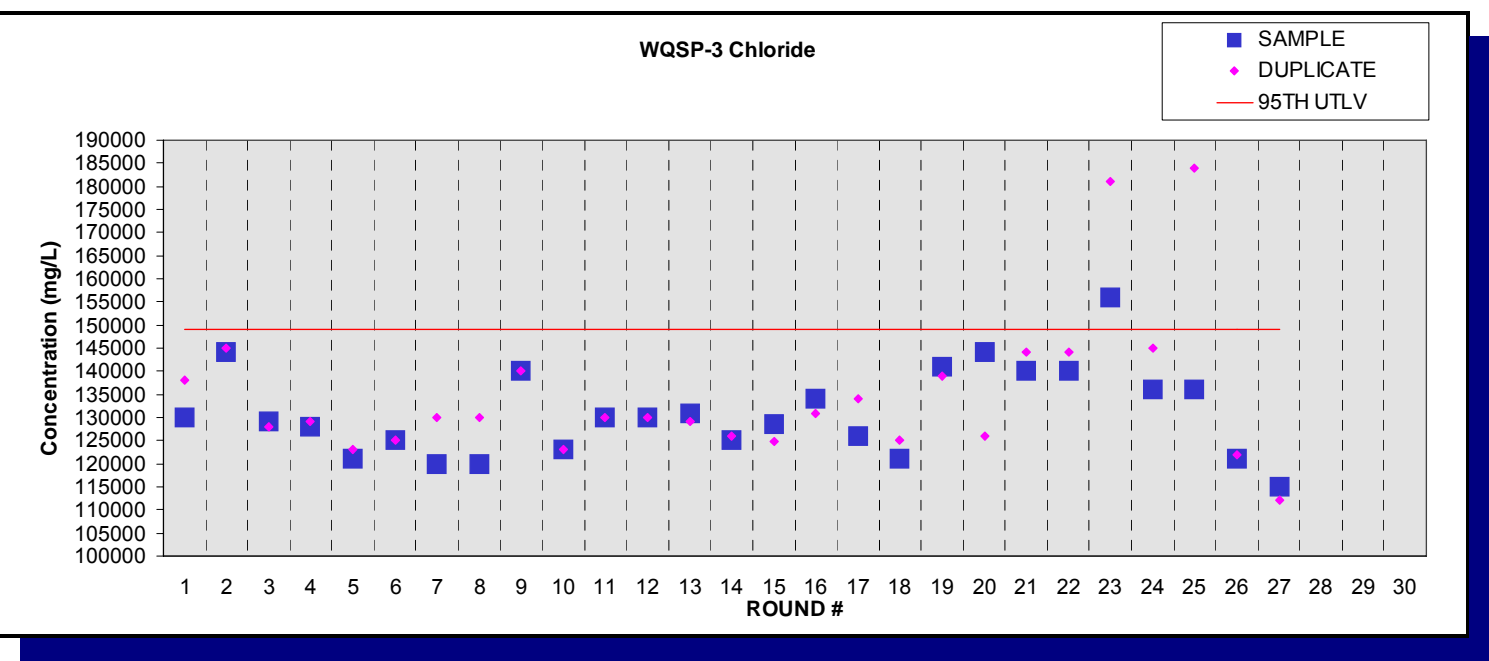

Figure E.31 - Time Trend Plot for Chloride at WQSP-3

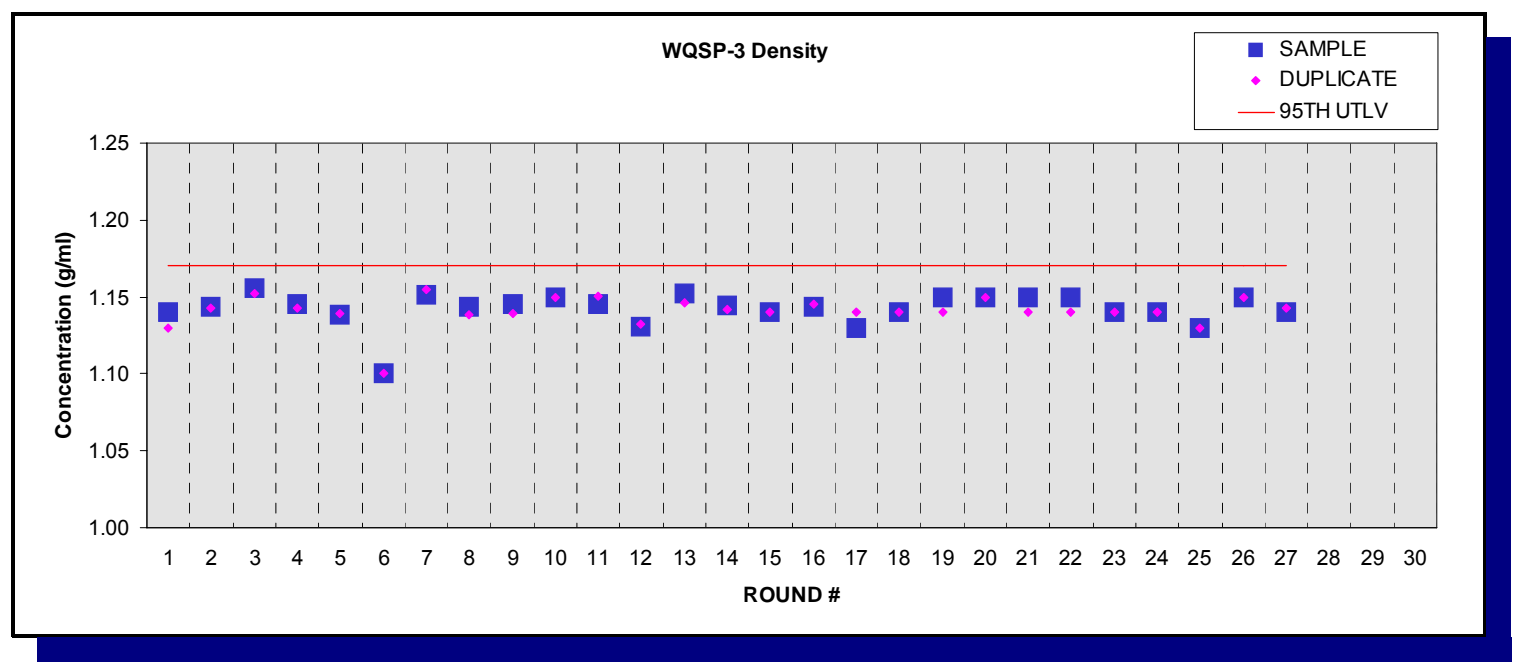

Figure E.32 - Time Trend Plot for Density at WQSP-3 


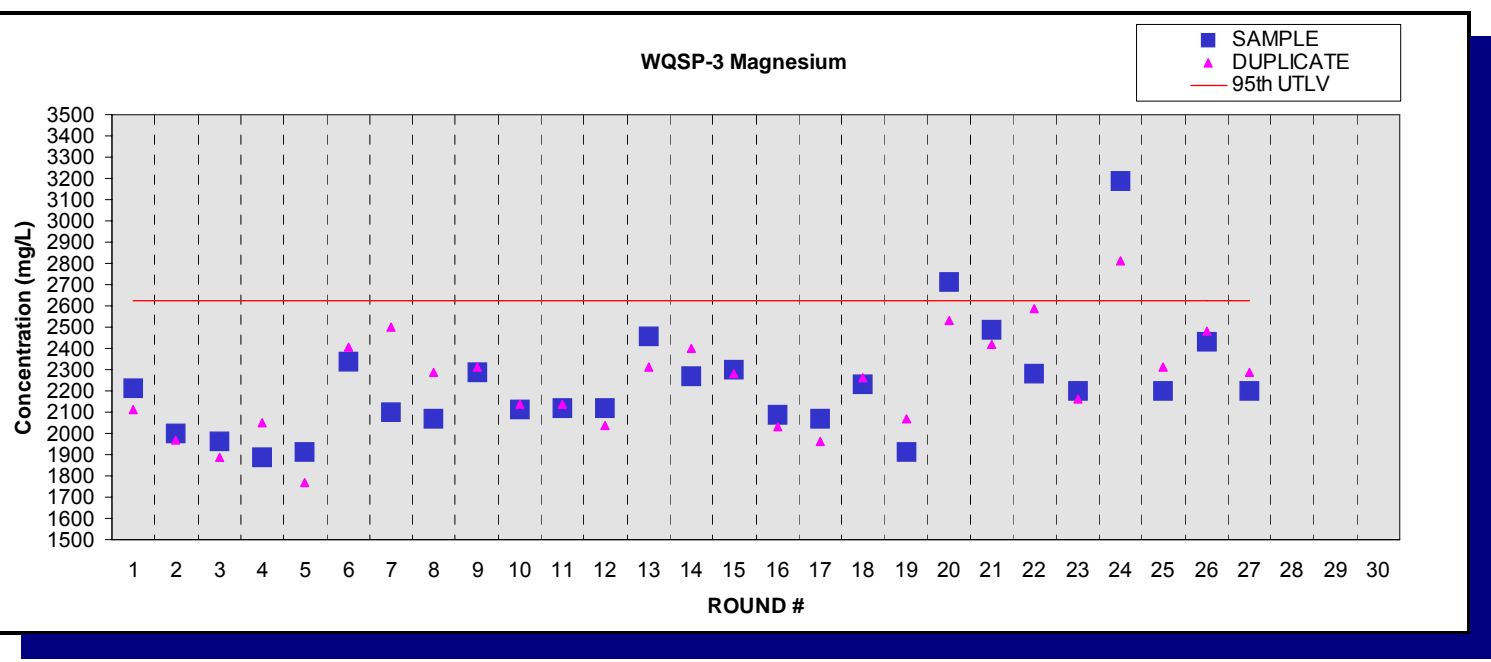

Figure E.33 - Time Trend Plot for Magnesium at WQSP-3

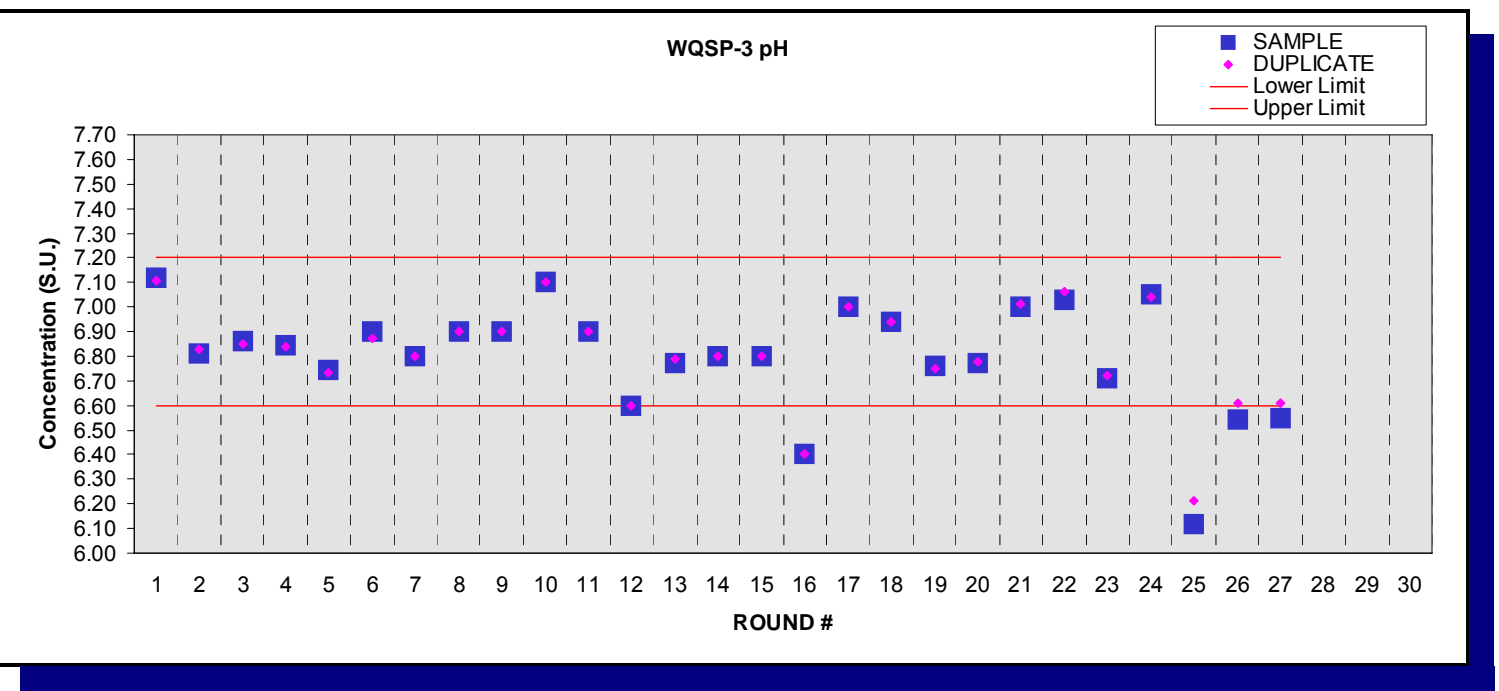

Figure E.34 - Time Trend Plot for $\mathrm{pH}$ at WQSP-3

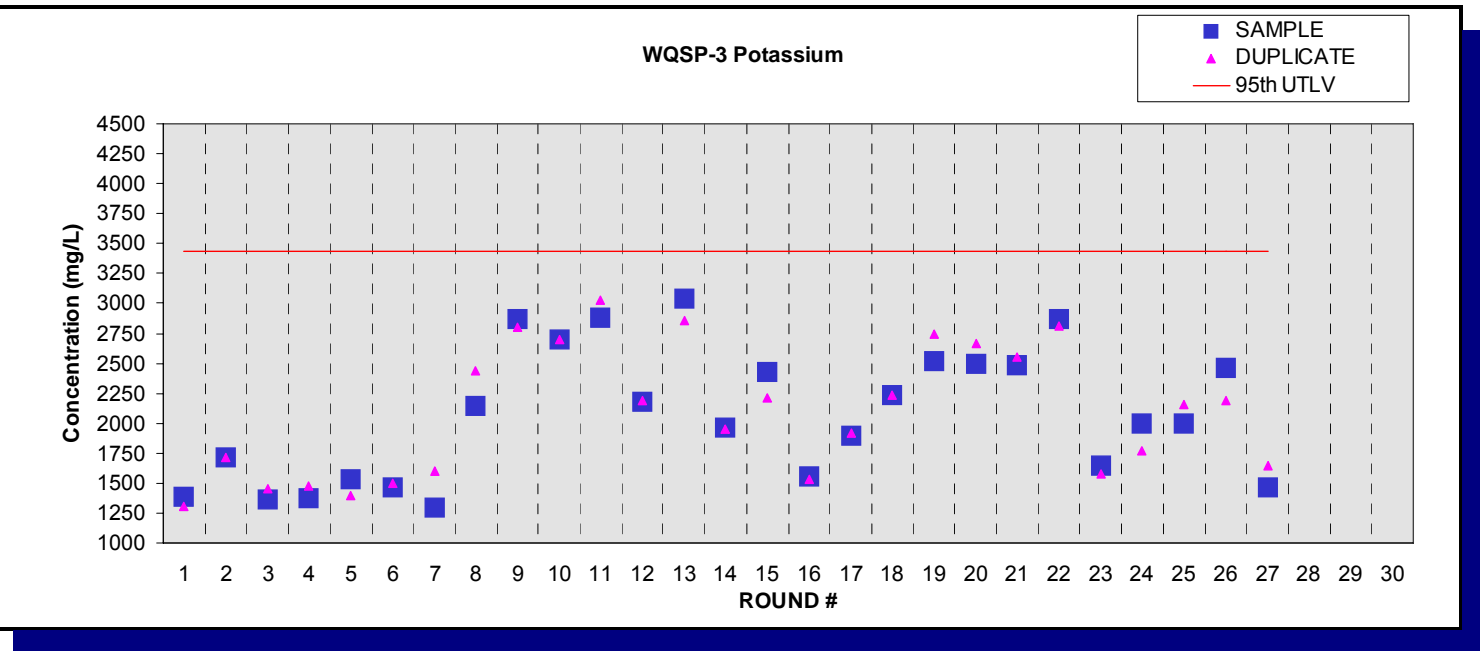

Figure E.35 - Time Trend Plot for Potassium at WQSP-3 
Waste Isolation Pilot Plant Annual Site Environmental Report for 2008

DOE/WIPP-09-2225 
Waste Isolation Pilot Plant Annual Site Environmental Report for 2008 DOE/WIPP-09-2225

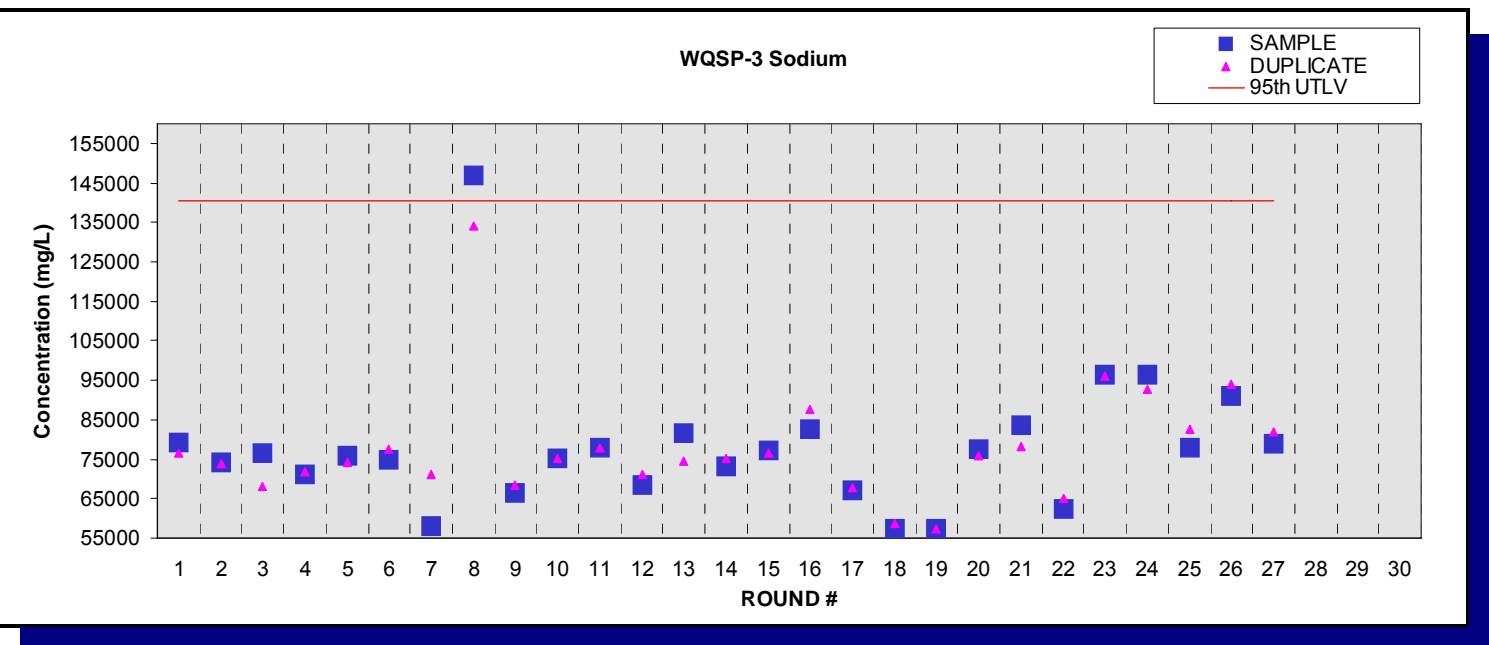

Figure E.36 - Time Trend Plot for Sodium at WQSP-3

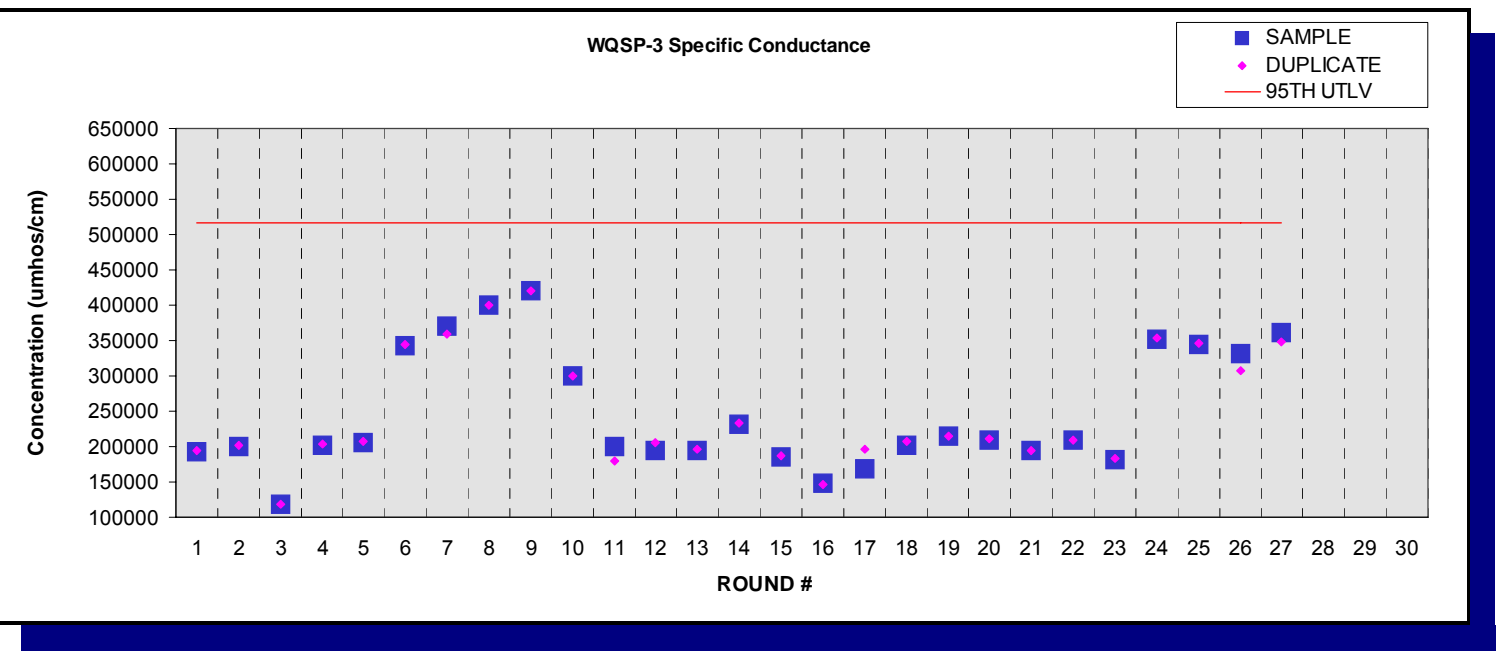

Figure E.37 - Time Trend Plot for Specific Conductance at WQSP-3

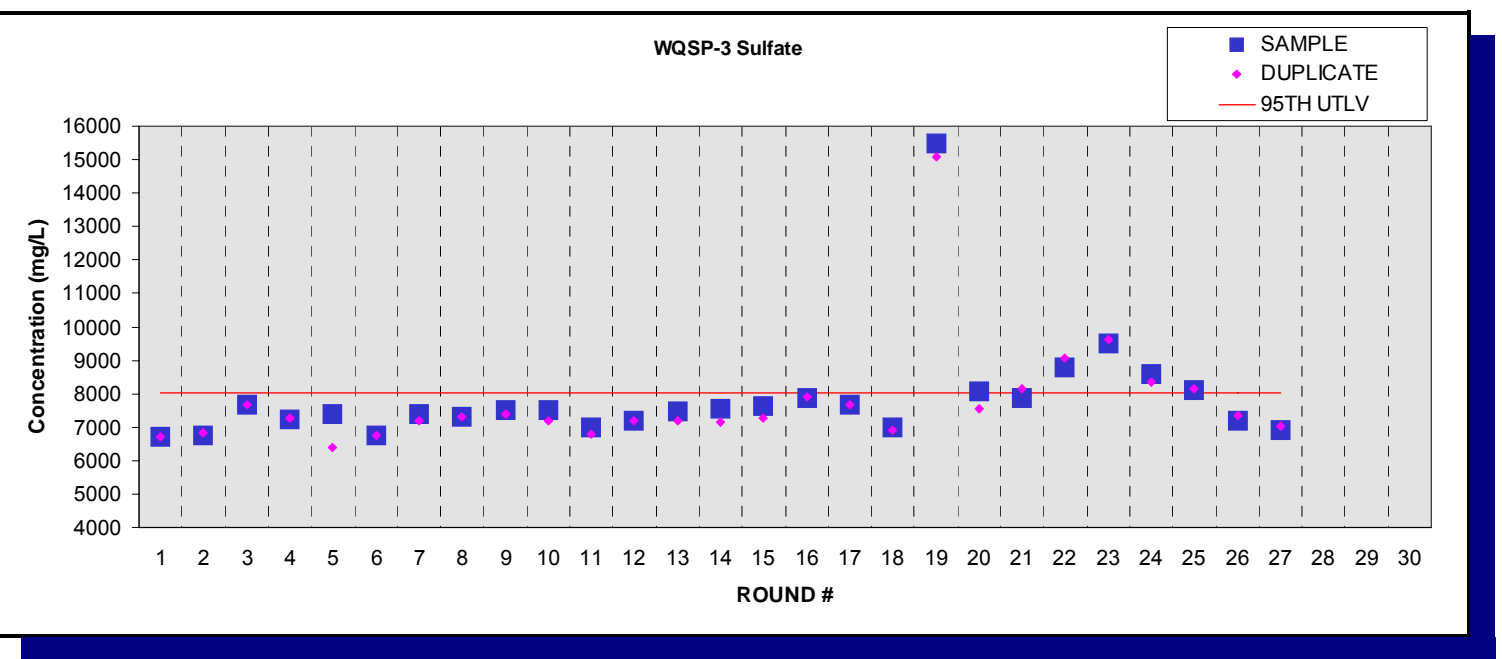

Figure E.38 - Time Trend Plot for Sulfate at WQSP-3 
Waste Isolation Pilot Plant Annual Site Environmental Report for 2008 DOE/WIPP-09-2225

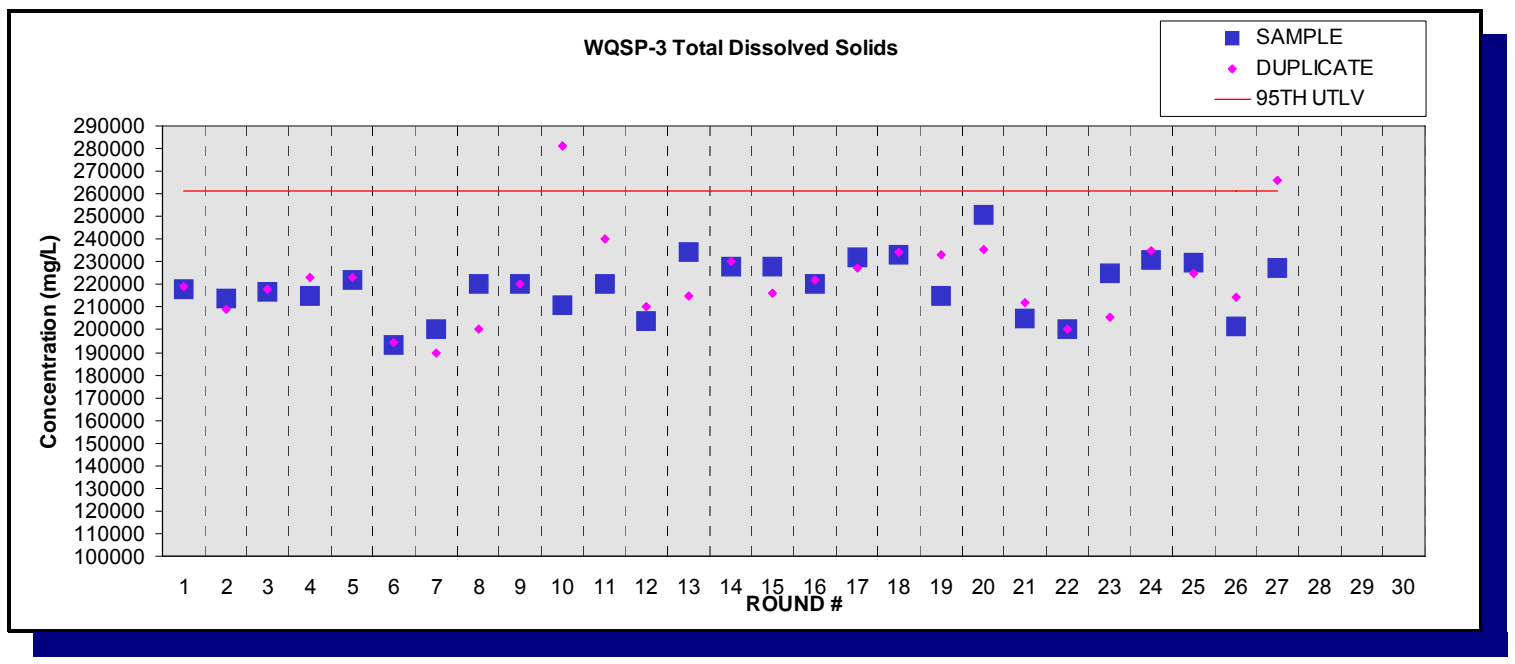

Figure E.39 - Time Trend Plot for Total Dissolved Solids at WQSP-3

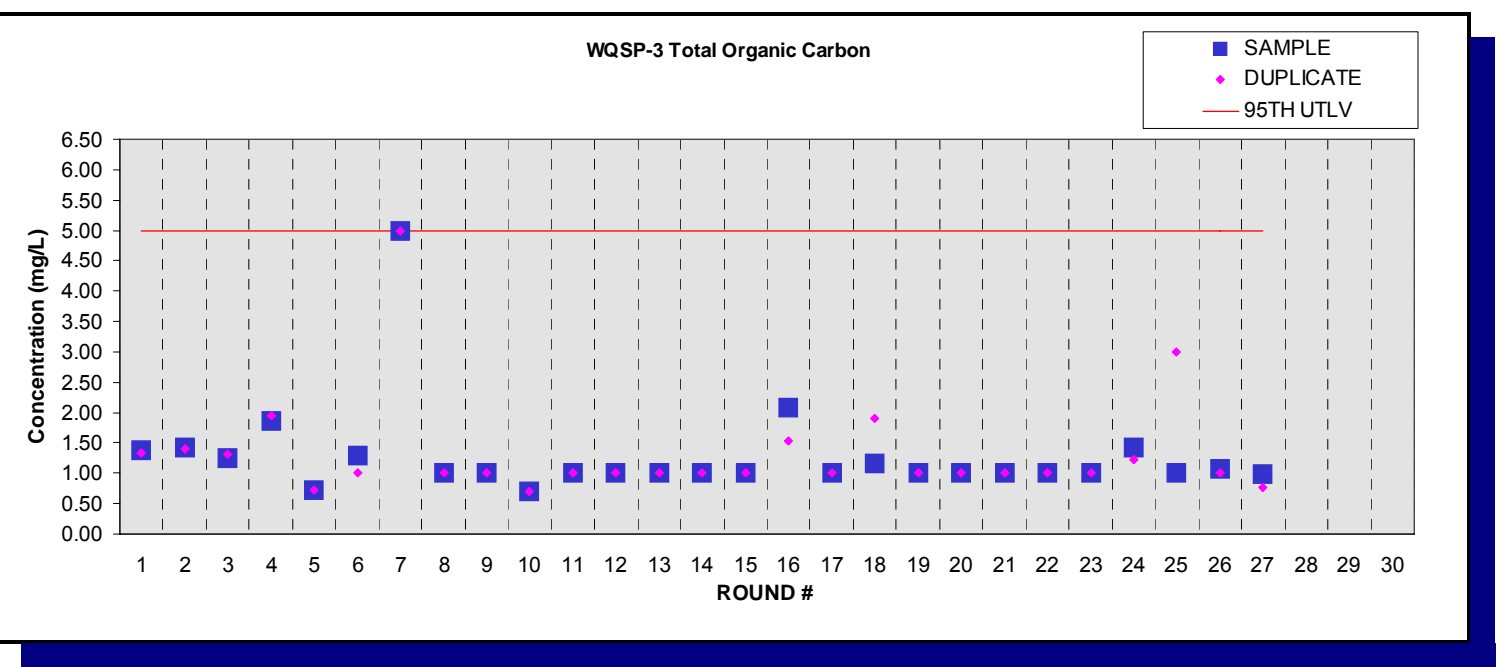

Figure E.40 - Time Trend Plot for Total Organic Carbon at WQSP-3

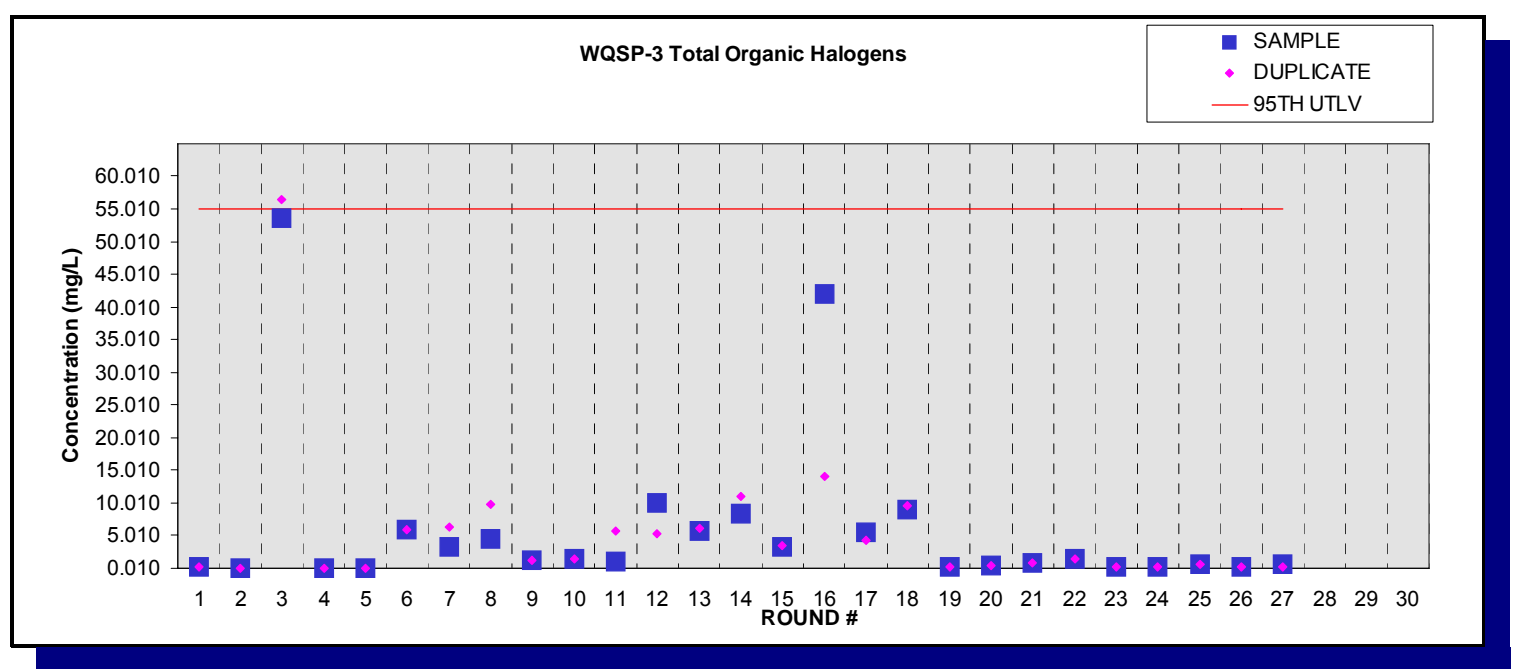

Figure E.41 - Time Trend Plot for Total Organic Halogens at WQSP-3 
Waste Isolation Pilot Plant Annual Site Environmental Report for 2008 DOE/WIPP-09-2225

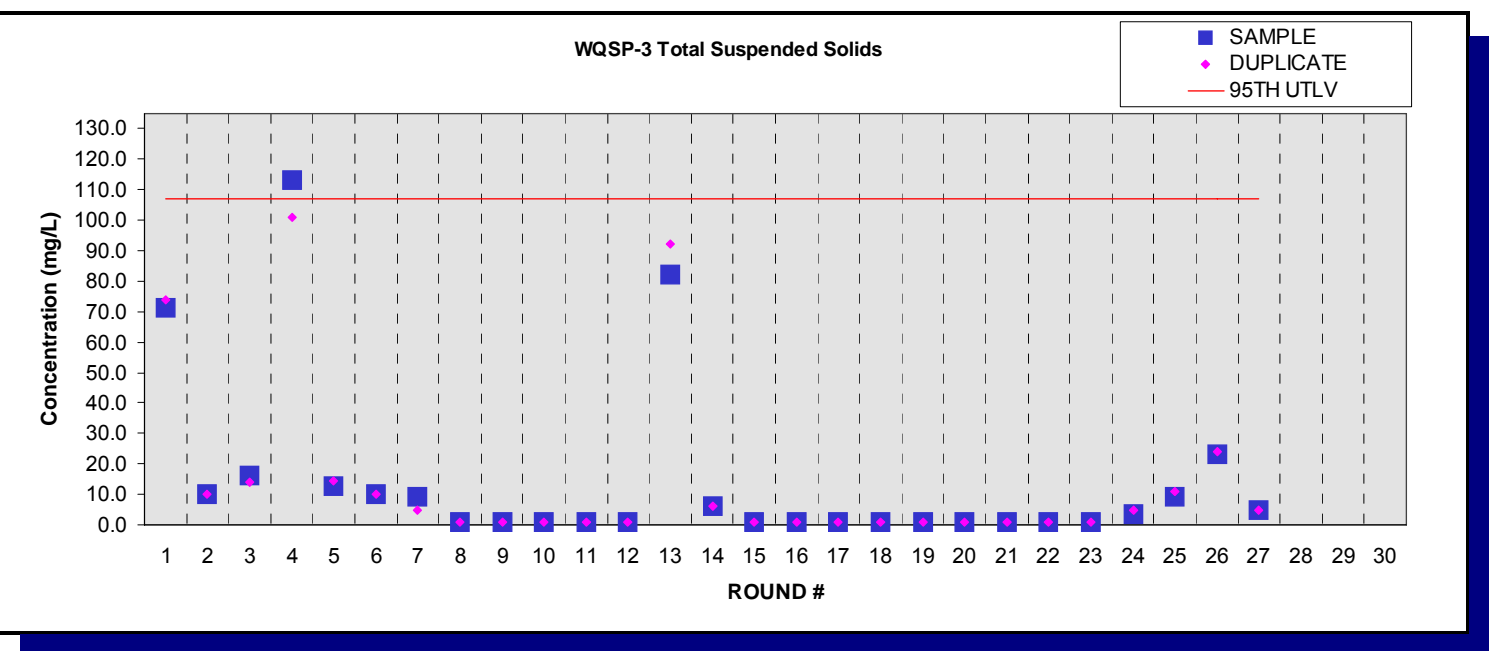

Figure E.42 - Time Trend Plot for Total Suspended Solids at WQSP-3

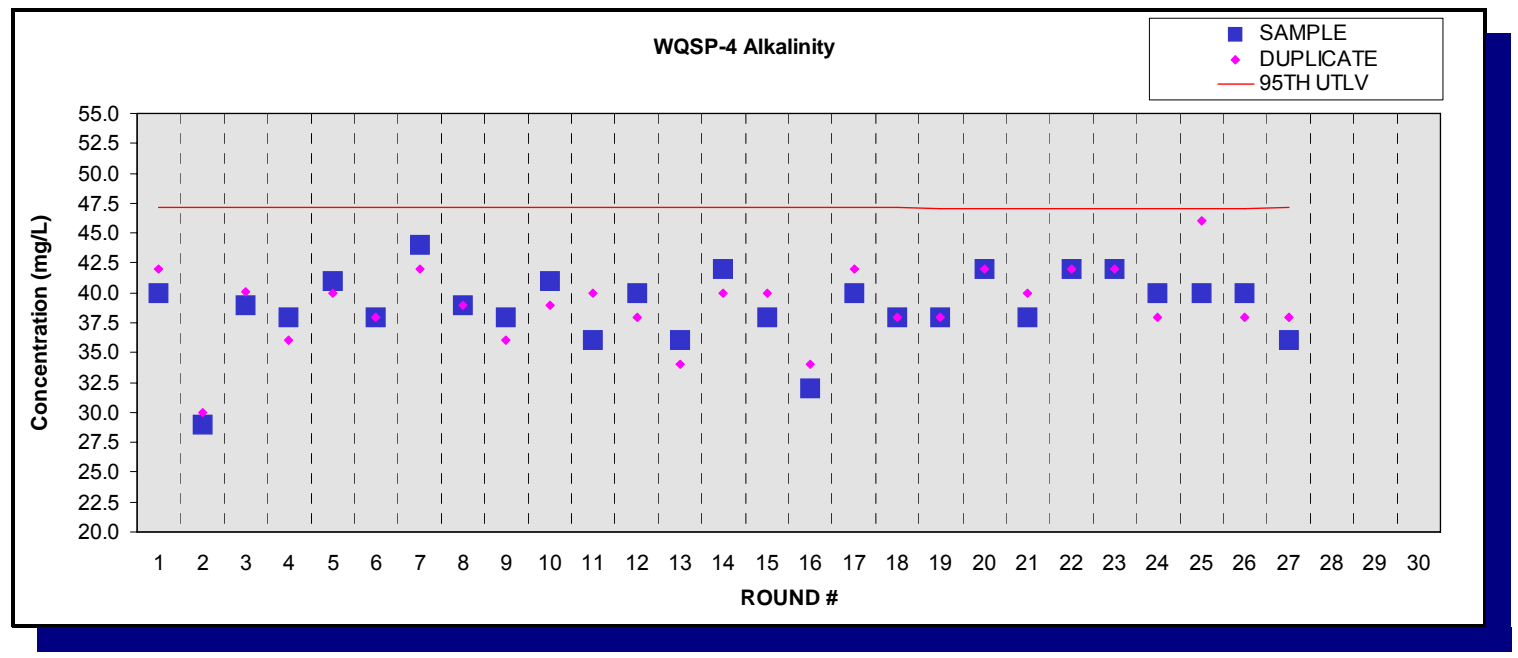

Figure E.43 - Time Trend Plot for Alkalinity for WQSP-4

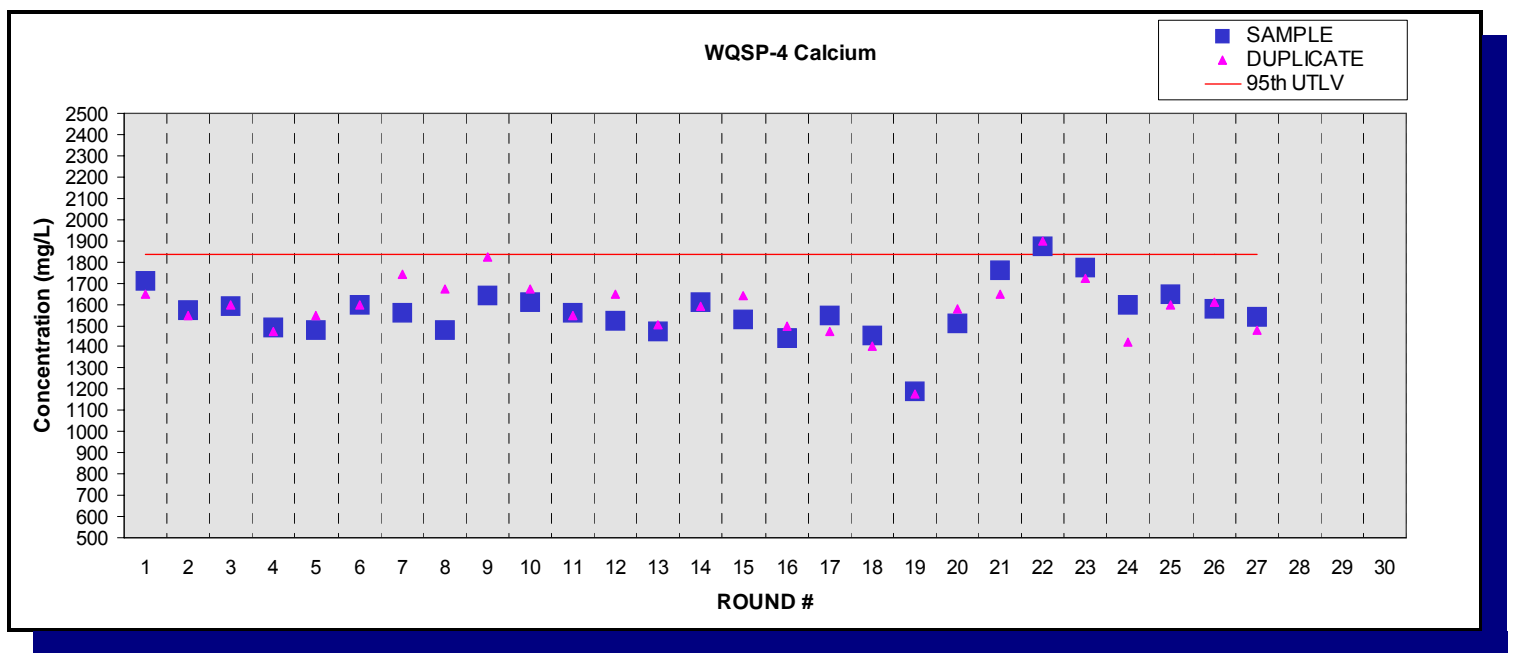

Figure E.44 - Time Trend Plot for Calcium at WQSP-4 
Waste Isolation Pilot Plant Annual Site Environmental Report for 2008 DOE/WIPP-09-2225

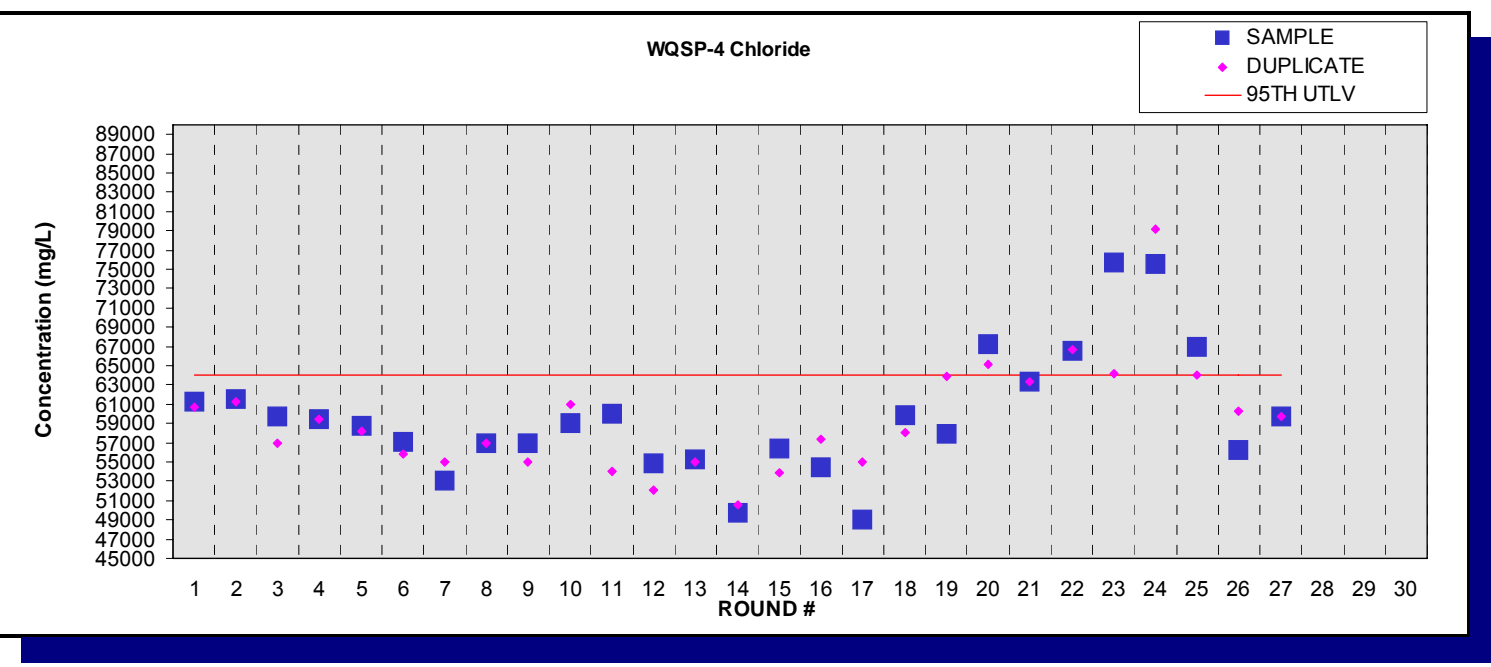

Figure E.45 - Time Trend Plot for Chloride at WQSP-4

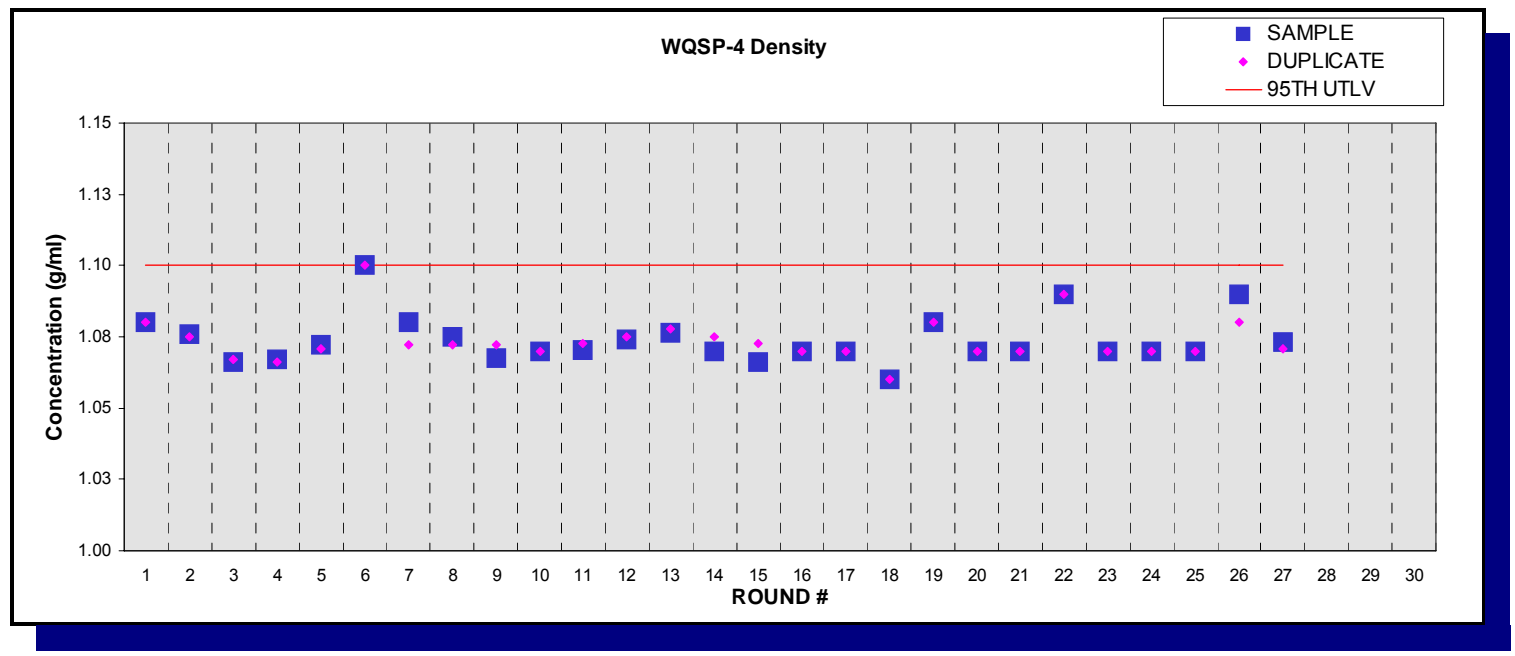

Figure E.46 - Time Trend Plot for Density at WQSP-4

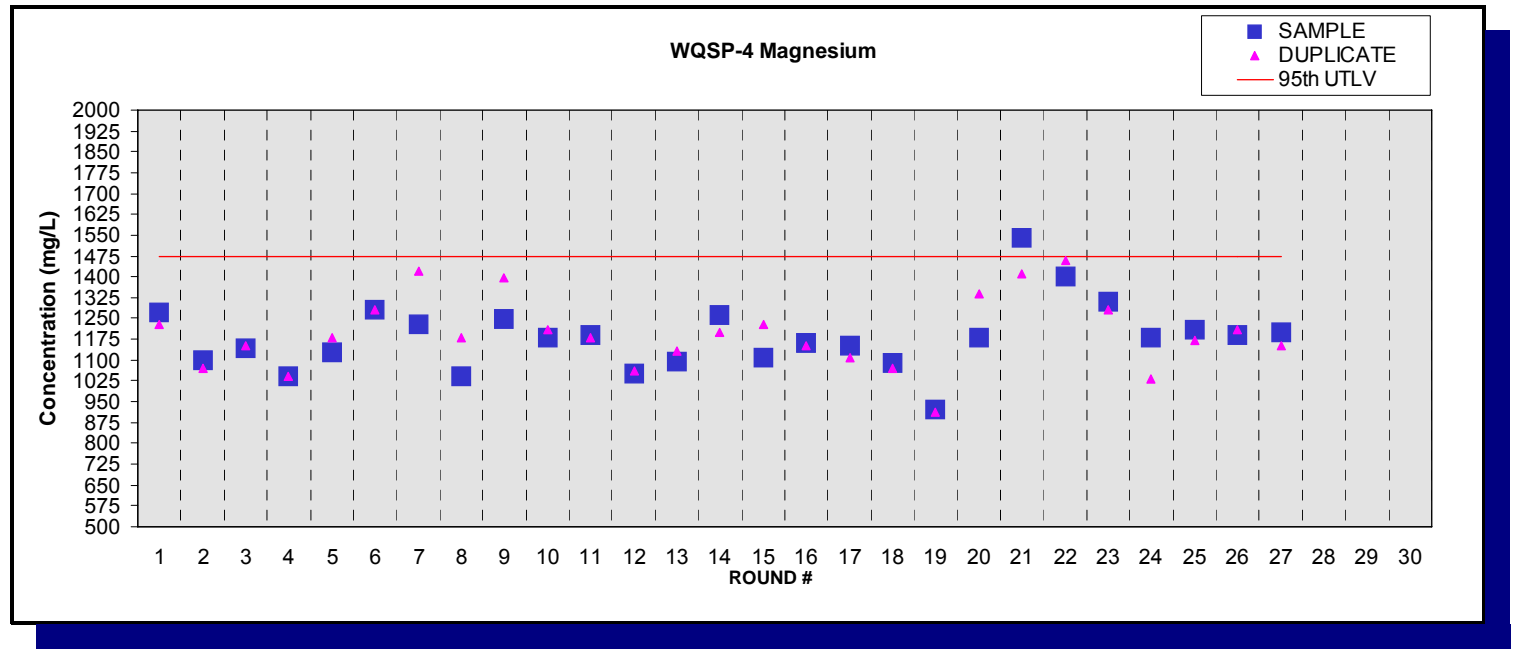

Figure E.47 - Time Trend Plot for Magnesium at WQSP-4 
Waste Isolation Pilot Plant Annual Site Environmental Report for 2008 DOE/WIPP-09-2225

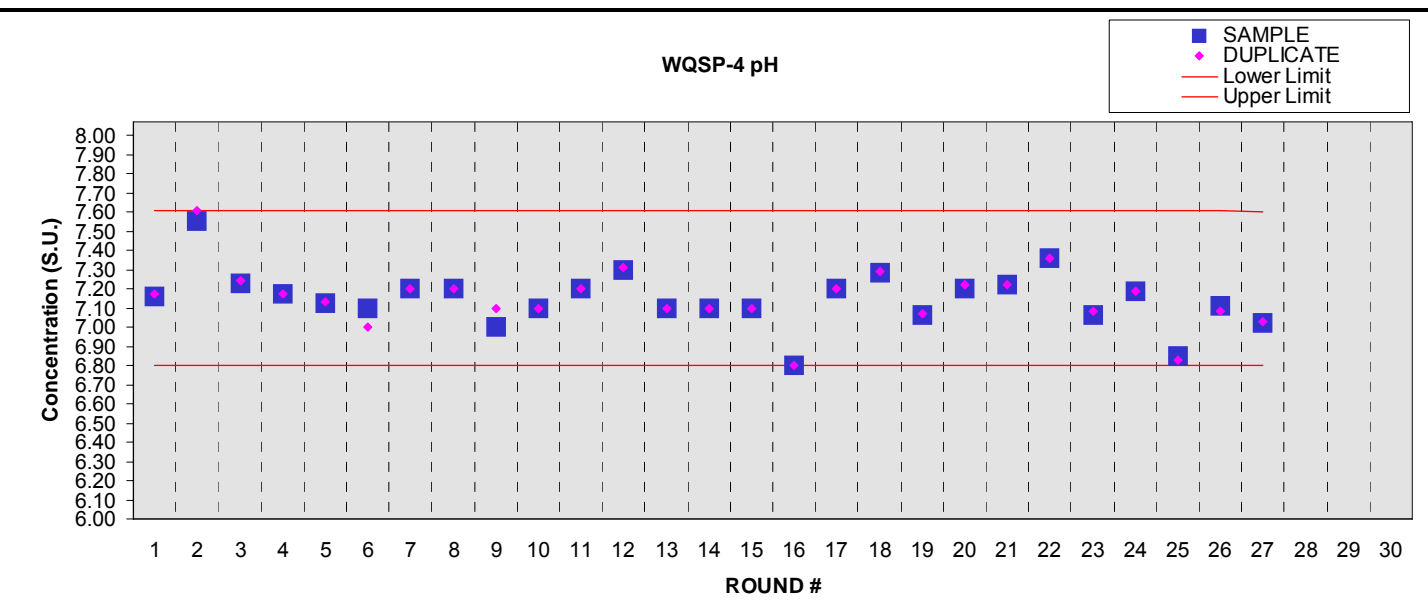

Figure E.48 - Time Trend Plot for pH at WQSP-4

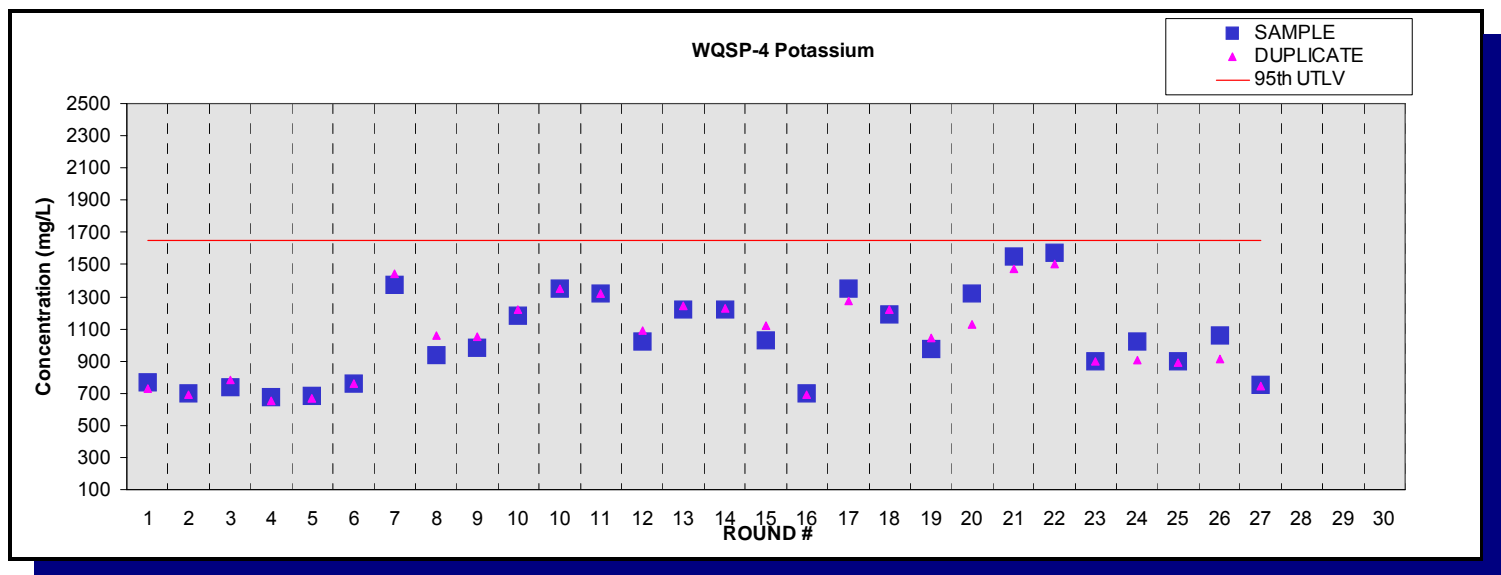

Figure E.49 - Time Trend Plot for Potassium at WQSP-4

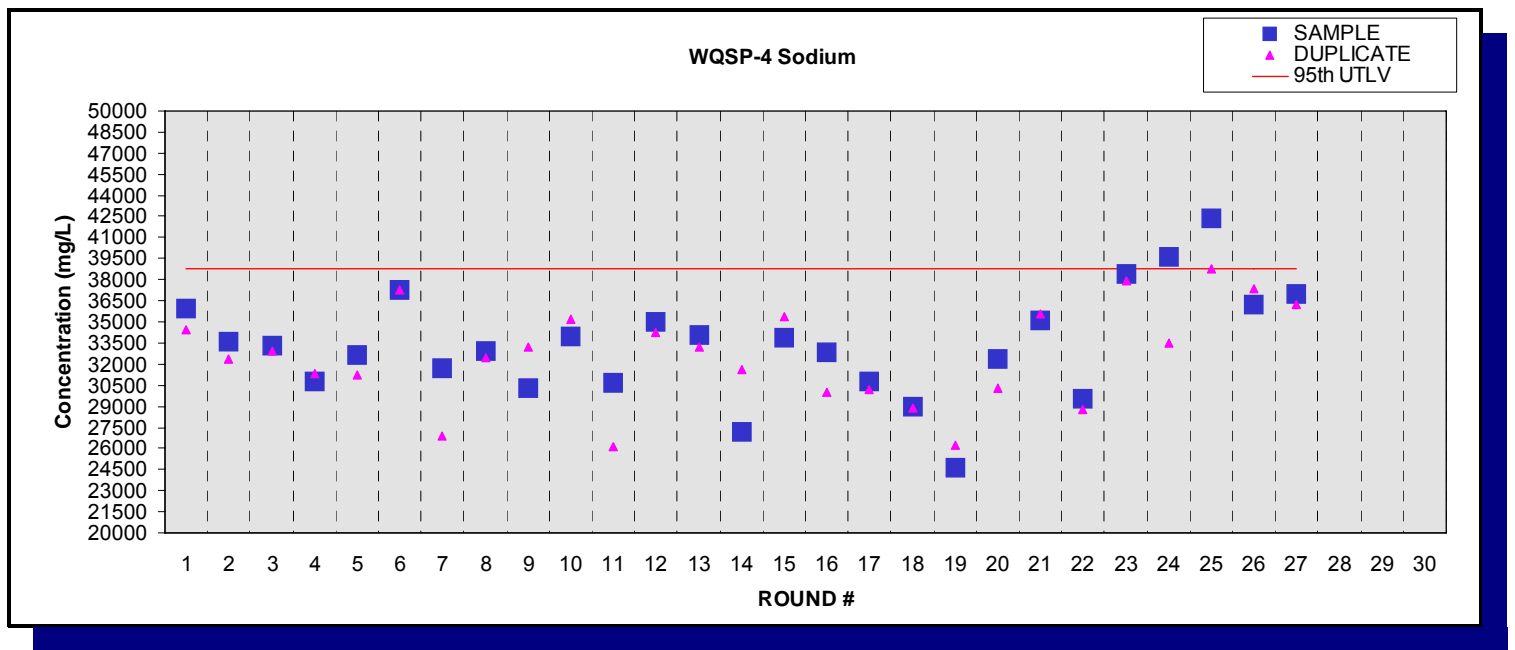

Figure E.50 - Time Trend Plot for Sodium at WQSP-4 
Waste Isolation Pilot Plant Annual Site Environmental Report for 2008 DOE/WIPP-09-2225

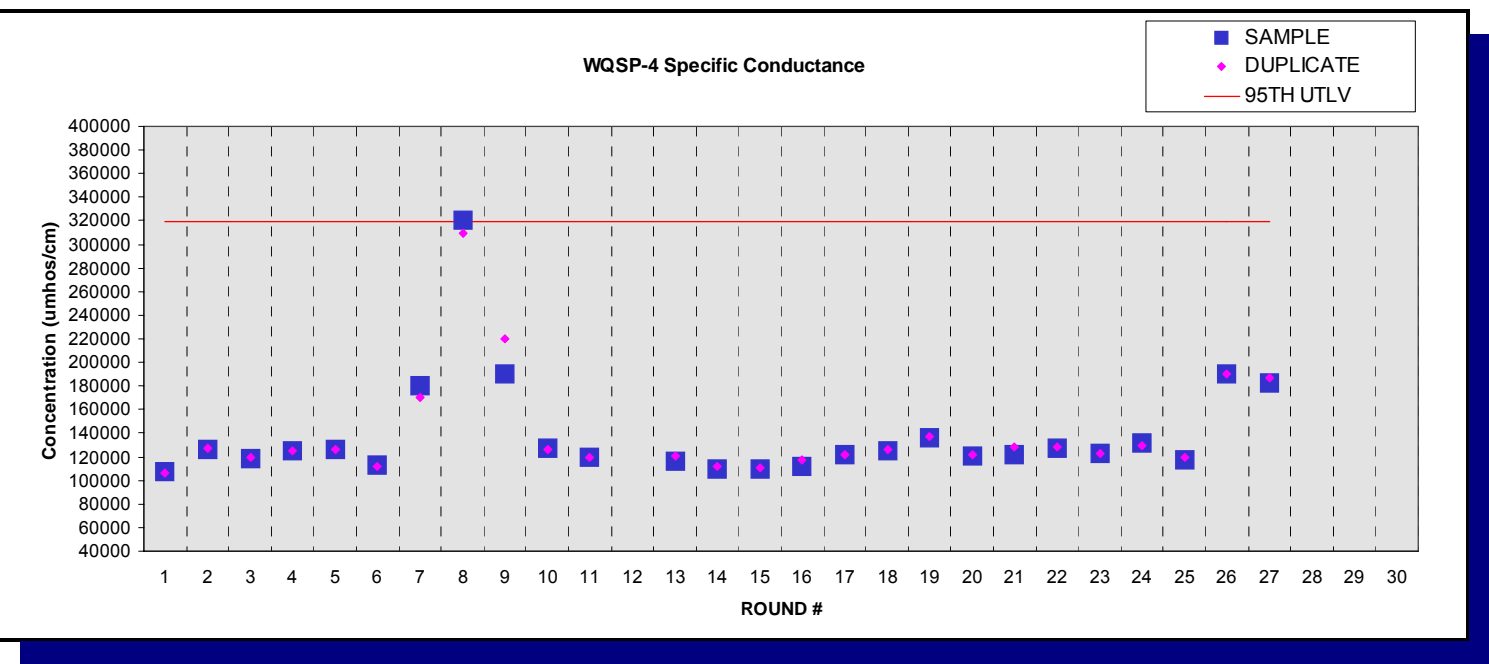

Figure E.51 - Time Trend Plot for Specific Conductance at WQSP-5

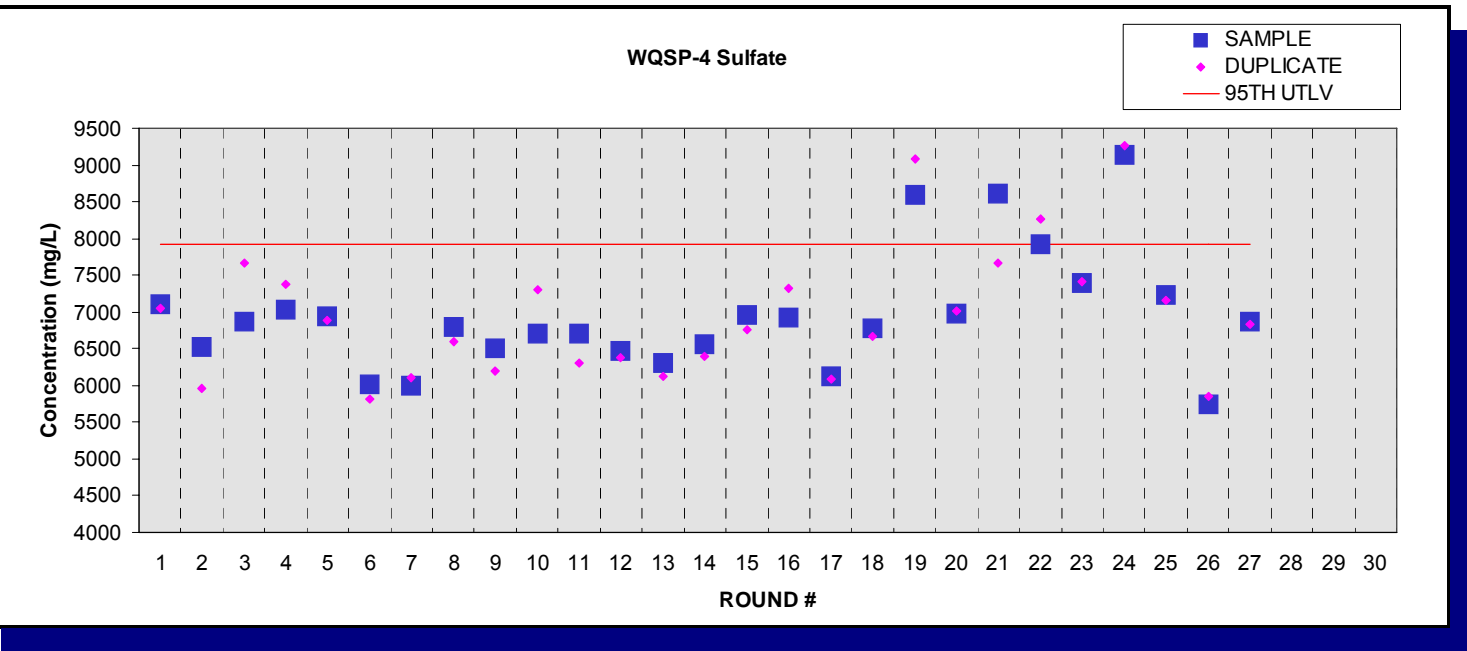

Figure E.52 - Time Trend Plot for Sulfate at WQSP-4

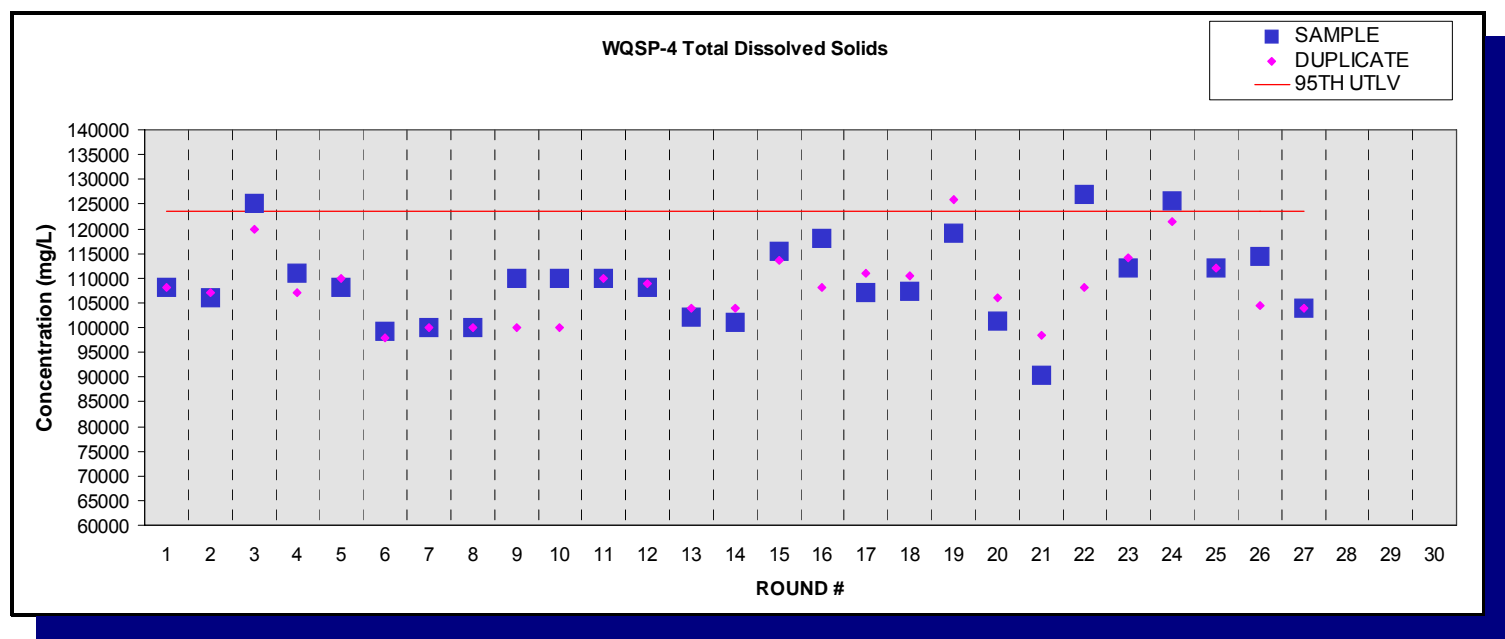

Figure E.53 - Time Trend Plot for Total Dissolved Solids at WQSP-4 
Waste Isolation Pilot Plant Annual Site Environmental Report for 2008 DOE/WIPP-09-2225

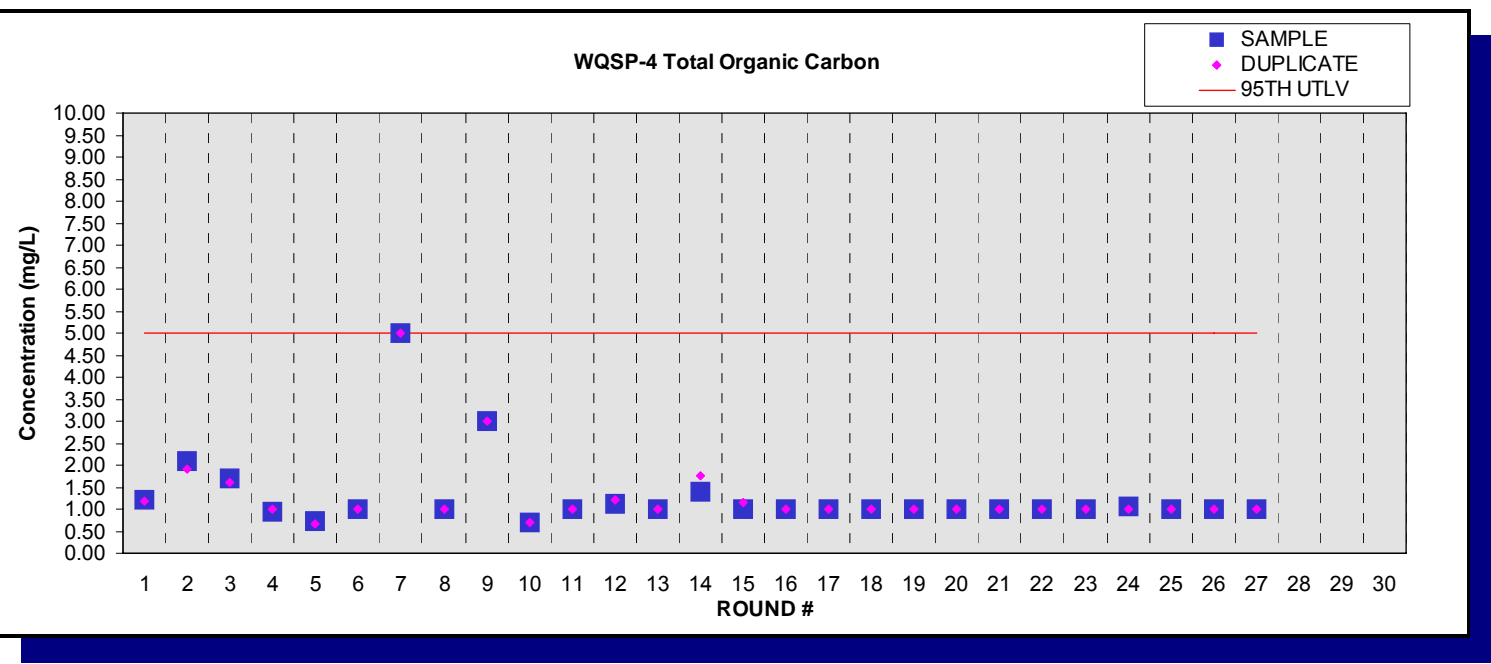

Figure E.54 - Time Trend Plot for Total Organic Carbon at WQSP-4

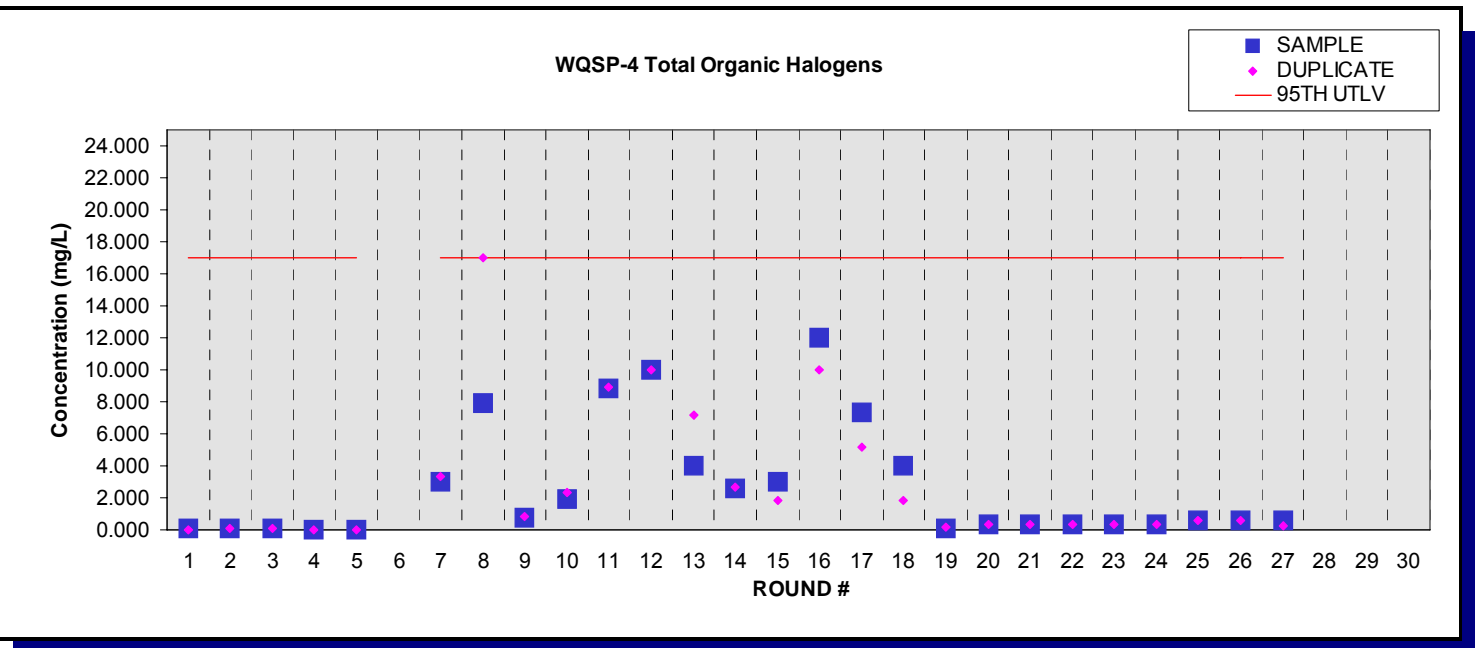

Figure E.55 - Time Trend Plot for Total Organic Halogens at WQSP-5

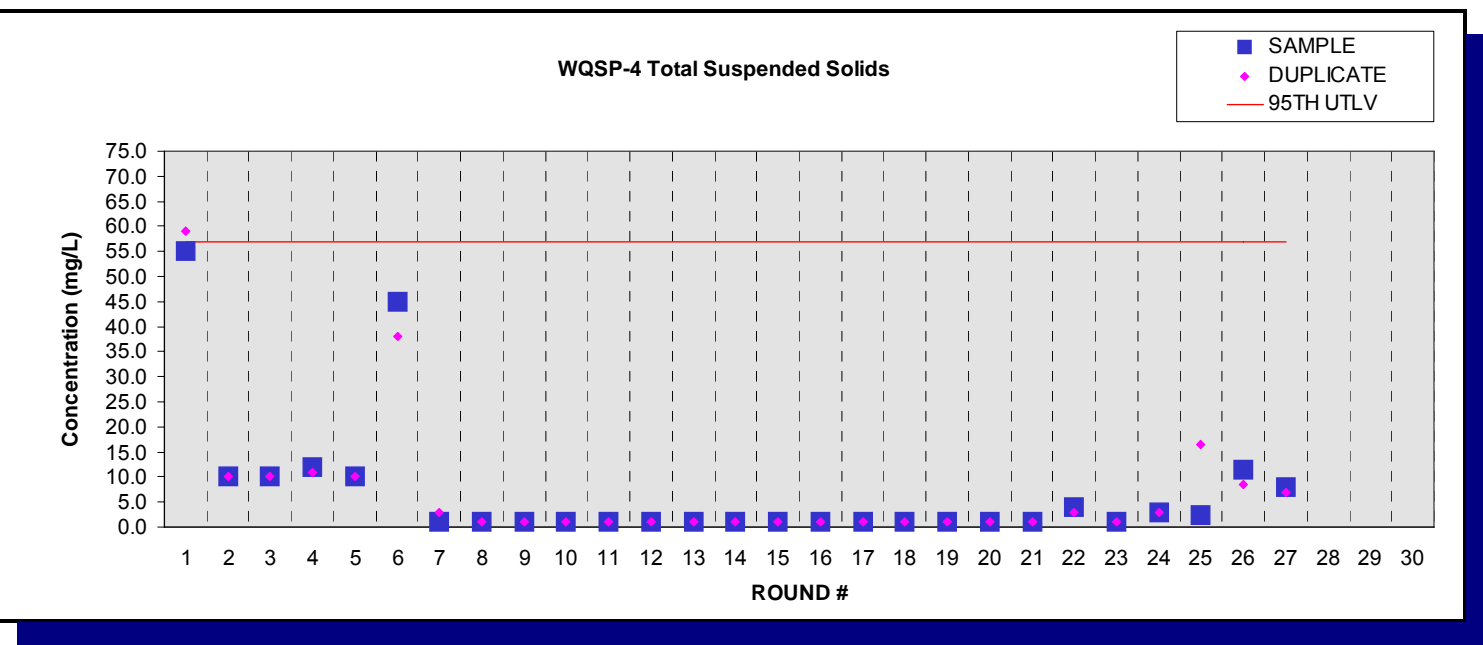

Figure E.56 - Time Trend Plot for Total Suspended Solids at WQSP-4 
Waste Isolation Pilot Plant Annual Site Environmental Report for 2008 DOE/WIPP-09-2225

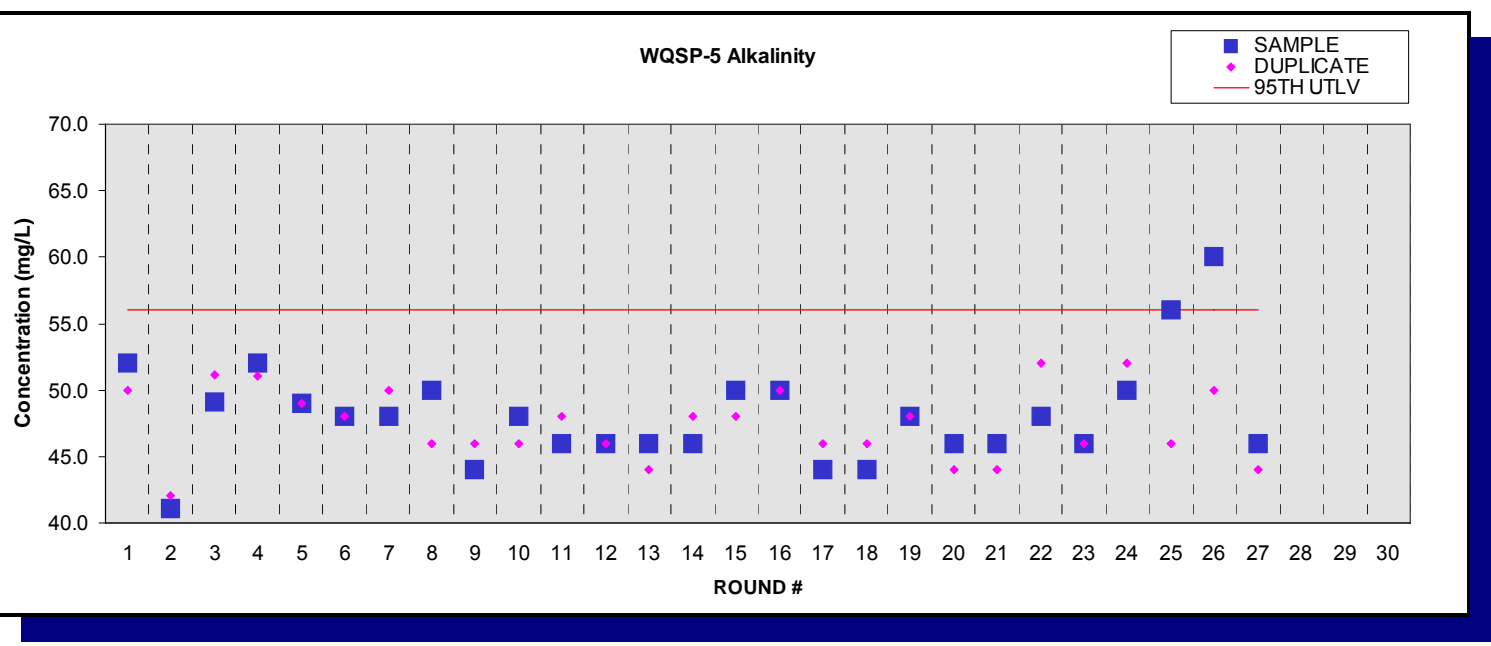

Figure E.57 - Time Trend Plot for Alkalinity at WQSP-5

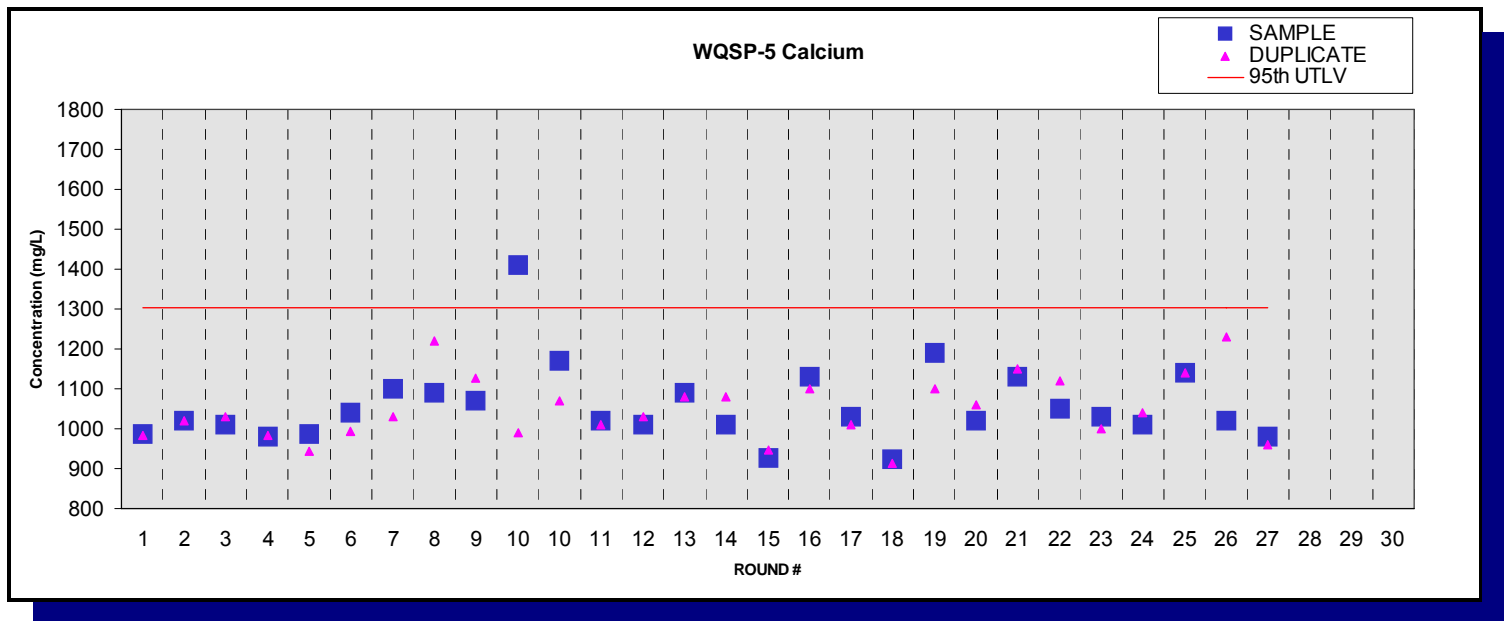

Figure E.58 - Time Trend Plot for Calcium at WQSP-5

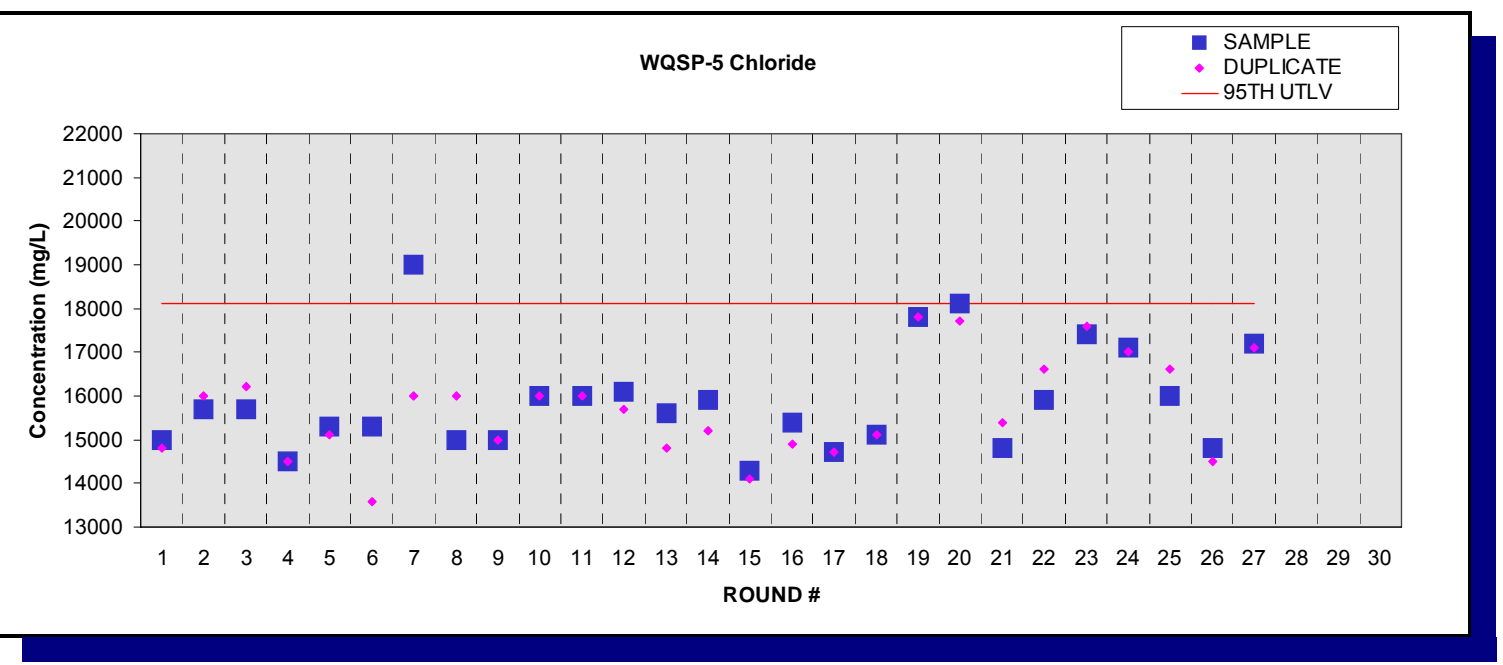

Figure E.59 - Time Trend Plot for Chloride at WQSP-5 
Waste Isolation Pilot Plant Annual Site Environmental Report for 2008 DOE/WIPP-09-2225

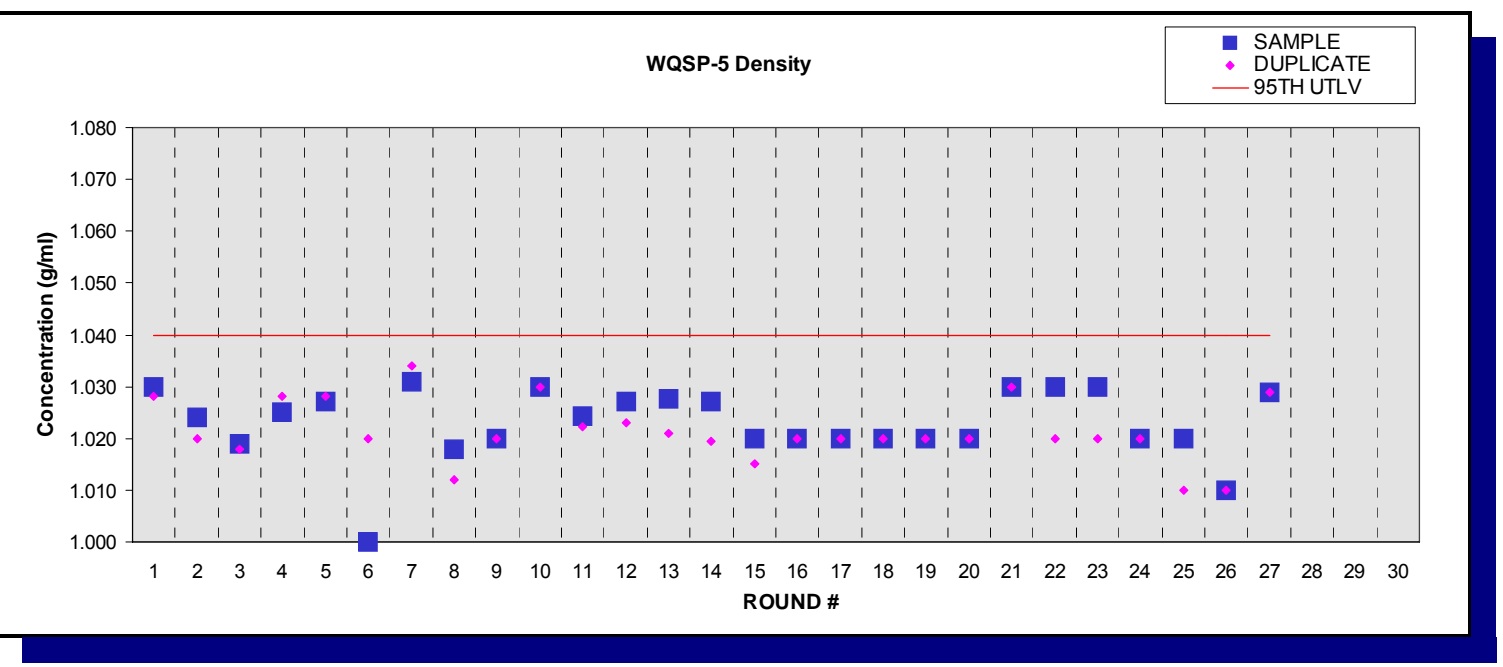

Figure E.60 - Time Trend Plot for Density at WQSP-5

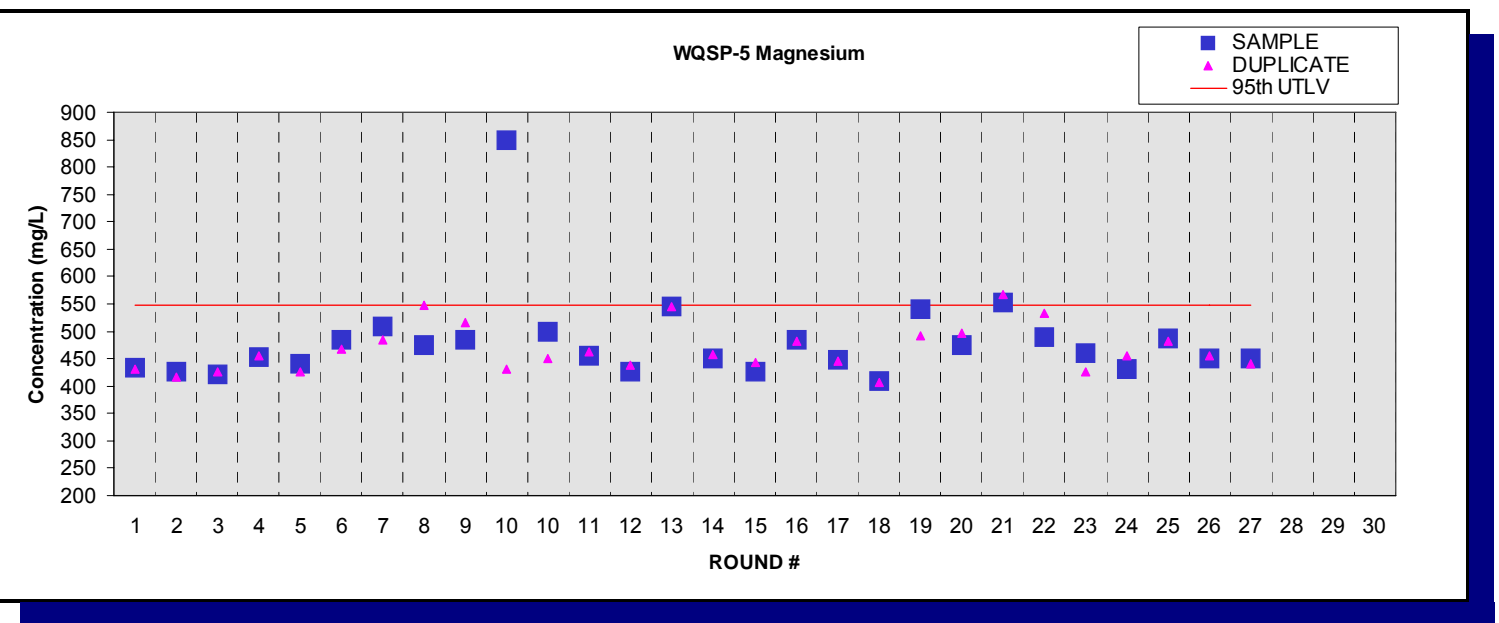

Figure E.61 - Time Trend Plot for Magnesium at WQSP-5

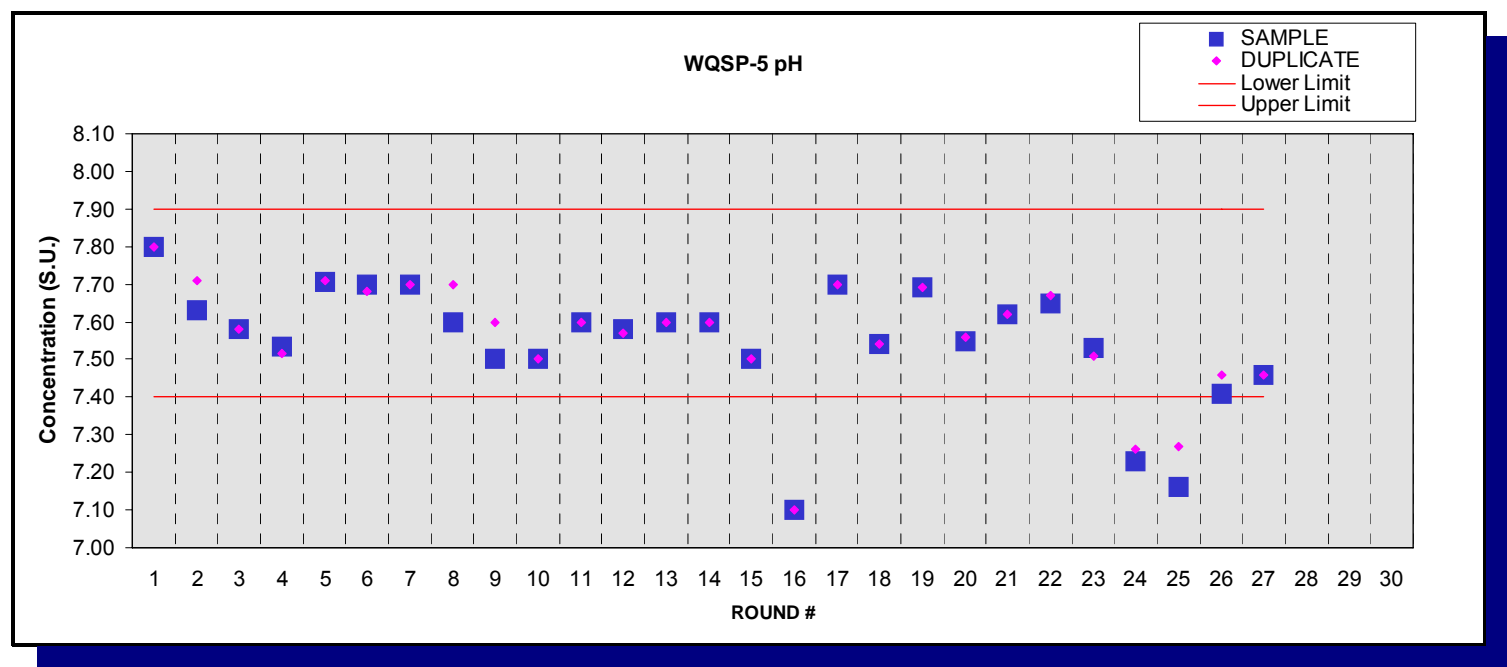

Figure E.62 - Time Trend Plot for $\mathrm{pH}$ at WQSP-5 
Waste Isolation Pilot Plant Annual Site Environmental Report for 2008 DOE/WIPP-09-2225

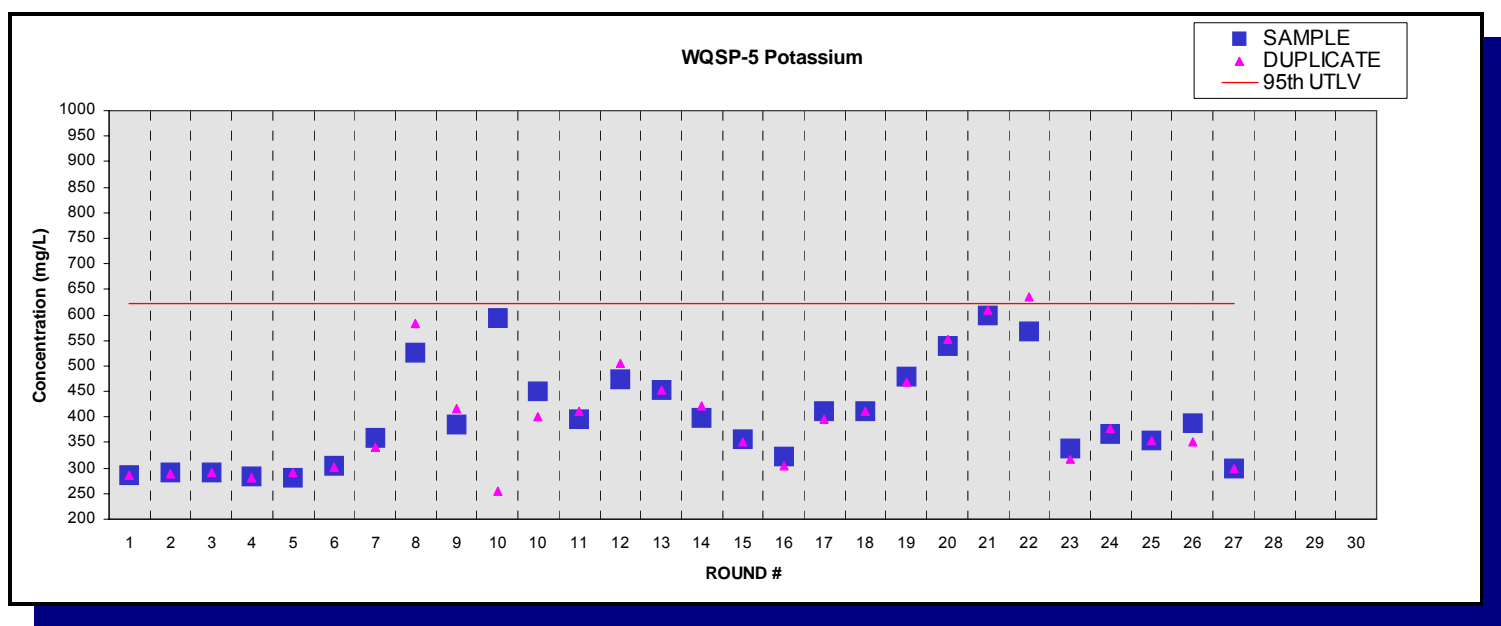

Figure E.63 - Time Trend Plot for Potassium at WQSP-5

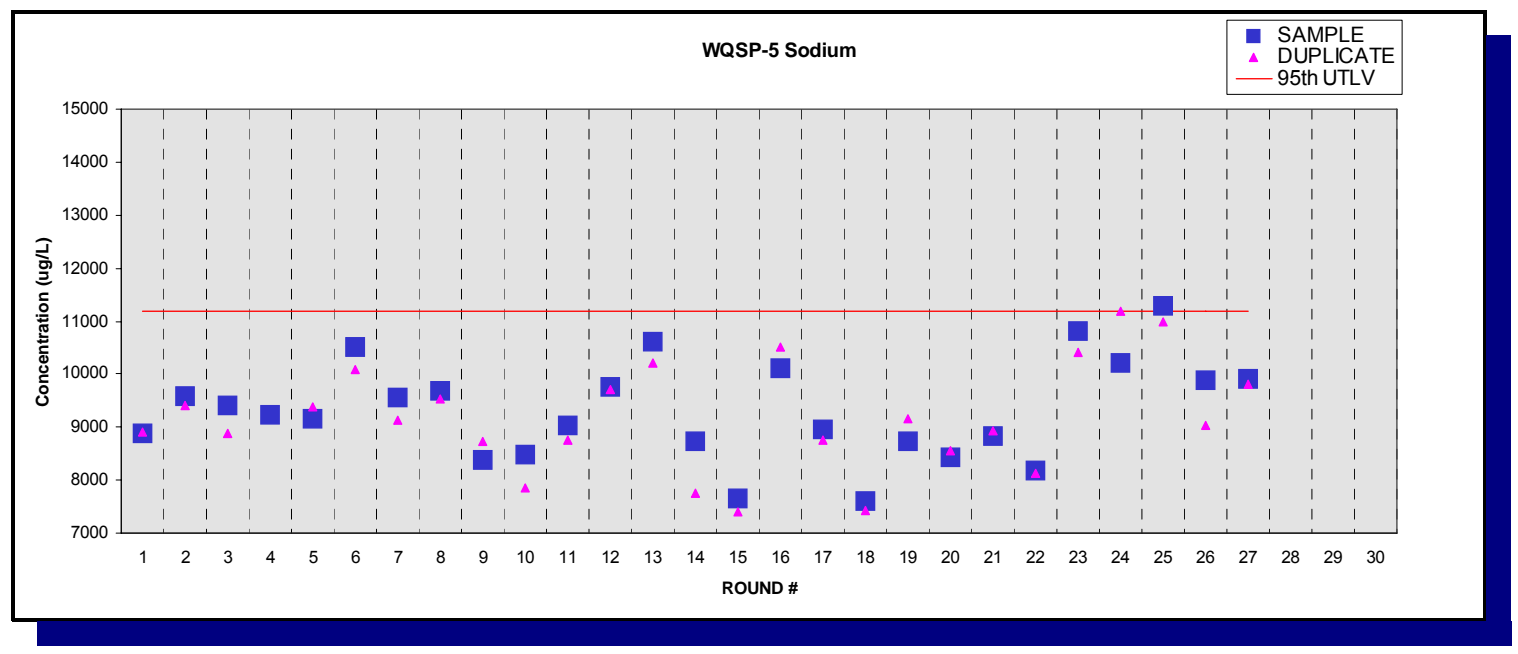

Figure E.64 - Time Trend Plot for Sodium at WQSP-5

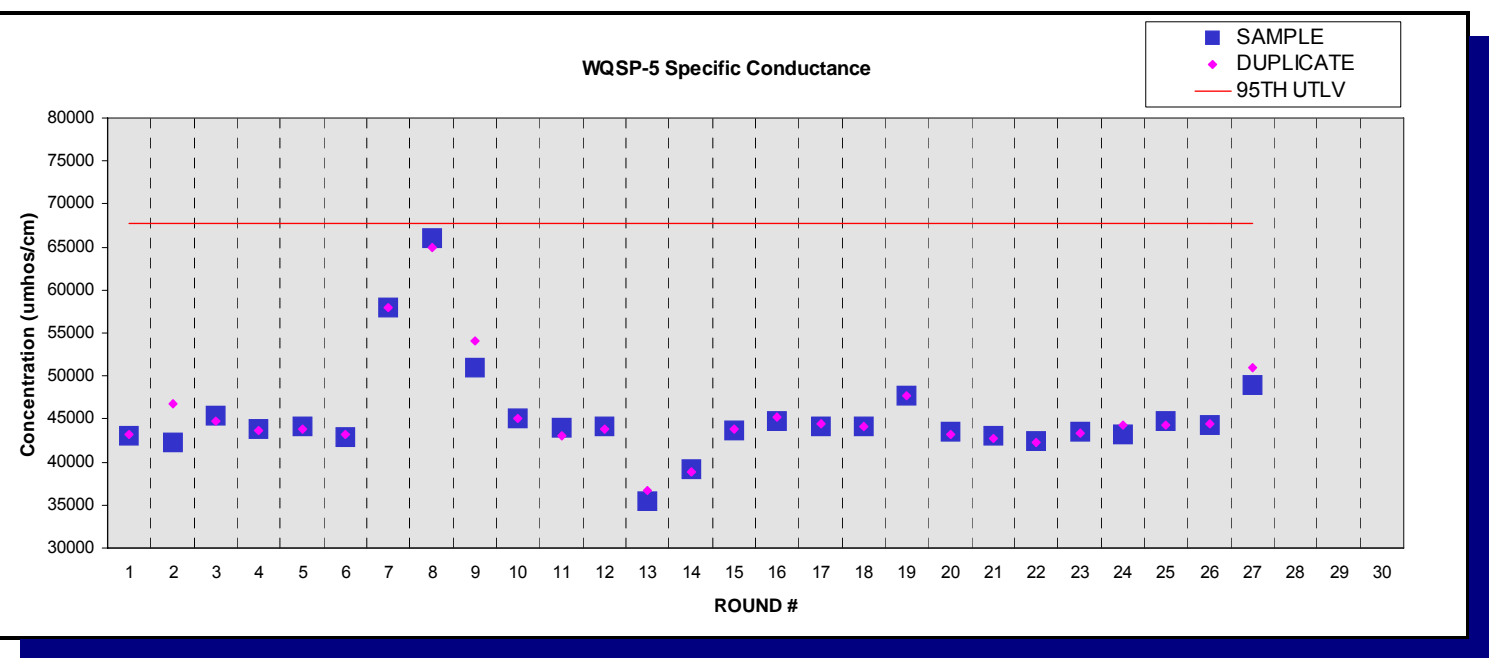

Figure E.65 - Time Trend Plot for Specific Conductance at WQSP-5 
Waste Isolation Pilot Plant Annual Site Environmental Report for 2008 DOE/WIPP-09-2225

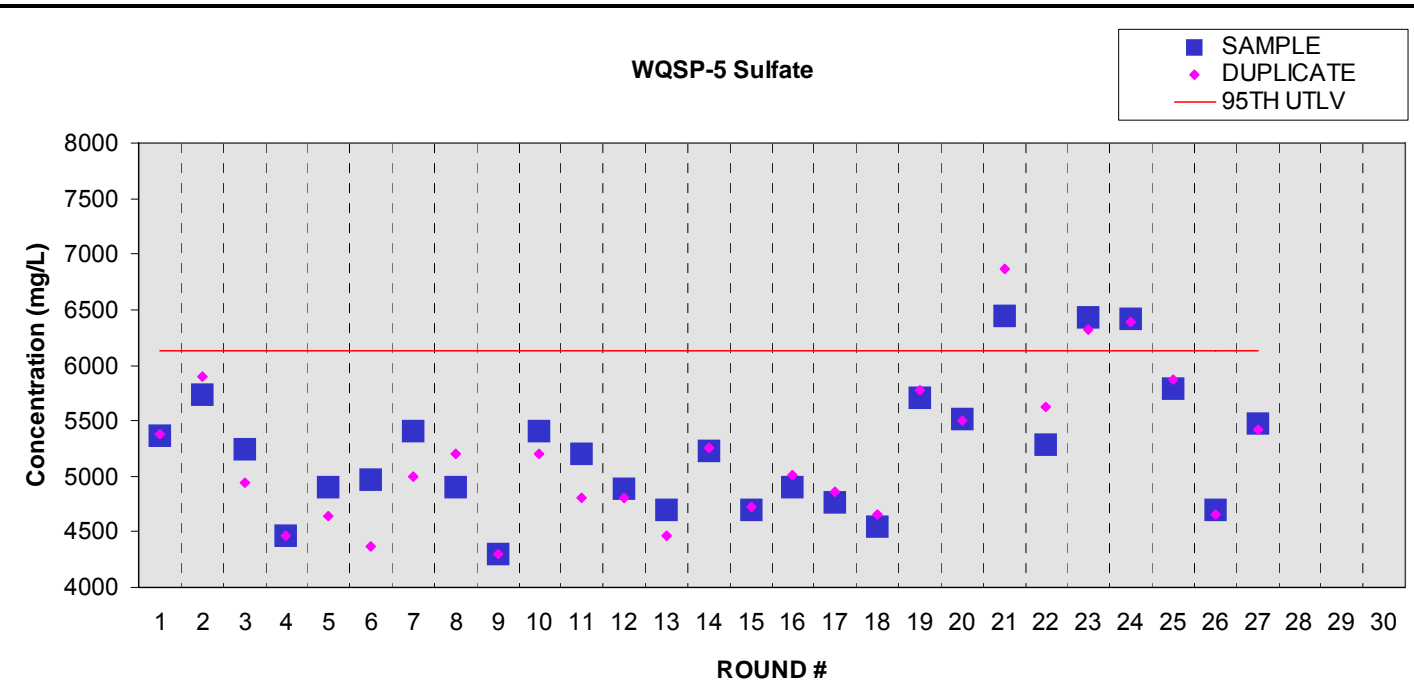

Figure E.66 - Time Trend Plot for Sulfate at WQSP-5

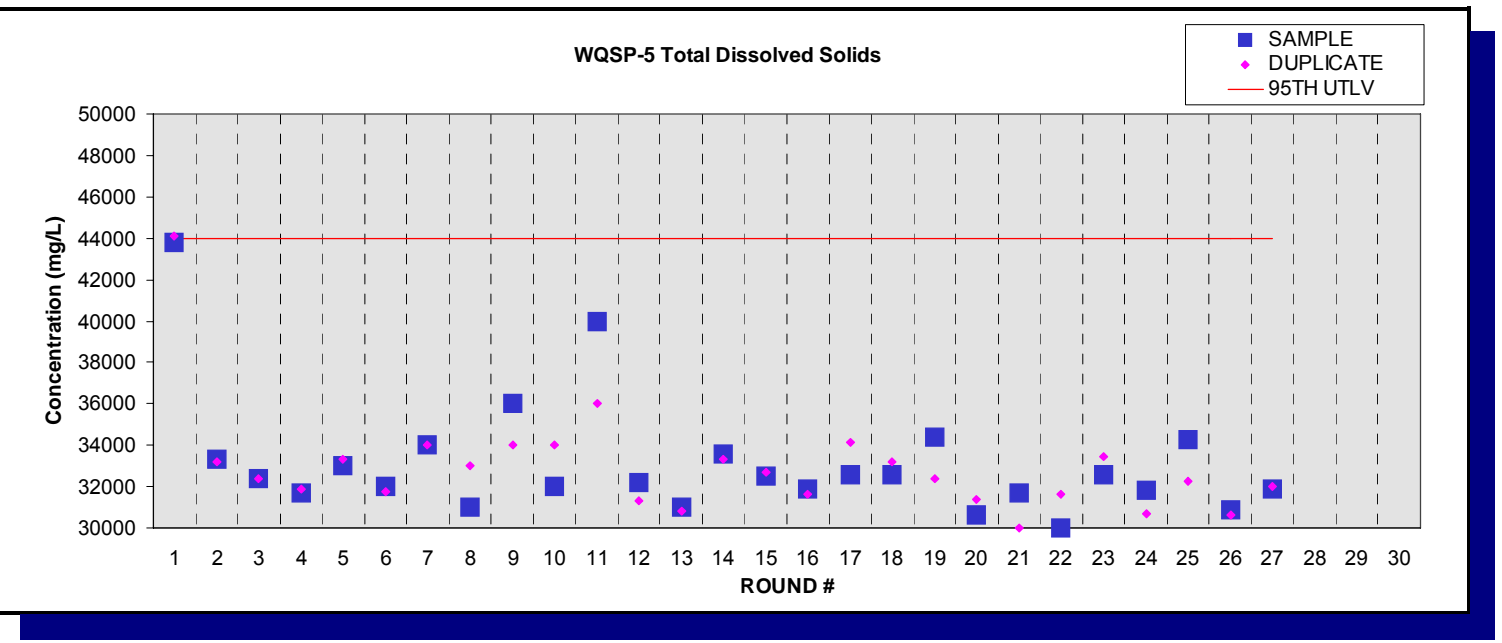

Figure E.67 - Time Trend Plot for Total Dissolved Solids at WQSP-5



Figure E.68 - Time Trend Plot for Total Organic Carbon at WQSP-5 
Waste Isolation Pilot Plant Annual Site Environmental Report for 2008 DOE/WIPP-09-2225 
Waste Isolation Pilot Plant Annual Site Environmental Report for 2008 DOE/WIPP-09-2225

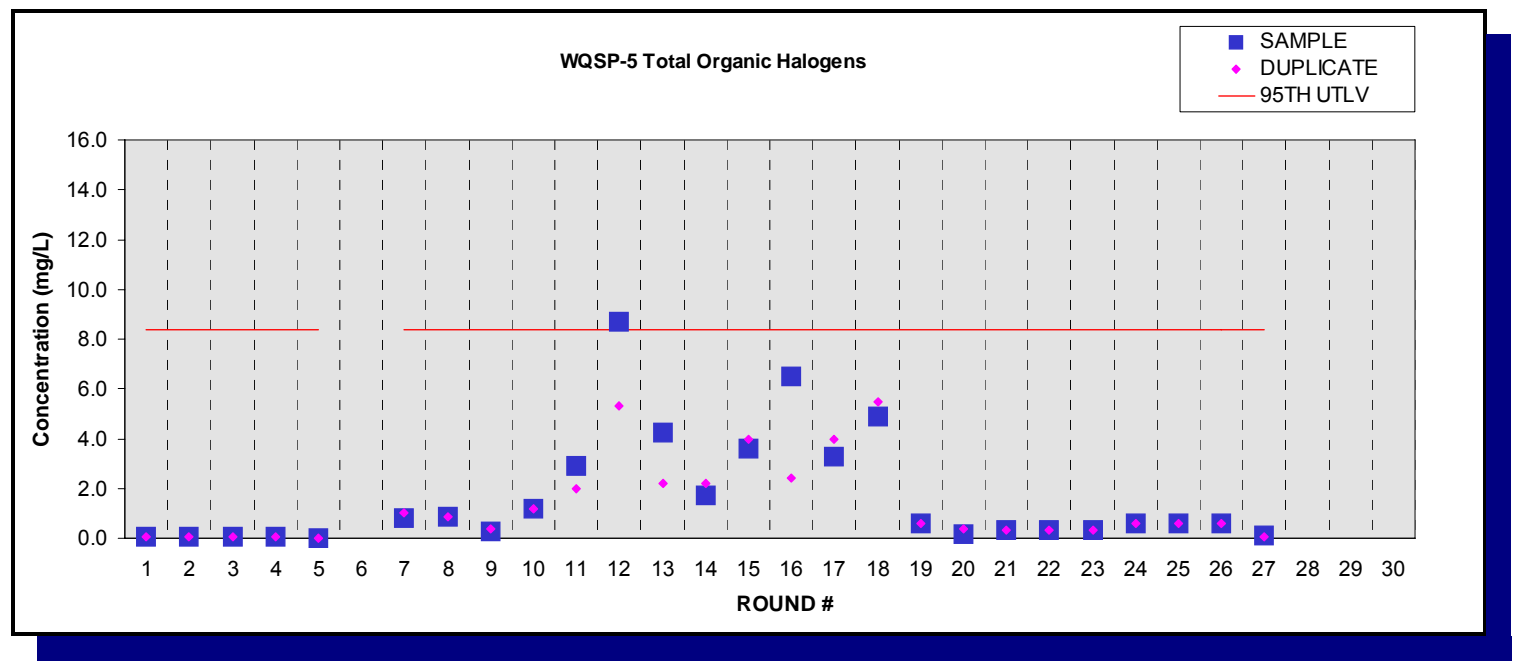

Figure E.69 - Time Trend Plot for Total Organic Halogens at WQSP-5

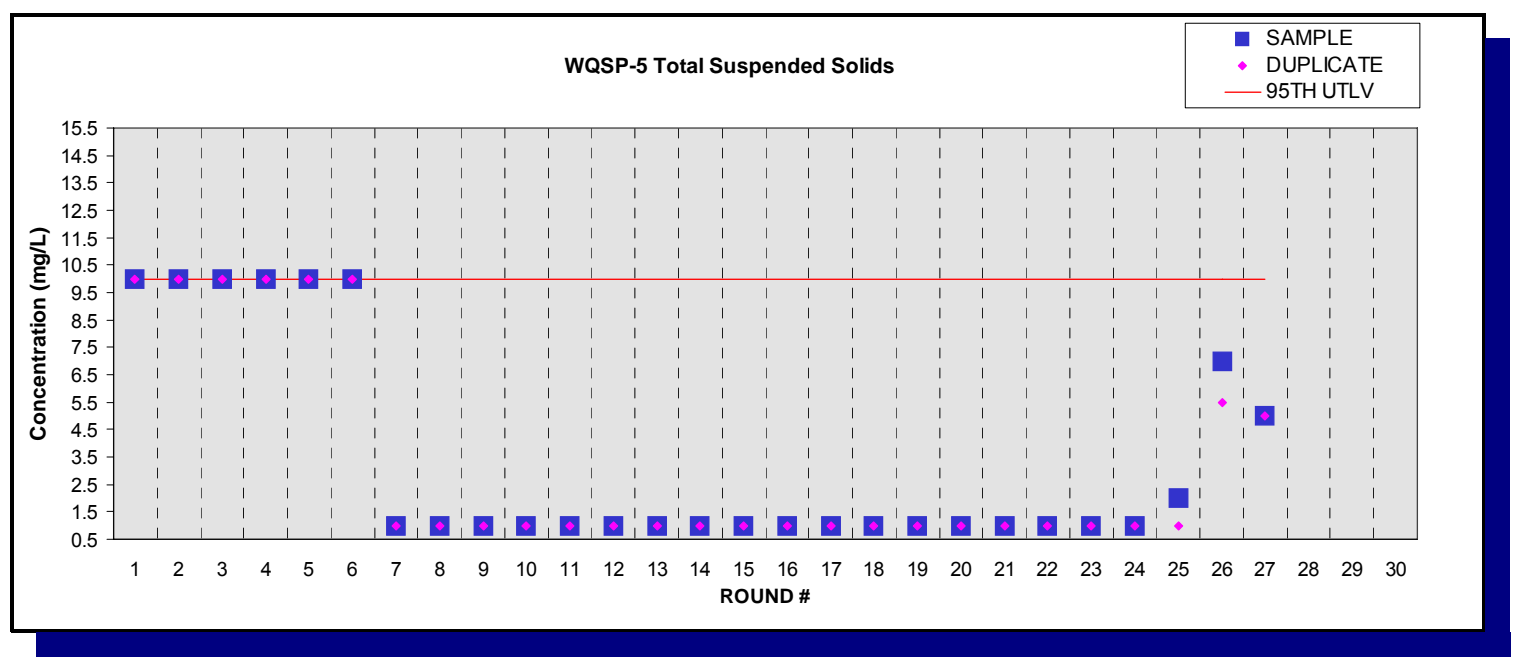

Figure E.70 - Time Trend Plot for Total Suspended Solids at WQSP-5

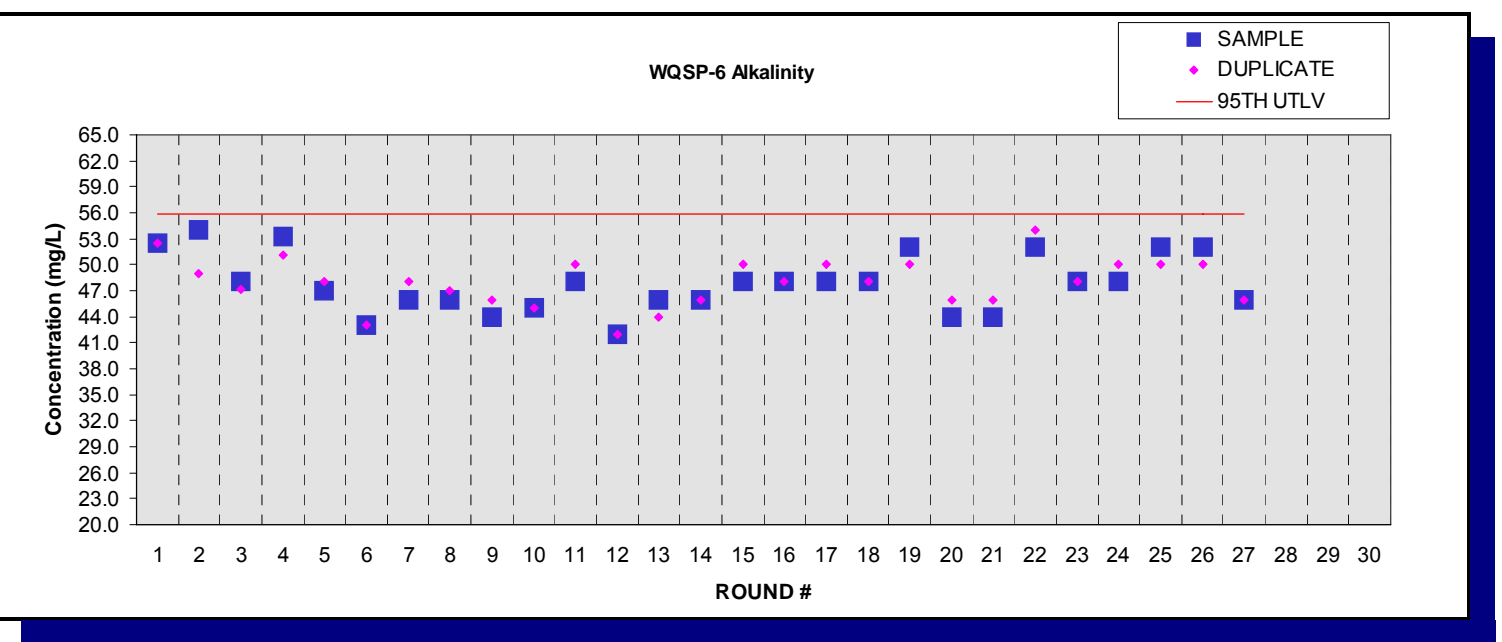

Figure E.71 - Time Trend Plot for Alkalinity at WQSP-6 
Waste Isolation Pilot Plant Annual Site Environmental Report for 2008 DOE/WIPP-09-2225

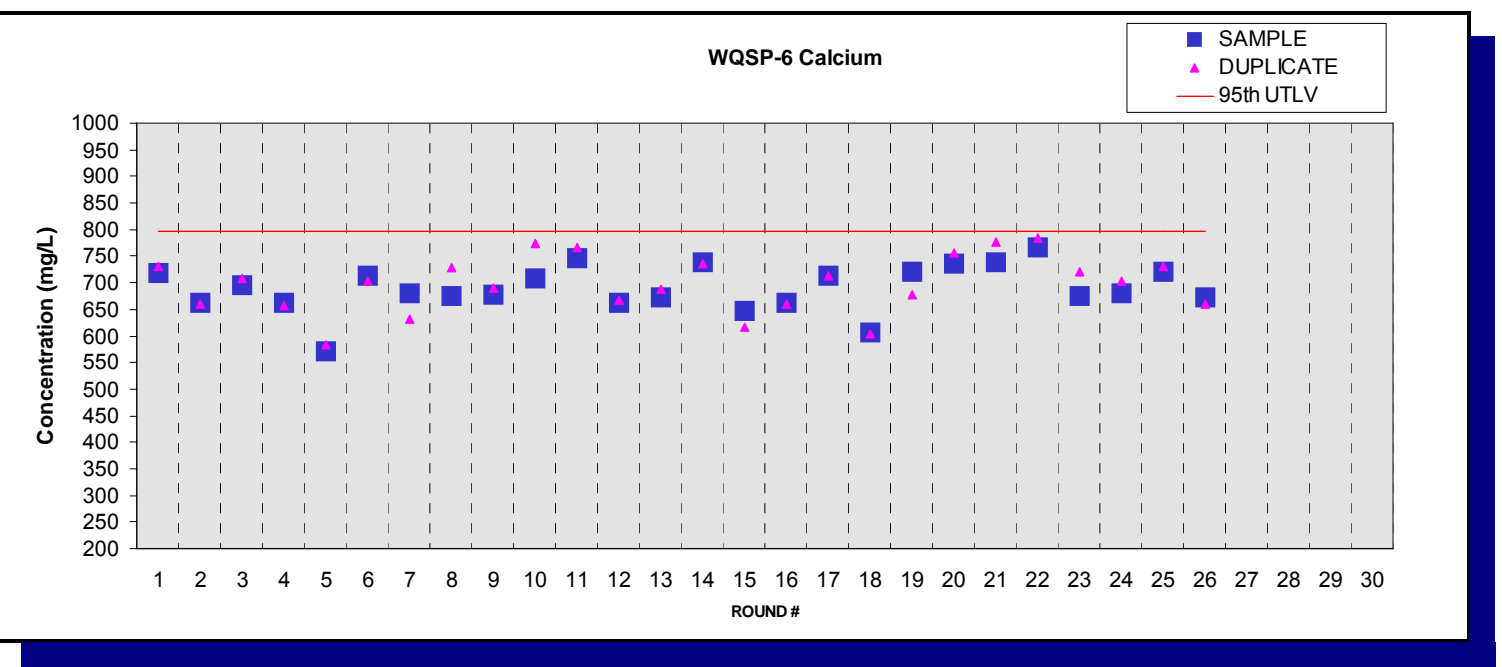

Figure E.72 - Time Trend Plot for Calcium at WQSP-6

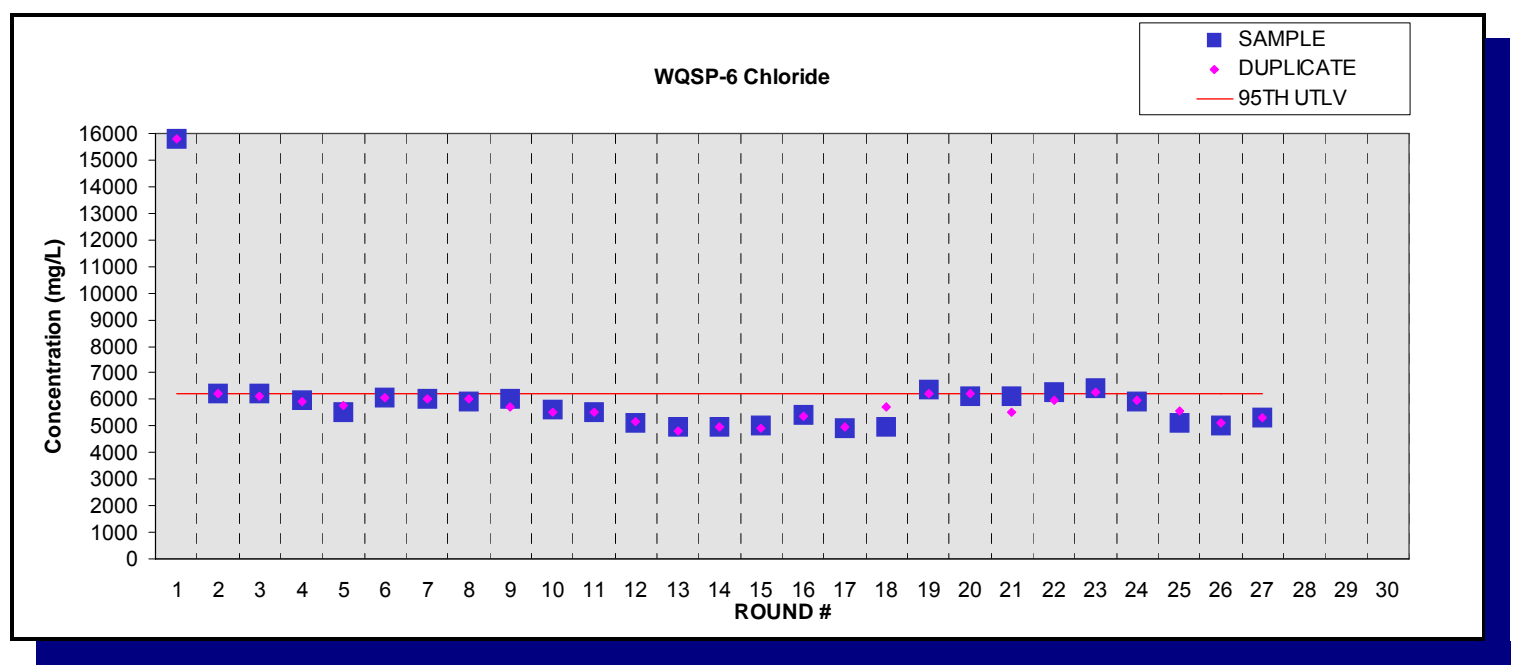

Figure E.73 - Time Trend Plot for Chloride at WQSP-6

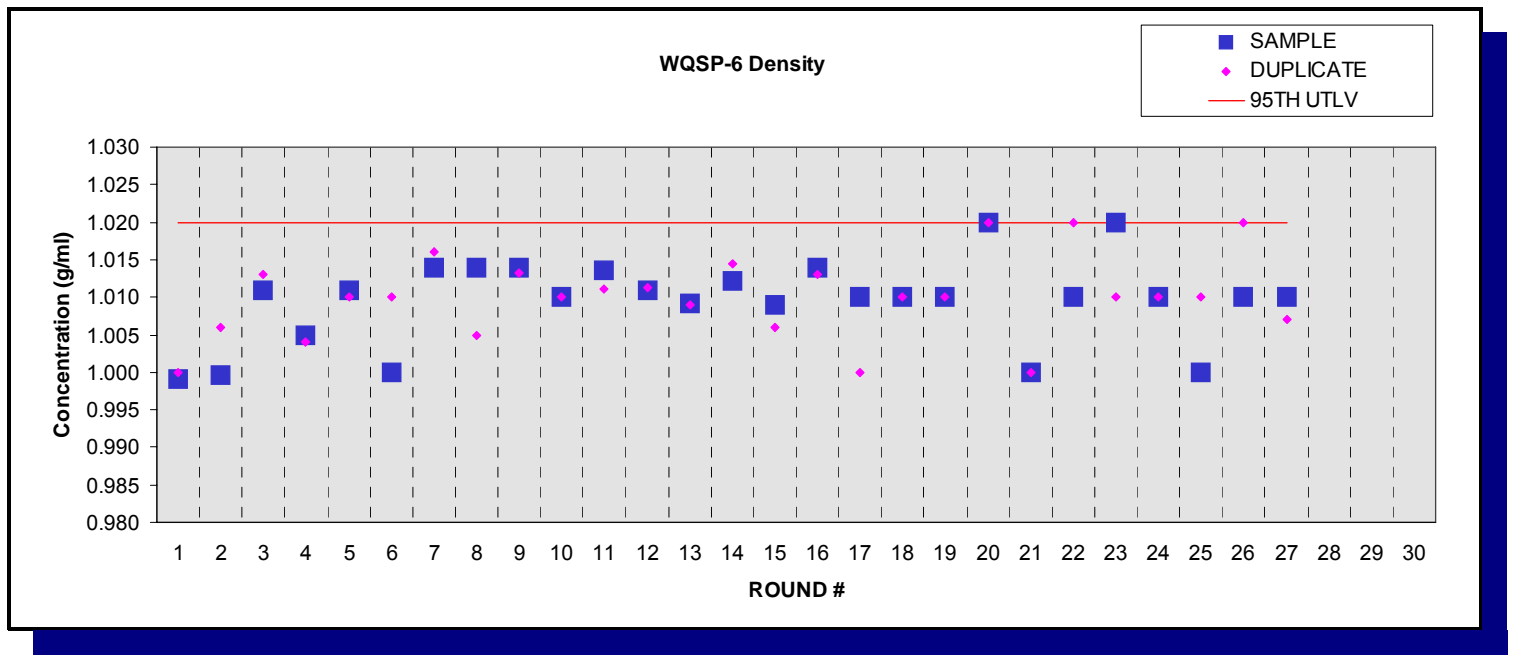

Figure E.74 - Time Trend Plot for Density at WQSP-6 
Waste Isolation Pilot Plant Annual Site Environmental Report for 2008 DOE/WIPP-09-2225

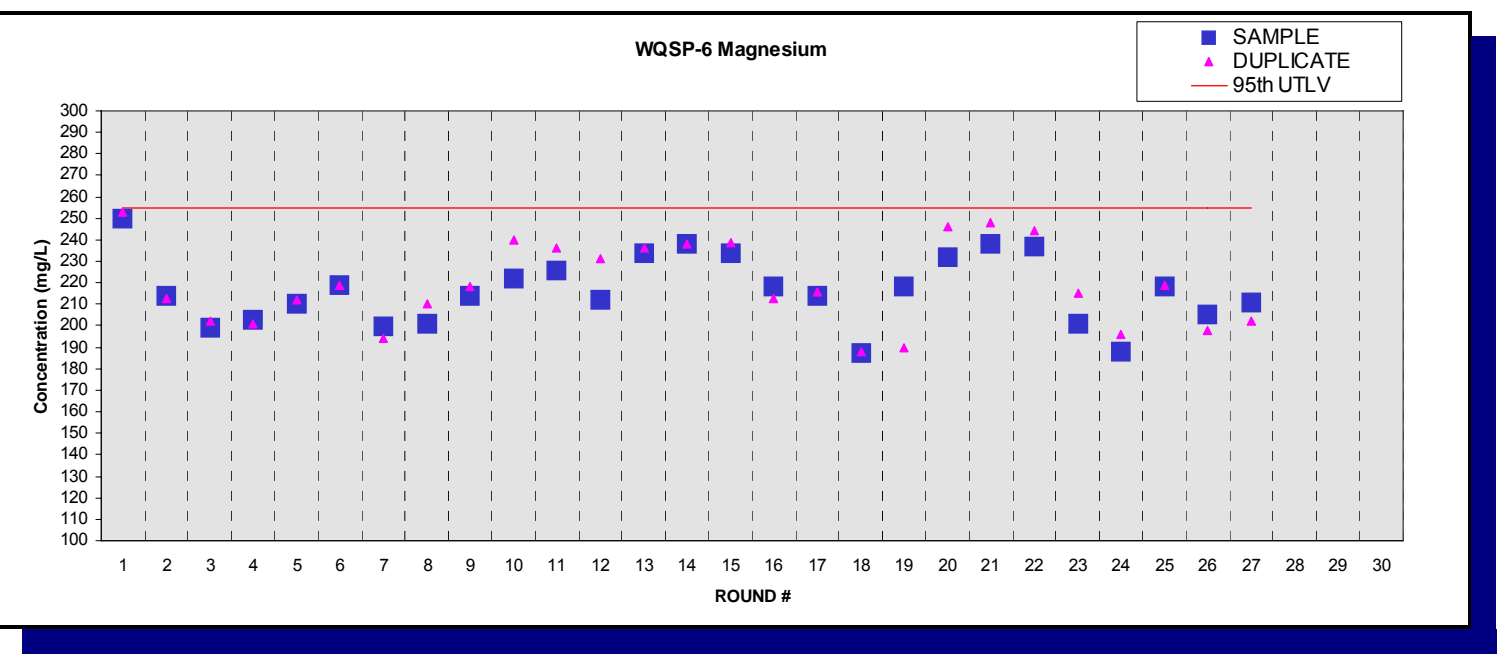

Figure E.75 - Time Trend Plot for Magnesium at WQSP-6

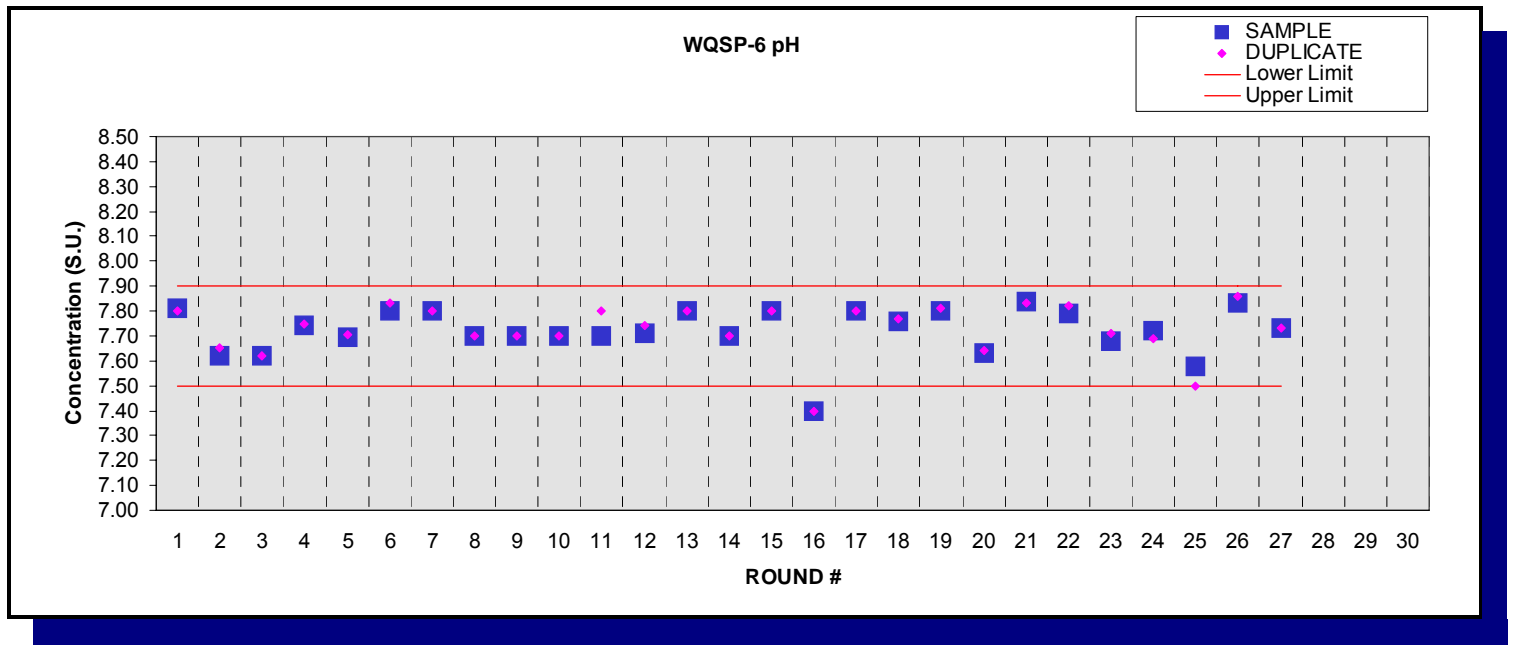

Figure E.76 - Time Trend Plot for pH at WQSP-6

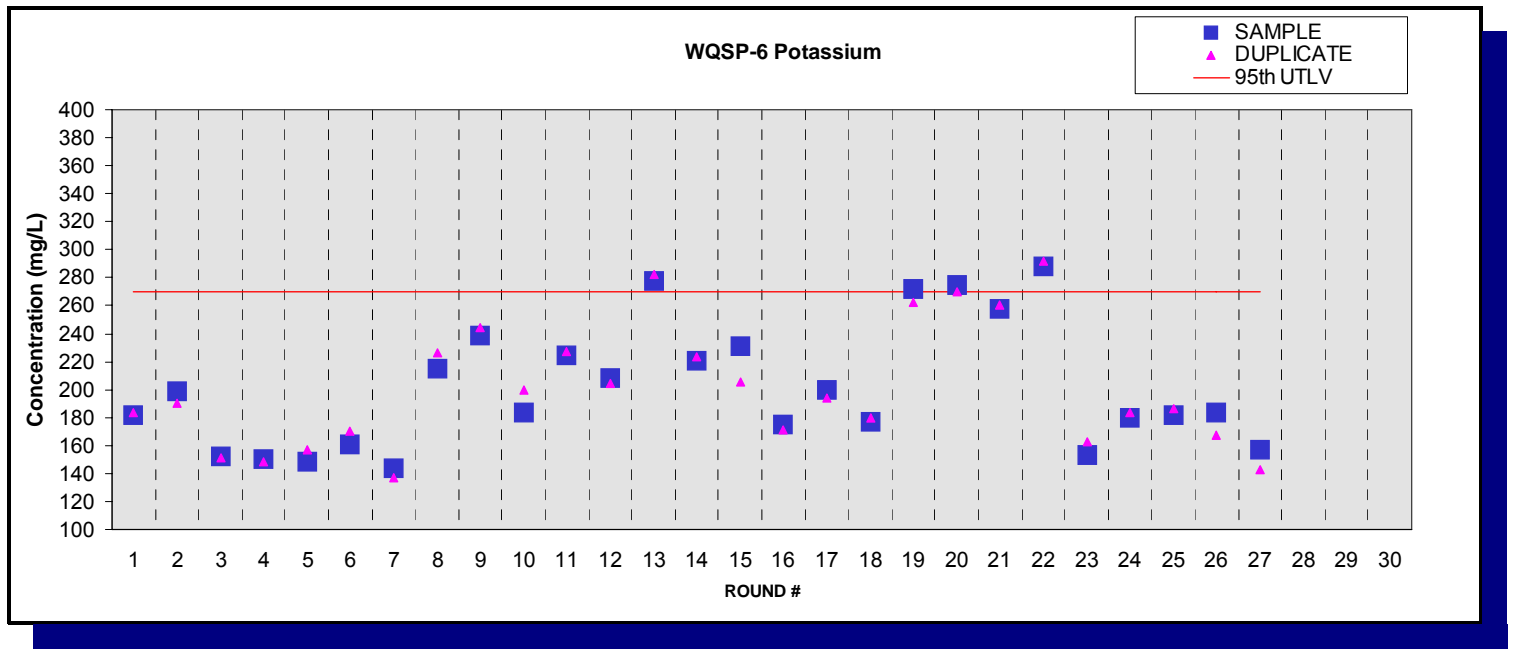

Figure E.77 - Time Trend Plot for Potassium at WQSP-6 
Waste Isolation Pilot Plant Annual Site Environmental Report for 2008 DOE/WIPP-09-2225

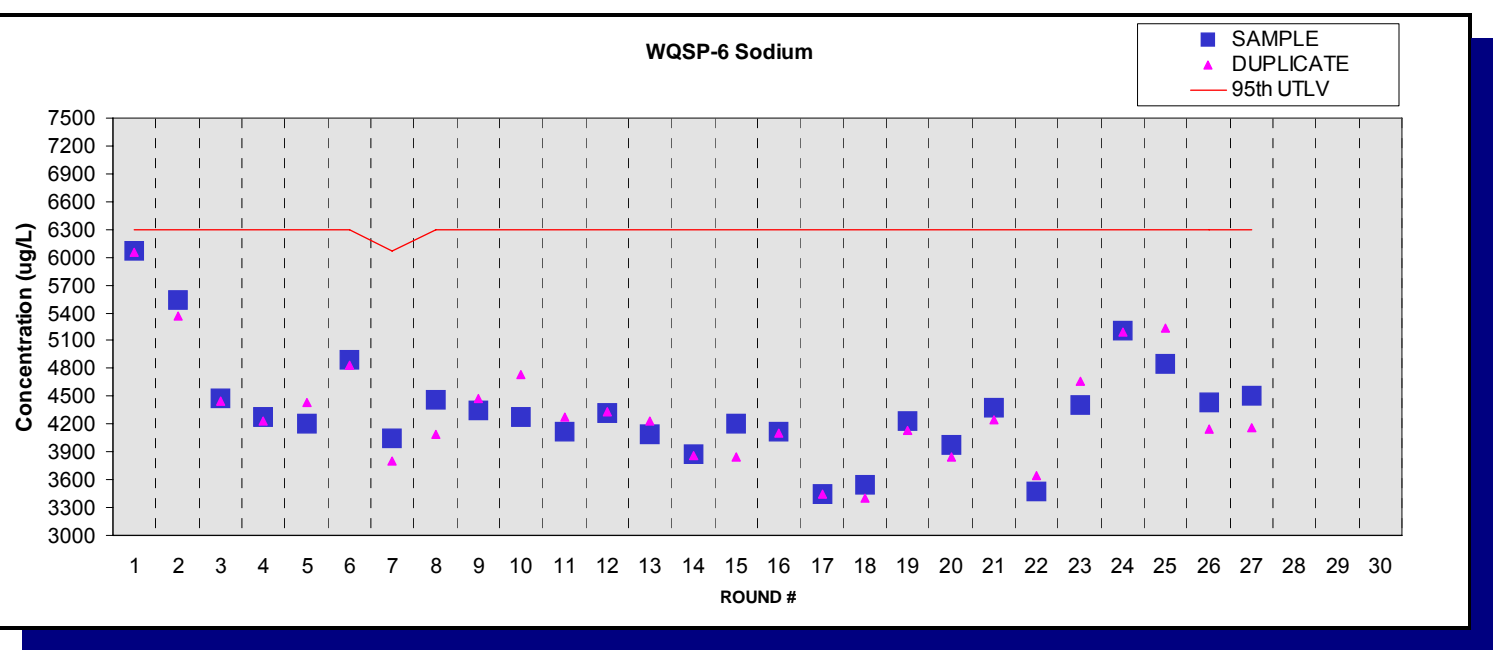

Figure E.78 - Time Trend Plot for Sodium at WQSP-6

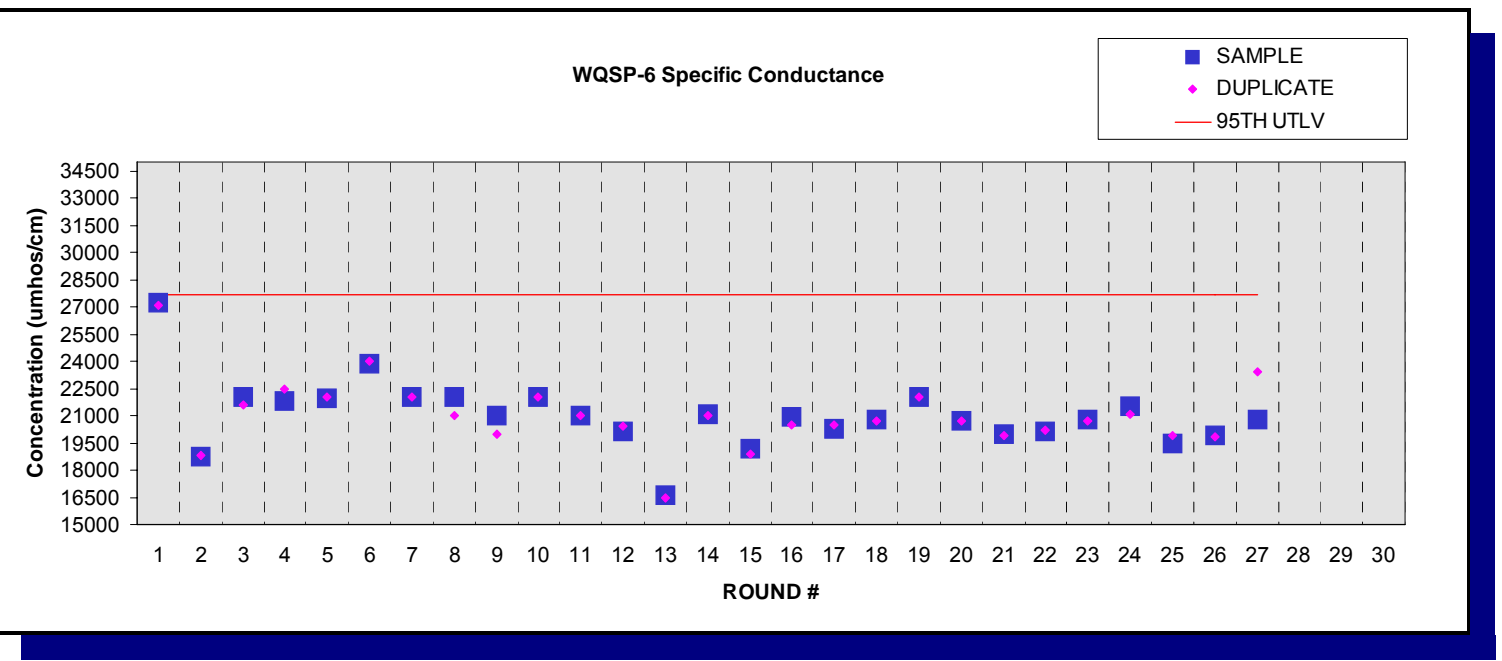

Figure E.79 - Time Trend Plot for Specific Conductance at WQSP-6

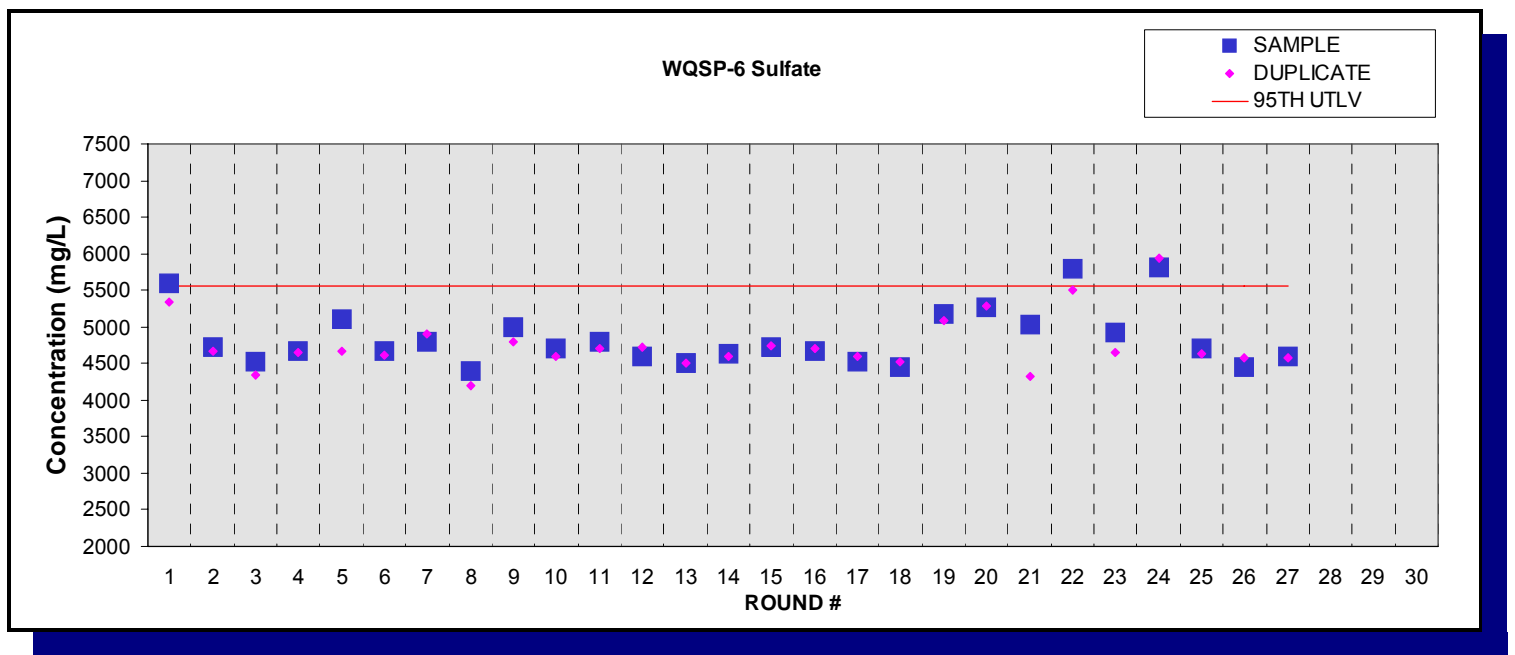

Figure E.80 - Time Trend Plot for Sulfate at WQSP-6 
Waste Isolation Pilot Plant Annual Site Environmental Report for 2008 DOE/WIPP-09-2225

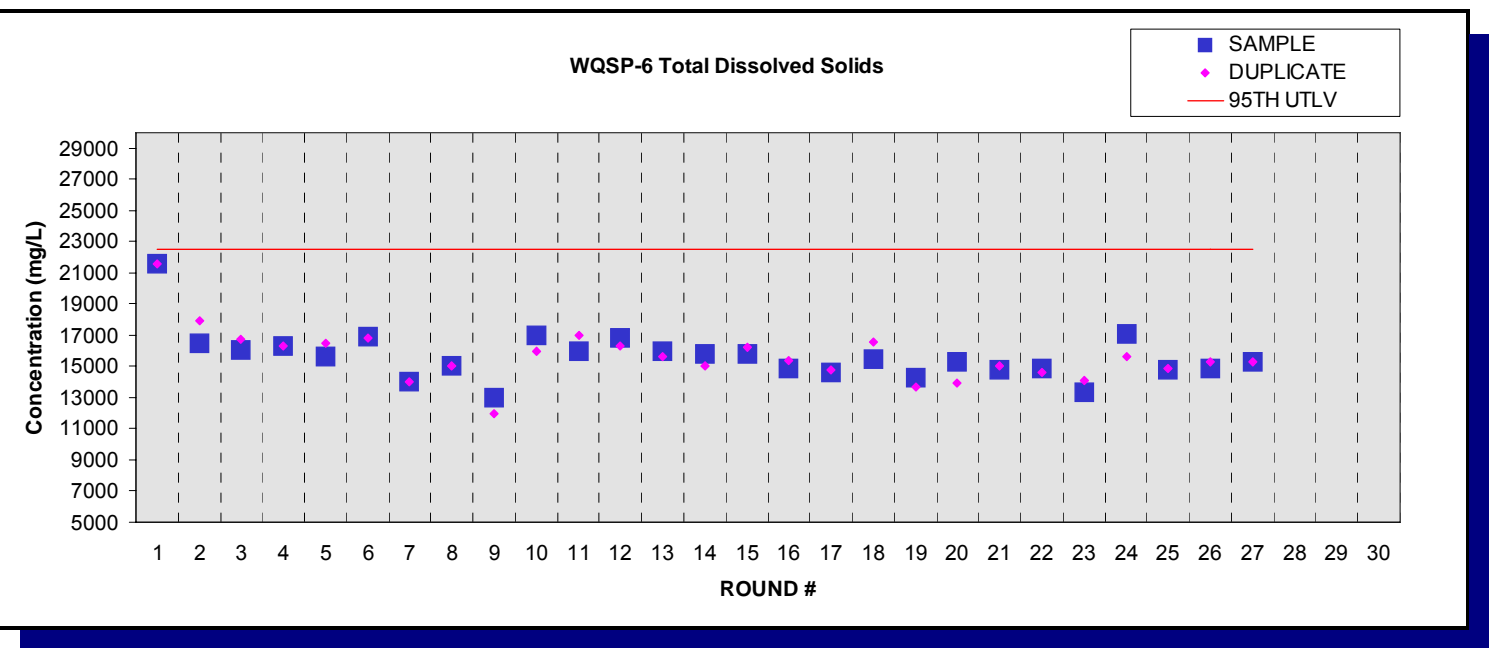

Figure E.81 - Time Trend Plot for Total Dissolved Solids at WQSP-6

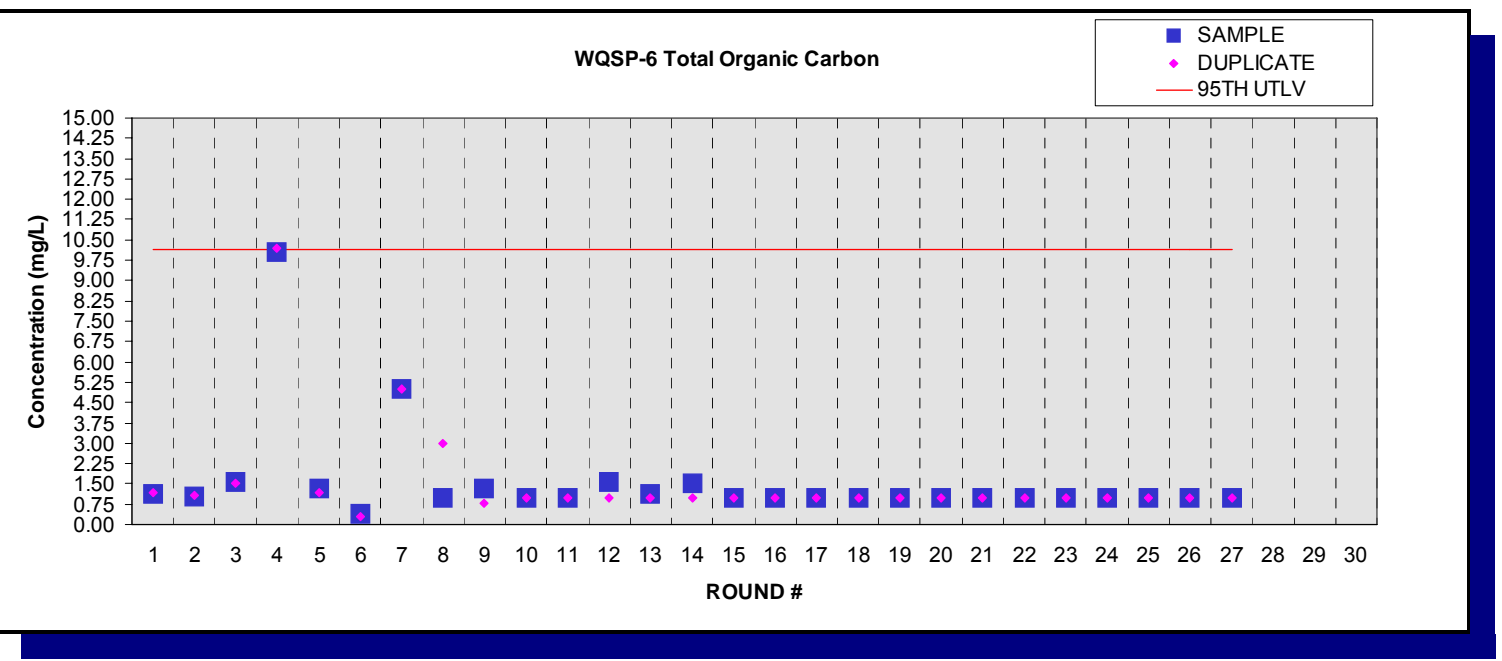

Figure E.82 - Time Trend Plot for Total Organic Carbon at WQSP-6

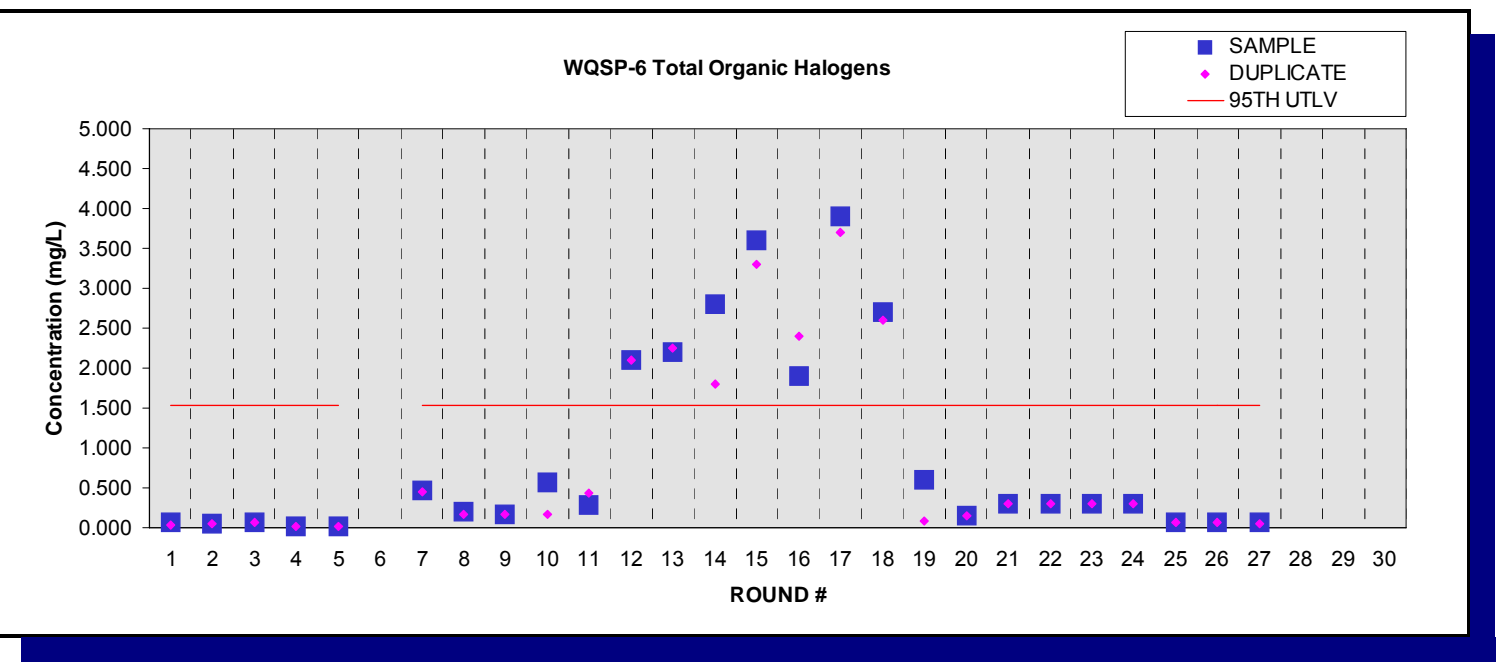

Figure E.83 - Time Trend Plot for Total Organic Halogens at WQSP-6 
Waste Isolation Pilot Plant Annual Site Environmental Report for 2008 DOE/WIPP-09-2225

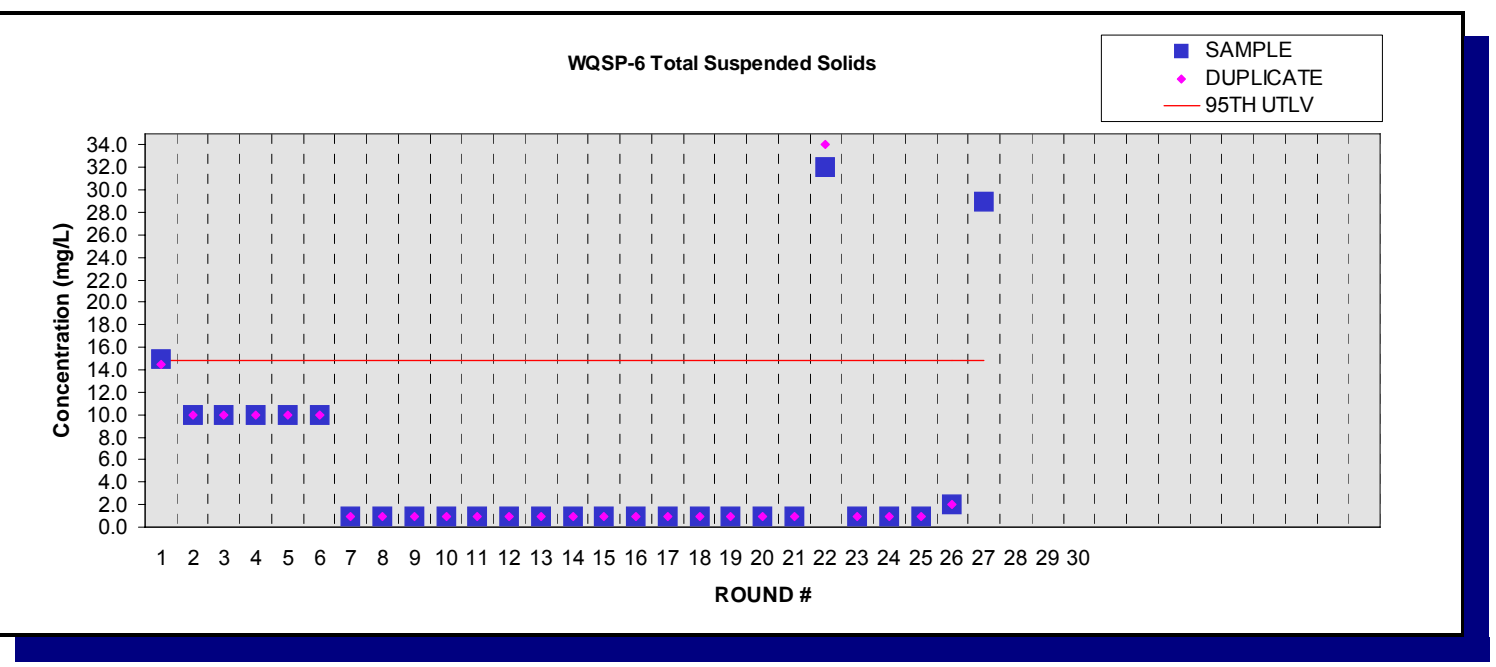

Figure E.84 - Time Trend Plot for Total Suspended Solids at WQSP-6

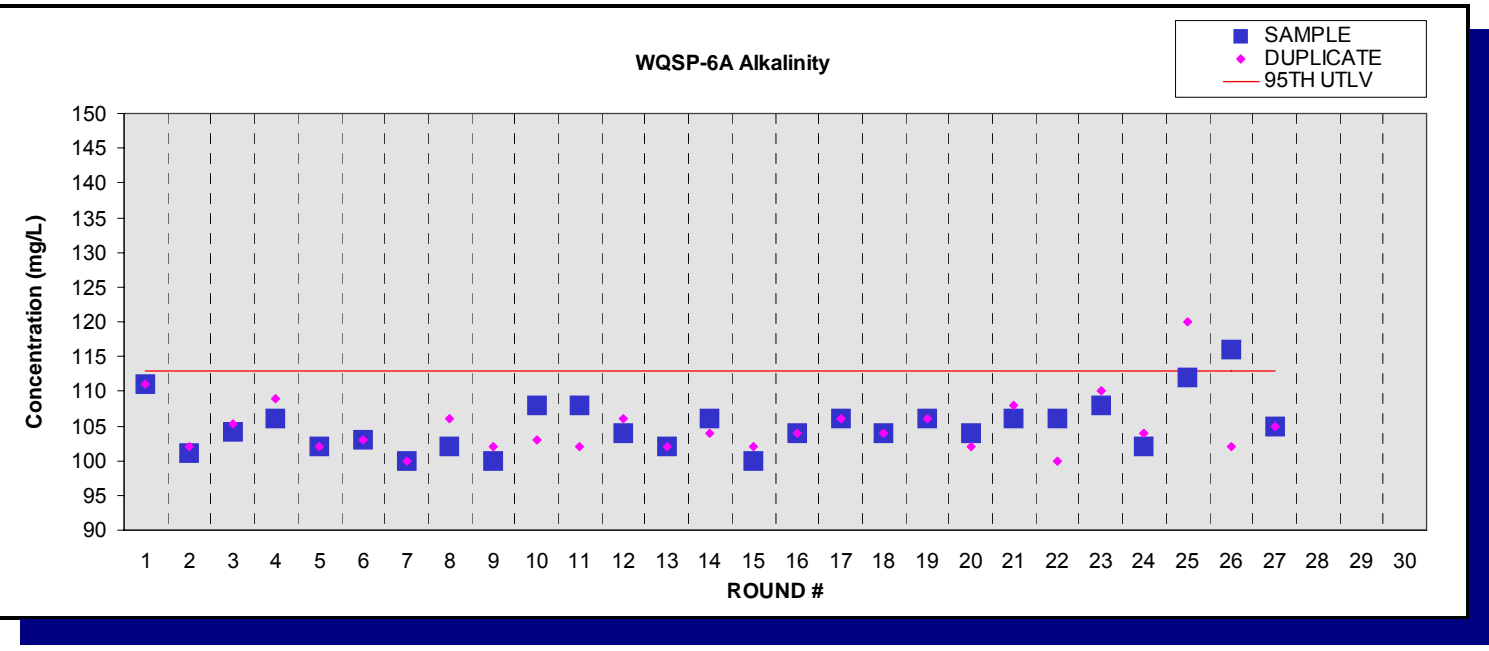

Figure E.85 - Time Trend Plot for Alkalinity at WQSP-6A

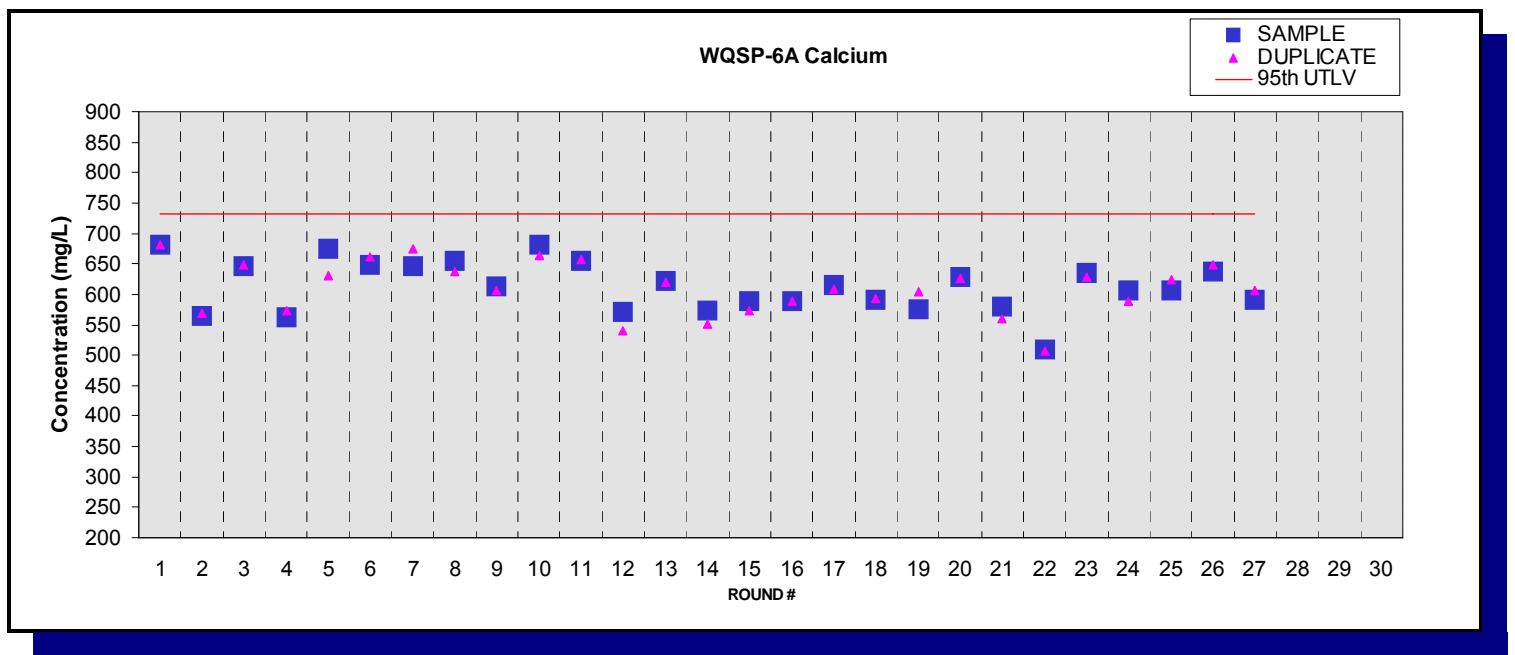

Figure E.86 - Time Trend Plot for Calcium at WQSP-6A 
Waste Isolation Pilot Plant Annual Site Environmental Report for 2008 DOE/WIPP-09-2225

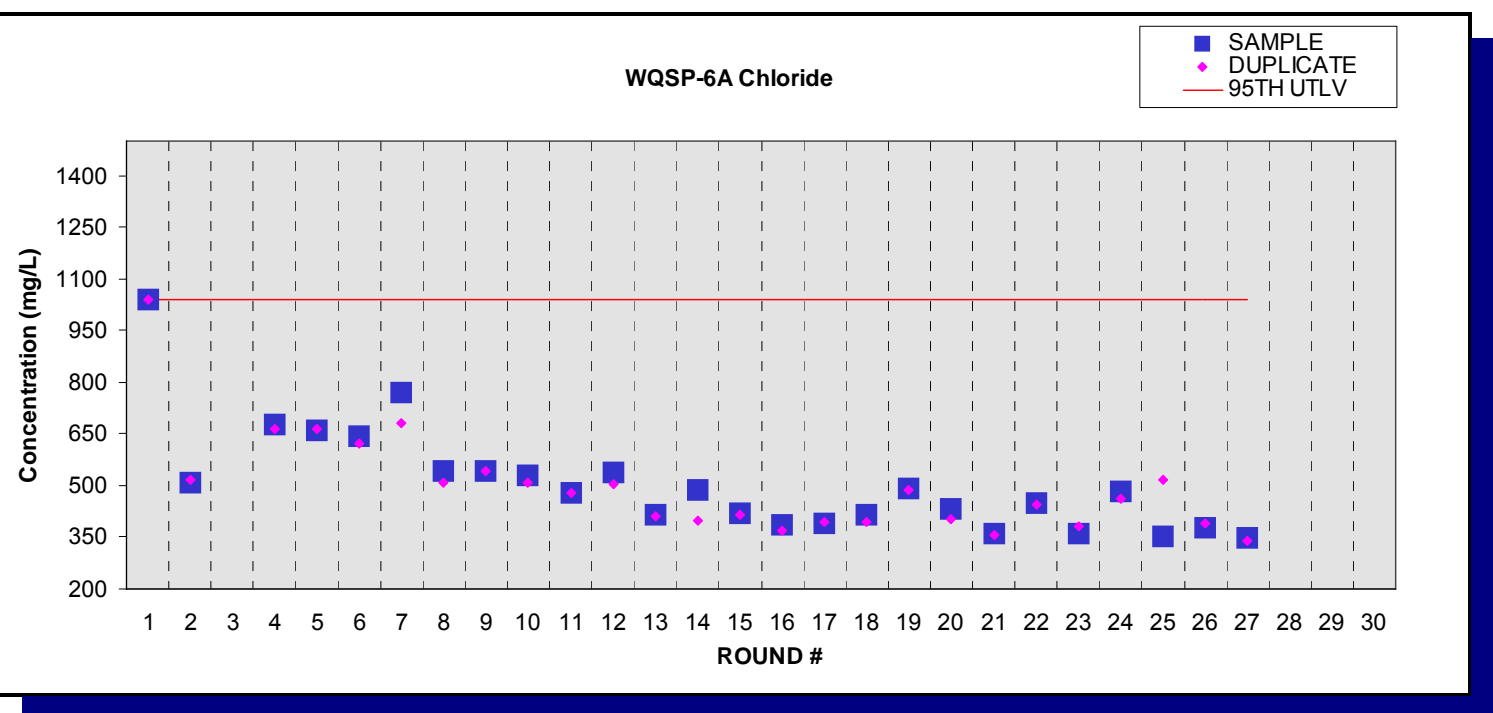

Figure E.87 - Time Trend Plot for Chloride at WQSP-6A

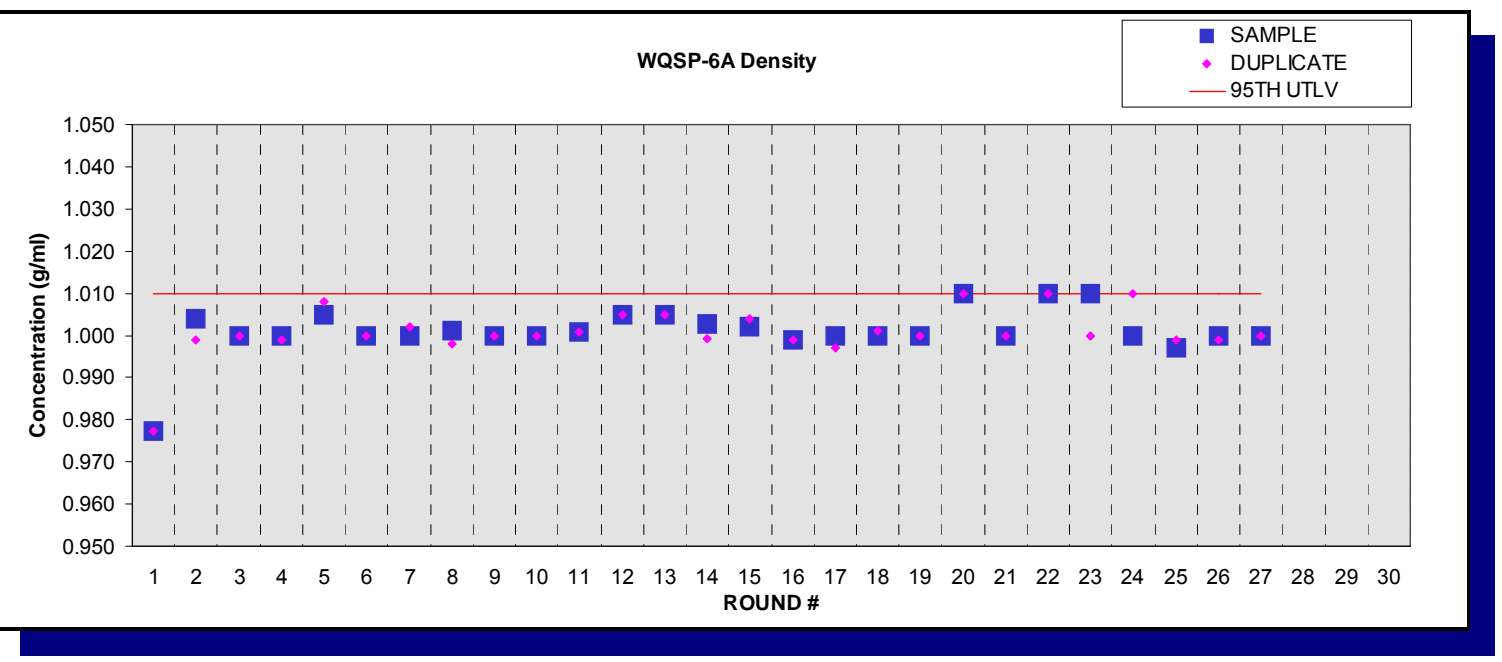

Figure E.88 - Time Trend Plot for Density at WQSP-6A

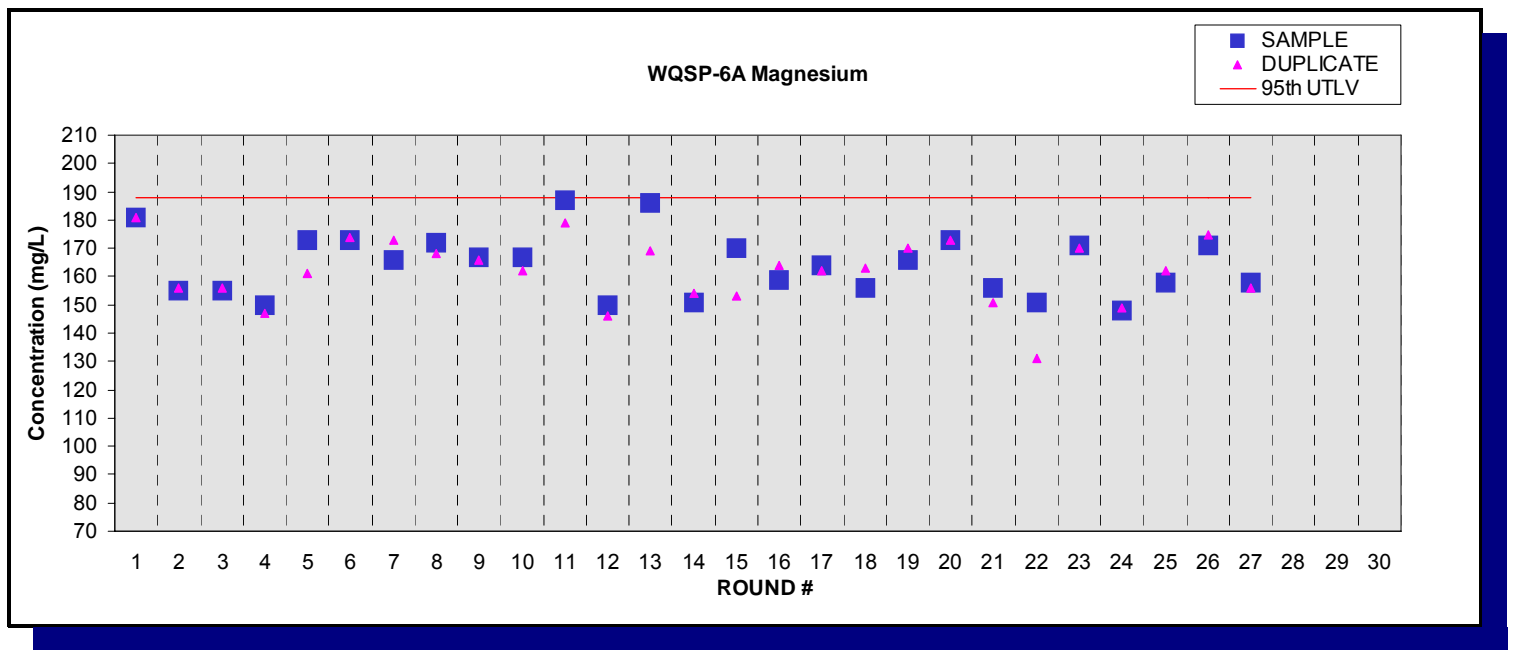

Figure E.89 - Time Trend Plot for Magnesium at WQSP-6A 
Waste Isolation Pilot Plant Annual Site Environmental Report for 2008 DOE/WIPP-09-2225

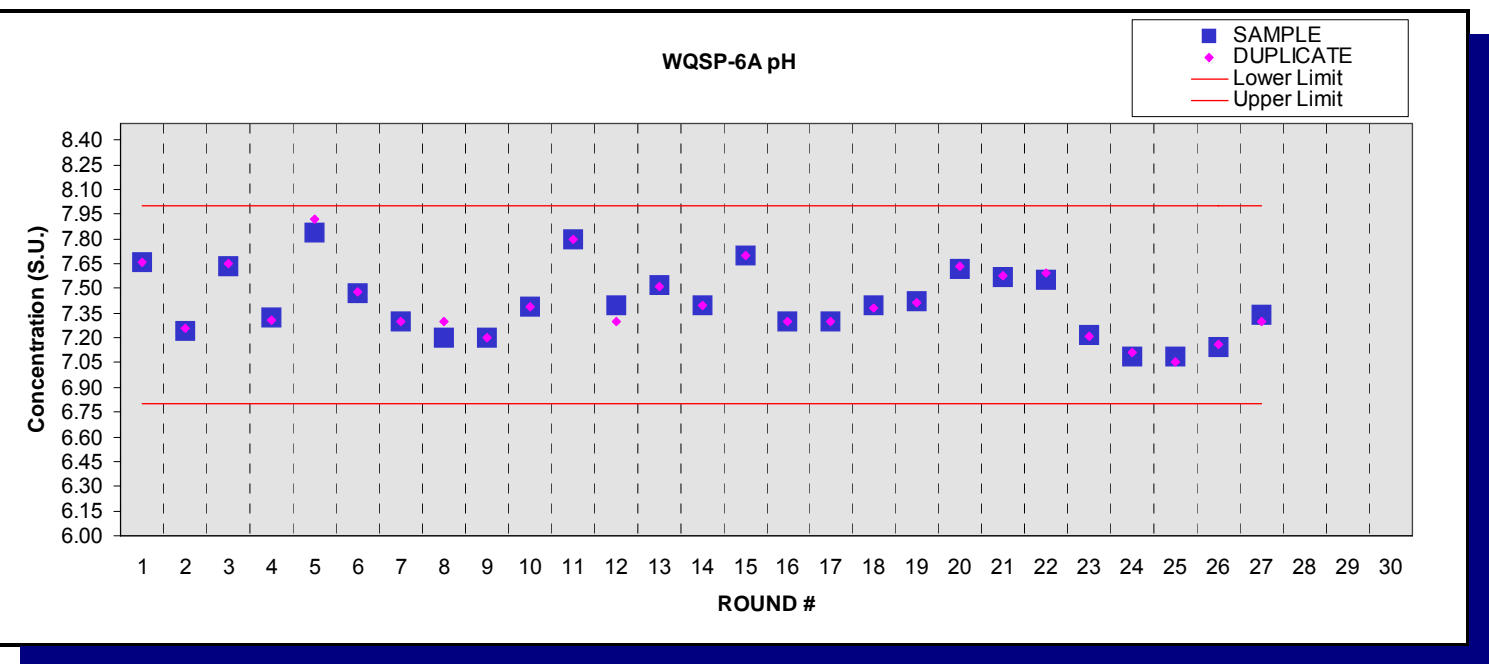

Figure E.90 - Time Trend Plot for $\mathrm{pH}$ at WQSP-6A

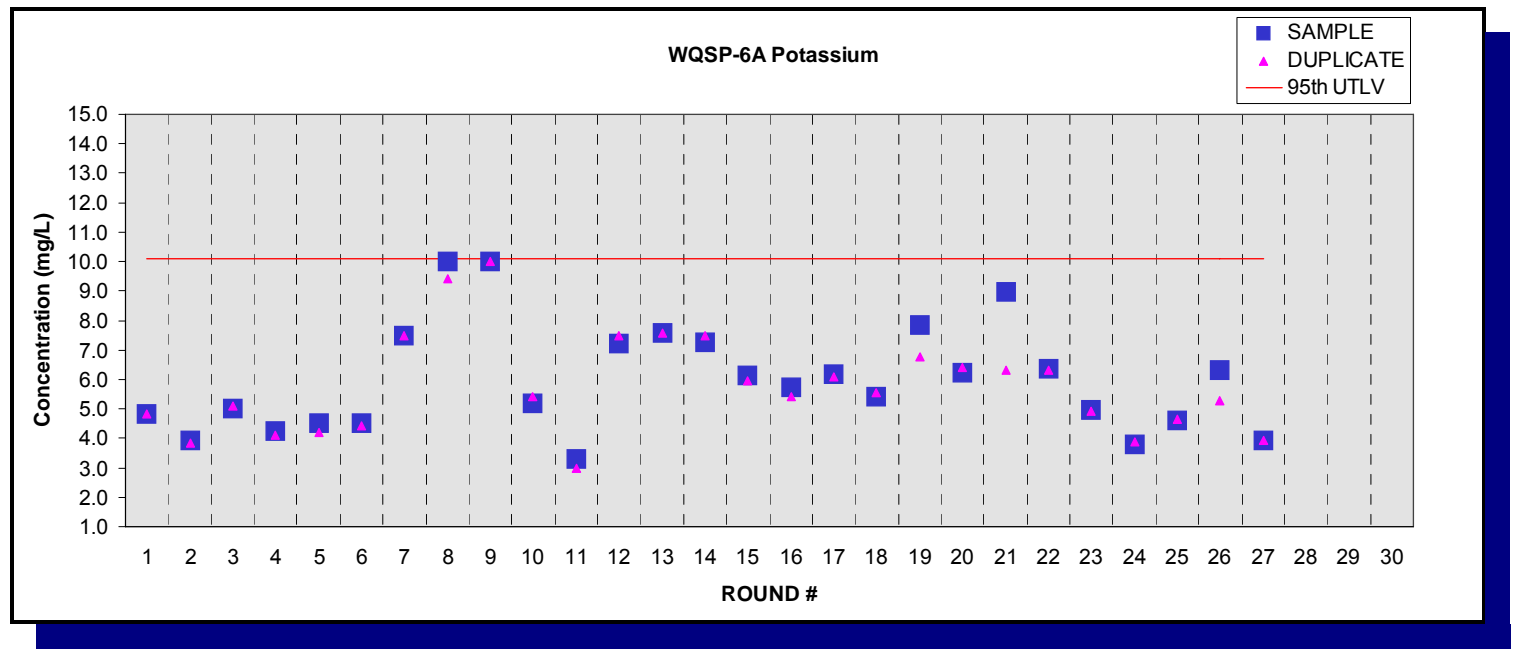

Figure E.91 - Time Trend Plot for Potassium at WQSP-6A

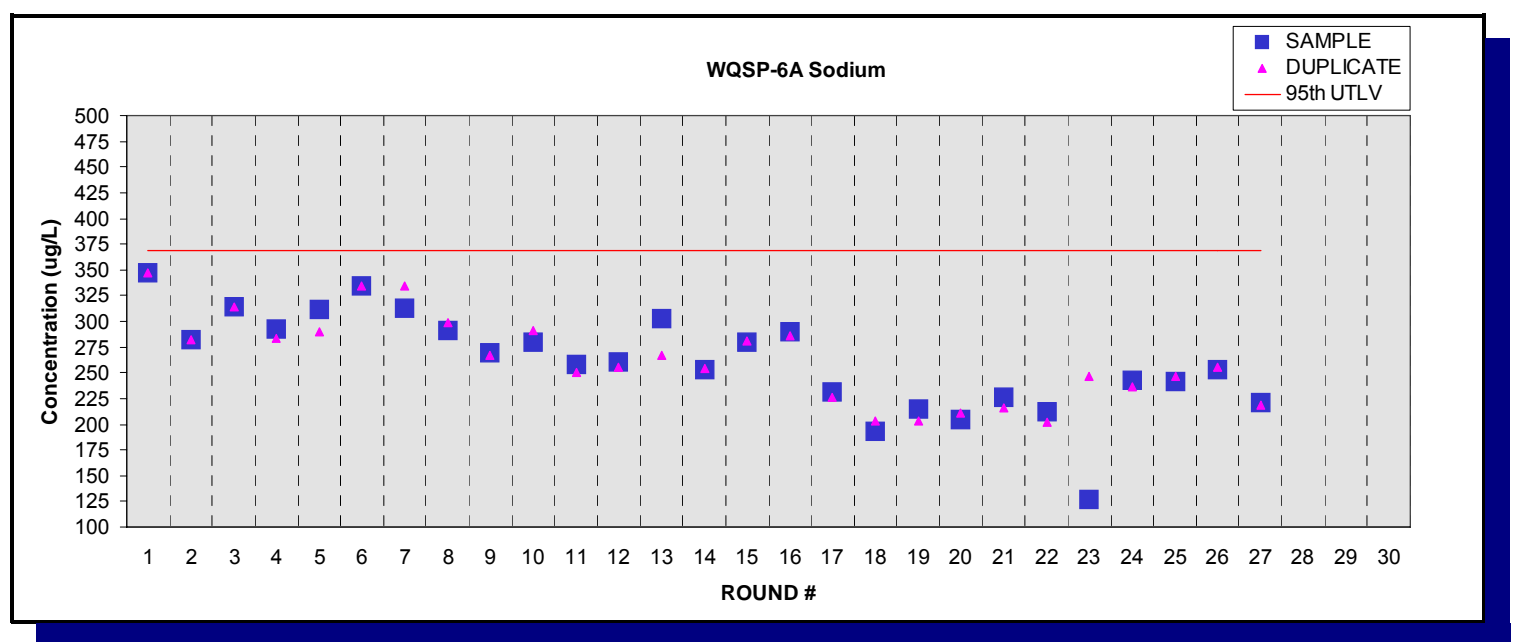

Figure E.92 - Time Trend Plot for Sodium at WQSP-6A 
Waste Isolation Pilot Plant Annual Site Environmental Report for 2008 DOE/WIPP-09-2225

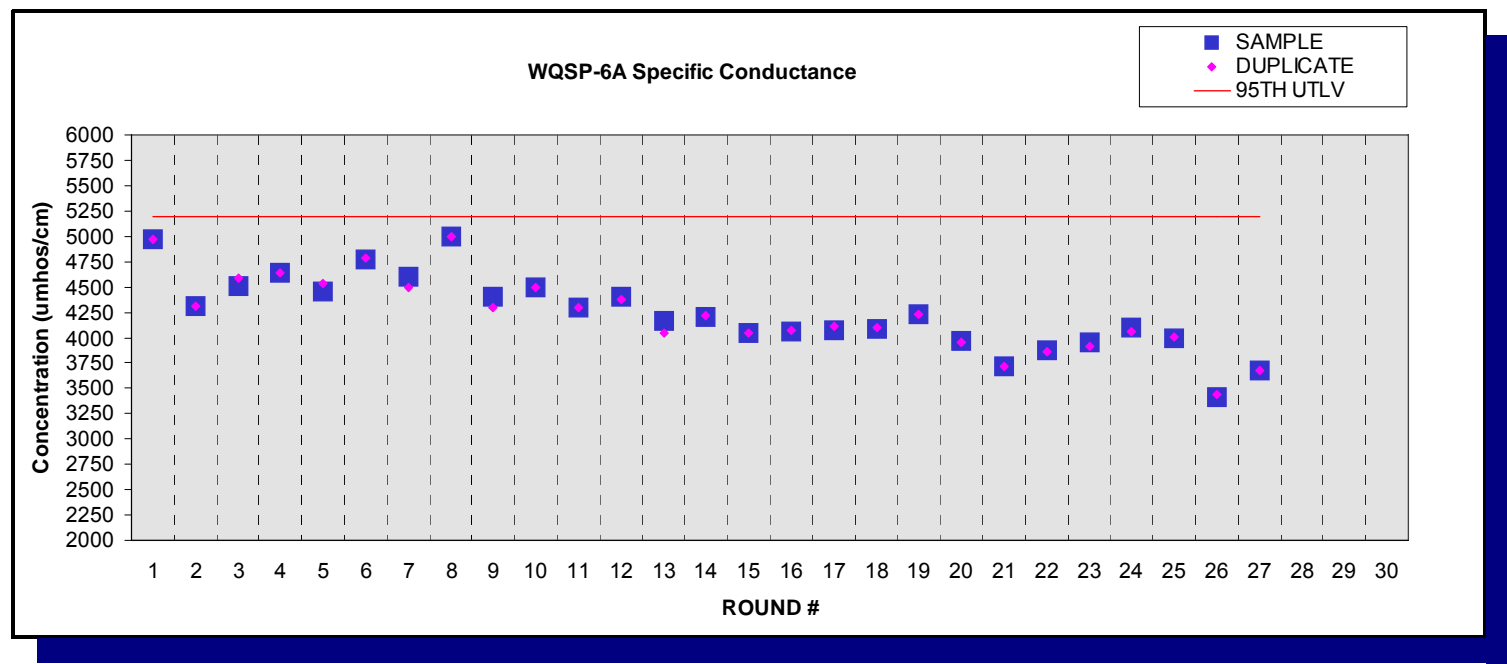

Figure E.93 - Time Trend Plot for Specific Conductance at WQSP-6A

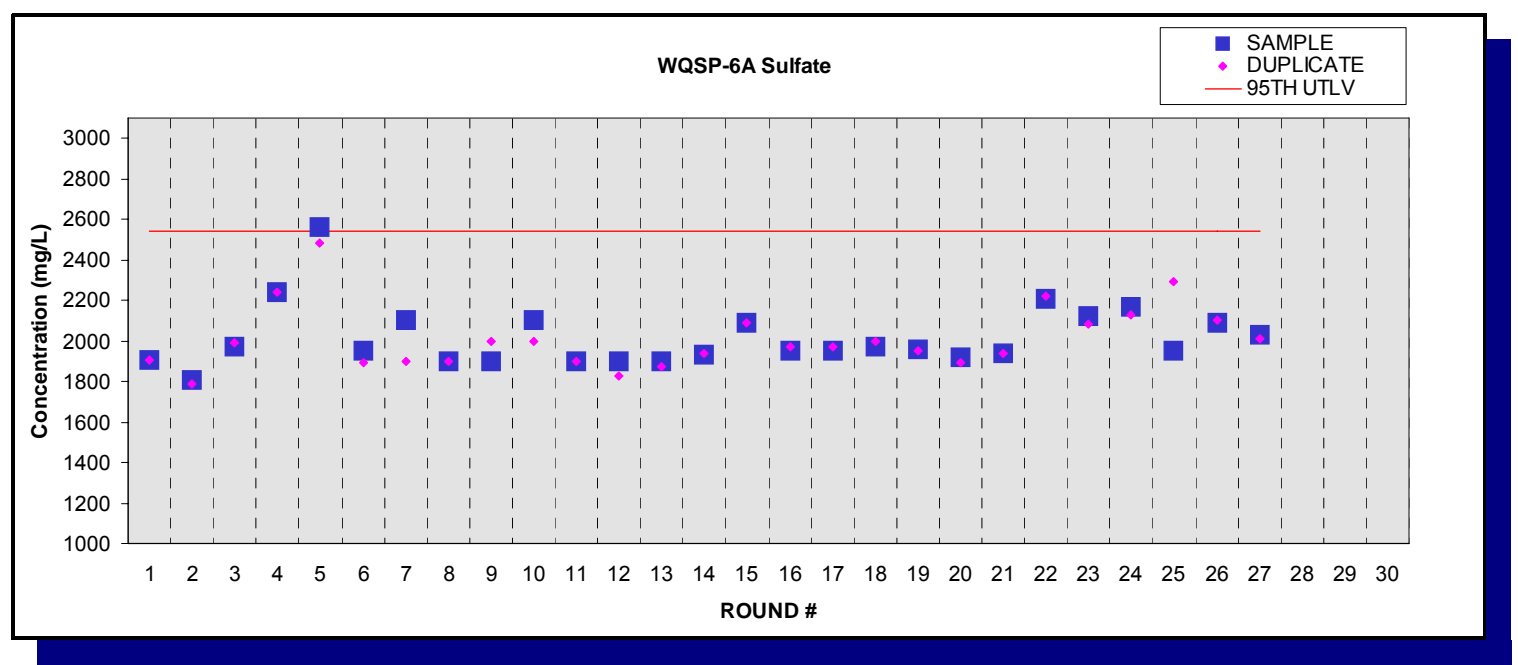

Figure E.94 - Time Trend Plot for Sulfate at WQSP-6A

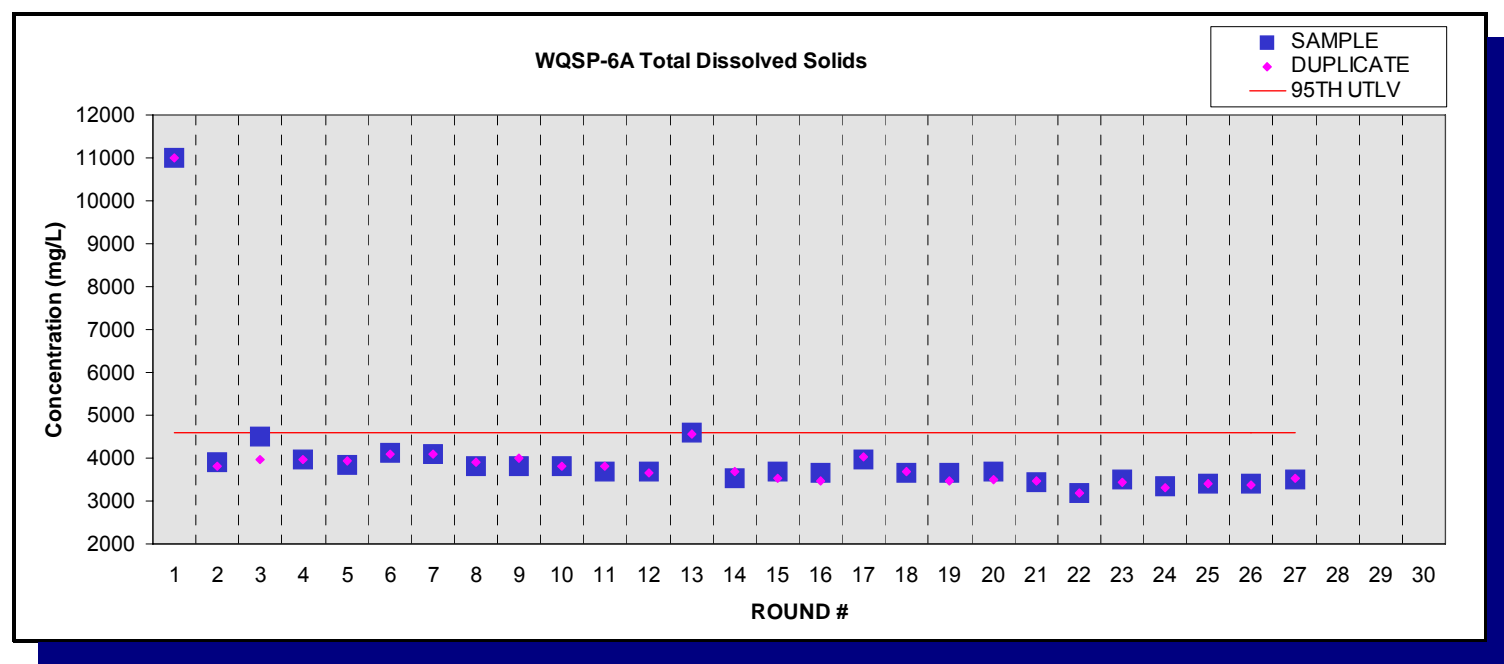

Figure E.95 - Time Trend Plot for Total Dissolved Solids at WQSP-6A 
Waste Isolation Pilot Plant Annual Site Environmental Report for 2008 DOE/WIPP-09-2225

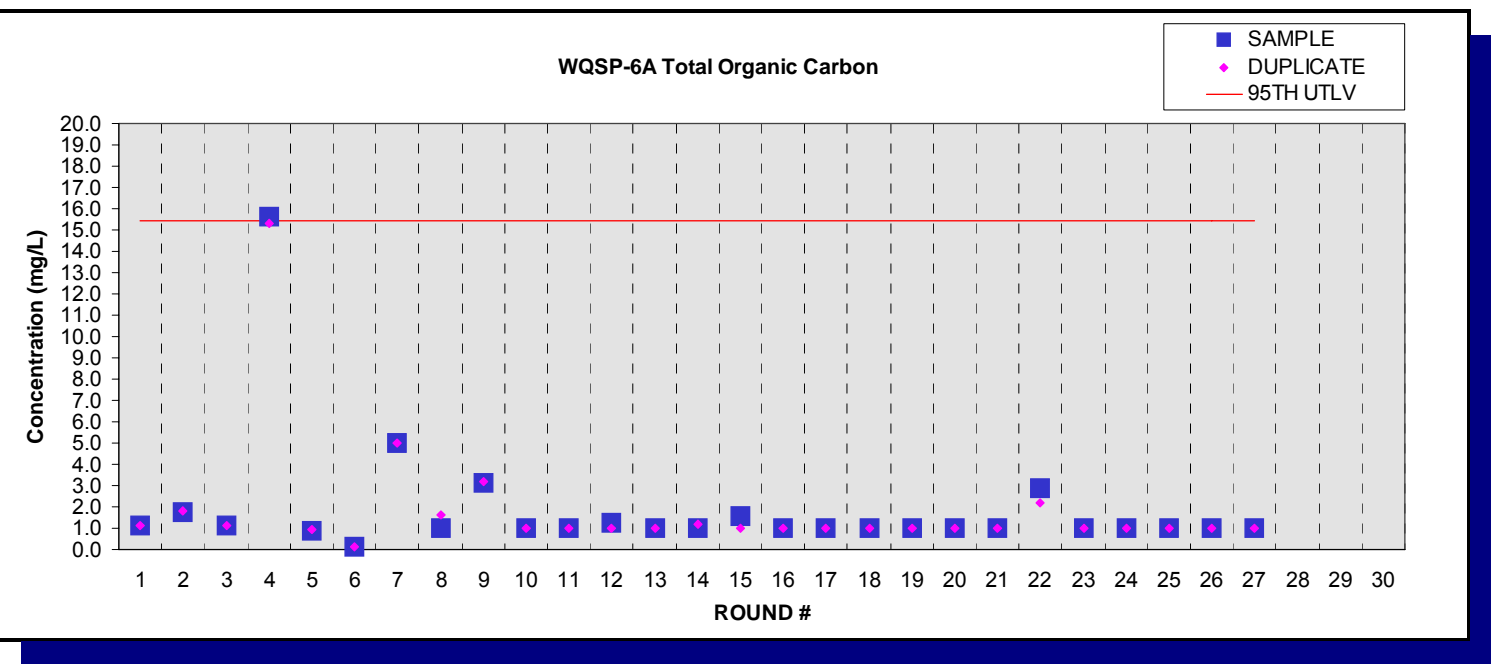

Figure E.96 - Time Trend Plot for Total Organic Carbon at WQSP-6A

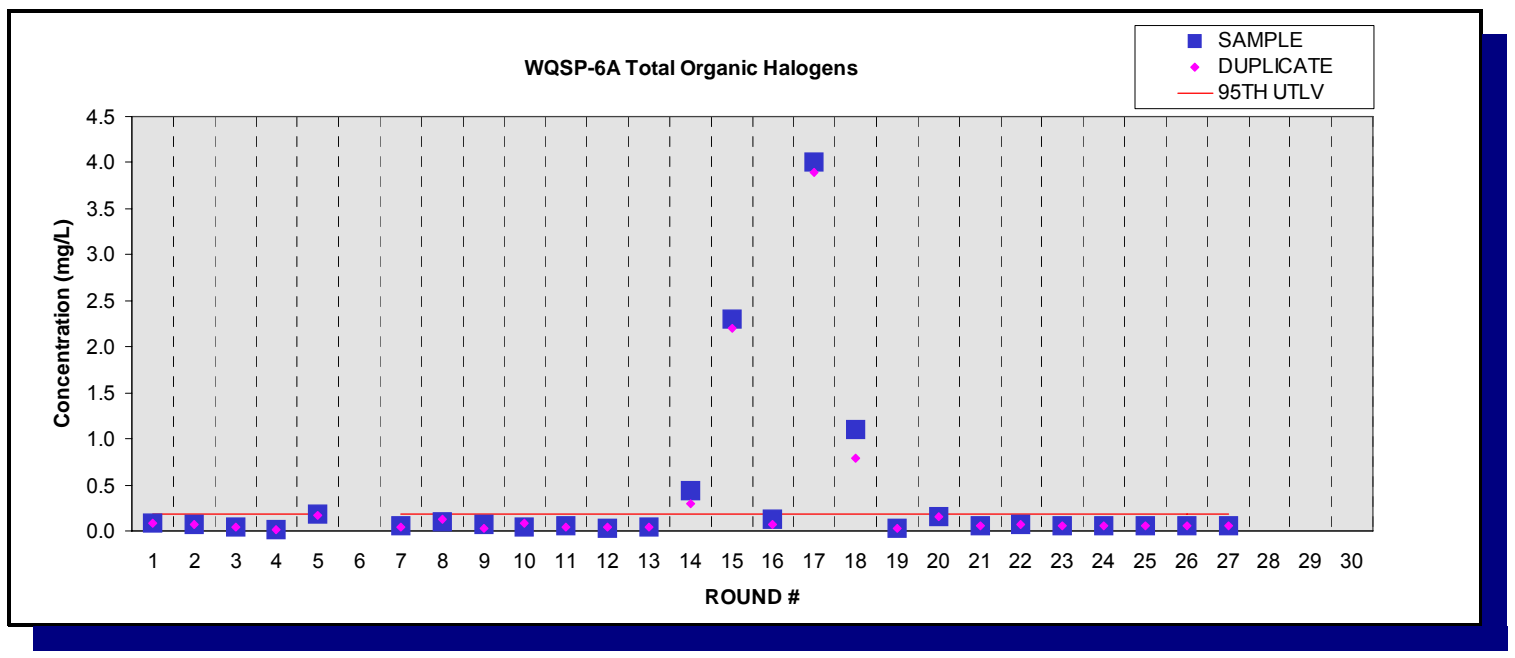

Figure E.97 - Time Trend Plot for Total Organic Halogens at WQSP-6A

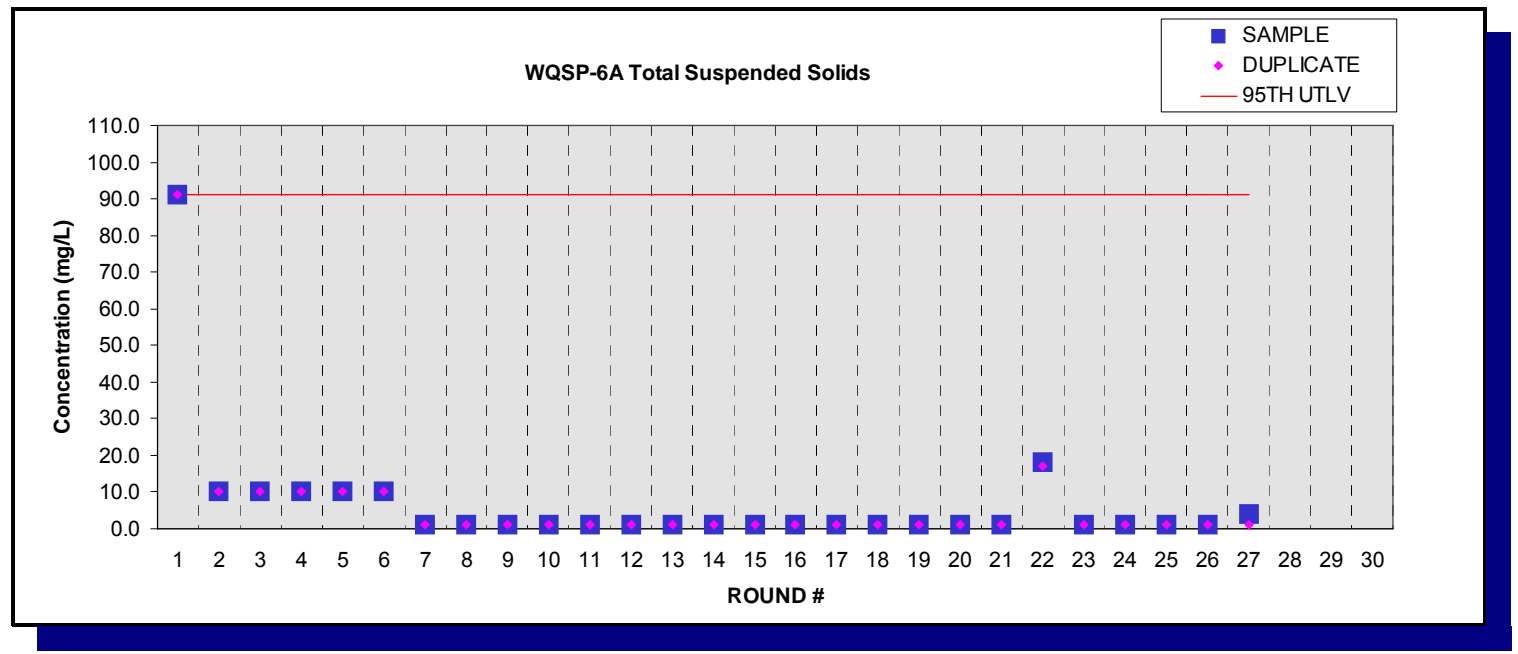

Figure E.98 - Time Trend Plot for Total Suspended Solids at WQSP-6A 
Waste Isolation Pilot Plant Annual Site Environmental Report for 2008

DOE/WIPP-09-2225

This page intentionally left blank 


\section{Appendix $F$ \\ Groundwater Data Tables}

\begin{tabular}{|c|c|c|c|c|c|c|c|c|}
\hline \multirow[b]{3}{*}{ Parameter } & \multicolumn{4}{|c|}{ Concentration, ug/L } & \multirow[b]{3}{*}{ Units } & \multirow{2}{*}{\multicolumn{2}{|c|}{ Reporting Limit }} & \multirow[b]{3}{*}{$\begin{array}{l}95^{\text {th }} \\
\text { UTLV }^{\text {a }}\end{array}$} \\
\hline & \multicolumn{2}{|c|}{ Round 26} & \multicolumn{2}{|c|}{ Round 27} & & & & \\
\hline & Sample & Dup. & Sample & Dup. & & $\begin{array}{l}\text { Round } \\
26\end{array}$ & $\begin{array}{c}\text { Round } \\
27\end{array}$ & \\
\hline 1,1,1-Trichloroethane & $<1$ & $<1$ & $<1$ & $<1$ & $\mu g / L$ & 1 & 1 & $<\mathrm{RL}^{\mathrm{b}}$ \\
\hline 1,1,2,2-Tetrachloroethane & $<1$ & $<1$ & $<1$ & $<1$ & $\mu \mathrm{g} / \mathrm{L}$ & 1 & 1 & $<R L$ \\
\hline 1,1,2-Trichloroethane & $<1$ & $<1$ & $<1$ & $<1$ & $\mu \mathrm{g} / \mathrm{L}$ & 1 & 1 & $<\mathrm{RL}$ \\
\hline 1,1-Dichloroethane & $<1$ & $<1$ & $<1$ & $<1$ & $\mu \mathrm{g} / \mathrm{L}$ & 1 & 1 & $<\mathrm{RL}$ \\
\hline 1,1-Dichloroethylene & $<1$ & $<1$ & $<1$ & $<1$ & $\mu \mathrm{g} / \mathrm{L}$ & 1 & 1 & $<\mathrm{RL}$ \\
\hline 1,2-Dichloroethane & $<1$ & $<1$ & $<1$ & $<1$ & $\mu \mathrm{g} / \mathrm{L}$ & 1 & 1 & $<\mathrm{RL}$ \\
\hline Carbon tetrachloride & $<1$ & $<1$ & $<1$ & $<1$ & $\mu g / L$ & 1 & 1 & $<\mathrm{RL}$ \\
\hline Chlorobenzene & $<1$ & $<1$ & $<1$ & $<1$ & $\mu \mathrm{g} / \mathrm{L}$ & 1 & 1 & $<\mathrm{RL}$ \\
\hline Chloroform & $<1$ & $<1$ & $<1$ & $<1$ & $\mu \mathrm{g} / \mathrm{L}$ & 1 & 1 & $<\mathrm{RL}$ \\
\hline cis-1,2-Dichloroethylene & $<1$ & $<1$ & $<1$ & $<1$ & $\mu \mathrm{g} / \mathrm{L}$ & 1 & 1 & $<\mathrm{RL}$ \\
\hline trans-1, 2-Dichloroethylene & $<1$ & $<1$ & $<1$ & $<1$ & $\mu \mathrm{g} / \mathrm{L}$ & 1 & 1 & $<\mathrm{RL}$ \\
\hline Methyl ethyl ketone & $<5$ & $<5$ & $<5$ & $<5$ & $\mu \mathrm{g} / \mathrm{L}$ & 5 & 5 & $<\mathrm{RL}$ \\
\hline Methylene chloride & $<5$ & $<5$ & $<5$ & $<5$ & $\mu \mathrm{g} / \mathrm{L}$ & 5 & 5 & $<\mathrm{RL}$ \\
\hline Tetrachloroethylene & $<1$ & $<1$ & $<1$ & $<1$ & $\mu \mathrm{g} / \mathrm{L}$ & 1 & 1 & $<\mathrm{RL}$ \\
\hline Toluene & $<1$ & $<1$ & $<1$ & $<1$ & $\mu \mathrm{g} / \mathrm{L}$ & 1 & 1 & $<\mathrm{RL}$ \\
\hline Trichloroethylene & $<1$ & $<1$ & $<1$ & $<1$ & $\mu \mathrm{g} / \mathrm{L}$ & 1 & 1 & $<\mathrm{RL}$ \\
\hline Trichlorofluoromethane & $<1$ & $<1$ & $<1$ & $<1$ & $\mu \mathrm{g} / \mathrm{L}$ & 1 & 1 & $<\mathrm{RL}$ \\
\hline Vinyl chloride & $<1$ & $<1$ & $<1$ & $<1$ & $\mu \mathrm{g} / \mathrm{L}$ & 1 & 1 & $<\mathrm{RL}$ \\
\hline Xylene & $<1$ & $<1$ & $<1$ & $<1$ & $\mu \mathrm{g} / \mathrm{L}$ & 1 & 1 & $<\mathrm{RL}$ \\
\hline 1,2-Dichlorobenzene & $<5$ & $<5$ & $<5$ & $<5$ & $\mu \mathrm{g} / \mathrm{L}$ & 5 & 5 & $<\mathrm{RL}$ \\
\hline 1,4-Dichlorobenzene & $<5$ & $<5$ & $<5$ & $<5$ & $\mu \mathrm{g} / \mathrm{L}$ & 5 & 5 & $<\mathrm{RL}$ \\
\hline 2,4-Dinitrophenol & $<5$ & $<5$ & $<5$ & $<5$ & $\mu \mathrm{g} / \mathrm{L}$ & 5 & 5 & $<\mathrm{RL}$ \\
\hline 2,4-Dinitrotoluene & $<5$ & $<5$ & $<5$ & $<5$ & $\mu \mathrm{g} / \mathrm{L}$ & 5 & 5 & $<R L$ \\
\hline 2-Methylphenol & $<5$ & $<5$ & $<5$ & $<5$ & $\mu \mathrm{g} / \mathrm{L}$ & 5 & 5 & $<\mathrm{RL}$ \\
\hline $\begin{array}{l}\text { 3-Methylphenol/ } \\
\text { 4-Methylphenol }\end{array}$ & $<5$ & $<5$ & $<5$ & $<5$ & $\mu \mathrm{g} / \mathrm{L}$ & 5 & 5 & $<\mathrm{RL}$ \\
\hline Hexachlorobenzene & $<5$ & $<5$ & $<5$ & $<5$ & $\mu \mathrm{g} / \mathrm{L}$ & 5 & 5 & $<\mathrm{RL}$ \\
\hline Hexachloroethane & $<5$ & $<5$ & $<5$ & $<5$ & $\mu \mathrm{g} / \mathrm{L}$ & 5 & 5 & $<\mathrm{RL}$ \\
\hline Nitrobenzene & $<5$ & $<5$ & $<5$ & $<5$ & $\mu \mathrm{g} / \mathrm{L}$ & 5 & 5 & $<\mathrm{RL}$ \\
\hline Pentachlorophenol & $<5$ & $<5$ & $<5$ & $<5$ & $\mu \mathrm{g} / \mathrm{L}$ & 5 & 5 & $<\mathrm{RL}$ \\
\hline Pyridine & $<5$ & $<5$ & $<5$ & $<5$ & $\mu \mathrm{g} / \mathrm{L}$ & 5 & 5 & $<\mathrm{RL}$ \\
\hline Isobutanol & $<5$ & $<5$ & $<5$ & $<5$ & $\mu \mathrm{g} / \mathrm{L}$ & 5 & 5 & $<\mathrm{RL}$ \\
\hline Alkalinity & 50 & 50 & 50 & 50 & $\mathrm{mg} / \mathrm{L}$ & 4 & 4 & 55.7 \\
\hline Chloride & 37,000 & 37,800 & 40,500 & 36,000 & $\mathrm{mg} / \mathrm{L}$ & 0.5 & 0.5 & 40,472 \\
\hline Density & 1.05 & 1.05 & 1.050 & 1.049 & $\mathrm{~g} / \mathrm{ml}$ & $N / A^{d}$ & $N / A^{d}$ & 1.072 \\
\hline Nitrate (as N) & $<0.1$ & $<0.1$ & 0.53 & 0.53 & $\mathrm{mg} / \mathrm{L}$ & 0.1 & 0.1 & 10 \\
\hline $\mathrm{pH}$ & 6.87 & 6.90 & 7.09 & 7.10 & $S U^{c}$ & $N / A^{d}$ & $N / A^{d}$ & $5.6-6.8$ \\
\hline Specific conductance & 96,500 & 92,800 & 109,000 & 109,000 & $\mu \mathrm{mhos} / \mathrm{cm}$ & $\mathrm{N} / \mathrm{A}$ & $\mathrm{N} / \mathrm{A}$ & 175,000 \\
\hline Sulfate & 5,470 & 5,560 & 4,490 & 4,570 & $\mathrm{mg} / \mathrm{L}$ & 0.5 & 0.5 & 5,757 \\
\hline Total dissolved solids & 68,200 & 68,400 & 64,700 & 63,100 & $\mathrm{mg} / \mathrm{L}$ & 10 & 10 & 80,700 \\
\hline Total organic carbon & $<1$ & $<1$ & $<1$ & $<1$ & $\mathrm{mg} / \mathrm{L}$ & 1 & 1 & $<5.0$ \\
\hline
\end{tabular}




\begin{tabular}{|c|c|c|c|c|c|c|c|c|}
\hline \multirow[b]{3}{*}{ Parameter } & \multicolumn{4}{|c|}{ Concentration, ug/L } & \multirow[b]{3}{*}{ Units } & & & \multirow[b]{3}{*}{$\begin{array}{c}95^{\text {th }} \\
\text { UTLV }\end{array}$} \\
\hline & \multicolumn{2}{|c|}{ Round 26} & \multicolumn{2}{|c|}{ Round 27} & & \multicolumn{2}{|c|}{ Reporting Limit } & \\
\hline & Sample & Dup. & Sample & Dup. & & $\begin{array}{c}\text { Round } \\
26\end{array}$ & $\begin{array}{c}\text { Round } \\
27\end{array}$ & \\
\hline Total organic halogen & $<0.6$ & $<0.6$ & 0.12 & 0.18 & $\mathrm{mg} / \mathrm{L}$ & 0.6 & 0.1 & 14.6 \\
\hline Total suspended solids & 13.5 & 8.0 & $<5$ & $<5$ & $\mathrm{mg} / \mathrm{L}$ & 1 & 5 & 33.3 \\
\hline Antimony & $<0.025$ & $<0.025$ & $<0.02$ & $<0.02$ & $\mathrm{mg} / \mathrm{L}$ & 0.025 & 0.02 & 0.33 \\
\hline Arsenic & $<0.05$ & $<0.05$ & $<0.02$ & $<0.02$ & $\mathrm{mg} / \mathrm{L}$ & 0.05 & 0.02 & 0.1 \\
\hline Barium & 0.034 & 0.037 & 0.034 & 0.038 & $\mathrm{mg} / \mathrm{L}$ & 0.02 & 0.02 & 1 \\
\hline Beryllium & $<0.01$ & $<0.01$ & $<0.01$ & $<0.01$ & $\mathrm{mg} / \mathrm{L}$ & 0.01 & 0.01 & 0.02 \\
\hline Cadmium & $<0.01$ & $<0.01$ & $<0.01$ & $<0.01$ & $\mathrm{mg} / \mathrm{L}$ & 0.01 & 0.01 & 0.2 \\
\hline Calcium & 1,890 & 1,800 & 1,490 & 1,540 & $\mathrm{mg} / \mathrm{L}$ & 0.5 & 0.5 & 2,087 \\
\hline Chromium & $<0.025$ & $<0.025$ & $<0.025$ & $<0.025$ & $\mathrm{mg} / \mathrm{L}$ & 0.025 & 0.058 & 0.5 \\
\hline Iron & $<0.5$ & $<0.5$ & $<0.5$ & $<0.5$ & $\mathrm{mg} / \mathrm{L}$ & 0.5 & 0.5 & 0.91 \\
\hline Lead & $<0.02$ & $<0.02$ & $<0.02$ & $<0.02$ & $\mathrm{mg} / \mathrm{L}$ & 0.02 & 0.02 & 0.105 \\
\hline Magnesium & 1,220 & 1,160 & 989 & 1,020 & $\mathrm{mg} / \mathrm{L}$ & 0.5 & 0.5 & 1,247 \\
\hline Mercury & $<0.0002$ & $<0.0002$ & $<0.0002$ & $<0.0002$ & $\mathrm{mg} / \mathrm{L}$ & 0.0002 & 0.0002 & 0.002 \\
\hline Nickel & $<0.025$ & $<0.025$ & $<0.025$ & $<0.025$ & $\mathrm{mg} / \mathrm{L}$ & 0.025 & 0.025 & 0.49 \\
\hline Potassium & 767 & 701 & 477 & 475 & $\mathrm{mg} / \mathrm{L}$ & 0.5 & 0.5 & 799 \\
\hline Selenium & $<0.025$ & $<0.025$ & $<0.02$ & $<0.02$ & $\mathrm{mg} / \mathrm{L}$ & 0.025 & 0.02 & 0.15 \\
\hline Silver & $<0.025$ & $<0.025$ & $<0.013$ & $<0.013$ & $\mathrm{mg} / \mathrm{L}$ & 0.013 & 0.023 & 0.5 \\
\hline Sodium & 23,500 & 23,600 & 18,000 & 17,800 & $\mathrm{mg} / \mathrm{L}$ & 0.5 & 0.5 & 22,090 \\
\hline Thallium & $<0.025$ & $<0.025$ & $<0.02$ & $<0.02$ & $\mathrm{mg} / \mathrm{L}$ & 0.025 & 0.02 & 0.98 \\
\hline Vanadium & $<0.025$ & $<0.025$ & $<0.025$ & $<0.025$ & $\mathrm{mg} / \mathrm{L}$ & 0.025 & 0.098 & 0.1 \\
\hline
\end{tabular}

Table F.2 - Analytical Results for Groundwater Sampled from Well WQSP-2

\begin{tabular}{|c|c|c|c|c|c|c|c|c|}
\hline \multirow[b]{3}{*}{ Parameter } & \multicolumn{4}{|c|}{ Concentration } & \multirow[b]{3}{*}{ Units } & & & \multirow[b]{3}{*}{$\begin{array}{c}95^{\text {th }} \\
\text { UTLV }^{\mathrm{a}}\end{array}$} \\
\hline & \multicolumn{2}{|c|}{ Round 26} & \multicolumn{2}{|c|}{ Round 27} & & \multicolumn{2}{|c|}{ Reporting Limit } & \\
\hline & Sample & Dup. & Sample & Dup. & & $\begin{array}{c}\text { Round } \\
26\end{array}$ & $\begin{array}{c}\text { Round } \\
27\end{array}$ & \\
\hline 1,1,1-Trichloroethane & $<1$ & $<1$ & $<1$ & $<1$ & $\mu g / L$ & 1 & 1 & $<\mathrm{RL}^{\mathrm{b}}$ \\
\hline 1,1,2,2-Tetrachloroethane & $<1$ & $<1$ & $<1$ & $<1$ & $\mu \mathrm{g} / \mathrm{L}$ & 1 & 1 & $<\mathrm{RL}$ \\
\hline 1,1,2-Trichloroethane & $<1$ & $<1$ & $<1$ & $<1$ & $\mu g / L$ & 1 & 1 & $<R L$ \\
\hline 1,1-Dichloroethane & $<1$ & $<1$ & $<1$ & $<1$ & $\mu g / L$ & 1 & 1 & $<R L$ \\
\hline 1,1-Dichloroethylene & $<1$ & $<1$ & $<1$ & $<1$ & $\mu g / L$ & 1 & 1 & $<R L$ \\
\hline 1,2-Dichloroethane & $<1$ & $<1$ & $<1$ & $<1$ & $\mu g / L$ & 1 & 1 & $<R L$ \\
\hline Carbon tetrachloride & $<1$ & $<1$ & $<1$ & $<1$ & $\mu \mathrm{g} / \mathrm{L}$ & 1 & 1 & $<R L$ \\
\hline Chlorobenzene & $<1$ & $<1$ & $<1$ & $<1$ & $\mu \mathrm{g} / \mathrm{L}$ & 1 & 1 & $<\mathrm{RL}$ \\
\hline Chloroform & $<1$ & $<1$ & $<1$ & $<1$ & $\mu \mathrm{g} / \mathrm{L}$ & 1 & 1 & $<\mathrm{RL}$ \\
\hline cis-1,2-Dichloroethylene & $<1$ & $<1$ & $<1$ & $<1$ & $\mu g / L$ & 1 & 1 & $<\mathrm{RL}$ \\
\hline trans-1,2-Dichloroethylene & $<1$ & $<1$ & $<1$ & $<1$ & $\mu \mathrm{g} / \mathrm{L}$ & 1 & 1 & $<\mathrm{RL}$ \\
\hline Methyl ethyl ketone & $<5$ & $<5$ & $<5$ & $<5$ & $\mu g / L$ & 5 & 5 & $<\mathrm{RL}$ \\
\hline Methylene chloride & $<5$ & $<5$ & $<5$ & $<5$ & $\mu \mathrm{g} / \mathrm{L}$ & 5 & 5 & $<R L$ \\
\hline Tetrachloroethylene & $<1$ & $<1$ & $<1$ & $<1$ & $\mu g / L$ & 1 & 1 & $<\mathrm{RL}$ \\
\hline
\end{tabular}




\begin{tabular}{|c|c|c|c|c|c|c|c|c|}
\hline \multirow[b]{3}{*}{ Parameter } & \multicolumn{4}{|c|}{ Concentration } & \multirow[b]{3}{*}{ Units } & \multirow{2}{*}{\multicolumn{2}{|c|}{ Reporting Limit }} & \multirow[b]{3}{*}{$\begin{array}{l}95^{\text {th }} \\
\text { UTLV }^{\text {a }}\end{array}$} \\
\hline & \multicolumn{2}{|c|}{ Round 26} & \multicolumn{2}{|c|}{ Round 27} & & & & \\
\hline & Sample & Dup. & Sample & Dup. & & $\begin{array}{c}\text { Round } \\
26\end{array}$ & $\begin{array}{c}\text { Round } \\
27\end{array}$ & \\
\hline Toluene & $<1$ & $<1$ & $<1$ & $<1$ & $\mu \mathrm{g} / \mathrm{L}$ & 1 & 1 & $<\mathrm{RL}$ \\
\hline Trichloroethylene & $<1$ & $<1$ & $<1$ & $<1$ & $\mu \mathrm{g} / \mathrm{L}$ & 1 & 1 & $<\mathrm{RL}$ \\
\hline Trichlorofluoromethane & $<1$ & $<1$ & $<1$ & $<1$ & $\mu \mathrm{g} / \mathrm{L}$ & 1 & 1 & $<\mathrm{RL}$ \\
\hline Vinyl chloride & $<1$ & $<1$ & $<1$ & $<1$ & $\mu \mathrm{g} / \mathrm{L}$ & 1 & 1 & $<\mathrm{RL}$ \\
\hline Xylene & $<1$ & $<1$ & $<1$ & $<1$ & $\mu \mathrm{g} / \mathrm{L}$ & 1 & 1 & $<\mathrm{RL}$ \\
\hline 1,2-Dichlorobenzene & $<5$ & $<5$ & $<5$ & $<5$ & $\mu \mathrm{g} / \mathrm{L}$ & 5 & 5 & $<\mathrm{RL}$ \\
\hline 1,4-Dichlorobenzene & $<5$ & $<5$ & $<5$ & $<5$ & $\mu \mathrm{g} / \mathrm{L}$ & 5 & 5 & $<\mathrm{RL}$ \\
\hline 2,4-Dinitrophenol & $<5$ & $<5$ & $<5$ & $<5$ & $\mu \mathrm{g} / \mathrm{L}$ & 5 & 5 & $<\mathrm{RL}$ \\
\hline 2,4-Dinitrotoluene & $<20$ & $<20$ & $<5$ & $<5$ & $\mu \mathrm{g} / \mathrm{L}$ & 20 & 5 & $<\mathrm{RL}$ \\
\hline 2-Methylphenol & $<5$ & $<5$ & $<5$ & $<5$ & $\mu \mathrm{g} / \mathrm{L}$ & 5 & 5 & $<\mathrm{RL}$ \\
\hline $\begin{array}{l}\text { 3-Methylphenol/ } \\
\text { 4-Methylphenol }\end{array}$ & $<5$ & $<5$ & $<5$ & $<5$ & $\mu \mathrm{g} / \mathrm{L}$ & 5 & 5 & $<\mathrm{RL}$ \\
\hline Hexachlorobenzene & $<5$ & $<5$ & $<5$ & $<5$ & $\mu \mathrm{g} / \mathrm{L}$ & 5 & 5 & $<R L$ \\
\hline Hexachloroethane & $<5$ & $<5$ & $<5$ & $<5$ & $\mu \mathrm{g} / \mathrm{L}$ & 5 & 5 & $<\mathrm{RL}$ \\
\hline Nitrobenzene & $<5$ & $<5$ & $<5$ & $<5$ & $\mu \mathrm{g} / \mathrm{L}$ & 5 & 5 & $<\mathrm{RL}$ \\
\hline Pentachlorophenol & $<5$ & $<5$ & $<5$ & $<5$ & $\mu \mathrm{g} / \mathrm{L}$ & 5 & 5 & $<\mathrm{RL}$ \\
\hline Pyridine & $<5$ & $<5$ & $<5$ & $<5$ & $\mu \mathrm{g} / \mathrm{L}$ & 5 & 5 & $<R L$ \\
\hline Isobutanol & $<5$ & $<5$ & $<5$ & $<5$ & $\mu g / L$ & 5 & 5 & $<\mathrm{RL}$ \\
\hline Alkalinity & 46 & 48 & 47 & 46 & $\mathrm{mg} / \mathrm{L}$ & 4 & 4 & 70.3 \\
\hline Chloride & 34,200 & 33,500 & 34,000 & 35,500 & $\mathrm{mg} / \mathrm{L}$ & 0.5 & 0.5 & 39,670 \\
\hline Density & 1.06 & 1.06 & 1.044 & 1.041 & $\mathrm{~g} / \mathrm{ml}$ & $N / A^{c}$ & $N / A^{c}$ & 1.06 \\
\hline Nitrate (as N) & $<0.1$ & $<0.1$ & $<5$ & $<5$ & $\mathrm{mg} / \mathrm{L}$ & 0.1 & 3.2 & 10 \\
\hline $\mathrm{pH}$ & 7.04 & 7.06 & 7.08 & 7.06 & $S U^{d}$ & $N / A^{c}$ & $N / A^{c}$ & $7.00-7.60$ \\
\hline Specific conductance & 81,700 & 79,600 & 94,900 & 105,000 & $\mu \mathrm{mhos} / \mathrm{cm}$ & $N / A^{c}$ & $N / A^{c}$ & 124,000 \\
\hline Sulfate & 5,810 & 6,200 & 5,500 & 5,400 & $\mathrm{mg} / \mathrm{L}$ & 0.5 & 0.5 & 6,590 \\
\hline Total dissolved solids & 63,800 & 65,400 & 61,600 & 63,500 & $\mathrm{mg} / \mathrm{L}$ & 10 & 10 & 80,500 \\
\hline Total organic carbon & $<1$ & $<1$ & $<1$ & $<1$ & $\mathrm{mg} / \mathrm{L}$ & 1 & 1 & 7.97 \\
\hline Total organic halogen & 0.61 & $<0.6$ & 0.20 & 0.26 & $\mathrm{mg} / \mathrm{L}$ & 0.6 & 0.1 & 63.8 \\
\hline Total suspended solids & 4.0 & 11.5 & $<5$ & $<5$ & $\mathrm{mg} / \mathrm{L}$ & 1 & 5 & 43 \\
\hline Antimony & $<0.025$ & $<0.025$ & $<0.02$ & $<0.02$ & $\mathrm{mg} / \mathrm{L}$ & 0.025 & 0.02 & 0.5 \\
\hline Arsenic & $<0.05$ & $<0.05$ & $<0.02$ & $<0.02$ & $\mathrm{mg} / \mathrm{L}$ & 0.05 & 0.02 & 0.062 \\
\hline Barium & $<0.05$ & $<0.05$ & $<0.02$ & $<0.02$ & $\mathrm{mg} / \mathrm{L}$ & 0.05 & 0.02 & 1 \\
\hline Beryllium & $<0.01$ & $<0.01$ & $<0.01$ & $<0.01$ & $\mathrm{mg} / \mathrm{L}$ & 0.01 & 0.01 & 1 \\
\hline Cadmium & $<0.01$ & $<0.01$ & $<0.01$ & $<0.01$ & $\mathrm{mg} / \mathrm{L}$ & 0.01 & 0.01 & 0.5 \\
\hline Calcium & 1,590 & 1,560 & 1,490 & 1,460 & $\mathrm{mg} / \mathrm{L}$ & 0.5 & 0.5 & 1,827 \\
\hline Chromium & $<0.05$ & $<0.05$ & $<0.025$ & $<0.025$ & $\mathrm{mg} / \mathrm{L}$ & 0.025 & 0.025 & 0.5 \\
\hline Iron & $<0.5$ & $<0.5$ & $<0.5$ & $<0.5$ & $\mathrm{mg} / \mathrm{L}$ & 0.5 & 0.5 & 1.32 \\
\hline Lead & $<0.05$ & $<0.05$ & $<0.02$ & $<0.02$ & $\mathrm{mg} / \mathrm{L}$ & 0.05 & 0.02 & 0.16 \\
\hline Magnesium & 1,080 & 1,050 & 1,020 & 996 & $\mathrm{mg} / \mathrm{L}$ & 0.5 & 0.5 & 1,244 \\
\hline Mercury & $<0.0002$ & $<0.0002$ & $<0.0002$ & $<0.0002$ & $\mathrm{mg} / \mathrm{L}$ & 0.0002 & 0.0002 & 0.002 \\
\hline Nickel & $<0.05$ & $<0.05$ & $<0.025$ & $<0.025$ & $\mathrm{mg} / \mathrm{L}$ & 0.05 & 0.025 & 0.49 \\
\hline Potassium & 701 & 651 & 482 & 487 & $\mathrm{mg} / \mathrm{L}$ & 0.5 & 0.5 & 845 \\
\hline Selenium & $<0.025$ & $<0.025$ & $<0.02$ & $<0.02$ & $\mathrm{mg} / \mathrm{L}$ & 0.025 & 0.02 & 0.15 \\
\hline Silver & $<0.025$ & $<0.025$ & $<0.013$ & $<0.013$ & $\mathrm{mg} / \mathrm{L}$ & 0.025 & 0.013 & 0.5 \\
\hline
\end{tabular}


Waste Isolation Pilot Plant Annual Site Environmental Report for 2008

DOE/WIPP-09-2225

Table F.2 - Analytical Results for Groundwater Sampled from Well WQSP-2

Concentration

\begin{tabular}{|c|c|c|c|c|c|c|c|c|}
\hline \multirow[b]{2}{*}{ Parameter } & \multicolumn{2}{|c|}{ Round 26} & \multicolumn{2}{|c|}{ Round 27} & \multirow[b]{2}{*}{ Units } & \multicolumn{2}{|c|}{ Reporting Limit } & \multirow[b]{2}{*}{$\begin{array}{l}9^{\text {th }} \\
\text { UTLV }^{\mathrm{a}}\end{array}$} \\
\hline & Sample & Dup. & Sample & Dup. & & $\begin{array}{c}\text { Round } \\
26\end{array}$ & $\begin{array}{c}\text { Round } \\
27\end{array}$ & \\
\hline Sodium & 24,500 & 23,800 & 20,300 & 19,900 & $\mathrm{mg} / \mathrm{L}$ & 0.5 & 0.5 & 21,900 \\
\hline Thallium & $<0.025$ & $<0.025$ & $<0.02$ & $<0.020$ & $\mathrm{mg} / \mathrm{L}$ & 0.025 & 0.020 & 0.98 \\
\hline Vanadium & $<0.025$ & $<0.025$ & $<0.025$ & $<0.025$ & $\mathrm{mg} / \mathrm{L}$ & 0.005 & 0.025 & 0.1 \\
\hline $\begin{array}{l}\text { a } 95^{\text {th }} \text { Upper tolerance } \\
{ }^{\mathrm{b}} \text { Reporting limit } \\
{ }^{\mathrm{C}} \text { Not applicable } \\
{ }^{\mathrm{d}} \text { Standard unit }\end{array}$ & , equivale & to $95 \% \mathrm{c}$ & dence lim & & & & & \\
\hline
\end{tabular}

Table F.3 - Analytical Results for Groundwater Sampled from Well WQSP-3

\begin{tabular}{|c|c|c|c|c|c|c|c|c|}
\hline \multirow[b]{3}{*}{ Parameter } & \multicolumn{4}{|c|}{ Concentration } & \multirow[b]{3}{*}{ Units } & & & \multirow[b]{3}{*}{$\begin{array}{l}9^{\text {th }} \\
\text { UTLV }\end{array}$} \\
\hline & \multicolumn{2}{|c|}{ Round 26} & \multicolumn{2}{|c|}{ Round 27} & & \multicolumn{2}{|c|}{ Reporting Limit } & \\
\hline & Sample & Dup. & Sample & Dup. & & $\begin{array}{l}\text { Round } \\
26\end{array}$ & $\begin{array}{c}\text { Round } \\
27\end{array}$ & \\
\hline 1,1,1-Trichloroethane & $<1$ & $<1$ & $<1$ & $<1$ & $\mu g / L$ & 1 & 1 & $<\mathrm{RL}^{\mathrm{b}}$ \\
\hline 1,1,2,2-Tetrachloroethane & $<1$ & $<1$ & $<1$ & $<1$ & $\mu g / L$ & 1 & 1 & $<\mathrm{RL}$ \\
\hline 1,1,2-Trichloroethane & $<1$ & $<1$ & $<1$ & $<1$ & $\mu g / L$ & 1 & 1 & $<\mathrm{RL}$ \\
\hline 1,1-Dichloroethane & $<1$ & $<1$ & $<1$ & $<1$ & $\mu g / L$ & 1 & 1 & $<R L$ \\
\hline 1,1-Dichloroethylene & $<1$ & $<1$ & $<1$ & $<1$ & $\mu g / L$ & 1 & 1 & $<R L$ \\
\hline 1,2-Dichloroethane & $<1$ & $<1$ & $<1$ & $<1$ & $\mu g / L$ & 1 & 1 & $<\mathrm{RL}$ \\
\hline Carbon tetrachloride & $<1$ & $<1$ & $<1$ & $<1$ & $\mu g / L$ & 1 & 1 & $<\mathrm{RL}$ \\
\hline Chlorobenzene & $<1$ & $<1$ & $<1$ & $<1$ & $\mu g / L$ & 1 & 1 & $<R L$ \\
\hline Chloroform & $<1$ & $<1$ & $<1$ & $<1$ & $\mu g / L$ & 1 & 1 & $<R L$ \\
\hline cis-1,2-Dichloroethylene & $<1$ & $<1$ & $<1$ & $<1$ & $\mu g / L$ & 1 & 1 & $<R L$ \\
\hline trans-1,2-Dichloroethylene & $<1$ & $<1$ & $<1$ & $<1$ & $\mu g / L$ & 1 & 1 & $<R L$ \\
\hline Methyl ethyl ketone & $<5$ & $<5$ & $<5$ & $<5$ & $\mu g / L$ & 5 & 5 & $<\mathrm{RL}$ \\
\hline Methylene chloride & $<5$ & $<5$ & $<5$ & $<5$ & $\mu g / L$ & 5 & 5 & $<R L$ \\
\hline Tetrachloroethylene & $<1$ & $<1$ & $<1$ & $<1$ & $\mu g / L$ & 1 & 1 & $<R L$ \\
\hline Toluene & $<1$ & $<1$ & $<1$ & $<1$ & $\mu g / L$ & 1 & 1 & $<\mathrm{RL}$ \\
\hline Trichloroethylene & $<1$ & $<1$ & $<1$ & $<1$ & $\mu g / L$ & 1 & 1 & $<\mathrm{RL}$ \\
\hline Trichlorofluoromethane & $<1$ & $<1$ & $<1$ & $<1$ & $\mu g / L$ & 1 & 1 & $<\mathrm{RL}$ \\
\hline Vinyl chloride & $<1$ & $<1$ & $<1$ & $<1$ & $\mu g / L$ & 1 & 1 & $<\mathrm{RL}$ \\
\hline Xylene & $<1$ & $<1$ & $<1$ & $<1$ & $\mu g / L$ & 1 & 1 & $<R L$ \\
\hline 1,2-Dichlorobenzene & $<5$ & $<5$ & $<5$ & $<5$ & $\mu g / L$ & 5 & 5 & $<\mathrm{RL}$ \\
\hline 1,4-Dichlorobenzene & $<5$ & $<5$ & $<5$ & $<5$ & $\mu g / L$ & 5 & 5 & $<R L$ \\
\hline 2,4-Dinitrophenol & $<20$ & $<20$ & $<5$ & $<5$ & $\mu g / L$ & 20 & 5 & $<\mathrm{RL}$ \\
\hline 2,4-Dinitrotoluene & $<5$ & $<5$ & $<5$ & $<5$ & $\mu g / L$ & 5 & 5 & $<\mathrm{RL}$ \\
\hline 2-Methylphenol & $<5$ & $<5$ & $<5$ & $<5$ & $\mu g / L$ & 5 & 5 & $<\mathrm{RL}$ \\
\hline $\begin{array}{l}\text { 3-Methylphenol/ } \\
\text { 4-Methylphenol }\end{array}$ & $<5$ & $<5$ & $<5$ & $<5$ & $\mu g / L$ & 5 & 5 & $<R L$ \\
\hline Hexachlorobenzene & $<5$ & $<5$ & $<5$ & $<5$ & $\mu g / L$ & 5 & 5 & $<R L$ \\
\hline Hexachloroethane & $<5$ & $<5$ & $<5$ & $<5$ & $\mu g / L$ & 5 & 5 & $<\mathrm{RL}$ \\
\hline Nitrobenzene & $<5$ & $<5$ & $<5$ & $<5$ & $\mu g / L$ & 5 & 5 & $<\mathrm{RL}$ \\
\hline Pentachlorophenol & $<5$ & $<5$ & $<5$ & $<5$ & $\mu g / L$ & 5 & 5 & $<\mathrm{RL}$ \\
\hline Pyridine & $<5$ & $<5$ & $<5$ & $<5$ & $\mu g / L$ & 5 & 5 & $<\mathrm{RL}$ \\
\hline Isobutanol & $<5$ & $<5$ & $<5$ & $<5$ & $\mu g / L$ & 5 & 5 & $<R L$ \\
\hline
\end{tabular}


Waste Isolation Pilot Plant Annual Site Environmental Report for 2008 DOE/WIPP-09-2225 Concentration

\begin{tabular}{|c|c|c|c|c|c|c|c|c|}
\hline \multirow[b]{3}{*}{ Parameter } & \multicolumn{4}{|c|}{ Concentration } & \multirow[b]{3}{*}{ Units } & & & \multirow[b]{3}{*}{$\begin{array}{l}95^{\text {th }} \\
\text { UTLV }^{\mathrm{a}}\end{array}$} \\
\hline & \multicolumn{2}{|c|}{ Round 26} & \multicolumn{2}{|c|}{ Round 27} & & \multicolumn{2}{|c|}{ Reporting Limit } & \\
\hline & Sample & Dup. & Sample & Dup. & & $\begin{array}{c}\text { Round } \\
26 \\
\end{array}$ & $\begin{array}{c}\text { Round } \\
27 \\
\end{array}$ & \\
\hline Alkalinity & 32 & 32 & 32 & 32 & $\mathrm{mg} / \mathrm{L}$ & 4 & 4 & 54.5 \\
\hline Chloride & 121,000 & 122,000 & 115,000 & 112,000 & $\mathrm{mg} / \mathrm{L}$ & 0.5 & 0.5 & 149,100 \\
\hline Density & 1.15 & 1.15 & 1.140 & 1.143 & $\mathrm{~g} / \mathrm{ml}$ & $N / A^{c}$ & $N / A^{c}$ & 1.17 \\
\hline Nitrate (as N) & $<0.1$ & $<0.1$ & $<0.1$ & $<0.1$ & $\mathrm{mg} / \mathrm{L}$ & 0.1 & 0.1 & 12 \\
\hline $\mathrm{pH}$ & 6.54 & 6.61 & 6.55 & 6.61 & $S U^{d}$ & $N / A^{c}$ & $N / A^{c}$ & $6.6-7.2$ \\
\hline Specific conductance & 332,000 & 307,000 & 362,000 & 348,000 & $\mu \mathrm{mhos} / \mathrm{cm}$ & $N / A^{c}$ & $N / A^{c}$ & 517,000 \\
\hline Sulfate & 7,190 & 7,340 & 6,910 & 7,020 & mg/L & 0.5 & 0.5 & 8,015 \\
\hline Total dissolved solids & 201,500 & 214,500 & 227,000 & 266,000 & $\mathrm{mg} / \mathrm{L}$ & 10 & 10 & 261,000 \\
\hline Total organic carbon & 1.07 & $<1$ & 0.99 & 0.76 & $\mathrm{mg} / \mathrm{L}$ & 1 & 1 & 5 \\
\hline Total organic halogen & $<0.3$ & $<0.3$ & 0.57 & 0.21 & $\mathrm{mg} / \mathrm{L}$ & 0.3 & 0.1 & 55 \\
\hline Total suspended solids & 23 & 24 & $<5$ & $<5$ & $\mathrm{mg} / \mathrm{L}$ & 1 & 5 & 107 \\
\hline Antimony & $<0.25$ & $<0.25$ & $<0.02$ & $<0.02$ & $\mathrm{mg} / \mathrm{L}$ & 0.25 & 0.02 & 1 \\
\hline Arsenic & $<0.25$ & $<0.25$ & $<0.02$ & $<0.02$ & $\mathrm{mg} / \mathrm{L}$ & 0.25 & 0.02 & 0.21 \\
\hline Barium & $<0.02$ & $<0.02$ & 0.040 & 0.052 & $\mathrm{mg} / \mathrm{L}$ & 0.02 & 0.02 & 1 \\
\hline Beryllium & $<0.01$ & $<0.01$ & $<0.018$ & $<0.018$ & $\mathrm{mg} / \mathrm{L}$ & 0.01 & 0.018 & 0.1 \\
\hline Cadmium & $<0.025$ & $<0.025$ & $<0.025$ & $<0.025$ & $\mathrm{mg} / \mathrm{L}$ & 0.025 & 0.025 & 0.5 \\
\hline Calcium & 1,510 & 1,540 & 1,360 & 1,420 & $\mathrm{mg} / \mathrm{L}$ & 0.5 & 0.5 & 1,680 \\
\hline Chromium & $<0.025$ & $<0.025$ & $<0.058$ & $<0.058$ & $\mathrm{mg} / \mathrm{L}$ & 0.025 & 0.058 & 2 \\
\hline Iron & $<0.5$ & $<0.5$ & $<0.5$ & $<0.5$ & $\mathrm{mg} / \mathrm{L}$ & 0.5 & 0.5 & $<4.0$ \\
\hline Lead & $<0.1$ & $<0.1$ & $<0.073$ & $<0.073$ & $\mathrm{mg} / \mathrm{L}$ & 0.1 & 0.073 & 0.8 \\
\hline Magnesium & 2,430 & 2,480 & 2,200 & 2,290 & $\mathrm{mg} / \mathrm{L}$ & 0.5 & 0.5 & 2,625 \\
\hline Mercury & $<0.0002$ & $<0.0002$ & $<0.0002$ & $<0.0002$ & $\mathrm{mg} / \mathrm{L}$ & 0.0002 & 0.0002 & 0.002 \\
\hline Nickel & $<0.05$ & $<0.05$ & $<0.025$ & $<0.025$ & $\mathrm{mg} / \mathrm{L}$ & 0.05 & 0.025 & 5 \\
\hline Potassium & 2,460 & 2,190 & 1,470 & 1,640 & $\mathrm{mg} / \mathrm{L}$ & 0.5 & 0.5 & 3,438 \\
\hline Selenium & $<0.25$ & $<0.25$ & $<0.02$ & $<0.02$ & $\mathrm{mg} / \mathrm{L}$ & 0.25 & 0.02 & 2 \\
\hline Silver & $<0.013$ & $<0.013$ & $<0.023$ & $<0.023$ & $\mathrm{mg} / \mathrm{L}$ & 0.013 & 0.023 & 0.31 \\
\hline Sodium & 91,100 & 93,900 & 78,800 & 81,900 & $\mathrm{mg} / \mathrm{L}$ & 0.5 & 0.5 & 140,400 \\
\hline Thallium & $<0.025$ & $<0.025$ & $<0.020$ & $<0.02$ & $\mathrm{mg} / \mathrm{L}$ & 0.025 & 0.02 & 5.8 \\
\hline Vanadium & $<0.05$ & $<0.05$ & $<0.098$ & $<0.098$ & $\mathrm{mg} / \mathrm{L}$ & 0.05 & 0.098 & 5 \\
\hline
\end{tabular}

${ }^{\text {a }} 95^{\text {th }}$ Upper tolerance limit value, equivalent to $95 \%$ confidence limit

${ }^{\mathrm{b}}$ Reporting limit

${ }^{c}$ Not applicable

d Standard unit 


\begin{tabular}{|c|c|c|c|c|c|c|c|c|}
\hline \multirow[b]{3}{*}{ Parameter } & \multicolumn{4}{|c|}{ Concentration } & \multirow[b]{3}{*}{ Units } & \multirow{2}{*}{\multicolumn{2}{|c|}{ Reporting Limit }} & \multirow[b]{3}{*}{$\begin{array}{c}9^{\text {th }} \\
\text { UTLV }^{\mathrm{a}}\end{array}$} \\
\hline & \multicolumn{2}{|c|}{ Round 26} & \multicolumn{2}{|c|}{$\begin{array}{l}\text { Round } 27 \\
\end{array}$} & & & & \\
\hline & Sample & Dup. & Sample & Dup. & & $\begin{array}{c}\text { Round } \\
26\end{array}$ & $\begin{array}{c}\text { Round } \\
27\end{array}$ & \\
\hline 1,1,1-Trichloroethane & $<1$ & $<1$ & $<1$ & $<1$ & $\mu g / L$ & 1 & 1 & $<\mathrm{RL}^{\mathrm{b}}$ \\
\hline 1,1,2,2-Tetrachloroethane & $<1$ & $<1$ & $<1$ & $<1$ & $\mu \mathrm{g} / \mathrm{L}$ & 1 & 1 & $<\mathrm{RL}$ \\
\hline 1,1,2-Trichloroethane & $<1$ & $<1$ & $<1$ & $<1$ & $\mu \mathrm{g} / \mathrm{L}$ & 1 & 1 & $<R L$ \\
\hline 1,1-Dichloroethane & $<1$ & $<1$ & $<1$ & $<1$ & $\mu \mathrm{g} / \mathrm{L}$ & 1 & 1 & $<\mathrm{RL}$ \\
\hline 1,1-Dichloroethylene & $<1$ & $<1$ & $<1$ & $<1$ & $\mu \mathrm{g} / \mathrm{L}$ & 1 & 1 & $<\mathrm{RL}$ \\
\hline 1,2-Dichloroethane & $<1$ & $<1$ & $<1$ & $<1$ & $\mu \mathrm{g} / \mathrm{L}$ & 1 & 1 & $<\mathrm{RL}$ \\
\hline Carbon tetrachloride & $<1$ & $<1$ & $<1$ & $<1$ & $\mu \mathrm{g} / \mathrm{L}$ & 1 & 1 & $<\mathrm{RL}$ \\
\hline Chlorobenzene & $<1$ & $<1$ & $<1$ & $<1$ & $\mu \mathrm{g} / \mathrm{L}$ & 1 & 1 & $<R L$ \\
\hline Chloroform & $<1$ & $<1$ & $<1$ & $<1$ & $\mu \mathrm{g} / \mathrm{L}$ & 1 & 1 & $<\mathrm{RL}$ \\
\hline cis-1,2-Dichloroethylene & $<1$ & $<1$ & $<1$ & $<1$ & $\mu \mathrm{g} / \mathrm{L}$ & 1 & 1 & $<\mathrm{RL}$ \\
\hline trans-1,2-Dichloroethylene & $<1$ & $<1$ & $<1$ & $<1$ & $\mu \mathrm{g} / \mathrm{L}$ & 1 & 1 & $<\mathrm{RL}$ \\
\hline Methyl ethyl ketone & $<5$ & $<5$ & $<5$ & $<5$ & $\mu \mathrm{g} / \mathrm{L}$ & 5 & 5 & $<\mathrm{RL}$ \\
\hline Methylene chloride & $<5$ & $<5$ & $<5$ & $<5$ & $\mu \mathrm{g} / \mathrm{L}$ & 5 & 5 & $<R L$ \\
\hline Tetrachloroethylene & $<1$ & $<1$ & $<1$ & $<1$ & $\mu \mathrm{g} / \mathrm{L}$ & 1 & 1 & $<\mathrm{RL}$ \\
\hline Toluene & $<1$ & $<1$ & $<1$ & $<1$ & $\mu \mathrm{g} / \mathrm{L}$ & 1 & 1 & $<R L$ \\
\hline Trichloroethylene & $<1$ & $<1$ & $<1$ & $<1$ & $\mu \mathrm{g} / \mathrm{L}$ & 1 & 1 & $<R L$ \\
\hline Trichlorofluoromethane & $<1$ & $<1$ & $<1$ & $<1$ & $\mu \mathrm{g} / \mathrm{L}$ & 1 & 1 & $<R L$ \\
\hline Vinyl chloride & $<1$ & $<1$ & $<1$ & $<1$ & $\mu \mathrm{g} / \mathrm{L}$ & 1 & 1 & $<\mathrm{RL}$ \\
\hline Xylene & $<1$ & $<1$ & $<1$ & $<1$ & $\mu \mathrm{g} / \mathrm{L}$ & 1 & 1 & $<R L$ \\
\hline 1,2-Dichlorobenzene & $<5$ & $<5$ & $<5$ & $<5$ & $\mu \mathrm{g} / \mathrm{L}$ & 5 & 5 & $<\mathrm{RL}$ \\
\hline 1,4-Dichlorobenzene & $<5$ & $<5$ & $<5$ & $<5$ & $\mu \mathrm{g} / \mathrm{L}$ & 5 & 5 & $<R L$ \\
\hline 2,4-Dinitrophenol & $<20$ & $<20$ & $<5$ & $<5$ & $\mu \mathrm{g} / \mathrm{L}$ & 20 & 5 & $<\mathrm{RL}$ \\
\hline 2,4-Dinitrotoluene & $<5$ & $<5$ & $<5$ & $<5$ & $\mu \mathrm{g} / \mathrm{L}$ & 5 & 5 & $<\mathrm{RL}$ \\
\hline 2-Methylphenol & $<5$ & $<5$ & $<5$ & $<5$ & $\mu g / L$ & 5 & 5 & $<\mathrm{RL}$ \\
\hline $\begin{array}{l}\text { 3-Methylphenol/ } \\
\text { 4-Methylphenol }\end{array}$ & $<5$ & $<5$ & $<5$ & $<5$ & $\mu \mathrm{g} / \mathrm{L}$ & 5 & 5 & $<\mathrm{RL}$ \\
\hline Hexachlorobenzene & $<5$ & $<5$ & $<5$ & $<5$ & $\mu \mathrm{g} / \mathrm{L}$ & 5 & 5 & $<R L$ \\
\hline Hexachloroethane & $<5$ & $<5$ & $<5$ & $<5$ & $\mu \mathrm{g} / \mathrm{L}$ & 5 & 5 & $<R L$ \\
\hline Nitrobenzene & $<5$ & $<5$ & $<5$ & $<5$ & $\mu \mathrm{g} / \mathrm{L}$ & 5 & 5 & $<\mathrm{RL}$ \\
\hline Pentachlorophenol & $<5$ & $<5$ & $<5$ & $<5$ & $\mu g / L$ & 5 & 5 & $<\mathrm{RL}$ \\
\hline Pyridine & $<5$ & $<5$ & $<5$ & $<5$ & $\mu g / L$ & 5 & 5 & $<R L$ \\
\hline Isobutanol & $<5$ & $<5$ & $<5$ & $<5$ & $\mu \mathrm{g} / \mathrm{L}$ & 5 & 5 & $<\mathrm{RL}$ \\
\hline Alkalinity & 40 & 38 & 36 & 38 & $\mathrm{mg} / \mathrm{L}$ & 4 & 4 & 47 \\
\hline Chloride & 56,200 & 60,300 & 59,700 & 59,700 & $\mathrm{mg} / \mathrm{L}$ & 0.5 & 0.5 & 63,960 \\
\hline Density & 1.09 & 1.08 & 1.073 & 1.071 & $\mathrm{~g} / \mathrm{ml}$ & $N / A^{c}$ & $N / A^{c}$ & 1.1 \\
\hline Nitrate (as N) & $<0.1$ & $<0.1$ & $<0.5$ & $<0.5$ & $\mathrm{mg} / \mathrm{L}$ & 0.1 & 0.5 & 10 \\
\hline $\mathrm{pH}$ & 7.11 & 7.08 & 7.02 & 7.03 & $S U^{d}$ & $N / A^{c}$ & $N / A^{c}$ & $6.80-7.61$ \\
\hline Specific conductance & 190,000 & 190,000 & 182,000 & 187,000 & $\mu \mathrm{mhos} / \mathrm{cm}$ & $N / A^{c}$ & $N / A^{c}$ & 319,800 \\
\hline Sulfate & 5,750 & 5,850 & 6,870 & 6,840 & mg/L & 0.5 & 0.5 & 7,927 \\
\hline Total dissolved solids & 114,500 & 104,500 & 104,000 & 104,000 & $\mathrm{mg} / \mathrm{L}$ & 10 & 10 & 123,500 \\
\hline Total organic carbon & $<1$ & $<1$ & $<1$ & $<1$ & $\mathrm{mg} / \mathrm{L}$ & 1 & 1 & 5 \\
\hline Total organic halogen & $<0.3$ & $<0.3$ & 0.57 & 0.21 & $\mathrm{mg} / \mathrm{L}$ & 0.3 & 0.1 & 17 \\
\hline Total suspended solids & 11.5 & 8.5 & 8 & 7 & $\mathrm{mg} / \mathrm{L}$ & 1 & 5 & 57 \\
\hline Antimony & $<0.05$ & $<0.05$ & $<0.02$ & $<0.02$ & $\mathrm{mg} / \mathrm{L}$ & 0.05 & 0.02 & 0.8 \\
\hline
\end{tabular}


Waste Isolation Pilot Plant Annual Site Environmental Report for 2008 DOE/WIPP-09-2225

\begin{tabular}{|c|c|c|c|c|c|c|c|c|}
\hline \multirow[b]{3}{*}{ Parameter } & \multicolumn{4}{|c|}{ Concentration } & \multirow[b]{3}{*}{ Units } & & & \multirow[b]{3}{*}{$\begin{array}{l}9^{\text {th }} \\
\text { UTLV }\end{array}$} \\
\hline & \multicolumn{2}{|c|}{ Round 26} & \multicolumn{2}{|c|}{ Round 27} & & \multicolumn{2}{|c|}{ Reporting Limit } & \\
\hline & Sample & Dup. & Sample & Dup. & & $\begin{array}{c}\text { Round } \\
26\end{array}$ & $\begin{array}{c}\text { Round } \\
27\end{array}$ & \\
\hline Arsenic & $<0.05$ & $<0.05$ & $<0.02$ & $<0.02$ & $\mathrm{mg} / \mathrm{L}$ & 0.05 & 0.02 & 0.5 \\
\hline Barium & $<0.02$ & $<0.02$ & 0.033 & 0.036 & $\mathrm{mg} / \mathrm{L}$ & 0.02 & 0.02 & 1 \\
\hline Beryllium & $<0.01$ & $<0.01$ & $<0.01$ & $<0.01$ & $\mathrm{mg} / \mathrm{L}$ & 0.01 & 0.01 & 0.25 \\
\hline Cadmium & $<0.01$ & $<0.01$ & $<0.01$ & $<0.01$ & $\mathrm{mg} / \mathrm{L}$ & 0.01 & 0.01 & 0.5 \\
\hline Calcium & 1,580 & 1,610 & 1,540 & 1,480 & $\mathrm{mg} / \mathrm{L}$ & 0.5 & 0.5 & 1,834 \\
\hline Chromium & $<0.1$ & $<0.1$ & $<0.025$ & $<0.025$ & $\mathrm{mg} / \mathrm{L}$ & 0.1 & 0.025 & 2 \\
\hline Iron & $<0.5$ & $<0.5$ & $<0.5$ & $<0.5$ & $\mathrm{mg} / \mathrm{L}$ & 0.5 & 0.5 & $<4.0$ \\
\hline Lead & $<0.05$ & $<0.05$ & $<0.029$ & $<0.029$ & $\mathrm{mg} / \mathrm{L}$ & 0.05 & 0.029 & 0.525 \\
\hline Magnesium & 1,190 & 1,210 & 1,200 & 1,150 & $\mathrm{mg} / \mathrm{L}$ & 0.5 & 0.5 & 1,472 \\
\hline Mercury & $<0.0002$ & $<0.0002$ & $<0.0002$ & $<0.0002$ & $\mathrm{mg} / \mathrm{L}$ & 0.0002 & 0.0002 & 0.002 \\
\hline Nickel & $<0.025$ & $<0.025$ & $<0.025$ & $<0.025$ & $\mathrm{mg} / \mathrm{L}$ & 0.025 & 0.025 & 5 \\
\hline Potassium & 1,060 & 916 & 750 & 744 & $\mathrm{mg} / \mathrm{L}$ & 0.5 & 0.5 & 1,648 \\
\hline Selenium & $<0.01$ & $<0.01$ & $<0.02$ & $<0.02$ & $\mathrm{mg} / \mathrm{L}$ & 0.01 & 0.02 & 2.009 \\
\hline Silver & $<0.05$ & $<0.05$ & $<0.013$ & $<0.013$ & $\mathrm{mg} / \mathrm{L}$ & 0.05 & 0.013 & 0.519 \\
\hline Sodium & 36,200 & 37,400 & 37,000 & 36,200 & $\mathrm{mg} / \mathrm{L}$ & 0.5 & 0.5 & 38,790 \\
\hline Thallium & $<0.05$ & $<0.05$ & $<0.02$ & $<0.02$ & $\mathrm{mg} / \mathrm{L}$ & 0.05 & 0.02 & 1 \\
\hline Vanadium & $<0.025$ & $<0.025$ & 0.043 & 0.046 & $\mathrm{mg} / \mathrm{L}$ & 0.025 & 0.025 & 5 \\
\hline
\end{tabular}

Table F.5 - Analytical Results for Groundwater Sampled from Well WQSP-5

\begin{tabular}{|c|c|c|c|c|c|c|c|c|}
\hline \multirow[b]{3}{*}{ Parameter } & \multicolumn{4}{|c|}{ Concentration } & \multirow[b]{3}{*}{ Units } & & & \multirow[b]{3}{*}{$\begin{array}{c}95^{\text {th }} \\
\text { UTLV }^{\mathrm{a}}\end{array}$} \\
\hline & \multicolumn{2}{|c|}{ Round 26} & \multicolumn{2}{|c|}{ Round 27} & & \multicolumn{2}{|c|}{ Reporting Limit } & \\
\hline & Sample & Dup. & Sample & Dup. & & $\begin{array}{c}\text { Round } \\
26\end{array}$ & $\begin{array}{c}\text { Round } \\
27\end{array}$ & \\
\hline 1,1,1-Trichloroethane & $<1$ & $<1$ & $<1$ & $<1$ & $\mu g / L$ & 1 & 1 & $<\mathrm{RL}^{\mathrm{b}}$ \\
\hline 1,1,2,2-Tetrachloroethane & $<1$ & $<1$ & $<1$ & $<1$ & $\mu g / L$ & 1 & 1 & $<\mathrm{RL}$ \\
\hline 1,1,2-Trichloroethane & $<1$ & $<1$ & $<1$ & $<1$ & $\mu \mathrm{g} / \mathrm{L}$ & 1 & 1 & $<R L$ \\
\hline 1,1-Dichloroethane & $<1$ & $<1$ & $<1$ & $<1$ & $\mu g / L$ & 1 & 1 & $<R L$ \\
\hline 1,1-Dichloroethylene & $<1$ & $<1$ & $<1$ & $<1$ & $\mu g / L$ & 1 & 1 & $<\mathrm{RL}$ \\
\hline 1,2-Dichloroethane & $<1$ & $<1$ & $<1$ & $<1$ & $\mu g / L$ & 1 & 1 & $<R L$ \\
\hline Carbon tetrachloride & $<1$ & $<1$ & $<1$ & $<1$ & $\mu g / L$ & 1 & 1 & $<\mathrm{RL}$ \\
\hline Chlorobenzene & $<1$ & $<1$ & $<1$ & $<1$ & $\mu g / L$ & 1 & 1 & $<R L$ \\
\hline Chloroform & $<1$ & $<1$ & $<1$ & $<1$ & $\mu g / L$ & 1 & 1 & $<\mathrm{RL}$ \\
\hline cis-1,2-Dichloroethylene & $<1$ & $<1$ & $<1$ & $<1$ & $\mu g / L$ & 1 & 1 & $<\mathrm{RL}$ \\
\hline trans-1,2-Dichloroethylene & $<1$ & $<1$ & $<1$ & $<1$ & $\mu g / L$ & 1 & 1 & $<\mathrm{RL}$ \\
\hline Methyl ethyl ketone & $<5$ & $<5$ & $<5$ & $<5$ & $\mu g / L$ & 5 & 5 & $<R L$ \\
\hline Methylene chloride & $<5$ & $<5$ & $<5$ & $<5$ & $\mu g / L$ & 5 & 5 & $<\mathrm{RL}$ \\
\hline Tetrachloroethylene & $<1$ & $<1$ & $<1$ & $<1$ & $\mu g / L$ & 1 & 1 & $<R L$ \\
\hline Toluene & $<1$ & $<1$ & $<1$ & $<1$ & $\mu g / L$ & 1 & 1 & $<\mathrm{RL}$ \\
\hline Trichloroethylene & $<1$ & $<1$ & $<1$ & $<1$ & $\mu g / L$ & 1 & 1 & $<R L$ \\
\hline Trichlorofluoromethane & $<1$ & $<1$ & $<1$ & $<1$ & $\mu g / L$ & 1 & 1 & $<\mathrm{RL}$ \\
\hline
\end{tabular}




\begin{tabular}{|c|c|c|c|c|c|c|c|c|}
\hline \multirow[b]{3}{*}{ Parameter } & \multicolumn{4}{|c|}{ Concentration } & \multirow[b]{3}{*}{ Units } & & & \multirow[b]{3}{*}{$\begin{array}{l}9^{\text {th }} \\
\text { UTLV }^{\mathrm{a}}\end{array}$} \\
\hline & \multicolumn{2}{|c|}{ Round 26} & \multicolumn{2}{|c|}{ Round 27} & & \multicolumn{2}{|c|}{ Reporting Limit } & \\
\hline & Sample & Dup. & Sample & Dup. & & $\begin{array}{c}\text { Round } \\
26\end{array}$ & $\begin{array}{c}\text { Round } \\
27\end{array}$ & \\
\hline Vinyl chloride & $<1$ & $<1$ & $<1$ & $<1$ & $\mu \mathrm{g} / \mathrm{L}$ & 1 & 1 & $<R L$ \\
\hline Xylene & $<1$ & $<1$ & $<1$ & $<1$ & $\mu g / L$ & 1 & 1 & $<\mathrm{RL}$ \\
\hline 1,2-Dichlorobenzene & $<5$ & $<5$ & $<5$ & $<5$ & $\mu \mathrm{g} / \mathrm{L}$ & 5 & 5 & $<\mathrm{RL}$ \\
\hline 1,4-Dichlorobenzene & $<5$ & $<5$ & $<5$ & $<5$ & $\mu g / L$ & 5 & 5 & $<\mathrm{RL}$ \\
\hline 2,4-Dinitrophenol & $<20$ & $<20$ & $<5$ & $<5$ & $\mu g / L$ & 20 & 5 & $<\mathrm{RL}$ \\
\hline 2,4-Dinitrotoluene & $<5$ & $<5$ & $<5$ & $<5$ & $\mu \mathrm{g} / \mathrm{L}$ & 5 & 5 & $<R L$ \\
\hline 2-Methylphenol & $<5$ & $<5$ & $<5$ & $<5$ & $\mu g / L$ & 5 & 5 & $<\mathrm{RL}$ \\
\hline $\begin{array}{l}\text { 3-Methylphenol/ } \\
\text { 4-Methylphenol }\end{array}$ & $<5$ & $<5$ & $<5$ & $<5$ & $\mu \mathrm{g} / \mathrm{L}$ & 5 & 5 & $<R L$ \\
\hline Hexachlorobenzene & $<5$ & $<5$ & $<5$ & $<5$ & $\mu g / L$ & 5 & 5 & $<\mathrm{RL}$ \\
\hline Hexachloroethane & $<5$ & $<5$ & $<5$ & $<5$ & $\mu g / L$ & 5 & 5 & $<\mathrm{RL}$ \\
\hline Nitrobenzene & $<5$ & $<5$ & $<5$ & $<5$ & $\mu \mathrm{g} / \mathrm{L}$ & 5 & 5 & $<R L$ \\
\hline Pentachlorophenol & $<5$ & $<5$ & $<5$ & $<5$ & $\mu g / L$ & 5 & 5 & $<\mathrm{RL}$ \\
\hline Pyridine & $<5$ & $<5$ & $<5$ & $<5$ & $\mu \mathrm{g} / \mathrm{L}$ & 5 & 5 & $<\mathrm{RL}$ \\
\hline Isobutanol & $<5$ & $<5$ & $<5$ & $<5$ & $\mu \mathrm{g} / \mathrm{L}$ & 5 & 5 & $<\mathrm{RL}$ \\
\hline Alkalinity & 60 & 50 & 46 & 44 & $\mathrm{mg} / \mathrm{L}$ & 4 & 4 & 56 \\
\hline Chloride & 14,800 & 14,500 & 17,200 & 17,100 & $\mathrm{mg} / \mathrm{L}$ & 0.5 & 0.5 & 18,100 \\
\hline Density & 1.01 & 1.01 & 1.029 & 1.029 & $\mathrm{~g} / \mathrm{ml}$ & $N / A^{c}$ & $N / A^{c}$ & 1.04 \\
\hline Nitrate (as N) & $<0.1$ & $<0.1$ & $<0.1$ & $<0.1$ & $\mathrm{mg} / \mathrm{L}$ & 0.1 & 0.1 & 10 \\
\hline $\mathrm{pH}$ & 7.41 & 7.46 & 7.46 & 7.46 & $S U^{d}$ & $N / A^{c}$ & $N / A^{c}$ & $7.40-7.90$ \\
\hline Specific conductance & 44,300 & 44,400 & 49,000 & 51,000 & $\mu \mathrm{mhos} / \mathrm{cm}$ & $N / A^{c}$ & $N / A^{c}$ & 67,700 \\
\hline Sulfate & 4,690 & 4,660 & 5,470 & 5,420 & mg/L & 0.5 & 0.5 & 6,129 \\
\hline Total dissolved solids & 30,850 & 30,650 & 31,900 & 32,000 & $\mathrm{mg} / \mathrm{L}$ & 10 & 10 & 43,950 \\
\hline Total organic carbon & $<1$ & $<1$ & $<1$ & $<1$ & $\mathrm{mg} / \mathrm{L}$ & 1 & 1 & 5 \\
\hline Total organic halogen & $<0.6$ & $<0.6$ & 0.11 & 0.079 & $\mathrm{mg} / \mathrm{L}$ & 0.6 & 0.1 & 8.37 \\
\hline Total suspended solids & 7.0 & 5.5 & $<5$ & $<5$ & $\mathrm{mg} / \mathrm{L}$ & 1 & 5 & 10 \\
\hline Antimony & $<0.025$ & $<0.025$ & $<0.01$ & $<0.01$ & $\mathrm{mg} / \mathrm{L}$ & 0.025 & 0.01 & 0.073 \\
\hline Arsenic & $<0.1$ & $<0.1$ & $<0.1$ & $<0.1$ & $\mathrm{mg} / \mathrm{L}$ & 0.1 & 0.1 & 0.5 \\
\hline Barium & $<0.02$ & $<0.02$ & $<0.02$ & $<0.02$ & $\mathrm{mg} / \mathrm{L}$ & 0.02 & 0.02 & 1 \\
\hline Beryllium & $<0.025$ & $<0.025$ & $<0.01$ & $<0.01$ & $\mathrm{mg} / \mathrm{L}$ & 0.025 & 0.01 & 0.02 \\
\hline Cadmium & $<0.01$ & $<0.01$ & $<0.01$ & $<0.01$ & $\mathrm{mg} / \mathrm{L}$ & 0.01 & 0.01 & 0.05 \\
\hline Calcium & 1,020 & 1,230 & 980 & 960 & $\mathrm{mg} / \mathrm{L}$ & 0.5 & 0.5 & 1,303 \\
\hline Chromium & $<0.025$ & $<0.025$ & $<0.025$ & $<0.025$ & $\mathrm{mg} / \mathrm{L}$ & 0.025 & 0.025 & 0.5 \\
\hline Iron & $<0.5$ & $<0.5$ & $<0.5$ & $<0.5$ & $\mathrm{mg} / \mathrm{L}$ & 0.5 & 0.5 & 0.795 \\
\hline Lead & $<0.05$ & $<0.05$ & 0.02 & $<0.02$ & $\mathrm{mg} / \mathrm{L}$ & 0.05 & 0.02 & 0.05 \\
\hline Magnesium & 451 & 454 & 450 & 440 & $\mathrm{mg} / \mathrm{L}$ & 0.5 & 0.5 & 547 \\
\hline Mercury & $<0.0002$ & $<0.0002$ & $<0.0002$ & $<0.0002$ & $\mathrm{mg} / \mathrm{L}$ & 0.0002 & 0.0002 & 0.002 \\
\hline Nickel & $<0.025$ & $<0.025$ & $<0.025$ & $<0.025$ & $\mathrm{mg} / \mathrm{L}$ & 0.025 & 0.025 & 0.1 \\
\hline Potassium & 387 & 352 & 300 & 300 & $\mathrm{mg} / \mathrm{L}$ & 0.5 & 0.5 & 622 \\
\hline Selenium & $<0.05$ & $<0.05$ & $<0.01$ & $<0.01$ & $\mathrm{mg} / \mathrm{L}$ & 0.05 & 0.01 & 0.1 \\
\hline Silver & $<0.013$ & $<0.013$ & $<0.013$ & $<0.013$ & $\mathrm{mg} / \mathrm{L}$ & 0.013 & 0.013 & 0.5 \\
\hline
\end{tabular}


Waste Isolation Pilot Plant Annual Site Environmental Report for 2008

DOE/WIPP-09-2225

Table F.5 - Analytical Results for Groundwater Sampled from Well WQSP-5

Concentration

\begin{tabular}{|c|c|c|c|c|c|c|c|c|}
\hline \multirow[b]{3}{*}{ Parameter } & \multirow{2}{*}{\multicolumn{2}{|c|}{ Round 26}} & \multirow{2}{*}{\multicolumn{2}{|c|}{ Round 27}} & \multirow[b]{3}{*}{ Units } & \multirow{2}{*}{\multicolumn{2}{|c|}{ Reporting Limit }} & \multirow[b]{3}{*}{$\begin{array}{c}95^{\text {th }} \\
\text { UTLV }\end{array}$} \\
\hline & & & & & & & & \\
\hline & Sample & Dup. & Sample & Dup. & & $\begin{array}{c}\text { Round } \\
26\end{array}$ & $\begin{array}{c}\text { Round } \\
27\end{array}$ & \\
\hline Sodium & 9,880 & 9,030 & 9,900 & 9,800 & $\mathrm{mg} / \mathrm{L}$ & 0.5 & 0.5 & 11,190 \\
\hline Thallium & $<0.1$ & $<0.1$ & $<0.01$ & $<0.01$ & $\mathrm{mg} / \mathrm{L}$ & 0.1 & 0.01 & 0.209 \\
\hline Vanadium & $<0.025$ & $<0.025$ & $<0.025$ & $<0.025$ & $\mathrm{mg} / \mathrm{L}$ & 0.025 & 0.025 & 2.7 \\
\hline
\end{tabular}

Table F.6 - Analytical Results for Groundwater Sampled from Well WQSP-6

Concentration

\begin{tabular}{|c|c|c|c|c|c|c|c|c|}
\hline \multirow[b]{2}{*}{ Parameter } & \multicolumn{2}{|c|}{ Round 26} & \multicolumn{2}{|c|}{ Round 27} & \multirow[b]{2}{*}{ Units } & \multicolumn{2}{|c|}{ Reporting LIMIT } & \multirow[b]{2}{*}{$\begin{array}{c}95^{\text {th }} \\
\text { UTLV }^{\mathrm{a}}\end{array}$} \\
\hline & Sample & Dup. & Sample & Dup. & & $\begin{array}{c}\text { Round } \\
26\end{array}$ & $\begin{array}{c}\text { Round } \\
27\end{array}$ & \\
\hline 1,1,1-Trichloroethane & $<1$ & $<1$ & $<1$ & $<1$ & $\mu g / L$ & 1 & 1 & $<\mathrm{RL}^{\mathrm{b}}$ \\
\hline 1,1,2,2-Tetrachloroethane & $<1$ & $<1$ & $<1$ & $<1$ & $\mu g / L$ & 1 & 1 & $<R L$ \\
\hline 1,1,2-Trichloroethane & $<1$ & $<1$ & $<1$ & $<1$ & $\mu g / L$ & 1 & 1 & $<R L$ \\
\hline 1,1-Dichloroethane & $<1$ & $<1$ & $<1$ & $<1$ & $\mu g / L$ & 1 & 1 & $<\mathrm{RL}$ \\
\hline 1,1-Dichloroethylene & $<1$ & $<1$ & $<1$ & $<1$ & $\mu g / L$ & 1 & 1 & $<R L$ \\
\hline 1,2-Dichloroethane & $<1$ & $<1$ & $<1$ & $<1$ & $\mu g / L$ & 1 & 1 & $<\mathrm{RL}$ \\
\hline Carbon tetrachloride & $<1$ & $<1$ & $<1$ & $<1$ & $\mu g / L$ & 1 & 1 & $<\mathrm{RL}$ \\
\hline Chlorobenzene & $<1$ & $<1$ & $<1$ & $<1$ & $\mu g / L$ & 1 & 1 & $<\mathrm{RL}$ \\
\hline Chloroform & $<1$ & $<1$ & $<1$ & $<1$ & $\mu g / L$ & 1 & 1 & $<\mathrm{RL}$ \\
\hline cis-1,2-Dichloroethylene & $<1$ & $<1$ & $<1$ & $<1$ & $\mu g / L$ & 1 & 1 & $<R L$ \\
\hline trans-1,2-Dichloroethylene & $<1$ & $<1$ & $<1$ & $<1$ & $\mu g / L$ & 1 & 1 & $<\mathrm{RL}$ \\
\hline Methyl ethyl ketone & $<5$ & $<5$ & $<5$ & $<5$ & $\mu g / L$ & 5 & 5 & $<R L$ \\
\hline Methylene chloride & $<5$ & $<5$ & $<5$ & $<5$ & $\mu g / L$ & 5 & 5 & $<\mathrm{RL}$ \\
\hline Tetrachloroethylene & $<1$ & $<1$ & $<1$ & $<1$ & $\mu g / L$ & 1 & 1 & $<R L$ \\
\hline Toluene & $<1$ & $<1$ & $<1$ & $<1$ & $\mu \mathrm{g} / \mathrm{L}$ & 1 & 1 & $<R L$ \\
\hline Trichloroethylene & $<1$ & $<1$ & $<1$ & $<1$ & $\mu g / L$ & 1 & 1 & $<R L$ \\
\hline Trichlorofluoromethane & $<1$ & $<1$ & $<1$ & $<1$ & $\mu g / L$ & 1 & 1 & $<R L$ \\
\hline Vinyl chloride & $<1$ & $<1$ & $<1$ & $<1$ & $\mu g / L$ & 1 & 1 & $<\mathrm{RL}$ \\
\hline Xylene & $<1$ & $<1$ & $<1$ & $<1$ & $\mu g / L$ & 1 & 1 & $<\mathrm{RL}$ \\
\hline 1,2-Dichlorobenzene & $<5$ & $<5$ & $<5$ & $<5$ & $\mu g / L$ & 5 & 5 & $<R L$ \\
\hline 1,4-Dichlorobenzene & $<5$ & $<5$ & $<5$ & $<5$ & $\mu g / L$ & 5 & 5 & $<\mathrm{RL}$ \\
\hline 2,4-Dinitrophenol & $<20$ & $<20$ & $<5$ & $<5$ & $\mu g / L$ & 20 & 5 & $<R L$ \\
\hline 2,4-Dinitrotoluene & $<5$ & $<5$ & $<5$ & $<5$ & $\mu g / L$ & 5 & 5 & $<R L$ \\
\hline 2-Methylphenol & $<5$ & $<5$ & $<5$ & $<5$ & $\mu g / L$ & 5 & 5 & $<R L$ \\
\hline $\begin{array}{l}\text { 3-Methylphenol } \\
\text { 4-Methylphenol }\end{array}$ & $<5$ & $<5$ & $<5$ & $<5$ & $\mu g / L$ & 5 & 5 & $<R L$ \\
\hline Hexachlorobenzene & $<5$ & $<5$ & $<5$ & $<5$ & $\mu g / L$ & 5 & 5 & $<R L$ \\
\hline Hexachloroethane & $<5$ & $<5$ & $<5$ & $<5$ & $\mu g / L$ & 5 & 5 & $<R L$ \\
\hline Nitrobenzene & $<5$ & $<5$ & $<5$ & $<5$ & $\mu g / L$ & 5 & 5 & $<\mathrm{RL}$ \\
\hline Pentachlorophenol & $<5$ & $<5$ & $<5$ & $<5$ & $\mu g / L$ & 5 & 5 & $<R L$ \\
\hline Pyridine & $<5$ & $<5$ & $<5$ & $<5$ & $\mu \mathrm{g} / \mathrm{L}$ & 5 & 5 & $<\mathrm{RL}$ \\
\hline
\end{tabular}


Waste Isolation Pilot Plant Annual Site Environmental Report for 2008 DOE/WIPP-09-2225

\begin{tabular}{|c|c|c|c|c|c|c|c|c|}
\hline \multirow[b]{3}{*}{ Parameter } & \multicolumn{4}{|c|}{ Concentration } & \multirow[b]{3}{*}{ Units } & & & \multirow[b]{3}{*}{$\begin{array}{c}95^{\text {th }} \\
\text { UTLV }^{\mathrm{a}}\end{array}$} \\
\hline & \multicolumn{2}{|c|}{ Round 26} & \multicolumn{2}{|c|}{ Round 27} & & \multicolumn{2}{|c|}{ Reporting LIMIT } & \\
\hline & Sample & Dup. & Sample & Dup. & & $\begin{array}{c}\text { Round } \\
26\end{array}$ & $\begin{array}{c}\text { Round } \\
27\end{array}$ & \\
\hline Isobutanol & $<5$ & $<5$ & $<5$ & $<5$ & $\mu \mathrm{g} / \mathrm{L}$ & 5 & 5 & 2,000 \\
\hline Alkalinity & 52 & 50 & 46 & 46 & $\mathrm{mg} / \mathrm{L}$ & 4 & 4 & 55.8 \\
\hline Chloride & 5,030 & 5,100 & 5,340 & 5,340 & $\mathrm{mg} / \mathrm{L}$ & 0.5 & 0.5 & 6,200 \\
\hline Density & 1.01 & 1.02 & 1.010 & 1.007 & $\mathrm{~g} / \mathrm{ml}$ & $N / A^{c}$ & $\mathrm{~N} / \mathrm{A}^{\mathrm{c}}$ & 1.02 \\
\hline Nitrate (as N) & $<0.1$ & $<0.1$ & $<0.1$ & $<0.1$ & $\mathrm{mg} / \mathrm{L}$ & 0.1 & 0.1 & 7.45 \\
\hline $\mathrm{pH}$ & 7.83 & 7.86 & 7.73 & 7.73 & $S U^{d}$ & $N / A^{c}$ & $N / A^{c}$ & $7.50-7.90$ \\
\hline Specific conductance & 19,880 & 19,820 & 20,800 & 23,400 & $\mu \mathrm{mhos} / \mathrm{cm}$ & $\mathrm{N} / \mathrm{A}^{\mathrm{c}}$ & $N / A^{c}$ & 27,660 \\
\hline Sulfate & 4,450 & 4,580 & 4,600 & 4,570 & $\mathrm{mg} / \mathrm{L}$ & 0.5 & 0.5 & 5,557 \\
\hline Total dissolved solids & 14,880 & 15,300 & 15,300 & 15,300 & $\mathrm{mg} / \mathrm{L}$ & 10 & 10 & 22,500 \\
\hline Total organic carbon & $<1$ & $<1$ & $<1$ & $<1$ & $\mathrm{mg} / \mathrm{L}$ & 1 & 1 & 10.14 \\
\hline Total organic halogen & $<0.6$ & $<0.6$ & $<0.1$ & $<0.1$ & $\mathrm{mg} / \mathrm{L}$ & 0.6 & 0.1 & 1.54 \\
\hline Total suspended solids & 2.0 & 2.0 & 29 & 38 & $\mathrm{mg} / \mathrm{L}$ & 1 & 5 & 14.8 \\
\hline Antimony & $<0.025$ & $<0.025$ & $<0.01$ & $<0.01$ & $\mathrm{mg} / \mathrm{L}$ & 0.025 & 0.01 & 0.14 \\
\hline Arsenic & $<0.1$ & $<0.1$ & $<0.01$ & $<0.01$ & $\mathrm{mg} / \mathrm{L}$ & 0.1 & 0.01 & 0.5 \\
\hline Barium & $<0.02$ & $<0.02$ & $<0.02$ & $<0.02$ & $\mathrm{mg} / \mathrm{L}$ & 0.02 & 0.02 & 1 \\
\hline Beryllium & $<0.01$ & $<0.01$ & $<0.01$ & $<0.01$ & $\mathrm{mg} / \mathrm{L}$ & 0.01 & 0.01 & 0.02 \\
\hline Cadmium & $<0.01$ & $<0.01$ & $<0.01$ & $<0.01$ & $\mathrm{mg} / \mathrm{L}$ & 0.01 & 0.01 & 0.05 \\
\hline Calcium & 672 & 659 & 673 & 680 & $\mathrm{mg} / \mathrm{L}$ & 0.5 & 0.5 & 796 \\
\hline Chromium & $<0.025$ & $<0.025$ & $<0.025$ & $<0.025$ & $\mathrm{mg} / \mathrm{L}$ & 0.025 & 0.025 & 0.5 \\
\hline Iron & $<0.5$ & $<0.5$ & $<0.5$ & $<0.5$ & $\mathrm{mg} / \mathrm{L}$ & 0.5 & 0.5 & 3.105 \\
\hline Lead & $<0.02$ & $<0.02$ & $<0.02$ & $<0.02$ & $\mathrm{mg} / \mathrm{L}$ & 0.02 & 0.02 & 0.15 \\
\hline Magnesium & 205 & 198 & 211 & 202 & $\mathrm{mg} / \mathrm{L}$ & 0.5 & 0.5 & 255 \\
\hline Mercury & $<0.0002$ & $<0.0002$ & $<0.0002$ & $<0.0002$ & $\mathrm{mg} / \mathrm{L}$ & 0.0002 & 0.0002 & 0.002 \\
\hline Nickel & $<0.03$ & $<0.03$ & $<0.025$ & $<0.025$ & $\mathrm{mg} / \mathrm{L}$ & 0.03 & 0.025 & 0.5 \\
\hline Potassium & 184 & 167 & 157 & 143 & $\mathrm{mg} / \mathrm{L}$ & 0.5 & 0.5 & 270 \\
\hline Selenium & $<0.025$ & $<0.025$ & $<0.01$ & $<0.01$ & $\mathrm{mg} / \mathrm{L}$ & 0.025 & 0.01 & 0.1 \\
\hline Silver & $<0.013$ & $<0.013$ & $<0.013$ & $<0.013$ & $\mathrm{mg} / \mathrm{L}$ & 0.013 & 0.013 & 0.5 \\
\hline Sodium & 4,430 & 4,150 & 4,510 & 4,160 & $\mathrm{mg} / \mathrm{L}$ & 0.5 & 0.5 & 6,290 \\
\hline Thallium & $<0.025$ & $<0.025$ & $<0.01$ & $<0.01$ & $\mathrm{mg} / \mathrm{L}$ & 0.025 & 0.01 & 0.56 \\
\hline Vanadium & $<0.025$ & $<0.025$ & $<0.025$ & $<0.025$ & $\mathrm{mg} / \mathrm{L}$ & 0.025 & 0.025 & 0.1 \\
\hline
\end{tabular}

${ }^{\text {a }} 95^{\text {th }}$ Upper tolerance limit value, equivalent to $95 \%$ confidence limit

${ }^{\mathrm{b}}$ Reporting limit

${ }^{c}$ Not applicable

d Standard unit 
Table F.7 - Analytical Results for Groundwater Sampled from Well WQSP-6A

Concentration

\begin{tabular}{|c|c|c|c|c|c|c|c|c|}
\hline \multirow[b]{2}{*}{ Parameter } & \multicolumn{2}{|c|}{ Round 26} & \multicolumn{2}{|c|}{ Round 27} & \multirow[b]{2}{*}{ Units } & \multicolumn{2}{|c|}{ Reporting LIMIT } & \multirow[b]{2}{*}{$\begin{array}{l}95^{\text {th }} \\
\text { UTLV }^{\text {a }}\end{array}$} \\
\hline & Sample & Dup. & Sample & Dup. & & $\begin{array}{c}\text { Round } \\
26\end{array}$ & $\begin{array}{c}\text { Round } \\
27\end{array}$ & \\
\hline 1,1,1-Trichloroethane & $<1$ & $<1$ & $<1$ & $<1$ & $\mu \mathrm{g} / \mathrm{L}$ & 1 & 1 & $<\mathrm{RL}^{\mathrm{b}}$ \\
\hline 1,1,2,2-Tetrachloroethane & $<1$ & $<1$ & $<1$ & $<1$ & $\mu \mathrm{g} / \mathrm{L}$ & 1 & 1 & $<\mathrm{RL}$ \\
\hline 1,1,2-Trichloroethane & $<1$ & $<1$ & $<1$ & $<1$ & $\mu \mathrm{g} / \mathrm{L}$ & 1 & 1 & $<\mathrm{RL}$ \\
\hline 1,1-Dichloroethane & $<1$ & $<1$ & $<1$ & $<1$ & $\mu \mathrm{g} / \mathrm{L}$ & 1 & 1 & $<\mathrm{RL}$ \\
\hline 1,1-Dichloroethylene & $<1$ & $<1$ & $<1$ & $<1$ & $\mu g / L$ & 1 & 1 & $<\mathrm{RL}$ \\
\hline 1,2-Dichloroethane & $<1$ & $<1$ & $<1$ & $<1$ & $\mu \mathrm{g} / \mathrm{L}$ & 1 & 1 & $<\mathrm{RL}$ \\
\hline Carbon tetrachloride & $<1$ & $<1$ & $<1$ & $<1$ & $\mu g / L$ & 1 & 1 & $<\mathrm{RL}$ \\
\hline Chlorobenzene & $<1$ & $<1$ & $<1$ & $<1$ & $\mu \mathrm{g} / \mathrm{L}$ & 1 & 1 & $<\mathrm{RL}$ \\
\hline Chloroform & $<1$ & $<1$ & $<1$ & $<1$ & $\mu \mathrm{g} / \mathrm{L}$ & 1 & 1 & $<\mathrm{RL}$ \\
\hline cis-1,2-Dichloroethylene & $<1$ & $<1$ & $<1$ & $<1$ & $\mu \mathrm{g} / \mathrm{L}$ & 1 & 1 & $<\mathrm{RL}$ \\
\hline trans-1,2-Dichloroethylene & $<1$ & $<1$ & $<1$ & $<1$ & $\mu \mathrm{g} / \mathrm{L}$ & 1 & 1 & $<\mathrm{RL}$ \\
\hline Methyl ethyl ketone & $<5$ & $<5$ & $<5$ & $<5$ & $\mu g / L$ & 5 & 5 & $<\mathrm{RL}$ \\
\hline Methylene chloride & $<5$ & $<5$ & $<5$ & $<5$ & $\mu \mathrm{g} / \mathrm{L}$ & 5 & 5 & $<\mathrm{RL}$ \\
\hline Tetrachloroethylene & $<1$ & $<1$ & $<1$ & $<1$ & $\mu \mathrm{g} / \mathrm{L}$ & 1 & 1 & $<\mathrm{RL}$ \\
\hline Toluene & $<1$ & $<1$ & $<1$ & $<1$ & $\mu g / L$ & 1 & 1 & $<\mathrm{RL}$ \\
\hline Trichloroethylene & $<1$ & $<1$ & $<1$ & $<1$ & $\mu \mathrm{g} / \mathrm{L}$ & 1 & 1 & $<\mathrm{RL}$ \\
\hline Trichlorofluoromethane & $<1$ & $<1$ & $<1$ & $<1$ & $\mu \mathrm{g} / \mathrm{L}$ & 1 & 1 & $<\mathrm{RL}$ \\
\hline Vinyl chloride & $<1$ & $<1$ & $<1$ & $<1$ & $\mu g / L$ & 1 & 1 & $<\mathrm{RL}$ \\
\hline Xylene & $<1$ & $<1$ & $<1$ & $<1$ & $\mu \mathrm{g} / \mathrm{L}$ & 1 & 1 & $<\mathrm{RL}$ \\
\hline 1,2-Dichlorobenzene & $<5$ & $<5$ & $<5$ & $<5$ & $\mu \mathrm{g} / \mathrm{L}$ & 5 & 5 & $<\mathrm{RL}$ \\
\hline 1,4-Dichlorobenzene & $<5$ & $<5$ & $<5$ & $<5$ & $\mu \mathrm{g} / \mathrm{L}$ & 5 & 5 & $<\mathrm{RL}$ \\
\hline 2,4-Dinitrophenol & $<20$ & $<20$ & $<5$ & $<5$ & $\mu \mathrm{g} / \mathrm{L}$ & 20 & 5 & $<\mathrm{RL}$ \\
\hline 2,4-Dinitrotoluene & $<5$ & $<5$ & $<5$ & $<5$ & $\mu \mathrm{g} / \mathrm{L}$ & 5 & 5 & $<\mathrm{RL}$ \\
\hline 2-Methylphenol & $<5$ & $<5$ & $<5$ & $<5$ & $\mu g / L$ & 5 & 5 & $<\mathrm{RL}$ \\
\hline $\begin{array}{l}\text { 3-Methylphenol/ } \\
\text { 4-Methylphenol }\end{array}$ & $<5$ & $<5$ & $<5$ & $<5$ & $\mu \mathrm{g} / \mathrm{L}$ & 5 & 5 & $<\mathrm{RL}$ \\
\hline Hexachlorobenzene & $<5$ & $<5$ & $<5$ & $<5$ & $\mu \mathrm{g} / \mathrm{L}$ & 5 & 5 & $<R L$ \\
\hline Hexachloroethane & $<5$ & $<5$ & $<5$ & $<5$ & $\mu \mathrm{g} / \mathrm{L}$ & 5 & 5 & $<R L$ \\
\hline Nitrobenzene & $<5$ & $<5$ & $<5$ & $<5$ & $\mu \mathrm{g} / \mathrm{L}$ & 5 & 5 & $<\mathrm{RL}$ \\
\hline Pentachlorophenol & $<5$ & $<5$ & $<5$ & $<5$ & $\mu g / L$ & 5 & 5 & $<\mathrm{RL}$ \\
\hline Pyridine & $<5$ & $<5$ & $<5$ & $<5$ & $\mu \mathrm{g} / \mathrm{L}$ & 5 & 5 & $<\mathrm{RL}$ \\
\hline Isobutanol & $<5$ & $<5$ & $<5$ & $<5$ & $\mathrm{mg} / \mathrm{L}$ & 5 & 5 & $<\mathrm{RL}$ \\
\hline Alkalinity & 116 & 102 & 105 & 105 & $\mathrm{mg} / \mathrm{L}$ & 4 & 4 & 113 \\
\hline Chloride & 378 & 388 & 348 & 338 & $\mathrm{mg} / \mathrm{L}$ & 2.0 & 2 & 1040 \\
\hline Density & 1.00 & 0.999 & 1.00 & 1.00 & $\mathrm{~g} / \mathrm{ml}$ & $N / A^{c}$ & $N / A^{c}$ & 1.01 \\
\hline Nitrate (as N) & 4.67 & 4.98 & 5.69 & 5.82 & $\mathrm{mg} / \mathrm{L}$ & 0.1 & 0.1 & 12.2 \\
\hline $\mathrm{pH}$ & 7.14 & 7.16 & 7.34 & 7.30 & $S U^{d}$ & $N / A^{c}$ & $N / A^{c}$ & $6.80-8.00$ \\
\hline Specific conductance & 3,415 & 3,433 & 3,670 & 3,680 & $\mu \mathrm{mhos} / \mathrm{cm}$ & $N / A^{c}$ & $N / A^{c}$ & 5,192 \\
\hline Sulfate & 2,090 & 2,100 & 2,030 & 2,010 & mg/L & 2.0 & 2 & 2,543 \\
\hline Total dissolved solids & 3,400 & 3,360 & 3,510 & 3,530 & $\mathrm{mg} / \mathrm{L}$ & 10 & 10 & 4,600 \\
\hline Total organic carbon & $<3.9$ & $<1$ & $<1$ & $<1$ & $\mathrm{mg} / \mathrm{L}$ & 1 & 1 & 15.45 \\
\hline Total organic halogen & $<0.06$ & $<0.06$ & $<0.06$ & $<0.06$ & $\mathrm{mg} / \mathrm{L}$ & 0.06 & 0.06 & 0.19 \\
\hline Total suspended solids & $<1$ & $<1$ & $<5$ & $<5$ & $\mathrm{mg} / \mathrm{L}$ & 1 & $<5$ & 91 \\
\hline Antimony & $<0.013$ & $<0.013$ & $<0.01$ & $<0.01$ & $\mathrm{mg} / \mathrm{L}$ & 0.013 & 0.01 & 0.48 \\
\hline
\end{tabular}


Waste Isolation Pilot Plant Annual Site Environmental Report for 2008 DOE/WIPP-09-2225

\begin{tabular}{|c|c|c|c|c|c|c|c|c|}
\hline \multirow[b]{3}{*}{ Parameter } & \multicolumn{4}{|c|}{ Concentration } & \multirow[b]{3}{*}{ Units } & & & \multirow[b]{3}{*}{$\begin{array}{c}9^{\text {th }} \\
\text { UTLV }\end{array}$} \\
\hline & \multicolumn{2}{|c|}{ Round 26} & \multicolumn{2}{|c|}{$\begin{array}{r}\text { Round } 27 \\
\end{array}$} & & \multicolumn{2}{|c|}{ Reporting LIMIT } & \\
\hline & Sample & Dup. & Sample & Dup. & & $\begin{array}{c}\text { Round } \\
26\end{array}$ & $\begin{array}{c}\text { Round } \\
27 \\
\end{array}$ & \\
\hline Arsenic & $<0.1$ & $<0.1$ & $<0.01$ & $<0.01$ & $\mathrm{mg} / \mathrm{L}$ & 0.1 & 0.01 & 0.5 \\
\hline Barium & $<0.02$ & $<0.02$ & $<0.02$ & $<0.02$ & $\mathrm{mg} / \mathrm{L}$ & 0.02 & 0.02 & 0.1 \\
\hline Beryllium & $<0.01$ & $<0.01$ & $<0.01$ & $<0.01$ & $\mathrm{mg} / \mathrm{L}$ & 0.01 & 0.01 & 0.01 \\
\hline Cadmium & $<0.01$ & $<0.01$ & $<0.01$ & $<0.01$ & $\mathrm{mg} / \mathrm{L}$ & 0.01 & 0.01 & 0.05 \\
\hline Calcium & 638 & 649 & 590 & 607 & $\mathrm{mg} / \mathrm{L}$ & 0.5 & 0.5 & 733 \\
\hline Chromium & $<0.025$ & $<0.025$ & $<0.025$ & $<0.025$ & $\mathrm{mg} / \mathrm{L}$ & 0.025 & 0.025 & 0.5 \\
\hline Iron & $<0.50$ & $<0.50$ & $<0.50$ & $<0.50$ & $\mathrm{mg} / \mathrm{L}$ & 0.5 & 0.5 & 0.505 \\
\hline Lead & $<0.02$ & $<0.02$ & $<0.02$ & $<0.02$ & $\mathrm{mg} / \mathrm{L}$ & 0.02 & 0.02 & 0.05 \\
\hline Magnesium & 171 & 175 & 158 & 156 & $\mathrm{mg} / \mathrm{L}$ & 0.5 & 0.5 & 188 \\
\hline Mercury & $<0.0002$ & $<0.0002$ & $<0.0002$ & $<0.0002$ & $\mathrm{mg} / \mathrm{L}$ & 0.0002 & 0.0002 & 0.002 \\
\hline Nickel & 0.034 & 0.031 & 0.038 & 0.038 & $\mathrm{mg} / \mathrm{L}$ & 0.025 & 0.025 & 0.284 \\
\hline Potassium & 6.3 & 5.3 & 3.93 & 3.93 & $\mathrm{mg} / \mathrm{L}$ & 0.5 & 0.5 & 10.1 \\
\hline Selenium & $<0.025$ & $<0.025$ & $<0.02$ & $<0.02$ & $\mathrm{mg} / \mathrm{L}$ & 0.025 & 0.02 & 0.22 \\
\hline Silver & $<0.013$ & $<0.013$ & $<0.013$ & $<0.013$ & $\mathrm{mg} / \mathrm{L}$ & 0.013 & 0.013 & 0.5 \\
\hline Sodium & 253 & 256 & 221 & 218 & $\mathrm{mg} / \mathrm{L}$ & 0.5 & 0.5 & 369 \\
\hline Thallium & $<0.025$ & $<0.025$ & $<0.01$ & $<0.01$ & $\mathrm{mg} / \mathrm{L}$ & 0.025 & 0.01 & 0.058 \\
\hline Vanadium & $<0.05$ & $<0.05$ & 0.049 & 0.049 & $\mathrm{mg} / \mathrm{L}$ & 0.05 & 0.05 & 0.5 \\
\hline
\end{tabular}

${ }^{a} 95^{\text {th }}$ Upper tolerance limit value, equivalent to $95 \%$ confidence limit

${ }^{\mathrm{b}}$ Reporting limit

${ }^{\mathrm{C}}$ Not applicable

${ }^{\mathrm{d}}$ Standard unit 
Waste Isolation Pilot Plant Annual Site Environmental Report for 2008 DOE/WIPP-09-2225

\begin{tabular}{|c|c|c|c|c|c|c|c|}
\hline \multicolumn{4}{|c|}{ Sorted By Active Wells at Year-End } & \multicolumn{4}{|c|}{$\begin{array}{c}\text { Sorted By Formation for Wells Measured at } \\
\text { Least Once in } 2008\end{array}$} \\
\hline Count & $\begin{array}{c}\text { Well } \\
\text { Number }\end{array}$ & Zone & Notes & Count & $\begin{array}{l}\text { Well } \\
\text { Number }\end{array}$ & Zone & $\begin{array}{c}\text { Reason Not Assessed } \\
\text { for Long-Term Water } \\
\text { Level Trend in } \\
\text { Culebra } \\
\end{array}$ \\
\hline 1 & AEC-7 & CUL & & 1 & CB-1(PIP) & $B / C$ & \\
\hline 2 & C-2505 & SR/DL & & 2 & DOE-2 & $\mathrm{B} / \mathrm{C}$ & \\
\hline 3 & C-2506 & SR/DL & & 3 & AEC-7 & CUL & \\
\hline 4 & C-2507 & SR/DL & & 4 & ERDA-9 & CUL & \\
\hline 5 & C-2737 & MAG/CUL & & 5 & $\mathrm{H}-02 \mathrm{~b} 2$ & CUL & \\
\hline 6 & $\mathrm{C}-2811$ & $\mathrm{SR} / \mathrm{DL}$ & & 6 & $\mathrm{H}-03 \mathrm{~b} 2$ & CUL & \\
\hline 7 & CB-1(PIP) & $\mathrm{B} / \mathrm{C}$ & & 7 & $\mathrm{H}-04 \mathrm{~b}$ & CUL & \\
\hline 8 & DOE-2 & $\mathrm{B} / \mathrm{C}$ & & 8 & $\mathrm{H}-05 \mathrm{~b}$ & CUL & \\
\hline 9 & ERDA-9 & CUL & & 9 & $\mathrm{H}-06 \mathrm{bR}$ & CUL & $\begin{array}{l}\text { Four months data after } \\
\text { installation (July, Aug., } \\
\text { Sept., Oct.) }\end{array}$ \\
\hline 10 & $\mathrm{H}-02 \mathrm{~b} 1$ & MAG & & 10 & $\mathrm{H}-07 \mathrm{~b}$ & CUL & \\
\hline 11 & $\mathrm{H}-02 \mathrm{~b} 2$ & CUL & & 11 & $\mathrm{H}-10 \mathrm{c}$ & CUL & \\
\hline 12 & $\mathrm{H}-03 \mathrm{~b} 1$ & MAG & & 12 & $\mathrm{H}-11 \mathrm{~b} 4$ & CUL & \\
\hline 13 & $\mathrm{H}-03 \mathrm{~b} 2$ & CUL & & 13 & $\mathrm{H}-12$ & CUL & $\begin{array}{l}\text { Bailing in November } \\
\text { water level significantly }\end{array}$ \\
\hline 14 & $\mathrm{H}-03 \mathrm{~d}$ & $\mathrm{SR} / \mathrm{DL}$ & Dry; not measured in 2008 & 14 & $\mathrm{H}-17$ & CUL & \\
\hline 15 & $\mathrm{H}-04 \mathrm{~b}$ & CUL & & 15 & $\mathrm{H}-19 \mathrm{b0}$ & CUL & \\
\hline 16 & $\mathrm{H}-04 \mathrm{c}$ & MAG & & 16 & $\mathrm{H}-19 \mathrm{~b} 2$ & CUL & Redundant to H19B0 \\
\hline 17 & $\mathrm{H}-05 \mathrm{~b}$ & CUL & & 17 & $\mathrm{H}-19 \mathrm{~b} 3$ & CUL & Redundant to $\mathrm{H} 19 \mathrm{~B} 0$ \\
\hline 18 & $\mathrm{H}-06 \mathrm{bR}$ & CUL & & 18 & $\mathrm{H}-19 \mathrm{~b} 4$ & CUL & Redundant to H19B0 \\
\hline 19 & $\mathrm{H}-06 \mathrm{c}$ & MAG & & 19 & $\mathrm{H}-19 \mathrm{~b} 5$ & CUL & Redundant to $\mathrm{H} 19 \mathrm{~B} 0$ \\
\hline 20 & $\mathrm{H}-07 \mathrm{~b} 1$ & CUL & & 20 & $\mathrm{H}-19 \mathrm{~b} 6$ & CUL & Redundant to H19B0 \\
\hline 21 & $\mathrm{H}-08 \mathrm{~A}$ & MAG & & 21 & $\mathrm{H}-19 \mathrm{~b} 7$ & CUL & Redundant to H19B0 \\
\hline 22 & $\mathrm{H}-09 \mathrm{c}$ & MAG/CUL & & 22 & |-461 & CUL & \\
\hline 23 & $\mathrm{H}-10 \mathrm{a}$ & MAG & & 23 & SNL-1 & CUL & \\
\hline 24 & $\mathrm{H}-10 \mathrm{c}$ & CUL & & 24 & SNL-2 & CUL & \\
\hline 25 & $\mathrm{H}-11 \mathrm{~b} 2$ & MAG & & 25 & SNL-3 & CUL & \\
\hline 26 & $\mathrm{H}-11 \mathrm{~b} 4$ & CUL & & 26 & SNL-5 & CUL & \\
\hline 27 & $\mathrm{H}-12$ & CUL & & 27 & SNL-6 & CUL & $\begin{array}{l}\text { Still in recovery from } \\
\text { bailing January } 2008\end{array}$ \\
\hline 28 & $\mathrm{H}-14$ & MAG & & 28 & SNL-8 & CUL & \\
\hline 29 & $\mathrm{H}-15 \mathrm{R}$ & CUL & New in July 2008 & 29 & SNL-9 & CUL & \\
\hline 30 & $\mathrm{H}-15$ & MAG & $\begin{array}{l}\text { Reconfigured in June-July } \\
2008 \text { to Magenta only }\end{array}$ & 30 & $H-15 R$ & CUL & $\begin{array}{l}\text { Two months data after } \\
\text { installation (July and } \\
\text { August) }\end{array}$ \\
\hline 31 & $\mathrm{H}-16$ & CUL & $\begin{array}{l}\text { Reconfigured in } 2008 \text { to } \\
\text { Culebra only }\end{array}$ & 31 & SNL-10 & CUL & \\
\hline 32 & $\mathrm{H}-17$ & CUL & & 32 & $\mathrm{H}-16$ & CUL & $\begin{array}{l}\text { New well conversion } \\
\text { limited data; okay for } \\
\text { head map }\end{array}$ \\
\hline 33 & $\mathrm{H}-18$ & MAG & & 33 & SNL-12 & CUL & \\
\hline 34 & $\mathrm{H}-19 \mathrm{~b} 0$ & CUL & & 34 & SNL-13 & CUL & \\
\hline 35 & $\mathrm{H}-19 \mathrm{~b} 2$ & CUL & & 35 & SNL-14 & CUL & \\
\hline 36 & $\mathrm{H}-19 \mathrm{~b} 3$ & CUL & & 36 & SNL-15 & CUL & $\begin{array}{l}\text { Depressed from } \\
\text { projected equilibrium }\end{array}$ \\
\hline
\end{tabular}


Waste Isolation Pilot Plant Annual Site Environmental Report for 2008 DOE/WIPP-09-2225

\begin{tabular}{|c|c|c|c|c|c|c|c|}
\hline \multicolumn{8}{|c|}{ Table F.8 - WIPP Well Inventory for 2008} \\
\hline \multicolumn{4}{|c|}{ Sorted By Active Wells at Year-End } & \multicolumn{4}{|c|}{$\begin{array}{c}\text { Sorted By Formation for Wells Measured at } \\
\text { Least Once in } 2008\end{array}$} \\
\hline Count & $\begin{array}{c}\text { Well } \\
\text { Number }\end{array}$ & Zone & Notes & Count & $\begin{array}{l}\text { Well } \\
\text { Number }\end{array}$ & Zone & $\begin{array}{c}\text { Reason Not Assessed } \\
\text { for Long-Term Water } \\
\text { Level Trend in } \\
\text { Culebra }\end{array}$ \\
\hline 37 & $\mathrm{H}-19 \mathrm{~B} 4$ & CUL & & 37 & SNL-16 & CUL & \\
\hline 38 & $\mathrm{H}-19 \mathrm{~B} 5$ & CUL & & 38 & SNL-17 & CUL & \\
\hline 39 & $\mathrm{H}-19 \mathrm{~B} 6$ & CUL & & 39 & SNL-18 & CUL & \\
\hline 40 & $\mathrm{H}-19 \mathrm{~B} 7$ & CUL & & 40 & SNL-19 & CUL & \\
\hline 41 & |-461 & CUL & & 41 & WIPP-11 & CUL & \\
\hline 42 & SNL-01 & CUL & & 42 & WIPP-13 & CUL & \\
\hline 43 & SNL-02 & CUL & & 43 & WIPP-19 & CUL & \\
\hline 44 & SNL-03 & CUL & & 44 & WQSP-1 & CUL & \\
\hline 45 & SNL-05 & CUL & & 45 & WQSP-2 & CUL & \\
\hline 46 & SNL-06 & CUL & & 46 & WQSP-3 & CUL & \\
\hline 47 & SNL-08 & CUL & & 47 & WQSP-4 & CUL & \\
\hline 48 & SNL-09 & CUL & & 48 & WQSP-5 & CUL & \\
\hline 49 & SNL-10 & CUL & & 49 & WQSP-6 & CUL & \\
\hline 50 & SNL-12 & CUL & & 50 & WQSP-6A & $\mathrm{DL}$ & \\
\hline 51 & SNL-13 & CUL & & 51 & $\mathrm{H}-02 \mathrm{~B} 1$ & MAG & \\
\hline 52 & SNL-14 & CUL & & 52 & $\mathrm{H}-03 \mathrm{~B} 1$ & MAG & \\
\hline 53 & SNL-15 & CUL & & 53 & $\mathrm{H}-04 \mathrm{C}$ & MAG & \\
\hline 54 & SNL-16 & CUL & & 54 & $\mathrm{H}-06 \mathrm{C}$ & MAG & \\
\hline 55 & SNL-17 & CUL & & 55 & $\mathrm{H}-08 \mathrm{~A}$ & MAG & \\
\hline 56 & SNL-18 & CUL & & 56 & $\mathrm{H}-09 \mathrm{C}$ & MAG/CUL & \\
\hline 57 & SNL-19 & CUL & & 57 & $\mathrm{H}-10 \mathrm{~A}$ & MAG & \\
\hline 58 & PZ-01 & SR/DL & & 58 & $\mathrm{H}-11 \mathrm{~B} 2$ & MAG & \\
\hline 59 & PZ-02 & SR/DL & & 59 & $\mathrm{H}-14$ & MAG & \\
\hline 60 & PZ-03 & SR/DL & & 60 & $\mathrm{H}-15$ & MAG & \\
\hline 61 & PZ-04 & SR/DL & & 61 & $\mathrm{H}-18$ & MAG & \\
\hline 62 & PZ-05 & SR/DL & & 62 & WIPP-18 & MAG & \\
\hline 63 & PZ-06 & SR/DL & & 63 & C-2727 & MAG/CUL & $\begin{array}{l}\text { Swabbed tubing } \\
\text { June 26, 2008, altered } \\
\text { density; okay for head } \\
\text { map }\end{array}$ \\
\hline 64 & PZ-07 & SR/DL & & 64 & WIPP-30 & MAG/CUL & \\
\hline 65 & PZ-08 & SR/DL & & 65 & C-2505 & SR/DL & \\
\hline 66 & PZ-09 & SR/DL & & 66 & C-2506 & SR/DL & \\
\hline 67 & PZ-10 & SR/DL & & 67 & C-2507 & SR/DL & \\
\hline 68 & $P Z-11$ & SR/DL & & 68 & C-2811 & SR/DL & \\
\hline 69 & $P Z-12$ & SR/DL & & 69 & PZ-01 & $\mathrm{SR} / \mathrm{DL}$ & \\
\hline 70 & PZ-13 & SR/DL & & 70 & PZ-02 & SR/DL & \\
\hline 71 & PZ-14 & SR/DL & & 71 & PZ-03 & $\mathrm{SR} / \mathrm{DL}$ & \\
\hline 72 & PZ-15 & SR/DL & & 72 & PZ-04 & SR/DL & \\
\hline 73 & WIPP-11 & CUL & & 73 & PZ-05 & $\mathrm{SR} / \mathrm{DL}$ & \\
\hline 74 & WIPP-13 & CUL & & 74 & PZ-06 & SR/DL & \\
\hline 75 & WIPP-18 & MAG & & 75 & PZ-07 & SR/DL & \\
\hline 76 & WIPP-19 & CUL & & 76 & PZ-08 & SR/DL & \\
\hline 77 & WIPP-25 & MAG/CUL & & 77 & PZ-09 & $\mathrm{SR} / \mathrm{DL}$ & \\
\hline 78 & WQSP-1 & CUL & & 78 & PZ-10 & SR/DL & \\
\hline
\end{tabular}


Waste Isolation Pilot Plant Annual Site Environmental Report for 2008 DOE/WIPP-09-2225

\begin{tabular}{|c|c|c|c|c|c|c|c|}
\hline \multicolumn{8}{|c|}{ Table F.8 - WIPP Well Inventory for 2008} \\
\hline \multicolumn{4}{|c|}{ Sorted By Active Wells at Year-End } & \multicolumn{4}{|c|}{$\begin{array}{l}\text { Sorted By Formation for Wells Measured at } \\
\text { Least Once in } 2008\end{array}$} \\
\hline Count & $\begin{array}{l}\text { Well } \\
\text { Number }\end{array}$ & Zone & Notes & Count & $\begin{array}{l}\text { Well } \\
\text { Number }\end{array}$ & Zone & $\begin{array}{c}\text { Reason Not Assessed } \\
\text { for Long-Term Water } \\
\text { Level Trend in } \\
\text { Culebra }\end{array}$ \\
\hline 79 & WQSP-2 & CUL & & 79 & $P Z-11$ & SR/DL & \\
\hline 80 & WQSP-3 & CUL & & 80 & PZ-12 & SR/DL & \\
\hline 81 & WQSP-4 & CUL & & 81 & PZ-13 & SR/DL & \\
\hline 82 & WQSP-5 & CUL & & 82 & PZ-14 & SR/DL & \\
\hline 83 & WQSP-6 & CUL & & 83 & PZ-15 & SR/DL & \\
\hline 84 & WQSP-6A & & & & & & \\
\hline
\end{tabular}


Waste Isolation Pilot Plant Annual Site Environmental Report for 2008 DOE/WIPP-09-2225

Table F.9 - Water Levels

\begin{tabular}{|c|c|c|c|c|c|c|c|}
\hline $\begin{array}{c}\text { Well } \\
\text { Number }\end{array}$ & Zone & Date & $\begin{array}{c}\text { Adjusted } \\
\text { Depth } \\
\text { Top of } \\
\text { Casing } \\
\text { (ft) }\end{array}$ & $\begin{array}{l}\text { Adjusted } \\
\text { Depth } \\
\text { Meters }\end{array}$ & $\begin{array}{c}\text { Water } \\
\text { Level } \\
\text { Elevation } \\
\text { (ft amsl) }\end{array}$ & $\begin{array}{c}\text { Elevation } \\
\text { in } \\
\text { Meters } \\
(\text { amsl) }\end{array}$ & $\begin{array}{c}\text { Adjusted } \\
\text { Freshwater } \\
\text { Head } \\
\text { (ft amsl) }\end{array}$ \\
\hline AEC-7 & CUL & $01 / 14 / 08$ & 446.19 & 136.00 & $3,210.80$ & 978.65 & $3,301.28$ \\
\hline AEC-7 & CUL & $02 / 11 / 08$ & 440.92 & 134.39 & $3,216.07$ & 980.26 & $3,307.66$ \\
\hline AEC-7 & CUL & $08 / 15 / 08$ & 614.96 & 187.44 & $3,043.38$ & 927.62 & $3,063.56$ \\
\hline AEC-7 & CUL & $09 / 22 / 08$ & 614.50 & 187.30 & $3,043.84$ & 927.76 & $3,064.06$ \\
\hline AEC-7 & CUL & $10 / 14 / 08$ & 614.36 & 187.26 & $3,043.98$ & 927.81 & $3,064.21$ \\
\hline AEC-7 & CUL & $11 / 04 / 08$ & 614.29 & 187.24 & $3,044.05$ & 927.83 & $3,064.29$ \\
\hline AEC-7 & CUL & $12 / 01 / 08$ & 614.29 & 187.24 & $3,044.05$ & 927.83 & $3,064.29$ \\
\hline $\mathrm{C}-2737$ (PIP) & CUL & $01 / 17 / 08$ & 382.03 & 116.44 & $3,018.73$ & 920.11 & $3,021.82$ \\
\hline C-2737 (PIP) & CUL & $02 / 14 / 08$ & 381.70 & 116.34 & $3,019.06$ & 920.21 & $3,022.15$ \\
\hline C-2737 (PIP) & CUL & $03 / 27 / 08$ & 381.63 & 116.32 & $3,019.13$ & 920.23 & $3,022.22$ \\
\hline C-2737 (PIP) & CUL & 04/09/08 & 381.63 & 116.32 & $3,019.13$ & 920.23 & $3,022.22$ \\
\hline C-2737 (PIP) & CUL & $05 / 13 / 08$ & 381.88 & 116.40 & $3,018.88$ & 920.15 & $3,021.97$ \\
\hline C-2737 (PIP) & CUL & $06 / 11 / 08$ & 382.33 & 116.53 & $3,018.43$ & 920.02 & $3,021.52$ \\
\hline C-2737 (PIP) & CUL & $07 / 09 / 08$ & 386.50 & 117.81 & $3,014.26$ & 918.75 & $3,023.09$ \\
\hline C-2737 (PIP) & CUL & $08 / 15 / 08$ & 386.45 & 117.79 & $3,014.31$ & 918.76 & $3,023.14$ \\
\hline C-2737 (PIP) & CUL & $09 / 24 / 08$ & 386.00 & 117.65 & $3,014.76$ & 918.90 & $3,023.61$ \\
\hline C-2737 (PIP) & CUL & $10 / 15 / 08$ & 386.21 & 117.72 & $3,014.55$ & 918.83 & $3,017.97$ \\
\hline C-2737 (PIP) & CUL & $11 / 05 / 08$ & 385.84 & 117.60 & $3,014.92$ & 918.95 & $3,017.97$ \\
\hline C-2737 (PIP) & CUL & $12 / 03 / 08$ & 385.98 & 117.65 & $3,014.78$ & 918.90 & $3,023.63$ \\
\hline ERDA-9 & CUL & $01 / 17 / 08$ & 396.89 & 120.97 & $3,013.28$ & 918.45 & $3,028.33$ \\
\hline ERDA-9 & CUL & $02 / 14 / 08$ & 396.85 & 120.96 & $3,013.32$ & 918.46 & $3,028.38$ \\
\hline ERDA-9 & CUL & $03 / 27 / 08$ & 396.74 & 120.93 & $3,013.43$ & 918.49 & $3,028.49$ \\
\hline ERDA-9 & CUL & 04/09/08 & 396.53 & 120.86 & $3,013.64$ & 918.56 & $3,028.71$ \\
\hline ERDA-9 & CUL & $05 / 13 / 08$ & 396.67 & 120.91 & $3,013.50$ & 918.51 & $3,028.56$ \\
\hline ERDA-9 & CUL & $06 / 11 / 08$ & 396.55 & 120.87 & $3,013.62$ & 918.55 & $3,028.69$ \\
\hline ERDA-9 & CUL & 07/09/08 & 397.01 & 121.01 & $3,013.16$ & 918.41 & $3,028.21$ \\
\hline ERDA-9 & CUL & $08 / 15 / 08$ & 397.50 & 121.16 & $3,012.67$ & 918.26 & $3,027.69$ \\
\hline ERDA-9 & CUL & $09 / 24 / 08$ & 397.61 & 121.19 & $3,012.56$ & 918.23 & $3,027.58$ \\
\hline ERDA-9 & CUL & $10 / 15 / 08$ & 397.65 & 121.20 & $3,012.52$ & 918.22 & $3,027.54$ \\
\hline ERDA-9 & CUL & $11 / 07 / 08$ & 397.65 & 121.20 & $3,012.52$ & 918.22 & $3,027.54$ \\
\hline ERDA-9 & CUL & $12 / 03 / 08$ & 397.73 & 121.23 & $3,012.44$ & 918.19 & $3,027.45$ \\
\hline $\mathrm{H}-02 \mathrm{~b} 2$ & CUL & $01 / 17 / 08$ & 331.83 & 101.14 & $3,046.53$ & 928.58 & $3,050.78$ \\
\hline $\mathrm{H}-02 \mathrm{~b} 2$ & CUL & $02 / 14 / 08$ & 331.45 & 101.03 & $3,046.91$ & 928.70 & $3,051.17$ \\
\hline $\mathrm{H}-02 \mathrm{~b} 2$ & CUL & $03 / 25 / 08$ & 331.58 & 101.07 & $3,046.78$ & 928.66 & $3,051.04$ \\
\hline $\mathrm{H}-02 \mathrm{~b} 2$ & CUL & $04 / 09 / 08$ & 331.46 & 101.03 & $3,046.90$ & 928.70 & $3,051.16$ \\
\hline $\mathrm{H}-02 \mathrm{~b} 2$ & CUL & $05 / 13 / 08$ & 331.57 & 101.06 & $3,046.79$ & 928.66 & $3,051.05$ \\
\hline $\mathrm{H}-02 \mathrm{~b} 2$ & CUL & $06 / 11 / 08$ & 331.67 & 101.09 & $3,046.69$ & 928.63 & $3,050.94$ \\
\hline $\mathrm{H}-02 \mathrm{~b} 2$ & CUL & $07 / 09 / 08$ & 331.94 & 101.18 & $3,046.42$ & 928.55 & $3,050.67$ \\
\hline $\mathrm{H}-02 \mathrm{~b} 2$ & CUL & $08 / 14 / 08$ & 331.97 & 101.18 & $3,046.39$ & 928.54 & $3,050.64$ \\
\hline $\mathrm{H}-02 \mathrm{~b} 2$ & CUL & $09 / 24 / 08$ & 332.10 & 101.22 & $3,046.26$ & 928.50 & $3,050.51$ \\
\hline $\mathrm{H}-02 \mathrm{~b} 2$ & CUL & $10 / 13 / 08$ & 332.05 & 101.21 & $3,046.31$ & 928.52 & $3,050.56$ \\
\hline $\mathrm{H}-02 \mathrm{~b} 2$ & CUL & $11 / 04 / 08$ & 331.86 & 101.15 & $3,046.50$ & 928.57 & $3,050.75$ \\
\hline
\end{tabular}


Waste Isolation Pilot Plant Annual Site Environmental Report for 2008 DOE/WIPP-09-2225

Table F.9 - Water Levels

\begin{tabular}{|c|c|c|c|c|c|c|c|}
\hline $\begin{array}{c}\text { Well } \\
\text { Number }\end{array}$ & Zone & Date & $\begin{array}{c}\text { Adjusted } \\
\text { Depth } \\
\text { Top of } \\
\text { Casing } \\
\text { (ft) }\end{array}$ & $\begin{array}{c}\text { Adjusted } \\
\text { Depth } \\
\text { Meters }\end{array}$ & $\begin{array}{c}\text { Water } \\
\text { Level } \\
\text { Elevation } \\
\text { (ft amsl) }\end{array}$ & $\begin{array}{c}\text { Elevation } \\
\text { in } \\
\text { Meters } \\
\text { (amsl) }\end{array}$ & $\begin{array}{c}\text { Adjusted } \\
\text { Freshwater } \\
\text { Head } \\
\text { (ft amsl) }\end{array}$ \\
\hline $\mathrm{H}-02 \mathrm{~b} 2$ & CUL & $12 / 03 / 08$ & 332.05 & 101.21 & $3,046.31$ & 928.52 & $3,050.56$ \\
\hline $\mathrm{H}-03 \mathrm{~b} 2$ & CUL & $01 / 17 / 08$ & 387.40 & 118.08 & $3,002.51$ & 915.17 & $3,015.12$ \\
\hline $\mathrm{H}-03 \mathrm{~b} 2$ & CUL & $02 / 14 / 08$ & 387.05 & 117.97 & $3,002.86$ & 915.27 & $3,015.49$ \\
\hline $\mathrm{H}-03 \mathrm{~b} 2$ & CUL & $03 / 26 / 08$ & 387.11 & 117.99 & $3,002.80$ & 915.25 & $3,015.43$ \\
\hline $\mathrm{H}-03 \mathrm{~b} 2$ & CUL & $04 / 09 / 08$ & 387.46 & 118.10 & $3,002.45$ & 915.15 & $3,015.06$ \\
\hline $\mathrm{H}-03 \mathrm{~b} 2$ & CUL & $05 / 13 / 08$ & 387.34 & 118.06 & $3,002.57$ & 915.18 & $3,015.19$ \\
\hline $\mathrm{H}-03 \mathrm{~b} 2$ & CUL & $06 / 11 / 08$ & 387.18 & 118.01 & $3,002.73$ & 915.23 & $3,015.35$ \\
\hline $\mathrm{H}-03 \mathrm{~b} 2$ & CUL & $07 / 09 / 08$ & 387.34 & 118.06 & $3,002.57$ & 915.18 & $3,015.19$ \\
\hline $\mathrm{H}-03 \mathrm{~b} 2$ & CUL & $08 / 15 / 08$ & 387.24 & 118.03 & $3,002.67$ & 915.21 & $3,015.29$ \\
\hline $\mathrm{H}-03 \mathrm{~b} 2$ & CUL & $09 / 24 / 08$ & 387.33 & 118.06 & $3,002.58$ & 915.19 & $3,015.20$ \\
\hline $\mathrm{H}-03 \mathrm{~b} 2$ & CUL & $10 / 14 / 08$ & 388.06 & 118.28 & $3,001.85$ & 914.96 & $3,014.44$ \\
\hline $\mathrm{H}-03 \mathrm{~b} 2$ & CUL & $11 / 05 / 08$ & 387.22 & 118.02 & $3,002.69$ & 915.22 & $3,015.31$ \\
\hline $\mathrm{H}-03 \mathrm{~b} 2$ & CUL & $12 / 03 / 08$ & 387.32 & 118.06 & $3,002.59$ & 915.19 & $3,015.21$ \\
\hline $\mathrm{H}-04 \mathrm{~b}$ & CUL & $01 / 17 / 08$ & 329.00 & 100.28 & $3,004.58$ & 915.80 & $3,007.21$ \\
\hline $\mathrm{H}-04 \mathrm{~b}$ & $\overline{C U L}$ & $02 / 14 / 08$ & 328.80 & 100.22 & $3,004.78$ & 915.86 & $3,007.41$ \\
\hline $\mathrm{H}-04 \mathrm{~b}$ & CUL & $03 / 25 / 08$ & 329.07 & 100.30 & $3,004.51$ & 915.77 & $3,007.14$ \\
\hline $\mathrm{H}-04 \mathrm{~b}$ & CUL & $04 / 08 / 08$ & 328.96 & 100.27 & $3,004.62$ & 915.81 & $3,007.25$ \\
\hline $\mathrm{H}-04 \mathrm{~b}$ & CUL & $05 / 13 / 08$ & 328.89 & 100.25 & $3,004.69$ & 915.83 & $3,007.32$ \\
\hline $\mathrm{H}-04 \mathrm{~b}$ & CUL & $06 / 10 / 08$ & 329.00 & 100.28 & $3,004.58$ & 915.80 & $3,007.21$ \\
\hline $\mathrm{H}-04 \mathrm{~b}$ & $\overline{\text { CUL }}$ & $07 / 09 / 08$ & 329.19 & 100.34 & $3,004.39$ & 915.74 & $3,007.01$ \\
\hline $\mathrm{H}-04 \mathrm{~b}$ & CUL & $08 / 11 / 08$ & 329.21 & 100.34 & $3,004.37$ & 915.73 & $3,006.99$ \\
\hline $\mathrm{H}-04 \mathrm{~b}$ & CUL & $09 / 24 / 08$ & 329.38 & 100.40 & $3,004.20$ & 915.68 & $3,006.82$ \\
\hline $\mathrm{H}-04 \mathrm{~b}$ & $\overline{\text { CUL }}$ & $10 / 13 / 08$ & 329.21 & 100.34 & $3,004.37$ & 915.73 & $3,006.99$ \\
\hline $\mathrm{H}-04 \mathrm{~b}$ & CUL & $11 / 04 / 08$ & 329.03 & 100.29 & $3,004.55$ & 915.79 & $3,007.18$ \\
\hline $\mathrm{H}-04 \mathrm{~b}$ & CUL & $12 / 02 / 08$ & 329.18 & 100.33 & $3,004.40$ & 915.74 & $3,007.02$ \\
\hline $\mathrm{H}-05 \mathrm{~b}$ & $\overline{C U L}$ & $01 / 14 / 08$ & 467.10 & 142.37 & $3,039.68$ & 926.49 & $3,080.01$ \\
\hline $\mathrm{H}-05 \mathrm{~b}$ & CUL & $02 / 11 / 08$ & 466.97 & 142.33 & $3,039.81$ & 926.53 & $3,080.15$ \\
\hline $\mathrm{H}-05 \mathrm{~b}$ & CUL & $03 / 24 / 08$ & 466.99 & 142.34 & $3,039.79$ & 926.53 & $3,080.13$ \\
\hline $\mathrm{H}-05 \mathrm{~b}$ & CUL & $04 / 07 / 08$ & 466.67 & 142.24 & $3,040.11$ & 926.63 & $3,080.48$ \\
\hline $\mathrm{H}-05 \mathrm{~b}$ & $\overline{\text { CUL }}$ & $05 / 12 / 08$ & 466.70 & 142.25 & $3,040.08$ & 926.62 & $3,080.45$ \\
\hline $\mathrm{H}-05 \mathrm{~b}$ & CUL & $06 / 09 / 08$ & 466.59 & 142.22 & $3,040.19$ & 926.65 & $3,080.57$ \\
\hline $\mathrm{H}-05 \mathrm{~b}$ & CUL & $07 / 07 / 08$ & 466.68 & 142.24 & $3,040.10$ & 926.62 & $3,080.47$ \\
\hline $\mathrm{H}-05 \mathrm{~b}$ & CUL & $08 / 12 / 08$ & 466.63 & 142.23 & $3,040.15$ & 926.64 & $3,080.52$ \\
\hline $\mathrm{H}-05 \mathrm{~b}$ & CUL & $09 / 22 / 08$ & 466.70 & 142.25 & $3,040.08$ & 926.62 & $3,080.45$ \\
\hline $\mathrm{H}-05 \mathrm{~b}$ & CUL & $10 / 14 / 08$ & 466.63 & 142.23 & $3,040.15$ & 926.64 & $3,080.52$ \\
\hline $\mathrm{H}-05 \mathrm{~b}$ & CUL & $11 / 04 / 08$ & 466.53 & 142.20 & $3,040.25$ & 926.67 & $3,080.63$ \\
\hline $\mathrm{H}-05 \mathrm{~b}$ & $\overline{\text { CUL }}$ & $12 / 01 / 08$ & 466.57 & 142.21 & $3,040.21$ & 926.66 & $3,080.59$ \\
\hline $\mathrm{H}-06 \mathrm{~b}$ & CUL & $01 / 15 / 08$ & 287.28 & 87.56 & $3,060.41$ & 932.81 & $3,071.60$ \\
\hline $\mathrm{H}-06 \mathrm{~b}$ & CUL & $02 / 14 / 08$ & 287.31 & 87.57 & $3,060.38$ & 932.80 & $3,071.57$ \\
\hline $\mathrm{H}-06 \mathrm{bR}$ & $\overline{\text { CUL }}$ & $07 / 08 / 08$ & 285.36 & 86.98 & $3,063.86$ & 933.86 & $3,074.81$ \\
\hline $\mathrm{H}-06 \mathrm{bR}$ & CUL & $08 / 14 / 08$ & 285.63 & 87.06 & $3,063.59$ & 933.78 & $3,074.54$ \\
\hline $\mathrm{H}-06 \mathrm{bR}$ & CUL & $09 / 23 / 08$ & 285.94 & 87.15 & $3,063.28$ & 933.69 & $3,074.22$ \\
\hline
\end{tabular}


Waste Isolation Pilot Plant Annual Site Environmental Report for 2008 DOE/WIPP-09-2225

Table F.9 - Water Levels

\begin{tabular}{|c|c|c|c|c|c|c|c|}
\hline $\begin{array}{c}\text { Well } \\
\text { Number }\end{array}$ & Zone & Date & $\begin{array}{c}\text { Adjusted } \\
\text { Depth } \\
\text { Top of } \\
\text { Casing } \\
\text { (ft) }\end{array}$ & $\begin{array}{c}\text { Adjusted } \\
\text { Depth } \\
\text { Meters }\end{array}$ & $\begin{array}{c}\text { Water } \\
\text { Level } \\
\text { Elevation } \\
\text { (ft amsl) }\end{array}$ & $\begin{array}{c}\text { Elevation } \\
\text { in } \\
\text { Meters } \\
\text { (amsl) }\end{array}$ & $\begin{array}{c}\text { Adjusted } \\
\text { Freshwater } \\
\text { Head } \\
\text { (ft amsl) }\end{array}$ \\
\hline $\mathrm{H}-06 \mathrm{bR}$ & CUL & $10 / 13 / 08$ & 286.20 & 87.23 & $3,063.02$ & 933.61 & $3,073.95$ \\
\hline $\mathrm{H}-07 \mathrm{~b} 1$ & CUL & $01 / 14 / 08$ & 163.86 & 49.94 & $2,999.86$ & 914.36 & $3,000.07$ \\
\hline $\mathrm{H}-07 \mathrm{~b} 1$ & CUL & $02 / 13 / 08$ & 163.87 & 49.95 & $2,999.85$ & 914.35 & $3,000.06$ \\
\hline $\mathrm{H}-07 \mathrm{~b} 1$ & CUL & $03 / 24 / 08$ & 164.11 & 50.02 & $2,999.61$ & 914.28 & $2,999.82$ \\
\hline $\mathrm{H}-07 \mathrm{~b} 1$ & CUL & $04 / 07 / 08$ & 163.95 & 49.97 & $2,999.77$ & 914.33 & $2,999.98$ \\
\hline $\mathrm{H}-07 \mathrm{~b} 1$ & CUL & $05 / 12 / 08$ & 163.89 & 49.95 & $2,999.83$ & 914.35 & $3,000.04$ \\
\hline $\mathrm{H}-07 \mathrm{~b} 1$ & CUL & $06 / 10 / 08$ & 164.24 & 50.06 & $2,999.48$ & 914.24 & $2,999.69$ \\
\hline $\mathrm{H}-07 \mathrm{~b} 1$ & CUL & $07 / 08 / 08$ & 164.39 & 50.11 & $2,999.33$ & 914.20 & $2,999.54$ \\
\hline $\mathrm{H}-07 \mathrm{~b} 1$ & CUL & $08 / 12 / 08$ & 164.41 & 50.11 & $2,999.31$ & 914.19 & $2,999.52$ \\
\hline $\mathrm{H}-07 \mathrm{~b} 1$ & CUL & $09 / 23 / 08$ & 164.69 & 50.20 & $2,999.03$ & 914.10 & $2,999.24$ \\
\hline $\mathrm{H}-07 \mathrm{~b} 1$ & CUL & $10 / 13 / 08$ & 164.64 & 50.18 & $2,999.08$ & 914.12 & $2,999.29$ \\
\hline $\mathrm{H}-07 \mathrm{~b} 1$ & CUL & $11 / 05 / 08$ & 164.43 & 50.12 & $2,999.29$ & 914.18 & $2,999.50$ \\
\hline $\mathrm{H}-07 \mathrm{~b} 1$ & CUL & $12 / 01 / 08$ & 164.91 & 50.26 & $2,998.81$ & 914.04 & $2,999.02$ \\
\hline $\mathrm{H}-09 \mathrm{c}(\mathrm{PIP})$ & CUL & $01 / 14 / 08$ & 411.12 & 125.31 & $2,995.93$ & 913.16 & $2,996.18$ \\
\hline $\mathrm{H}-09 \mathrm{c}$ (PIP) & $\overline{\text { CUL }}$ & $02 / 11 / 08$ & 410.90 & 125.24 & $2,996.15$ & 913.23 & $2,996.40$ \\
\hline $\mathrm{H}-09 \mathrm{c}$ (PIP) & CUL & $03 / 24 / 08$ & 410.93 & 125.25 & $2,996.12$ & 913.22 & $2,996.37$ \\
\hline $\mathrm{H}-09 \mathrm{c}$ (PIP) & CUL & $04 / 07 / 08$ & 410.28 & 125.05 & $2,996.77$ & 913.42 & $2,997.02$ \\
\hline $\mathrm{H}-09 \mathrm{c}(\mathrm{PIP})$ & CUL & $05 / 14 / 08$ & 410.03 & 124.98 & $2,997.02$ & 913.49 & $2,997.27$ \\
\hline $\mathrm{H}-09 \mathrm{c}(\mathrm{PIP})$ & CUL & $06 / 10 / 08$ & 410.45 & 125.11 & $2,996.60$ & 913.36 & $2,996.85$ \\
\hline $\mathrm{H}-09 \mathrm{c}$ (PIP) & CUL & $07 / 08 / 08$ & 410.58 & 125.14 & $2,996.47$ & 913.32 & $2,996.72$ \\
\hline $\mathrm{H}-09 \mathrm{c}$ (PIP) & CUL & $08 / 12 / 08$ & 410.66 & 125.17 & $2,996.39$ & 913.30 & $2,996.64$ \\
\hline $\mathrm{H}-09 \mathrm{c}$ (PIP) & CUL & $09 / 23 / 08$ & 410.05 & 124.98 & $2,997.00$ & 913.49 & $2,997.25$ \\
\hline $\mathrm{H}-09 \mathrm{c}(\mathrm{PIP})$ & CUL & $10 / 14 / 08$ & 410.19 & 125.03 & $2,996.86$ & 913.44 & $2,997.11$ \\
\hline $\mathrm{H}-09 \mathrm{c}$ (PIP) & CUL & $11 / 05 / 08$ & 410.41 & 125.09 & $2,996.64$ & 913.38 & $2,996.89$ \\
\hline $\mathrm{H}-09 \mathrm{c}$ (PIP) & CUL & $12 / 01 / 08$ & 410.68 & 125.18 & $2,996.37$ & 913.29 & $2,996.62$ \\
\hline $\mathrm{H}-10 \mathrm{c}$ & CUL & $01 / 14 / 08$ & 664.55 & 202.55 & $3,023.85$ & 921.67 & $3,029.51$ \\
\hline $\mathrm{H}-10 \mathrm{c}$ & CUL & $02 / 11 / 08$ & 664.60 & 202.57 & $3,023.80$ & 921.65 & $3,029.46$ \\
\hline $\mathrm{H}-10 \mathrm{c}$ & CUL & $03 / 24 / 08$ & 664.87 & 202.65 & $3,023.53$ & 921.57 & $3,029.19$ \\
\hline $\mathrm{H}-10 \mathrm{c}$ & CUL & $04 / 07 / 08$ & 664.60 & 202.57 & $3,023.80$ & 921.65 & $3,029.46$ \\
\hline $\mathrm{H}-10 \mathrm{c}$ & $\overline{\text { CUL }}$ & $05 / 15 / 08$ & 664.63 & 202.58 & $3,023.77$ & 921.65 & $3,029.43$ \\
\hline $\mathrm{H}-10 \mathrm{c}$ & CUL & $06 / 10 / 08$ & 664.69 & 202.60 & $3,023.71$ & 921.63 & $3,029.37$ \\
\hline $\mathrm{H}-10 \mathrm{c}$ & CUL & $07 / 07 / 08$ & 664.82 & 202.64 & $3,023.58$ & 921.59 & $3,029.24$ \\
\hline $\mathrm{H}-10 \mathrm{c}$ & CUL & $08 / 12 / 08$ & 664.82 & 202.64 & $3,023.58$ & 921.59 & $3,029.24$ \\
\hline $\mathrm{H}-10 \mathrm{c}$ & CUL & $09 / 23 / 08$ & 664.95 & 202.68 & $3,023.45$ & 921.55 & $3,029.11$ \\
\hline $\mathrm{H}-10 \mathrm{c}$ & $\overline{\text { CUL }}$ & $10 / 14 / 08$ & 664.88 & 202.66 & $3,023.52$ & 921.57 & $3,029.18$ \\
\hline $\mathrm{H}-10 \mathrm{c}$ & CUL & $11 / 05 / 08$ & 664.65 & 202.59 & $3,023.75$ & 921.64 & $3,029.41$ \\
\hline $\mathrm{H}-10 \mathrm{c}$ & CUL & $12 / 01 / 08$ & 664.82 & 202.64 & $3,023.58$ & 921.59 & $3,029.24$ \\
\hline $\mathrm{H}-11 \mathrm{~b} 4$ & CUL & $01 / 15 / 08$ & 422.62 & 128.81 & $2,988.17$ & 910.79 & $3,010.12$ \\
\hline $\mathrm{H}-11 \mathrm{~b} 4$ & CUL & $02 / 14 / 08$ & 422.57 & 128.80 & $2,988.22$ & 910.81 & $3,010.17$ \\
\hline $\mathrm{H}-11 \mathrm{~b} 4$ & $\overline{\text { CUL }}$ & $03 / 24 / 08$ & 422.92 & 128.91 & $2,987.87$ & 910.70 & $3,009.80$ \\
\hline $\mathrm{H}-11 \mathrm{~b} 4$ & CUL & $04 / 09 / 08$ & 422.57 & 128.80 & $2,988.22$ & 910.81 & $3,010.17$ \\
\hline $\mathrm{H}-11 \mathrm{~b} 4$ & CUL & $05 / 12 / 08$ & 422.65 & 128.82 & $2,988.14$ & 910.79 & $3,010.09$ \\
\hline
\end{tabular}


Waste Isolation Pilot Plant Annual Site Environmental Report for 2008 DOE/WIPP-09-2225

Table F.9 - Water Levels

\begin{tabular}{|c|c|c|c|c|c|c|c|}
\hline $\begin{array}{c}\text { Well } \\
\text { Number }\end{array}$ & Zone & Date & $\begin{array}{c}\text { Adjusted } \\
\text { Depth } \\
\text { Top of } \\
\text { Casing } \\
\text { (ft) }\end{array}$ & $\begin{array}{l}\text { Adjusted } \\
\text { Depth } \\
\text { Meters }\end{array}$ & $\begin{array}{c}\text { Water } \\
\text { Level } \\
\text { Elevation } \\
\text { (ft amsl) }\end{array}$ & $\begin{array}{c}\text { Elevation } \\
\text { in } \\
\text { Meters } \\
\text { (amsl) }\end{array}$ & $\begin{array}{c}\text { Adjusted } \\
\text { Freshwater } \\
\text { Head } \\
\text { (ft amsl) }\end{array}$ \\
\hline $\mathrm{H}-11 \mathrm{~b} 4$ & CUL & $06 / 09 / 08$ & 422.71 & 128.84 & $2,988.08$ & 910.77 & $3,010.02$ \\
\hline $\mathrm{H}-11 \mathrm{~b} 4$ & CUL & $07 / 07 / 08$ & 422.74 & 128.85 & $2,988.05$ & 910.76 & $3,009.99$ \\
\hline $\mathrm{H}-11 \mathrm{~b} 4$ & $\overline{C U L}$ & $08 / 14 / 08$ & 422.83 & 128.88 & $2,987.96$ & 910.73 & $3,009.90$ \\
\hline $\mathrm{H}-11 \mathrm{~b} 4$ & $\overline{C U L}$ & $09 / 22 / 08$ & 422.81 & 128.87 & $2,987.98$ & 910.74 & $3,009.92$ \\
\hline $\mathrm{H}-11 \mathrm{~b} 4$ & CUL & $10 / 14 / 08$ & 422.75 & 128.85 & $2,988.04$ & 910.75 & $3,009.98$ \\
\hline $\mathrm{H}-11 \mathrm{~b} 4$ & CUL & $11 / 05 / 08$ & 422.38 & 128.74 & $2,988.41$ & 910.87 & $3,010.38$ \\
\hline $\mathrm{H}-11 \mathrm{~b} 4$ & $\overline{C U L}$ & $12 / 02 / 08$ & 422.62 & 128.81 & $2,988.17$ & 910.79 & $3,010.12$ \\
\hline $\mathrm{H}-12$ & $\overline{\text { CUL }}$ & $01 / 14 / 08$ & 457.00 & 139.29 & $2,970.33$ & 905.36 & $3,007.33$ \\
\hline $\mathrm{H}-12$ & $\overline{C U L}$ & $02 / 11 / 08$ & 456.88 & 139.26 & $2,970.45$ & 905.39 & $3,007.46$ \\
\hline $\mathrm{H}-12$ & CUL & $03 / 24 / 08$ & 456.92 & 139.27 & $2,970.41$ & 905.38 & $3,007.42$ \\
\hline $\mathrm{H}-12$ & CUL & $04 / 07 / 08$ & 456.62 & 139.18 & $2,970.71$ & 905.47 & $3,007.75$ \\
\hline $\mathrm{H}-12$ & $\overline{C U L}$ & $05 / 15 / 08$ & 456.51 & 139.14 & $2,970.82$ & 905.51 & $3,007.87$ \\
\hline $\mathrm{H}-12$ & $\overline{\text { CUL }}$ & $06 / 10 / 08$ & 456.52 & 139.15 & $2,970.81$ & 905.50 & $3,007.86$ \\
\hline $\mathrm{H}-12$ & CUL & $07 / 07 / 08$ & 456.58 & 139.17 & $2,970.75$ & 905.48 & $3,007.79$ \\
\hline $\mathrm{H}-12$ & CUL & $08 / 12 / 08$ & 456.51 & 139.14 & $2,970.82$ & 905.51 & $3,007.87$ \\
\hline $\mathrm{H}-12$ & $\overline{C U L}$ & $09 / 23 / 08$ & 456.65 & 139.19 & $2,970.68$ & 905.46 & $3,007.71$ \\
\hline $\mathrm{H}-12$ & $\overline{\text { CUL }}$ & $10 / 14 / 08$ & 456.53 & 139.15 & $2,970.80$ & 905.50 & $3,007.84$ \\
\hline $\mathrm{H}-12$ & CUL & $11 / 05 / 08$ & 456.38 & 139.10 & $2,970.95$ & 905.55 & $3,008.01$ \\
\hline $\mathrm{H}-12$ & CUL & $12 / 01 / 08$ & 447.78 & 136.48 & $2,979.55$ & 908.17 & $3,017.44$ \\
\hline $\mathrm{H}-15$ (PIP) & $\overline{\text { CUL }}$ & $01 / 17 / 08$ & 484.59 & 147.70 & $2,996.30$ & 913.27 & $3,016.83$ \\
\hline $\mathrm{H}-15$ (PIP) & $\overline{C U L}$ & $02 / 14 / 08$ & 486.33 & 148.23 & $2,994.56$ & 912.74 & $3,014.99$ \\
\hline $\mathrm{H}-15 \mathrm{R}$ & $\overline{C U L}$ & $07 / 09 / 08$ & 513.30 & 156.45 & $2,968.72$ & 904.87 & $3,015.44$ \\
\hline $\mathrm{H}-15 \mathrm{R}$ & CUL & $08 / 15 / 08$ & 509.26 & 155.22 & $2,972.76$ & 906.10 & $3,020.01$ \\
\hline $\mathrm{H}-16$ & $\overline{C U L}$ & $09 / 25 / 08$ & 372.93 & 113.67 & $3,037.13$ & 925.72 & $3,050.45$ \\
\hline $\mathrm{H}-16$ & CUL & $10 / 15 / 08$ & 373.05 & 113.71 & $3,037.01$ & 925.68 & $3,050.32$ \\
\hline $\mathrm{H}-16$ & CUL & $11 / 07 / 08$ & 372.22 & 113.45 & $3,037.84$ & 925.93 & $3,051.19$ \\
\hline $\mathrm{H}-16$ & $\overline{C U L}$ & $12 / 04 / 08$ & 373.61 & 113.88 & $3,036.45$ & 925.51 & $3,049.74$ \\
\hline $\mathrm{H}-17$ & CUL & $01 / 15 / 08$ & 418.16 & 127.46 & $2,967.08$ & 904.37 & $3,007.28$ \\
\hline $\mathrm{H}-17$ & CUL & $02 / 14 / 08$ & 417.96 & 127.39 & $2,967.28$ & 904.43 & $3,007.51$ \\
\hline $\mathrm{H}-17$ & CUL & $03 / 24 / 08$ & 418.24 & 127.48 & $2,967.00$ & 904.34 & $3,007.19$ \\
\hline $\mathrm{H}-17$ & $\overline{\text { CUL }}$ & $04 / 09 / 08$ & 417.95 & 127.39 & $2,967.29$ & 904.43 & $3,007.52$ \\
\hline $\mathrm{H}-17$ & CUL & $05 / 12 / 08$ & 417.96 & 127.39 & $2,967.28$ & 904.43 & $3,007.51$ \\
\hline $\mathrm{H}-17$ & CUL & $06 / 09 / 08$ & 417.80 & 127.35 & $2,967.44$ & 904.48 & $3,007.69$ \\
\hline $\mathrm{H}-17$ & CUL & $07 / 07 / 08$ & 417.90 & 127.38 & $2,967.34$ & 904.45 & $3,007.58$ \\
\hline $\mathrm{H}-17$ & CUL & $08 / 14 / 08$ & 417.93 & 127.39 & $2,967.31$ & 904.44 & $3,007.54$ \\
\hline $\mathrm{H}-17$ & $\overline{\text { CUL }}$ & $09 / 22 / 08$ & 417.95 & 127.39 & $2,967.29$ & 904.43 & $3,007.52$ \\
\hline $\mathrm{H}-17$ & CUL & $10 / 14 / 08$ & 417.85 & 127.36 & $2,967.39$ & 904.46 & $3,007.63$ \\
\hline $\mathrm{H}-17$ & CUL & $11 / 05 / 08$ & 417.60 & 127.28 & $2,967.64$ & 904.54 & $3,007.92$ \\
\hline $\mathrm{H}-17$ & CUL & $12 / 02 / 08$ & 417.88 & 127.37 & $2,967.36$ & 904.45 & $3,007.60$ \\
\hline $\mathrm{H}-19 \mathrm{b0}$ & CUL & $01 / 16 / 08$ & 424.79 & 129.48 & $2,993.54$ & 912.43 & $3,015.92$ \\
\hline $\mathrm{H}-19 \mathrm{b0}$ & $\overline{C U L}$ & $02 / 14 / 08$ & 424.67 & 129.44 & $2,993.66$ & 912.47 & $3,016.05$ \\
\hline $\mathrm{H}-19 \mathrm{~b} 0$ & CUL & $03 / 26 / 08$ & 424.77 & 129.47 & $2,993.56$ & 912.44 & $3,015.94$ \\
\hline
\end{tabular}


Waste Isolation Pilot Plant Annual Site Environmental Report for 2008 DOE/WIPP-09-2225

Table F.9 - Water Levels

\begin{tabular}{|c|c|c|c|c|c|c|c|}
\hline $\begin{array}{c}\text { Well } \\
\text { Number }\end{array}$ & Zone & Date & $\begin{array}{c}\text { Adjusted } \\
\text { Depth } \\
\text { Top of } \\
\text { Casing } \\
\text { (ft) }\end{array}$ & $\begin{array}{l}\text { Adjusted } \\
\text { Depth } \\
\text { Meters }\end{array}$ & $\begin{array}{c}\text { Water } \\
\text { Level } \\
\text { Elevation } \\
\text { (ft amsl) }\end{array}$ & $\begin{array}{c}\text { Elevation } \\
\text { in } \\
\text { Meters } \\
\text { (amsl) }\end{array}$ & $\begin{array}{c}\text { Adjusted } \\
\text { Freshwater } \\
\text { Head } \\
\text { (ft amsl) }\end{array}$ \\
\hline $\mathrm{H}-19 \mathrm{b0}$ & CUL & $04 / 07 / 08$ & 424.96 & 129.53 & $2,993.37$ & 912.38 & $3,015.74$ \\
\hline $\mathrm{H}-19 \mathrm{~b} 0$ & CUL & $05 / 13 / 08$ & 424.94 & 129.52 & $2,993.39$ & 912.39 & $3,015.76$ \\
\hline $\mathrm{H}-19 \mathrm{~b} 0$ & $\overline{C U L}$ & $06 / 11 / 08$ & 424.84 & 129.49 & $2,993.49$ & 912.42 & $3,015.87$ \\
\hline $\mathrm{H}-19 \mathrm{b0}$ & CUL & $07 / 09 / 08$ & 425.04 & 129.55 & $2,993.29$ & 912.35 & $3,015.65$ \\
\hline $\mathrm{H}-19 \mathrm{~b} 0$ & CUL & $08 / 11 / 08$ & 424.95 & 129.52 & $2,993.38$ & 912.38 & $3,015.75$ \\
\hline $\mathrm{H}-19 \mathrm{~b} 0$ & CUL & $09 / 24 / 08$ & 425.01 & 129.54 & $2,993.32$ & 912.36 & $3,015.69$ \\
\hline $\mathrm{H}-19 \mathrm{b0}$ & $\overline{C U L}$ & $10 / 14 / 08$ & 425.66 & 129.74 & $2,992.67$ & 912.17 & $3,014.99$ \\
\hline $\mathrm{H}-19 \mathrm{b0}$ & CUL & $11 / 05 / 08$ & 424.85 & 129.49 & $2,993.48$ & 912.41 & $3,015.86$ \\
\hline $\mathrm{H}-19 \mathrm{b0}$ & CUL & $12 / 03 / 08$ & 424.92 & 129.52 & $2,993.41$ & 912.39 & $3,015.78$ \\
\hline $\mathrm{H}-19 \mathrm{~b} 2$ & $\overline{\text { CUL }}$ & $03 / 26 / 08$ & 426.10 & 129.88 & $2,992.83$ & 912.21 & $3,016.26$ \\
\hline $\mathrm{H}-19 \mathrm{~b} 2$ & CUL & $06 / 11 / 08$ & 426.18 & 129.90 & $2,992.75$ & 912.19 & $3,016.17$ \\
\hline $\mathrm{H}-19 \mathrm{~b} 2$ & $\overline{C U L}$ & $09 / 24 / 08$ & 426.36 & 129.95 & $2,992.57$ & 912.14 & $3,015.98$ \\
\hline $\mathrm{H}-19 \mathrm{~b} 2$ & $\overline{\text { CUL }}$ & $12 / 03 / 08$ & 426.47 & 129.99 & $2,992.46$ & 912.10 & $3,015.86$ \\
\hline $\mathrm{H}-19 \mathrm{~b} 3$ & CUL & $03 / 26 / 08$ & 426.33 & 129.95 & $2,992.69$ & 912.17 & $3,019.94$ \\
\hline $\mathrm{H}-19 \mathrm{~b} 3$ & CUL & $06 / 11 / 08$ & 426.41 & 129.97 & $2,992.61$ & 912.15 & $3,019.85$ \\
\hline $\mathrm{H}-19 \mathrm{~b} 3$ & CUL & $09 / 24 / 08$ & 426.59 & 130.02 & $2,992.43$ & 912.09 & $3,019.66$ \\
\hline $\mathrm{H}-19 \mathrm{~b} 3$ & $\overline{\text { CUL }}$ & $12 / 03 / 08$ & 426.50 & 130.00 & $2,992.52$ & 912.12 & $3,019.75$ \\
\hline $\mathrm{H}-19 \mathrm{~b} 4$ & CUL & $03 / 26 / 08$ & 425.58 & 129.72 & $2,993.40$ & 912.39 & $3,018.40$ \\
\hline $\mathrm{H}-19 \mathrm{~b} 4$ & CUL & $06 / 11 / 08$ & 425.66 & 129.74 & $2,993.32$ & 912.36 & $3,018.32$ \\
\hline $\mathrm{H}-19 \mathrm{~b} 4$ & $\overline{\text { CUL }}$ & $09 / 24 / 08$ & 425.85 & 129.80 & $2,993.13$ & 912.31 & $3,018.11$ \\
\hline $\mathrm{H}-19 \mathrm{~b} 4$ & $\overline{C U L}$ & $12 / 03 / 08$ & 425.75 & 129.77 & $2,993.23$ & 912.34 & $3,018.22$ \\
\hline $\mathrm{H}-19 \mathrm{~b} 5$ & $\overline{C U L}$ & $03 / 26 / 08$ & 425.60 & 129.72 & $2,992.98$ & 912.26 & $3,019.27$ \\
\hline $\mathrm{H}-19 \mathrm{~b} 5$ & CUL & $06 / 11 / 08$ & 425.66 & 129.74 & $2,992.92$ & 912.24 & $3,019.20$ \\
\hline $\mathrm{H}-19 \mathrm{b5}$ & $\overline{C U L}$ & $09 / 24 / 08$ & 425.83 & 129.79 & $2,992.75$ & 912.19 & $3,019.02$ \\
\hline $\mathrm{H}-19 \mathrm{~b} 5$ & CUL & $12 / 03 / 08$ & 425.74 & 129.77 & $2,992.84$ & 912.22 & $3,019.12$ \\
\hline $\mathrm{H}-19 \mathrm{~b} 6$ & CUL & $03 / 26 / 08$ & 426.25 & 129.92 & $2,992.77$ & 912.20 & $3,020.02$ \\
\hline $\mathrm{H}-19 \mathrm{~b} 6$ & $\overline{C U L}$ & $06 / 11 / 08$ & 426.33 & 129.95 & $2,992.69$ & 912.17 & $3,019.94$ \\
\hline $\mathrm{H}-19 \mathrm{~b} 6$ & CUL & $09 / 24 / 08$ & 426.51 & 130.00 & $2,992.51$ & 912.12 & $3,019.74$ \\
\hline $\mathrm{H}-19 \mathrm{~b} 6$ & CUL & $12 / 03 / 08$ & 426.41 & 129.97 & $2,992.61$ & 912.15 & $3,019.85$ \\
\hline $\mathrm{H}-19 \mathrm{~b} 7$ & CUL & $03 / 26 / 08$ & 426.30 & 129.94 & $2,992.64$ & 912.16 & $3,019.23$ \\
\hline $\mathrm{H}-19 \mathrm{~b} 7$ & $\overline{\text { CUL }}$ & $06 / 11 / 08$ & 426.37 & 129.96 & $2,992.57$ & 912.14 & $3,019.15$ \\
\hline $\mathrm{H}-19 \mathrm{~b} 7$ & CUL & $09 / 24 / 08$ & 426.54 & 130.01 & $2,992.40$ & 912.08 & $3,018.97$ \\
\hline $\mathrm{H}-19 \mathrm{~b} 7$ & CUL & $12 / 03 / 08$ & 426.45 & 129.98 & $2,992.49$ & 912.11 & $3,019.07$ \\
\hline $\mathrm{I}-461$ & CUL & $01 / 15 / 08$ & 236.64 & 72.13 & $3,046.97$ & 928.72 & $3,047.67$ \\
\hline $\mathrm{I}-461$ & CUL & $02 / 13 / 08$ & 236.92 & 72.21 & $3,046.69$ & 928.63 & $3,047.39$ \\
\hline $\mathrm{I}-461$ & $\overline{\text { CUL }}$ & $03 / 24 / 08$ & 237.41 & 72.36 & $3,046.20$ & 928.48 & $3,046.90$ \\
\hline $\mathrm{I}-461$ & CUL & $04 / 08 / 08$ & 237.53 & 72.40 & $3,046.08$ & 928.45 & $3,046.77$ \\
\hline $\mathrm{I}-461$ & CUL & $05 / 12 / 08$ & 237.70 & 72.45 & $3,045.91$ & 928.39 & $3,046.60$ \\
\hline $\mid-461$ & CUL & $06 / 09 / 08$ & 237.98 & 72.54 & $3,045.63$ & 928.31 & $3,046.32$ \\
\hline $\mathrm{I}-461$ & CUL & $07 / 07 / 08$ & 238.17 & 72.59 & $3,045.44$ & 928.25 & $3,046.13$ \\
\hline $\mid-461$ & CUL & $08 / 14 / 08$ & 238.36 & 72.65 & $3,045.25$ & 928.19 & $3,045.94$ \\
\hline $\mid-461$ & CUL & $09 / 23 / 08$ & 237.97 & 72.53 & $3,045.64$ & 928.31 & $3,046.33$ \\
\hline
\end{tabular}


Waste Isolation Pilot Plant Annual Site Environmental Report for 2008 DOE/WIPP-09-2225

Table F.9 - Water Levels

\begin{tabular}{|c|c|c|c|c|c|c|c|}
\hline $\begin{array}{c}\text { Well } \\
\text { Number }\end{array}$ & Zone & Date & $\begin{array}{c}\text { Adjusted } \\
\text { Depth } \\
\text { Top of } \\
\text { Casing } \\
\text { (ft) }\end{array}$ & $\begin{array}{l}\text { Adjusted } \\
\text { Depth } \\
\text { Meters }\end{array}$ & $\begin{array}{c}\text { Water } \\
\text { Level } \\
\text { Elevation } \\
\text { (ft amsl) }\end{array}$ & $\begin{array}{c}\text { Elevation } \\
\text { in } \\
\text { Meters } \\
(\text { amsl) }\end{array}$ & $\begin{array}{c}\text { Adjusted } \\
\text { Freshwater } \\
\text { Head } \\
\text { (ft amsl) }\end{array}$ \\
\hline $\mid-461$ & CUL & $10 / 13 / 08$ & 238.19 & 72.60 & $3,045.42$ & 928.24 & $3,046.11$ \\
\hline $\mid-461$ & CUL & $11 / 04 / 08$ & 237.66 & 72.44 & $3,045.95$ & 928.41 & $3,046.64$ \\
\hline $\mathrm{I}-461$ & CUL & $12 / 02 / 08$ & 237.69 & 72.45 & $3,045.92$ & 928.40 & $3,046.61$ \\
\hline SNL-01 & CUL & $01 / 15 / 08$ & 429.08 & 130.78 & $3,083.76$ & 939.93 & $3,089.82$ \\
\hline SNL-01 & CUL & $02 / 13 / 08$ & 429.59 & 130.94 & $3,083.25$ & 939.77 & $3,089.30$ \\
\hline SNL-01 & CUL & $03 / 25 / 08$ & 430.45 & 131.20 & $3,082.39$ & 939.51 & $3,088.41$ \\
\hline SNL-01 & CUL & $04 / 07 / 08$ & 430.51 & 131.22 & $3,082.33$ & 939.49 & $3,088.35$ \\
\hline SNL-01 & CUL & $05 / 12 / 08$ & 431.08 & 131.39 & $3,081.76$ & 939.32 & $3,087.76$ \\
\hline SNL-01 & CUL & $06 / 09 / 08$ & 431.67 & 131.57 & $3,081.17$ & 939.14 & $3,087.15$ \\
\hline SNL-01 & CUL & $07 / 08 / 08$ & 432.14 & 131.72 & $3,080.70$ & 939.00 & $3,086.66$ \\
\hline SNL-01 & CUL & $08 / 14 / 08$ & 432.57 & 131.85 & $3,080.27$ & 938.87 & $3,086.22$ \\
\hline SNL-01 & $\overline{\text { CUL }}$ & $09 / 23 / 08$ & 433.08 & 132.00 & $3,079.76$ & 938.71 & $3,085.69$ \\
\hline SNL-01 & CUL & $10 / 15 / 08$ & 433.17 & 132.03 & $3,079.67$ & 938.68 & $3,085.60$ \\
\hline SNL-01 & CUL & $11 / 04 / 08$ & 432.85 & 131.93 & $3,079.99$ & 938.78 & $3,085.93$ \\
\hline SNL-01 & CUL & $12 / 02 / 08$ & 432.95 & 131.96 & $3,079.89$ & 938.75 & $3,085.83$ \\
\hline SNL-02 & CUL & $01 / 15 / 08$ & 248.13 & 75.63 & $3,074.93$ & 937.24 & $3,077.60$ \\
\hline SNL-02 & CUL & $02 / 13 / 08$ & 248.47 & 75.73 & $3,074.59$ & 937.14 & $3,077.26$ \\
\hline SNL-02 & CUL & $03 / 25 / 08$ & 249.06 & 75.91 & $3,074.00$ & 936.96 & $3,076.66$ \\
\hline SNL-02 & CUL & $04 / 07 / 08$ & 249.22 & 75.96 & $3,073.84$ & 936.91 & $3,076.50$ \\
\hline SNL-02 & CUL & $05 / 12 / 08$ & 249.68 & 76.10 & $3,073.38$ & 936.77 & $3,076.03$ \\
\hline SNL-02 & $\overline{\text { CUL }}$ & $06 / 09 / 08$ & 250.20 & 76.26 & $3,072.86$ & 936.61 & $3,075.51$ \\
\hline SNL-02 & $\overline{C U L}$ & $07 / 08 / 08$ & 250.48 & 76.35 & $3,072.58$ & 936.52 & $3,075.22$ \\
\hline SNL-02 & CUL & $08 / 14 / 08$ & 250.73 & 76.42 & $3,072.33$ & 936.45 & $3,074.97$ \\
\hline SNL-02 & CUL & $09 / 23 / 08$ & 251.13 & 76.54 & $3,071.93$ & 936.32 & $3,074.57$ \\
\hline SNL-02 & CUL & $10 / 13 / 08$ & 251.91 & 76.78 & $3,071.15$ & 936.09 & $3,073.78$ \\
\hline SNL-02 & CUL & $11 / 04 / 08$ & 249.64 & 76.09 & $3,073.42$ & 936.78 & $3,076.07$ \\
\hline SNL-02 & CUL & $12 / 02 / 08$ & 250.05 & 76.22 & $3,073.01$ & 936.65 & $3,075.66$ \\
\hline SNL-03 & CUL & $01 / 15 / 08$ & 414.35 & 126.29 & $3,076.00$ & 937.56 & $3,084.10$ \\
\hline SNL-03 & CUL & $02 / 13 / 08$ & 414.63 & 126.38 & $3,075.72$ & 937.48 & $3,083.81$ \\
\hline SNL-03 & CUL & $03 / 26 / 08$ & 415.08 & 126.52 & $3,075.27$ & 937.34 & $3,083.35$ \\
\hline SNL-03 & $\overline{\text { CUL }}$ & $04 / 07 / 08$ & 415.20 & 126.55 & $3,075.15$ & 937.31 & $3,083.23$ \\
\hline SNL-03 & CUL & $05 / 12 / 08$ & 415.63 & 126.68 & $3,074.72$ & 937.17 & $3,082.79$ \\
\hline SNL-03 & CUL & $06 / 10 / 08$ & 416.18 & 126.85 & $3,074.17$ & 937.01 & $3,082.23$ \\
\hline SNL-03 & CUL & $07 / 08 / 08$ & 416.48 & 126.94 & $3,073.87$ & 936.92 & $3,081.92$ \\
\hline SNL-03 & CUL & $08 / 14 / 08$ & 416.77 & 127.03 & $3,073.58$ & 936.83 & $3,081.62$ \\
\hline SNL-03 & CUL & $09 / 23 / 08$ & 417.21 & 127.17 & $3,073.14$ & 936.69 & $3,081.17$ \\
\hline SNL-03 & $\overline{\text { CUL }}$ & $10 / 14 / 08$ & 417.25 & 127.18 & $3,073.10$ & 936.68 & $3,081.13$ \\
\hline SNL-03 & CUL & $11 / 04 / 08$ & 417.08 & 127.13 & $3,073.27$ & 936.73 & $3,081.31$ \\
\hline SNL-03 & CUL & $12 / 02 / 08$ & 417.16 & 127.15 & $3,073.19$ & 936.71 & $3,081.23$ \\
\hline SNL-05 & CUL & $01 / 15 / 08$ & 303.04 & 92.37 & $3,076.94$ & 937.85 & $3,080.40$ \\
\hline SNL-05 & $\overline{\text { CUL }}$ & $02 / 13 / 08$ & 303.19 & 92.41 & $3,076.79$ & 937.81 & $3,080.25$ \\
\hline SNL-05 & CUL & $03 / 25 / 08$ & 303.65 & 92.55 & $3,076.33$ & 937.67 & $3,079.78$ \\
\hline
\end{tabular}


Waste Isolation Pilot Plant Annual Site Environmental Report for 2008 DOE/WIPP-09-2225

Table F.9 - Water Levels

\begin{tabular}{|c|c|c|c|c|c|c|c|}
\hline $\begin{array}{c}\text { Well } \\
\text { Number }\end{array}$ & Zone & Date & $\begin{array}{c}\text { Adjusted } \\
\text { Depth } \\
\text { Top of } \\
\text { Casing } \\
\text { (ft) }\end{array}$ & $\begin{array}{l}\text { Adjusted } \\
\text { Depth } \\
\text { Meters }\end{array}$ & $\begin{array}{c}\text { Water } \\
\text { Level } \\
\text { Elevation } \\
\text { (ft amsl) }\end{array}$ & $\begin{array}{c}\text { Elevation } \\
\text { in } \\
\text { Meters } \\
\text { (amsl) }\end{array}$ & $\begin{array}{c}\text { Adjusted } \\
\text { Freshwater } \\
\text { Head } \\
\text { (ft amsl) }\end{array}$ \\
\hline SNL-05 & CUL & $04 / 07 / 08$ & 303.72 & 92.57 & $3,076.26$ & 937.64 & $3,079.71$ \\
\hline SNL-05 & CUL & $05 / 12 / 08$ & 304.27 & 92.74 & $3,075.71$ & 937.48 & $3,079.16$ \\
\hline SNL-05 & $\overline{C U L}$ & $06 / 09 / 08$ & 304.80 & 92.90 & $3,075.18$ & 937.31 & $3,078.62$ \\
\hline SNL-05 & CUL & $07 / 08 / 08$ & 304.90 & 92.93 & $3,075.08$ & 937.28 & $3,078.52$ \\
\hline SNL-05 & CUL & $08 / 14 / 08$ & 305.25 & 93.04 & $3,074.73$ & 937.18 & $3,078.17$ \\
\hline SNL-05 & CUL & $09 / 23 / 08$ & 305.64 & 93.16 & $3,074.34$ & 937.06 & $3,077.77$ \\
\hline SNL-05 & CUL & $10 / 13 / 08$ & 305.85 & 93.22 & $3,074.13$ & 936.99 & $3,077.56$ \\
\hline SNL-05 & CUL & $11 / 04 / 08$ & 305.45 & 93.10 & $3,074.53$ & 937.12 & $3,077.97$ \\
\hline SNL-05 & CUL & $12 / 02 / 08$ & 305.48 & 93.11 & $3,074.50$ & 937.11 & $3,077.94$ \\
\hline$\overline{\text { SNL-06 }}$ & $\overline{\text { CUL }}$ & $01 / 14 / 08$ & 866.53 & 264.12 & $2,779.58$ & 847.22 & $2,895.61$ \\
\hline SNL-06 & CUL & $02 / 11 / 08$ & 929.92 & 283.44 & $2,716.19$ & 827.89 & $2,816.63$ \\
\hline SNL-06 & $\overline{C U L}$ & $03 / 24 / 08$ & 917.98 & 279.80 & $2,728.13$ & 831.53 & $2,831.51$ \\
\hline SNL-06 & $\overline{C U L}$ & $04 / 07 / 08$ & 912.98 & 278.28 & $2,733.13$ & 833.06 & $2,837.74$ \\
\hline SNL-06 & CUL & $05 / 12 / 08$ & 903.31 & 275.33 & $2,742.80$ & 836.01 & $2,849.79$ \\
\hline SNL-06 & CUL & $06 / 09 / 08$ & 896.39 & 273.22 & $2,749.72$ & 838.11 & $2,858.41$ \\
\hline SNL-06 & CUL & $07 / 07 / 08$ & 888.97 & 270.96 & $2,757.14$ & 840.38 & $2,867.65$ \\
\hline SNL-06 & $\overline{C U L}$ & $08 / 12 / 08$ & 879.67 & 268.12 & $2,766.44$ & 843.21 & $2,879.24$ \\
\hline SNL-06 & $\overline{C U L}$ & $09 / 22 / 08$ & 869.39 & 264.99 & $2,776.72$ & 846.34 & $2,892.05$ \\
\hline SNL-06 & CUL & $10 / 14 / 08$ & 863.20 & 263.10 & $2,782.91$ & 848.23 & $2,899.76$ \\
\hline SNL-06 & $\overline{\text { CUL }}$ & $11 / 04 / 08$ & 857.90 & 261.49 & $2,788.21$ & 849.85 & $2,906.37$ \\
\hline SNL-06 & $\overline{C U L}$ & $12 / 01 / 08$ & 851.52 & 259.54 & $2,794.59$ & 851.79 & $2,914.32$ \\
\hline SNL-08 & $\overline{C U L}$ & $01 / 14 / 08$ & 542.22 & 165.27 & $3,013.51$ & 918.52 & $3,057.54$ \\
\hline SNL-08 & CUL & $02 / 11 / 08$ & 542.52 & 165.36 & $3,013.21$ & 918.43 & $3,057.21$ \\
\hline SNL-08 & CUL & $03 / 24 / 08$ & 543.29 & 165.59 & $3,012.44$ & 918.19 & $3,056.36$ \\
\hline SNL-08 & CUL & $04 / 07 / 08$ & 543.06 & 165.52 & $3,012.67$ & 918.26 & $3,056.62$ \\
\hline SNL-08 & CUL & $05 / 12 / 08$ & 543.45 & 165.64 & $3,012.28$ & 918.14 & $3,056.19$ \\
\hline SNL-08 & CUL & $06 / 09 / 08$ & 543.58 & 165.68 & $3,012.15$ & 918.10 & $3,056.04$ \\
\hline SNL-08 & CUL & $07 / 07 / 08$ & 544.18 & 165.87 & $3,011.55$ & 917.92 & $3,055.38$ \\
\hline SNL-08 & CUL & $08 / 12 / 08$ & 544.01 & 165.81 & $3,011.72$ & 917.97 & $3,055.57$ \\
\hline SNL-08 & CUL & $09 / 22 / 08$ & 544.24 & 165.88 & $3,011.49$ & 917.90 & $3,055.32$ \\
\hline SNL-08 & CUL & $10 / 14 / 08$ & 544.23 & 165.88 & $3,011.50$ & 917.91 & $3,055.33$ \\
\hline SNL-08 & CUL & $11 / 05 / 08$ & 543.99 & 165.81 & $3,011.74$ & 917.98 & $3,055.59$ \\
\hline SNL-08 & CUL & $12 / 01 / 08$ & 544.32 & 165.91 & $3,011.41$ & 917.88 & $3,055.23$ \\
\hline SNL-09 & CUL & $01 / 15 / 08$ & 308.17 & 93.93 & $3,052.79$ & 930.49 & $3,059.01$ \\
\hline SNL-09 & CUL & $02 / 14 / 08$ & 308.16 & 93.93 & $3,052.80$ & 930.49 & $3,059.02$ \\
\hline SNL-09 & $\overline{\text { CUL }}$ & $03 / 26 / 08$ & 308.63 & 94.07 & $3,052.33$ & 930.35 & $3,058.53$ \\
\hline SNL-09 & CUL & $04 / 08 / 08$ & 308.77 & 94.11 & $3,052.19$ & 930.31 & $3,058.39$ \\
\hline SNL-09 & CUL & $05 / 12 / 08$ & 308.99 & 94.18 & $3,051.97$ & 930.24 & $3,058.17$ \\
\hline SNL-09 & CUL & $06 / 10 / 08$ & 309.34 & 94.29 & $3,051.62$ & 930.13 & $3,057.81$ \\
\hline SNL-09 & CUL & $07 / 07 / 08$ & 309.54 & 94.35 & $3,051.42$ & 930.07 & $3,057.60$ \\
\hline SNL-09 & CUL & $08 / 14 / 08$ & 309.70 & 94.40 & $3,051.26$ & 930.02 & $3,057.44$ \\
\hline SNL-09 & CUL & $09 / 22 / 08$ & 309.65 & 94.38 & $3,051.31$ & 930.04 & $3,057.49$ \\
\hline
\end{tabular}


Waste Isolation Pilot Plant Annual Site Environmental Report for 2008 DOE/WIPP-09-2225

Table F.9 - Water Levels

\begin{tabular}{|c|c|c|c|c|c|c|c|}
\hline $\begin{array}{c}\text { Well } \\
\text { Number }\end{array}$ & Zone & Date & $\begin{array}{c}\text { Adjusted } \\
\text { Depth } \\
\text { Top of } \\
\text { Casing } \\
\text { (ft) }\end{array}$ & $\begin{array}{l}\text { Adjusted } \\
\text { Depth } \\
\text { Meters }\end{array}$ & $\begin{array}{c}\text { Water } \\
\text { Level } \\
\text { Elevation } \\
\text { (ft amsl) }\end{array}$ & $\begin{array}{c}\text { Elevation } \\
\text { in } \\
\text { Meters } \\
\text { (amsl) }\end{array}$ & $\begin{array}{c}\text { Adjusted } \\
\text { Freshwater } \\
\text { Head } \\
\text { (ft amsl) }\end{array}$ \\
\hline SNL-09 & CUL & $10 / 13 / 08$ & 309.90 & 94.46 & $3,051.06$ & 929.96 & $3,057.23$ \\
\hline SNL-09 & CUL & $11 / 04 / 08$ & 309.34 & 94.29 & $3,051.62$ & 930.13 & $3,057.81$ \\
\hline SNL-09 & $\overline{C U L}$ & $12 / 02 / 08$ & 309.11 & 94.22 & $3,051.85$ & 930.20 & $3,058.04$ \\
\hline SNL-10 & CUL & $01 / 14 / 08$ & 323.51 & 98.61 & $3,054.08$ & 930.88 & $3,057.27$ \\
\hline SNL-10 & CUL & $02 / 13 / 08$ & 323.53 & 98.61 & $3,054.06$ & 930.88 & $3,057.25$ \\
\hline SNL-10 & CUL & $03 / 26 / 08$ & 323.60 & 98.63 & $3,053.99$ & 930.86 & $3,057.18$ \\
\hline SNL-10 & CUL & $04 / 08 / 08$ & 323.61 & 98.64 & $3,053.98$ & 930.85 & $3,057.17$ \\
\hline SNL-10 & CUL & $05 / 12 / 08$ & 323.90 & 98.72 & $3,053.69$ & 930.76 & $3,056.88$ \\
\hline SNL-10 & CUL & $06 / 09 / 08$ & 324.06 & 98.77 & $3,053.53$ & 930.72 & $3,056.71$ \\
\hline SNL-10 & $\overline{\text { CUL }}$ & $07 / 07 / 08$ & 324.26 & 98.83 & $3,053.33$ & 930.65 & $3,056.51$ \\
\hline SNL-10 & CUL & $08 / 14 / 08$ & 324.50 & 98.91 & $3,053.09$ & 930.58 & $3,056.27$ \\
\hline SNL-10 & $\overline{C U L}$ & $09 / 22 / 08$ & 324.63 & 98.95 & $3,052.96$ & 930.54 & $3,056.14$ \\
\hline SNL-10 & $\overline{C U L}$ & $10 / 13 / 08$ & 324.60 & 98.94 & $3,052.99$ & 930.55 & $3,056.17$ \\
\hline SNL-10 & CUL & $11 / 05 / 08$ & 324.46 & 98.90 & $3,053.13$ & 930.59 & $3,056.31$ \\
\hline SNL-10 & CUL & $12 / 02 / 08$ & 324.50 & 98.91 & $3,053.09$ & 930.58 & $3,056.27$ \\
\hline SNL-12 & CUL & $01 / 14 / 08$ & 337.08 & 102.74 & $3,002.38$ & 915.13 & $3,003.55$ \\
\hline SNL-12 & $\overline{C U L}$ & $02 / 11 / 08$ & 336.89 & 102.68 & $3,002.57$ & 915.18 & $3,003.74$ \\
\hline SNL-12 & $\overline{C U L}$ & $03 / 24 / 08$ & 337.24 & 102.79 & $3,002.22$ & 915.08 & $3,003.39$ \\
\hline SNL-12 & CUL & $04 / 07 / 08$ & 336.83 & 102.67 & $3,002.63$ & 915.20 & $3,003.80$ \\
\hline SNL-12 & $\overline{\text { CUL }}$ & $05 / 12 / 08$ & 336.54 & 102.58 & $3,002.92$ & 915.29 & $3,004.09$ \\
\hline SNL-12 & $\overline{C U L}$ & $06 / 10 / 08$ & 336.81 & 102.66 & $3,002.65$ & 915.21 & $3,003.82$ \\
\hline$\overline{S N L-12}$ & $\overline{C U L}$ & $07 / 08 / 08$ & 337.04 & 102.73 & $3,002.42$ & 915.14 & $3,003.59$ \\
\hline SNL-12 & CUL & $08 / 12 / 08$ & 337.07 & 102.74 & $3,002.39$ & 915.13 & $3,003.56$ \\
\hline SNL-12 & CUL & $09 / 23 / 08$ & 337.18 & 102.77 & $3,002.28$ & 915.09 & $3,003.45$ \\
\hline SNL-12 & CUL & $10 / 14 / 08$ & 336.95 & 102.70 & $3,002.51$ & 915.17 & $3,003.68$ \\
\hline SNL-12 & CUL & $11 / 05 / 08$ & 336.73 & 102.64 & $3,002.73$ & 915.23 & $3,003.90$ \\
\hline SNL-12 & CUL & $12 / 01 / 08$ & 337.15 & 102.76 & $3,002.31$ & 915.10 & $3,003.48$ \\
\hline SNL-13 & CUL & $01 / 14 / 08$ & 284.69 & 86.77 & $3,009.53$ & 917.30 & $3,012.67$ \\
\hline SNL-13 & CUL & $02 / 11 / 08$ & 284.42 & 86.69 & $3,009.80$ & 917.39 & $3,012.95$ \\
\hline SNL-13 & CUL & $03 / 25 / 08$ & 284.45 & 86.70 & $3,009.77$ & 917.38 & $3,012.92$ \\
\hline SNL-13 & $\overline{\text { CUL }}$ & $04 / 09 / 08$ & 284.26 & 86.64 & $3,009.96$ & 917.44 & $3,013.12$ \\
\hline SNL-13 & CUL & $05 / 12 / 08$ & 284.36 & 86.67 & $3,009.86$ & 917.41 & $3,013.01$ \\
\hline SNL-13 & CUL & $06 / 09 / 08$ & 284.34 & 86.67 & $3,009.88$ & 917.41 & $3,013.03$ \\
\hline SNL-13 & CUL & $07 / 07 / 08$ & 284.42 & 86.69 & $3,009.80$ & 917.39 & $3,012.95$ \\
\hline SNL-13 & CUL & $08 / 14 / 08$ & 284.53 & 86.72 & $3,009.69$ & 917.35 & $3,012.84$ \\
\hline SNL-13 & CUL & $09 / 22 / 08$ & 284.64 & 86.76 & $3,009.58$ & 917.32 & $3,012.72$ \\
\hline SNL-13 & CUL & $10 / 13 / 08$ & 284.55 & 86.73 & $3,009.67$ & 917.35 & $3,012.82$ \\
\hline SNL-13 & CUL & $11 / 05 / 08$ & 284.42 & 86.69 & $3,009.80$ & 917.39 & $3,012.95$ \\
\hline SNL-13 & CUL & $12 / 02 / 08$ & 284.59 & 86.74 & $3,009.63$ & 917.34 & $3,012.78$ \\
\hline SNL-14 & CUL & $01 / 15 / 08$ & 376.04 & 114.62 & $2,992.37$ & 912.07 & $3,006.46$ \\
\hline SNL-14 & CUL & $02 / 14 / 08$ & 376.00 & 114.60 & $2,992.41$ & 912.09 & $3,006.50$ \\
\hline SNL-14 & CUL & $03 / 24 / 08$ & 376.39 & 114.72 & $2,992.02$ & 911.97 & $3,006.09$ \\
\hline
\end{tabular}


Waste Isolation Pilot Plant Annual Site Environmental Report for 2008 DOE/WIPP-09-2225

Table F.9 - Water Levels

\begin{tabular}{|c|c|c|c|c|c|c|c|}
\hline $\begin{array}{c}\text { Well } \\
\text { Number }\end{array}$ & Zone & Date & $\begin{array}{c}\text { Adjusted } \\
\text { Depth } \\
\text { Top of } \\
\text { Casing } \\
\text { (ft) }\end{array}$ & $\begin{array}{c}\text { Adjusted } \\
\text { Depth } \\
\text { Meters }\end{array}$ & $\begin{array}{l}\text { Water } \\
\text { Level } \\
\text { Elevation } \\
\text { (ft amsl) }\end{array}$ & $\begin{array}{c}\text { Elevation } \\
\text { in } \\
\text { Meters } \\
\text { (amsl) }\end{array}$ & $\begin{array}{c}\text { Adjusted } \\
\text { Freshwater } \\
\text { Head } \\
\text { (ft amsl) }\end{array}$ \\
\hline SNL-14 & CUL & $04 / 09 / 08$ & 375.99 & 114.60 & $2,992.42$ & 912.09 & $3,006.51$ \\
\hline SNL-14 & CUL & $05 / 12 / 08$ & 376.00 & 114.60 & $2,992.41$ & 912.09 & $3,006.50$ \\
\hline SNL-14 & CUL & $06 / 09 / 08$ & 376.05 & 114.62 & $2,992.36$ & 912.07 & $3,006.45$ \\
\hline SNL-14 & CUL & $07 / 07 / 08$ & 376.16 & 114.65 & $2,992.25$ & 912.04 & $3,006.33$ \\
\hline SNL-14 & $\overline{\text { CUL }}$ & $08 / 14 / 08$ & 376.26 & 114.68 & $2,992.15$ & 912.01 & $3,006.23$ \\
\hline SNL-14 & CUL & $09 / 22 / 08$ & 376.31 & 114.70 & $2,992.10$ & 911.99 & $3,006.17$ \\
\hline SNL-14 & CUL & $10 / 14 / 08$ & 376.13 & 114.64 & $2,992.28$ & 912.05 & $3,006.36$ \\
\hline SNL-14 & CUL & $11 / 05 / 08$ & 375.82 & 114.55 & $2,992.59$ & 912.14 & $3,006.69$ \\
\hline SNL-14 & CUL & $12 / 02 / 08$ & 376.12 & 114.64 & $2,992.29$ & 912.05 & $3,006.37$ \\
\hline SNL-15 & CUL & $01 / 14 / 08$ & 659.54 & 201.03 & $2,820.39$ & 859.65 & $2,880.42$ \\
\hline SNL-15 & CUL & $02 / 11 / 08$ & 656.42 & 200.08 & $2,823.51$ & 860.61 & $2,884.25$ \\
\hline SNL-15 & CUL & $03 / 24 / 08$ & 652.96 & 199.02 & $2,826.97$ & 861.66 & $2,888.50$ \\
\hline SNL-15 & CUL & $04 / 07 / 08$ & 650.51 & 198.28 & $2,829.42$ & 862.41 & $2,891.51$ \\
\hline SNL-15 & CUL & $05 / 12 / 08$ & 647.05 & 197.22 & $2,832.88$ & 863.46 & $2,895.76$ \\
\hline SNL-15 & $\overline{\text { CUL }}$ & $06 / 09 / 08$ & 644.35 & 196.40 & $2,835.58$ & 864.28 & $2,899.07$ \\
\hline SNL-15 & CUL & $07 / 07 / 08$ & 641.75 & 195.61 & $2,838.18$ & 865.08 & $2,902.27$ \\
\hline SNL-15 & $\overline{\text { CUL }}$ & $08 / 12 / 08$ & 638.37 & 194.58 & $2,841.56$ & 866.11 & $2,906.42$ \\
\hline SNL-15 & CUL & $09 / 23 / 08$ & 634.64 & 193.44 & $2,845.29$ & 867.24 & $2,911.00$ \\
\hline SNL-15 & CUL & $10 / 14 / 08$ & 632.83 & 192.89 & $2,847.10$ & 867.80 & $2,913.22$ \\
\hline SNL-15 & $\overline{\text { CUL }}$ & $11 / 05 / 08$ & 631.12 & 192.37 & $2,848.81$ & 868.32 & $2,915.32$ \\
\hline SNL-15 & $\overline{C U L}$ & $12 / 01 / 08$ & 628.79 & 191.66 & $2,851.14$ & 869.03 & $2,918.18$ \\
\hline$\overline{S N L-16}$ & $\overline{\text { CUL }}$ & $01 / 14 / 08$ & 122.40 & 37.31 & $3,010.60$ & 917.63 & $3,011.44$ \\
\hline SNL-16 & CUL & $02 / 13 / 08$ & 122.50 & 37.34 & $3,010.50$ & 917.60 & $3,011.34$ \\
\hline SNL-16 & $\overline{C U L}$ & $03 / 24 / 08$ & 122.85 & 37.44 & $3,010.15$ & 917.49 & $3,010.98$ \\
\hline SNL-16 & CUL & $04 / 07 / 08$ & 122.81 & 37.43 & $3,010.19$ & 917.51 & $3,011.02$ \\
\hline SNL-16 & CUL & $05 / 12 / 08$ & 122.86 & 37.45 & $3,010.14$ & 917.49 & $3,010.97$ \\
\hline SNL-16 & CUL & $06 / 09 / 08$ & 123.26 & 37.57 & $3,009.74$ & 917.37 & $3,010.57$ \\
\hline SNL-16 & CUL & $07 / 07 / 08$ & 123.33 & 37.59 & $3,009.67$ & 917.35 & $3,010.50$ \\
\hline SNL-16 & CUL & $08 / 12 / 08$ & 123.39 & 37.61 & $3,009.61$ & 917.33 & $3,010.44$ \\
\hline SNL-16 & $\overline{\text { CUL }}$ & $09 / 22 / 08$ & 123.11 & 37.52 & $3,009.89$ & 917.41 & $3,010.72$ \\
\hline SNL-16 & CUL & $10 / 13 / 08$ & 123.15 & 37.54 & $3,009.85$ & 917.40 & $3,010.68$ \\
\hline SNL-16 & CUL & $11 / 05 / 08$ & 122.90 & 37.46 & $3,010.10$ & 917.48 & $3,010.93$ \\
\hline SNL-16 & CUL & $12 / 02 / 08$ & 123.17 & 37.54 & $3,009.83$ & 917.40 & $3,010.66$ \\
\hline SNL-17 & CUL & $01 / 14 / 08$ & 230.98 & 70.40 & $3,007.08$ & 916.56 & $3,007.79$ \\
\hline SNL-17 & CUL & $02 / 11 / 08$ & 230.82 & 70.35 & $3,007.24$ & 916.61 & $3,007.95$ \\
\hline SNL-17 & CUL & $03 / 24 / 08$ & 231.13 & 70.45 & $3,006.93$ & 916.51 & $3,007.64$ \\
\hline SNL-17 & CUL & $04 / 07 / 08$ & 230.89 & 70.38 & $3,007.17$ & 916.59 & $3,007.88$ \\
\hline SNL-17 & CUL & $05 / 12 / 08$ & 230.83 & 70.36 & $3,007.23$ & 916.60 & $3,007.94$ \\
\hline SNL-17 & CUL & $06 / 10 / 08$ & 231.05 & 70.42 & $3,007.01$ & 916.54 & $3,007.72$ \\
\hline SNL-17 & $\overline{\text { CUL }}$ & $07 / 08 / 08$ & 231.20 & 70.47 & $3,006.86$ & 916.49 & $3,007.57$ \\
\hline SNL-17 & CUL & $08 / 12 / 08$ & 231.23 & 70.48 & $3,006.83$ & 916.48 & $3,007.54$ \\
\hline SNL-17 & CUL & $09 / 23 / 08$ & 231.41 & 70.53 & $3,006.65$ & 916.43 & $3,007.36$ \\
\hline
\end{tabular}


Waste Isolation Pilot Plant Annual Site Environmental Report for 2008 DOE/WIPP-09-2225

Table F.9 - Water Levels

\begin{tabular}{|c|c|c|c|c|c|c|c|}
\hline $\begin{array}{c}\text { Well } \\
\text { Number }\end{array}$ & Zone & Date & $\begin{array}{l}\text { Adjusted } \\
\text { Depth } \\
\text { Top of } \\
\text { Casing } \\
\text { (ft) }\end{array}$ & $\begin{array}{l}\text { Adjusted } \\
\text { Depth } \\
\text { Meters }\end{array}$ & $\begin{array}{c}\text { Water } \\
\text { Level } \\
\text { Elevation } \\
\text { (ft amsl) }\end{array}$ & $\begin{array}{c}\text { Elevation } \\
\text { in } \\
\text { Meters } \\
\text { (amsl) }\end{array}$ & $\begin{array}{c}\text { Adjusted } \\
\text { Freshwater } \\
\text { Head } \\
\text { (ft amsl) }\end{array}$ \\
\hline SNL-17 & CUL & $10 / 13 / 08$ & 231.32 & 70.51 & $3,006.74$ & 916.45 & $3,007.45$ \\
\hline SNL-17 & CUL & $11 / 05 / 08$ & 231.18 & 70.46 & $3,006.88$ & 916.50 & $3,007.59$ \\
\hline SNL-17 & CUL & $12 / 01 / 08$ & 231.53 & 70.57 & $3,006.53$ & 916.39 & $3,007.24$ \\
\hline SNL-18 & CUL & $01 / 15 / 08$ & 298.11 & 90.86 & $3,077.33$ & 937.97 & $3,084.42$ \\
\hline SNL-18 & CUL & $02 / 13 / 08$ & 298.23 & 90.90 & $3,077.21$ & 937.93 & $3,084.29$ \\
\hline SNL-18 & CUL & $03 / 25 / 08$ & 298.72 & 91.05 & $3,076.72$ & 937.78 & $3,083.79$ \\
\hline SNL-18 & CUL & $04 / 07 / 08$ & 298.77 & 91.07 & $3,076.67$ & 937.77 & $3,083.74$ \\
\hline SNL-18 & CUL & $05 / 12 / 08$ & 298.83 & 91.08 & $3,076.61$ & 937.75 & $3,083.68$ \\
\hline SNL-18 & $\overline{\text { CUL }}$ & $06 / 09 / 08$ & 299.26 & 91.21 & $3,076.18$ & 937.62 & $3,083.24$ \\
\hline SNL-18 & CUL & $07 / 08 / 08$ & 299.14 & 91.18 & $3,076.30$ & 937.66 & $3,083.36$ \\
\hline SNL-18 & CUL & $08 / 14 / 08$ & 299.53 & 91.30 & $3,075.91$ & 937.54 & $3,082.96$ \\
\hline SNL-18 & CUL & $09 / 23 / 08$ & 299.89 & 91.41 & $3,075.55$ & 937.43 & $3,082.59$ \\
\hline SNL-18 & $\overline{C U L}$ & $10 / 15 / 08$ & 300.12 & 91.48 & $3,075.32$ & 937.36 & $3,082.35$ \\
\hline SNL-18 & $\overline{C U L}$ & $11 / 04 / 08$ & 299.58 & 91.31 & $3,075.86$ & 937.52 & $3,082.91$ \\
\hline SNL-18 & CUL & $12 / 02 / 08$ & 299.72 & 91.35 & $3,075.72$ & 937.48 & $3,082.76$ \\
\hline SNL-19 & CUL & $01 / 15 / 08$ & 146.75 & 44.73 & $3,075.90$ & 937.53 & $3,076.52$ \\
\hline SNL-19 & CUL & $02 / 13 / 08$ & 147.10 & 44.84 & $3,075.55$ & 937.43 & $3,076.17$ \\
\hline SNL-19 & CUL & $03 / 25 / 08$ & 147.81 & 45.05 & $3,074.84$ & 937.21 & $3,075.46$ \\
\hline SNL-19 & CUL & $04 / 07 / 08$ & 147.95 & 45.10 & $3,074.70$ & 937.17 & $3,075.32$ \\
\hline SNL-19 & CUL & $05 / 12 / 08$ & 148.42 & 45.24 & $3,074.23$ & 937.03 & $3,074.85$ \\
\hline SNL-19 & CUL & $06 / 09 / 08$ & 148.98 & 45.41 & $3,073.67$ & 936.85 & $3,074.29$ \\
\hline SNL-19 & CUL & $07 / 08 / 08$ & 149.23 & 45.49 & $3,073.42$ & 936.78 & $3,074.04$ \\
\hline SNL-19 & CUL & $08 / 14 / 08$ & 149.55 & 45.58 & $3,073.10$ & 936.68 & $3,073.72$ \\
\hline SNL-19 & $\overline{C U L}$ & $09 / 23 / 08$ & 149.66 & 45.62 & $3,072.99$ & 936.65 & $3,073.61$ \\
\hline SNL-19 & CUL & $10 / 13 / 08$ & 150.40 & 45.84 & $3,072.25$ & 936.42 & $3,072.86$ \\
\hline SNL-19 & CUL & $11 / 04 / 08$ & 148.30 & 45.20 & $3,074.35$ & 937.06 & $3,074.97$ \\
\hline SNL-19 & CUL & $12 / 02 / 08$ & 149.00 & 45.42 & $3,073.65$ & 936.85 & $3,074.27$ \\
\hline WIPP-11 & $\overline{C U L}$ & $01 / 15 / 08$ & 359.36 & 109.53 & $3,068.42$ & 935.25 & $3,087.36$ \\
\hline WIPP-11 & CUL & $02 / 13 / 08$ & 359.58 & 109.60 & $3,068.20$ & 935.19 & $3,087.13$ \\
\hline WIPP-11 & CUL & $03 / 25 / 08$ & 359.99 & 109.72 & $3,067.79$ & 935.06 & $3,086.71$ \\
\hline WIPP-11 & CUL & $04 / 07 / 08$ & 360.06 & 109.75 & $3,067.72$ & 935.04 & $3,086.63$ \\
\hline WIPP-11 & CUL & $05 / 12 / 08$ & 360.60 & 109.91 & $3,067.18$ & 934.88 & $3,086.07$ \\
\hline WIPP-11 & CUL & $06 / 10 / 08$ & 361.03 & 110.04 & $3,066.75$ & 934.75 & $3,085.63$ \\
\hline WIPP-11 & CUL & $07 / 08 / 08$ & 361.23 & 110.10 & $3,066.55$ & 934.68 & $3,085.42$ \\
\hline WIPP-11 & CUL & $08 / 14 / 08$ & 361.60 & 110.22 & $3,066.18$ & 934.57 & $3,085.03$ \\
\hline WIPP-11 & CUL & $09 / 22 / 08$ & 361.78 & 110.27 & $3,066.00$ & 934.52 & $3,084.85$ \\
\hline WIPP-11 & CUL & $10 / 13 / 08$ & 362.01 & 110.34 & $3,065.77$ & 934.45 & $3,084.61$ \\
\hline WIPP-11 & $\overline{C U L}$ & $11 / 04 / 08$ & 361.75 & 110.26 & $3,066.03$ & 934.53 & $3,084.88$ \\
\hline WIPP-11 & CUL & $12 / 02 / 08$ & 361.71 & 110.25 & $3,066.07$ & 934.54 & $3,084.92$ \\
\hline WIPP-13 & CUL & $01 / 15 / 08$ & 341.00 & 103.94 & $3,064.67$ & 934.11 & $3,084.51$ \\
\hline WIPP-13 & CUL & $02 / 14 / 08$ & 341.11 & 103.97 & $3,064.56$ & 934.08 & $3,084.40$ \\
\hline WIPP-13 & CUL & $03 / 26 / 08$ & 341.65 & 104.13 & $3,064.02$ & 933.91 & $3,083.83$ \\
\hline
\end{tabular}


Waste Isolation Pilot Plant Annual Site Environmental Report for 2008 DOE/WIPP-09-2225

Table F.9 - Water Levels

\begin{tabular}{|c|c|c|c|c|c|c|c|}
\hline $\begin{array}{c}\text { Well } \\
\text { Number }\end{array}$ & Zone & Date & $\begin{array}{c}\text { Adjusted } \\
\text { Depth } \\
\text { Top of } \\
\text { Casing } \\
\text { (ft) }\end{array}$ & $\begin{array}{c}\text { Adjusted } \\
\text { Depth } \\
\text { Meters }\end{array}$ & $\begin{array}{l}\text { Water } \\
\text { Level } \\
\text { Elevation } \\
\text { (ft amsl) }\end{array}$ & $\begin{array}{c}\text { Elevation } \\
\text { in } \\
\text { Meters } \\
(\text { amsl) }\end{array}$ & $\begin{array}{c}\text { Adjusted } \\
\text { Freshwater } \\
\text { Head } \\
\text { (ft amsl) }\end{array}$ \\
\hline WIPP-13 & $\overline{\text { CUL }}$ & $04 / 08 / 08$ & 341.86 & 104.20 & $3,063.81$ & 933.85 & $3,083.61$ \\
\hline WIPP-13 & CUL & $05 / 13 / 08$ & 342.38 & 104.36 & $3,063.29$ & 933.69 & $3,083.06$ \\
\hline WIPP-13 & CUL & $06 / 10 / 08$ & 342.74 & 104.47 & $3,062.93$ & 933.58 & $3,082.68$ \\
\hline WIPP-13 & CUL & $07 / 08 / 08$ & 342.99 & 104.54 & $3,062.68$ & 933.50 & $3,082.42$ \\
\hline WIPP-13 & CUL & $08 / 14 / 08$ & 343.36 & 104.66 & $3,062.31$ & 933.39 & $3,082.03$ \\
\hline WIPP-13 & $\overline{C U L}$ & $09 / 22 / 08$ & 343.52 & 104.70 & $3,062.15$ & 933.34 & $3,081.86$ \\
\hline WIPP-13 & CUL & $10 / 13 / 08$ & 343.76 & 104.78 & $3,061.91$ & 933.27 & $3,081.61$ \\
\hline WIPP-13 & CUL & $11 / 04 / 08$ & 343.52 & 104.70 & $3,062.15$ & 933.34 & $3,081.86$ \\
\hline WIPP-13 & CUL & $12 / 02 / 08$ & 343.50 & 104.70 & $3,062.17$ & 933.35 & $3,081.88$ \\
\hline WIPP-19 & $\overline{\text { CUL }}$ & $01 / 16 / 08$ & 387.30 & 118.05 & $3,047.81$ & 928.97 & $3,064.65$ \\
\hline WIPP-19 & CUL & $02 / 14 / 08$ & 387.27 & 118.04 & $3,047.84$ & 928.98 & $3,064.68$ \\
\hline WIPP-19 & CUL & $03 / 27 / 08$ & 387.40 & 118.08 & $3,047.71$ & 928.94 & $3,064.55$ \\
\hline WIPP-19 & CUL & $04 / 08 / 08$ & 387.53 & 118.12 & $3,047.58$ & 928.90 & $3,064.41$ \\
\hline WIPP-19 & CUL & $05 / 13 / 08$ & 387.69 & 118.17 & $3,047.42$ & 928.85 & $3,064.25$ \\
\hline WIPP-19 & CUL & $06 / 11 / 08$ & 387.93 & 118.24 & $3,047.18$ & 928.78 & $3,064.00$ \\
\hline WIPP-19 & CUL & $07 / 09 / 08$ & 388.18 & 118.32 & $3,046.93$ & 928.70 & $3,063.73$ \\
\hline WIPP-19 & CUL & $08 / 14 / 08$ & 388.44 & 118.40 & $3,046.67$ & 928.63 & $3,063.46$ \\
\hline WIPP-19 & CUL & $09 / 24 / 08$ & 388.63 & 118.45 & $3,046.48$ & 928.57 & $3,063.27$ \\
\hline WIPP-19 & CUL & $10 / 15 / 08$ & 388.66 & 118.46 & $3,046.45$ & 928.56 & $3,063.23$ \\
\hline WIPP-19 & $\overline{\text { CUL }}$ & $11 / 06 / 08$ & 388.66 & 118.46 & $3,046.45$ & 928.56 & $3,063.23$ \\
\hline WIPP-19 & CUL & $12 / 03 / 08$ & 388.75 & 118.49 & $3,046.36$ & 928.53 & $3,063.14$ \\
\hline WIPP-25 (PIP) & $\overline{C U L}$ & $01 / 15 / 08$ & 146.65 & 44.70 & $3,067.59$ & 935.00 & $3,071.06$ \\
\hline WIPP-25 (PIP) & CUL & $02 / 13 / 08$ & 146.79 & 44.74 & $3,067.45$ & 934.96 & $3,070.92$ \\
\hline WIPP-25 (PIP) & CUL & $03 / 24 / 08$ & 147.17 & 44.86 & $3,067.07$ & 934.84 & $3,070.53$ \\
\hline WIPP-25 (PIP) & CUL & $04 / 08 / 08$ & 147.15 & 44.85 & $3,067.09$ & 934.85 & $3,070.55$ \\
\hline WIPP-25 (PIP) & CUL & $05 / 12 / 08$ & 147.37 & 44.92 & $3,066.87$ & 934.78 & $3,070.33$ \\
\hline WIPP-25 (PIP) & CUL & 06/09/08 & 147.75 & 45.03 & $3,066.49$ & 934.67 & $3,069.95$ \\
\hline WIPP-25 (PIP) & CUL & $07 / 08 / 08$ & 148.00 & 45.11 & $3,066.24$ & 934.59 & $3,069.69$ \\
\hline WIPP-25 (PIP) & CUL & $08 / 14 / 08$ & 148.12 & 45.15 & $3,066.12$ & 934.55 & $3,069.57$ \\
\hline WIPP-25 (PIP) & $\overline{C U L}$ & $09 / 23 / 08$ & 148.26 & 45.19 & $3,065.98$ & 934.51 & $3,069.43$ \\
\hline WIPP-25 (PIP) & CUL & $10 / 13 / 08$ & 148.60 & 45.29 & $3,065.64$ & 934.41 & $3,069.09$ \\
\hline WIPP-25 (PIP) & CUL & $11 / 04 / 08$ & 147.50 & 44.96 & $3,066.74$ & 934.74 & $3,070.20$ \\
\hline WIPP-25 (PIP) & CUL & $12 / 02 / 08$ & 147.33 & 44.91 & $3,066.91$ & 934.79 & $3,070.37$ \\
\hline WQSP-1 & CUL & $01 / 16 / 08$ & 355.65 & 108.40 & $3,063.60$ & 933.79 & $3,080.78$ \\
\hline WQSP-1 & $\overline{C U L}$ & $02 / 14 / 08$ & 355.82 & 108.45 & $3,063.43$ & 933.73 & $3,080.61$ \\
\hline WQSP-1 & CUL & $03 / 25 / 08$ & 356.35 & 108.62 & $3,062.90$ & 933.57 & $3,080.05$ \\
\hline WQSP-1 & CUL & $04 / 08 / 08$ & 356.49 & 108.66 & $3,062.76$ & 933.53 & $3,079.90$ \\
\hline WQSP-1 & CUL & $05 / 13 / 08$ & 357.05 & 108.83 & $3,062.20$ & 933.36 & $3,079.32$ \\
\hline WQSP-1 & CUL & $06 / 11 / 08$ & 357.16 & 108.86 & $3,062.09$ & 933.33 & $3,079.20$ \\
\hline WQSP-1 & $\overline{C U L}$ & $07 / 08 / 08$ & 357.57 & 108.99 & $3,061.68$ & 933.20 & $3,078.77$ \\
\hline WQSP-1 & CUL & $08 / 14 / 08$ & 357.92 & 109.09 & $3,061.33$ & 933.09 & $3,078.41$ \\
\hline WQSP-1 & CUL & $09 / 24 / 08$ & 358.26 & 109.20 & $3,060.99$ & 932.99 & $3,078.05$ \\
\hline
\end{tabular}


Waste Isolation Pilot Plant Annual Site Environmental Report for 2008 DOE/WIPP-09-2225

Table F.9 - Water Levels

\begin{tabular}{|c|c|c|c|c|c|c|c|}
\hline $\begin{array}{c}\text { Well } \\
\text { Number }\end{array}$ & Zone & Date & $\begin{array}{c}\text { Adjusted } \\
\text { Depth } \\
\text { Top of } \\
\text { Casing } \\
\text { (ft) }\end{array}$ & $\begin{array}{c}\text { Adjusted } \\
\text { Depth } \\
\text { Meters }\end{array}$ & $\begin{array}{l}\text { Water } \\
\text { Level } \\
\text { Elevation } \\
\text { (ft amsl) }\end{array}$ & $\begin{array}{c}\text { Elevation } \\
\text { in } \\
\text { Meters } \\
\text { (amsl) }\end{array}$ & $\begin{array}{c}\text { Adjusted } \\
\text { Freshwater } \\
\text { Head } \\
\text { (ft amsl) }\end{array}$ \\
\hline WQSP-1 & CUL & $10 / 15 / 08$ & 358.43 & 109.25 & $3,060.82$ & 932.94 & $3,077.87$ \\
\hline WQSP-1 & CUL & $11 / 06 / 08$ & 358.17 & 109.17 & $3,061.08$ & 933.02 & $3,078.14$ \\
\hline WQSP-1 & CUL & $12 / 04 / 08$ & 358.33 & 109.22 & $3,060.92$ & 932.97 & $3,077.98$ \\
\hline WQSP-2 & CUL & $01 / 16 / 08$ & 395.15 & 120.44 & $3,068.72$ & 935.35 & $3,089.36$ \\
\hline WQSP-2 & $\overline{\text { CUL }}$ & $02 / 14 / 08$ & 395.37 & 120.51 & $3,068.50$ & 935.28 & $3,089.13$ \\
\hline WQSP-2 & CUL & $03 / 27 / 08$ & 395.75 & 120.62 & $3,068.12$ & 935.16 & $3,088.73$ \\
\hline WQSP-2 & $\overline{C U L}$ & $04 / 08 / 08$ & 396.00 & 120.70 & $3,067.87$ & 935.09 & $3,088.47$ \\
\hline WQSP-2 & CUL & $05 / 13 / 08$ & 396.65 & 120.90 & $3,067.22$ & 934.89 & $3,087.78$ \\
\hline WQSP-2 & CUL & $06 / 11 / 08$ & 396.78 & 120.94 & $3,067.09$ & 934.85 & $3,087.65$ \\
\hline WQSP-2 & CUL & $07 / 09 / 08$ & 397.23 & 121.08 & $3,066.64$ & 934.71 & $3,087.18$ \\
\hline WQSP-2 & $\overline{C U L}$ & $08 / 14 / 08$ & 397.54 & 121.17 & $3,066.33$ & 934.62 & $3,086.85$ \\
\hline WQSP-2 & CUL & $09 / 24 / 08$ & 397.84 & 121.26 & $3,066.03$ & 934.53 & $3,086.54$ \\
\hline WQSP-2 & CUL & $10 / 15 / 08$ & 398.01 & 121.31 & $3,065.86$ & 934.47 & $3,086.36$ \\
\hline WQSP-2 & CUL & $11 / 06 / 08$ & 397.82 & 121.26 & $3,066.05$ & 934.53 & $3,086.56$ \\
\hline WQSP-2 & CUL & $12 / 03 / 08$ & 397.70 & 121.22 & $3,066.17$ & 934.57 & $3,086.68$ \\
\hline WQSP-3 & CUL & $01 / 16 / 08$ & 460.86 & 140.47 & $3,019.28$ & 920.28 & $3,077.53$ \\
\hline WQSP-3 & $\overline{\text { CUL }}$ & $02 / 14 / 08$ & 469.73 & 143.17 & $3,010.41$ & 917.57 & $3,067.37$ \\
\hline WQSP-3 & CUL & $03 / 27 / 08$ & 460.73 & 140.43 & $3,019.41$ & 920.32 & $3,077.68$ \\
\hline WQSP-3 & CUL & $04 / 08 / 08$ & 460.76 & 140.44 & $3,019.38$ & 920.31 & $3,077.65$ \\
\hline WQSP-3 & $\overline{\text { CUL }}$ & $05 / 13 / 08$ & 462.91 & 141.09 & $3,017.23$ & 919.65 & $3,075.18$ \\
\hline WQSP-3 & $\overline{C U L}$ & $06 / 11 / 08$ & 461.91 & 140.79 & $3,018.23$ & 919.96 & $3,076.33$ \\
\hline WQSP-3 & $\overline{C U L}$ & $07 / 09 / 08$ & 462.00 & 140.82 & $3,018.14$ & 919.93 & $3,076.22$ \\
\hline WQSP-3 & CUL & $08 / 14 / 08$ & 462.01 & 140.82 & $3,018.13$ & 919.93 & $3,076.21$ \\
\hline WQSP-3 & CUL & $09 / 24 / 08$ & 462.13 & 140.86 & $3,018.01$ & 919.89 & $3,076.08$ \\
\hline WQSP-3 & CUL & $10 / 15 / 08$ & 462.11 & 140.85 & $3,018.03$ & 919.90 & $3,076.10$ \\
\hline WQSP-3 & CUL & $11 / 06 / 08$ & 463.79 & 141.36 & $3,016.35$ & 919.38 & $3,074.17$ \\
\hline WQSP-3 & CUL & $12 / 03 / 08$ & 462.80 & 141.06 & $3,017.34$ & 919.69 & $3,075.31$ \\
\hline WQSP-4 & CUL & $01 / 16 / 08$ & 442.06 & 134.74 & $2,991.03$ & 911.67 & $3,016.44$ \\
\hline WQSP-4 & CUL & $02 / 14 / 08$ & 441.97 & 134.71 & $2,991.12$ & 911.69 & $3,016.54$ \\
\hline WQSP-4 & CUL & $03 / 26 / 08$ & 442.02 & 134.73 & $2,991.07$ & 911.68 & $3,016.49$ \\
\hline WQSP-4 & CUL & $04 / 08 / 08$ & 442.22 & 134.79 & $2,990.87$ & 911.62 & $3,016.27$ \\
\hline WQSP-4 & CUL & $05 / 13 / 08$ & 442.21 & 134.79 & $2,990.88$ & 911.62 & $3,016.28$ \\
\hline WQSP-4 & CUL & $06 / 11 / 08$ & 442.12 & 134.76 & $2,990.97$ & 911.65 & $3,016.38$ \\
\hline WQSP-4 & CUL & $07 / 09 / 08$ & 442.33 & 134.82 & $2,990.76$ & 911.58 & $3,016.15$ \\
\hline WQSP-4 & CUL & $08 / 11 / 08$ & 442.23 & 134.79 & $2,990.86$ & 911.61 & $3,016.26$ \\
\hline WQSP-4 & CUL & $09 / 24 / 08$ & 442.32 & 134.82 & $2,990.77$ & 911.59 & $3,016.16$ \\
\hline WQSP-4 & CUL & $10 / 14 / 08$ & 442.87 & 134.99 & $2,990.22$ & 911.42 & $3,015.57$ \\
\hline WQSP-4 & CUL & $11 / 07 / 08$ & 442.47 & 134.86 & $2,990.62$ & 911.54 & $3,016.00$ \\
\hline WQSP-4 & CUL & $12 / 03 / 08$ & 442.17 & 134.77 & $2,990.92$ & 911.63 & $3,016.32$ \\
\hline WQSP-5 & CUL & $01 / 16 / 08$ & 377.69 & 115.12 & $3,006.69$ & 916.44 & $3,013.71$ \\
\hline WQSP-5 & CUL & $02 / 14 / 08$ & 377.50 & 115.06 & $3,006.88$ & 916.50 & $3,013.91$ \\
\hline WQSP-5 & CUL & $03 / 26 / 08$ & 377.54 & 115.07 & $3,006.84$ & 916.48 & $3,013.87$ \\
\hline
\end{tabular}


Waste Isolation Pilot Plant Annual Site Environmental Report for 2008 DOE/WIPP-09-2225

Table F.9 - Water Levels

\begin{tabular}{|c|c|c|c|c|c|c|c|}
\hline $\begin{array}{c}\text { Well } \\
\text { Number }\end{array}$ & Zone & Date & $\begin{array}{c}\text { Adjusted } \\
\text { Depth } \\
\text { Top of } \\
\text { Casing } \\
\text { (ft) }\end{array}$ & $\begin{array}{c}\text { Adjusted } \\
\text { Depth } \\
\text { Meters }\end{array}$ & $\begin{array}{l}\text { Water } \\
\text { Level } \\
\text { Elevation } \\
\text { (ft amsl) }\end{array}$ & $\begin{array}{c}\text { Elevation } \\
\text { in } \\
\text { Meters } \\
\text { (amsl) }\end{array}$ & $\begin{array}{c}\text { Adjusted } \\
\text { Freshwater } \\
\text { Head } \\
\text { (ft amsl) }\end{array}$ \\
\hline WQSP-5 & CUL & $04 / 08 / 08$ & 378.61 & 115.40 & $3,005.77$ & 916.16 & $3,012.77$ \\
\hline WQSP-5 & CUL & $05 / 13 / 08$ & 377.80 & 115.15 & $3,006.58$ & 916.41 & $3,013.60$ \\
\hline WQSP-5 & CUL & $06 / 11 / 08$ & 377.62 & 115.10 & $3,006.76$ & 916.46 & $3,013.79$ \\
\hline WQSP-5 & CUL & $07 / 09 / 08$ & 377.73 & 115.13 & $3,006.65$ & 916.43 & $3,013.67$ \\
\hline WQSP-5 & CUL & $08 / 11 / 08$ & 377.65 & 115.11 & $3,006.73$ & 916.45 & $3,013.76$ \\
\hline WQSP-5 & CUL & $09 / 24 / 08$ & 377.73 & 115.13 & $3,006.65$ & 916.43 & $3,013.67$ \\
\hline WQSP-5 & CUL & $10 / 14 / 08$ & 378.54 & 115.38 & $3,005.84$ & 916.18 & $3,012.84$ \\
\hline WQSP-5 & CUL & $11 / 06 / 08$ & 377.84 & 115.17 & $3,006.54$ & 916.39 & $3,013.56$ \\
\hline WQSP-5 & CUL & $12 / 03 / 08$ & 377.65 & 115.11 & $3,006.73$ & 916.45 & $3,013.76$ \\
\hline WQSP-6 & CUL & $01 / 16 / 08$ & 342.82 & 104.49 & $3,021.90$ & 921.08 & $3,025.46$ \\
\hline WQSP-6 & CUL & $02 / 14 / 08$ & 342.60 & 104.42 & $3,022.12$ & 921.14 & $3,025.68$ \\
\hline WQSP-6 & CUL & $03 / 26 / 08$ & 345.10 & 105.19 & $3,019.62$ & 920.38 & $3,023.15$ \\
\hline WQSP-6 & CUL & $04 / 08 / 08$ & 343.34 & 104.65 & $3,021.38$ & 920.92 & $3,024.93$ \\
\hline WQSP-6 & CUL & $05 / 13 / 08$ & 342.72 & 104.46 & $3,022.00$ & 921.11 & $3,025.56$ \\
\hline WQSP-6 & CUL & $06 / 11 / 08$ & 342.62 & 104.43 & $3,022.10$ & 921.14 & $3,025.66$ \\
\hline WQSP-6 & CUL & $07 / 09 / 08$ & 342.67 & 104.45 & $3,022.05$ & 921.12 & $3,025.61$ \\
\hline WQSP-6 & $\overline{\text { CUL }}$ & $08 / 11 / 08$ & 342.58 & 104.42 & $3,022.14$ & 921.15 & $3,025.70$ \\
\hline WQSP-6 & CUL & $09 / 24 / 08$ & 345.29 & 105.24 & $3,019.43$ & 920.32 & $3,022.96$ \\
\hline WQSP-6 & CUL & $10 / 14 / 08$ & 343.25 & 104.62 & $3,021.47$ & 920.94 & $3,025.02$ \\
\hline WQSP-6 & $\overline{\text { CUL }}$ & $11 / 06 / 08$ & 342.81 & 104.49 & $3,021.91$ & 921.08 & $3,025.47$ \\
\hline WQSP-6 & CUL & $12 / 02 / 08$ & 342.65 & 104.44 & $3,022.07$ & 921.13 & $3,025.63$ \\
\hline C-2737 (ANNULUS) & $\overline{M A G}$ & $01 / 17 / 08$ & 254.91 & 77.70 & $3,145.85$ & 958.86 & \\
\hline C-2737 (ANNULUS) & MAG & $02 / 14 / 08$ & 256.29 & 78.12 & $3,144.47$ & 958.43 & \\
\hline C-2737 (ANNULUS) & MAG & $03 / 27 / 08$ & 256.28 & 78.11 & $3,144.48$ & 958.44 & \\
\hline C-2737 (ANNULUS) & $\overline{M A G}$ & $04 / 09 / 08$ & 256.22 & 78.10 & $3,144.54$ & 958.46 & \\
\hline C-2737 (ANNULUS) & MAG & $05 / 13 / 08$ & 256.24 & 78.10 & $3,144.52$ & 958.45 & \\
\hline C-2737 (ANNULUS) & MAG & $06 / 11 / 08$ & 256.28 & 78.11 & $3,144.48$ & 958.44 & \\
\hline C-2737 (ANNULUS) & MAG & $07 / 09 / 08$ & 256.49 & 78.18 & $3,144.27$ & 958.37 & \\
\hline C-2737 (ANNULUS) & MAG & $08 / 15 / 08$ & 256.45 & 78.16 & $3,144.31$ & 958.39 & \\
\hline C-2737 (ANNULUS) & $\overline{M A G}$ & $09 / 24 / 08$ & 256.80 & 78.27 & $3,143.96$ & 958.28 & \\
\hline C-2737 (ANNULUS) & MAG & $10 / 15 / 08$ & 256.70 & 78.24 & $3,144.06$ & 958.31 & \\
\hline C-2737 (ANNULUS) & MAG & $11 / 05 / 08$ & 256.49 & 78.18 & $3,144.27$ & 958.37 & \\
\hline C-2737 (ANNULUS) & MAG & $12 / 03 / 08$ & 256.62 & 78.22 & $3,144.14$ & 958.33 & \\
\hline $\mathrm{H}-02 \mathrm{~b} 1$ & MAG & $01 / 17 / 08$ & 235.48 & 71.77 & $3,143.01$ & 957.99 & \\
\hline $\mathrm{H}-02 \mathrm{~b} 1$ & MAG & $02 / 14 / 08$ & 235.41 & 71.75 & $3,143.08$ & 958.01 & \\
\hline $\mathrm{H}-02 \mathrm{~b} 1$ & MAG & $03 / 27 / 08$ & 235.33 & 71.73 & $3,143.16$ & 958.04 & \\
\hline $\mathrm{H}-02 \mathrm{~b} 1$ & MAG & $04 / 09 / 08$ & 235.31 & 71.72 & $3,143.18$ & 958.04 & \\
\hline $\mathrm{H}-02 \mathrm{~b} 1$ & MAG & $05 / 13 / 08$ & 235.25 & 71.70 & $3,143.24$ & 958.06 & \\
\hline $\mathrm{H}-02 \mathrm{~b} 1$ & MAG & $06 / 11 / 08$ & 235.20 & 71.69 & $3,143.29$ & 958.07 & \\
\hline $\mathrm{H}-02 \mathrm{~b} 1$ & MAG & $07 / 09 / 08$ & 235.30 & 71.72 & $3,143.19$ & 958.04 & \\
\hline $\mathrm{H}-02 \mathrm{~b} 1$ & MAG & $08 / 14 / 08$ & 235.21 & 71.69 & $3,143.28$ & 958.07 & \\
\hline $\mathrm{H}-02 \mathrm{~b} 1$ & MAG & $09 / 24 / 08$ & 235.17 & 71.68 & $3,143.32$ & 958.08 & \\
\hline
\end{tabular}


Waste Isolation Pilot Plant Annual Site Environmental Report for 2008 DOE/WIPP-09-2225

Table F.9 - Water Levels

\begin{tabular}{|c|c|c|c|c|c|c|c|}
\hline $\begin{array}{c}\text { Well } \\
\text { Number }\end{array}$ & Zone & Date & $\begin{array}{c}\text { Adjusted } \\
\text { Depth } \\
\text { Top of } \\
\text { Casing } \\
\text { (ft) }\end{array}$ & $\begin{array}{c}\text { Adjusted } \\
\text { Depth } \\
\text { Meters }\end{array}$ & $\begin{array}{c}\text { Water } \\
\text { Level } \\
\text { Elevation } \\
\text { (ft amsl) }\end{array}$ & $\begin{array}{c}\text { Elevation } \\
\text { in } \\
\text { Meters } \\
\text { (amsl) }\end{array}$ & $\begin{array}{c}\text { Adjusted } \\
\text { Freshwater } \\
\text { Head } \\
\text { (ft amsl) }\end{array}$ \\
\hline $\mathrm{H}-02 \mathrm{~b} 1$ & MAG & $10 / 13 / 08$ & 235.16 & 71.68 & $3,143.33$ & 958.09 & \\
\hline $\mathrm{H}-02 \mathrm{~b} 1$ & MAG & $11 / 04 / 08$ & 235.15 & 71.67 & $3,143.34$ & 958.09 & \\
\hline $\mathrm{H}-02 \mathrm{~b} 1$ & MAG & $12 / 03 / 08$ & 235.12 & 71.66 & $3,143.37$ & 958.10 & \\
\hline $\mathrm{H}-03 \mathrm{~b} 1$ & MAG & $01 / 17 / 08$ & 243.84 & 74.32 & $3,146.88$ & 959.17 & \\
\hline $\mathrm{H}-03 \mathrm{~b} 1$ & $\overline{M A G}$ & $02 / 14 / 08$ & 243.71 & 74.28 & $3,147.01$ & 959.21 & \\
\hline $\mathrm{H}-03 \mathrm{~b} 1$ & $\overline{M A G}$ & $03 / 26 / 08$ & 243.76 & 74.30 & $3,146.96$ & 959.19 & \\
\hline $\mathrm{H}-03 \mathrm{~b} 1$ & MAG & $04 / 09 / 08$ & 243.61 & 74.25 & $3,147.11$ & 959.24 & \\
\hline $\mathrm{H}-03 \mathrm{~b} 1$ & MAG & $05 / 13 / 08$ & 243.67 & 74.27 & $3,147.05$ & 959.22 & \\
\hline $\mathrm{H}-03 \mathrm{~b} 1$ & MAG & $06 / 11 / 08$ & 243.69 & 74.28 & $3,147.03$ & 959.21 & \\
\hline $\mathrm{H}-03 \mathrm{~b} 1$ & MAG & $07 / 09 / 08$ & 243.85 & 74.33 & $3,146.87$ & 959.17 & \\
\hline $\mathrm{H}-03 \mathrm{~b} 1$ & MAG & $08 / 15 / 08$ & 243.96 & 74.36 & $3,146.76$ & 959.13 & \\
\hline $\mathrm{H}-03 \mathrm{~b} 1$ & MAG & $09 / 24 / 08$ & 244.13 & 74.41 & $3,146.59$ & 959.08 & \\
\hline $\mathrm{H}-03 \mathrm{~b} 1$ & MAG & $10 / 14 / 08$ & 244.05 & 74.39 & $3,146.67$ & 959.11 & \\
\hline $\mathrm{H}-03 \mathrm{~b} 1$ & MAG & $11 / 05 / 08$ & 243.92 & 74.35 & $3,146.80$ & 959.14 & \\
\hline $\mathrm{H}-03 \mathrm{~b} 1$ & $\overline{M A G}$ & $12 / 03 / 08$ & 244.06 & 74.39 & $3,146.66$ & 959.10 & \\
\hline $\mathrm{H}-04 \mathrm{c}$ & MAG & $01 / 17 / 08$ & 187.58 & 57.17 & $3,146.70$ & 959.11 & \\
\hline $\mathrm{H}-04 \mathrm{c}$ & $\overline{M A G}$ & $02 / 14 / 08$ & 187.43 & 57.13 & $3,146.85$ & 959.16 & \\
\hline $\mathrm{H}-04 \mathrm{c}$ & MAG & $03 / 25 / 08$ & 187.36 & 57.11 & $3,146.92$ & 959.18 & \\
\hline $\mathrm{H}-04 \mathrm{c}$ & MAG & $04 / 08 / 08$ & 187.21 & 57.06 & $3,147.07$ & 959.23 & \\
\hline $\mathrm{H}-04 \mathrm{c}$ & $\overline{M A G}$ & $05 / 13 / 08$ & 187.11 & 57.03 & $3,147.17$ & 959.26 & \\
\hline $\mathrm{H}-04 \mathrm{c}$ & MAG & $06 / 10 / 08$ & 187.02 & 57.00 & $3,147.26$ & 959.28 & \\
\hline $\mathrm{H}-04 \mathrm{c}$ & $\overline{M A G}$ & $07 / 09 / 08$ & 187.10 & 57.03 & $3,147.18$ & 959.26 & \\
\hline $\mathrm{H}-04 \mathrm{c}$ & MAG & $08 / 11 / 08$ & 187.00 & 57.00 & $3,147.28$ & 959.29 & \\
\hline $\mathrm{H}-04 \mathrm{c}$ & MAG & $09 / 24 / 08$ & 186.98 & 56.99 & $3,147.30$ & 959.30 & \\
\hline $\mathrm{H}-04 \mathrm{c}$ & MAG & $10 / 13 / 08$ & 186.88 & 56.96 & $3,147.40$ & 959.33 & \\
\hline $\mathrm{H}-04 \mathrm{c}$ & MAG & $11 / 04 / 08$ & 186.85 & 56.95 & $3,147.43$ & 959.34 & \\
\hline $\mathrm{H}-04 \mathrm{c}$ & MAG & $12 / 02 / 08$ & 186.85 & 56.95 & $3,147.43$ & 959.34 & \\
\hline $\mathrm{H}-06 \mathrm{c}$ & MAG & $01 / 15 / 08$ & 279.20 & 85.10 & $3,069.49$ & 935.58 & \\
\hline $\mathrm{H}-06 \mathrm{c}$ & MAG & $02 / 14 / 08$ & 278.83 & 84.99 & $3,069.86$ & 935.69 & \\
\hline $\mathrm{H}-06 \mathrm{c}$ & MAG & $03 / 27 / 08$ & 278.78 & 84.97 & $3,069.91$ & 935.71 & \\
\hline $\mathrm{H}-06 \mathrm{c}$ & MAG & $04 / 08 / 08$ & 278.81 & 84.98 & $3,069.88$ & 935.70 & \\
\hline $\mathrm{H}-06 \mathrm{c}$ & MAG & $05 / 13 / 08$ & 282.67 & 86.16 & $3,066.02$ & 934.52 & \\
\hline $\mathrm{H}-06 \mathrm{c}$ & MAG & $06 / 10 / 08$ & 281.22 & 85.72 & $3,067.47$ & 934.96 & \\
\hline $\mathrm{H}-06 \mathrm{c}$ & MAG & $07 / 08 / 08$ & 280.60 & 85.53 & $3,068.09$ & 935.15 & \\
\hline $\mathrm{H}-06 \mathrm{c}$ & MAG & $08 / 14 / 08$ & 280.01 & 85.35 & $3,068.68$ & 935.33 & \\
\hline $\mathrm{H}-06 \mathrm{c}$ & MAG & $09 / 23 / 08$ & 279.56 & 85.21 & $3,069.13$ & 935.47 & \\
\hline $\mathrm{H}-06 \mathrm{c}$ & MAG & $10 / 13 / 08$ & 279.37 & 85.15 & $3,069.32$ & 935.53 & \\
\hline $\mathrm{H}-06 \mathrm{c}$ & MAG & $11 / 06 / 08$ & 279.23 & 85.11 & $3,069.46$ & 935.57 & \\
\hline $\mathrm{H}-06 \mathrm{c}$ & MAG & $12 / 03 / 08$ & 279.06 & 85.06 & $3,069.63$ & 935.62 & \\
\hline $\mathrm{H}-08 \mathrm{a}$ & MAG & $01 / 14 / 08$ & 405.98 & 123.74 & $3,027.30$ & 922.72 & \\
\hline $\mathrm{H}-08 \mathrm{a}$ & MAG & $02 / 11 / 08$ & 405.93 & 123.73 & $3,027.35$ & 922.74 & \\
\hline $\mathrm{H}-08 \mathrm{a}$ & MAG & $03 / 24 / 08$ & 405.96 & 123.74 & $3,027.32$ & 922.73 & \\
\hline
\end{tabular}


Waste Isolation Pilot Plant Annual Site Environmental Report for 2008 DOE/WIPP-09-2225

Table F.9 - Water Levels

\begin{tabular}{|c|c|c|c|c|c|c|c|}
\hline $\begin{array}{c}\text { Well } \\
\text { Number }\end{array}$ & Zone & Date & $\begin{array}{c}\text { Adjusted } \\
\text { Depth } \\
\text { Top of } \\
\text { Casing } \\
\text { (ft) }\end{array}$ & $\begin{array}{l}\text { Adjusted } \\
\text { Depth } \\
\text { Meters }\end{array}$ & $\begin{array}{l}\text { Water } \\
\text { Level } \\
\text { Elevation } \\
\text { (ft amsl) }\end{array}$ & $\begin{array}{c}\text { Elevation } \\
\text { in } \\
\text { Meters } \\
\text { (amsl) }\end{array}$ & $\begin{array}{c}\text { Adjusted } \\
\text { Freshwater } \\
\text { Head } \\
\text { (ft amsl) }\end{array}$ \\
\hline $\mathrm{H}-08 \mathrm{a}$ & MAG & $04 / 07 / 08$ & 405.94 & 123.73 & $3,027.34$ & 922.73 & \\
\hline $\mathrm{H}-08 \mathrm{a}$ & MAG & $05 / 14 / 08$ & 405.94 & 123.73 & $3,027.34$ & 922.73 & \\
\hline $\mathrm{H}-08 \mathrm{a}$ & MAG & $06 / 10 / 08$ & 405.88 & 123.71 & $3,027.40$ & 922.75 & \\
\hline $\mathrm{H}-08 \mathrm{a}$ & MAG & $07 / 08 / 08$ & 405.99 & 123.75 & $3,027.29$ & 922.72 & \\
\hline $\mathrm{H}-08 \mathrm{a}$ & MAG & $08 / 12 / 08$ & 405.98 & 123.74 & $3,027.30$ & 922.72 & \\
\hline $\mathrm{H}-08 \mathrm{a}$ & MAG & $09 / 23 / 08$ & 406.00 & 123.75 & $3,027.28$ & 922.71 & \\
\hline $\mathrm{H}-08 \mathrm{a}$ & MAG & $10 / 14 / 08$ & 406.03 & 123.76 & $3,027.25$ & 922.71 & \\
\hline $\mathrm{H}-08 \mathrm{a}$ & MAG & $11 / 05 / 08$ & 405.95 & 123.73 & $3,027.33$ & 922.73 & \\
\hline $\mathrm{H}-08 \mathrm{a}$ & MAG & $12 / 01 / 08$ & 406.00 & 123.75 & $3,027.28$ & 922.71 & \\
\hline H-09c (ANNULUS) & MAG & $01 / 14 / 08$ & 270.17 & 82.35 & $3,136.88$ & 956.12 & \\
\hline H-09c (ANNULUS) & MAG & $02 / 11 / 08$ & 269.85 & 82.25 & $3,137.20$ & 956.22 & \\
\hline H-09c (ANNULUS) & MAG & $03 / 24 / 08$ & 269.89 & 82.26 & $3,137.16$ & 956.21 & \\
\hline H-09c (ANNULUS) & MAG & $04 / 07 / 08$ & 269.53 & 82.15 & $3,137.52$ & 956.32 & \\
\hline H-09c (ANNULUS) & MAG & $05 / 15 / 08$ & 269.37 & 82.10 & $3,137.68$ & 956.36 & \\
\hline H-09c (ANNULUS) & MAG & $06 / 10 / 08$ & 269.39 & 82.11 & $3,137.66$ & 956.36 & \\
\hline H-09c (ANNULUS) & MAG & $07 / 08 / 08$ & 269.37 & 82.10 & $3,137.68$ & 956.36 & \\
\hline H-09c (ANNULUS) & MAG & $08 / 12 / 08$ & 269.27 & 82.07 & $3,137.78$ & 956.40 & \\
\hline $\mathrm{H}-09 \mathrm{c}$ (ANNULUS) & MAG & $09 / 23 / 08$ & 269.23 & 82.06 & $3,137.82$ & 956.41 & \\
\hline H-09c (ANNULUS) & MAG & $10 / 14 / 08$ & 269.15 & 82.04 & $3,137.90$ & 956.43 & \\
\hline H-09c (ANNULUS) & MAG & $11 / 05 / 08$ & 268.87 & 81.95 & $3,138.18$ & 956.52 & \\
\hline H-09c (ANNULUS) & MAG & $12 / 01 / 08$ & 269.12 & 82.03 & $3,137.93$ & 956.44 & \\
\hline $\mathrm{H}-10 \mathrm{a}$ & MAG & $01 / 14 / 08$ & 465.30 & 141.82 & $3,223.15$ & 982.42 & \\
\hline $\mathrm{H}-10 \mathrm{a}$ & MAG & $02 / 11 / 08$ & 465.40 & 141.85 & $3,223.05$ & 982.39 & \\
\hline $\mathrm{H}-10 \mathrm{a}$ & MAG & $03 / 24 / 08$ & 465.59 & 141.91 & $3,222.86$ & 982.33 & \\
\hline $\mathrm{H}-10 \mathrm{a}$ & MAG & $04 / 07 / 08$ & 465.56 & 141.90 & $3,222.89$ & 982.34 & \\
\hline $\mathrm{H}-10 \mathrm{a}$ & MAG & $05 / 15 / 08$ & 465.65 & 141.93 & $3,222.80$ & 982.31 & \\
\hline $\mathrm{H}-10 \mathrm{a}$ & MAG & $06 / 10 / 08$ & 465.69 & 141.94 & $3,222.76$ & 982.30 & \\
\hline $\mathrm{H}-10 \mathrm{a}$ & MAG & $07 / 07 / 08$ & 465.86 & 141.99 & $3,222.59$ & 982.25 & \\
\hline $\mathrm{H}-10 \mathrm{a}$ & MAG & $08 / 12 / 08$ & 465.95 & 142.02 & $3,222.50$ & 982.22 & \\
\hline $\mathrm{H}-10 \mathrm{a}$ & MAG & $09 / 23 / 08$ & 466.06 & 142.06 & $3,222.39$ & 982.18 & \\
\hline $\mathrm{H}-10 \mathrm{a}$ & MAG & $10 / 14 / 08$ & 466.10 & 142.07 & $3,222.35$ & 982.17 & \\
\hline $\mathrm{H}-10 \mathrm{a}$ & MAG & $11 / 05 / 08$ & 466.02 & 142.04 & $3,222.43$ & 982.20 & \\
\hline $\mathrm{H}-10 \mathrm{a}$ & MAG & $12 / 01 / 08$ & 466.12 & 142.07 & $3,222.33$ & 982.17 & \\
\hline $\mathrm{H}-11 \mathrm{~b} 2$ & MAG & $07 / 07 / 08$ & 277.73 & 84.65 & $3,134.13$ & 955.28 & \\
\hline $\mathrm{H}-11 \mathrm{~b} 2$ & MAG & $08 / 14 / 08$ & 274.81 & 83.76 & $3,137.05$ & 956.17 & \\
\hline $\mathrm{H}-11 \mathrm{~b} 2$ & MAG & $09 / 22 / 08$ & 274.39 & 83.63 & $3,137.47$ & 956.30 & \\
\hline $\mathrm{H}-11 \mathrm{~b} 2$ & MAG & $10 / 14 / 08$ & 274.18 & 83.57 & $3,137.68$ & 956.36 & \\
\hline $\mathrm{H}-11 \mathrm{~b} 2$ & MAG & $11 / 05 / 08$ & 273.89 & 83.48 & $3,137.97$ & 956.45 & \\
\hline $\mathrm{H}-11 \mathrm{~b} 2$ & MAG & $12 / 02 / 08$ & 273.90 & 83.48 & $3,137.96$ & 956.45 & \\
\hline $\mathrm{H}-14$ & MAG & $03 / 26 / 08$ & 237.31 & 72.33 & $3,109.77$ & 947.86 & \\
\hline $\mathrm{H}-14$ & MAG & $04 / 09 / 08$ & 233.97 & 71.31 & $3,113.11$ & 948.88 & \\
\hline $\mathrm{H}-14$ & MAG & $05 / 12 / 08$ & 227.88 & 69.46 & $3,119.20$ & 950.73 & \\
\hline
\end{tabular}


Waste Isolation Pilot Plant Annual Site Environmental Report for 2008 DOE/WIPP-09-2225

Table F.9 - Water Levels

\begin{tabular}{|c|c|c|c|c|c|c|c|}
\hline $\begin{array}{c}\text { Well } \\
\text { Number }\end{array}$ & Zone & Date & $\begin{array}{c}\text { Adjusted } \\
\text { Depth } \\
\text { Top of } \\
\text { Casing } \\
\text { (ft) }\end{array}$ & $\begin{array}{l}\text { Adjusted } \\
\text { Depth } \\
\text { Meters }\end{array}$ & $\begin{array}{c}\text { Water } \\
\text { Level } \\
\text { Elevation } \\
\text { (ft amsl) }\end{array}$ & $\begin{array}{c}\text { Elevation } \\
\text { in } \\
\text { Meters } \\
\text { (amsl) }\end{array}$ & $\begin{array}{c}\text { Adjusted } \\
\text { Freshwater } \\
\text { Head } \\
\text { (ft amsl) }\end{array}$ \\
\hline $\mathrm{H}-14$ & MAG & $06 / 09 / 08$ & 224.11 & 68.31 & $3,122.97$ & 951.88 & \\
\hline $\mathrm{H}-14$ & MAG & $07 / 07 / 08$ & 221.28 & 67.45 & $3,125.80$ & 952.74 & \\
\hline $\mathrm{H}-14$ & MAG & $08 / 14 / 08$ & 218.31 & 66.54 & $3,128.77$ & 953.65 & \\
\hline $\mathrm{H}-15$ & MAG & $01 / 17 / 08$ & 357.49 & 108.96 & $3,123.40$ & 952.01 & \\
\hline $\mathrm{H}-15$ & MAG & $02 / 14 / 08$ & 357.24 & 108.89 & $3,123.65$ & 952.09 & \\
\hline $\mathrm{H}-15$ & MAG & $04 / 09 / 08$ & 362.96 & 110.63 & $3,120.54$ & 951.14 & \\
\hline $\mathrm{H}-15$ & MAG & $07 / 09 / 08$ & 362.49 & 110.49 & $3,121.01$ & 951.28 & \\
\hline $\mathrm{H}-15$ & MAG & $08 / 15 / 08$ & 360.66 & 109.93 & $3,122.84$ & 951.84 & \\
\hline $\mathrm{H}-15$ & MAG & $09 / 24 / 08$ & 359.54 & 109.59 & $3,123.96$ & 952.18 & \\
\hline $\mathrm{H}-15$ & MAG & $10 / 14 / 08$ & 358.83 & 109.37 & $3,124.67$ & 952.40 & \\
\hline $\mathrm{H}-15$ & MAG & $11 / 05 / 08$ & 358.05 & 109.13 & $3,125.45$ & 952.64 & \\
\hline $\mathrm{H}-15$ & MAG & $12 / 03 / 08$ & 357.68 & 109.02 & $3,125.82$ & 952.75 & \\
\hline $\mathrm{H}-18$ & MAG & $01 / 15 / 08$ & 267.13 & 81.42 & $3,147.08$ & 959.23 & \\
\hline $\mathrm{H}-18$ & MAG & $02 / 14 / 08$ & 266.53 & 81.24 & $3,147.68$ & 959.41 & \\
\hline $\mathrm{H}-18$ & MAG & $03 / 25 / 08$ & 266.24 & 81.15 & $3,147.97$ & 959.50 & \\
\hline $\mathrm{H}-18$ & MAG & $04 / 08 / 08$ & 266.04 & 81.09 & $3,148.17$ & 959.56 & \\
\hline $\mathrm{H}-18$ & MAG & $05 / 13 / 08$ & 265.66 & 80.97 & $3,148.55$ & 959.68 & \\
\hline $\mathrm{H}-18$ & MAG & $06 / 10 / 08$ & 265.53 & 80.93 & $3,148.68$ & 959.72 & \\
\hline $\mathrm{H}-18$ & MAG & $07 / 08 / 08$ & 265.34 & 80.88 & $3,148.87$ & 959.78 & \\
\hline $\mathrm{H}-18$ & MAG & $08 / 14 / 08$ & 265.04 & 80.78 & $3,149.17$ & 959.87 & \\
\hline $\mathrm{H}-18$ & MAG & $09 / 23 / 08$ & 264.70 & 80.68 & $3,149.51$ & 959.97 & \\
\hline $\mathrm{H}-18$ & MAG & $10 / 15 / 08$ & 264.51 & 80.62 & $3,149.70$ & 960.03 & \\
\hline $\mathrm{H}-18$ & MAG & $11 / 04 / 08$ & 264.13 & 80.51 & $3,150.08$ & 960.14 & \\
\hline $\mathrm{H}-18$ & MAG & $12 / 02 / 08$ & 264.00 & 80.47 & $3,150.21$ & 960.18 & \\
\hline WIPP-18 & MAG & $01 / 16 / 08$ & 307.81 & 93.82 & $3,149.76$ & 960.05 & \\
\hline WIPP-18 & MAG & $02 / 14 / 08$ & 307.69 & 93.78 & $3,149.88$ & 960.08 & \\
\hline WIPP-18 & MAG & $03 / 27 / 08$ & 307.63 & 93.77 & $3,149.94$ & 960.10 & \\
\hline WIPP-18 & MAG & $04 / 08 / 08$ & 307.53 & 93.74 & $3,150.04$ & 960.13 & \\
\hline WIPP-18 & MAG & $05 / 13 / 08$ & 307.48 & 93.72 & $3,150.09$ & 960.15 & \\
\hline WIPP-18 & MAG & $06 / 11 / 08$ & 307.46 & 93.71 & $3,150.11$ & 960.15 & \\
\hline WIPP-18 & MAG & $07 / 09 / 08$ & 307.65 & 93.77 & $3,149.92$ & 960.10 & \\
\hline WIPP-18 & MAG & $08 / 14 / 08$ & 307.69 & 93.78 & $3,149.88$ & 960.08 & \\
\hline WIPP-18 & MAG & $09 / 24 / 08$ & 307.84 & 93.83 & $3,149.73$ & 960.04 & \\
\hline WIPP-18 & MAG & $10 / 15 / 08$ & 307.80 & 93.82 & $3,149.77$ & 960.05 & \\
\hline WIPP-18 & MAG & $11 / 06 / 08$ & 307.75 & 93.80 & $3,149.82$ & 960.07 & \\
\hline WIPP-18 & MAG & $12 / 03 / 08$ & 307.81 & 93.82 & $3,149.76$ & 960.05 & \\
\hline WIPP-25 (ANNULUS) & MAG & $01 / 15 / 08$ & 145.95 & 44.49 & $3,068.29$ & 935.21 & \\
\hline WIPP-25 (ANNULUS) & MAG & $02 / 13 / 08$ & 147.06 & 44.82 & $3,067.18$ & 934.88 & \\
\hline WIPP-25 (ANNULUS) & MAG & $03 / 24 / 08$ & 146.58 & 44.68 & $3,067.66$ & 935.02 & \\
\hline WIPP-25 (ANNULUS) & MAG & $04 / 08 / 08$ & 147.56 & 44.98 & $3,066.68$ & 934.72 & \\
\hline WIPP-25 (ANNULUS) & MAG & $05 / 12 / 08$ & 147.75 & 45.03 & $3,066.49$ & 934.67 & \\
\hline WIPP-25 (ANNULUS) & MAG & $06 / 09 / 08$ & 148.09 & 45.14 & $3,066.15$ & 934.56 & \\
\hline
\end{tabular}


Waste Isolation Pilot Plant Annual Site Environmental Report for 2008 DOE/WIPP-09-2225

Table F.9 - Water Levels

\begin{tabular}{|c|c|c|c|c|c|c|c|}
\hline $\begin{array}{c}\text { Well } \\
\text { Number }\end{array}$ & Zone & Date & $\begin{array}{c}\text { Adjusted } \\
\text { Depth } \\
\text { Top of } \\
\text { Casing } \\
\text { (ft) }\end{array}$ & $\begin{array}{l}\text { Adjusted } \\
\text { Depth } \\
\text { Meters }\end{array}$ & $\begin{array}{c}\text { Water } \\
\text { Level } \\
\text { Elevation } \\
\text { (ft amsl) }\end{array}$ & $\begin{array}{c}\text { Elevation } \\
\text { in } \\
\text { Meters } \\
\text { (amsl) }\end{array}$ & $\begin{array}{c}\text { Adjusted } \\
\text { Freshwater } \\
\text { Head } \\
\text { (ft amsl) }\end{array}$ \\
\hline WIPP-25 (ANNULUS) & MAG & $07 / 08 / 08$ & 148.33 & 45.21 & $3,065.91$ & 934.49 & \\
\hline WIPP-25 (ANNULUS) & $\overline{M A G}$ & $08 / 14 / 08$ & 148.39 & 45.23 & $3,065.85$ & 934.47 & \\
\hline WIPP-25 (ANNULUS) & MAG & $09 / 23 / 08$ & 148.33 & 45.21 & $3,065.91$ & 934.49 & \\
\hline WIPP-25 (ANNULUS) & MAG & $10 / 13 / 08$ & 148.70 & 45.32 & $3,065.54$ & 934.38 & \\
\hline WIPP-25 (ANNULUS) & $\overline{M A G}$ & $11 / 04 / 08$ & 147.61 & 44.99 & $3,066.63$ & 934.71 & \\
\hline WIPP-25 (ANNULUS) & $\overline{M A G}$ & $12 / 02 / 08$ & 147.40 & 44.93 & $3,066.84$ & 934.77 & \\
\hline WQSP-6a & $\mathrm{DL}$ & $01 / 16 / 08$ & 166.78 & 50.83 & $3,197.02$ & 974.45 & \\
\hline WQSP-6a & $\overline{D L}$ & $02 / 14 / 08$ & 166.72 & 50.82 & $3,197.08$ & 974.47 & \\
\hline WQSP-6a & $\mathrm{DL}$ & $03 / 26 / 08$ & 166.87 & 50.86 & $3,196.93$ & 974.42 & \\
\hline WQSP-6a & $\overline{\mathrm{DL}}$ & $04 / 08 / 08$ & 166.90 & 50.87 & $3,196.90$ & 974.42 & \\
\hline WQSP-6a & $\overline{D L}$ & $05 / 13 / 08$ & 166.85 & 50.86 & $3,196.95$ & 974.43 & \\
\hline WQSP-6a & $\mathrm{DL}$ & $06 / 11 / 08$ & 166.91 & 50.87 & $3,196.89$ & 974.41 & \\
\hline WQSP-6a & $\overline{\mathrm{DL}}$ & $07 / 09 / 08$ & 166.98 & 50.90 & $3,196.82$ & 974.39 & \\
\hline WQSP-6a & $\mathrm{DL}$ & $08 / 11 / 08$ & 167.00 & 50.90 & $3,196.80$ & 974.38 & \\
\hline WQSP-6a & $\overline{D L}$ & $09 / 24 / 08$ & 167.17 & 50.95 & $3,196.63$ & 974.33 & \\
\hline WQSP-6a & $\overline{D L}$ & $10 / 14 / 08$ & 167.14 & 50.94 & $3,196.66$ & 974.34 & \\
\hline WQSP-6a & $\overline{D L}$ & $11 / 06 / 08$ & 166.91 & 50.87 & $3,196.89$ & 974.41 & \\
\hline WQSP-6a & $\mathrm{DL}$ & $12 / 03 / 08$ & 166.79 & 50.84 & $3,197.01$ & 974.45 & \\
\hline CB-1 & $\mathrm{B} / \mathrm{C}$ & $01 / 15 / 08$ & 596.86 & 181.92 & $2,731.94$ & 832.70 & \\
\hline CB-1 & $\mathrm{B} / \mathrm{C}$ & $02 / 14 / 08$ & 596.68 & 181.87 & $2,732.12$ & 832.75 & \\
\hline CB-1 & $\mathrm{B} / \mathrm{C}$ & $04 / 09 / 08$ & 705.59 & 215.06 & $2,623.53$ & 799.65 & \\
\hline$\overline{C B}-1$ & $\mathrm{~B} / \mathrm{C}$ & $05 / 12 / 08$ & 704.86 & 214.84 & $2,624.26$ & 799.87 & \\
\hline CB-1 & $\mathrm{B} / \mathrm{C}$ & $07 / 07 / 08$ & 349.48 & 106.52 & $2,979.64$ & 908.19 & \\
\hline CB-1 & $\mathrm{B} / \mathrm{C}$ & $08 / 14 / 08$ & 332.22 & 101.26 & $2,996.90$ & 913.46 & \\
\hline CB-1 & $\mathrm{B} / \mathrm{C}$ & $09 / 22 / 08$ & 328.08 & 100.00 & $3,001.04$ & 914.72 & \\
\hline CB-1 & $\mathrm{B} / \mathrm{C}$ & $10 / 14 / 08$ & 326.76 & 99.60 & $3,002.36$ & 915.12 & \\
\hline CB-1 & $\mathrm{B} / \mathrm{C}$ & $11 / 05 / 08$ & 325.66 & 99.26 & $3,003.46$ & 915.45 & \\
\hline CB-1 & $\mathrm{B} / \mathrm{C}$ & $12 / 02 / 08$ & 325.01 & 99.06 & $3,004.11$ & 915.65 & \\
\hline DOE-2 & $\mathrm{B} / \mathrm{C}$ & $01 / 15 / 08$ & 724.99 & 220.98 & $2,694.65$ & 821.33 & \\
\hline DOE-2 & $\mathrm{B} / \mathrm{C}$ & $02 / 14 / 08$ & 724.61 & 220.86 & $2,695.03$ & 821.45 & \\
\hline DOE-2 & $\mathrm{B} / \mathrm{C}$ & $04 / 09 / 08$ & 390.23 & 118.94 & $3,028.95$ & 923.22 & \\
\hline DOE-2 & $\mathrm{B} / \mathrm{C}$ & $05 / 13 / 08$ & 361.69 & 110.24 & $3,057.49$ & 931.92 & \\
\hline DOE-2 & $\mathrm{B} / \mathrm{C}$ & $06 / 10 / 08$ & 358.12 & 109.15 & $3,061.06$ & 933.01 & \\
\hline DOE-2 & $\mathrm{B} / \mathrm{C}$ & $07 / 08 / 08$ & 356.37 & 108.62 & $3,062.81$ & 933.54 & \\
\hline DOE-2 & $\mathrm{B} / \mathrm{C}$ & $08 / 14 / 08$ & 354.73 & 108.12 & $3,064.45$ & 934.04 & \\
\hline DOE-2 & $\mathrm{B} / \mathrm{C}$ & $09 / 24 / 08$ & 354.17 & 107.95 & $3,065.01$ & 934.22 & \\
\hline DOE-2 & $\mathrm{B} / \mathrm{C}$ & $10 / 13 / 08$ & 353.84 & 107.85 & $3,065.34$ & 934.32 & \\
\hline DOE-2 & $\mathrm{B} / \mathrm{C}$ & $11 / 04 / 08$ & 353.66 & 107.80 & $3,065.52$ & 934.37 & \\
\hline DOE-2 & $\mathrm{B} / \mathrm{C}$ & $12 / 02 / 08$ & 353.52 & 107.75 & $3,065.66$ & 934.41 & \\
\hline C-2505 & SR/DL & $03 / 27 / 08$ & 42.88 & 13.07 & $3,370.05$ & $1,027.19$ & \\
\hline C-2505 & SR/DL & $06 / 12 / 08$ & 43.37 & 13.22 & $3,369.56$ & $1,027.04$ & \\
\hline C-2505 & SR/DL & $09 / 25 / 08$ & 43.93 & 13.39 & $3,369.00$ & $1,026.87$ & \\
\hline
\end{tabular}


Waste Isolation Pilot Plant Annual Site Environmental Report for 2008 DOE/WIPP-09-2225

Table F.9 - Water Levels

\begin{tabular}{|c|c|c|c|c|c|c|c|}
\hline $\begin{array}{c}\text { Well } \\
\text { Number }\end{array}$ & Zone & Date & $\begin{array}{c}\text { Adjusted } \\
\text { Depth } \\
\text { Top of } \\
\text { Casing } \\
\text { (ft) }\end{array}$ & $\begin{array}{l}\text { Adjusted } \\
\text { Depth } \\
\text { Meters }\end{array}$ & $\begin{array}{l}\text { Water } \\
\text { Level } \\
\text { Elevation } \\
\text { (ft amsl) }\end{array}$ & $\begin{array}{c}\text { Elevation } \\
\text { in } \\
\text { Meters } \\
\text { (amsl) }\end{array}$ & $\begin{array}{c}\text { Adjusted } \\
\text { Freshwater } \\
\text { Head } \\
\text { (ft amsl) }\end{array}$ \\
\hline C-2505 & SR/DL & $12 / 04 / 08$ & 44.19 & 13.47 & $3,368.74$ & $1,026.79$ & \\
\hline C-2506 & $\begin{array}{l}\text { SR/DL } \\
\end{array}$ & $03 / 27 / 08$ & 42.28 & 12.89 & $3,370.56$ & $1,027.35$ & \\
\hline C-2506 & 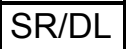 & $06 / 12 / 08$ & 42.80 & 13.05 & $3,370.04$ & $1,027.19$ & \\
\hline C-2506 & SR/DL & $09 / 25 / 08$ & 43.37 & 13.22 & $3,369.47$ & $1,027.01$ & \\
\hline C-2506 & $\overline{S R / D L}$ & $12 / 04 / 08$ & 43.60 & 13.29 & $3,369.24$ & $1,026.94$ & \\
\hline C-2507 & $\overline{S R / D L}$ & $03 / 27 / 08$ & 42.85 & 13.06 & $3,367.06$ & $1,026.28$ & \\
\hline C-2507 & $\overline{S R / D L}$ & $06 / 12 / 08$ & 43.37 & 13.22 & $3,366.54$ & $1,026.12$ & \\
\hline C-2507 & $\begin{array}{l}\text { SR/DL } \\
\end{array}$ & $09 / 25 / 08$ & 43.92 & 13.39 & $3,365.99$ & $1,025.95$ & \\
\hline C-2507 & SR/DL & $12 / 04 / 08$ & 44.15 & 13.46 & $3,365.76$ & $1,025.88$ & \\
\hline C-2811 & $\overline{S R / D L}$ & $03 / 27 / 08$ & 51.41 & 15.67 & $3,347.43$ & $1,020.30$ & \\
\hline C-2811 & $\overline{S R / D L}$ & $06 / 11 / 08$ & 51.91 & 15.82 & $3,346.93$ & $1,020.14$ & \\
\hline C-2811 & SR/DL & $09 / 24 / 08$ & 52.97 & 16.15 & $3,345.87$ & $1,019.82$ & \\
\hline C-2811 & SR/DL & $12 / 03 / 08$ & 52.53 & 16.01 & $3,346.31$ & $1,019.95$ & \\
\hline $\mathrm{PZ}-01$ & SR/DL & $03 / 27 / 08$ & 39.90 & 12.16 & $3,373.38$ & $1,028.21$ & \\
\hline PZ-01 & $\overline{S R / D L}$ & $06 / 12 / 08$ & 40.27 & 12.27 & $3,373.01$ & $1,028.09$ & \\
\hline PZ-01 & SR/DL & $09 / 25 / 08$ & 40.70 & 12.41 & $3,372.58$ & $1,027.96$ & \\
\hline PZ-01 & $\overline{S R / D L}$ & $12 / 04 / 08$ & 40.98 & 12.49 & $3,372.30$ & $1,027.88$ & \\
\hline PZ-02 & SR/DL & $03 / 27 / 08$ & 40.00 & 12.19 & $3,373.36$ & $1,028.20$ & \\
\hline $\mathrm{PZ}-02$ & SR/DL & $06 / 12 / 08$ & 40.47 & 12.34 & $3,372.89$ & $1,028.06$ & \\
\hline PZ-02 & SR/DL & $09 / 25 / 08$ & 41.05 & 12.51 & $3,372.31$ & $1,027.88$ & \\
\hline PZ-02 & $\overline{S R / D L}$ & $12 / 04 / 08$ & 41.36 & 12.61 & $3,372.00$ & $1,027.78$ & \\
\hline PZ-03 & $\overline{S R / D L}$ & $03 / 27 / 08$ & 41.56 & 12.67 & $3,374.56$ & $1,028.57$ & \\
\hline PZ-03 & SR/DL & $06 / 12 / 08$ & 41.90 & 12.77 & $3,374.22$ & $1,028.46$ & \\
\hline PZ-03 & SR/DL & $09 / 25 / 08$ & 42.45 & 12.94 & $3,373.67$ & $1,028.30$ & \\
\hline PZ-03 & $\overline{S R / D L}$ & $12 / 04 / 08$ & 42.73 & 13.02 & $3,373.39$ & $1,028.21$ & \\
\hline PZ-04 & $\overline{S R / D L}$ & $03 / 27 / 08$ & 43.21 & 13.17 & $3,368.80$ & $1,026.81$ & \\
\hline PZ-04 & SR/DL & $06 / 12 / 08$ & 44.04 & 13.42 & $3,367.97$ & $1,026.56$ & \\
\hline PZ-04 & SR/DL & $09 / 25 / 08$ & 44.60 & 13.59 & $3,367.41$ & $1,026.39$ & \\
\hline PZ-04 & SR/DL & $12 / 04 / 08$ & 44.84 & 13.67 & $3,367.17$ & $1,026.31$ & \\
\hline PZ-05 & SR/DL & $03 / 27 / 08$ & 39.95 & 12.18 & $3,375.29$ & $1,028.79$ & \\
\hline PZ-05 & SR/DL & $06 / 12 / 08$ & 40.40 & 12.31 & $3,374.84$ & $1,028.65$ & \\
\hline PZ-05 & SR/DL & $09 / 25 / 08$ & 40.90 & 12.47 & $3,374.34$ & $1,028.50$ & \\
\hline PZ-05 & SR/DL & $12 / 04 / 08$ & 41.21 & 12.56 & $3,374.03$ & $1,028.40$ & \\
\hline PZ-06 & SR/DL & $03 / 27 / 08$ & 41.15 & 12.54 & $3,372.18$ & $1,027.84$ & \\
\hline PZ-06 & $\begin{array}{l}S R / D L \\
\end{array}$ & $06 / 12 / 08$ & 41.64 & 12.69 & $3,371.69$ & $1,027.69$ & \\
\hline PZ-06 & $\overline{S R / D L}$ & $09 / 25 / 08$ & 42.02 & 12.81 & $3,371.31$ & $1,027.57$ & \\
\hline PZ-06 & $\overline{S R / D L}$ & $12 / 04 / 08$ & 42.22 & 12.87 & $3,371.11$ & $1,027.51$ & \\
\hline PZ-07 & SR/DL & $03 / 27 / 08$ & 35.21 & 10.73 & $3,378.63$ & $1,029.81$ & \\
\hline PZ-07 & SR/DL & $06 / 12 / 08$ & 35.56 & 10.84 & $3,378.28$ & $1,029.70$ & \\
\hline PZ-07 & SR/DL & $09 / 24 / 08$ & 36.04 & 10.98 & $3,377.80$ & $1,029.55$ & \\
\hline PZ-07 & SR/DL & $12 / 03 / 08$ & 35.91 & 10.95 & $3,377.93$ & $1,029.59$ & \\
\hline PZ-08 & SR/DL & $03 / 27 / 08$ & 62.74 & 19.12 & $3,355.45$ & $1,022.74$ & \\
\hline
\end{tabular}


Waste Isolation Pilot Plant Annual Site Environmental Report for 2008 DOE/WIPP-09-2225

Table F.9 - Water Levels

\begin{tabular}{|c|c|c|c|c|c|c|c|}
\hline $\begin{array}{c}\text { Well } \\
\text { Number }\end{array}$ & Zone & Date & $\begin{array}{l}\text { Adjusted } \\
\text { Depth } \\
\text { Top of } \\
\text { Casing } \\
\text { (ft) }\end{array}$ & $\begin{array}{l}\text { Adjusted } \\
\text { Depth } \\
\text { Meters }\end{array}$ & $\begin{array}{c}\text { Water } \\
\text { Level } \\
\text { Elevation } \\
\text { (ft amsl) }\end{array}$ & $\begin{array}{c}\text { Elevation } \\
\text { in } \\
\text { Meters } \\
(\text { amsl) }\end{array}$ & $\begin{array}{c}\text { Adjusted } \\
\text { Freshwater } \\
\text { Head } \\
\text { (ft amsl) }\end{array}$ \\
\hline PZ-08 & SR/DL & $06 / 12 / 08$ & 62.36 & 19.01 & $3,355.83$ & $1,022.86$ & \\
\hline PZ-08 & SR/DL & $09 / 24 / 08$ & 62.59 & 19.08 & $3,355.60$ & $1,022.79$ & \\
\hline PZ-08 & SR/DL & $12 / 03 / 08$ & 62.58 & 19.07 & $3,355.61$ & $1,022.79$ & \\
\hline PZ-09 & SR/DL & $03 / 27 / 08$ & 56.09 & 17.10 & $3,365.00$ & $1,025.65$ & \\
\hline PZ-09 & SR/DL & $06 / 12 / 08$ & 56.28 & 17.15 & $3,364.81$ & $1,025.59$ & \\
\hline PZ-09 & SR/DL & $09 / 24 / 08$ & 56.60 & 17.25 & $3,364.49$ & $1,025.50$ & \\
\hline PZ-09 & SR/DL & $12 / 03 / 08$ & 56.35 & 17.18 & $3,364.74$ & $1,025.57$ & \\
\hline PZ-10 & SR/DL & $03 / 27 / 08$ & 34.29 & 10.45 & $3,371.44$ & $1,027.61$ & \\
\hline PZ-10 & SR/DL & $06 / 12 / 08$ & 35.26 & 10.75 & $3,370.47$ & $1,027.32$ & \\
\hline PZ-10 & SR/DL & $09 / 24 / 08$ & 35.56 & 10.84 & $3,370.17$ & $1,027.23$ & \\
\hline PZ-10 & SR/DL & $12 / 03 / 08$ & 35.65 & 10.87 & $3,370.08$ & $1,027.20$ & \\
\hline PZ-11 & SR/DL & $03 / 27 / 08$ & 43.02 & 13.11 & $3,375.76$ & $1,028.93$ & \\
\hline $\mathrm{PZ}-11$ & SR/DL & $06 / 12 / 08$ & 43.17 & 13.16 & $3,375.61$ & $1,028.89$ & \\
\hline PZ-11 & SR/DL & $09 / 24 / 08$ & 43.74 & 13.33 & $3,375.04$ & $1,028.71$ & \\
\hline PZ-11 & SR/DL & $12 / 03 / 08$ & 43.62 & 13.30 & $3,375.16$ & $1,028.75$ & \\
\hline $\mathrm{PZ}-12$ & SR/DL & $03 / 27 / 08$ & 48.82 & 14.88 & $3,360.10$ & $1,024.16$ & \\
\hline PZ-12 & SR/DL & $06 / 12 / 08$ & 49.54 & 15.10 & $3,359.38$ & $1,023.94$ & \\
\hline $\mathrm{PZ}-12$ & SR/DL & $09 / 24 / 08$ & 49.93 & 15.22 & $3,358.99$ & $1,023.82$ & \\
\hline PZ-12 & SR/DL & $12 / 03 / 08$ & 49.89 & 15.21 & $3,359.03$ & $1,023.83$ & \\
\hline PZ-13 & SR/DL & $03 / 27 / 08$ & 64.50 & 19.66 & $3,357.74$ & $1,023.44$ & \\
\hline PZ-13 & SR/DL & $06 / 12 / 08$ & 64.25 & 19.58 & $3,357.99$ & $1,023.52$ & \\
\hline PZ-13 & SR/DL & $09 / 24 / 08$ & 64.55 & 19.67 & $3,357.69$ & $1,023.42$ & \\
\hline $\mathrm{PZ}-13$ & SR/DL & $12 / 03 / 08$ & 64.53 & 19.67 & $3,357.71$ & $1,023.43$ & \\
\hline PZ-14 & SR/DL & $03 / 27 / 08$ & 66.31 & 20.21 & $3,354.27$ & $1,022.38$ & \\
\hline PZ-14 & SR/DL & $06 / 12 / 08$ & 66.32 & 20.21 & $3,354.26$ & $1,022.38$ & \\
\hline PZ-14 & SR/DL & $09 / 24 / 08$ & 66.55 & 20.28 & $3,354.03$ & $1,022.31$ & \\
\hline PZ-14 & SR/DL & $12 / 03 / 08$ & 66.43 & 20.25 & $3,354.15$ & $1,022.35$ & \\
\hline PZ-15 & SR/DL & $03 / 27 / 08$ & 45.65 & 13.91 & $3,385.21$ & $1,031.81$ & \\
\hline PZ-15 & SR/DL & $06 / 12 / 08$ & 46.04 & 14.03 & $3,384.82$ & $1,031.69$ & \\
\hline PZ-15 & SR/DL & $09 / 24 / 08$ & 46.38 & 14.14 & $3,384.48$ & $1,031.59$ & \\
\hline PZ-15 & SR/DL & $12 / 03 / 08$ & 46.10 & 14.05 & $3,384.76$ & $1,031.67$ & \\
\hline
\end{tabular}




\section{Appendix G \\ Air Sampling Data: Concentrations of Radionuclides in Air Filter Composites}

Table G.1 - Radionuclide Concentrations (Bq/m3) in Quarterly Composite Air Filters Collected from Locations Surrounding the WIPP Site. See Appendix C for Sampling Location Codes.

\begin{tabular}{|c|c|c|c|c|c|c|c|c|c|c|}
\hline Location & Quarter & [RN] $^{\mathrm{a}}$ & $2 \times$ TPU $^{b}$ & $M^{\prime} C^{c}$ & {$[\mathrm{RN}]^{\mathrm{a}}$} & $2 \times$ TPU $^{b}$ & $M^{\prime} C^{c}$ & {$[\mathrm{RN}]^{\mathrm{a}}$} & $2 \times$ TPU $^{b}$ & $M^{\prime} C^{c}$ \\
\hline & & & ${ }^{241} \mathrm{Am}$ & & & ${ }^{238} \mathrm{Pu}$ & & & ${ }^{239 / 240} \mathrm{Pu}$ & \\
\hline \multirow[t]{4}{*}{ CBD } & 1 & 3.69E-08 & $1.08 \mathrm{E}-07$ & $2.48 \mathrm{E}-04$ & $3.43 \mathrm{E}-08$ & $7.87 \mathrm{E}-08$ & $5.70 \mathrm{E}-05$ & $1.53 \mathrm{E}-08$ & $5.70 \mathrm{E}-08$ & $1.09 \mathrm{E}-04$ \\
\hline & 2 & 6.56E-09 & 3.88E-08 & 1.73E-04 & 5.19E-09 & 4.83E-08 & 4.98E-06 & 2.72E-08 & $5.01 \mathrm{E}-08$ & 3.84E-05 \\
\hline & 3 & 6.94E-08 & 7.60E-08 & $3.55 \mathrm{E}-04$ & 4.49E-09 & 4.03E-08 & 4.78E-06 & 2.12E-08 & 4.99E-08 & 4.78E-06 \\
\hline & 4 & $5.55 \mathrm{E}-08$ & 9.84E-08 & 2.95E-04 & 2.44E-08 & $6.40 \mathrm{E}-08$ & 7.12E-05 & 6.76E-09 & 4.94E-08 & 1.43E-05 \\
\hline \multirow[t]{4}{*}{ MLR } & 1 & $3.50 \mathrm{E}-08$ & $6.73 \mathrm{E}-08$ & 2.48E-04 & $-3.94 \mathrm{E}-09$ & $1.54 \mathrm{E}-08$ & 5.70E-05 & 1.96E-08 & $5.10 \mathrm{E}-08$ & 1.09E-04 \\
\hline & 2 & 2.71E-08 & $5.28 \mathrm{E}-08$ & 1.73E-04 & $-3.16 \mathrm{E}-09$ & 4.59E-08 & 4.99E-06 & $1.89 \mathrm{E}-08$ & 5.17E-08 & 3.84E-05 \\
\hline & 3 (Avg) & 3.63E-08 & 7.22E-08 & $3.55 \mathrm{E}-04$ & 4.07E-09 & 3.85E-08 & 4.78E-06 & $1.20 \mathrm{E}-08$ & 5.23E-08 & 4.78E-06 \\
\hline & 4 & 5.17E-08 & $8.52 \mathrm{E}-08$ & $2.95 \mathrm{E}-04$ & $-1.22 \mathrm{E}-08$ & $2.62 \mathrm{E}-08$ & 7.12E-05 & $-2.68 \mathrm{E}-08$ & $3.88 \mathrm{E}-08$ & 1.43E-05 \\
\hline \multirow[t]{4}{*}{ SEC } & 1 & 6.42E-08 & 9.63E-08 & 2.48E-04 & $-2.05 E-08$ & 3.28E-08 & 5.70E-05 & $-3.74 \mathrm{E}-08$ & 4.43E-08 & $1.09 \mathrm{E}-04$ \\
\hline & 2 & $2.15 \mathrm{E}-08$ & $5.16 \mathrm{E}-08$ & 1.73E-04 & 2.32E-08 & 5.95E-08 & 4.99E-06 & 4.33E-09 & 3.69E-08 & 3.84E-05 \\
\hline & 3 & 5.97E-08 & 7.42E-08 & $3.55 \mathrm{E}-04$ & 6.52E-09 & 3.74E-08 & 4.78E-06 & -7.03E-09 & 2.02E-08 & 4.78E-06 \\
\hline & 4 (Avg) & 5.19E-08 & 7.96E-08 & $2.95 \mathrm{E}-04$ & 3.22E-08 & 5.50E-08 & 7.12E-05 & 2.62E-08 & 5.46E-08 & 1.43E-05 \\
\hline \multirow[t]{4}{*}{ SMR } & 1 & 3.93E-08 & $1.04 \mathrm{E}-07$ & 2.48E-04 & $-6.82 E-09$ & $1.94 \mathrm{E}-08$ & 5.70E-05 & $-7.48 \mathrm{E}-09$ & 2.03E-08 & 1.09E-04 \\
\hline & 2 & $-3.63 E-08$ & 5.68E-08 & 1.73E-04 & $-3.06 \mathrm{E}-09$ & 4.45E-08 & 4.99E-06 & 1.68E-08 & 5.09E-08 & 3.84E-05 \\
\hline & 3 & 4.57E-08 & 7.87E-08 & $3.55 \mathrm{E}-04$ & $-1.76 \mathrm{E}-08$ & 3.06E-08 & 4.78E-06 & $-1.13 \mathrm{E}-08$ & 4.53E-08 & 4.78E-06 \\
\hline & 4 & $1.26 \mathrm{E}-08$ & 5.79E-08 & 2.95E-04 & $-3.41 E-09$ & 4.01E-08 & 7.12E-05 & $-2.26 \mathrm{E}-08$ & $3.44 \mathrm{E}-08$ & 1.43E-05 \\
\hline \multirow[t]{4}{*}{ WEE } & 1 (Avg) & 5.61E-09 & $1.18 \mathrm{E}-07$ & 2.48E-04 & $2.29 \mathrm{E}-10$ & $3.86 \mathrm{E}-08$ & 5.70E-05 & $-6.70 \mathrm{E}-10$ & 3.94E-08 & 1.09E-04 \\
\hline & 2 & 4.15E-08 & 6.44E-08 & 1.73E-04 & 1.41E-08 & 4.96E-08 & 2.53E-08 & 3.19E-08 & 5.54E-08 & 3.84E-05 \\
\hline & 3 & $7.40 \mathrm{E}-08$ & 8.07E-08 & $3.55 \mathrm{E}-04$ & $1.89 \mathrm{E}-08$ & 4.55E-08 & 4.78E-06 & 4.67E-08 & $6.02 E-08$ & 4.78E-06 \\
\hline & 4 & 2.34E-08 & $5.28 \mathrm{E}-08$ & 2.95E-04 & 2.84E-08 & 4.94E-08 & 7.12E-05 & $-9.02 E-09$ & 2.11E-08 & 1.43E-05 \\
\hline \multirow[t]{4}{*}{ WFF } & 1 & 7.88E-09 & 9.99E-08 & 2.48E-04 & 3.10E-09 & 4.07E-08 & 5.70E-05 & 5.15E-08 & $6.54 \mathrm{E}-08$ & 1.09E-04 \\
\hline & 2 & 4.03E-08 & 7.14E-08 & 1.73E-04 & $-1.20 \mathrm{E}-08$ & 5.12E-08 & 4.99E-06 & 9.91E-09 & 3.59E-08 & 3.84E-05 \\
\hline & 3 & $5.14 \mathrm{E}-08$ & 7.62E-08 & $3.55 \mathrm{E}-04$ & 1.37E-08 & 4.64E-08 & 4.78E-06 & $-1.04 E-08$ & 2.34E-08 & 4.78E-06 \\
\hline & 4 & 6.30E-09 & 3.57E-08 & 2.95E-04 & 3.82E-08 & 5.58E-08 & 7.12E-05 & 4.06E-08 & $5.45 E-08$ & $1.43 \mathrm{E}-05$ \\
\hline \multirow[t]{7}{*}{ WSS } & 1 & $5.78 \mathrm{E}-08$ & $1.04 \mathrm{E}-07$ & 2.48E-04 & $-1.29 E-08$ & 2.93E-08 & 5.70E-05 & $-2.15 E-08$ & 3.77E-08 & 1.09E-04 \\
\hline & 2 (Avg) & 4.37E-08 & 7.10E-08 & 8.67E-05 & $-4.91 E-09$ & 4.35E-08 & 4.99E-06 & $-6.21 \mathrm{E}-09$ & 3.33E-08 & $1.92 \mathrm{E}-05$ \\
\hline & 3 & 3.91E-08 & $6.54 \mathrm{E}-08$ & 3.55E-04 & 1.76E-08 & 4.80E-08 & 4.78E-06 & -1.17E-08 & $2.56 \mathrm{E}-08$ & 4.78E-06 \\
\hline & 4 & 2.17E-08 & $6.58 \mathrm{E}-08$ & $2.95 \mathrm{E}-04$ & $-1.15 \mathrm{E}-08$ & 2.53E-08 & 7.12E-05 & 3.07E-08 & $5.55 \mathrm{E}-08$ & $1.43 \mathrm{E}-05$ \\
\hline & Mean & $3.54 \mathrm{E}-08$ & $7.51 \mathrm{E}-08$ & $2.65 \mathrm{E}-04$ & 5.59E-09 & $4.29 E-08$ & $3.43 E-05$ & 7.41E-09 & 4.34E-08 & $\overline{4.09 E-05}$ \\
\hline & Minimum & $-3.63 E-08$ & 3.57E-08 & 8.67E-05 & $-2.05 E-08$ & $1.54 \mathrm{E}-08$ & $2.53 \mathrm{E}-08$ & $-3.74 \mathrm{E}-08$ & $2.02 \mathrm{E}-08$ & 4.78E-06 \\
\hline & Maximum & 7.40E-08 & $1.18 \mathrm{E}-07$ & 3.55E-04 & 3.82E-08 & 7.87E-08 & 7.12E-05 & 5.15E-08 & $6.54 \mathrm{E}-08$ & 1.09E-04 \\
\hline \multirow{4}{*}{$\begin{array}{c}\text { WAB } \\
\text { (Blank) }\end{array}$} & 1 & $-7.16 \mathrm{E}-05$ & $2.22 \mathrm{E}-04$ & 7.33E-04 & $9.60 \mathrm{E}-05$ & 2.81E-04 & 4.04E-04 & $1.28 \mathrm{E}-04$ & $2.50 \mathrm{E}-04$ & 4.55E-04 \\
\hline & 2 & $-9.07 E-05$ & 2.10E-04 & 5.17E-04 & $-8.22 E-05$ & 1.84E-04 & 2.95E-04 & 7.48E-05 & 2.39E-04 & $3.28 \mathrm{E}-04$ \\
\hline & 3 & 1.29E-04 & 4.39E-04 & 7.05E-04 & $-9.71 E-06$ & $3.02 E-04$ & 2.94E-04 & 8.69E-05 & $2.26 \mathrm{E}-04$ & 2.93E-04 \\
\hline & 4 & $1.51 \mathrm{E}-04$ & 5.79E-04 & 7.49E-04 & $-1.31 E-04$ & 2.57E-04 & 4.27E-04 & $2.40 \mathrm{E}-04$ & $3.78 \mathrm{E}-04$ & $3.69 \mathrm{E}-04$ \\
\hline \multirow[t]{2}{*}{ Location } & Quarter & {$[\mathrm{RN}]^{\mathrm{a}}$} & $2 \times T^{\prime b} U^{b}$ & MDC $^{c}$ & {$[\mathrm{RN}]^{\mathrm{a}}$} & $2 \times T^{T P U^{b}}$ & $\mathrm{MDC}^{\mathrm{C}}$ & {$[\mathrm{RN}]^{\mathrm{a}}$} & $2 \times T^{\prime b}{ }^{b}$ & $M^{\prime} C^{c}$ \\
\hline & & & ${ }^{234} \mathrm{U}$ & & & ${ }^{235} \mathrm{U}$ & & & ${ }^{238} \mathrm{U}$ & \\
\hline \multirow[t]{4}{*}{ CBD } & 1 & $1.49 \mathrm{E}-06$ & 3.13E-07 & 5.94E-04 & 7.86E-08 & $8.10 \mathrm{E}-08$ & 4.21E-05 & 1.27E-06 & $2.88 \mathrm{E}-07$ & $4.08 \mathrm{E}-04$ \\
\hline & 2 & 1.17E-06 & $2.58 \mathrm{E}-07$ & 5.69E-04 & 4.12E-08 & $6.51 \mathrm{E}-08$ & 2.36E-05 & 1.25E-06 & $2.66 \mathrm{E}-07$ & 4.70E-04 \\
\hline & 3 & 7.33E-07 & $2.01 \mathrm{E}-07$ & 6.56E-04 & $9.54 \mathrm{E}-08$ & 8.55E-08 & 6.19E-05 & $6.63 E-07$ & $1.90 \mathrm{E}-07$ & 5.57E-04 \\
\hline & 4 & 9.31E-07 & $4.02 \mathrm{E}-07$ & 7.30E-04 & $1.34 \mathrm{E}-07$ & $1.94 \mathrm{E}-07$ & 5.71E-05 & 8.47E-07 & 3.81E-07 & $5.41 \mathrm{E}-04$ \\
\hline \multirow[t]{4}{*}{ MLR } & 1 & 1.17E-06 & $2.69 \mathrm{E}-07$ & 5.94E-04 & $5.48 \mathrm{E}-08$ & $6.64 \mathrm{E}-08$ & $4.21 \mathrm{E}-05$ & 7.84E-07 & 2.18E-07 & 4.08E-04 \\
\hline & 2 & 1.53E-06 & 3.20E-07 & 5.69E-04 & 7.59E-08 & 8.34E-08 & 2.36E-05 & 1.27E-06 & 2.89E-07 & 4.70E-04 \\
\hline & $3($ Avg) & 8.36E-07 & $2.44 \mathrm{E}-07$ & 6.56E-04 & $6.49 \mathrm{E}-08$ & $8.25 \mathrm{E}-08$ & 6.19E-05 & 7.02E-07 & 2.24E-07 & 5.57E-04 \\
\hline & 4 & 4.30E-07 & $3.20 \mathrm{E}-07$ & 7.30E-04 & 3.73E-08 & $1.38 \mathrm{E}-07$ & 5.71E-05 & $6.55 \mathrm{E}-07$ & 3.89E-07 & $5.41 \mathrm{E}-04$ \\
\hline \multirow[t]{2}{*}{ SEC } & 1 & 1.16E-06 & 2.62E-07 & 5.94E-04 & 4.80E-08 & $6.56 \mathrm{E}-08$ & 4.21E-05 & 1.29E-06 & $2.75 \mathrm{E}-07$ & 4.08E-04 \\
\hline & 2 & $1.04 \mathrm{E}-06$ & $2.50 \mathrm{E}-07$ & 5.69E-04 & 5.07E-08 & 6.58E-08 & 2.36E-05 & 9.82E-07 & 2.42E-07 & 4.70E-04 \\
\hline
\end{tabular}


Waste Isolation Pilot Plant Annual Site Environmental Report for 2008 DOE/WIPP-09-2225

Table G.1 - Radionuclide Concentrations (Bq/m3) in Quarterly Composite Air Filters Collected from Locations Surrounding the WIPP Site. See Appendix C for Sampling Location Codes.

\begin{tabular}{|c|c|c|c|c|c|c|c|c|c|c|}
\hline Location & Quarter & {$[\mathrm{RN}]^{\mathrm{a}}$} & $2 \times$ TPU $^{b}$ & $M C^{c}$ & {$[\mathrm{RN}]^{\mathrm{a}}$} & $2 \times T^{\prime b} U^{b}$ & MDC $^{c}$ & {$[\mathrm{RN}]^{\mathrm{a}}$} & $2 \times$ TPU $^{b}$ & $M^{\prime} C^{c}$ \\
\hline & 3 & 8.62E-07 & $2.40 \mathrm{E}-07$ & $6.56 \mathrm{E}-04$ & 1.60E-07 & $1.14 \mathrm{E}-07$ & 6.19E-05 & 7.81E-07 & $2.26 \mathrm{E}-07$ & 5.57E-04 \\
\hline & 4 (Avg) & $6.50 \mathrm{E}-07$ & $3.71 \mathrm{E}-07$ & 7.30E-04 & $9.45 \mathrm{E}-08$ & $1.70 \mathrm{E}-07$ & 5.71E-05 & 5.58E-07 & 3.35E-07 & $5.41 \mathrm{E}-04$ \\
\hline \multirow[t]{4}{*}{ SMR } & 1 & 1.13E-06 & 2.71E-07 & 5.94E-04 & 7.49E-08 & 8.24E-08 & 4.21E-05 & 9.59E-07 & 2.49E-07 & 4.08E-04 \\
\hline & 2 & 1.17E-06 & 2.62E-07 & 5.69E-04 & 3.34E-08 & 5.25E-08 & 2.36E-05 & $1.63 \mathrm{E}-06$ & 3.08E-07 & 4.70E-04 \\
\hline & 3 & 7.83E-07 & 2.16E-07 & $6.56 \mathrm{E}-04$ & 5.47E-08 & 6.29E-08 & 6.19E-05 & 1.02E-06 & $2.45 \mathrm{E}-07$ & 5.57E-04 \\
\hline & 4 & $6.48 \mathrm{E}-07$ & 3.07E-07 & 7.30E-04 & 8.39E-08 & $1.22 \mathrm{E}-07$ & 5.70E-05 & 5.81E-07 & 2.88E-07 & 5.41E-04 \\
\hline \multirow[t]{4}{*}{ WEE } & 1 (Avg) & 1.20E-06 & 2.93E-07 & 5.94E-04 & 4.86E-08 & 7.21E-08 & 4.21E-05 & 1.12E-06 & 2.83E-07 & 4.08E-04 \\
\hline & 2 & $1.53 \mathrm{E}-06$ & 3.13E-07 & $5.69 \mathrm{E}-04$ & 3.53E-08 & 5.69E-08 & 2.36E-05 & $1.52 \mathrm{E}-06$ & $3.11 \mathrm{E}-07$ & 4.70E-04 \\
\hline & 3 & $5.82 \mathrm{E}-07$ & 1.99E-07 & 6.56E-04 & 3.34E-08 & 7.88E-08 & 6.19E-05 & 5.64E-07 & 1.96E-07 & 5.57E-04 \\
\hline & 4 & 9.95E-07 & 4.65E-07 & 7.30E-04 & 1.62E-07 & 2.61E-07 & 5.71E-05 & $9.85 \mathrm{E}-07$ & 4.64E-07 & 5.41E-04 \\
\hline \multirow[t]{4}{*}{ WFF } & 1 & $1.22 \mathrm{E}-06$ & $3.11 \mathrm{E}-07$ & 5.94E-04 & 1.78E-08 & 5.35E-08 & 4.21E-05 & $9.47 \mathrm{E}-07$ & 2.72E-07 & 4.08E-04 \\
\hline & 2 & 1.07E-06 & 2.64E-07 & 5.69E-04 & -7.82E-09 & $2.45 \mathrm{E}-08$ & 2.36E-05 & $1.22 \mathrm{E}-06$ & 2.80E-07 & 4.70E-04 \\
\hline & 3 & 8.08E-07 & 2.27E-07 & $6.56 \mathrm{E}-04$ & 7.46E-08 & 7.96E-08 & 6.19E-05 & 8.53E-07 & 2.32E-07 & 5.57E-04 \\
\hline & 4 & $8.21 \mathrm{E}-07$ & 3.57E-07 & 7.30E-04 & $-1.30 \mathrm{E}-08$ & 4.85E-08 & 5.70E-05 & $9.30 \mathrm{E}-07$ & 3.79E-07 & 5.41E-04 \\
\hline \multirow[t]{7}{*}{ WSS } & 1 & $1.30 \mathrm{E}-06$ & $2.80 \mathrm{E}-07$ & 5.94E-04 & $2.58 \mathrm{E}-08$ & 5.83E-08 & 4.21E-05 & $9.71 \mathrm{E}-07$ & $2.41 \mathrm{E}-07$ & 4.08E-04 \\
\hline & 2 (Avg) & $1.07 E-06$ & 2.47E-07 & 5.69E-04 & 4.70E-08 & 5.75E-08 & 2.36E-05 & 1.10E-06 & 2.49E-07 & 4.70E-04 \\
\hline & 3 & 8.30E-07 & 2.32E-07 & $6.56 \mathrm{E}-04$ & 5.17E-08 & 7.36E-08 & 6.19E-05 & $6.95 \mathrm{E}-07$ & 2.12E-07 & 5.57E-04 \\
\hline & 4 & 9.35E-07 & 4.13E-07 & 7.30E-04 & $1.44 \mathrm{E}-07$ & 2.02E-07 & $5.71 \mathrm{E}-05$ & $7.45 \mathrm{E}-07$ & 3.72E-07 & 5.41E-04 \\
\hline & Mean & $1.00 \mathrm{E}-06$ & $2.90 \mathrm{E}-07$ & 6.37E-04 & $6.43 \mathrm{E}-08$ & $9.28 \mathrm{E}-08$ & 4.62E-05 & $9.61 \mathrm{E}-07$ & 2.82E-07 & $4.94 \mathrm{E}-04$ \\
\hline & Minimum & 4.30E-07 & $1.99 \mathrm{E}-07$ & 5.69E-04 & $-1.30 \mathrm{E}-08$ & $2.45 \mathrm{E}-08$ & 2.36E-05 & $5.58 \mathrm{E}-07$ & $1.90 \mathrm{E}-07$ & 4.08E-04 \\
\hline & Maximum & $1.53 \mathrm{E}-06$ & 4.65E-07 & 7.30E-04 & $1.62 \mathrm{E}-07$ & 2.61E-07 & 6.19E-05 & $1.63 \mathrm{E}-06$ & 4.64E-07 & 5.57E-04 \\
\hline \multirow{4}{*}{$\begin{array}{l}\text { WAB } \\
\text { (Blank) }\end{array}$} & 1 & $6.52 \mathrm{E}-03$ & 2.39E-03 & 1.19E-03 & 2.36E-04 & 5.67E-04 & 7.78E-04 & $5.41 \mathrm{E}-03$ & $2.17 \mathrm{E}-03$ & $1.00 \mathrm{E}-03$ \\
\hline & 2 & 3.05E-03 & $1.21 \mathrm{E}-03$ & 8.93E-04 & $-4.42 \mathrm{E}-05$ & $1.58 \mathrm{E}-04$ & 4.23E-04 & $2.70 \mathrm{E}-03$ & 1.13E-03 & 7.92E-04 \\
\hline & 3 & 4.41E-03 & $1.49 \mathrm{E}-03$ & 9.94E-04 & 5.59E-04 & 6.31E-04 & 4.79E-04 & 4.17E-03 & $1.44 \mathrm{E}-03$ & 8.94E-04 \\
\hline & 4 & 8.12E-03 & 4.44E-03 & 2.27E-03 & $-2.56 \mathrm{E}-04$ & 8.30E-04 & $1.95 \mathrm{E}-03$ & 8.75E-03 & 4.54E-03 & 2.07E-03 \\
\hline
\end{tabular}

\begin{tabular}{|c|c|c|c|c|c|c|c|c|c|c|}
\hline Location & Quarter & {$[\mathrm{RN}]^{\mathrm{a}}$} & $2 \times$ TPU $^{b}$ & MDC $^{c}$ & {$[\mathrm{RN}]^{\mathrm{a}}$} & $2 \times T^{T} U^{b}$ & MDC $^{c}$ & {$[\mathrm{RN}]^{\mathrm{a}}$} & $2 \times$ TPU $^{b}$ & MDC $^{c}$ \\
\hline & & & & ${ }^{40} \mathrm{~K}$ & & & ${ }^{60} \mathrm{Co}$ & & & ${ }^{137} \mathrm{Cs}$ \\
\hline \multirow[t]{4}{*}{ CBD } & 1 & 6.97E-04 & 7.01E-04 & 8.00E-04 & 7.51E-05 & 6.86E-05 & 8.01E-05 & $-2.90 \mathrm{E}-05$ & 6.33E-05 & 7.74E-05 \\
\hline & 2 & 4.33E-04 & 4.85E-04 & 7.77E-04 & $-4.39 \mathrm{E}-06$ & 7.01E-05 & 7.81E-05 & $-6.28 \mathrm{E}-05$ & 6.99E-05 & 7.53E-05 \\
\hline & 3 & 3.56E-04 & $6.52 \mathrm{E}-04$ & 8.85E-04 & $-3.78 \mathrm{E}-05$ & 8.34E-05 & 8.38E-05 & $-4.28 \mathrm{E}-05$ & $6.22 \mathrm{E}-05$ & $6.53 \mathrm{E}-05$ \\
\hline & 4 & $1.30 \mathrm{E}-05$ & 1.19E-03 & 1.32E-03 & 1.14E-04 & 1.11E-04 & $1.45 \mathrm{E}-04$ & $-4.35 \mathrm{E}-05$ & $1.14 \mathrm{E}-04$ & 1.30E-04 \\
\hline \multirow[t]{4}{*}{ MLR } & 1 & $1.23 \mathrm{E}-03$ & 6.62E-04 & 7.77E-04 & $6.29 E-06$ & 7.09E-05 & 7.97E-05 & $-6.67 \mathrm{E}-05$ & 6.54E-05 & 7.44E-05 \\
\hline & 2 & $1.04 \mathrm{E}-03$ & $6.68 \mathrm{E}-04$ & 7.77E-04 & 8.64E-05 & $6.76 \mathrm{E}-05$ & 7.94E-05 & $-1.00 \mathrm{E}-04$ & 7.21E-05 & 7.46E-05 \\
\hline & 3 (Avg) & 8.50E-04 & 9.77E-04 & $1.28 \mathrm{E}-03$ & $-1.33 E-05$ & 1.04E-04 & 1.19E-04 & $-6.07 \mathrm{E}-05$ & $1.02 \mathrm{E}-04$ & $1.12 \mathrm{E}-04$ \\
\hline & 4 & 1.71E-04 & 1.42E-03 & $1.62 \mathrm{E}-03$ & $-1.10 \mathrm{E}-05$ & 1.47E-04 & $1.66 \mathrm{E}-04$ & $-1.67 \mathrm{E}-05$ & 1.69E-02 & $1.94 \mathrm{E}-02$ \\
\hline \multirow[t]{4}{*}{ SEC } & 1 & $3.55 \mathrm{E}-04$ & $3.49 E-04$ & 4.39E-04 & $-2.93 E-05$ & 3.96E-05 & 4.03E-05 & $-4.97 \mathrm{E}-06$ & 2.89E-05 & 3.35E-05 \\
\hline & 2 & 2.49E-04 & 1.83E-04 & 2.75E-04 & 3.51E-05 & 3.50E-05 & 4.42E-05 & 7.94E-07 & 2.81E-05 & 3.32E-05 \\
\hline & 3 & 1.13E-04 & 9.97E-04 & $1.22 \mathrm{E}-03$ & $-6.66 \mathrm{E}-05$ & 1.16E-04 & 1.16E-04 & 6.49E-05 & 8.06E-05 & 1.05E-04 \\
\hline & $4(\mathrm{Avg})$ & $6.19 \mathrm{E}-04$ & 1.29E-03 & 1.51E-03 & $-3.83 E-05$ & $1.46 \mathrm{E}-04$ & 1.61E-04 & $-1.02 \mathrm{E}-04$ & 1.57E-04 & $1.72 \mathrm{E}-04$ \\
\hline \multirow[t]{4}{*}{ SMR } & 1 & $2.79 \mathrm{E}-05$ & 3.74E-04 & 4.30E-04 & $1.88 \mathrm{E}-05$ & $3.56 \mathrm{E}-05$ & 4.31E-05 & 1.86E-05 & $2.75 \mathrm{E}-05$ & 3.39E-05 \\
\hline & 2 & 4.29E-04 & 3.13E-04 & 4.12E-04 & 2.57E-05 & $3.65 E-05$ & 4.46E-05 & 1.35E-05 & 2.84E-05 & 3.46E-05 \\
\hline & 3 & $1.94 \mathrm{E}-04$ & 1.38E-03 & $1.58 \mathrm{E}-03$ & $-1.99 \mathrm{E}-05$ & 1.47E-04 & $1.65 \mathrm{E}-04$ & $-2.48 \mathrm{E}-05$ & 1.35E-04 & $1.54 \mathrm{E}-04$ \\
\hline & 4 & 2.69E-03 & 1.42E-03 & $1.85 \mathrm{E}-03$ & 8.74E-05 & $1.46 \mathrm{E}-04$ & 1.77E-04 & $-1.00 \mathrm{E}-04$ & 1.77E-04 & $1.94 \mathrm{E}-04$ \\
\hline \multirow[t]{4}{*}{ WEE } & 1 (Avg) & 5.36E-04 & $5.22 \mathrm{E}-04$ & $6.05 E-04$ & 2.64E-05 & 5.22E-05 & 6.06E-05 & $-6.62 E-05$ & $5.25 \mathrm{E}-05$ & 5.52E-05 \\
\hline & 2 & 4.35E-04 & 3.45E-04 & 4.44E-04 & $3.45 \mathrm{E}-06$ & 3.62E-05 & 4.17E-05 & 2.11E-05 & 2.78E-05 & 3.43E-05 \\
\hline & 3 & 7.63E-04 & 7.38E-04 & 1.16E-03 & 1.41E-04 & 1.30E-04 & 1.66E-04 & $-1.01 \mathrm{E}-04$ & $1.42 \mathrm{E}-04$ & $1.53 \mathrm{E}-04$ \\
\hline & 4 & $1.80 \mathrm{E}-03$ & 1.36E-03 & 1.71E-03 & 1.16E-04 & $1.42 \mathrm{E}-02$ & 1.73E-04 & $-1.74 \mathrm{E}-04$ & $1.82 \mathrm{E}-04$ & $1.92 \mathrm{E}-04$ \\
\hline \multirow[t]{4}{*}{ WFF } & 1 & $2.40 \mathrm{E}-04$ & 1.91E-04 & 2.92E-04 & $2.10 \mathrm{E}-05$ & 3.54E-05 & 4.30E-05 & 7.77E-06 & 2.73E-05 & 3.30E-05 \\
\hline & 2 & $1.08 \mathrm{E}-03$ & 6.86E-04 & 7.96E-04 & 8.82E-05 & $6.85 E-05$ & 8.03E-05 & $-8.02 E-05$ & 7.23E-05 & 7.67E-05 \\
\hline & 3 & 4.74E-04 & $6.28 \mathrm{E}-04$ & 8.94E-04 & 4.46E-05 & $6.59 \mathrm{E}-05$ & $9.11 \mathrm{E}-05$ & $-3.84 \mathrm{E}-05$ & $6.55 \mathrm{E}-05$ & $6.96 \mathrm{E}-05$ \\
\hline & 4 & 4.98E-04 & $9.58 \mathrm{E}-04$ & $1.20 \mathrm{E}-03$ & 2.42E-05 & 1.05E-04 & 1.26E-04 & 3.42E-05 & 1.13E-04 & 1.36E-04 \\
\hline
\end{tabular}


Waste Isolation Pilot Plant Annual Site Environmental Report for 2008 DOE/WIPP-09-2225

Table G.1 - Radionuclide Concentrations (Bq/m3) in Quarterly Composite Air Filters Collected from Locations Surrounding the WIPP Site. See Appendix C for Sampling Location Codes.

\begin{tabular}{|c|c|c|c|c|c|c|c|c|c|c|}
\hline Location & Quarter & {$[\mathrm{RN}]^{\mathrm{a}}$} & $2 \times T^{T P} U^{b}$ & MDC $^{c}$ & {$[\mathrm{RN}]^{\mathrm{a}}$} & $2 \times T^{T P U^{b}}$ & $\mathrm{MDC}^{\mathrm{c}}$ & {$[\mathrm{RN}]^{\mathrm{a}}$} & $2 \times T^{T P}{ }^{b}$ & MDC $^{c}$ \\
\hline \multirow[t]{7}{*}{ WSS } & 1 & $4.18 \mathrm{E}-04$ & $3.50 \mathrm{E}-04$ & 4.47E-04 & 4.01E-06 & 3.72E-05 & 4.27E-05 & $3.43 \mathrm{E}-06$ & 2.77E-05 & 3.30E-05 \\
\hline & 2 (Avg) & 7.35E-04 & $4.21 \mathrm{E}-04$ & $5.26 \mathrm{E}-04$ & 2.62E-05 & 5.15E-05 & 5.90E-05 & $-4.80 \mathrm{E}-05$ & 5.06E-05 & 5.47E-05 \\
\hline & 3 & 5.37E-04 & 8.32E-04 & 1.15E-03 & 3.35E-05 & 1.05E-04 & 1.36E-04 & $2.23 \mathrm{E}-05$ & 8.55E-05 & $1.02 \mathrm{E}-04$ \\
\hline & 4 & 7.46E-04 & $1.00 \mathrm{E}-03$ & $1.29 \mathrm{E}-03$ & 6.17E-05 & 1.22E-04 & $1.49 \mathrm{E}-04$ & $-3.90 \mathrm{E}-05$ & $1.24 \mathrm{E}-04$ & 1.43E-04 \\
\hline & Mean & $6.33 \mathrm{E}-04$ & $7.53 \mathrm{E}-04$ & $9.45 E-04$ & $2.92 \mathrm{E}-05$ & $5.87 E-04$ & 9.96E-05 & $-3.62 E-05$ & $6.81 \mathrm{E}-04$ & $7.80 \mathrm{E}-04$ \\
\hline & Minimum & $1.30 \mathrm{E}-05$ & 1.83E-04 & $2.75 \mathrm{E}-04$ & $-6.66 \mathrm{E}-05$ & $3.50 \mathrm{E}-05$ & 4.03E-05 & $-1.74 \mathrm{E}-04$ & $2.73 \mathrm{E}-05$ & 3.30E-05 \\
\hline & Maximum & 2.69E-03 & 1.42E-03 & 1.85E-03 & 1.41E-04 & $1.42 \mathrm{E}-02$ & 1.77E-04 & $6.49 \mathrm{E}-05$ & 1.69E-02 & 1.94E-02 \\
\hline \multirow[t]{4}{*}{ WAB } & 1 & $1.20 \mathrm{E}+01$ & $5.04 \mathrm{E}+00$ & $5.95 \mathrm{E}+00$ & $-4.91 E-02$ & 5.34E-01 & 5.94E-01 & $-3.50 \mathrm{E}-01$ & $5.02 \mathrm{E}-01$ & 5.77E-01 \\
\hline & 2 & $3.79 \mathrm{E}+00$ & $4.94 \mathrm{E}+00$ & $5.62 \mathrm{E}+00$ & $1.08 \mathrm{E}-01$ & 5.14E-01 & 5.81E-01 & $-1.32 E+00$ & $5.85 \mathrm{E}-01$ & 5.58E-01 \\
\hline & 3 & $-4.78 \mathrm{E}-01$ & $8.74 \mathrm{E}+00$ & $1.00 \mathrm{E}+01$ & 1.19E-01 & 7.38E-01 & $9.30 \mathrm{E}-01$ & $-2.43 \mathrm{E}-01$ & $6.72 \mathrm{E}-01$ & 7.27E-01 \\
\hline & 4 & $9.29 \mathrm{E}+00$ & $7.42 \mathrm{E}+00$ & $1.02 \mathrm{E}+01$ & 4.54E-01 & $8.61 \mathrm{E}-01$ & $1.07 \mathrm{E}+00$ & $1.80 \mathrm{E}-01$ & $9.01 \mathrm{E}-01$ & $1.08 \mathrm{E}+00$ \\
\hline
\end{tabular}

\begin{tabular}{|c|c|c|c|c|}
\hline Location & Quarter & {$[\mathrm{RN}]^{\mathrm{a}}$} & $2 \times$ TPU $^{b}$ & $\mathrm{MDC}^{\mathrm{c}}$ \\
\hline & & & ${ }^{90} \mathrm{Sr}$ & \\
\hline \multirow[t]{4}{*}{ CBD } & 1 & 5.01E-07 & $5.14 \mathrm{E}-06$ & $\overline{6.72 \mathrm{E}-05}$ \\
\hline & 2 & $-2.44 \mathrm{E}-06$ & 4.27E-06 & $3.22 \mathrm{E}-04$ \\
\hline & 3 & $-9.26 \mathrm{E}-07$ & 4.70E-06 & $7.62 \mathrm{E}-05$ \\
\hline & 4 & $-1.73 E-06$ & 5.05E-06 & $2.95 \mathrm{E}-04$ \\
\hline \multirow[t]{4}{*}{ MLR } & 1 & $-2.40 \mathrm{E}-07$ & 5.08E-06 & $6.71 \mathrm{E}-05$ \\
\hline & 2 & $-2.65 E-07$ & 4.16E-06 & $3.22 \mathrm{E}-04$ \\
\hline & 3 (Avg) & $-2.17 \mathrm{E}-06$ & 4.45E-06 & 7.62E-05 \\
\hline & 4 & $-4.96 \mathrm{E}-06$ & $5.02 \mathrm{E}-06$ & $2.95 \mathrm{E}-04$ \\
\hline \multirow[t]{4}{*}{ SEC } & 1 & $-1.08 \mathrm{E}-06$ & 5.07E-06 & $6.71 \mathrm{E}-05$ \\
\hline & 2 & $-7.50 \mathrm{E}-07$ & $4.18 \mathrm{E}-06$ & $3.22 \mathrm{E}-04$ \\
\hline & 3 & $2.80 \mathrm{E}-07$ & 4.71E-06 & $7.62 \mathrm{E}-05$ \\
\hline & 4 (Avg) & $-3.05 E-06$ & 5.11E-06 & $2.95 \mathrm{E}-04$ \\
\hline \multirow[t]{4}{*}{ SMR } & 1 & $-2.34 \mathrm{E}-06$ & 5.06E-06 & 6.71E-05 \\
\hline & 2 & $-2.52 \mathrm{E}-06$ & $3.97 \mathrm{E}-06$ & $3.22 \mathrm{E}-04$ \\
\hline & 3 & $-2.88 E-06$ & 4.57E-06 & $7.62 \mathrm{E}-05$ \\
\hline & 4 & $-3.40 \mathrm{E}-06$ & $5.20 \mathrm{E}-06$ & 2.95E-04 \\
\hline \multirow[t]{4}{*}{ WEE } & 1 (Avg) & $-1.08 \mathrm{E}-06$ & 5.22E-06 & $6.72 \mathrm{E}-05$ \\
\hline & 2 & $-5.40 \mathrm{E}-07$ & $4.18 \mathrm{E}-06$ & $3.22 \mathrm{E}-04$ \\
\hline & 3 & $-1.48 \mathrm{E}-06$ & 4.29E-06 & 7.61E-05 \\
\hline & 4 & $-9.38 E-08$ & 5.04E-06 & $2.95 \mathrm{E}-04$ \\
\hline \multirow[t]{4}{*}{ WFF } & 1 & $-2.12 \mathrm{E}-06$ & 5.51E-06 & $6.72 \mathrm{E}-05$ \\
\hline & 2 & $-3.43 E-06$ & 3.98E-06 & $3.22 \mathrm{E}-04$ \\
\hline & 3 & $-2.61 \mathrm{E}-06$ & 4.25E-06 & $7.61 \mathrm{E}-05$ \\
\hline & 4 & 4.78E-07 & 5.02E-06 & 2.95E-04 \\
\hline \multirow[t]{7}{*}{ WSS } & 1 & $-1.06 \mathrm{E}-06$ & 5.07E-06 & $6.71 \mathrm{E}-05$ \\
\hline & $2($ Avg) & $-7.46 \mathrm{E}-07$ & 4.27E-06 & $3.22 \mathrm{E}-04$ \\
\hline & 3 & $-1.71 \mathrm{E}-07$ & 4.43E-06 & $7.62 \mathrm{E}-05$ \\
\hline & 4 & $-2.52 \mathrm{E}-06$ & $5.20 \mathrm{E}-06$ & $2.95 \mathrm{E}-04$ \\
\hline & Mean & $-1.55 \mathrm{E}-06$ & $4.72 \mathrm{E}-06$ & $1.90 \mathrm{E}-04$ \\
\hline & Minimum & $-4.96 E-06$ & 3.97E-06 & 6.71E-05 \\
\hline & Maximum & 5.01E-07 & 5.51E-06 & $3.22 \mathrm{E}-04$ \\
\hline \multirow{4}{*}{$\begin{array}{c}\text { WAB } \\
\text { (Blank) }\end{array}$} & 1 & $-5.35 E-03$ & 3.79E-02 & $2.49 \mathrm{E}-03$ \\
\hline & 2 & $-1.38 \mathrm{E}-02$ & 3.10E-02 & $2.35 \mathrm{E}-03$ \\
\hline & 3 & $-1.05 E-02$ & 3.57E-02 & $2.59 \mathrm{E}-03$ \\
\hline & 4 & $-1.85 E-02$ & 4.01E-02 & $2.89 \mathrm{E}-03$ \\
\hline
\end{tabular}


Waste Isolation Pilot Plant Annual Site Environmental Report for 2008

DOE/WIPP-09-2225

This page intentionally left blank 


\section{Appendix $\mathrm{H}$ \\ Comparison of Detected Radionuclides to the Radiological Baseline}

The figures in this appendix show the highest detected radionuclides from 2008 environmental monitoring sample analysis results compared to the 99 percent confidence interval radiological baseline values established for these isotopes (DOE/WIPP-92-037). Figures address air filter composite, groundwater, surface water, sediment, soil, and vegetation results. Note, all results with the exception of vegetation were compared to the baseline upper 99 percentile probability value. The baseline did not include probability distributions for vegetation; therefore, vegetation sample results are compared to the baseline mean values. A detailed discussion of environmental monitoring radionuclide sample results is presented in Chapter 4.

\section{Comparison of Detected U-233/234 in Groundwater to the Baseline}

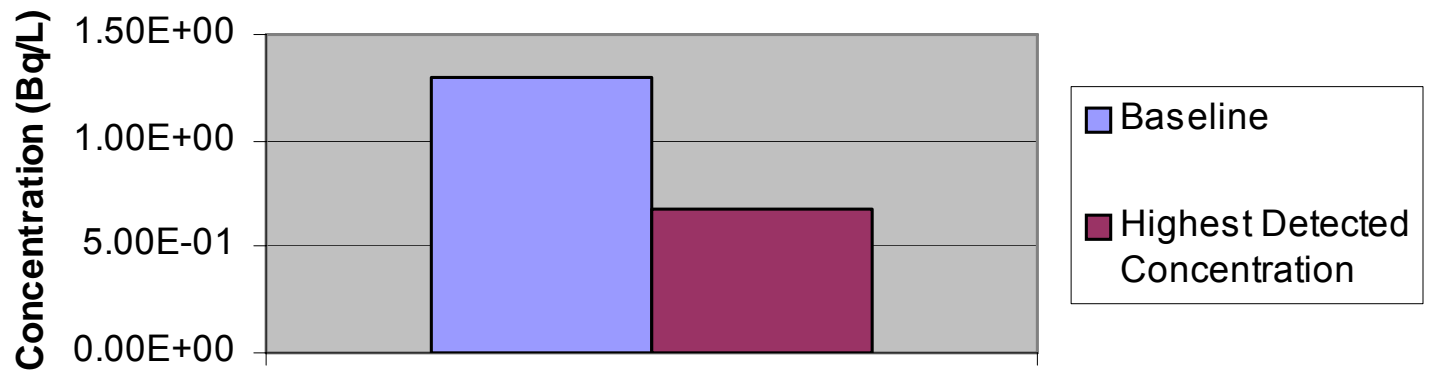

WQSP-1 Round 26

\section{Comparison of Detected U-235 in Groundwater to the} Baseline

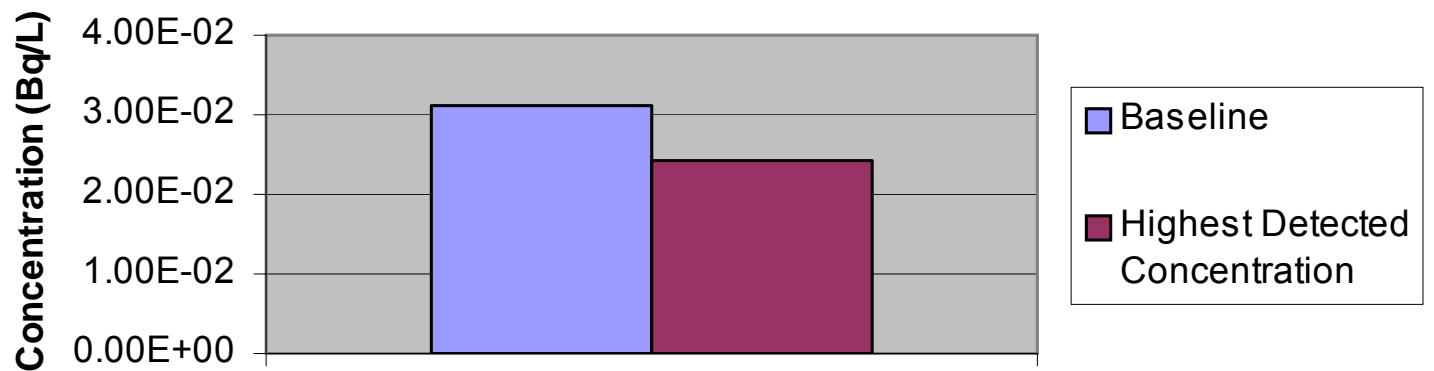

WQSP-1 Round 27 
Comparison of Detected U-238 in Groundwater to the Baseline
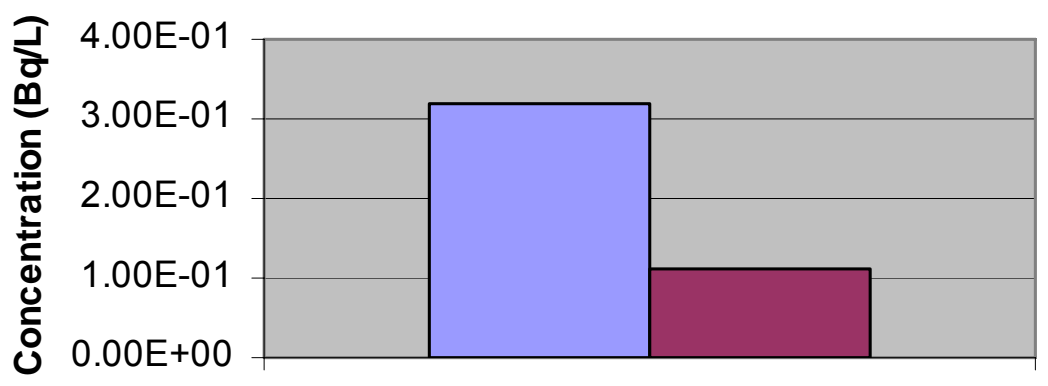

$\square$ Baseline

$\square$ Highest Detected

Concentration

WQSP-1 Round 26

Comparison of Detected K-40 in Groundwater to the Baseline
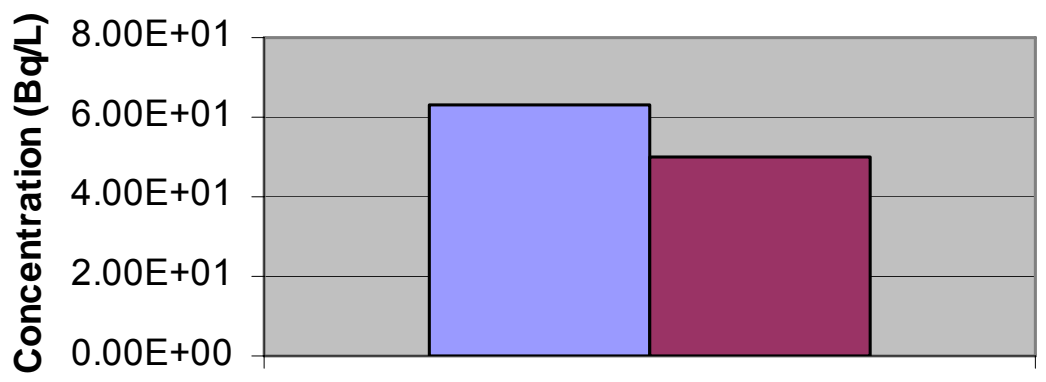

Baseline

$\square$ Highest Detected Concentration

WQSP-3 Round 26 


\section{Comparison of Detected U-233/234 in Surface Water to the Baseline}

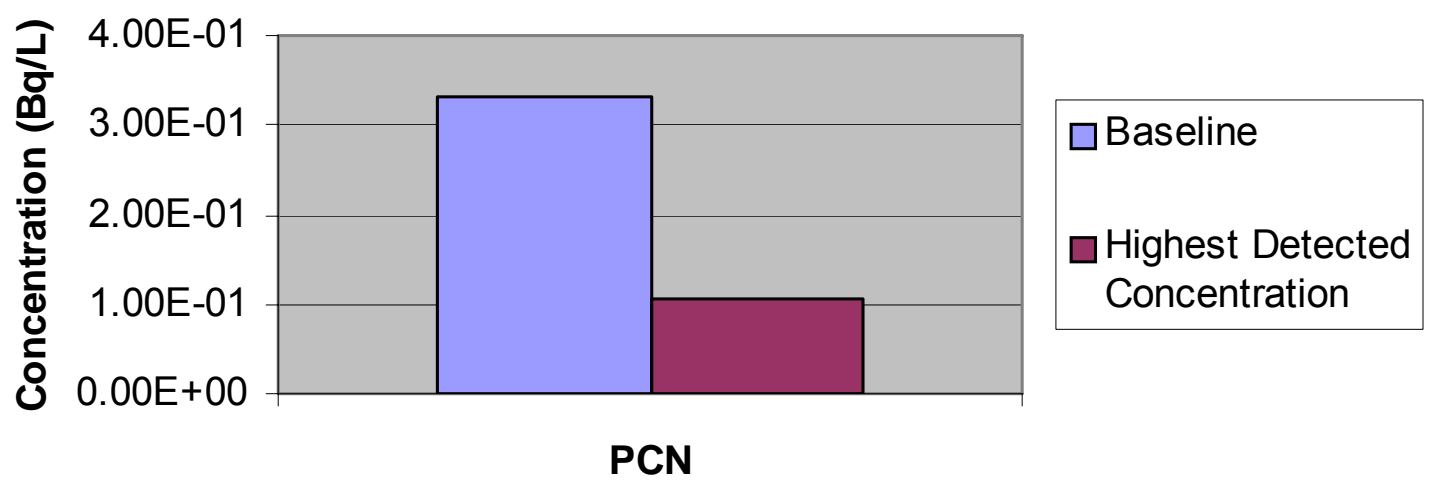

Comparison of Detected U-235 in Surface Water to the Baseline

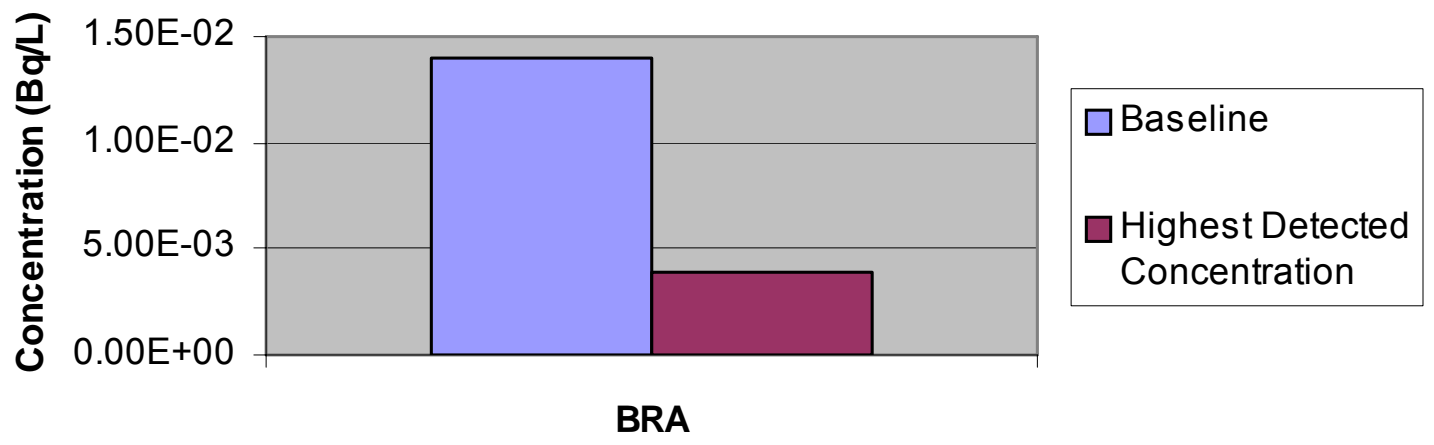




\section{Comparison of Detected U-238 in Surface Water to} the Baseline
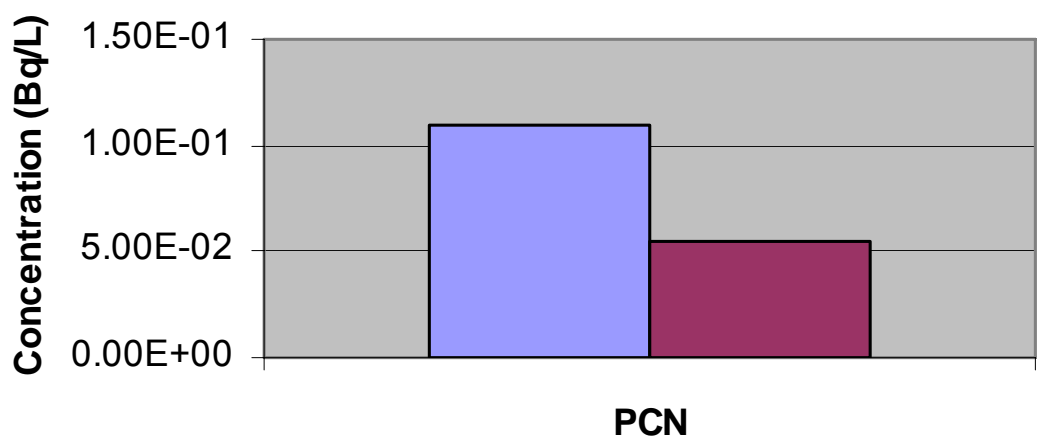

$\square$ Baseline

$\square$ Highest Detected

Concentration

Comparison of Detected U-233/234 in Sediment to the Baseline

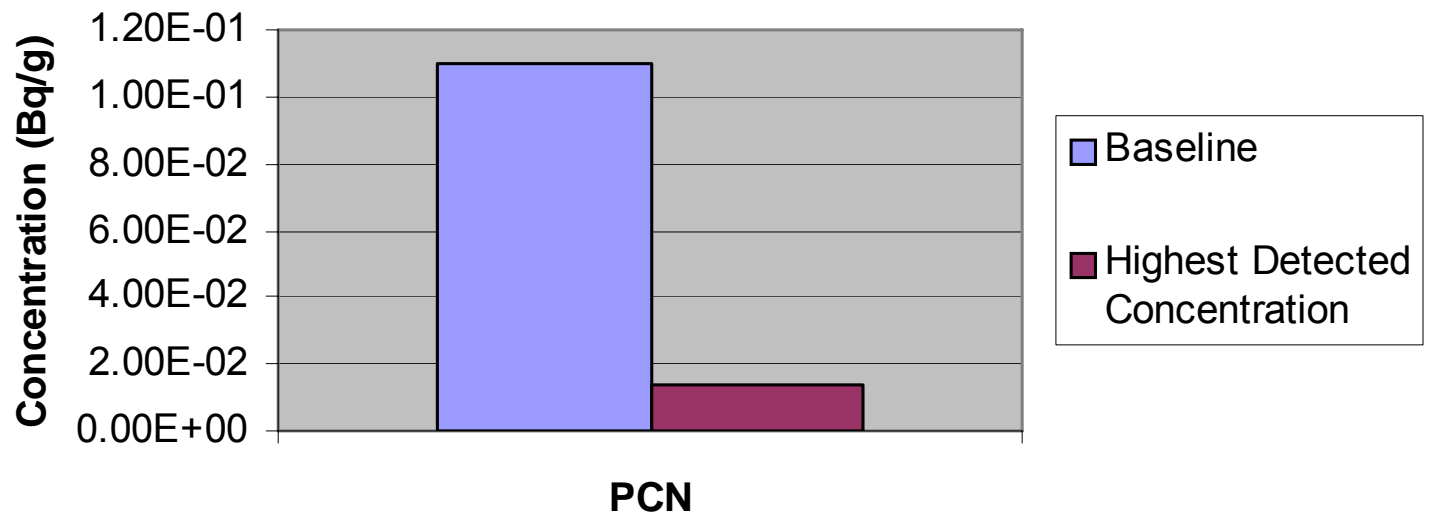




\section{Comparison of Detected K-40 in Surface Water to the Baseline}

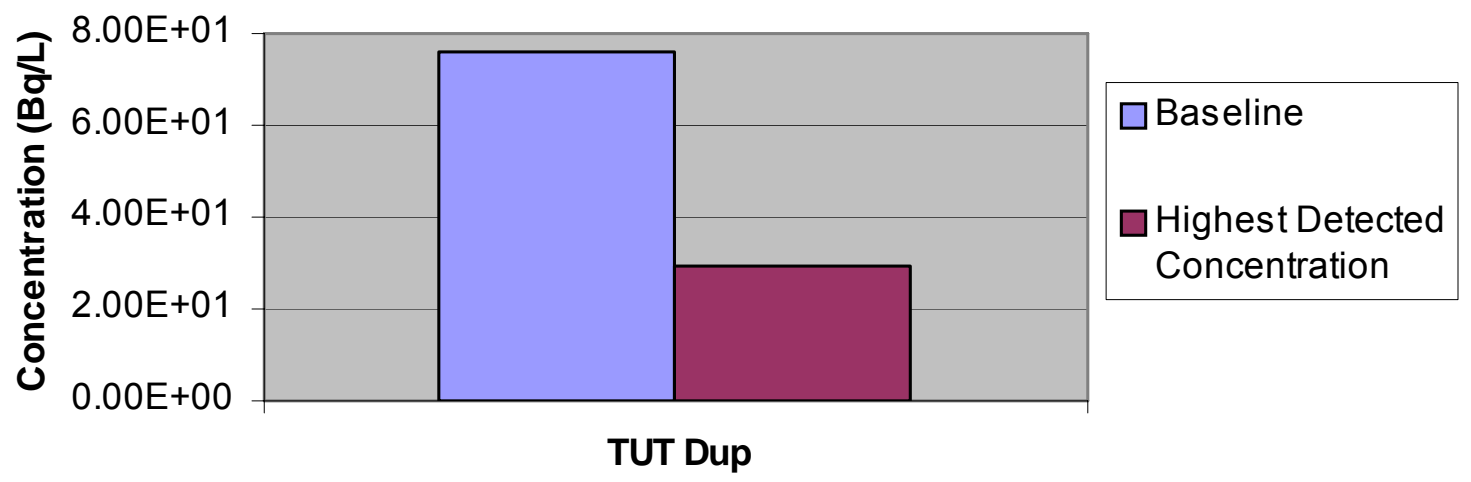

Comparison of Detected U-235 in Sediment to the Baseline

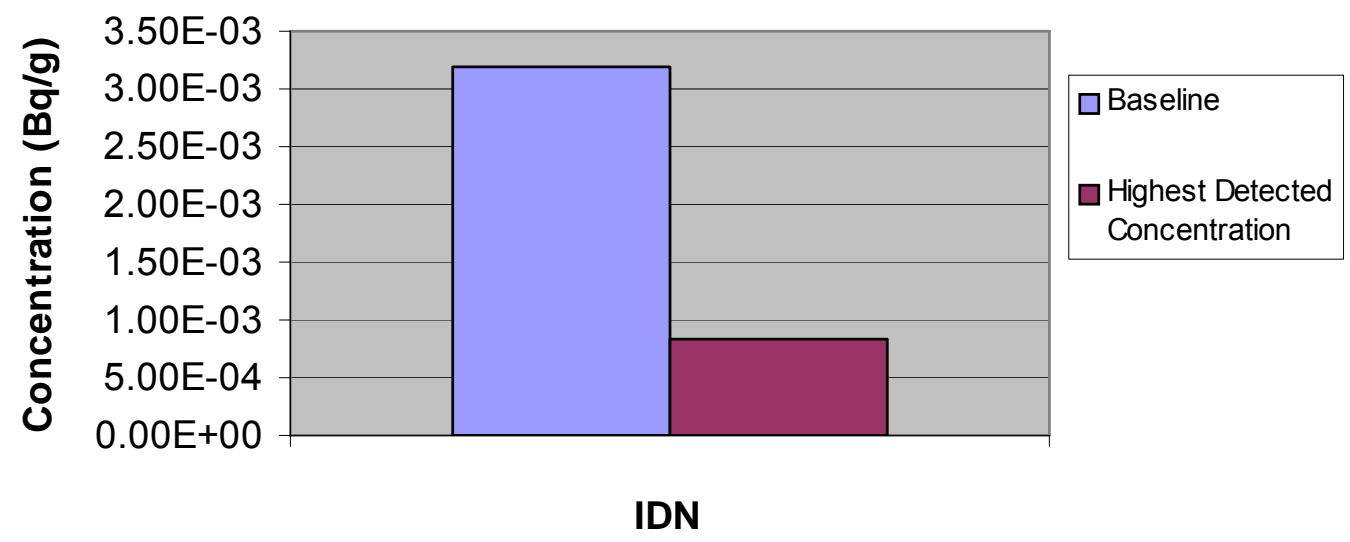


Comparison of Detected U-238 in Sediment to the Baseline

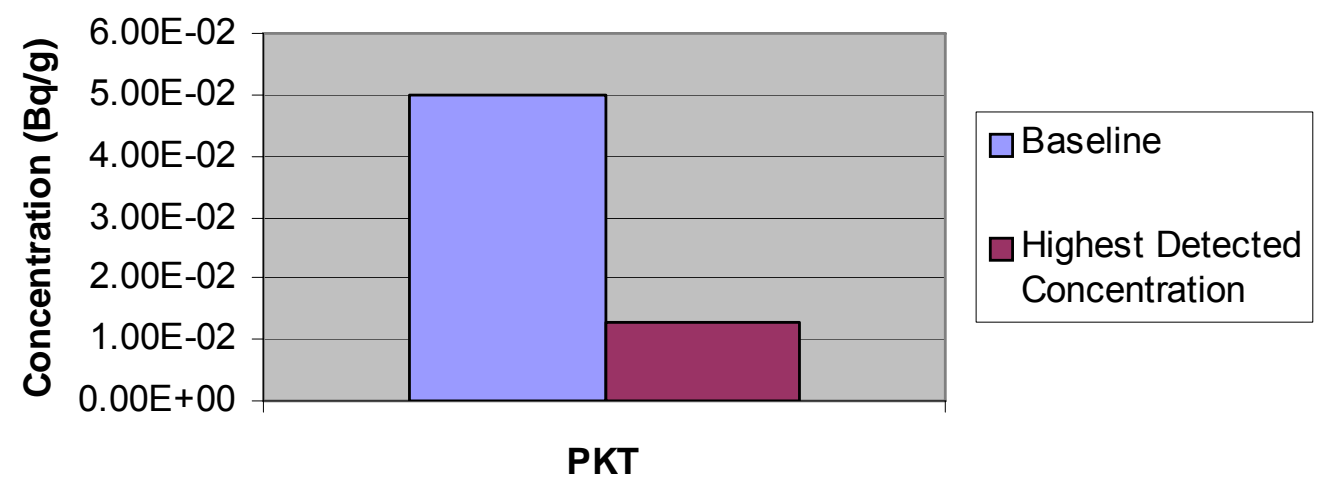

\section{Comparison of Detected Cs-137 in Sediment to the Baseline}

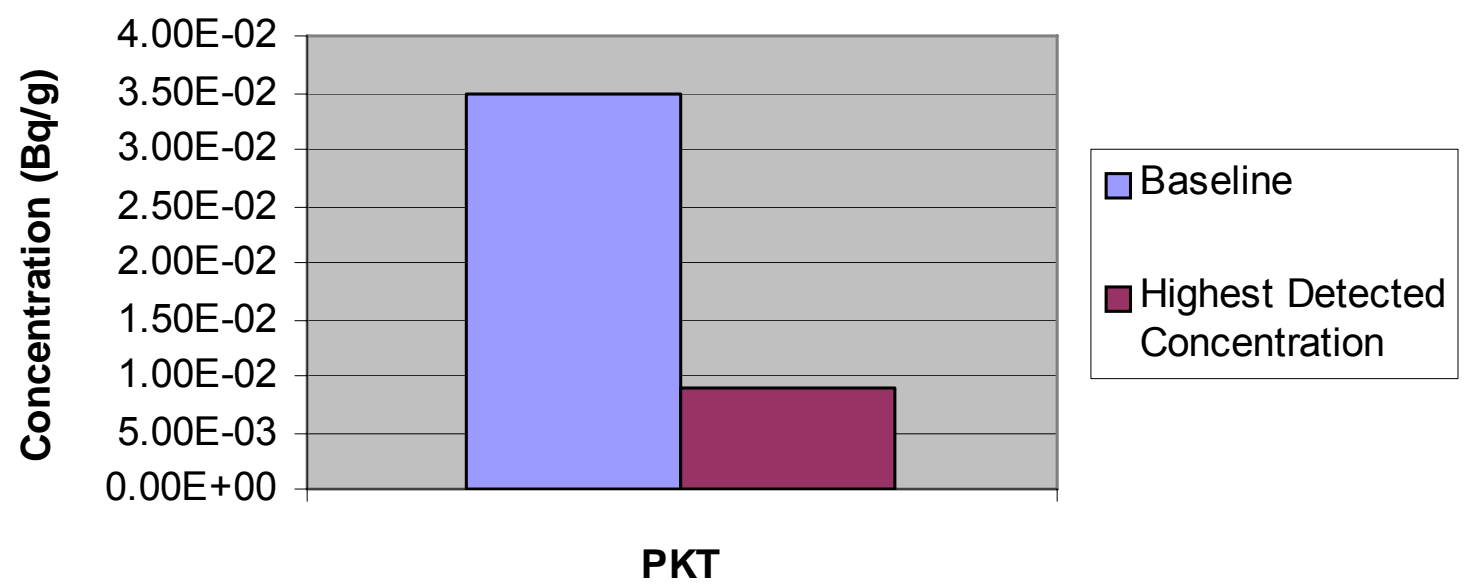


Comparison of Detected K-40 in Sediment to the Baseline (Pecos River)

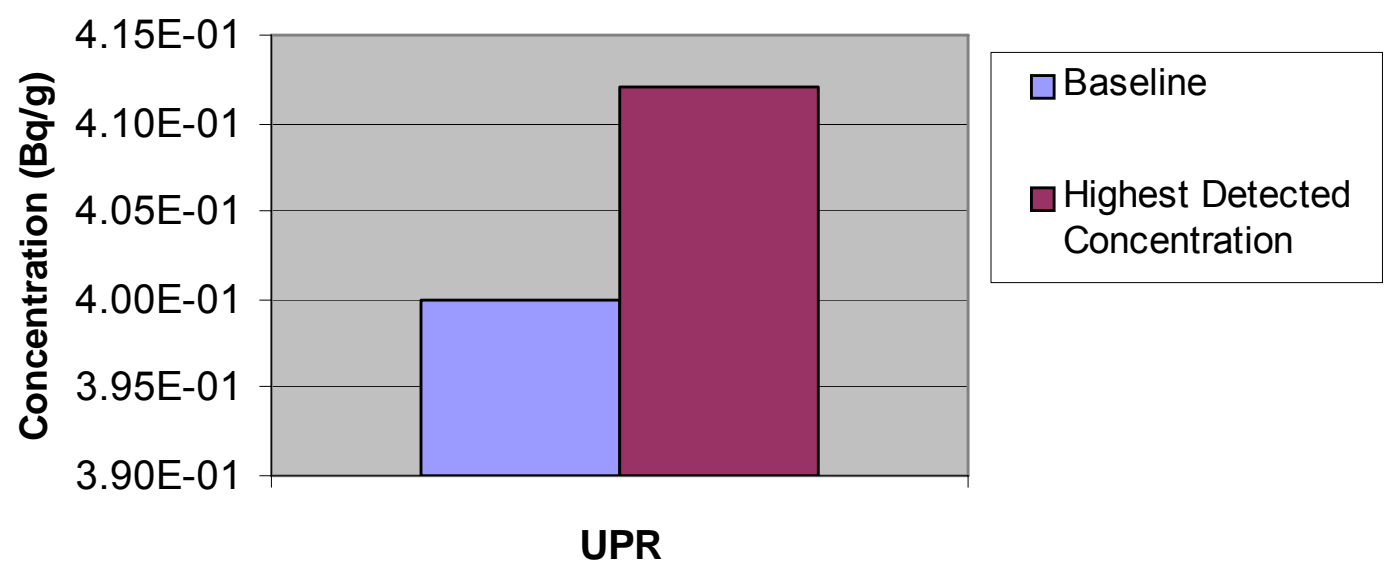

Comparison of Detected K-40 in Sediment to the Baseline (Tanks and Tank-Like Structures)

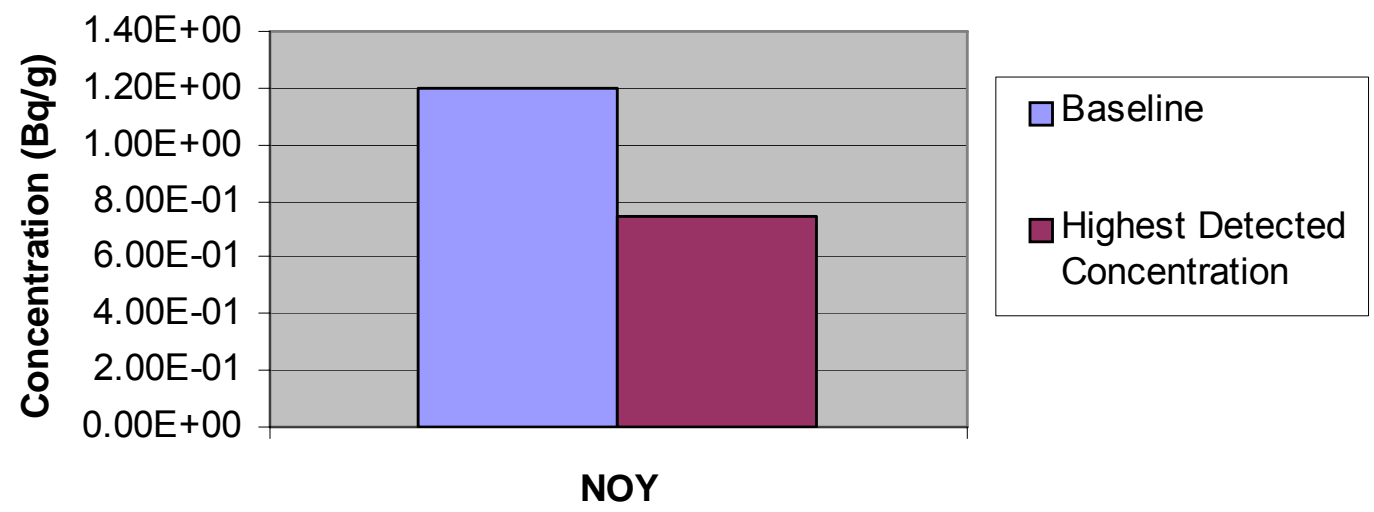




\section{Comparison of Detected Pu-239/240 in Soil to the Baseline}

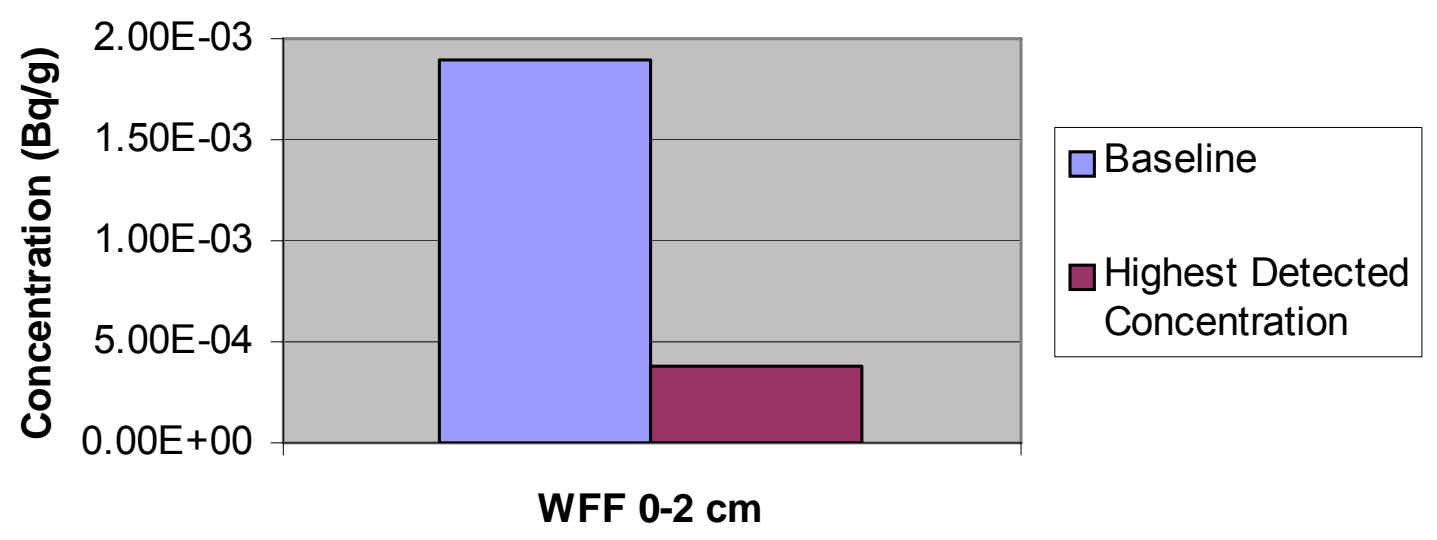

Comparison of Detected U-233/234 in Soil to the Baseline

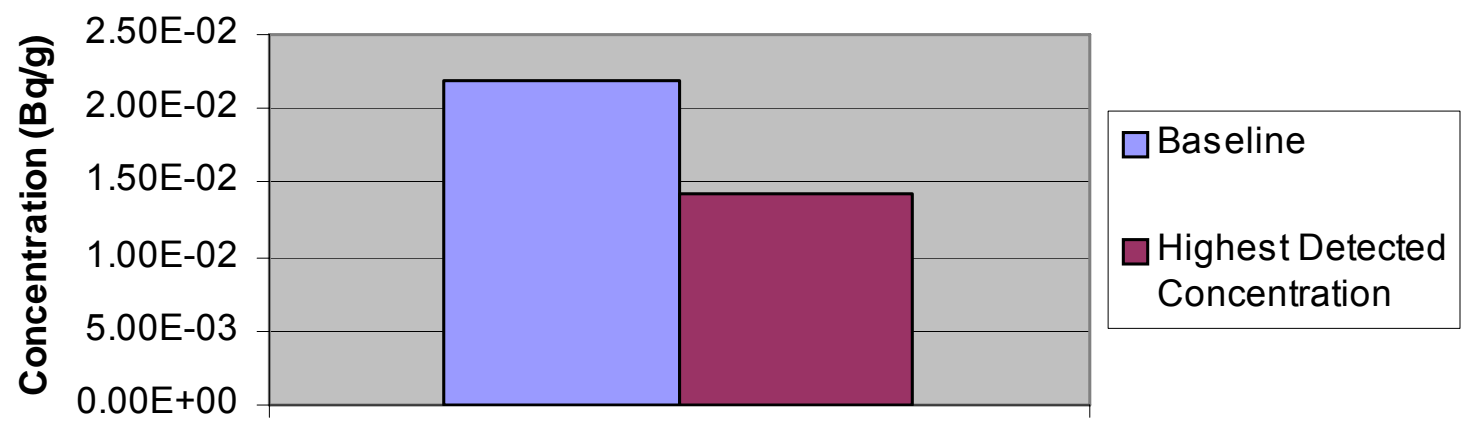

WEE 0-2 cm 


\section{Comparison of Detected U-235 in Soil to the Baseline}

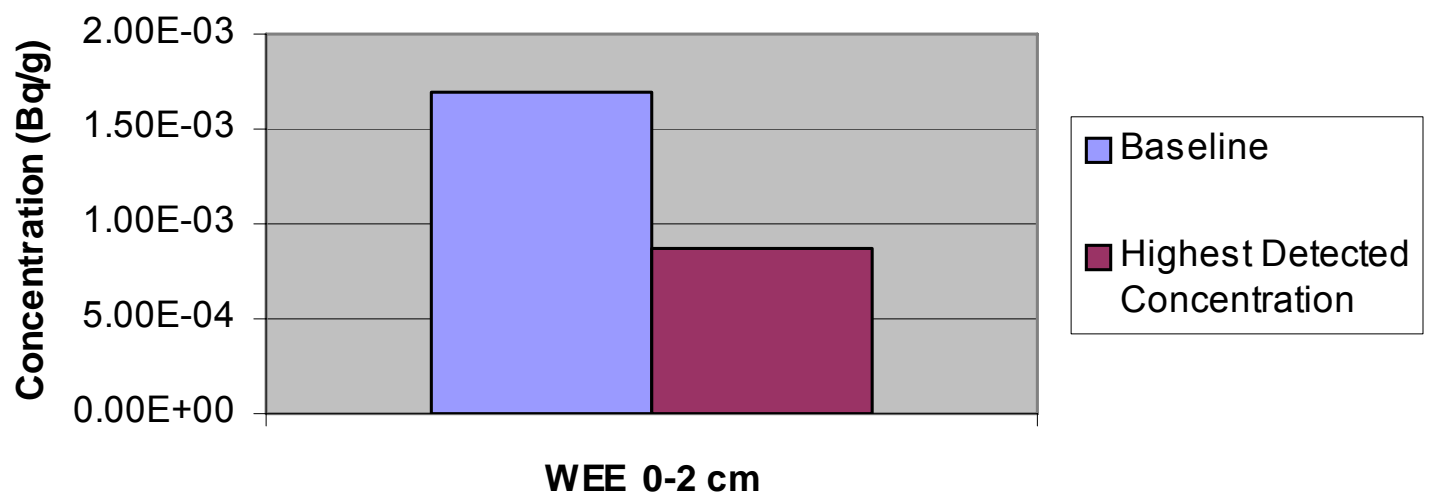

Comparison of Detected U-238 in Soil to the Baseline

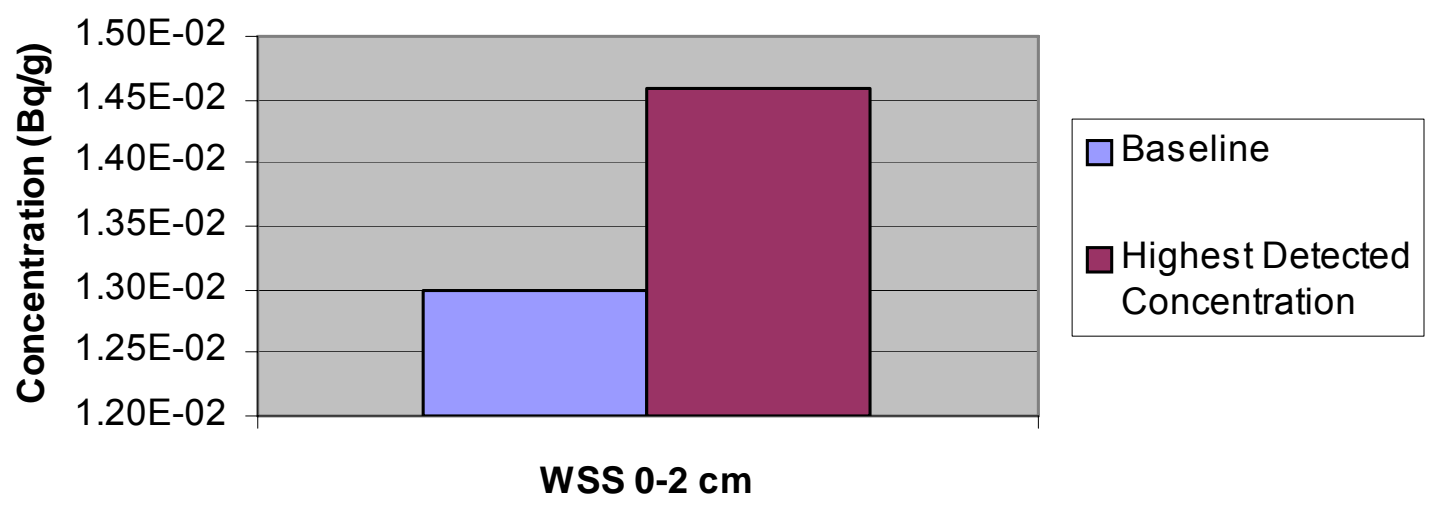




\section{Comparison of Detected Cs-137 in Soil to the}

Baseline

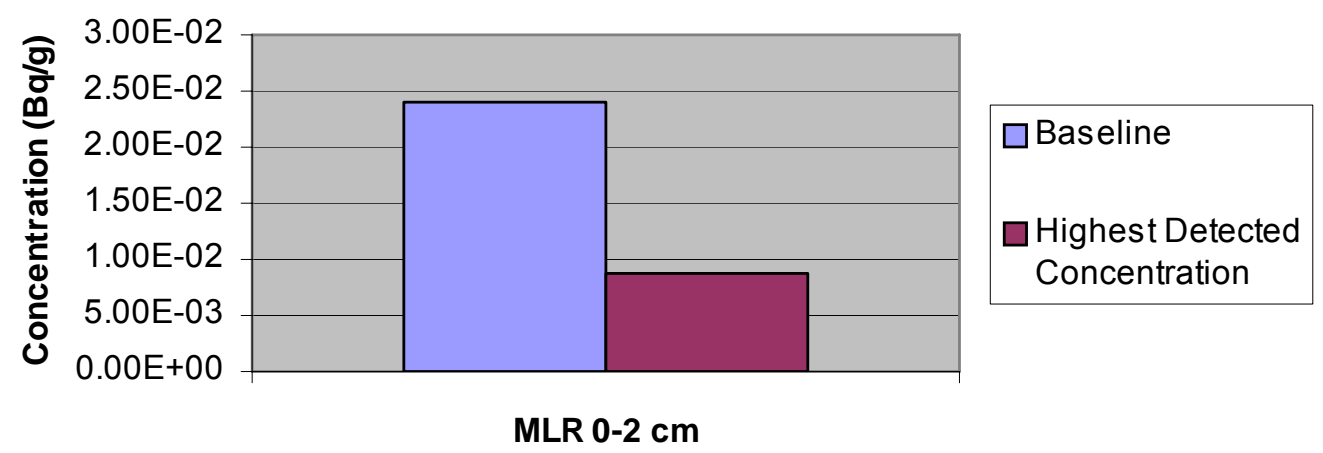

Comparison of Detected K-40 in Soil to the Baseline

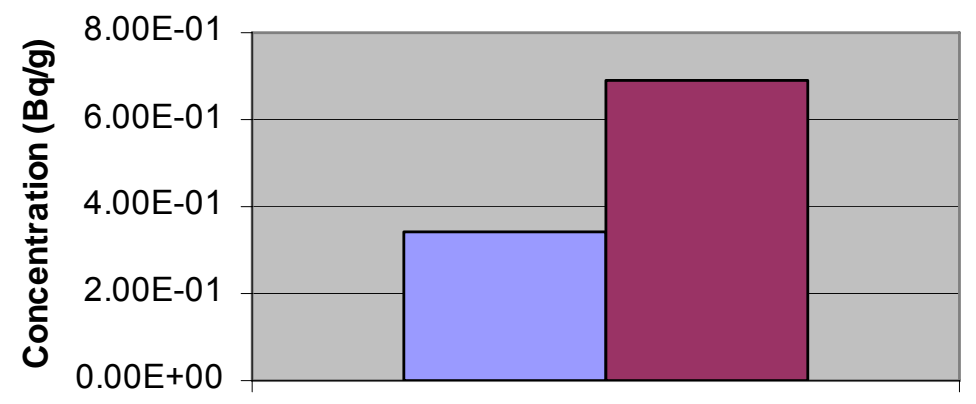

$\square$ Baseline

$\square$ Highest Detected

Concentration

SMR 5-10 cm 


\section{Comparison of Detected K-40 in Vegetation to the}

Baseline

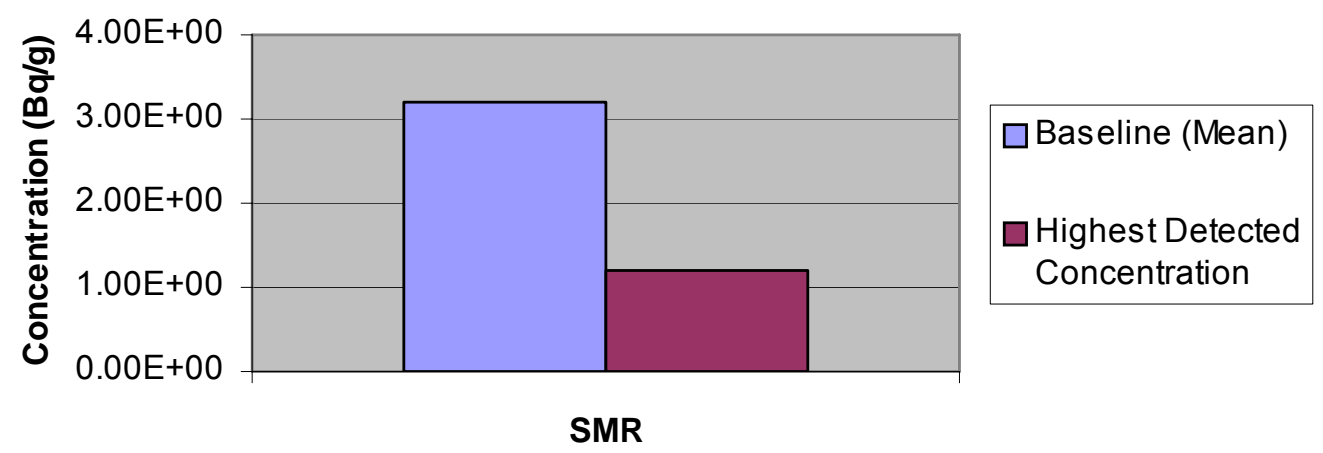

